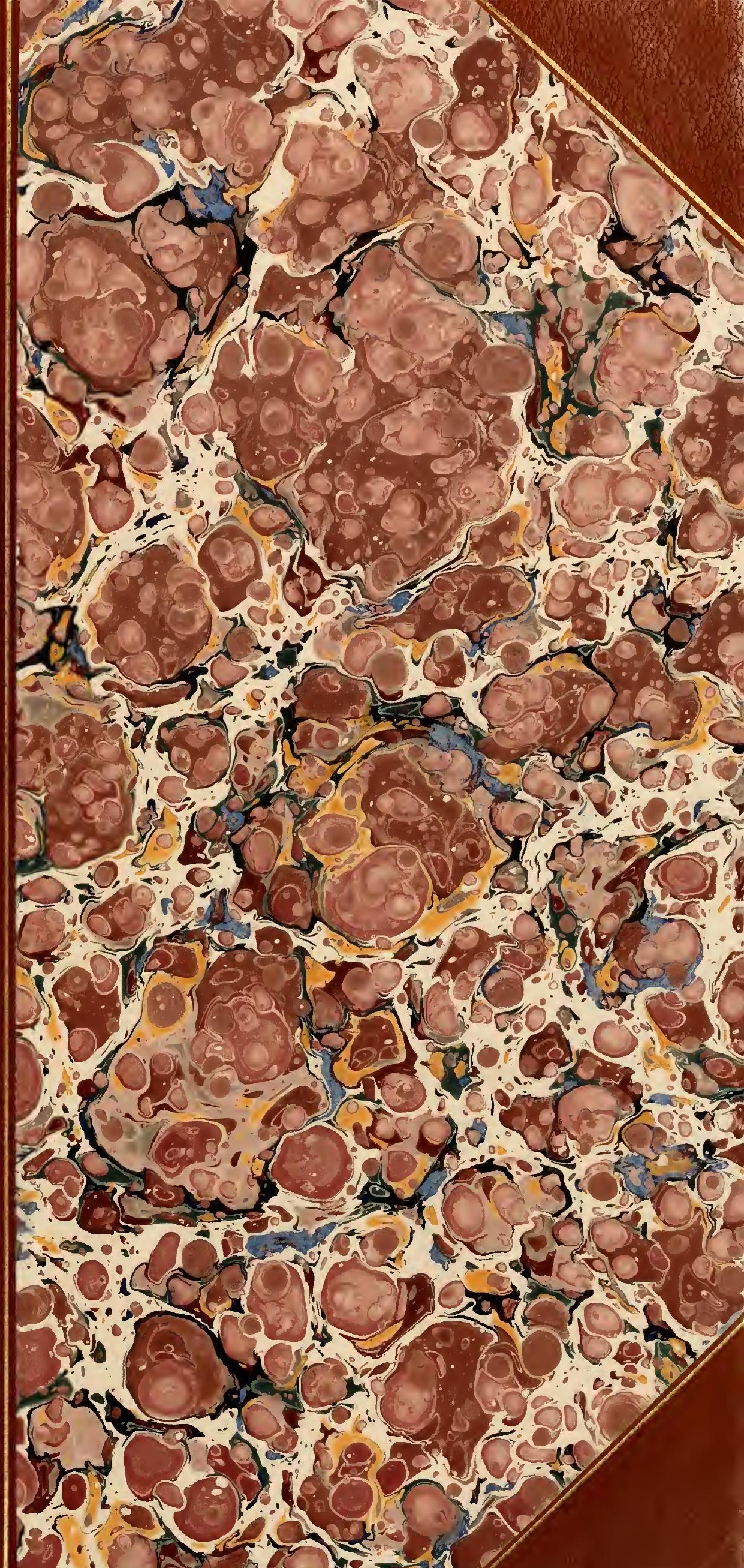




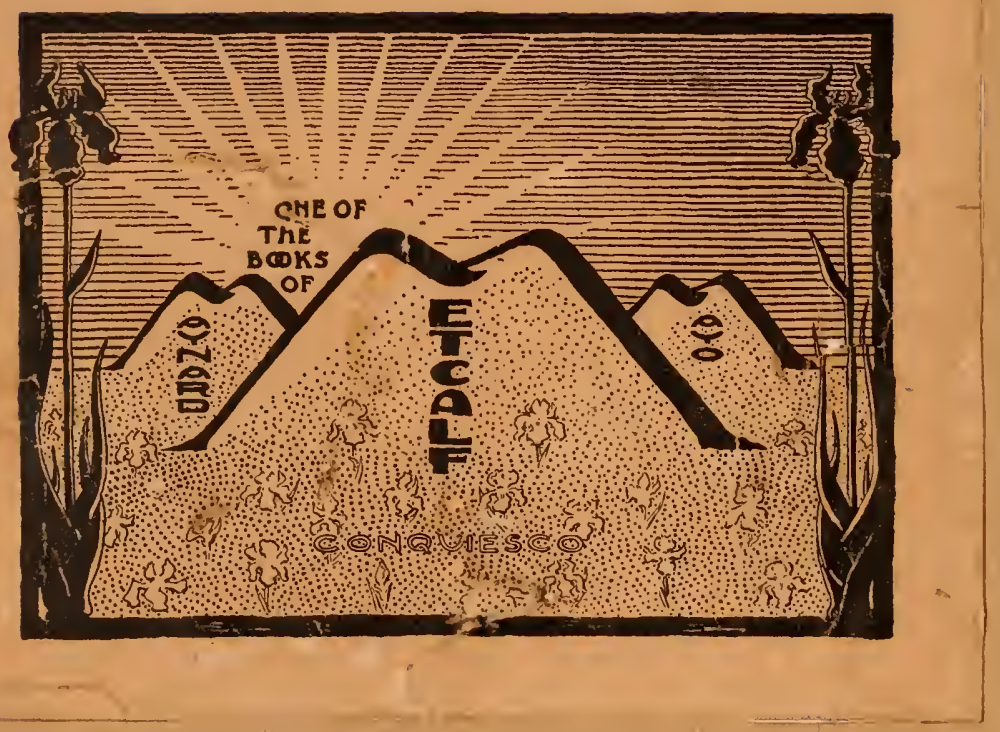




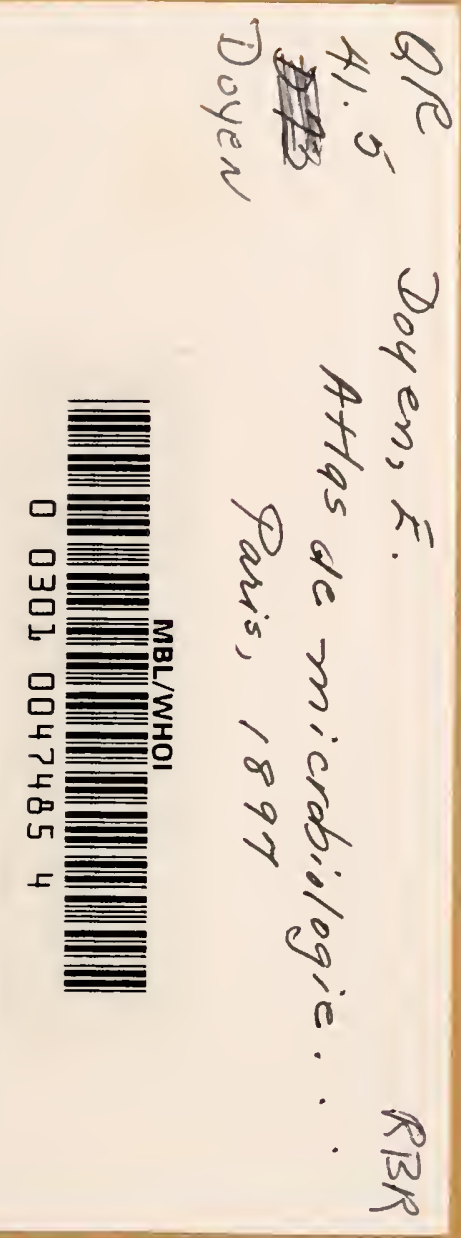




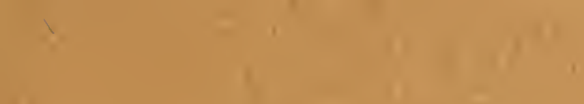

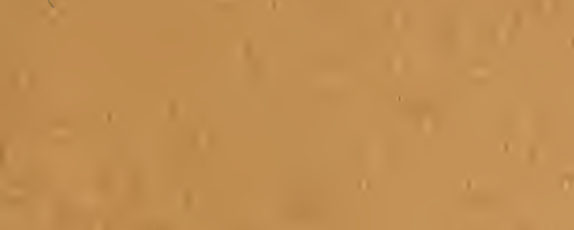

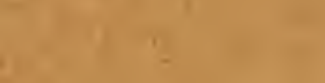

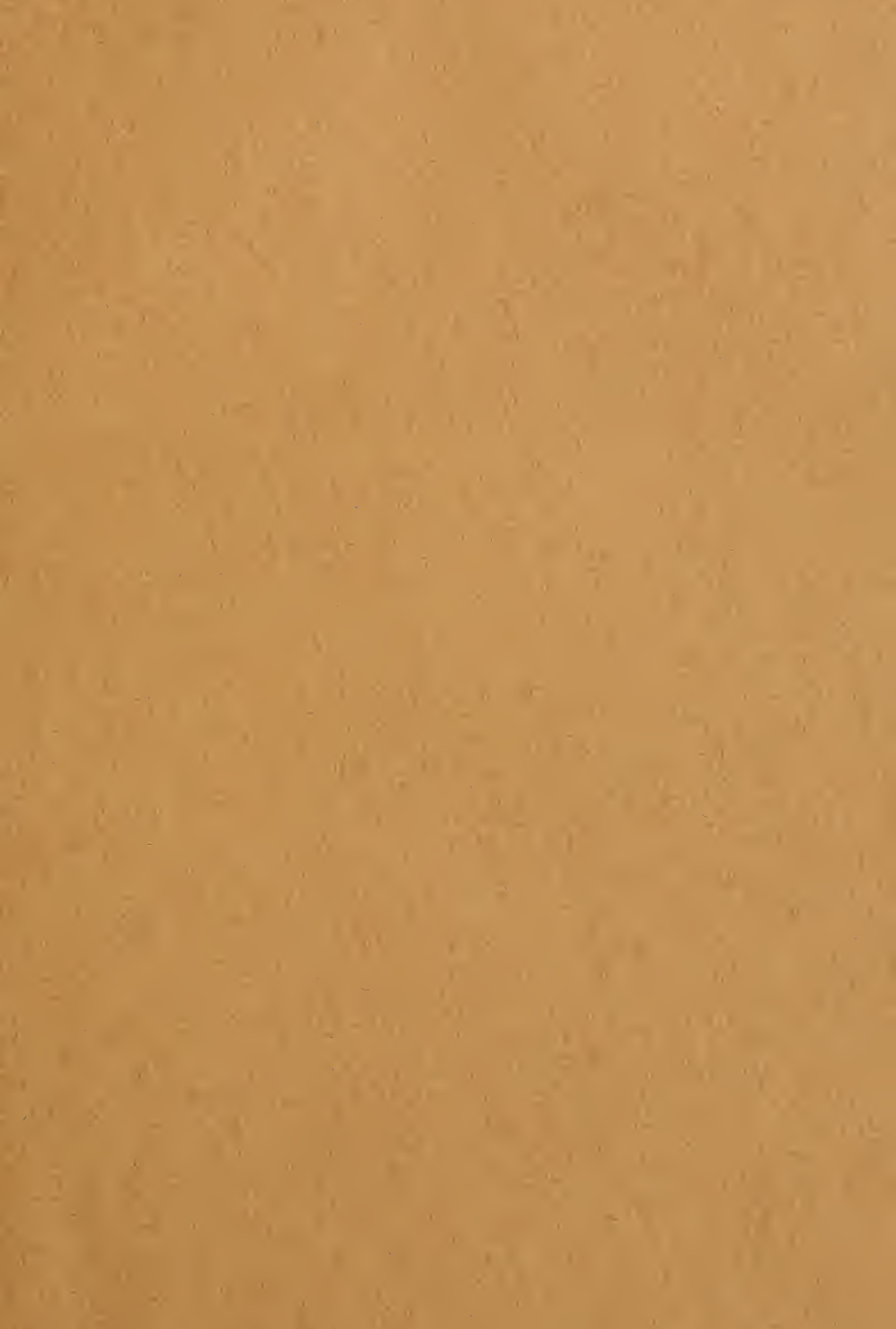


$1, \quad x$

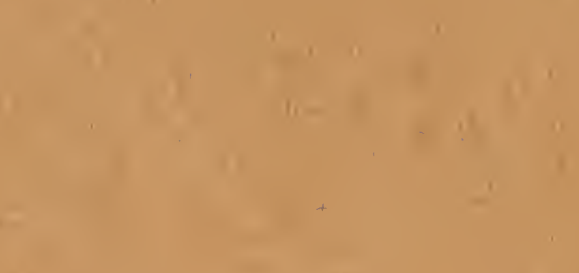

(1)

${ }_{1.2}+2=$

th

th

I

$+2$

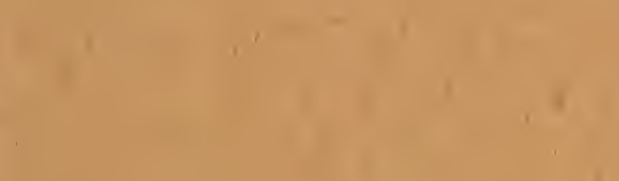

1

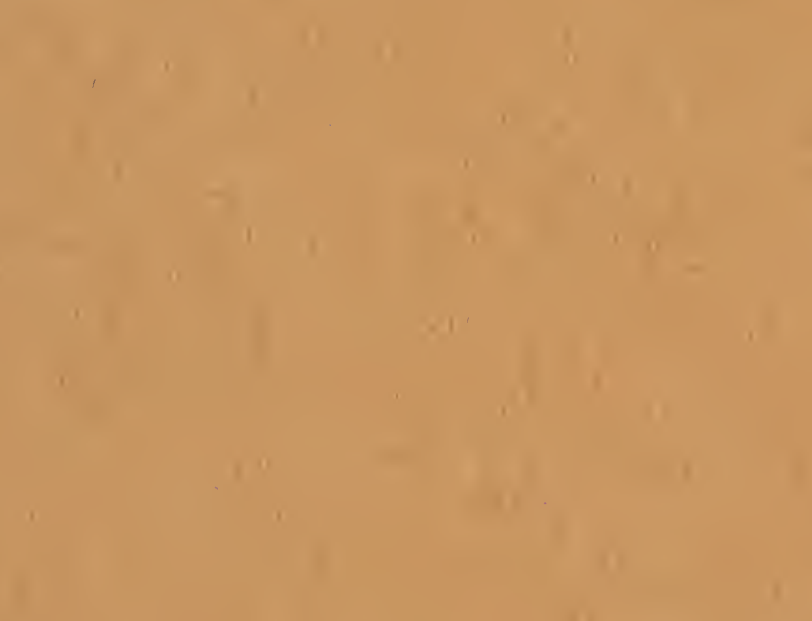

1

18
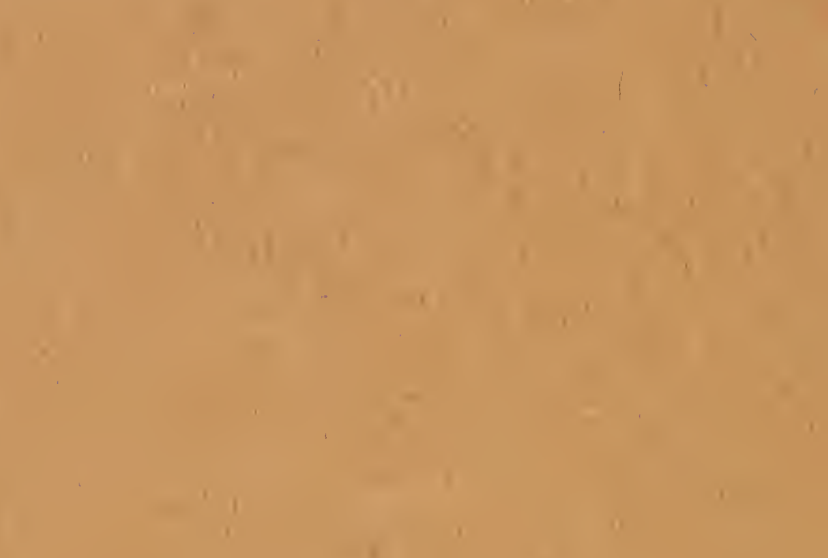

I

If 


\section{ATLAS}

VICROBIOLOGIE 
PARIS. IMPRIMERIE LAHURE

9, RUE DE FleURUS, 9 


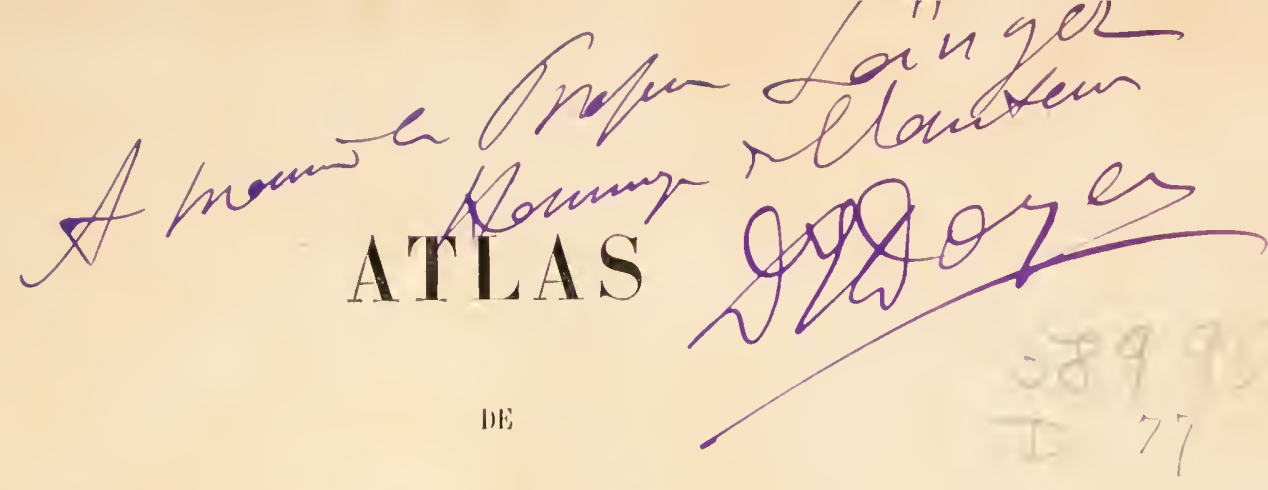

\section{MICROBIOLOGIE}

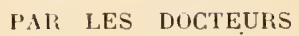

\section{E. DOYEN}

E'T

G. ROUSSEL

AVELiA COLLABORATION DE MA.
E. CHAZAREN
BACTÉRIOLOGISTE
F. ROTHIER
PHotigraphe a ReIMS

AVEG 541 FIGURES TIREES EN PHOTOTYPIE DANS LE TEXTE

\section{PARIS}

RUEFF ET C ${ }^{1 E}$, EDITEURS

106, BOULEVARD IAINT-GERMAIN, 106 



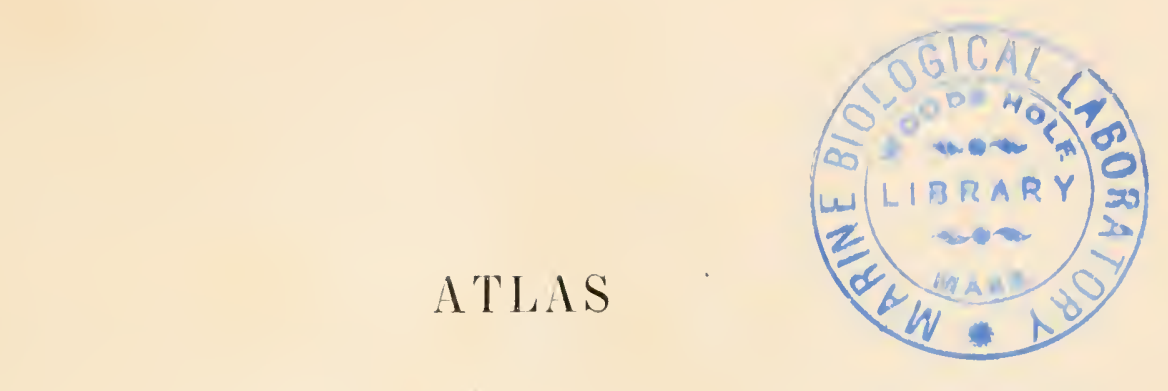

\section{DE MICROBIOLOGIE}

L’insuffisance du dessin, déjà si flagrante en anatomie descriptive et en histologie, devient telle en Microbiologie, que les planches les plus soignées n’ont servi bien souvent qu’à jeter la confusion entre des espèces parasitaires roisines.

Une épreuve photographique seule est susceptible de représenter avec précision la structure et la morphologie des infiniment petits. On y retrouvera les moindres détails, souvent presque inappréciables à l'wil aidé du microscope, mais qu'aura fixés, dans son exquise sensibilité, la plaque de gélatino-bromure.

Nous passerons successivement en rerue les Mucorinées et les Moisissures qui infectent le plus souvent nos milieux de culture : les Aspergillus el les Pénicillum; - nous étudierons ensuite les Botrylis et les Teignes. - les Oïdium, - les Beggiatoa, - les Fusisporium, les Cladothrix, - les Streptotrix et particulierement l'Actinomycose, - puis les Saccharomycètes. 
Cette élude préliminaire, dont l’importance croìt en Microbiologie depuis qu’on y différencie des espéces pathogines de plus en plus nombreuses, nous conduit à la description des Microcoques, des Bacilles et des Spirilles.

Nous terminerons en représentant des parasites moins bien comnus, tols que les Coccidies, qui, tout en s'éloignant dı règne régétal pour alleindre les degrés les plus infimes du règne animal, n’en sont pas moins, en raison de leurs dimensions exiguës, dı domaine de la Vicrobiologie.

Tos cliclıés onl été oblenus dans notre laboratoire privé, à l'aide des instruments les plus perfectionnés. Nos appareils optiques provienuent de la maison Carl Zeiss, d’éna: les plaques sensibles ortho. chromatiques d'Otto Perutz jusqu'en $1892 \mathrm{et}$, depuis celle époque, les plaques isochromatiques d'Attoul-Tailfer, fabriqucies par la maison Isunière, de Lyon, sont celles qui nous ont donné les meilleurs résultats.

Grâce à une série de dispositifs particuliers, nous photographions sans difficulté les préparations incolores, moisissures el lirures. l.es préparalions colorées peuvent ìtre indifféremment teintes en bleı, en violet, en rouge on en brun.

Les teintes les moins photogéniques domnent d'excrllents rísullats, si l'on modilie eonvenablement l'éclairage de la prépraration à l'aille d'une cuve remplie d’une solution plus ou moins concentrée d’acide pierique ou de bichromate d’ammoniaque. Nous employons de prólíprence comme source de lumière une lampe à are de 60 rolts, débitant 16 ampères.

Les lubes et les cristallisoirs ont ité pholographies à la lumière du jour, dans le laboratoire de M. Rothicer. 
Avant de passer a l'étude des différentes espèces microbiennes, nous sommes heurenx d'artresser nos rencreiements il tous les bateriofogistes qui ont apporté, chacun it une partic de notre ouvage, leur précieuse collaboration: JIJ. Jes professeurs Cornil, Laveran, Nocarl, Sinufelicen,

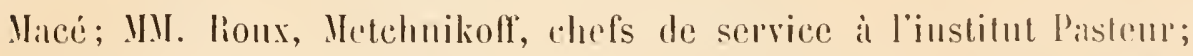
II. Netter, professeur agrégé à lat Faculté de médecine de Parris; M. Nicolle, professeur de médecine expérimentale à Constantinople; II. Ie Ir Tullio Rossi Dorial, assistant à la clinique gynécologirjue de Rome; MY. Yron et Berlioz; MII. Sabouraud, Bodin, Borrel, Cantacuzène, etc....

Nous indiquerons l'origine de toutes celles des préparations figurées dins ce livre qui ne proviennent pas de notre laboratoire privé.

Tous nos clichés sont reproduits dans le texte, tout en étant tirés sur gélatine bichromatée.

Le lecteur appréciera les avantages de cette disposition sur les planches intercalées a part, telles qu'on les observe dans les publications analogues (Atlas de Frænkel et Pfeiffur, cte.).

C'est à II. Silvestre qu’appartient l'imgénieuse ilée de réunir sur une mème planche, et de tirer d'un seul coup le texte, primitivement typographic, et les figmres, reproduites en phototypie.

Le mérite de l'édition revient particulièrement à III. Ruefl' et Cie, qui n'ont reculé devant aucun sacrifice pour assurer à celle nourelle publication toute la perfection et l'originalité désirables. 


\section{MUGORINÉES}

Les Mucorinées, qui affectionnent tout particulièrement les milieux sucrés, se développent également sur la gélatine pepione ordinaire. Le moût de bière, houblonné ou non, est leur miliea de prédilection.

\section{PHYCOMYCES NITENS}

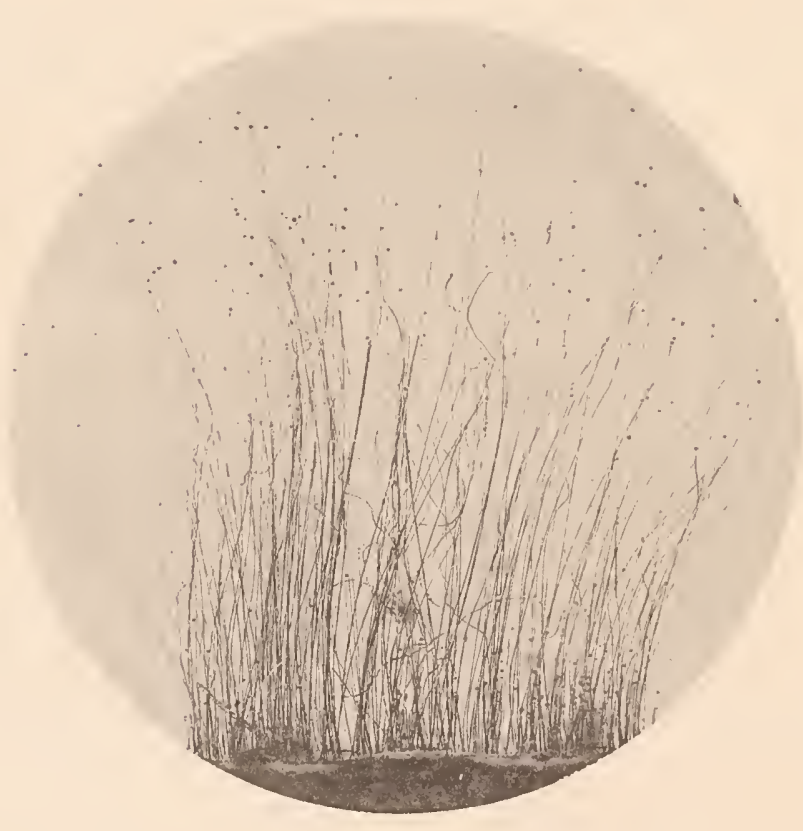

Fig. 1.

Phycomyces nitens (grandeur naturelle).

Nous ligurons ci-contre une colonie de Phycomyces brillants, sspece remarquahle par le développement de la tige ou pédicelle, qui peut alteindre 10,15 et mème 20 centimètres de longueur (fig. 1):

Un $y_{*}$ ossissement de soixante diamètres (lig. 2) nous monte is mode d'implanlation les sproranges sur le pédicelle. On devine, dars linte- 
rieur des sporanges, l'existence des spores, qui sont encore dans le premier stade de leur développement.

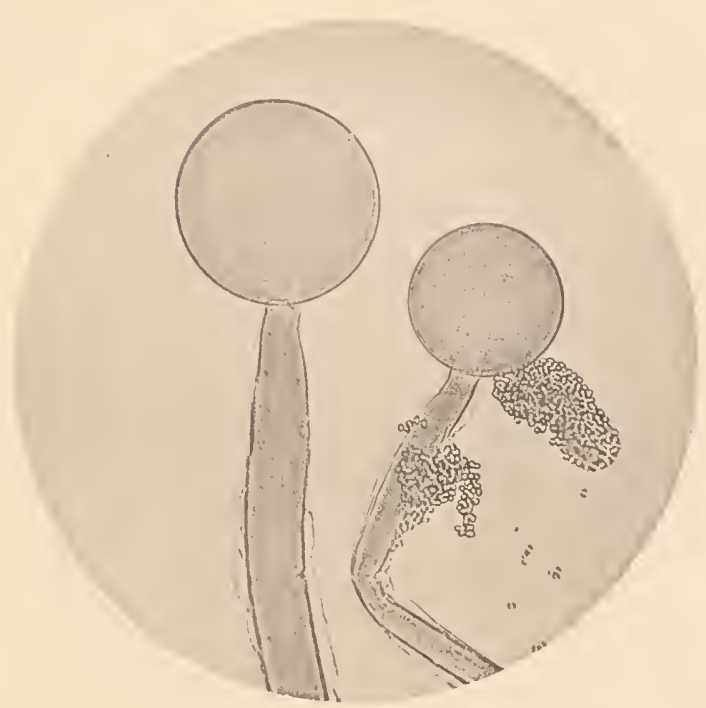

Fig. 2.

Sporanges de Phycomyces nitens (gr. 50 diam.).

L.es spores se laissent entrevoir figure 5, où l'on distingue leur forme ovale et la disposition régulière de la couche périphérique.
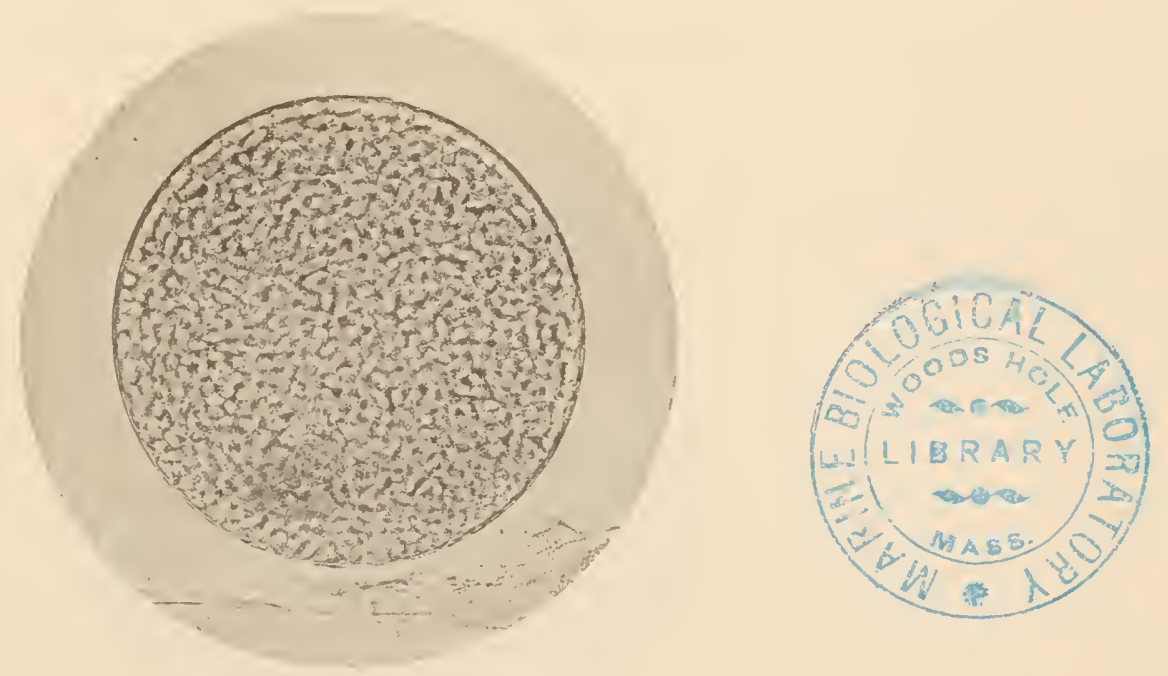

Fig. 5.

Sporange de Phycomyces nitens (gr. 180 diam.).

La figure 4 représente l'aspect des spores ovalaires du Phycomyces 
nitens, qui viennent d'ùtre mises en liberté par suite de l'écrasement d'un sporange sous une légère pression de la lamelle.

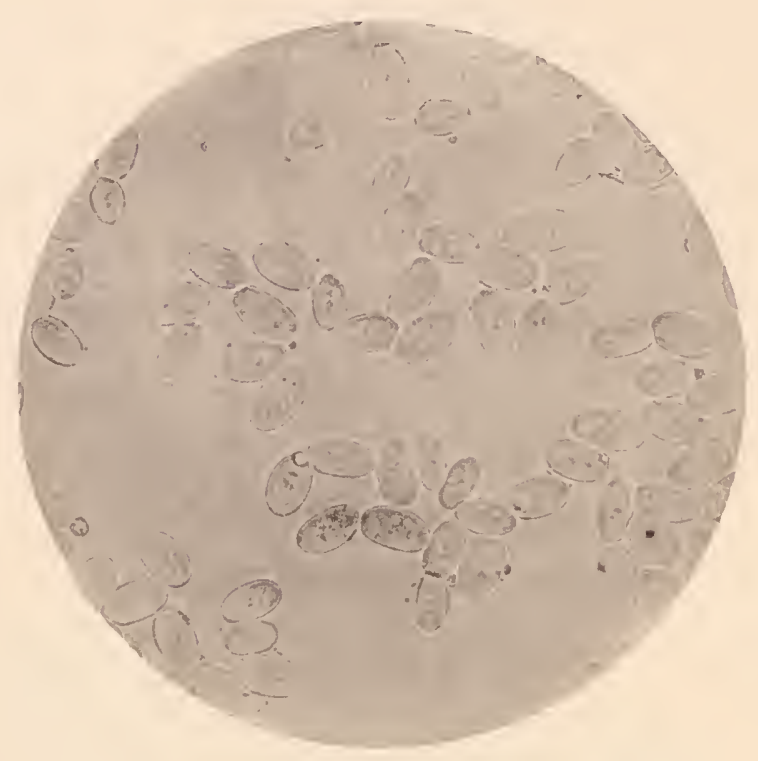

Fig. 4.

Spores de Phycomyces nilens (gr. 400 diam.).

\section{MUCOR SPINOSUS}

Le. Mucor spinosus est l'un des plus petits mucors conuus. La figure 5

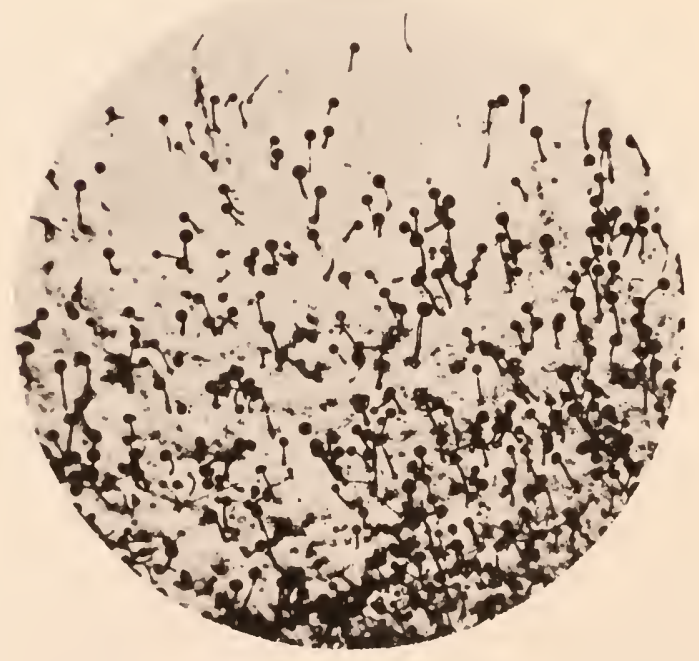

Hig. 5.

Colonie de Yucor spinosus (gr. 20 diam). 


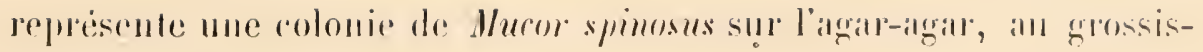
sement de 20 diamitres.

Nous rejuésentons, figure 6, 111 groupre de Mucor sprimosus an grossissement de löo diamètres; on yobserve des sponanges a tous les degrés de maturite. Les sporanges mùn's sont d'un noir intense.

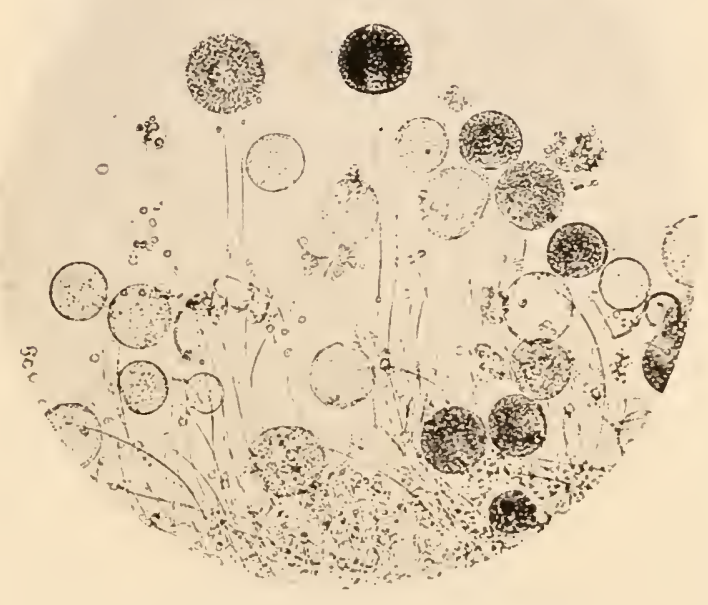

FIG. 6.

Sporanges de Mucor spinosus (gr. 150 diam.).

A gauche du sporange le plus volumineux, qui se trouve en haut et sur la gauche de la préparation, une columelle mise à nu par suite de la déhiscence de la membrane d'enveloppe montre deux prolongements épineux terminaux qui ont donné lieu à l'appellation de cette espèce (Jörgensen).

La figure 7 montre le développement d'un pédicelle sur les rameaux aériens du .Incor spinosus, qui offre à ce nivean une cloison transversale. Le sporange, très jeune, est hérissé à sa surface de petites aspérités.

\section{MUCOR RACEMOSUS}

Le Mucor racemosus (fig. 8) est remarquable par le développement et les ramifications encherêtrées des rameaux aériens. Ces rameaux forment, 
à la surface des liquides sucrés et des milieux de culture solides, non

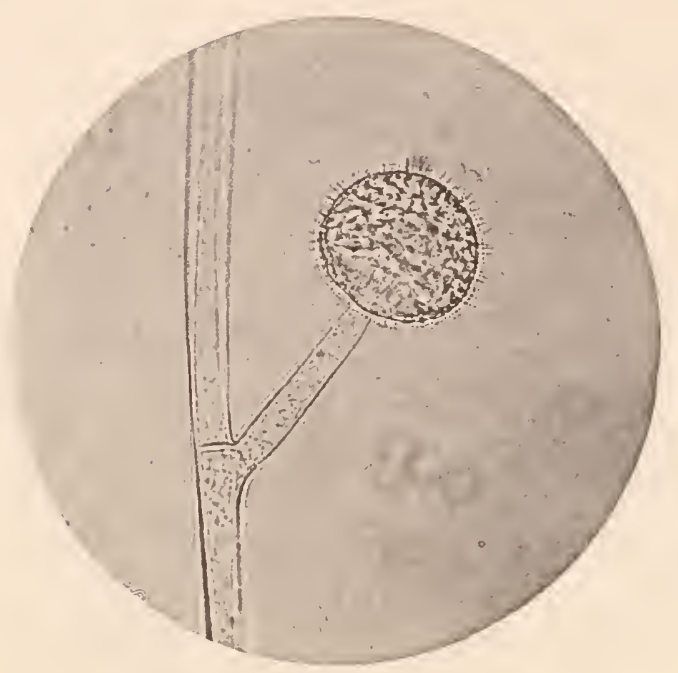

FIG. 7.

Sporange jeune de Mucor spinosus (gr. 400 diam.).

plus des tiges droites comme celles du Phycomyres nitens, du Mucor

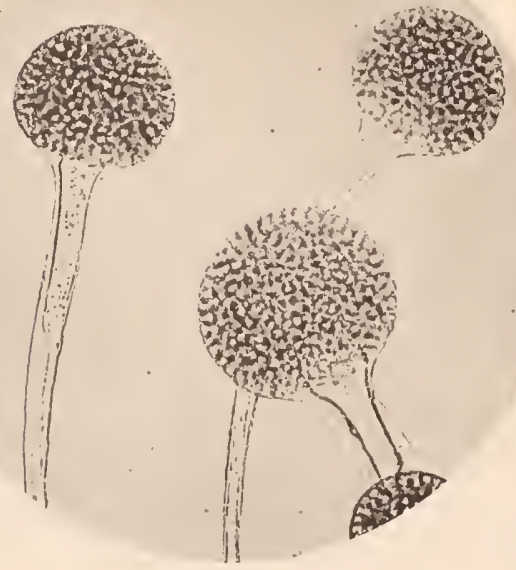

FIG. 8.

Sporanges de Mucor racemosus (gr. 200 diam.).

mucedu ou du Wheor spinosus, mais an paquet de filaments grisitues où l'on remarque, à un examen altentil', de nombrenx pédicelles surmontés 
chacun d'un sporange d'abord grisâtre, puis franchement noirâtre. Nous représentons, figure 8 , trois de ces sporanges encore jeunes, qui laissent entrevoir leur contenu au travers de la membrane d'enve-

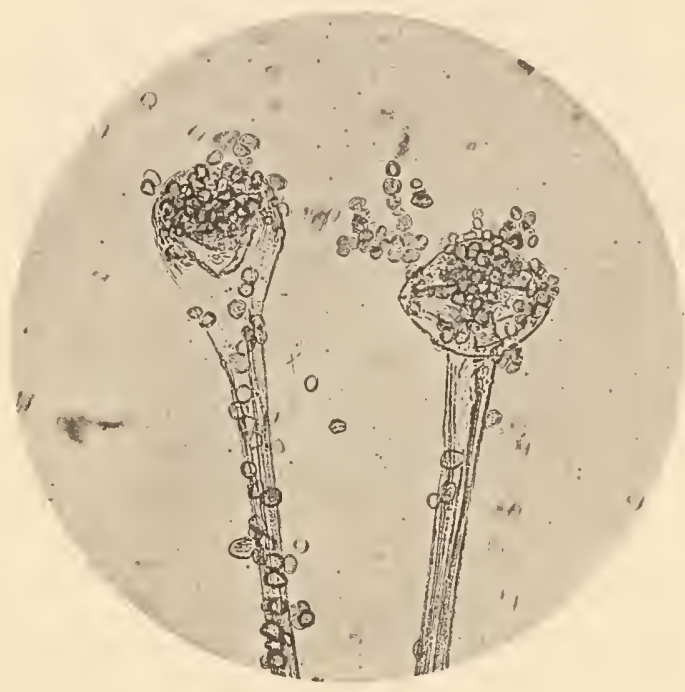

FIs. 9.

Sporanges jeunes de Mucor racemosus écrasés (gr. 160 diam.).

loppe. Cette membrane est plus résistante que celle du Mucor spinosus et se plisse après s'être rompue sous la pression de la lamelle.

On voit, figure 9 , deux sporanges écrasés, ayant déversé leur contenu dans le liquide de la préparation.

\section{MUGOR MUCEDO}

Nous figurons, page 14 (fig. 10), un sporange de Mucor mucedo qui vient de céder à la pression de la lamelle et déverse ses spores au dehors. Les pédicelles du Mucor mucedo sont blanchâtres, et atteignent 10 , 15 et jusqu'à 20 millimètres de hauteur.

\section{MUGOR STOLONIFER}

Le Mucor stolonifer ou Rhizopus nigricans (fig. 11 et suiv.) se développe avec rapidité sur les poires cuites, sur le pain imbibé d'une solution sucrée, etc., et présente cette particularité que ses filaments 


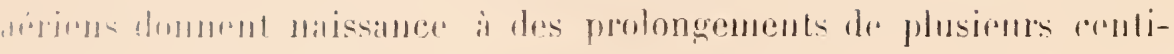

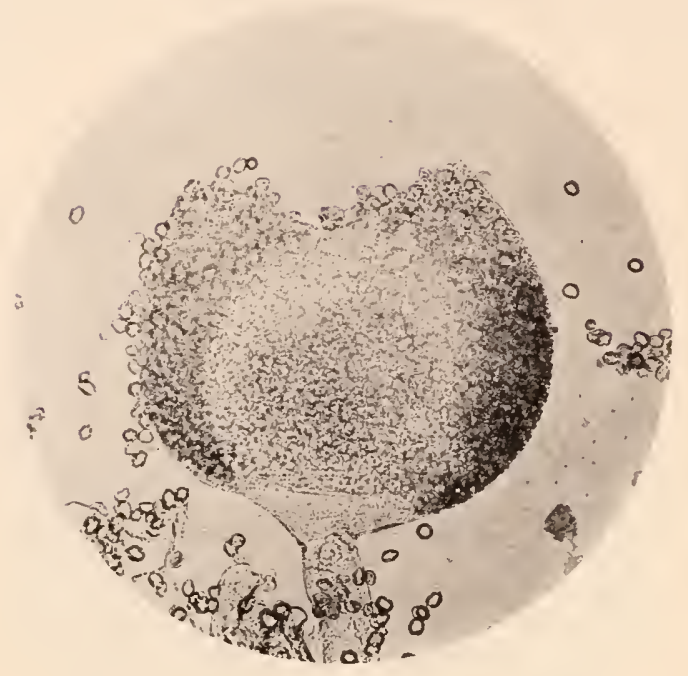

Hiv. III.

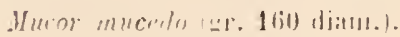

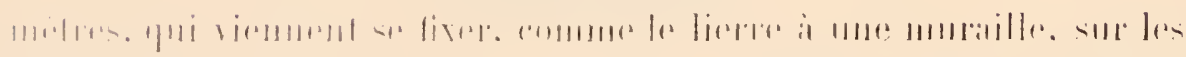

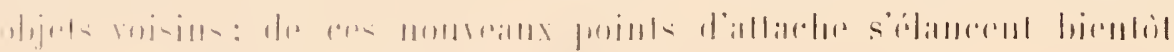

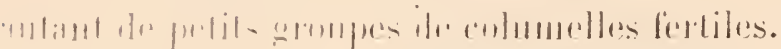

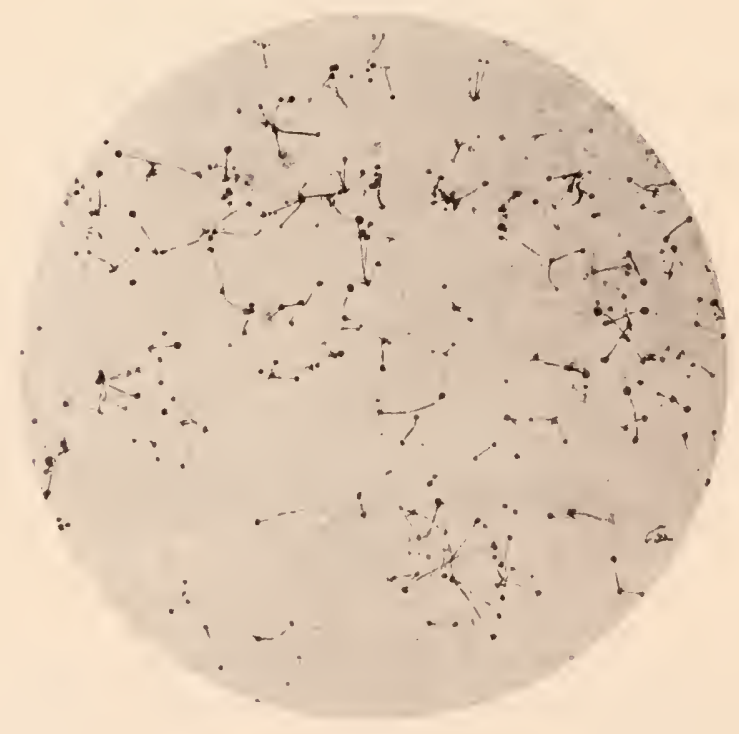

Fin. 11.

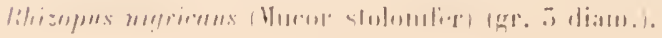


Lat figure 11 représente le couvercle d'un cristallisoir ou se sont développés des bouquets secondaires de Rhizopus nigricans.

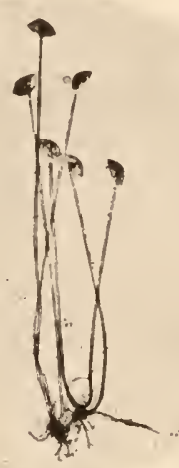

Fig. 12.

Groupe de Mucor stolonifer (gr. 15 diam.).

Un de ces bouquets est reproduit, figure 12, au grossissement de 15 diamètres. Les sporanges se sont rompus au montage de la préparation.

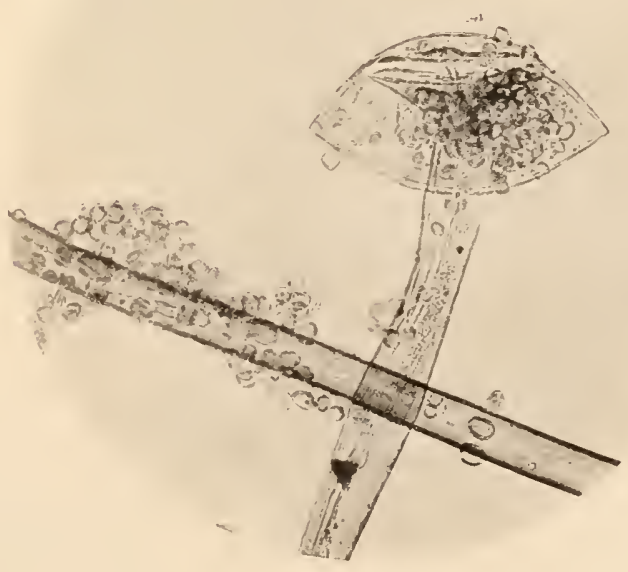

Fig. 15.

lléhiscence du Hucor stolonifer (gr. 200 diam.).

$\$$ un grossissement de 200 diamètres (fig. 15) on remarquera mieux le mode de délisscence du Mucor stoloni/er, déjà visible sur la préparation 
précédente. La membrane des sporanges, très résistante, se retourne en forme de parapluie et demeure adhérente à l'extrémité du pédicelle.

\section{THAMNIDIUM ELEGANS}

Le Thamnidium elegans est remarquable par son double mode de fructification. Autour d'un pédicelle central, porteur d'un sporange arrondi, se développent des sporangioles secondaires, portés par des pédicelles dichotomiquement divisés. Nos cultures de Thamnidium elegans proviennent du laboratoire du professeur Macé, de Nancy.

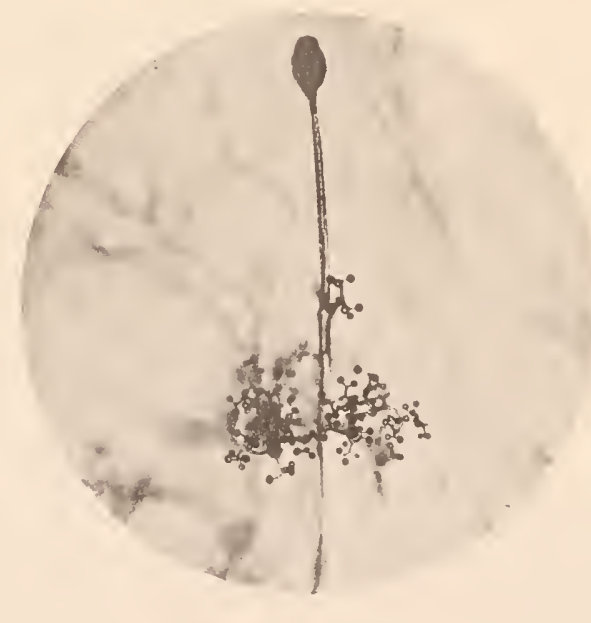

Fig. 14 .

Thamnidium elegans (gr. 70 diam.)

La figure 14 représente un sporaige visie et un groupe de sporangioles secondaires photographiés dans l'aip sans aucun artifice de préparation.

Il nous a été impossible de monter sous une lamelle, sans en détruire le groupement remarquabie, les éléments du Thamnidium elegans. - La figure 15 démontre l'identité de structure des sporanges centraux 
avec ceux des autres esperes de Mureminres. On y romareque, an milien

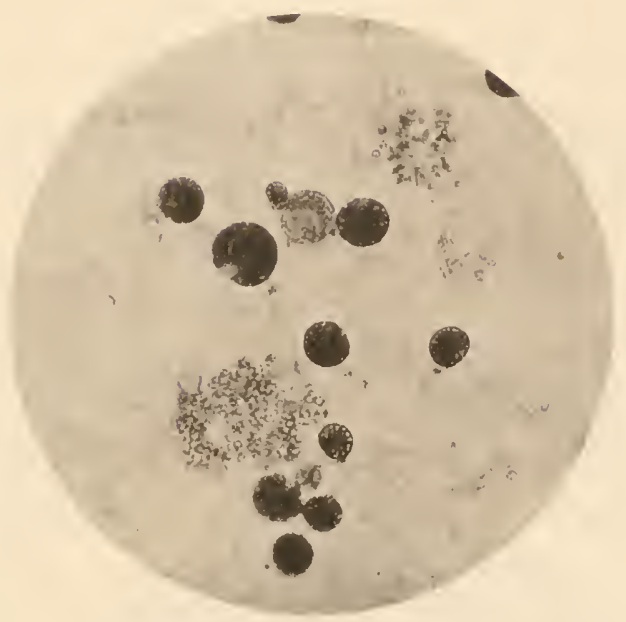

Fig. 15.

Groupe de Thamnidium elegans (gr. 70 diam.).

des sporanges principaux à diver's degrés de malurité, deux groupes de sporangioles secondaires.

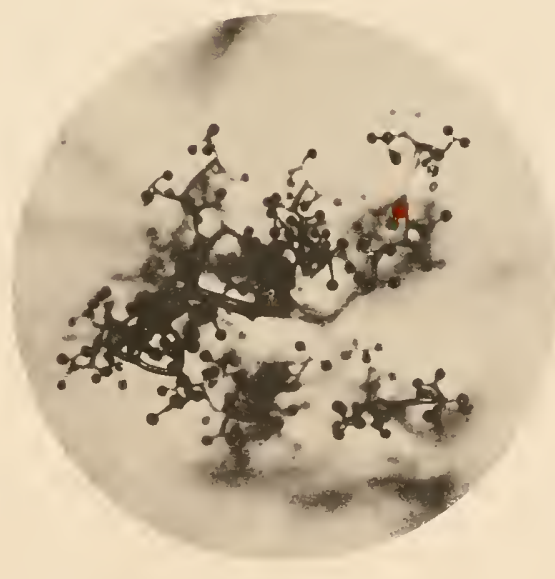

Fig, 16.

Sporatgiole de Thamnilium elegans ( $₫ 100$ dian.).

Xous arnos representi fignres 10 et 17 deux de ces sporangioles secondaires. Le prenier (lig. I(i) est photographié daus l’air. 
Le second (fig. 17) est monté dans l'acide acétique cristallisable. On y distinguc le mode de ramification du pédicelle et le groupement des spores.

\section{PROPRIÉTÉS BIOLOGIQUES DES MUCORINEES}

Aucune de ces moisissures n'est pathogène. Elles agissent comme ferments alcooliques dans les milieux sucrés et sont susceptibles de donner dans un moùt de bière houblonné, contenant 14 grammes d'extrait, de 5 à 5 pour 100 (Mucor mucedo), à 5,50 pour 100 (Mucor

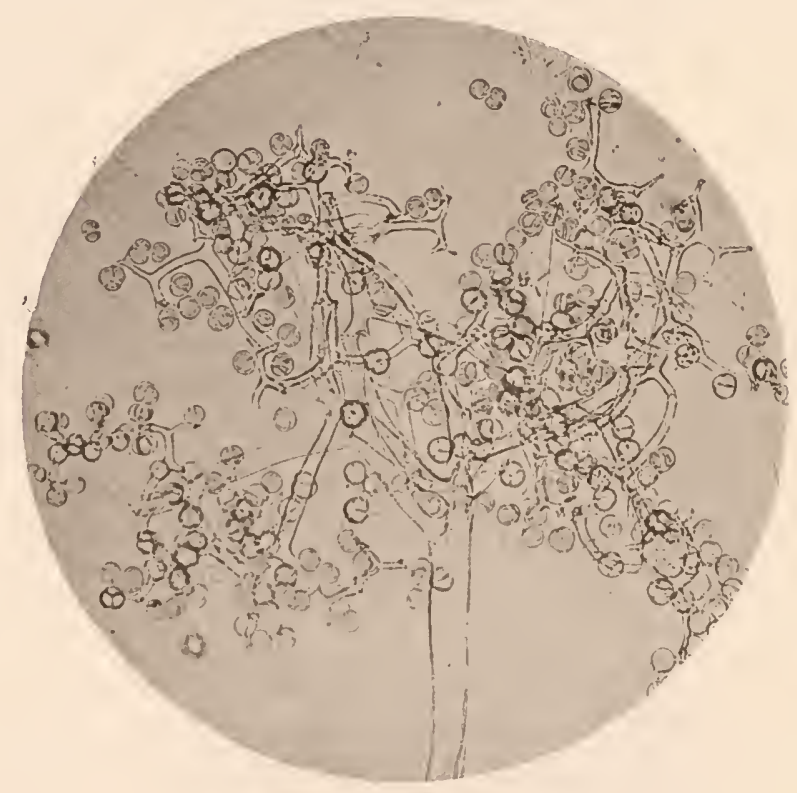

FIG. 1\%。

Sporangiole de Thamnidium elegans (gr. 180 diam.).

spinosus), 7 pour 100 (Mucor racemosus), et même 8 pour 100 (Mucor rectus) d'alcool.

Celte dernière espèce se développe sur les pommes de terre pourries t a le mème aspect que le Nucor racemosus. On l'en distingue par ion resudement alcoolique.

Le Hacor racemosus produit de l'invertine et fermente directement e sucre de canne interverti. 


\section{MOISISSURES}

\section{ASPERGILLUS NIGER}

Parmi les moisissures, le genre Aspergilius est l’un des mieux étudiés.

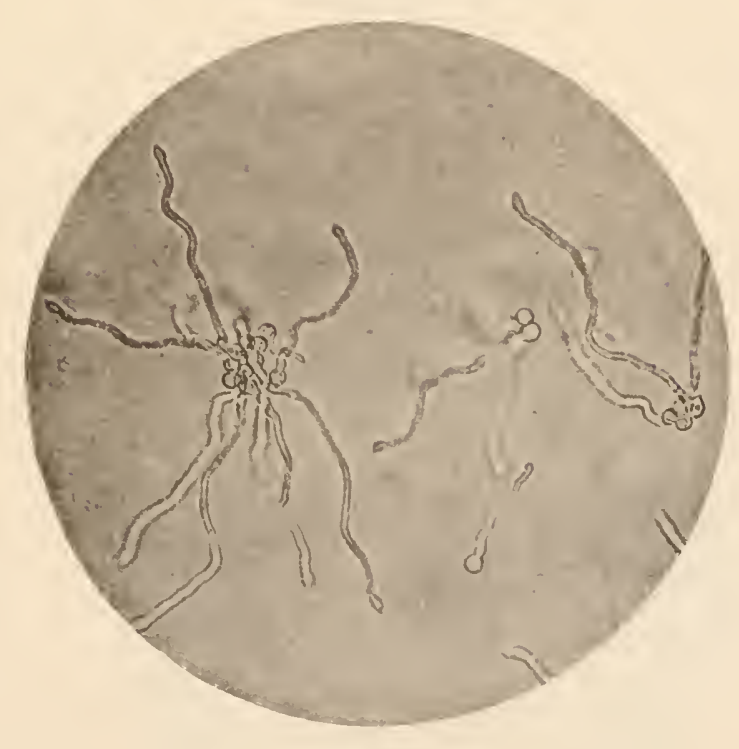

F1G. 18.

Germination des spores de i'Aspergilius niger (g!. 250 diam.).

Nous figurons ci-contre (fig. 18) le mode de gerningation des spores de l'Aspergillus niger.

La figure 19 représente la mène cuiture sur plaque, plus âgée. ()n y constate des cristaux d'oxalate de chaux. 
l'aspect d'une colonie d Aspergillus est reconnaissable ì l'œil nu ou

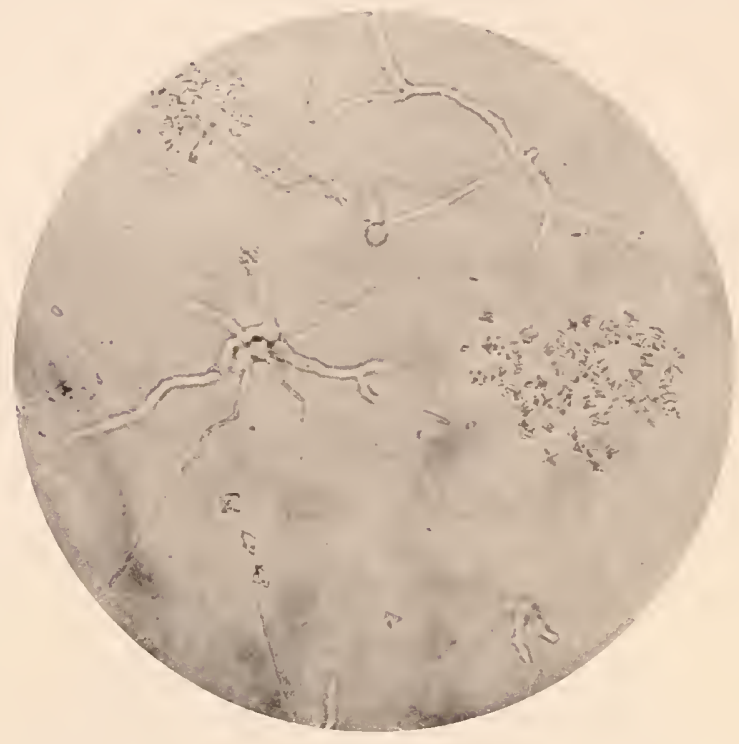

Fig. 19 .

Germination des spores de l'Aspergillus niger. - Cristaux (gr. 250 diam.).

à un grossissement de 5 à 10 diamètres. On y remarque très bien le mode de fructification spécial aux Aspergillées.

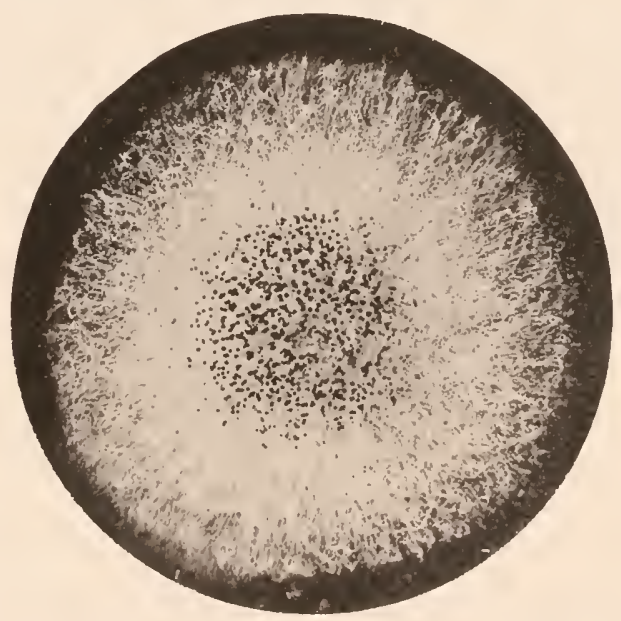

Fig. 20.

Colonie d'Aspergellus niger (gr. 7 diam.)

La figmre 20 reproduit unc colonice d'Aspergillus niger sur agar-agar Les tètes noiràtres tranchent sur' l'aspect blanchâtre des rameaux aériens 
Pour étudier la structure de l'Aspergillus niger, il faut examiner

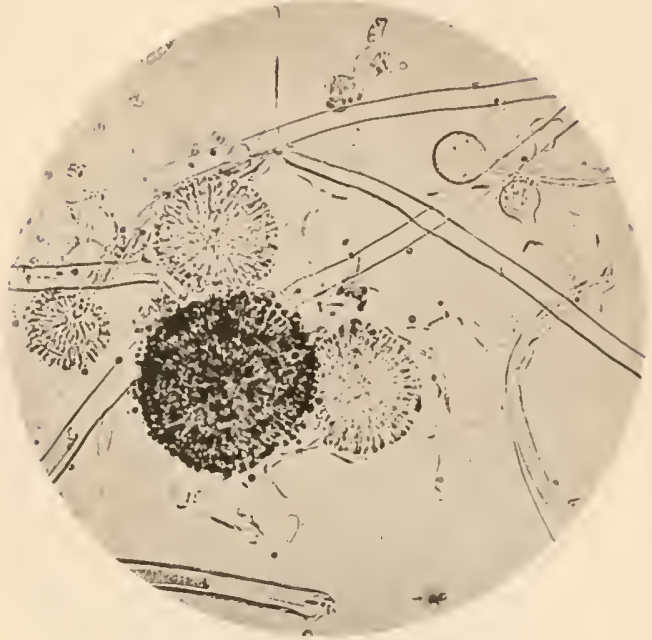

Fig. 21.

Aspergillus niger à divers degrés de maturité (gr. 200 diam.).

les tètes très jeunes, avant l'apparition du pigment noirâtre, qui bientôt voile jusqu'au moindre détail.

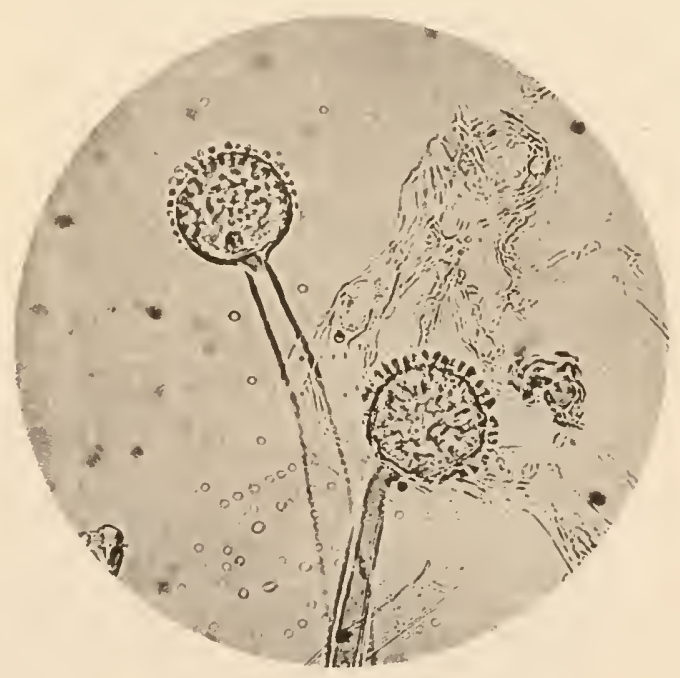

F1G. 22.

Aspergillus niger. Stérigmates principaux (gr. 350 diam.).

On remarquera (fig. 21), en haut et à droite de la préparation, une tête très jeune, encore vésiculeuse et simulant à s'y méprendre une tite de Mucor. Cet aspect est très fugace; bientôt poussent les sté- 
rigmates primitifs, visibles sur les têtes voisines, puis les stérigmates secondaires qui doivent porter les spores.

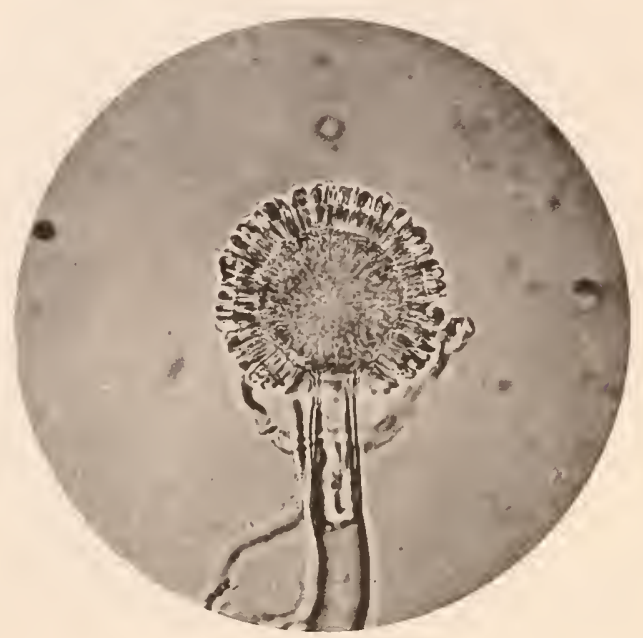

Fig. 23.

Aspergillus niger. Stérigmates secondaires (gr. 400 diam.).

La naissance des stérigmates primitifs de l'Aspergillus niger est particulièrement manifeste sur la figure 22.

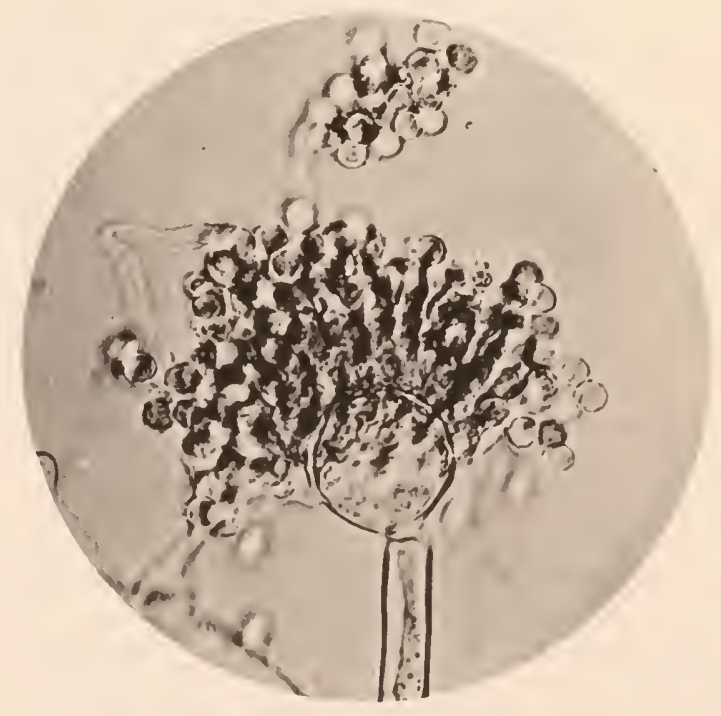

Fig. 24.

Aspergillus niger. Naissance des spores (gr. 800 diam.). 
On observera (fig. 25), li naissance des stérigmates secondaires qui caractérisent la variété dite : Stcrigmatocystis. A leur tour se produisent, à l'extrémité des stérigmates secondaires, des chapelets de spores rondes à double coutour (fig. 24).

\section{ASPERGILLUS FUMIGATUS}

L'Aspergillus fumigatus. dont li culture est d'abord d'un vert intense,

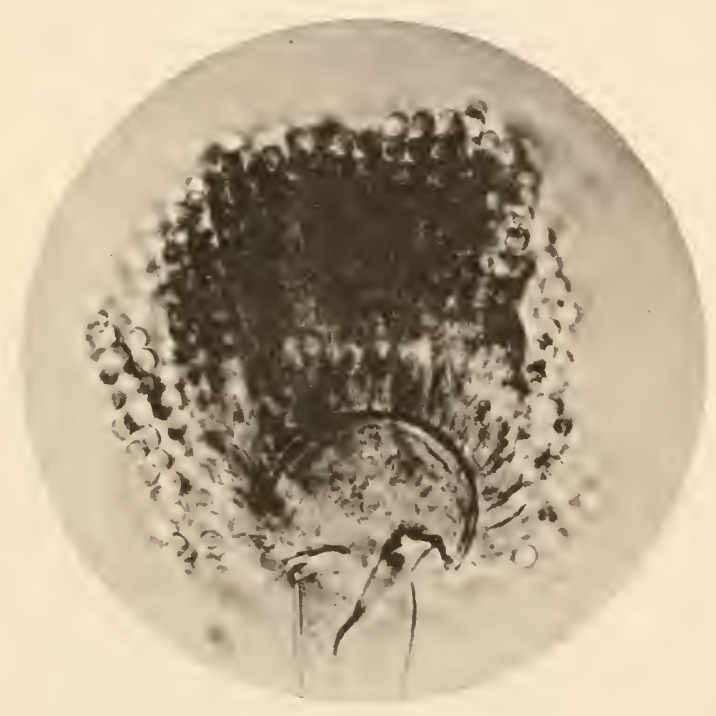

Fig. 25.

Aspergillus fumigatus (gr. 1000 diam.).

de la même teinte qu'une culture vivace de Penicillum glaucum, brunî́ peu à peu par suite de la pigmentation des spores. Cette espèce ne possède qu'une seule rangée de stérigmates.

\section{ASPERGILLUS ORIZAE}

Il en est de même de l'Aspergillus orizx, dont la culture est d'un yert plus pâle.

Comme nous le verrons plus loin, l'Aspergillus orizæ sert à la 
fabrication d'une boisson des Japonais, le Saké. Ses cultures sont d'un

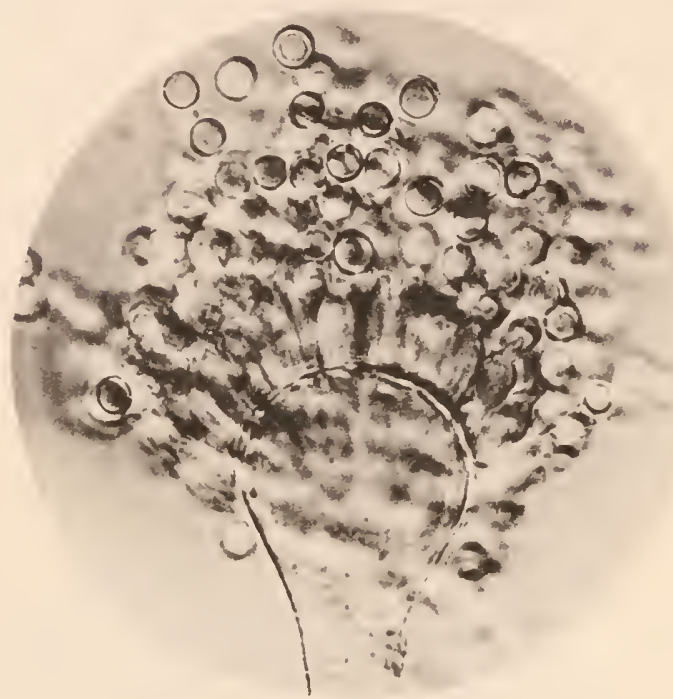

Fig. 26.

Aspergillus orizæ (gr. 1000 diam.).

beau vert pâle et ne présentent jamais l'aspect fuligineux des cultures d'Aspergillus fumigatus.

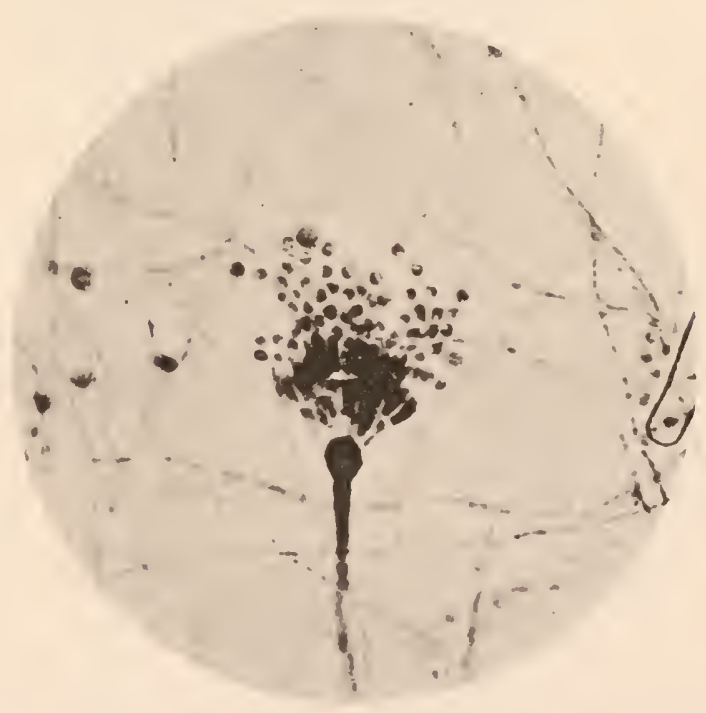

Fig. 27.

Structure d'un Stérigmatocyste (gr. 1000 diam.) 


\section{STRUCTURE D'UN STERIGMATOCYSTE}

Le mode d'insertion des stérigmates primitifs et des stérigmates secondaires, qui caractérisent le genre Stérigmatocyste, puis le mode d'insertion des spores sur ces derniers, sont très évidents sur la figure 27, qui représente au grossissement de 1000 diamètres un petit Stérigmatocyste d'espèce non déterminée.

\section{STERIGMATOCYSTIS GLAUCUS}

Une des variétés les plus curieuses par ses formes de souffrance est le Sterigmatocystis glaucus (fig. 28), qui se développe en couches duveteuses

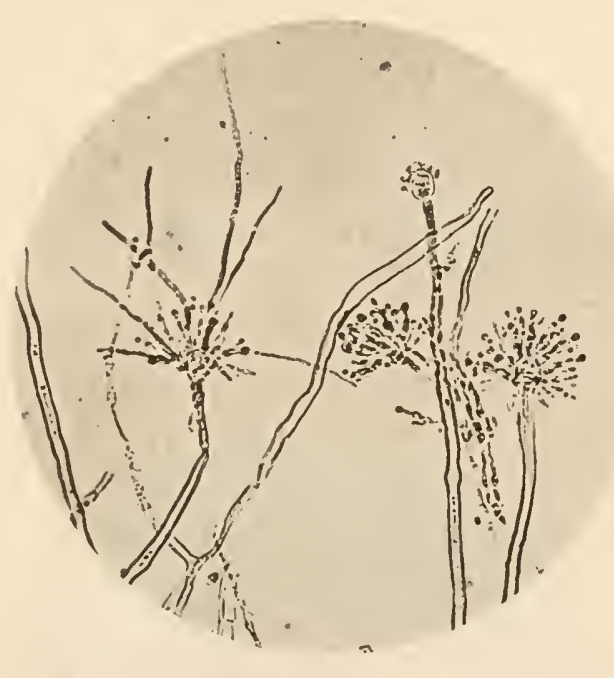

FIG. 28.

Sterigmatocystis glaucus (gr. 300 diam.).

de 4 à 6 millimètres d'épaisseur. Les fructifications sont si grêles qu'on a peine à les distinguer à l'œil nu.

Sur le moût de bière, la culture est d'un beau vert tendre.

Sur l'agar-agar au jus de viande, les organes de fructification demeurent au contraire d'un blanc éclatant.

Cette espèce présente comme particularité ce fait que les 
tètes fructifères portent parfois des stérigmates d'une longueur anormale (fig. 28).

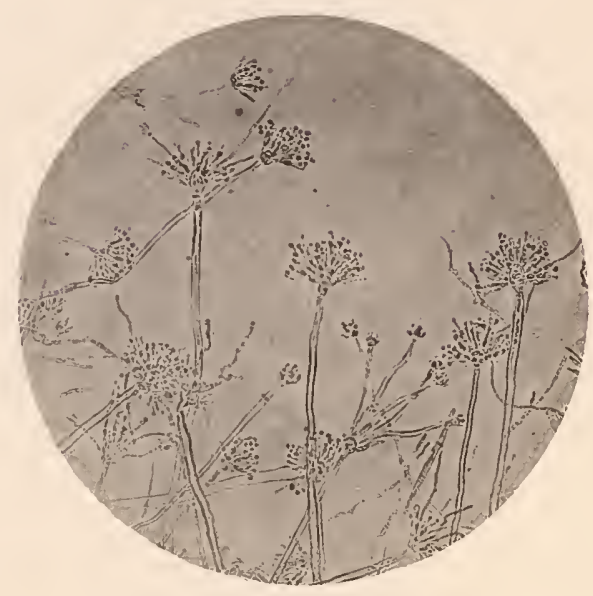

Fig. 29.

Sterigmatocystis glaucus (gr. 180 diam.).

Ces stérigmates anormaux sont susceptibles eux-mèmes de se bifur-

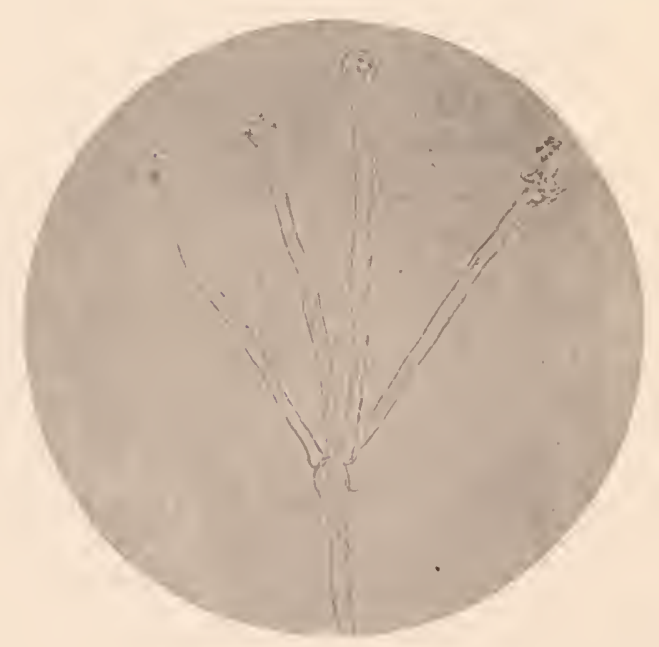

Fig. 30 .

Sterigmatocystis glaucus (gr. 350 diam.). 
quer et de donner naissance ì des renflements conidiens sur lesquels se développent de noureaux stérigmates, puis des spores externes (fig. 29 et 50 ).

Nous n'avons pas cru devoir figurer d'autres espèces d'Aspergillus : A. flavus, A. glaucus, A. ochraceus, etc., qui n'offrent pas en microbiologie d'intérêt particulier.

\section{PROPRIÉTÉS BIOLOGIQUES DES ASPERGILLUS}

Les Aspergillus affectionnent particulièrement les milieux sucrés et légèrement acides. Le pigment des spores ne se développe bien que sur ces derniers, et telle espèce qui croît mal et demeure d'un blanc de neige sur un milieu paure (Sterigmatocystis glaucus) prend une teinte d'un beau vert tendre sur le moût de bière.

Une des espèces que nous avons figurées, l'A. orizæ, jouit d'un pouvoir saccharifiant utilisé dans la préparation du Saké, boisson des Japonais. Cette boisson est produite par l'action saccharifiante de ce champignon sur l'amidon du riz, qui est transformé en glucose et en dextrine, tandis que les albuminoïdes sont peptonisés et deviennent solubles.

\section{ACTION PATHOGÈNE}

Certains Aspergillus sont pathogènes. On a trouvé, chez l'homme, des colonies d'Aspergillus dans un cas de kératite purulente, consécutive à une blessure de la cornée par un grain d'avoine. Quelques espèces, notamment l'Aspergillus niger, ont été rencontrées dans le conduit auditif externe.

Chez quelques animaux, l'injection dans le sang des spores d'Aspergillus fumigatus est susceptible de déterminer une mycose viscérale mortelle (pseudo-tuberculose aspergillairs: du pigeon, du lapin). Il en est de même pour le poumon à la suite de l'inhalation de ces spores. 
Nous représentons, figure 51 , deux foyers infectieux déterminés

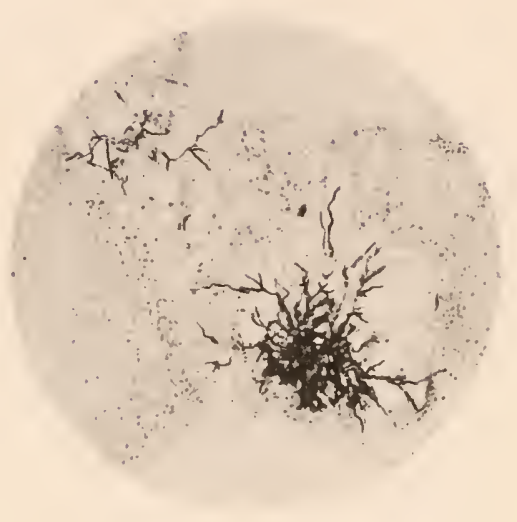

Fig. 31.

Aspergillus fumigatus dans le poumon du pigeon (gr. 150 diam.).

dans le poumon du pigeon par l'inhalation d'air chargé de spores d'Aspergillus fumigatus.

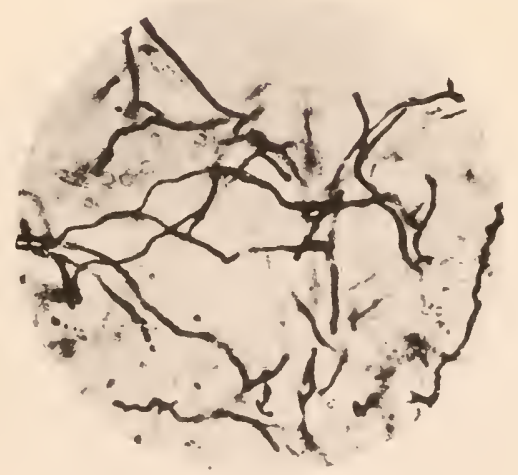

Fig. 32.

Alvéole pulmonaire du canard (Aspergillus fumigatus) (gr. 250 diam.).

La figure 32 représente le développement des tubes mycéliens dans un alvéole pulmonaire de canard. 
La figure 53, une végétation en forme de pinceau à la surface d'une nodosité péribronchique.

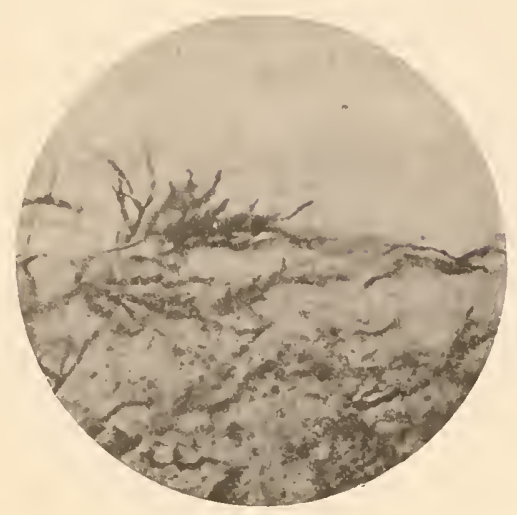

Fig 33

Alvéole pulmonaire du canard (Aspergillus fumigatus) (gr. 250 diam.).

D)ans ce cas, le mycélium a traversé au loin le tissu pulmonaire

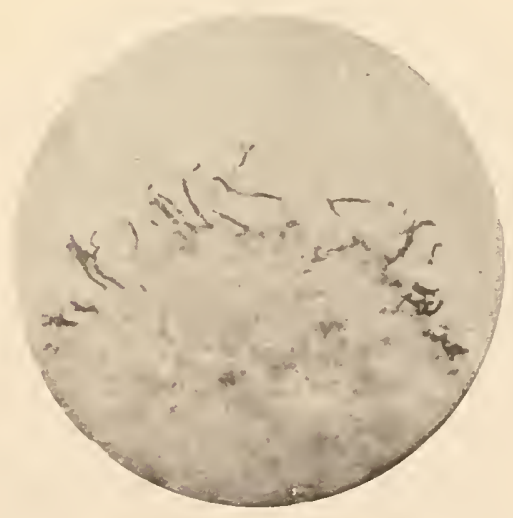

Fir. 34.

Surface de la plèvre près du point que montre la figure 33 (gr. 250 diam.).

pour former de nouveaux foyers intra-pleuraux à la surface de la séreuse (fig. 54) et $\mathrm{y}$ déterminer un processus inflammatoire intense. 
Les figures 55 et 36 représentent, au grossissement de 800 diamètres, deux tubercules pulmonaires du pigeon, infiltrés par

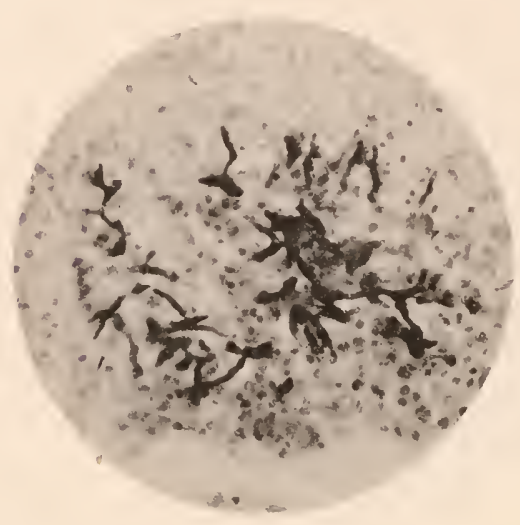

Fig. 35 .

Tubercule pulmonaire du pigeon (Aspergillus fumigatus) (gr. 800 diam.).

l'A. fumigatus. Le mycélium, dans l'un d'eux (fig. 55̃), affecte une

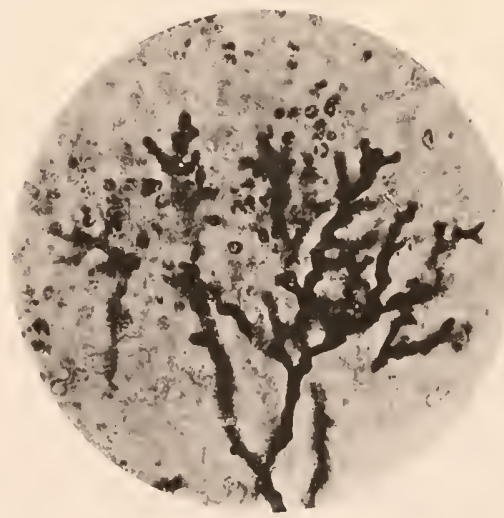

Fig. 36.

Tubercule pulmonaire du pigeon (Aspergillus fumigatus) (gr. 800 diam.).

disposition radiée, et, dans l'autre (fig. 56), une disposition arborescente.

Ces préparations nous ont été confiées par le professeur Cornil. 
Le Penicillum glaucum est l'une des moisissures les plus répandues.

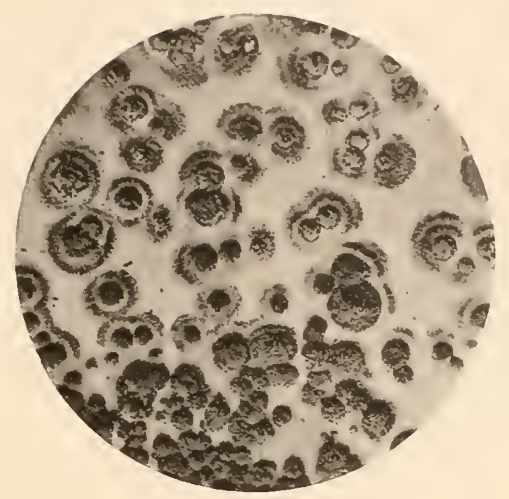

Fic. 37.

Colonies de Penicillum glaucum sur agar-agar (grandeur naturelle).

Elle se développe sur des-milieux très divers et infecte presque toujours les plaques de culture exposées à l'air.

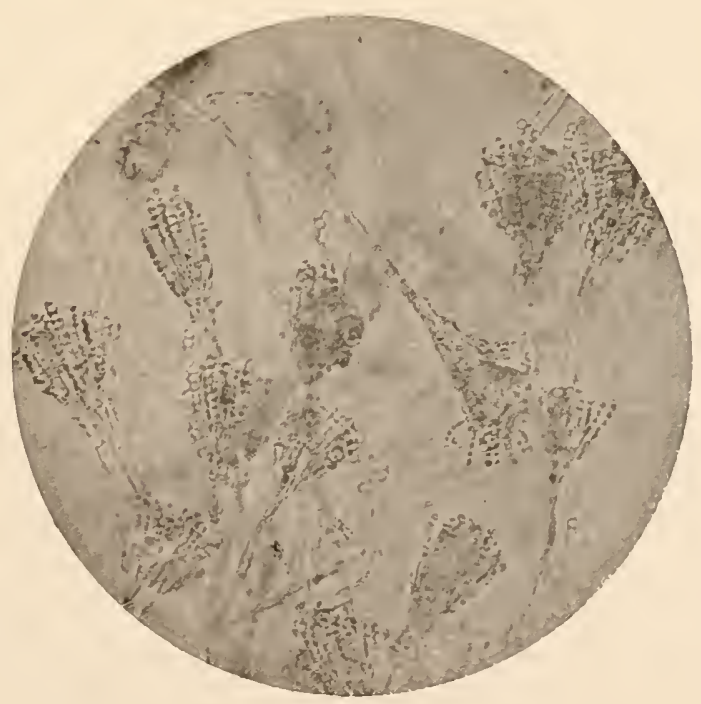

Fig. 38.

Groupe de pinceaux fructifëres du Penicillum glaucum (gr. 200 diam.).

Ia figure 37 reprësente une série de colonies de Penicillum glaucum 
sur agar-agar. Ces colonies sont d'un vert intense; lemr pourtour

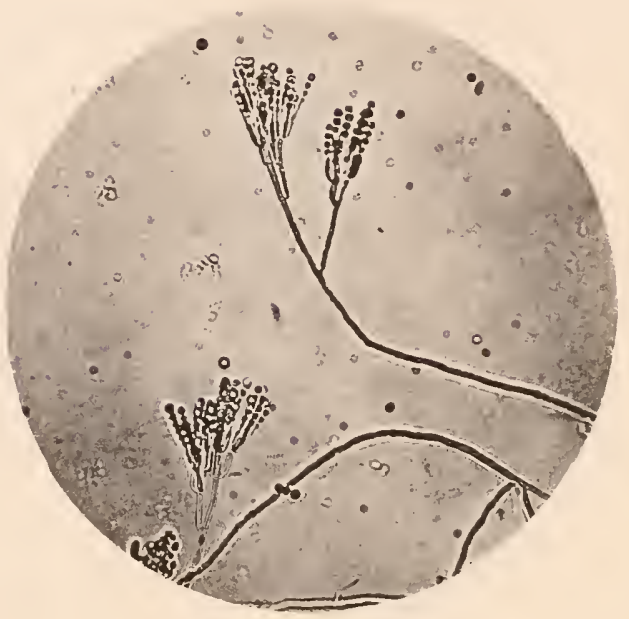

F1G. 39

Penicillum glaucum. Détail des organes de fructification.

est en général blanchàtre, le pigment se montrant d'autant plus

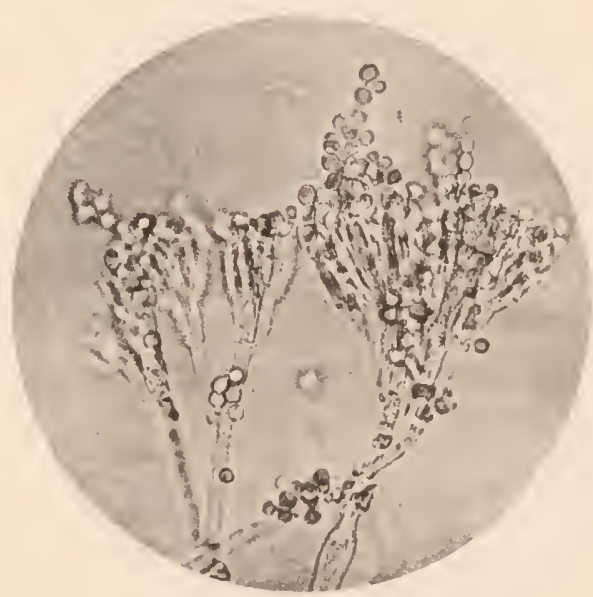

Fig. 40

Penicillum glaucum. Pinceaux fructifëres (gr. 500 diam.).

accentué que les fructifications sont plus anciennes. La fructification commence au centre de ì colonie. 
On a décrit un certain nombre d'espèces de Penicillum glue nous n’arons pas retrources.

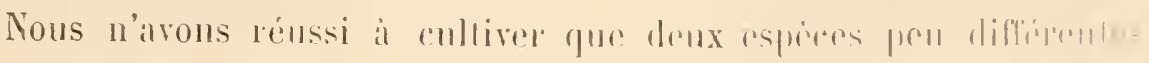

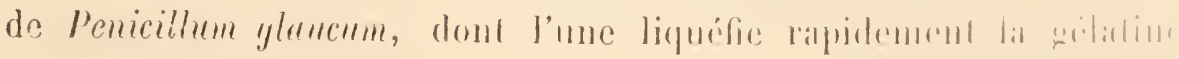
peptone.

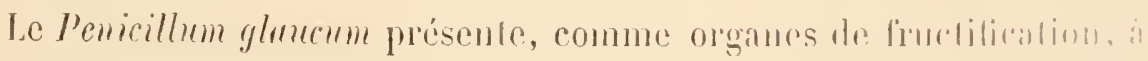
l'extrémité d’un pédicello nop renllé, plusionts rantifirations dirhotomiques an bout de rhacume desquelles se developpe mu long whapelet de spores verdàtres.

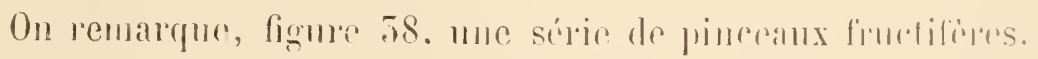

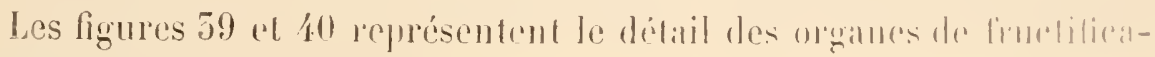
tion du Penicillum glunemm.

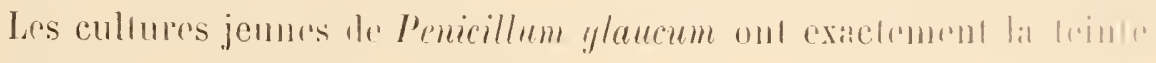
des cultures d'Asprepillus firmigntus.

Les vieilles cultures devienuent, comme celles de l'Aspratlus fumi-

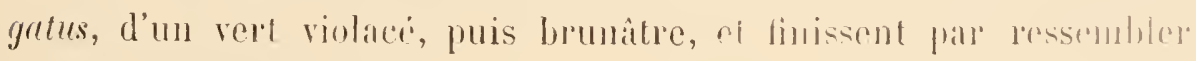
à une couche de suie.

A l'almi de l'air libre, el dans des miliens pen mulrilib. dans

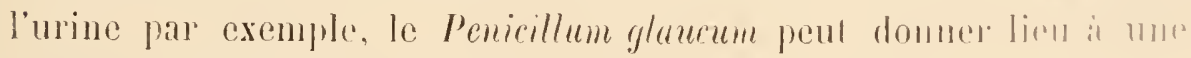
végétation hlanchàtre, alssolument privée de pigment.

\section{PROPRIÉTÉS BIOLOGIQUES DES PENIGILLUM}

Sur les milicux mulrilils liquides, le Penicillum glunemm forme nne conche épaisse, vériblule croute lidlie, el irriguliere il sil litce infé-

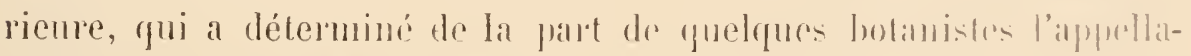
tion de Penicillum crustaceum.

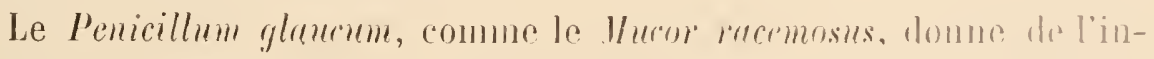

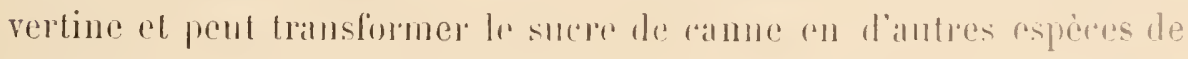
sucres, mais il est incapbiblede déterminer mor fermentaltion alleooligue.

Les cultures ont une odeur franche dr « moisi ».

Le Penicillum glancum n'est pals pathogine. 


\section{MYGOSFS EXTERNES DE L'HOMIME ET DES ANIMAUX}

\section{TRICHOPHYTIES - FAVUS - PITYRIASIS VERSIGOLORE ERYTHRASMA}

Parmi les maladies du tégument externe, un certain nombre sont aujourl'hui classées dans la catégorie des affections parasitaires.

Le Pityriasis versicolore, l'Erylhrasma sont dus à l'évolution de parasites spciciaux; nous rerrons que ees parasites, bien que très évidents lorsque l'on conploic pour l'examen des Squames épidermiques me technique spćciale (Malassez et Gram) sont encore peu connus. Leur culture sur les milieux artificiels demeure un problèmé insoluble. Leur elassification botanique est impossible.

L'étude des maladies parasitaires dı cuir chevelu est plus avancée, depuis que les Trichoplıtons ont pu ère cultivés artificiellement et assimilés, d’après les caractères de leurs organes de fructification, au groupe des Botrytis.

L'étude des Teignes vient ainsi prendre place apres celle des moisissures.

Nous décrirons d'aloord les Trichoplịties et la Teigne spéciale de Grüby, qui sont aujourd'hui les mieux connues au point de vue parasitaire.

Nous ne pouvons faire micux que de reproduire, pour cette partie de notre atlas, le travail remarquahle de M. Sabourand sur les Trichophỵties humaines et animales, travail qui est le document le plus récent, et de beaucoup le plus complet sur ce point intéressant de la pathologie culanée.

Nons étudierons ensuite, avee le Dr Bodin, le Fatus, le Pityriasis versicolore et l'Erythrasma.

Les préparations des I) Silbouraud et Bodin ont été photographićes à Reims, dans notre laboratoire ou dans celui de netre ami 1 . Rothier. 


\section{LES TEIGNES}

Le mot Teigne (tinea), qui, selon quelques auteurs, parait dériver de l'arabe, a été employé depuis le xı siècle pour désigner les maladies graves et rebelles du cuir chevelu.

Ces maladies étaient alor's confuses dans l'esprit des médecins et le mot Teigne ne doit conserver qu'une signification de siège bien déterminée.

On désignait ainsi les affections chroniques du cuir cherelu, par opposition aux dartres et aux éruptions des autres parties du corps.

La contagiosité des Teignes était connue dans l'antiquité. Pline l'Ancien relate l'histoire d'une épidémie de Mentagre qui fut importée d'Égypte à Rome. Ambroise Paré remarqua la nature contagieuse de certaines teignes et recommanda l'épilation.

Nais la découverte des éléments parasitaires ne date que d'une cinquantaine d'années.

L'histoire des Teignes se divise done en deux grandes périodes que sépare un fait capital : la découverte de leur nature parasitaire.

Schœnlein décrivit l'Achorion en 1859. Le Trichophyton tonsurans et le Microsporoin Audouïni furent découverts à leur tour, de 1841 à 1845, par Grülyy.

Lorry, Alibert, Biett, Willan, Mahon, avaient déjà distingué cliniquement, quelques années auparavant, le Favus des Teignes tondantes.

Le Farus est caraclérisé par la production de croûtes jaunâtres arrondies, au niveau desquelles on observe des dépressions en forme de gorlets.

Le Godet favique est tellement caractéristique que son aspect seul entraîne le diagnostic de la lésion et de son parasite.

Les chereux, aux points altérés, sont ternes, secs, et n'offrent plus qu'une faible adhérence.

L'odeur des godets faviques rappelle celle de la souris. 
L'Achorion Schænlernii, le parasite du Favus, peut envahir les ongles et même les parties glabres, où il détermine des lésions spéciales.

Tout autre est l'aspect des Teignes tondantes : ces dernières doivent leur appellation à cette particularité, que les cheveux envahis se cassent uniformément à quelques millimètres au-dessus de la surface de la peau.

On distingue, chez l'homme, deux variétés de Teigne tondante : la Teigne Trichophytique, causée par le Trichophyton tonsurans, et la Teigne spéciale de Grüby, autrelois confondue avec la Pelade, et occasionnée par le développement du Microsporon Audoüni.

Les Teignes se développent surtout sur les jeunes sujets et sévissent particulièrement dans la classe pauvre.

La cause déterminante est toujours la contagion, par transmission directe ou indirecte du parasite d'un individu malade à un sujet sain.

Il est possible aussi que, dans certains cas, la contagion soit d'origine animale, ear le chien, la poule, la souris, le cheval, le chat et d'autres animaux sont susceptibles d'être atteints de Teignes qui présentent avee le Favus et les Teignes tondantes une grande analogie.

La durée des Teignes est habituellement longue. On les observe souvent, les Teignes tondantes surtout, en vastes foyers épidémiques, léveloppés en quelques semaines et comptant parfois cent cas et plus.

Les Teignes sont des maladies tout à fait bénignes en ce sens qu'elles n’altèrent pas la santé générale et que touie leur évolution est indolore. Elles sont bénignes aussi en ce sens qu'elles guérissent toujours, mème spontanément, et ne dépassent guère l'époque de la puberté.

Elles ne sont done redoutables qu'en raison de leur ténacité.

Leur durée peut atteindre et dépasser trois ans, pendant lesquels les enfants conlaminés demeurent contagieux et, comme tels, privés de l'école ou hospitalisés. Les traitements les mieux conduits n’aboutissent à la guérison que dans un laps de temps de six mois à un an. 
Si hemignes que soienl, par comscipurnl, ces aflections an point de

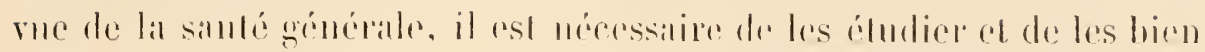

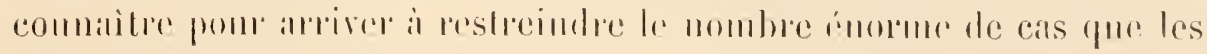

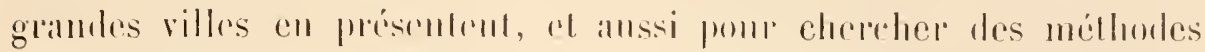

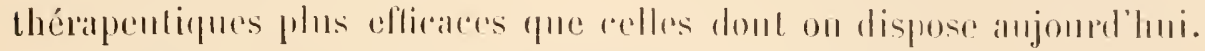

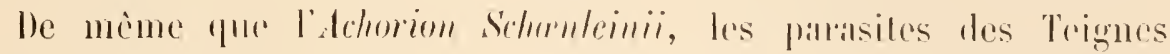

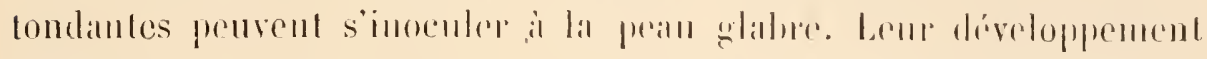

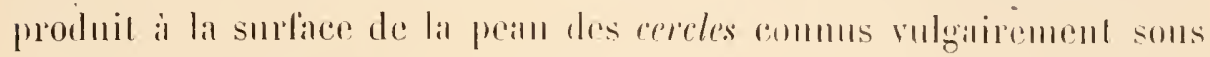

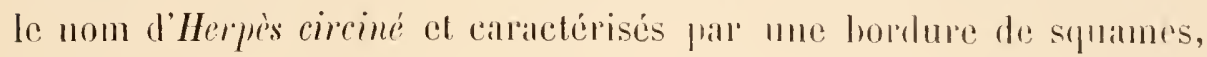
de résicules, de pustules on de cronles. On roit soment lillerpes circinc coexister sur le mème sujet aree la Teigne tondinte.

Les ongles penvent ètro alleinls; ils sont alors diversement allérés, llos épaissis, jambitres, exlolies en surface.

lihomme adulte pent igalement contracter cette maladie a la barbe.

les alléralions do poil sont alors analognes an alléralions des elevenx de linfint.

Xous avons vu plus haut qu’il existe deux rarictés de Teigne tondante.

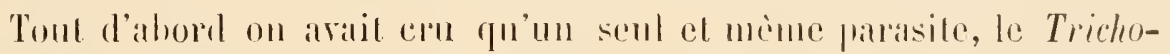

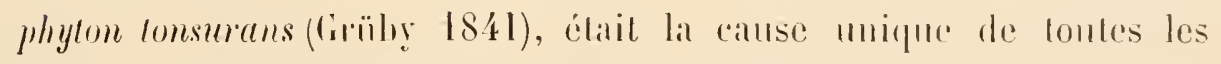
lísions gue nous renons de passer en lovme.

Il est anjomblumi bien démontré qu’il existe, en dolors de la

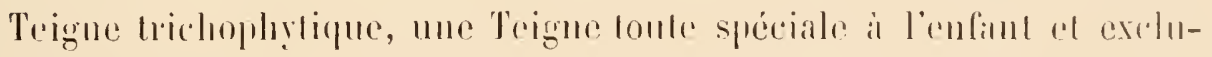
sivement localisée an cuir cherelu, Teigme domb le parasile est imeatpable de se développer, comme on lobserve an conlraire ponte le Trichophyton, an niveau de la pean glabre, des ongles on de lit hallw, chez l’adulte. Celte leigne spéciale est causéc par le Microsporon Audoüni de Grïlyg; nous la dénommerons Tejgne à prolites sprores.

L'autre toudinte, la Teigne trichophylipue, comprend de nombreuses formes cliniques, qui semblent correspondre il des parasifes différents. C'est ainsi que les Trichophytons des animanx sont seuls capables d'envahir les poils de la barbe chez l'homme adulte.

Nous aurons donc à étudier successivement :

$1^{\circ}$ Les Trichophyties, et, parmi ces dernières, nous distinguerons 
la Teigne tondante de l'enfant et les Trichophyties d'origine animale, qui, seules, sont susceptibles de s'inoculer à la barbe de l'homme adulte et de causer le Sycosis parasitaire.

$2^{\circ}$ La Teigne tondante spéciale à petites spores, de Grüby, qui est due au Microsporon Audouïni.

Ces deux maladies, bien qu'absolument différentes et chacune spécifique, méritent d'ètre étudiées còte à côte, ì cause de leurs nombreux points de ressemblance, qui ont favorisé leur confusion jusqu'ì ce jour.

Les Trichophytons appartiennent au groupe des Botrytis.

Les Botrytis sont des moisissures ì rameaux aériens grisàtres, dont les fructifications (fig. 147, 148 et 1.99) ont l'aspect de grappes microseopiques.

Le Botrytis cinerea, qui se développe très bien sur le vin ou sur le moût de bière, exhale en culture une odeur de souris.

Le premier Botrytis pathogène connu a été le Botrytis Bassiana, le champignon de la Muscardine du ver à soie.

Sa découverte date de 1855 . Elle a done précédé de quelques années la déconverte des parasites du Farus et des Teignes tondantes.

D'un autre còté, le Trichophyton ayant été décrit daus les cheveux, par. Grüby, bien avant qu'on ait pu déterminer sa classification botanique (Buclaux, 1886), nous croyons bien faire en étudiant, avec le I) Sabouraud, les trichophyties analytiquement et en commençant par l'étude du cheveu, pour suirre cusuite les parasites dans les différents starles de leur développement. 


\title{
TEIGNE TRICHOPHYTIQUE
}

E' 1 I

\author{
TEIGME SPECIALE JE GRÜBY
}

\section{LES TRICHOPHYTIES}

Avant d'étudier les trichophyties, au double point de vue anatomopathologique et mỵcologique, deux questions préjudicielles se posenı it doivent être d'abord mises en lumière :

$1^{\circ}$ L'influence de la composition chimique du milieu de culture;

20 Le fait du commensalisme de plusieurs espèces cryptogamiques, dom une senle pathogène, dans les diverses lésions mycosiques que peuvent créer les Trichophytons.

$\mathrm{f}^{\circ}$ - Influence de la composition chimique du milieu de culture sur la forme des cultures cryptogamiques.

Si l'on prend pour milieu de culture une gélose peptonisée et maltosée. en augmentant d'une culture à l'autre la proportion de maltose et elı faisant successivement décroitre la quantité de peptone, on obtiendra. avec le mème germe, différents aspects des cultures

1. Toutes les cultures que nous figurerons dans cette partie de notre Atlas (cultures sur tubes et sur cristallisoirs) sont représentées grandeur naturelle. (Dr Dores). 


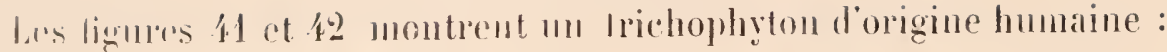

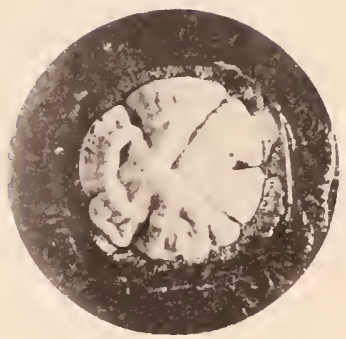

Fin. 11 .

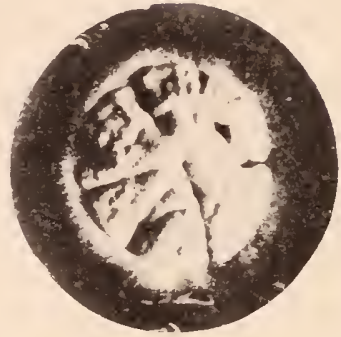

Fig. 49.

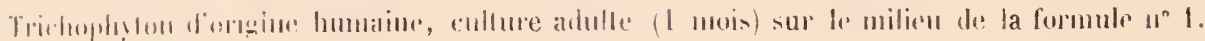

linlur alun molis sul mue gélose contenant :

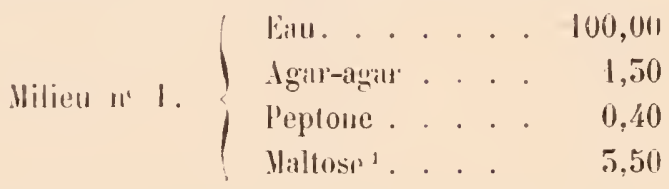

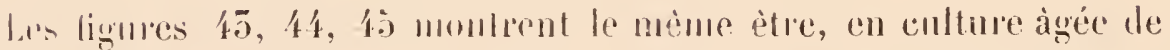

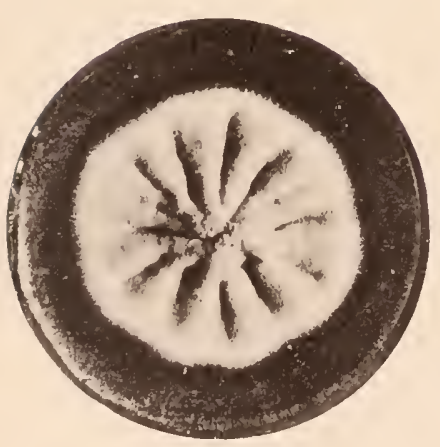

Fig. 价.

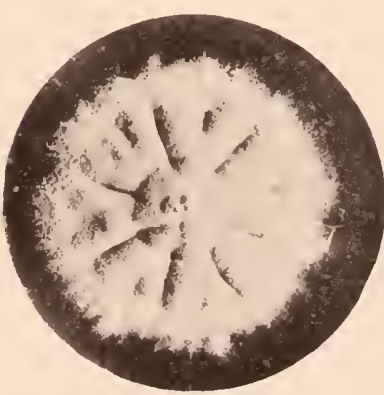

Fig. 4'.

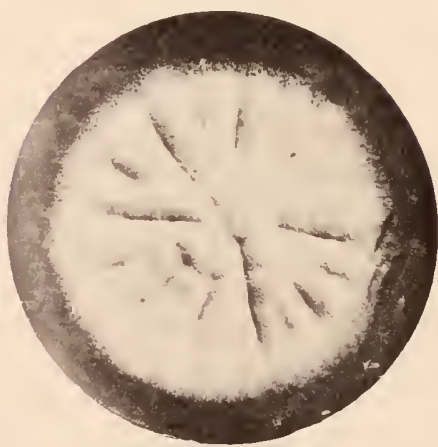

Fig. (4).

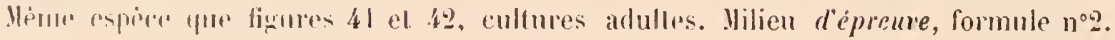

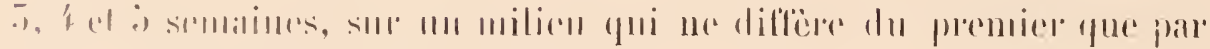

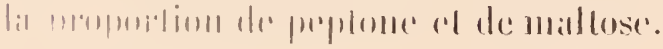

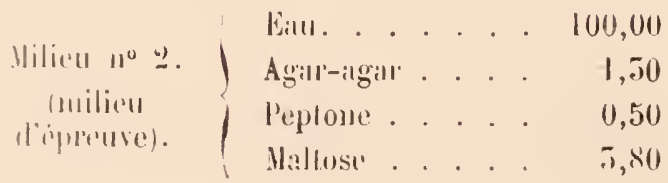

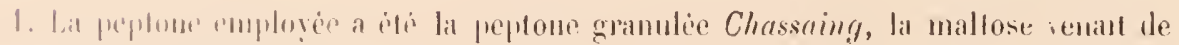
l'lsime de creil. 


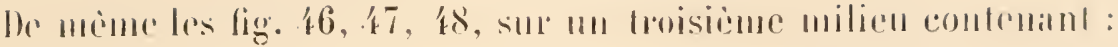

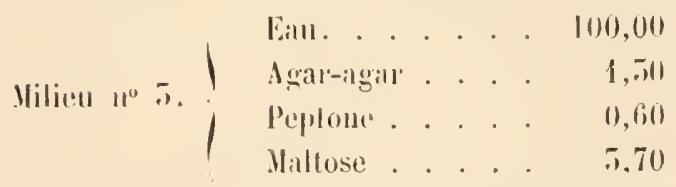

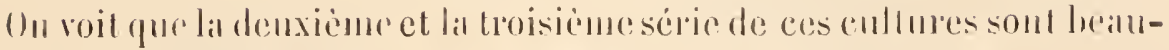

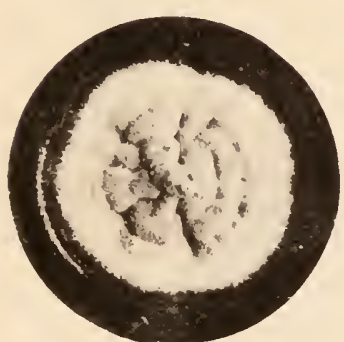

F11. 46 .

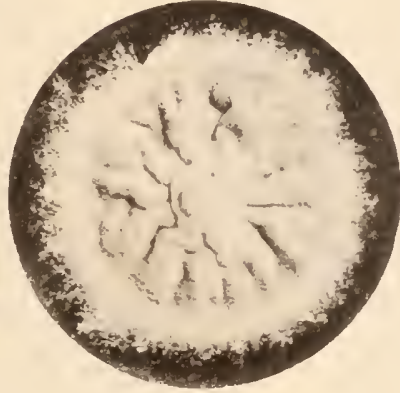

Fig. 47 .

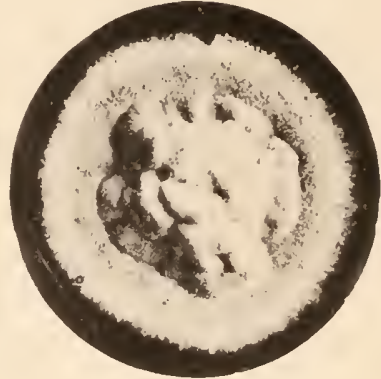

Fig. is.

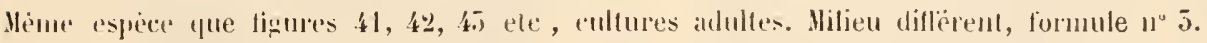

(oup plus vivaces que la premiere, que la deuxieme est remaurquable par sal disposition géomébique, que la hroisiène est la plus exubérante.

Linc antre espece de trichophlylon humain encore non classée el assez rare, nous domnc corollatrentent les cultures diflérentes que roici sur les mèmes miliens que la série prócédente.

Fig. 49. Vilieu $\Perp^{\circ} 1$.

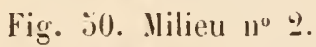

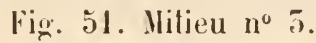

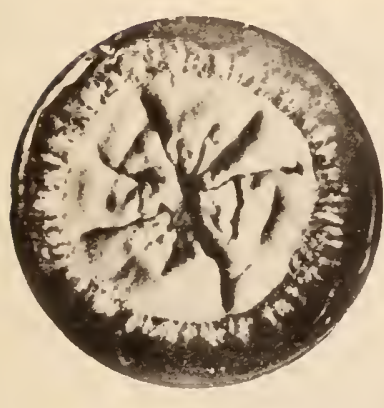

Fig. \{!!.

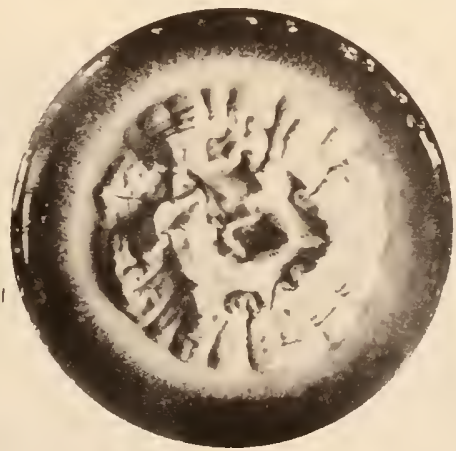

FIG. $j 0$.

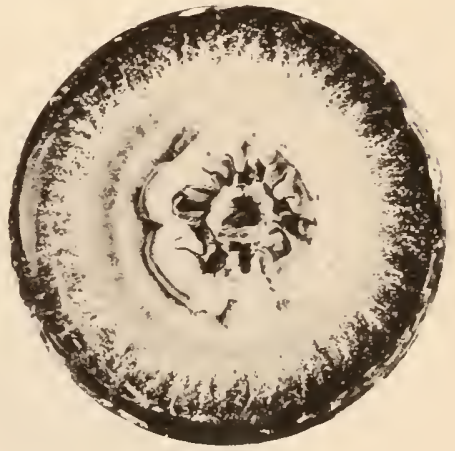

Fif. il

Variations de formes d'une meme espece Trichoph!lique snivant le milien de culture

Or ces cultures ont une forme et un aspect caractiristique inva. riables si elles sont pratiquées sur un milieu de culture toujours chi. 
miquement identique et placé dans les mêmes conditions physiques d’aération et de température.

\section{II. - Les associations cryptogamiques dans les trichophyties.}

Les associations cryptogamiques ont été mentionnées par Kràl (dePrague) en cequi concernele favus; elles sont aussi de règle presque sans exemption dans les trichophyties humaines et animales. Elles se montrenl dans les cultures sous denx formes:

T'antòt le champignon commensal apparait sur la culture trichophṛ-

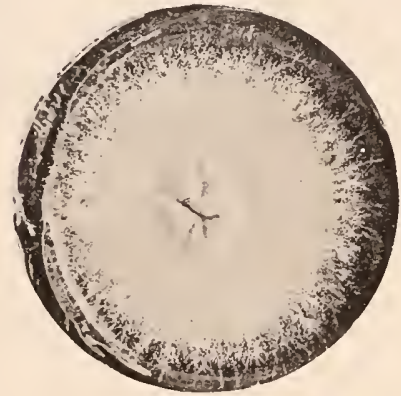

Fig. 5\%.

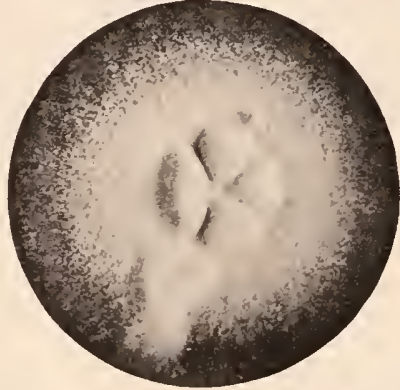

Fig. 55.

Commensalisne parasitaire dans les eullures trichophytiques. Colonies isolées.

tique sous forme de colonies isolées (lig. 52, כ̌5). Tantôt le trichophyton et son commensal sont plus étroitement juxtaposés dans le champ de la

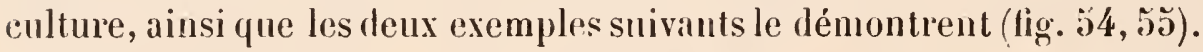

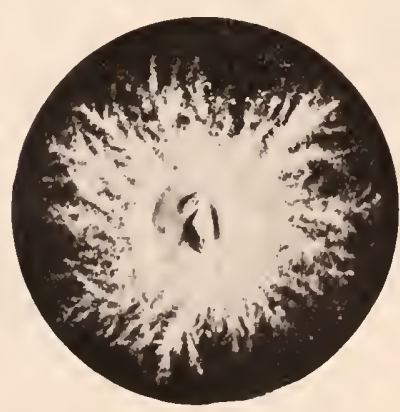

Fig. ذ่.

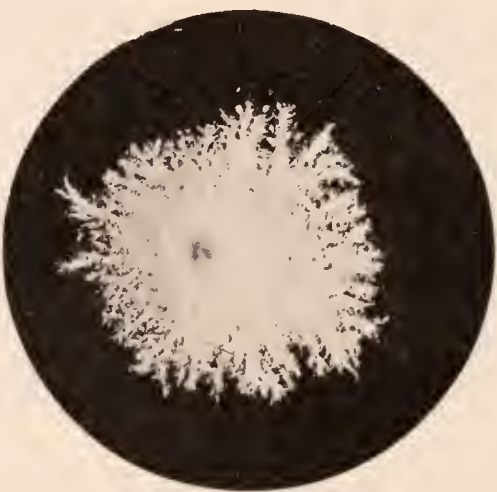

Fic. 5ว.

Commensalisme.

Fïg. 54. - Juxtaposition tolale du Trichophylon et de som Commensal.
Fig. 55. - Le meme Trichoplugton sipare de son Commensal. 
Les champignons commensaux des trichophytons sont d'espèces peu nombreuses et se retrourent presque toujours les mèmes. En roici quelques cultures (lig. i6-61), sur gélose peptone maltosice (milien n²).

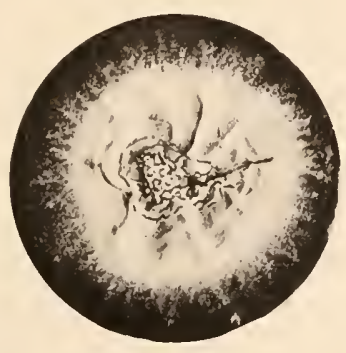

Fig. 56.

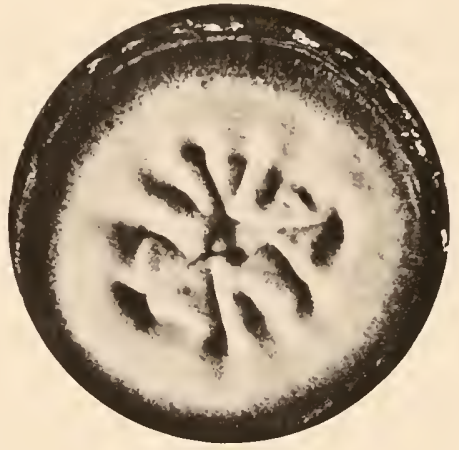

FIG. วั7.

Leux Commensanx du Trichophỵton dans sa lésion.

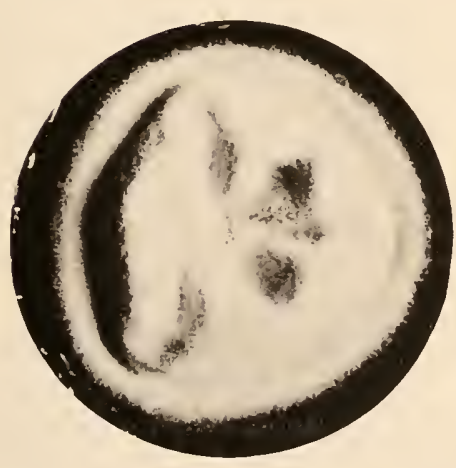

Fit. id.

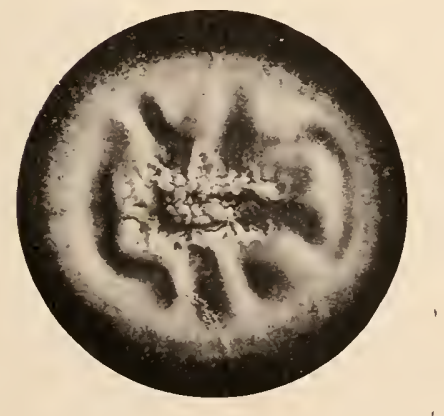

Fis. till.

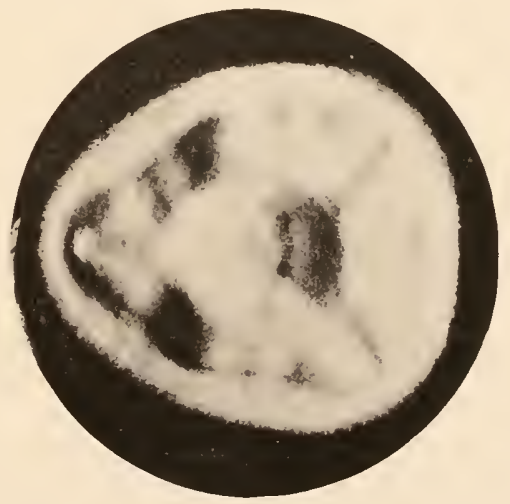

Fig. j!\%.

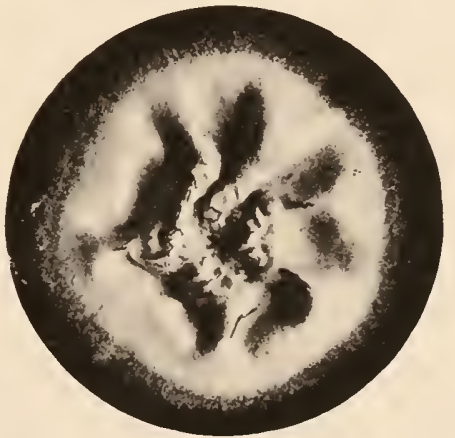

Fig. 61 .

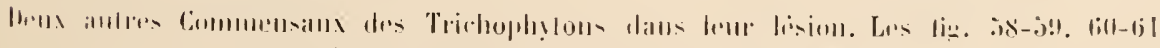

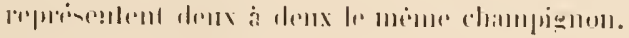


Les milieux tris sucrés, peu atzotés, conviennent mienx anx trichophytons qu'ì leurs commensiux. Les milienx pen sucrés, très arotés. conviennent mieux aux commensaux des trichophytons qu'ilux trichophytons enx-mèmes.

Il s'ensuit qu'après me séric de eultures an milienx azotís, on pent ne plus retrouver trace du trichophyton initial.
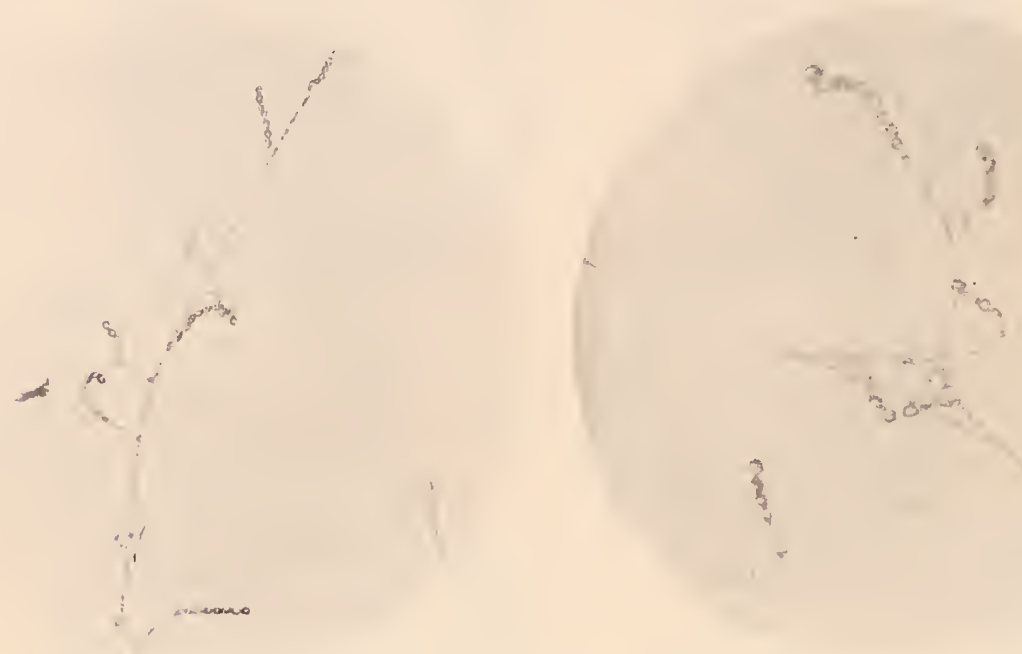

FiG. 62.

(gr. 200 diam.)

(gr. 500 diam.)

Sommensal ayant pris la place d'un Trichophyton dans la culture trichophyticue primitive.

Les lign. 62, 65, montreut les firmetificalions d'un oospora yni s'esl ainsi progressivement substitué an trichophyton dans sal culture après plusieurs générations.

Les deux points que nous venons d'élablir, l'importance du milien dans la forme des cultures et le fait des associations eryptogamiques sont d'une importance cipitale et ne doivent jamais être perdus de rue, non seulement dins l'étude des trichophytons, mais diuns touk recherche mycologique.

\section{LES TRICHOPIITTIES DOORIGINE HUMAIVE}

Le trichophyton, dans le cheven (teigne tondante triehophytique), est issentiellement constitué par des filanents mycéliens réguliers, composés de cellules a double contour qui sont des spores mycé- 
e’est en ce point que ses éléments cellulaires sont le plus égaux, le p!us semblables, et aussi le plus différenciés (spore mycélienne). Jans la squame ou l'ongle, les éléments du trichophỵton sont irréguliers et trop) variables (cellules mỵcéliennes non sporulées, mỵcćlium de plusieurs diamètres, spores mỵcéliennes aḷ̣piques, etc...) pour servir à la différenciation microscopique d'espèces parasitaires voisines.

Le cheveu des trichophyties tondantes, dans l'immense majorité des cas, montre le parasite constitué par des files de spores, toutes contemues dans l'épaisseur mème du cheveu et ne dépassant pas sa cuticule d'enveloppe [trichophyton endothrix] (fig. 65-66).

En examinant un cheveu placé sur le bord de la lésion trichophytique, on peut trouver un cheveu moins envahi; alors les filaments sont assez peu nombreux pour ne pas se masquer l'un l'autre. et pour qu'on distingue entre eux le tissu proper du cheveu (fiğ. 67).

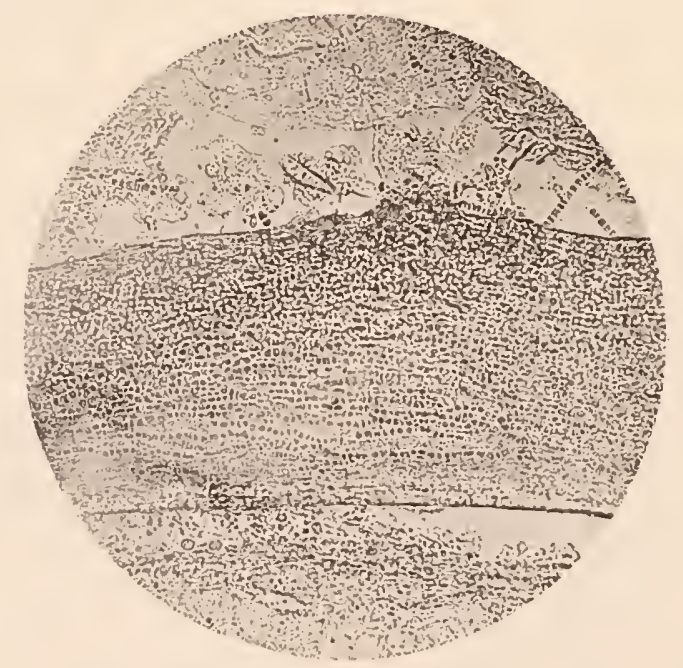

Fig. 67 .

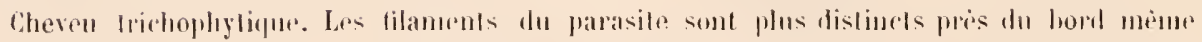
du clueven (er. 200 diam.).

Mais si lon examine les dhereux du centre des plaques malades, on y troure les éléments parasitaires tellement tassés qu’ils oecupent. lit hotalite du chereu (fiğ. 68): ceest ce qui explique sa fracture spon- 
tance dans cette maladie. On sait que le cheveu cassé à peu de distance de la peau est le symptome caractéristique des teignes tondantes.

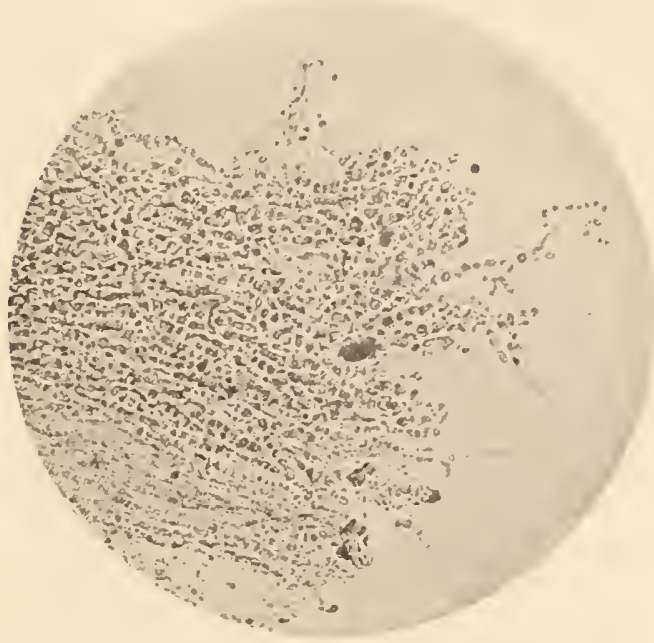

Fig. 68 .

Trichophyton endothrix, chereu completement envahi (gr. 280 diam.).

Quand on pousse très loin la dissolution du cheveu dans une solution potassique concentrée $(400 / 0)$, on peut observer que certaines tondantes sont causées par un trichophyton di mycélium résistant. Je

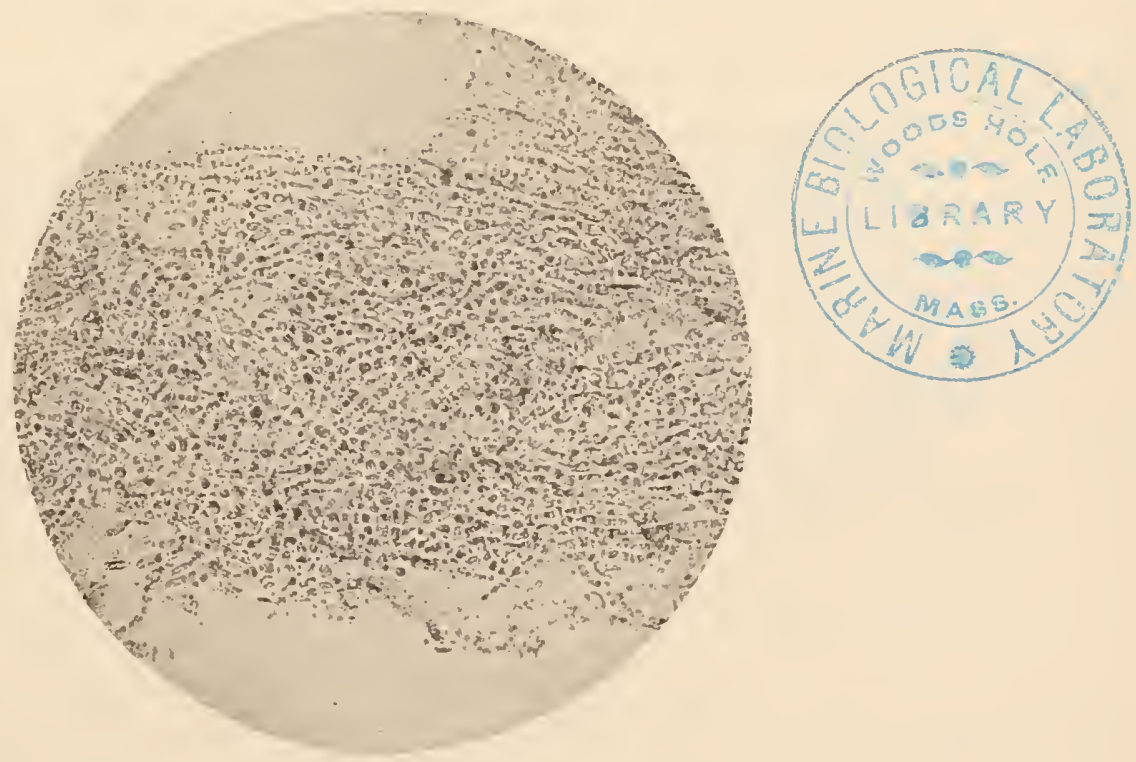

Fisi, 69.

Chereu dissocié par laction de la potasse. Les filaments mỵcéliens restent entiers (gr. 280 dian.). 
cheven dissous, les filiments du parasite sont dissociés, milis les spores ne s'ogrènent pas (fig. 69).

On peut ainsi parvenir a faire disparaitre la substance propre du cheveu en respectant les filaments parasitaires. C'est alors qu'on peul le mieux vérifier la parfaite similitude de toutes les spores entre elles, les

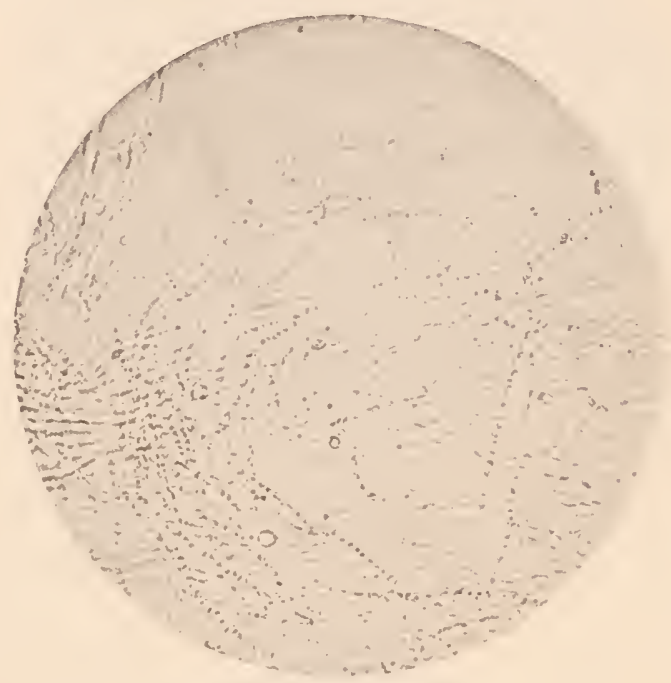

Fis. 70 .

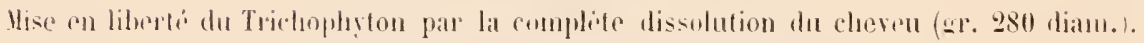

rubuns qu'elles forment par leur juxtaposition, enfin lit division des filaments par dichotomie (lig. 70).

En examinant ces filaments ì de plus forts grossissements, la double

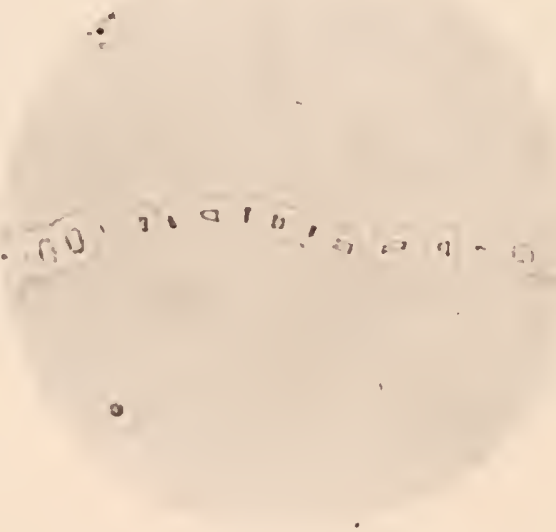

Fig. 71.

Hène préparation (gr. 1000 dian.). 


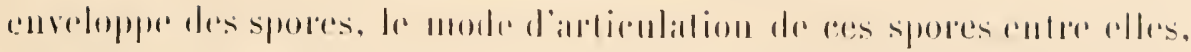

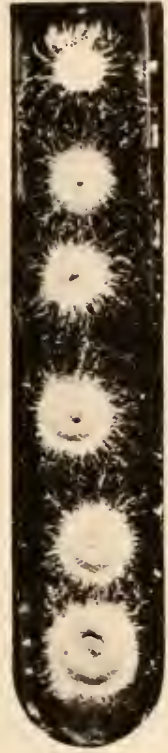

Fig. 72.

Culture sur moùt de bière, cultur' direcle d'un cheveu atteint de Trichophyton elIdothrix à mycélium résistant.

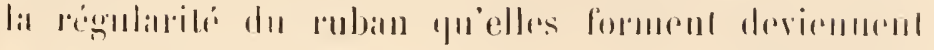
plus rivlenls (lig. Tl).

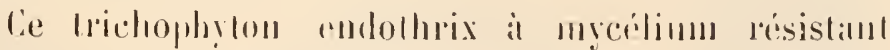

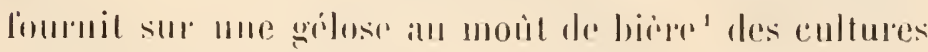

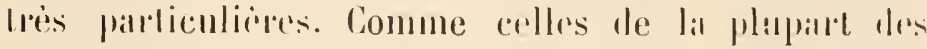

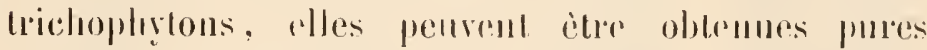
d'emblée sinon de toule issocialion cryptoyamiquer, an moins de lomte association hacléricune, en farlanl dr lit rarrinc du cheveu malade (fiç. 72).

En porlant ces vultures sur mur minc gélose all lond d'un matras, on peut laisser la culture prendre son développement spontané en tous sens. Elle allerele la forme d'un soleil de poudre jaune ayaut en son centre une calotte hémisphérique (fig. 75-75).

Et ì mesure que la culture vieillit, les rayoms arborescents de son pourtour premuent de plus en plus d'importance dans sa forme objective (lig. 76, 77, $73,79,80)$.

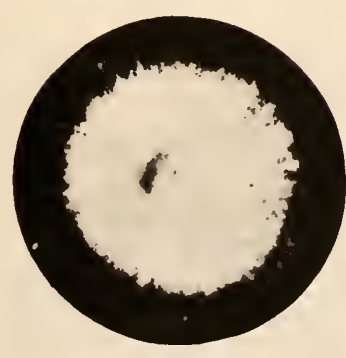

FIr. 75.

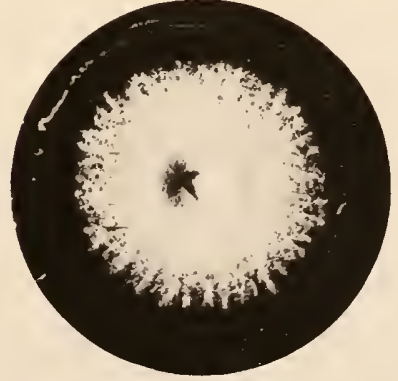

Fig. 74

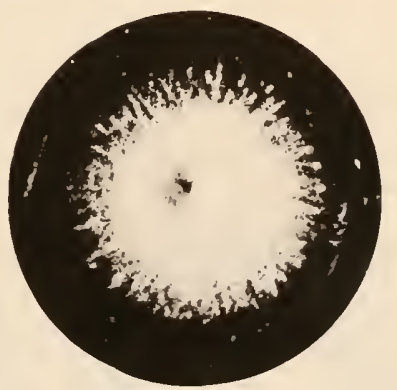

Fig. 75.

Nème culture que fig. 7‥ Wime culture que fig. 72. Ige, 5 semaines. Age, 4 semaines.

Mimse culture que fig. 72 . dee, \& spmaines.

1. Nous notons expressement la composition du moût de bière dont nous nous

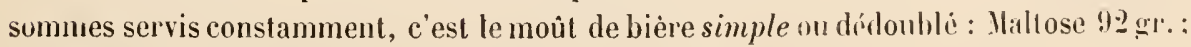
llbuminoïdes $1 \mathrm{gr} .7$ : dextrines 5 gr. (pour mille). 
Si l'on porte cette espèce trichophytique à mycélium résistant sur le

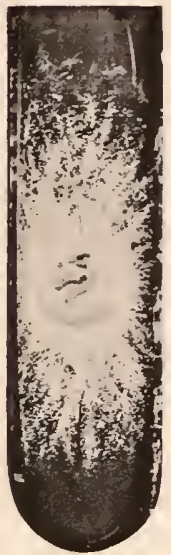

Fifi. 76. milieu (formule $n^{\circ} \mathbf{2}$ ) dont nous avons donné plus haut

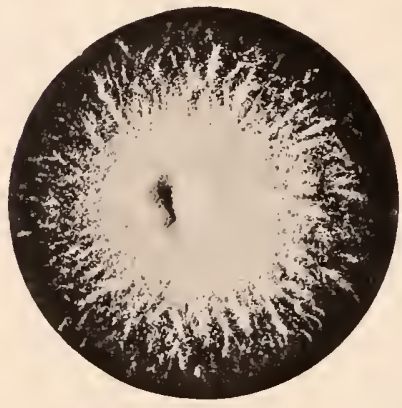

Pirs. 77.

Heme culture que lig. 72. dwe, 5 semaines.

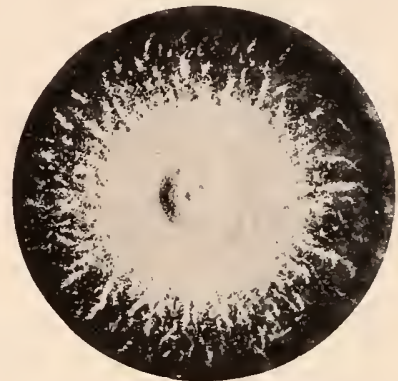

Fig. 78.

llème culture que fig. it. A.ge, is semaines.

Mime culure que la composition centésimale, milieu dont une recherehe fig. 72.

Age, 5 semaines. empirique a établi la formule et que nous appelons milieu d’épreuve parce qu'it donne aux trichophylons leur aspect

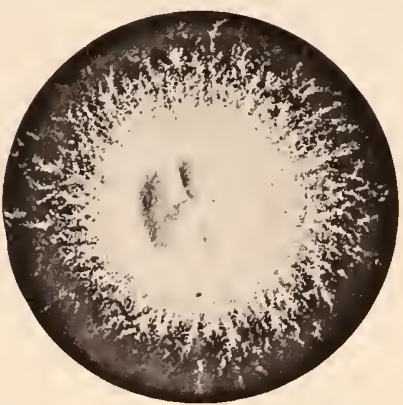

is. 79 .

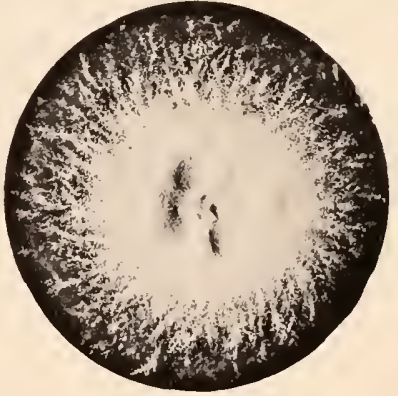

Firi. sil.

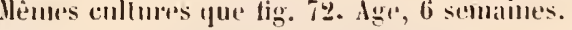

diflérentiel le plus accusé, les eultures prennent une disposition cratériforme absolument caracléristi(que (fig. 81, 82, 850).

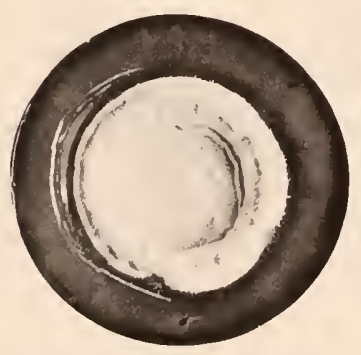

Fir. 81.

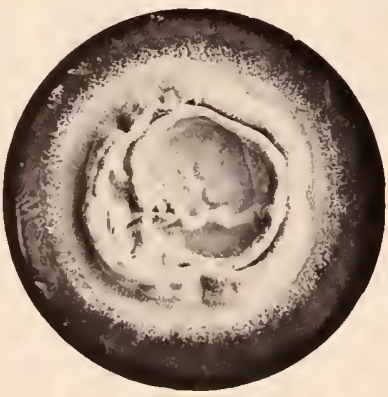

FIti. 8.2.

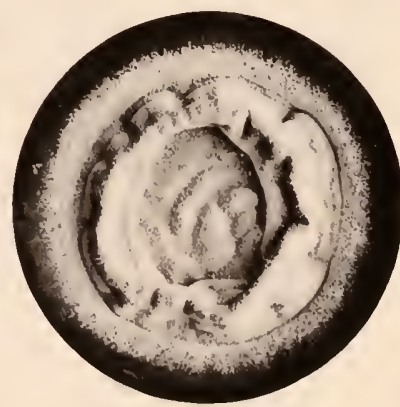

Fig. $8 \overline{3}$.

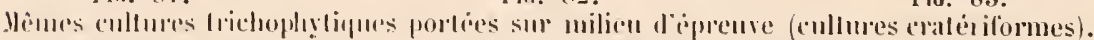

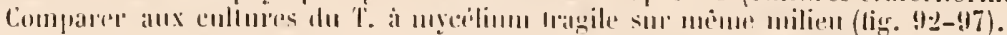

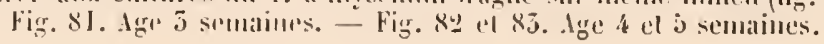


La teigne tondante trichophrtique pent ètre calnsie par une espece parasilaire dilfërente de la précédente. La localisalion du parasite dans le cheveu est la mime, il remplit l’intéricur du cheveu salus dépalsser

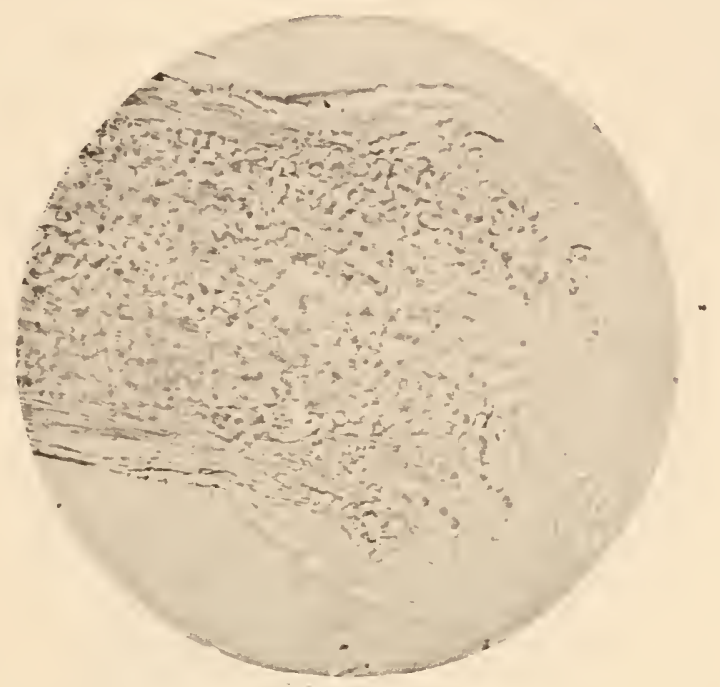

Fic. 84 .

Trichophỵton endolhrix ì mycélimm fragile (gr. Liol) diann.).

sa cuticule (fig. 84). Mais ici les spores ne sont plus carrées, elles sont rondes, en sorte que le mỵcélium sporulé n'est plus un ruban,

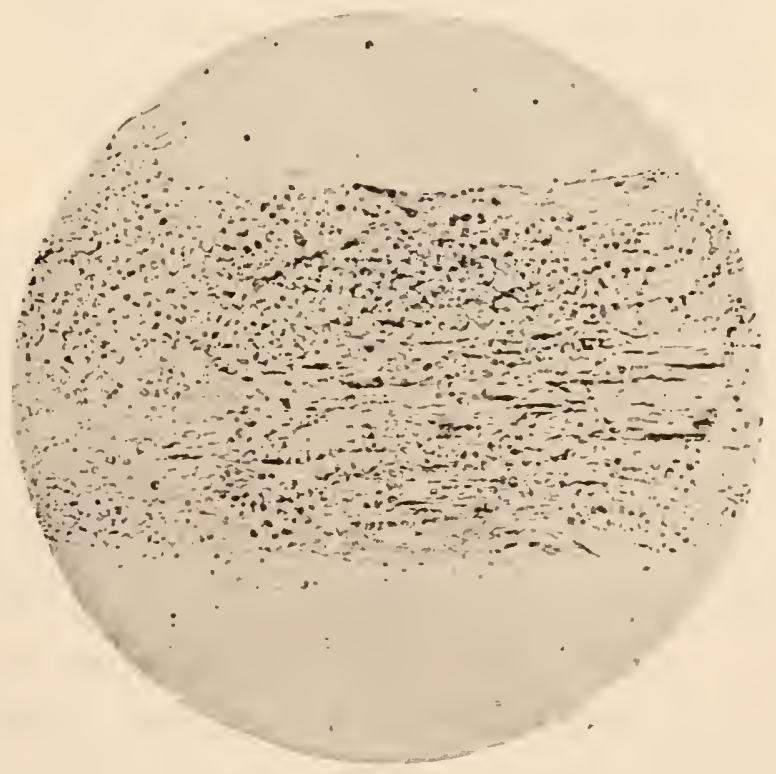

ค่เ. 8ลั.

Mème cheren apres laction de la potasso 1200 dianu.). 


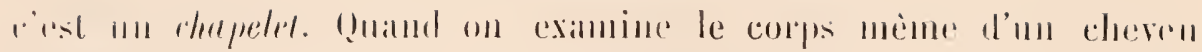
malade, lagminalion des spores en liles régulieres! est moins áviWrule que quand il śagil d'un mycélimu résistamt. Ici le cheven est tmurri de speres, comme un sale de noix. Si l’on pousse un peu loin Jil discolı!ion du cheren diuns la solution potassipue, on observera qur dalls celle esprece, all contraire de ee que nous arons vu pour l'esprier

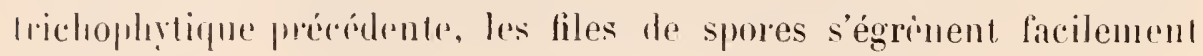
(tiw.

C̈est un trichnphlyglom a mycélinm frayile. Si l’on écrase tant soit pen lat priparition (lig. sib), les spores toutes dissociées seront alors juxti-

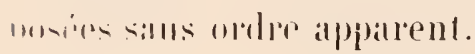

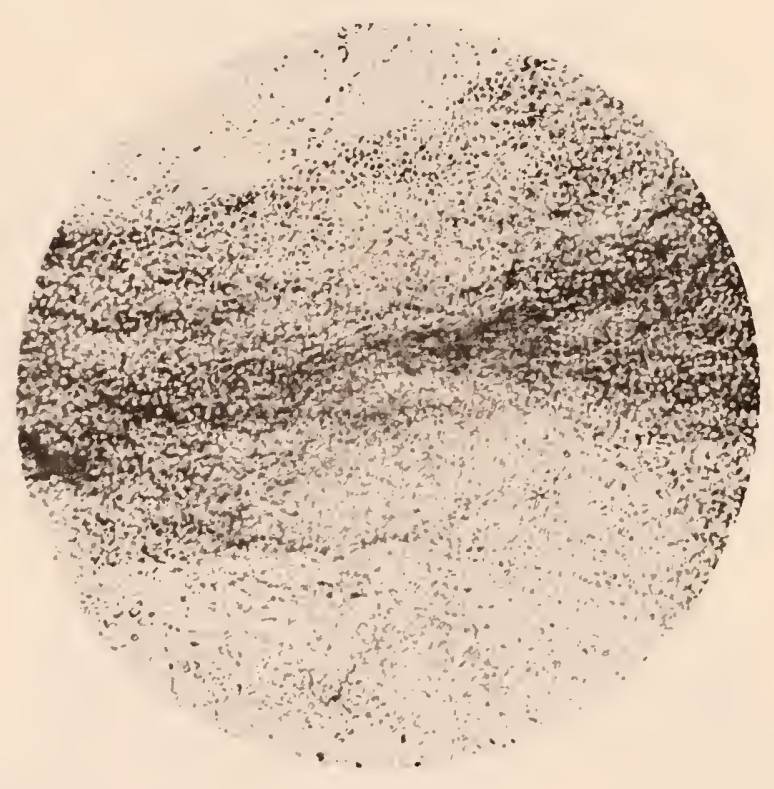

Fir. $\times 6$.

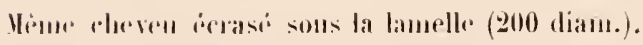

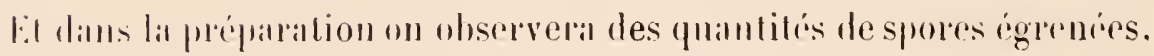
lihres ol flollintes (lig. si).

lat culture du trichophyton entothrix a mycélium fragile, obtemur

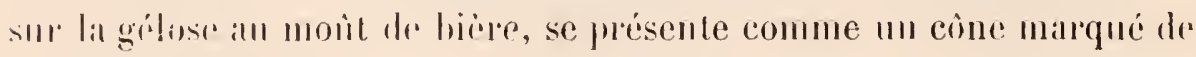

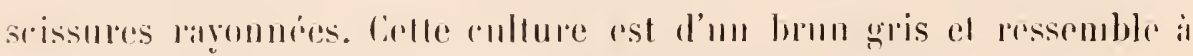

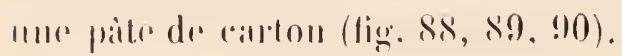




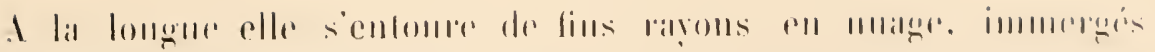

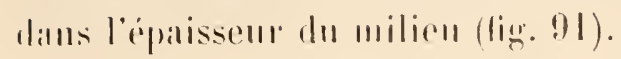

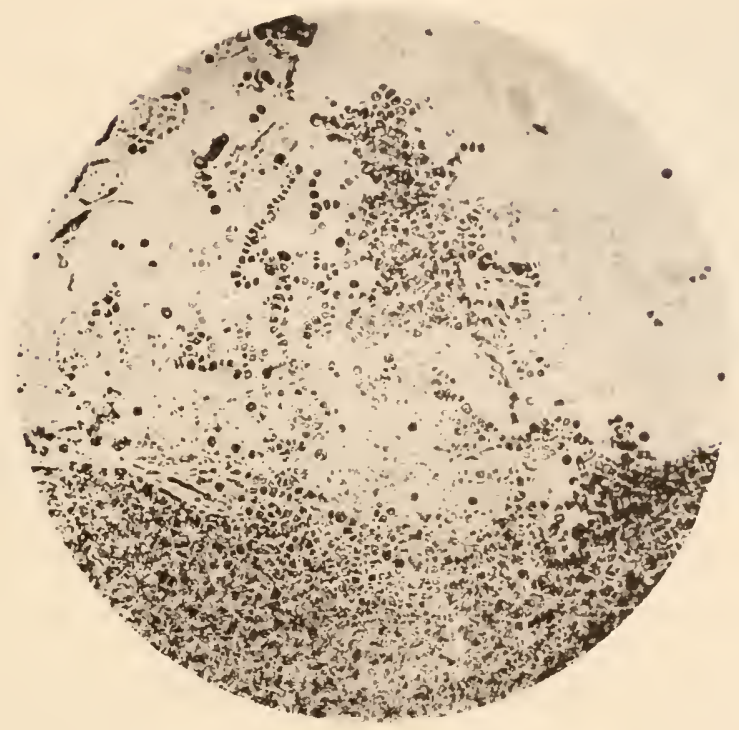

Fig. 87 .

Jène cheveu. Les spores sont entièrement mises en liberio (200) diam.).

Sur la gélose maltosée (formule n $^{\circ}$ ), milieu d'éprewre dont la cumposition est donnée plus haut, la culture du trichophỵton endollurix à
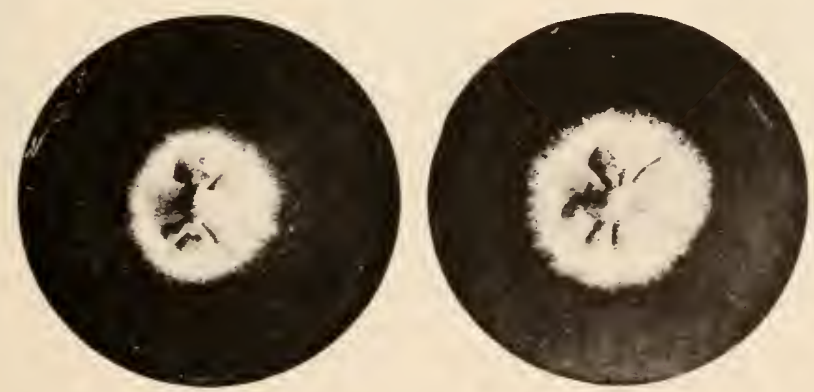

Fic. 8!!.

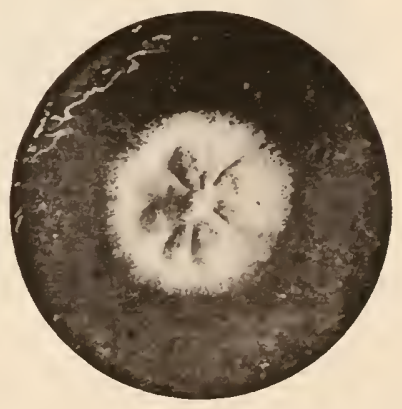

Fis, !)

Cultures du Trichophỵton endothrix à myeélim fiagile sur gílosi an mont de bierr. Compares anx rullures de Trichophytons a mycelium résistant sme le meme milinu (Fig. 7.7 r. snir.). Ellos sont do mome àgo. 
myrélium fragile, diffëre alsolument de celle du trichophṛton endothrix ì myrélinm résistant. Celni-ci donnait une culture cratériforme (fig. \$1,

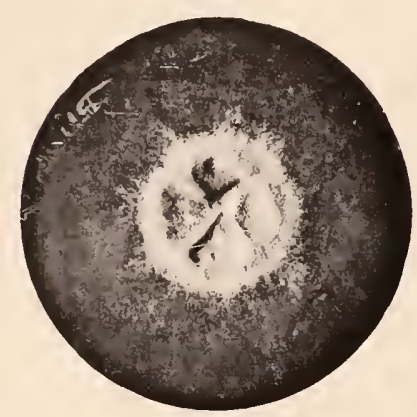

Fir. 91.

Heime collure. Age, is semains. $82,85)$; le trichophyton it mycélium fragile fournit une culture acuminée (fig. 92, 95, 94). C'est un cône très aplati, partagé en secteurs réguliers par des scissures plus ou moins profondes.

lit it mesure que la culture vieillit, ces scissures se multiplient avec une régularité géométrique (lig. 95.96, 97).

l'immense majorité des tondantes trichophỹliques est causée par l'une ou fril l'aulre des deux especes que nous venous de présenter, et dont. la premicre est la plus fréquente.

1.) Le T. enduthrix ì mycélium résistunt, à culture crutériforme.

11.) Le T. oudothrix à mycélium frugile à culture acuminće.

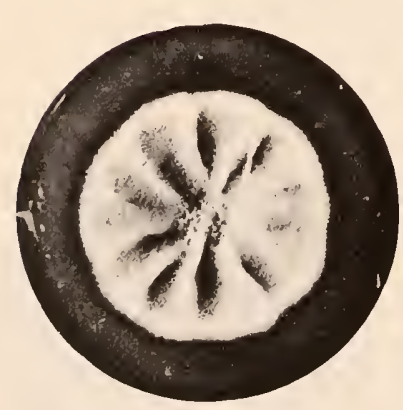

Fiis. 19.

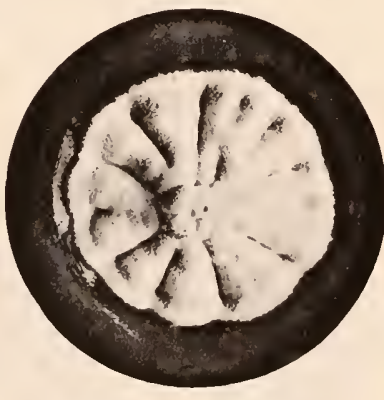

Fis. 9.).

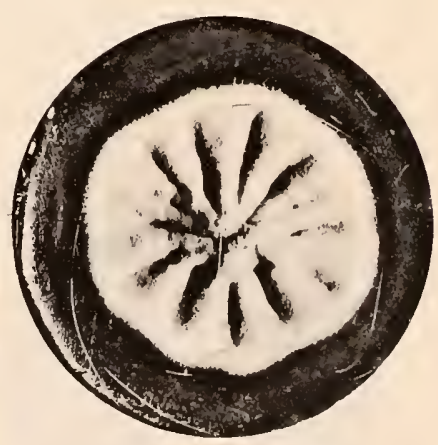

Fig. 94.

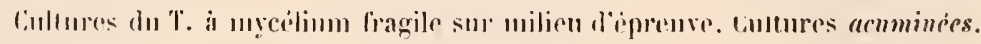

(Vuir lig. 81, 82, 85). Jge, 5 ol 4 simaines.

Il lanl i!muler que fr parasile, dans lous les eheveux doune mime litu, est idenlique. Le cheven ost plus ou moins envahi, mais duns tous les chevenx drume mème tète, la morphologie du parasite (dimension el lomm de la spore agminalion des spores entre elles. habilat dans 
le cheven) est absolument illenlique. Somblablement, les cultures failes avee des chevenx malantes queleonques de la mème tète sont toujours pareilles.

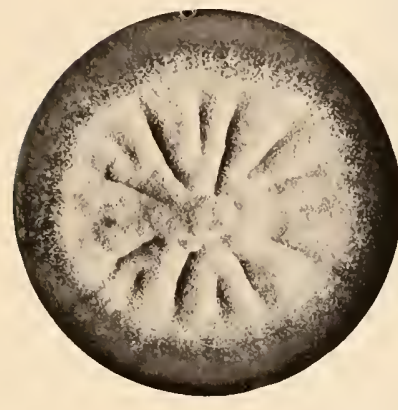

Fir. 9.\%

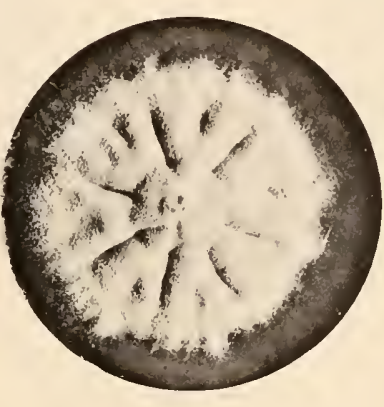

Fig. 96.

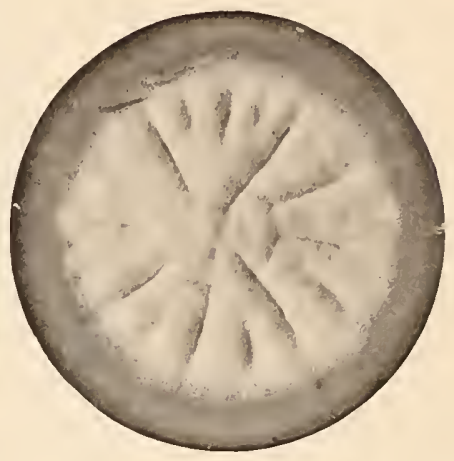

Fis. 97 .

لyemurs cultures. Age ö et 6 semaines.

Dans quelques cas, le trichophyton, cause de lit tondante, offre des détails morphologiques différents. La spore est ovoïde, sans double contour, etc. La culture, dans ces cas, est particulière (fig. 98) sur moùt de bière, et aussi sur le milien d’épreuve (fig. 99).

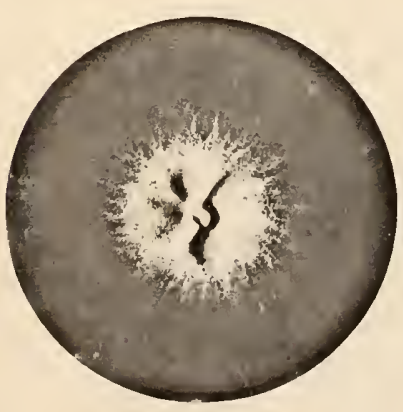

Fig. 98.

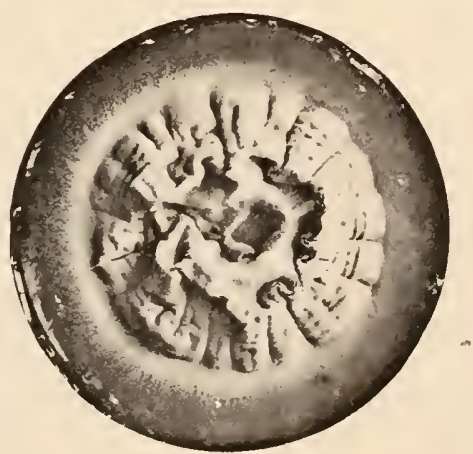

Fig. !9!.

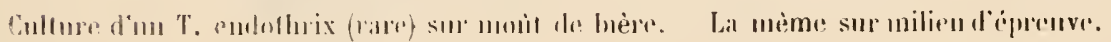

On troure ansi de lemps it anlle, el sur un grand nombe de lon-

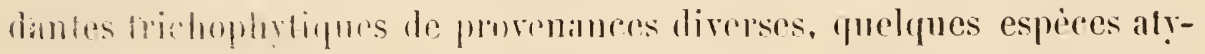
piçues encore non classies (fig. 100). 


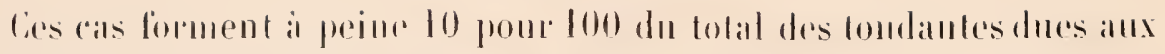

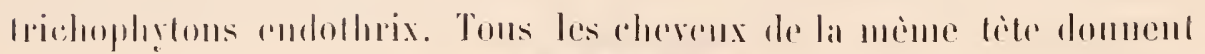

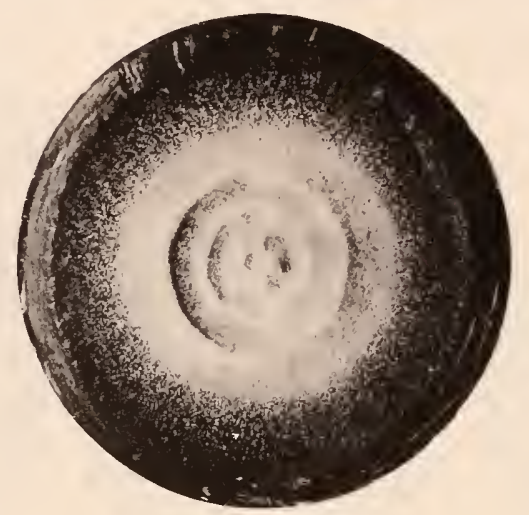

Fig. 100.

Aulre espèce rare de T. endolhrix (milien d'épreuve).

licu encore i uno rulture semblable, et de mìme, tous les individus contaminés dans une épidémie familiale.

\section{I.ES TRICHOPHYTIES MIMALES TRANSPORTÉES SUR L'HOMVE}

Il y a dres teignes tondantes trichophytiques de caractires objectils particuliors, présentant des surproduclions diverses (albès folliculaire.

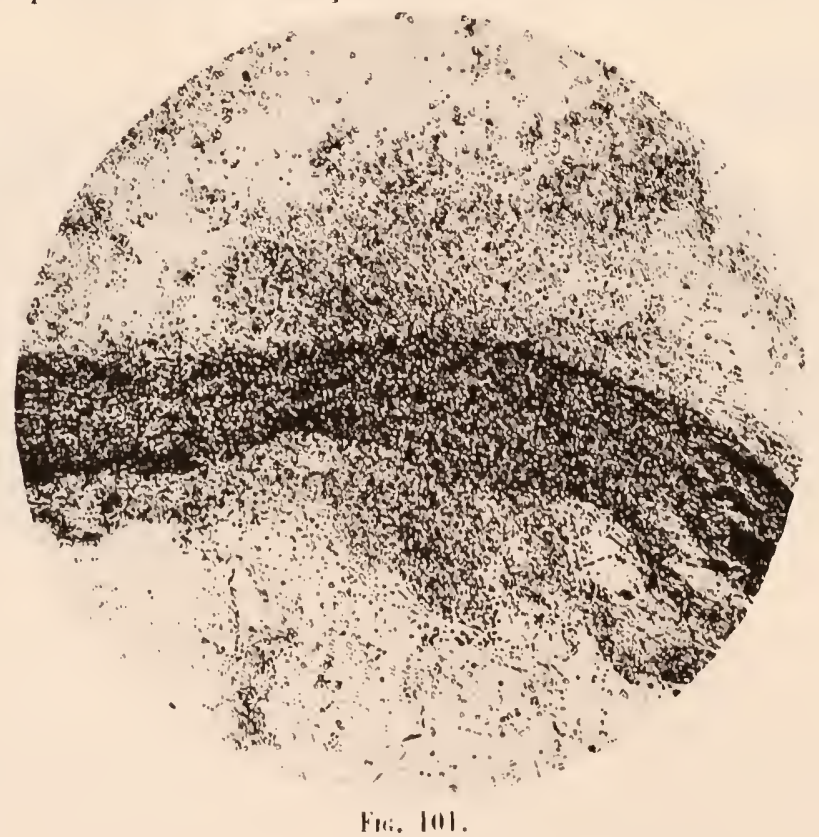

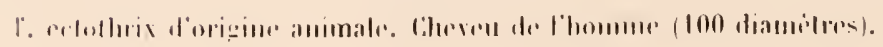




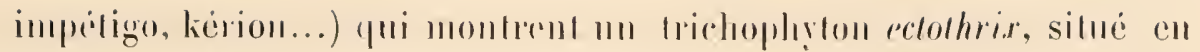
dehors du cheren, entre lui el sal gaine follienlaire (ligg. 101).

lei le parasite an lien d'ilre inclus dans le cheren lui lorme comme

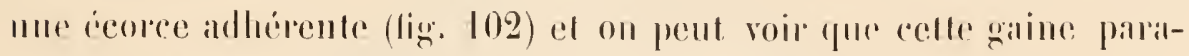

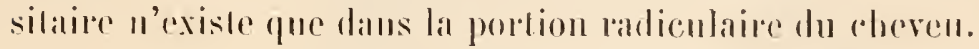

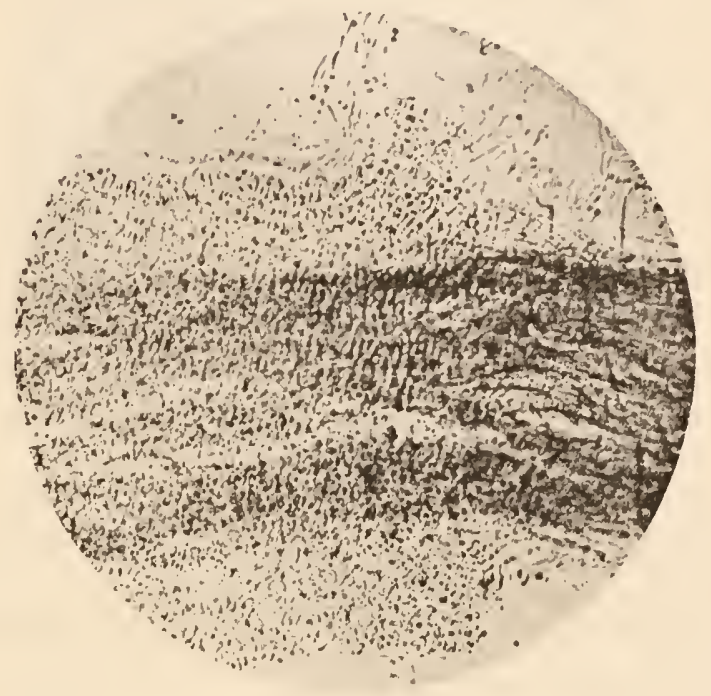

Fig. 10\%.

Racine d'un poil enrahi (Iso diam.).

Ces cas forment l’infime minorité des triclıophyties du cuir chevelu. mais au contraire la totalité des trichophy̧lies de la barbe présentent cette localisation spéciale du parasite.

Suivant le cas, la morphologie du parasite est différente. Certains cas présentent des spores très grosses, d'autres des spores relativement prites. Le mycélium est quelquefois résistant, d’autres fois il est fragile. Entiu certaines especes ectothrix offrent ce caractere de préscuter leurs spores mycéliemues nucléces. Leur noyan rond et central ist d'une couleur sépia (fig. 105).

La plus grande partie des filaments parasitaires adhère an cheveu of est exlirpéc avec le cheren on le poil. Cependant quelques filaments pémètrent et dissocient les éléments ipidermiques du follicule (fig. 104).

Cetle localisation spéciale des trichoplytoms ectothrix, nom plus 
dans le poil mais autour de lui, n'est pas un accident mais une règle absolue qui se reproduit sur tous les chevenx ou poils malades de la

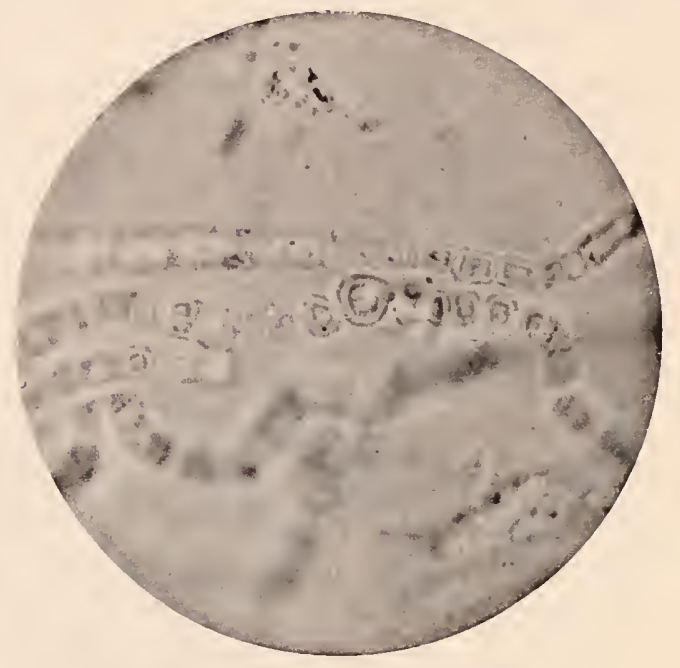

Fic. 105.

Spores inycéliennes nucléées d'un 'T', ectolhrix (gr. I000 diam.).

région. Et cette systématisation se retrouve jusques autour des poils follets les plus minuscules (fig. 105).

Ce type microscopique des T. ectollrix correspond aux trichophytons

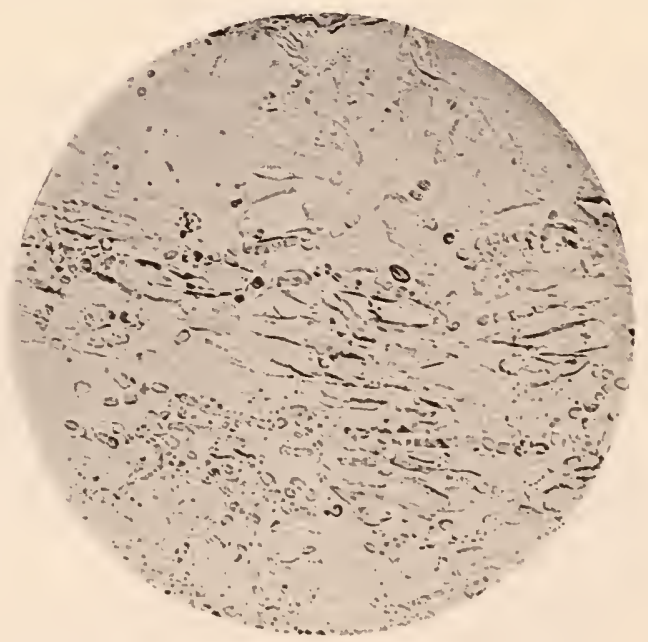

Fir. 101.

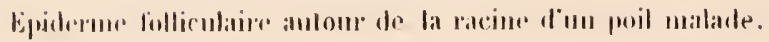

animanx quand ils sont volonlairement ou accidentellement inoculés à l'homme, ainsi que de trís nombreuses expériences l'élablissent. 
Le plus grand nombre des trichophyties d'origine animale que l'on rencontre sur l'homme se rattiche au groupe des T. Ectothix $\dot{a}$

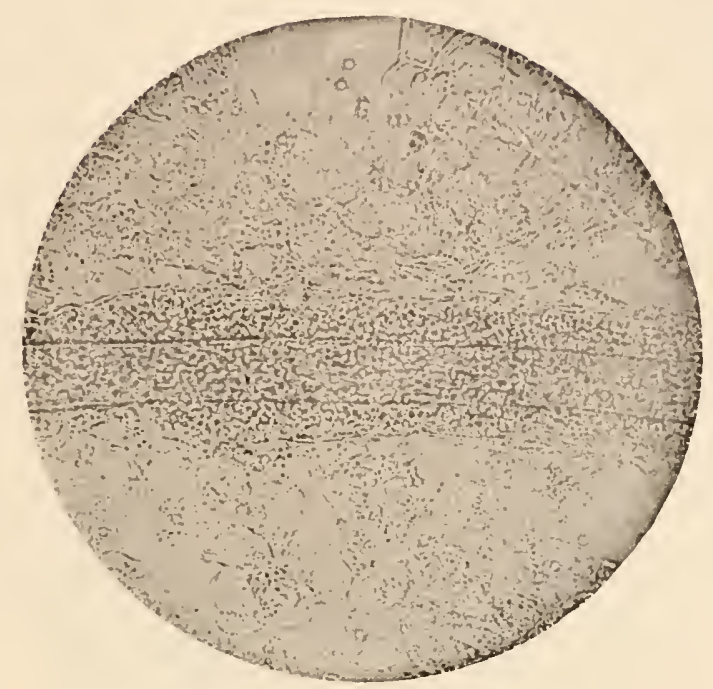

Fig. 10j.

Poil follet atteint par un T. ectothrix (I50 diam.).

cultures blanches qui eansent des lésions trichophỵtiques suppurées. Ces trichophytons, dont la vitalité en culture est extraordinaire. sont des organismes pyogines, quand ils possèdent leur virulence maxima et leurs lésions sont suppurées, pour cette cause et non d'autre.

De plus chacune des espèces de ce gronpe, quind elle n'est pas de virulence atténuée, cause sur l'homme une lésion spécifique de caractères objectifs spéciaux.

A ce groupe appartient d'abord le trichophỵton du chat dont la lésion est l'herpès iris vésiculeux de Biett (fig̨. 106).

On le rencontre le plus sourent chez l'enfant du premier ange et chez la femme, très rarement chez l'hounme. Chez l'enfant, comme chez la femme, on ne le rencontre gure que sous la forme de trichophrifie des régions glabres, très rarement chez l'enfant sous la forme de tondante. 
Sil culture sur mont de hirpe est lout a fait spéciale (lig. 107, 108). Sa caractéristique est l'ètre l'mn blane pur, d’un blanc de neige.

Cette culture, qui péscute sur mont le bière les ravons périphi-

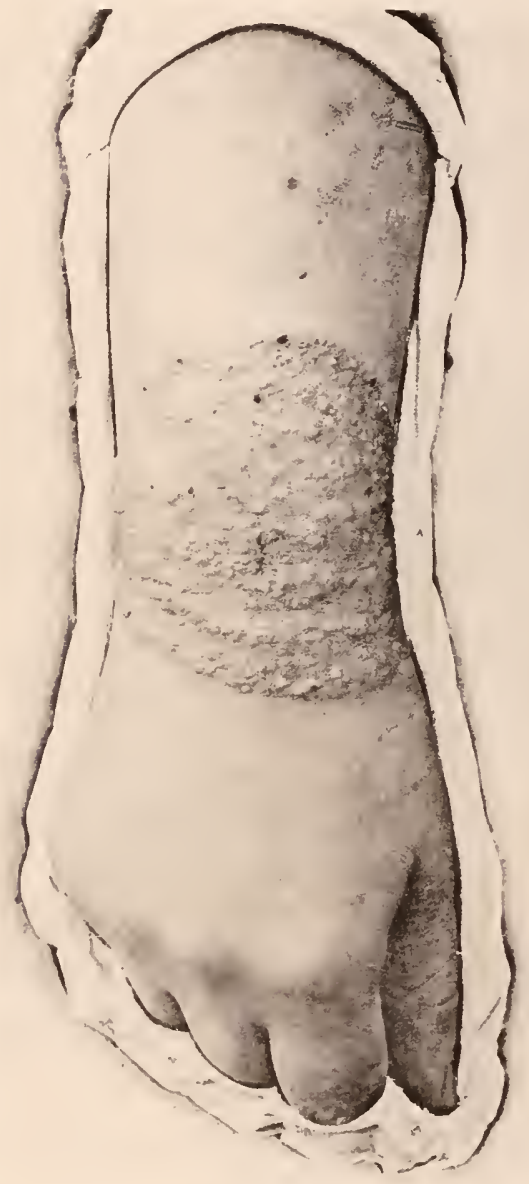

Fig. [0)i.

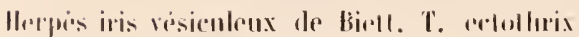
du chal. riques que toutes les cultures trichophytiques présentent su ce milieu, offre en outre cette particularité d'être duveteuse en son centre.

Sur une grande surface plane

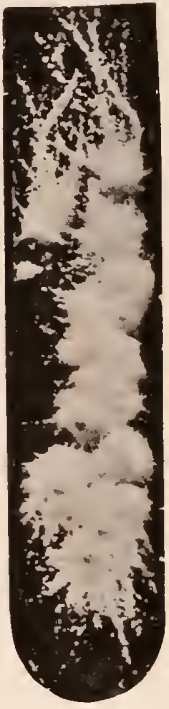

Fig. 107.

T. ectothrix dı chat. Culture dipecte de la lísion sur tube de moùl le bière gélosé.

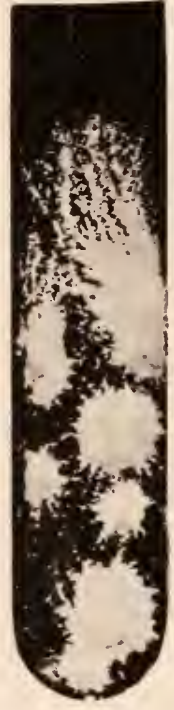

Fig. 108.

T. ectothrix du chat.Culture faite: ivec le pus de la même lísion.

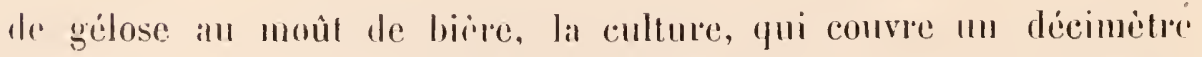
carré en moins de cing semaines, se présente avec un centre menpe par des cercles concentriques, finement duveteux. l'inunmbrables raygus fius of flexuenx ocempent sa périphérie. Ces

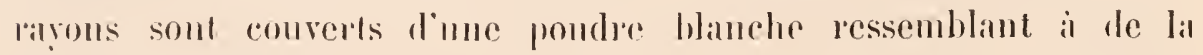
litrine (fig. 109).

le michophytom du chat lomenit la cullure la plus helle de 


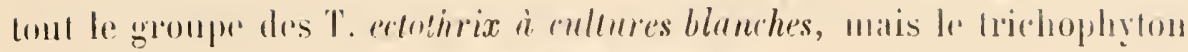

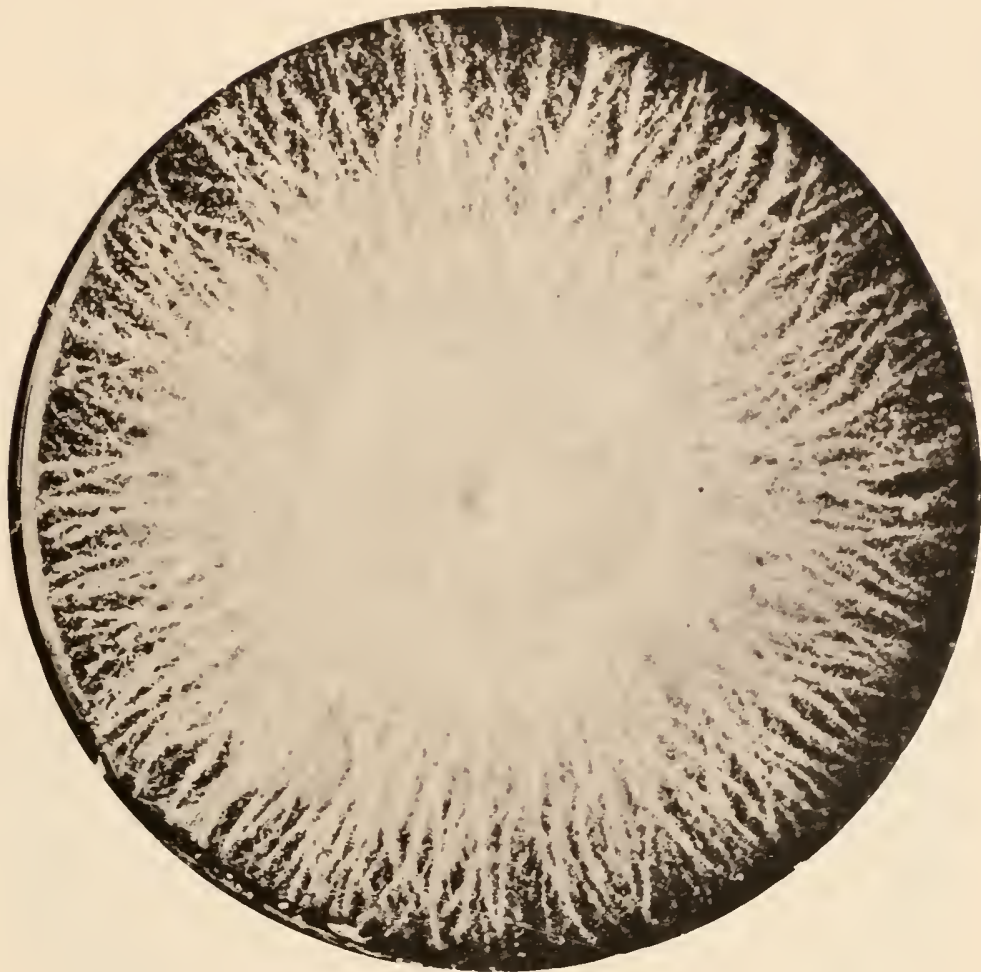

Fig. 109.

Culture de Trichophỵton du chat après 5̃ semaines (moùt de bière gélosé).

du cheval, qui appartient au mème groupe, est infiniment plus fréquent

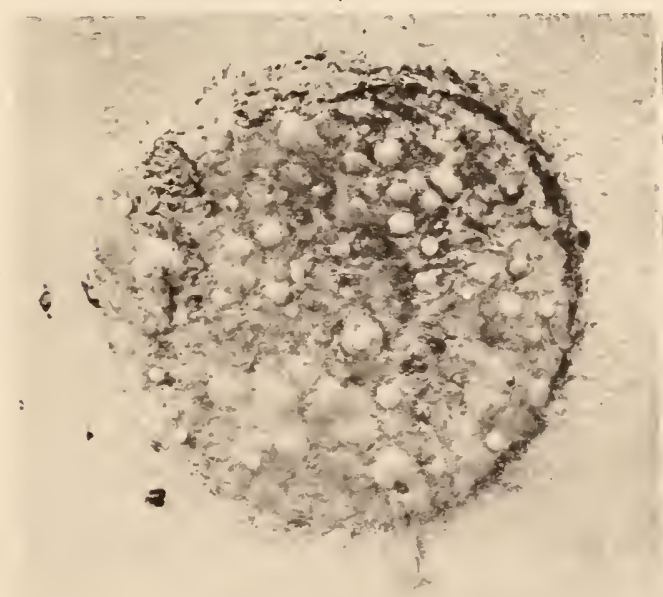

Fig. III).

Le Srrovis. Perifulliculite ağmine. Trichophṣton du cheval. 
chez l'homme. Sa lésion est plus caractéristique aussi et plus grave.

Cette lésion est le "syeosis », gàteau surélevé, exulcéré, suintant, couvert d’abcès folliculaires. C’est une périfolliculite agminée en placards.

Elle se montre ordinairement ì la barbe chez l'homme adulte en

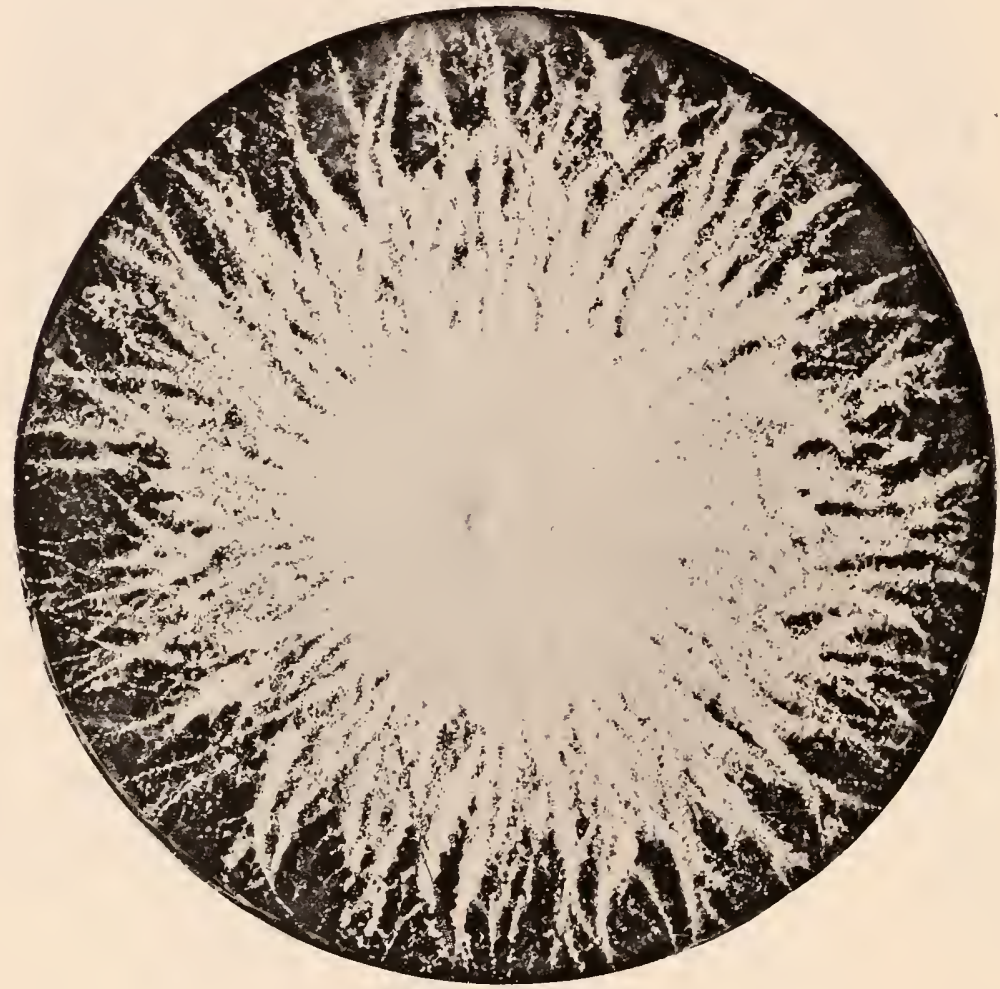

Fig. 111 .

Culture du trichophylon du cheval après 3 semaines (mout de bière gitosé).

Comparer cette figure à la figure 109. Les deux cultures ont ète faites ensemble sur un milieu fait en mème temps dans le mène vase. Leur ensemencement a été pratiqué ensemble. Elles ont passé par les mènes conditions d'aération, de température. Elles ont ite interrompues au môme noment.

contacl fréguent ave; le cheval. Elle peut se rencontrer comme tondante chez l'enfint et mime chez l'adulte; clle est exceptionnelle chez lat femme.

Sur mont de biere, sal culture ressemble beancoup à celle du triehophyton du chat (fig. 111). Mais la partie duvetense du centre est bean- 


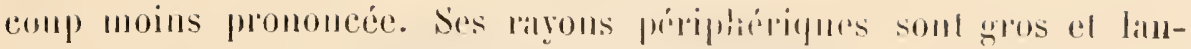

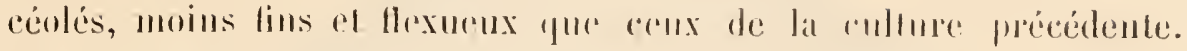

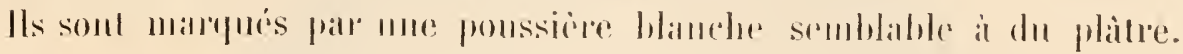

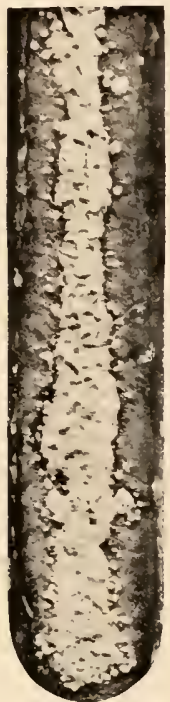

Fig. 112.

f. ectohtrix du rheral. Cullure sur ponthe do lerre.

Ige, 5 semaines.

Enlin la comlem de lat collume asl sammonice el non fits rigomensement hlanche romme rello du bichophỵton du chat.

Sur pomme de lerere, ecte espece se dillérencie

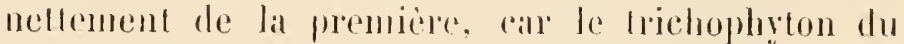

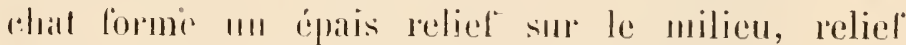
rombert d'mo duret comb al serre, lamdis que le tri-

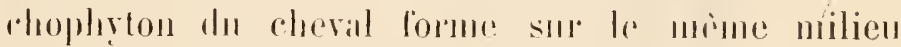

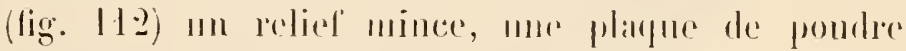
blanche et finc, quelquefors dresurfarer un pen ganliée.

Pour se convainere de l'absolue spécilicite de aes demx trichophytoms, il faut les culliver sur m milisu moins nutritif que le mont de bicie pur, sur une gélose an mont de bive, dilue an 1/10, par exemple, alors ces deux cultures cesseront alsolument de se ressembler (fig. 115 a 114).

Pour dilléroncier les espreces de ee groupe, le

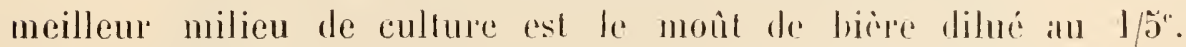
l.e trichophyton du cheval prend sul ce milien l'aspect indigué par la ligure 1 1

Un trichophyton du veau qui appartient au méme groupe prend sur ee milieu la forme indiquée par la figure 116.0n le retroure ordinarement chez les bergers, les nourrissem's, etc...

Le mime milicu permet de diffirencier la trichoplsyton du pore

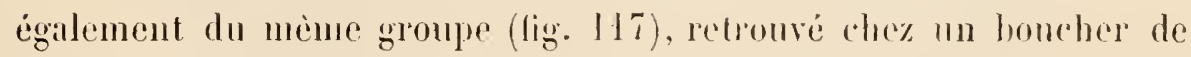
l'abattoir spécial des pores de l'aris.

Enfin il existe dans le mème grompe des especes ou rariétés, botaniquement tris proches des précédentes, el ilont l’origgine animale ne saurait faire de doutes, mais qui nout éli rencontrées que sur l'homme et dont l'animal d'origine est incommu (ligr. 118, 11!). 


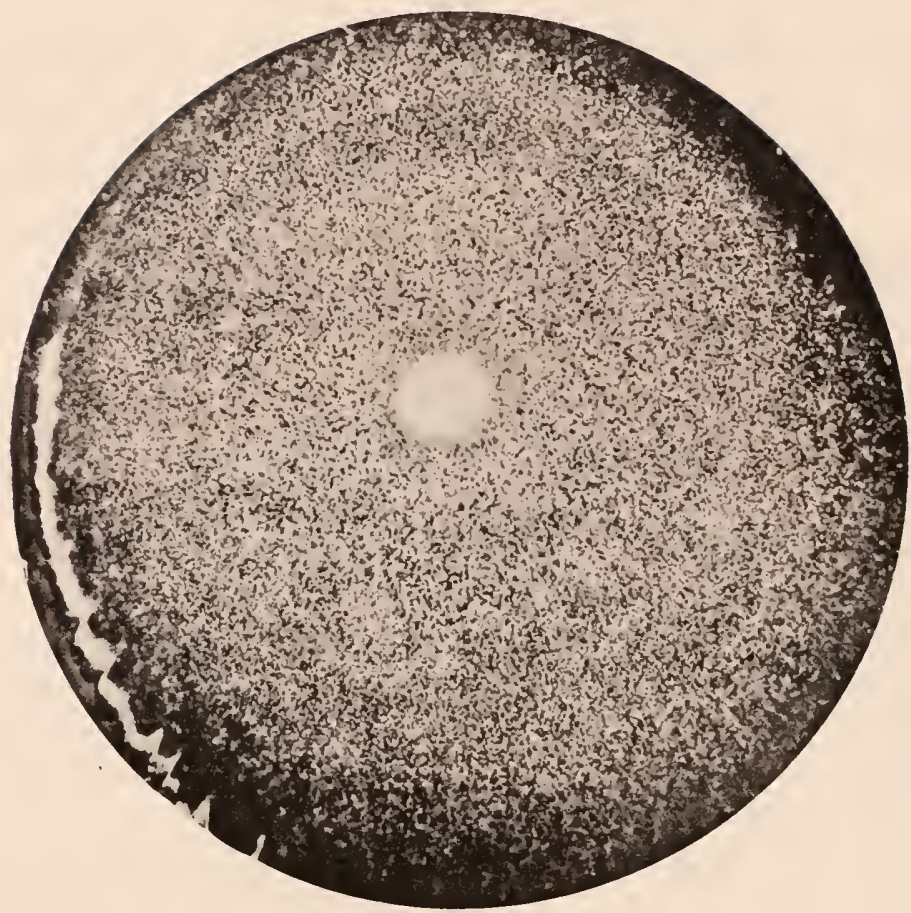

Figr. 115. - T. ectuthrix du chat. Mème espèce que la fig. 109. Culture de 10 semaines sur gélose an moùt de bière au $110^{\circ}$.

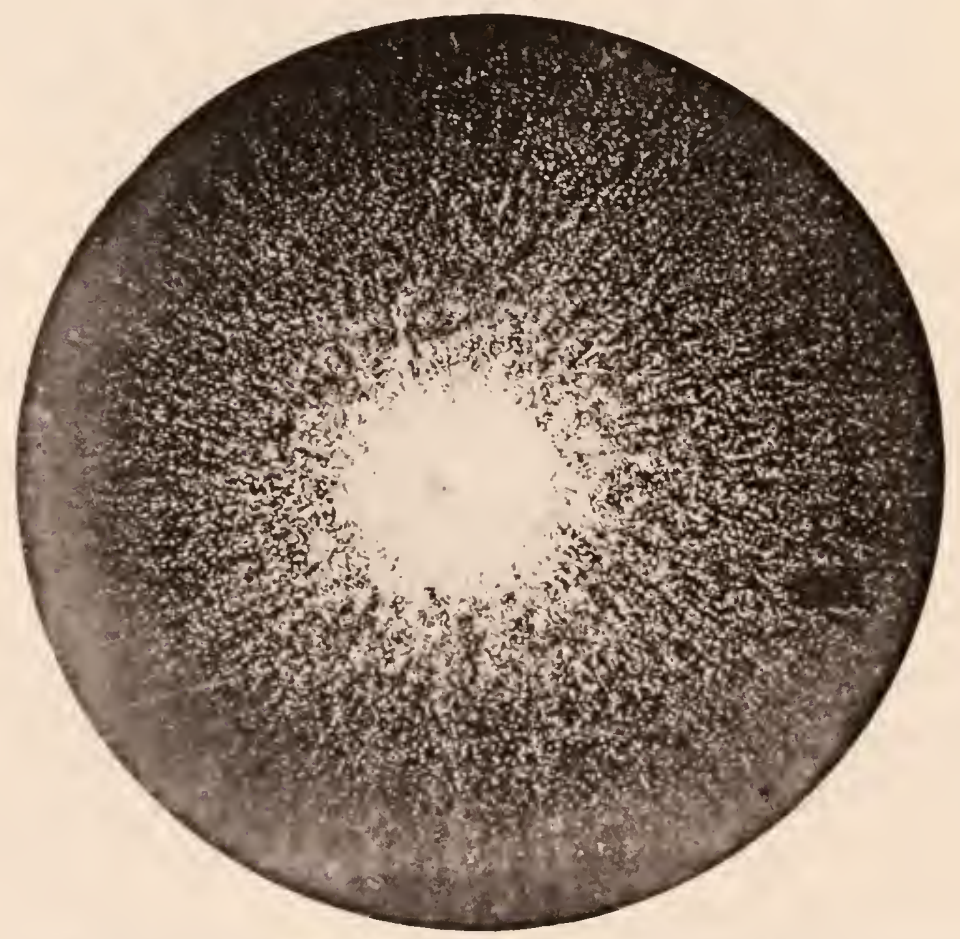

Fin. 116. - T, rctothrix du cheval, Mime espice que la fig. 111. Culture de 10 semaines sur gélose au mont de bière an $1 / 10$. 


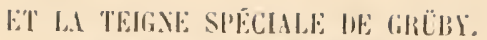

(i.)

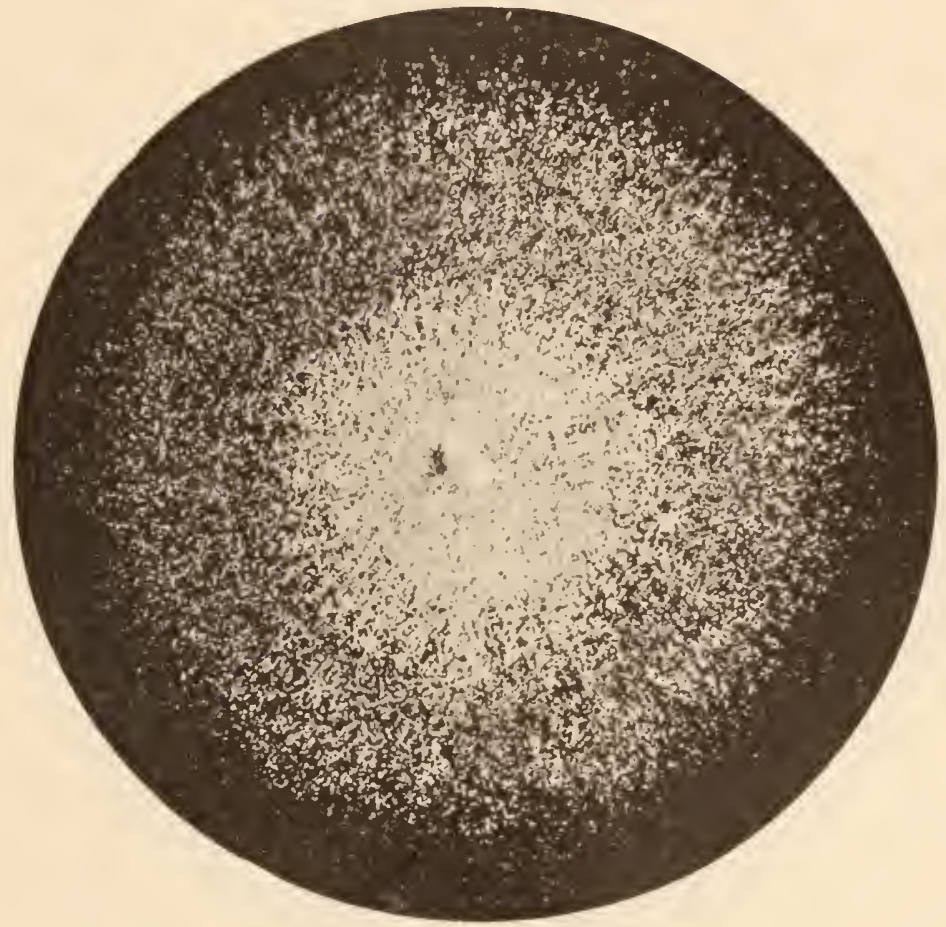

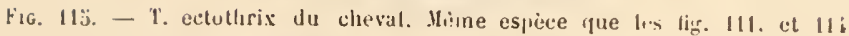

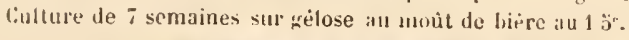

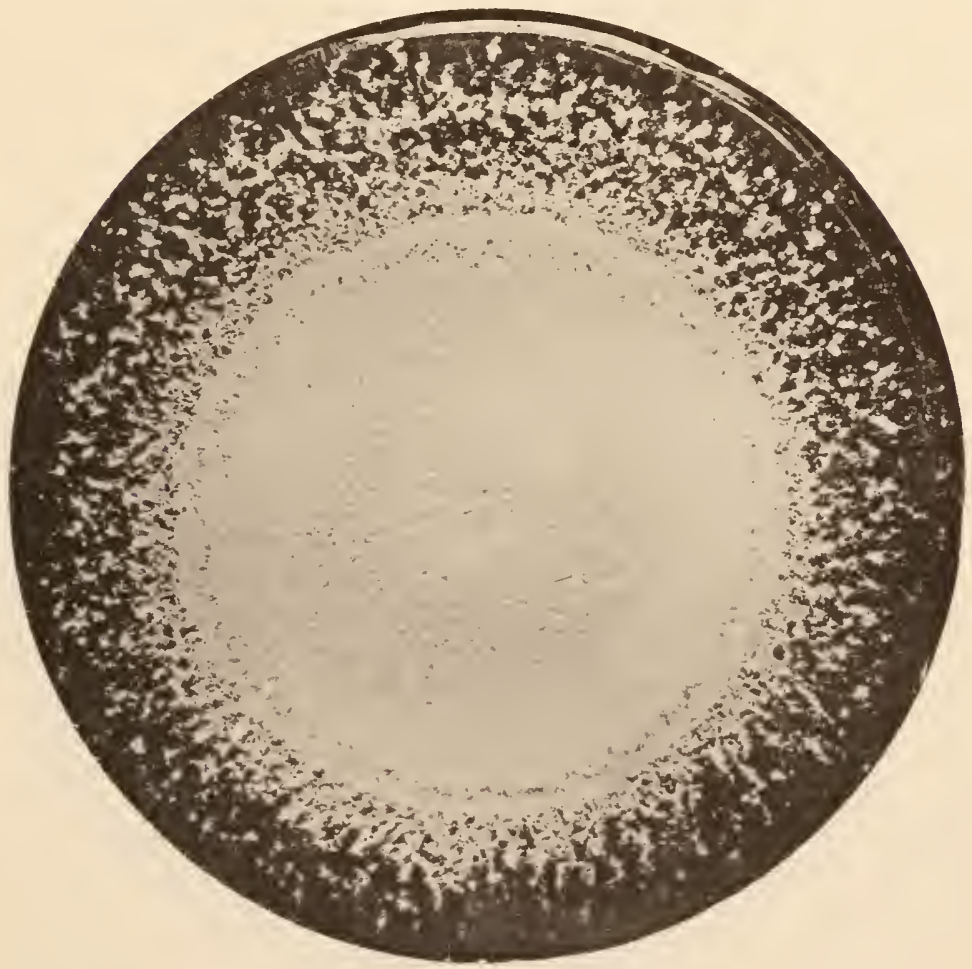

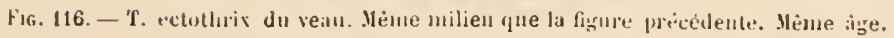




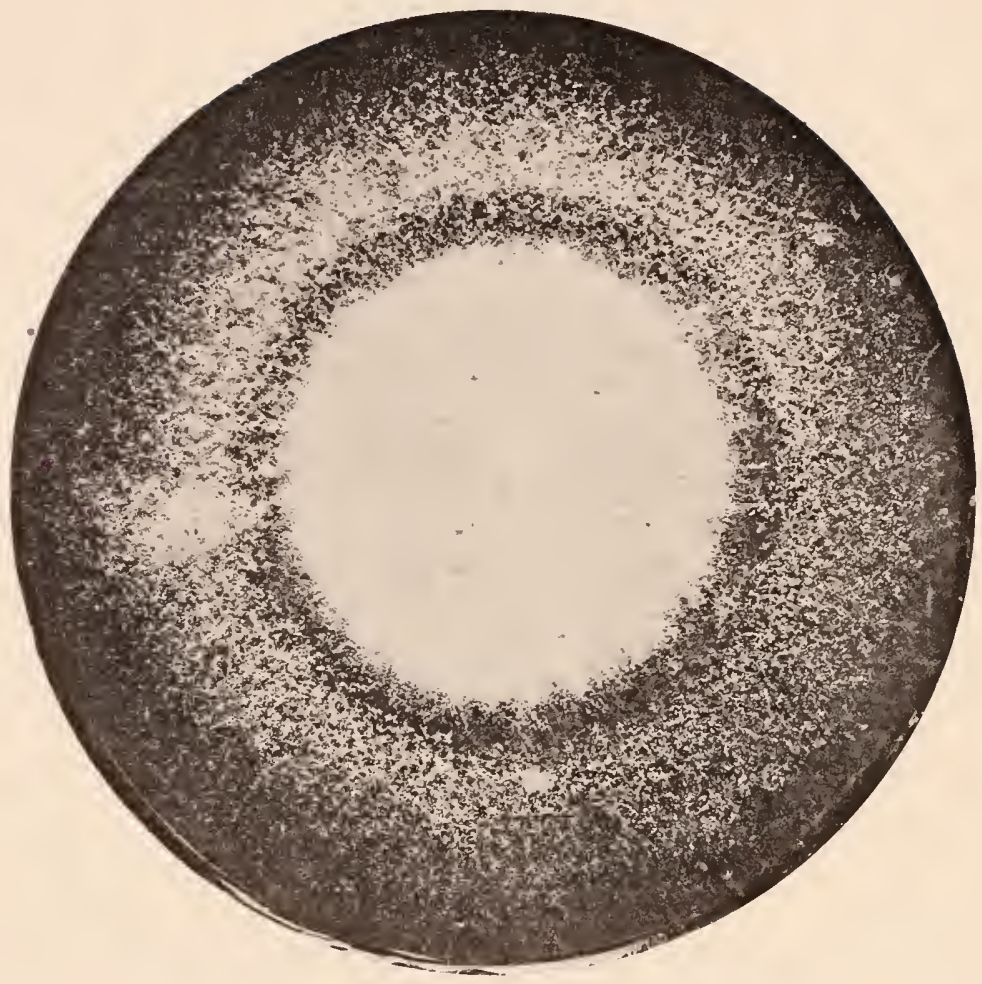

Fıg. 117. - Trichophyton du porc. Mème milicu que la fiğure 115. Mème áge.

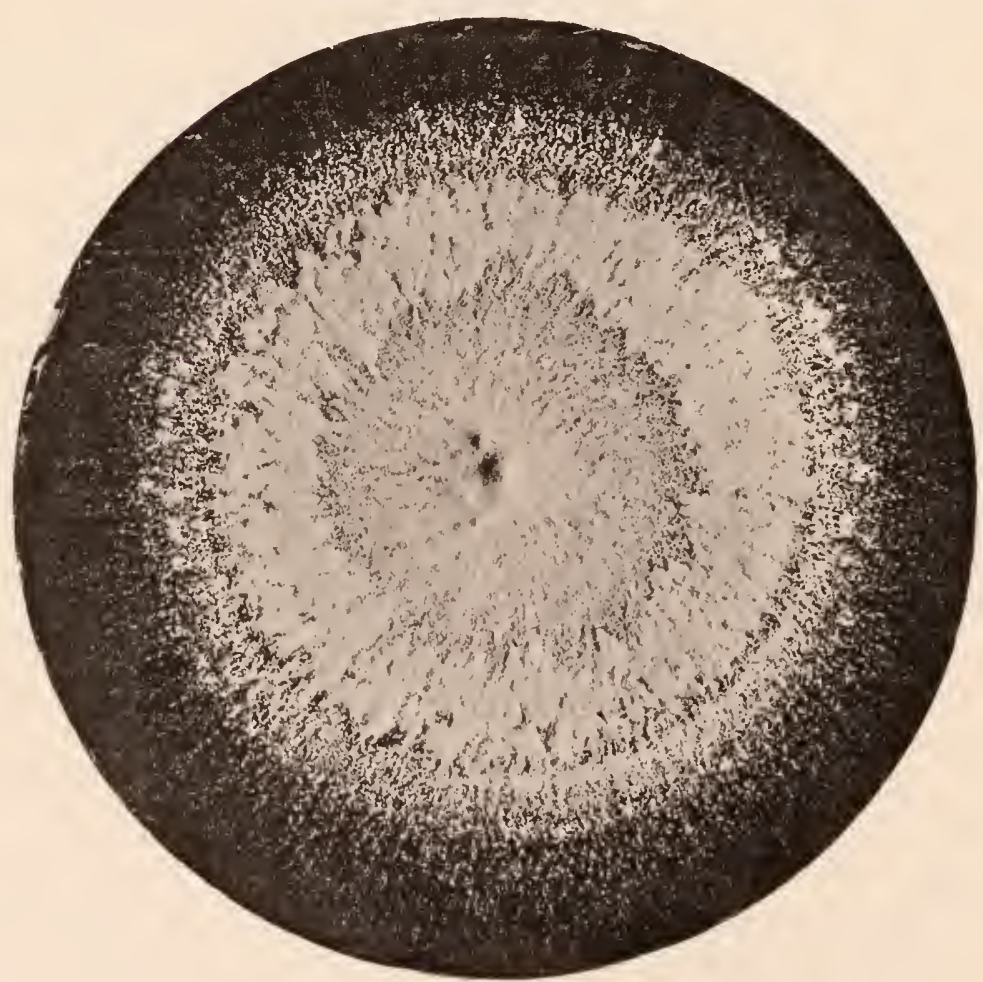

ris, 118. - T, du mène groupe, mais dont l'animal d'origgine est inconnu. 


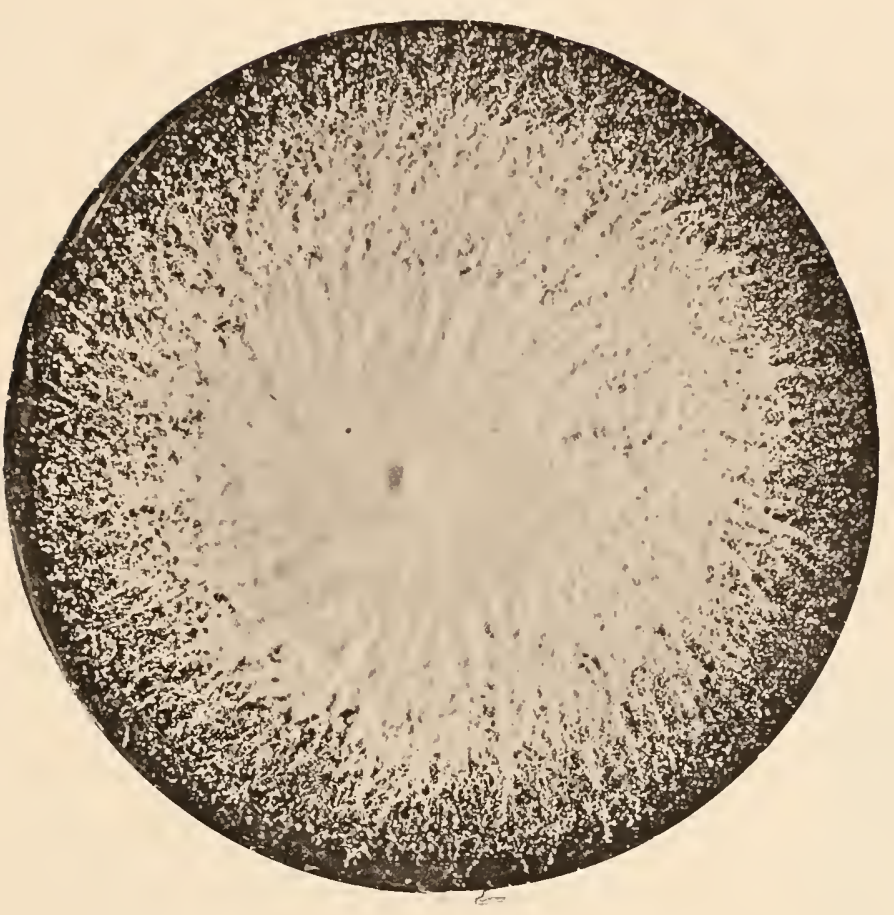

Fif 119. - Autre Trichoph, du mène groupe, d'origine incounue.

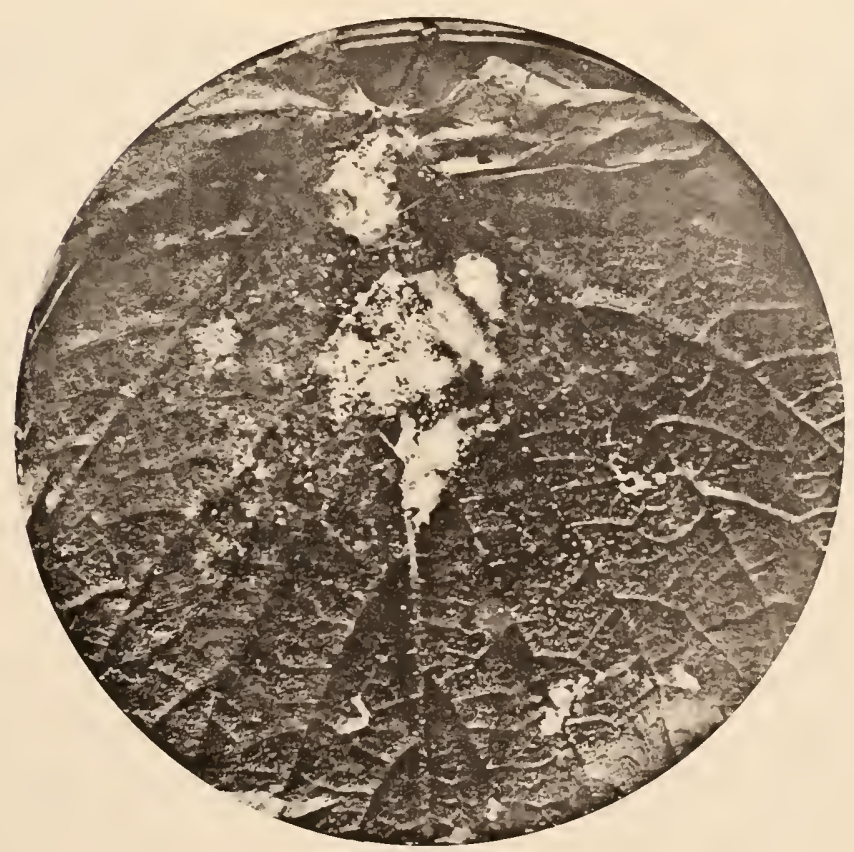

Fis, 120, - Culture du Trichoplı. du cheval (fig. 111), sur la feuille du murier. 
L'extrême vitalité de ces espèces, mème quand elles sont portées sur des milieux artificiels paurres, a fait penser à leur origine saprophyte. Cette origine n’est pas démontrée mais ces espèces se eultivent très bien sur le bois, les graines, sur la feuille du mùrier (fig. 120) et mème, quoique paurrement, sur le liquide exclusivement minéral de Winogradsky.

\section{LES TRICHOPHYTIES DE LA BARBE}

Les trichophyties de la barbe chez l'homme sont exclusivement causées par des trichophỵtons ectothrix, c'est-it-dire d'origine animale. La plupart relèrent du trichophỵton du cheval à cultures blanches

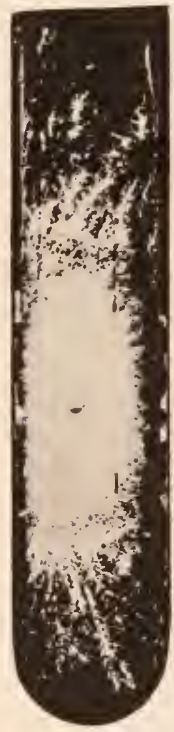

Fig. 121 .

T. ectolhrix a culture jaune, ( $2^{\circ}$ espece d'origine équine), moùt de bière gélosé.

(fig. 111) étudié plus haut. Mais il existe des trichophyties de la barbe de forme moins inflammatoire que le sycosis et qui ont pour cause une deuxième espèce d'origine équine que ses caractères botaniques rapprochent du groupe des trichophrtons a cultures blanches, sans qu'elle en fasse cependant partie, an point de vue objectif des cultures (fig. 121).

Cette espèce observéedansune épidémie équine de 250 chevaux avec sept contagions humaines, a fourni sur moùt de bière les cultures suivantes (fig. 121122 et suiv.), d'une couleur jaune-brun

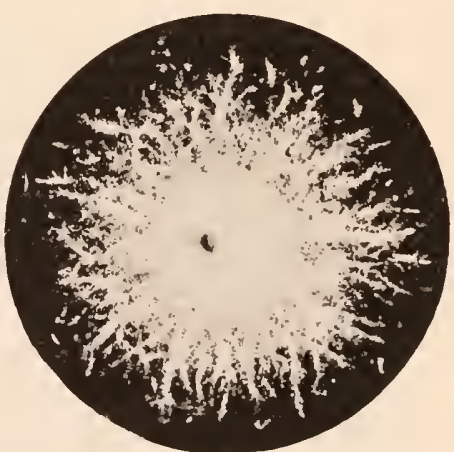

Fig. 122.

T. ectollırix à culture jaune. Culture de 4 semaines en matras, moût de bière gélosé.

rappelant celle du trichophyton endothrix à mycélium résistant sur le mème milicu, mais dépourvues de grosse éminence centrale.

De plus les spores externes de ces cultures sont facilement déhiscentes et donnent lieu à des colonies secondaires quand le vase le culture a été agité (fig. 125). 
Les figures l2.t el 125 montrent l'aspect que prenment ees colonies sur le milieu d'ípreuve.

Ces cullures quon pourrait prendre à torl comme représentant une.

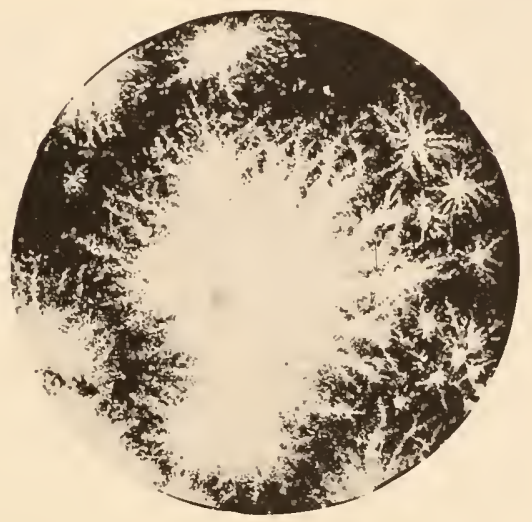

Fig. 125.

T. eetothrix a culture jaune. Culture de \& semaines en matras (mime milieu).

simple variété des premières espèces endothrix, dorigine humaine, décrites plus haut, est tout à fait spéciale, non senlement palr

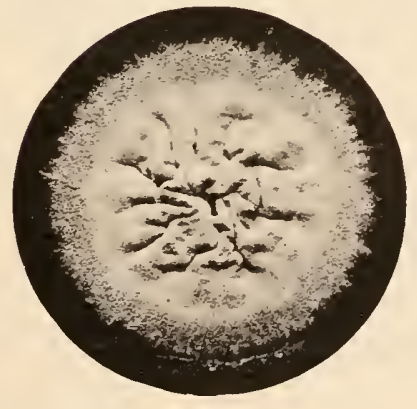

Fig. 12'.

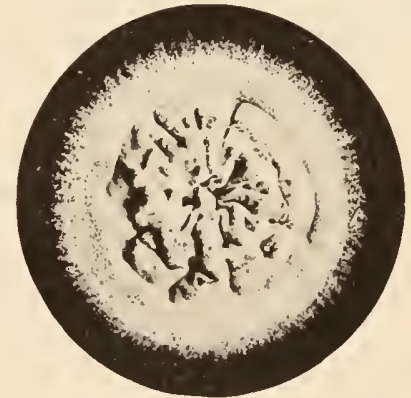

Fir. 129.

Culture dn mene Trich. sur milien d’éprente, \& semaines. cultures crapuelées vermiculaires, jammes.

ec fait qu'elle régète hors du poil, à sa bise (T'. ectothrix), mais encore par ce fait botanique très important que sa culture est la seule culture trichophỵtique qui domne lien ì des ébauches de périthèque. 
C'est encore une autre espece trichophytique dorigine animale,

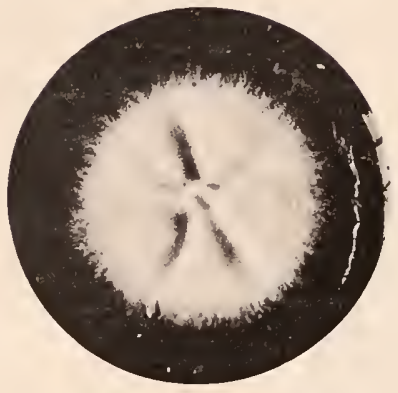

Fig. 126.

Espece de Trich. ectothrix d'origine al viaire (?). Cultures roses sur moût In biëre gélosé ( 6 semaines). probablement d'origine aviaire, qui cause les trichophyties pilaires sèches de lil barbe chez l'homme. Cette espece fournit sur moùt de bière (fig. 126) une culture d'un beau rose, fleur de pècher, dont la face dorsale est d'un violet framboise. Sur gélose maltosée (formule du milieu d'épreuve) la culture garde sa couleur d'un rose pâle ct tendre, elle a des tendances it prendre sur ce milieu une forme mamelonnaire et contournéc (lig. 127, 128).

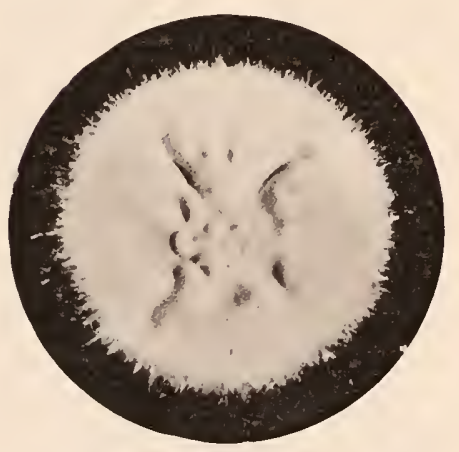

Fis. 127 .

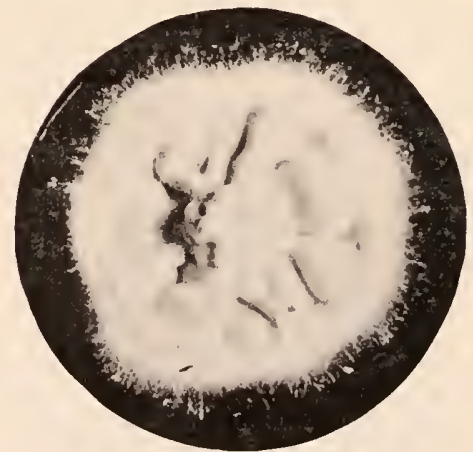

Fig. 128.

Hème espéce. Culture de six semaines sur milieu d'épreure. (Formule $\mathrm{n}^{\circ}$ 2.)

\section{LES TRICHOPHYTIES EXOTIQUES}

Il est vaisemblab)le que les trichophytous qui sont très nombreux en III mème jaḷs ne sont pas les mèmes en tous payss.

La teigne imbriquée (Patrick Ianson) des îles dn Pacifique, qui se caraclérise par une lésion si proche de nos trichophrties d'Europe, (lig. 129) el qui s'en distingne cependant par sal chronicité, par sil tendance à l'extension indélinie (lig. 150) el surtout par sa forme spéciale (la constaner de plusieurs cercles d’exfoliation épidermique 
inscrits les uns dams les autres), doit itre due it une espece très voisine de nos trichophytons ectothrix d'Europe.

La squane (figg. 151) montre des filaments sporulés qui se mulliplien!

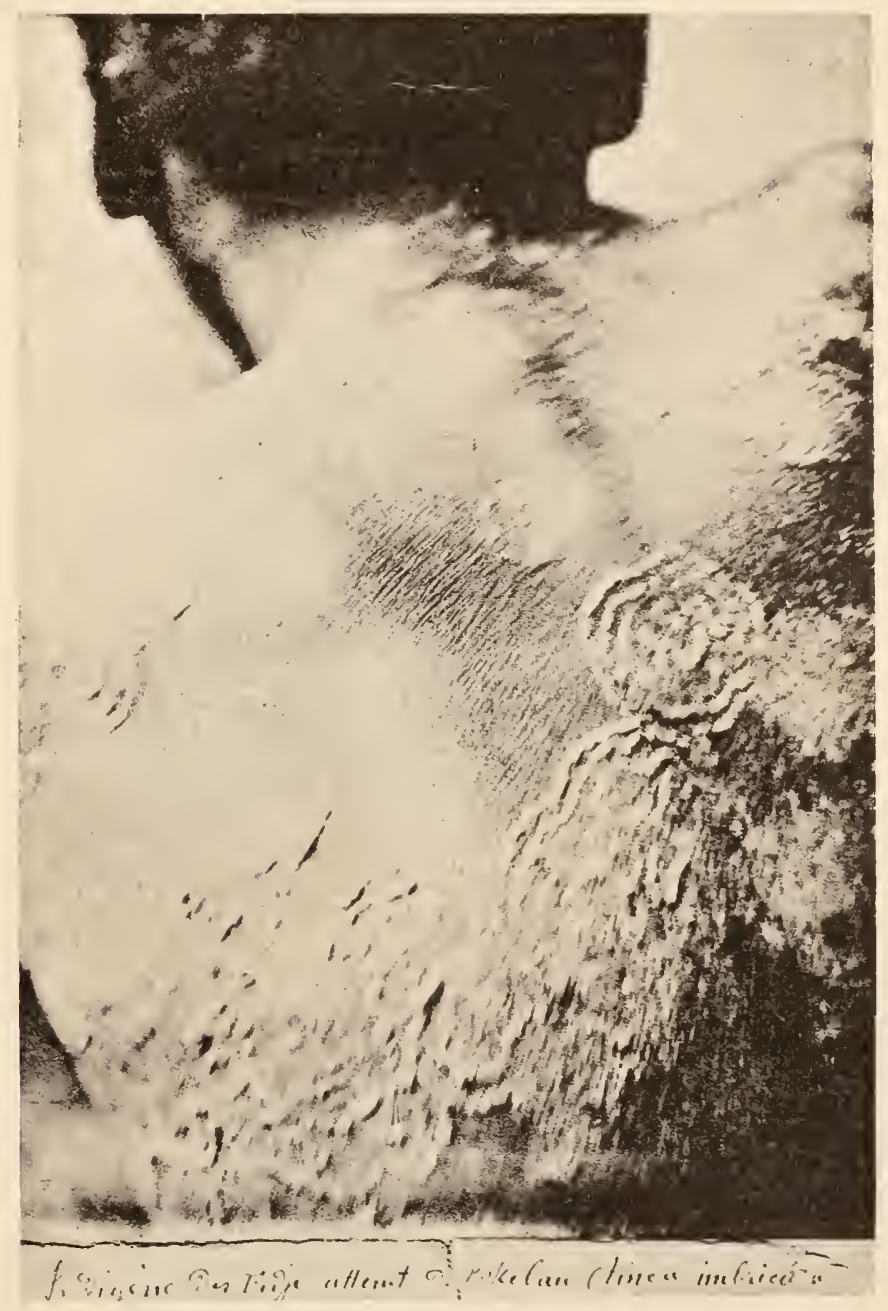

FIg. 129.

Teigne imbriquée de Patrick Manson. (Cette photographie nous a été contiée par II. Ir Dr lionnafy, médecin en chef de la marine, qui a publié rẻcemment une excellente monographie sur le sujet.)

par dichotomie. Ces filaments sonl presque alsolument identiques à ceux que montrent les trichophyties serpigineuses siches de nos pays.

La culture de ec parasite u’a pı êlre obtenue des squanes trop vicilles apportées en Europe. Nais il est extrèmement probable qu'clle 
se ripporterait i 10 type voisin de cenx que nous renons deetudior.

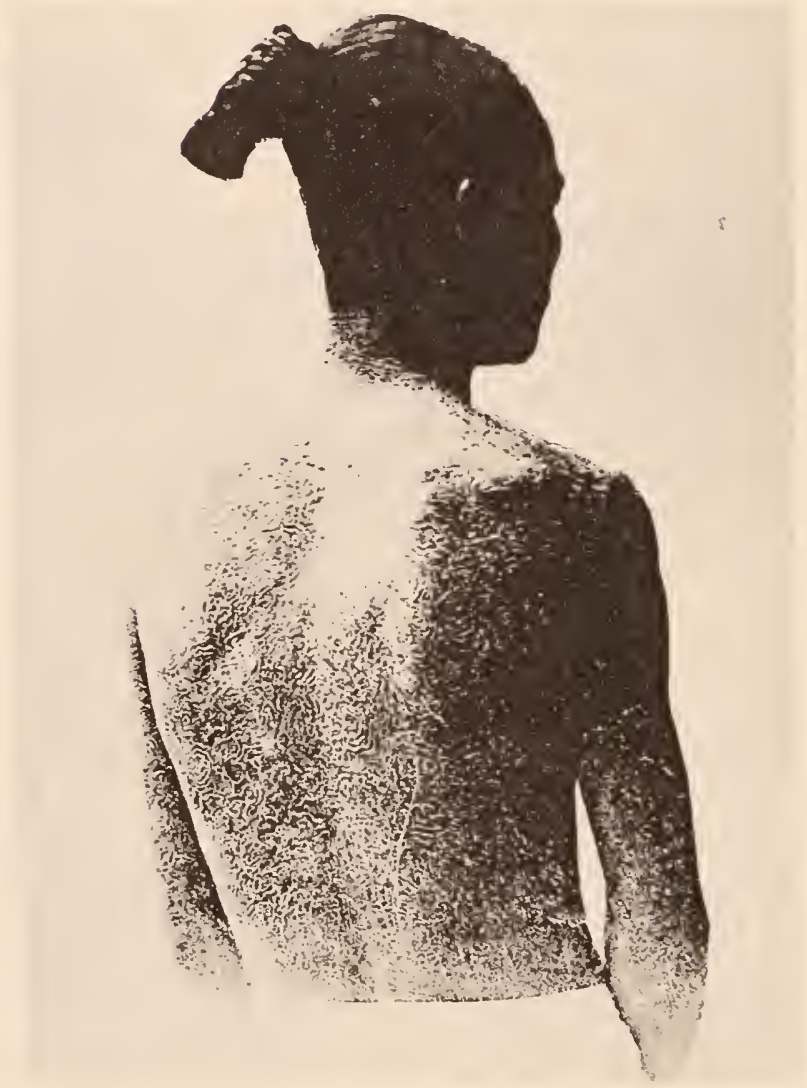

Fig. 150.

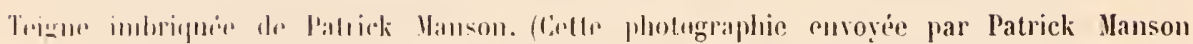

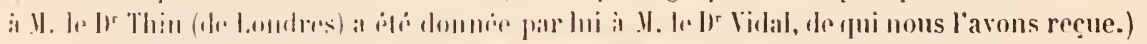

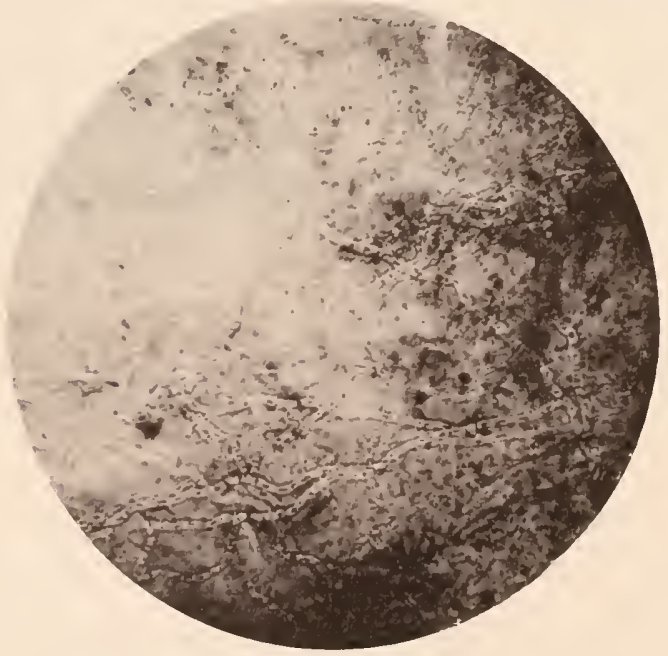

Viki. 1 II.

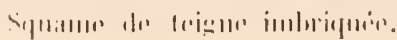




\section{ETUDE MYCOLOGIQUE IDS TRICHOPIYTONS}

l.es trichophyglons dans la vie patrasilaire, eheren, poil, squame et ongle, ne fournissent que des spores mycélienues ou des filaments myecliens of jamais de spores extermes portées sur des hyphes sporiféres; au contraire, rans la vie en culture arlificielle, en quelques jours, les cul-

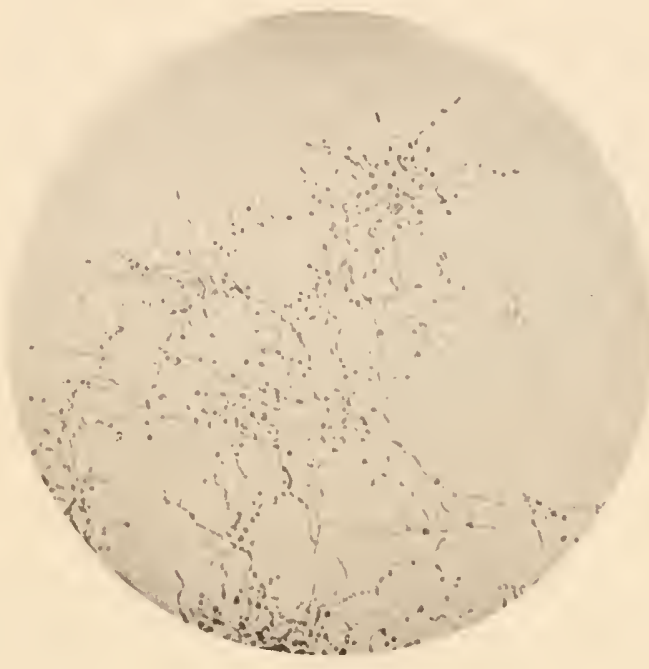

Fig. 132.

Culture trichophytique jeunc. Sporulation externe commençante (gr. 250 diam.).

tures jeunes, formées de filaments mycéliens non sporulés, se couvrent le spores externes, supportées chacune par un pédicule court (fig. 152).

An bout de huit ou dix jours, la culture en goutte suspendue est derenue tellement touffue et tellement couverte de spores, qu'elle forme un tissu impénétrable à l'œil. Et e'est sur le bord de la culture qu'on peut roir le mode de suspension des spores sur les hyphes sporifères (fig. 155).

Dins certaines des espéces dont nous commaissons la culture (T. endothrix) les tilaments mycećliens donnent lien latéralement à des spores externes solitaires, el celi sur de grandes parties de leur longueur.

Les spores sont chacune isolées. La cellule qui leur a donné naissance est courte. La spore est supportéce sur un rameau fructifère très liref (fig. 154).

Sous ce rapport, le trichophyton endothrix à mycélium fragile est 
colui dont la sporulation externe est le plus disséminéc. Ce caractère

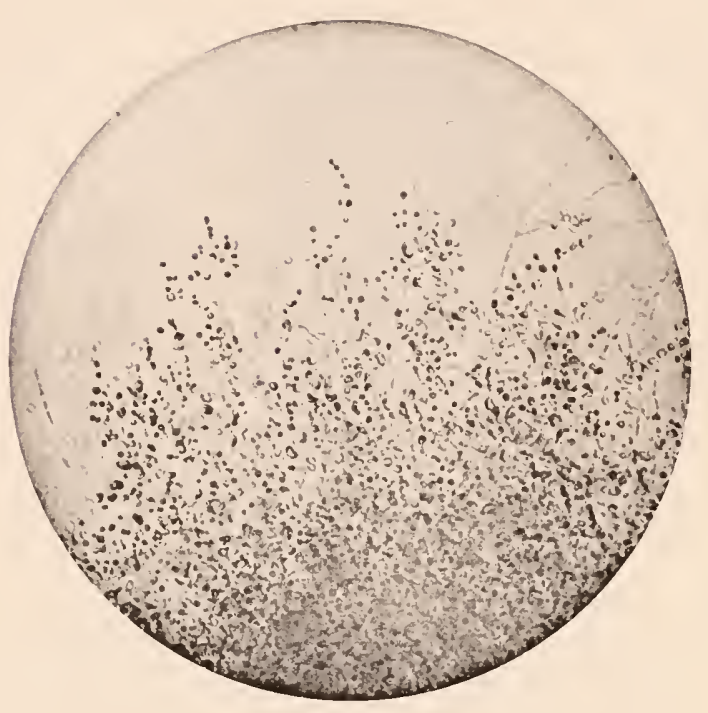

Fig. 15.5 .

Culture Irichophytique adulte (gr. 250 diam.).

rapproche ce parasite du groupe des Sporotrichum de Liık. Mais sur certaines espèces, sans que les filaments mỵeéliens perdent

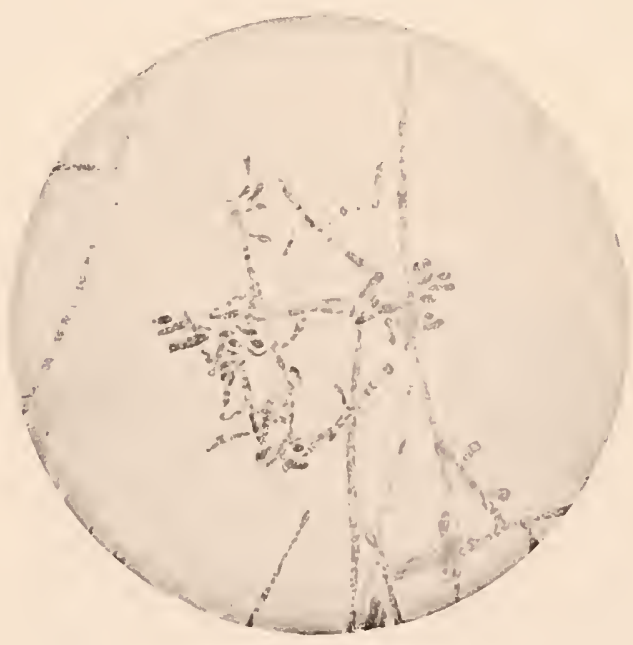

Fig. 15.4.

spores arcessoires, porties directement sur le mycélium (gr. 600 dian.).

le pouroir d'émethe lalriralement des spores externes isolíns, ees spores ont une tendance manileste a s'agniner on forme de grappes terminales (fig. 156). 
En alfaiblissant le pournir nutrilif du milien de ces cultures, on purn

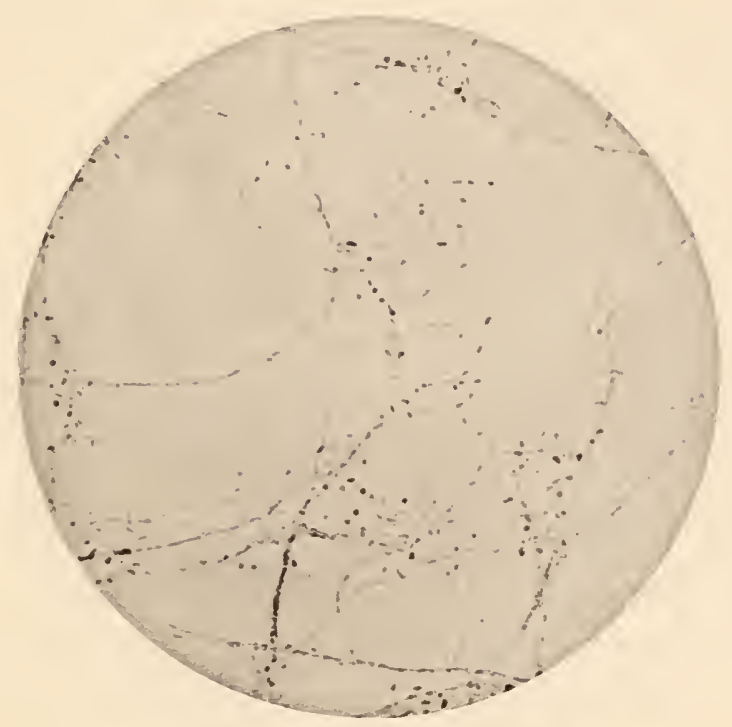

Fig. 153 .

sporulation externe disséminéc. Trich. à mỵcélium fragile (gr. 500 diam.).

roir que la sporulation externe redevient latérale et isolée (fig. 157).

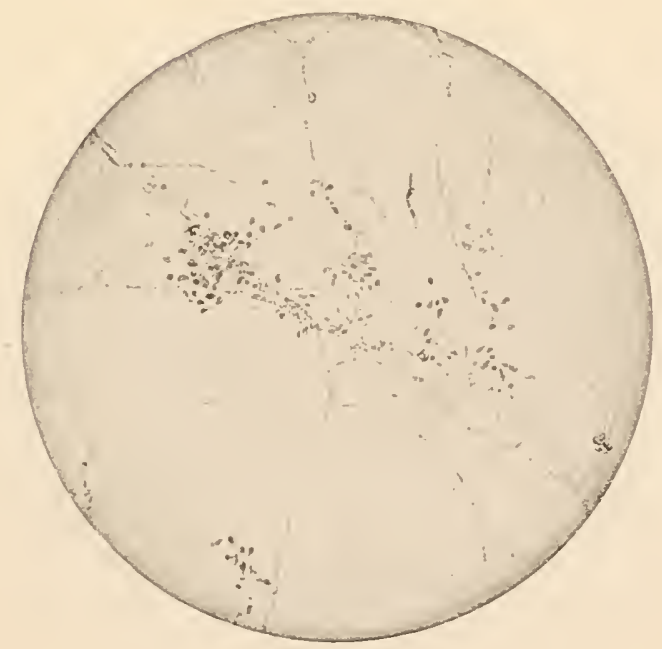

Fli. 156.

Sporulation exterue. Tendance à l'agmination en crappe (gr. 200 diam.).

Au contraire, quand le milieu nutritif est liche, ef dins certaines espices ectnthrix. on peut roir l'hỵphe sporifire se différencier te 
plus en plus. Il n’y a plus de spores isoleces latérales aux mycéliums.

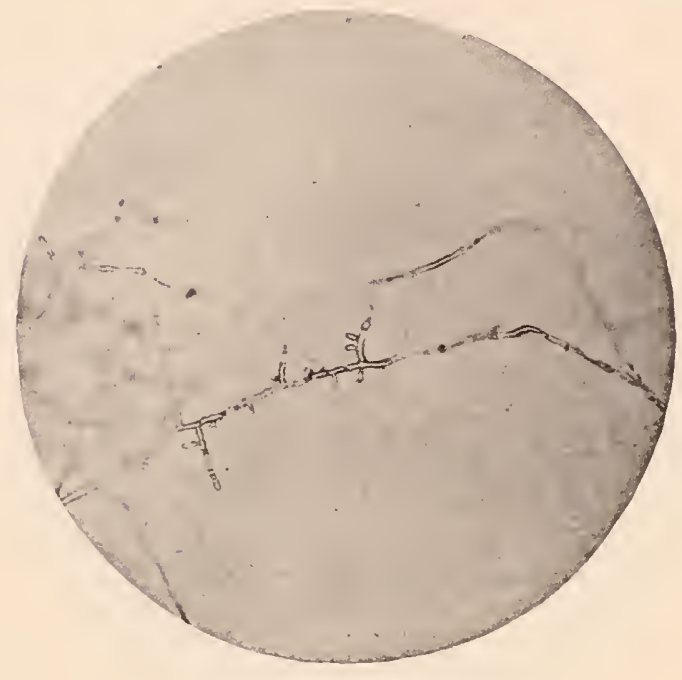

Fig. 157.

Sporulation externe en milieu paure. Les spores externes rederimment solitaires (or. 250 diam.).

Les spores forment des grappes tout i fait diffërenciécs (fiğ. 158).

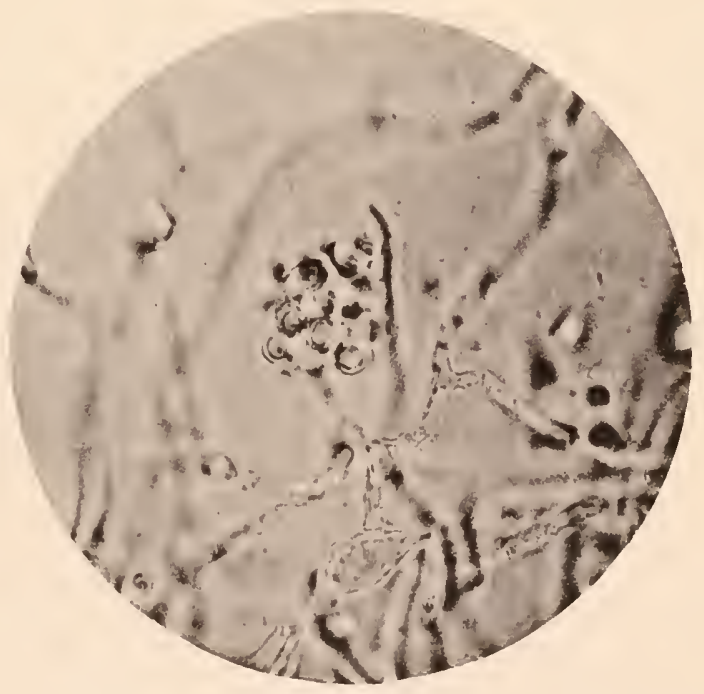

Fin. 1.is.

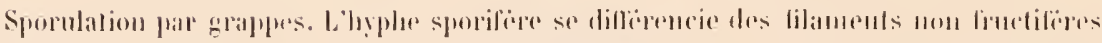
(ㅍr. 1000 diallit.).

Les especes cetolluix fonruissent d'iutres, formes de reproduction 
que la spore externe en grappe. Cee sont de longs fuseanx multiloculaires (lign. 159).

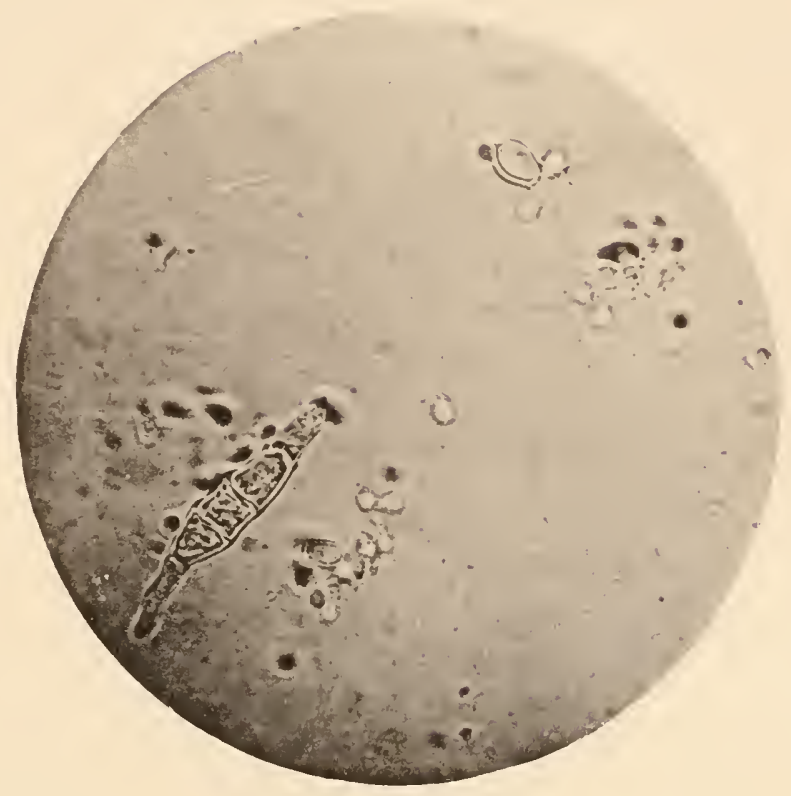

Fig. 13i?.

Clilanydospores des espèces a cultures blanches (III. 850 diam

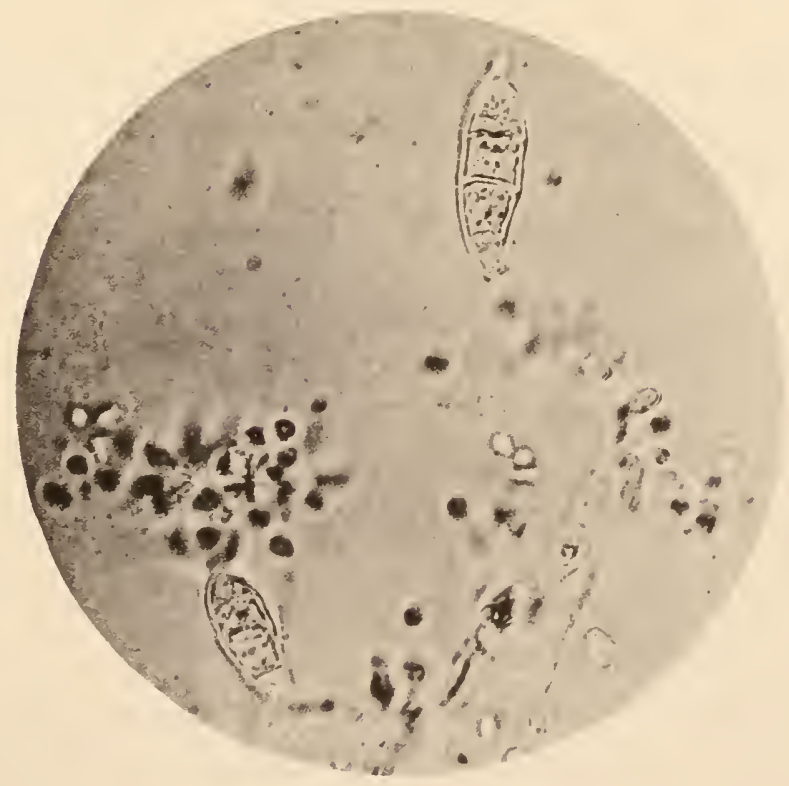

Fig. 140 .

Chlamydospores à éperon saillant. Forme chlamydosporée supportant deux grappes (gr. 800 diam.). 
Ces firseaux peuvent dins une grappe oceuper la plate d'ume spore on celle du pédicule de la grappe (fig. 140).

Beancoup sont terminées par un éperon saillant. Leur forme variable, leur enreloppe épaisse ì double contour, leur siège sourent terminal

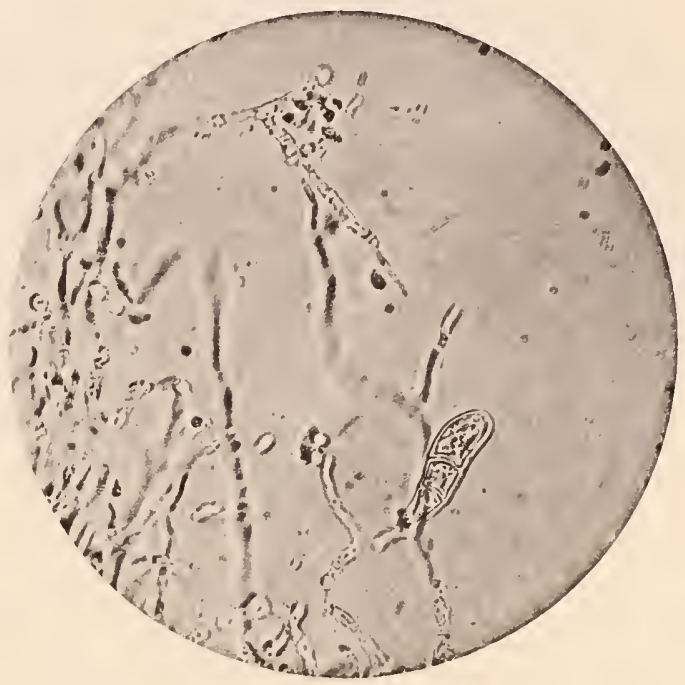

Fig. 141 .

Chlanydospore terminale (gr. 500 diam.).

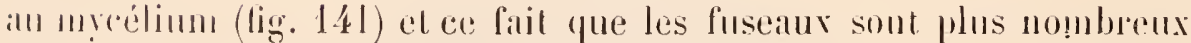
quand la cullure est vieille el qu etle soullie, entin leme nombre inversement proportionnel it celui des spores externes lemtent it litire considérer ces organes comme des chlemydospores.

En dehors de ces formes spréciales, il fant mentionner l'existence

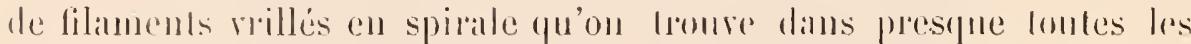

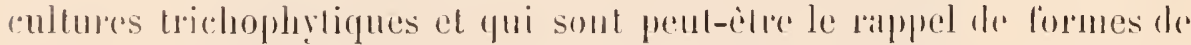
lipuclifieation de familles voisines. Linfin il fint mentionnepanssi parmi les lilanents sporiföres lintiles, l'existence de nuycéliums inféconds al

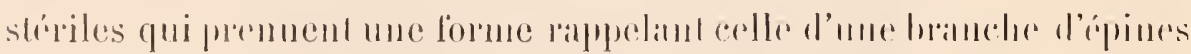
déprouillée de feuilles (tign. 142).

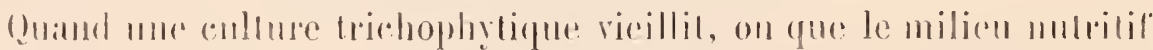
derient intpropre il sal végétalion, les spores myeéliennes reparaissent.

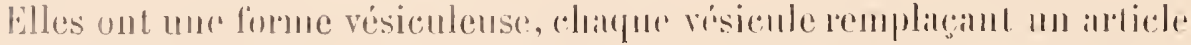
mucélien (fịg. 145). 
Lat masse de ces cellules renflées at vacuolaires remplace progressi-

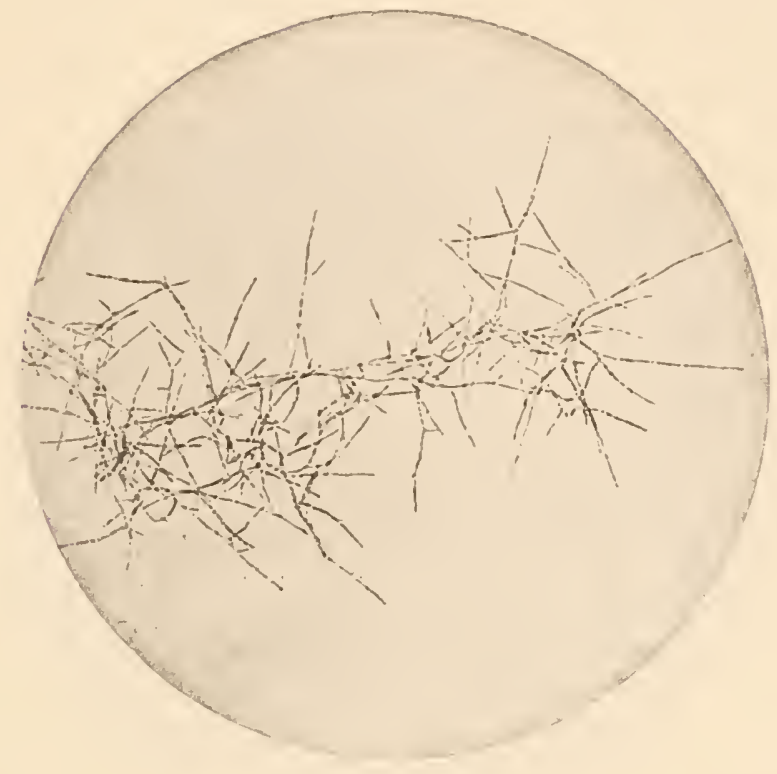

FIG, 142 .

Filaments nuycéliers terminaux stériles (gr. 200 diam.).

vement le mycélium tin et élancé du début (fign. 144). Ce sont lii des formes de dégénérescence.

On peut faire naitre, dans les cultures trichophytiques, d'autres

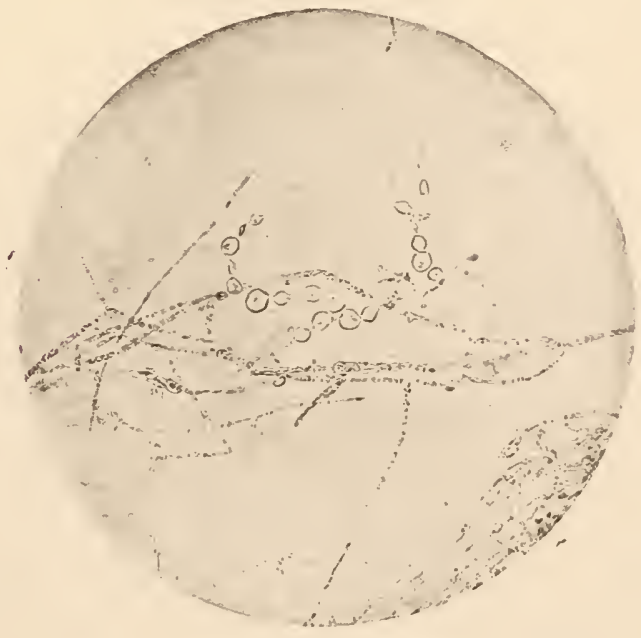

Fifi. 14.5.

Śpores mycéliennes de dégénérescence. Spores grosses et vísiculeuses (gr. 400 diam.). 
lor'mẹs de spores migećliennes qui semblent plutôt des formes de résislance et d'adiptition qur des formes de dégénéreseence (lig. 145).

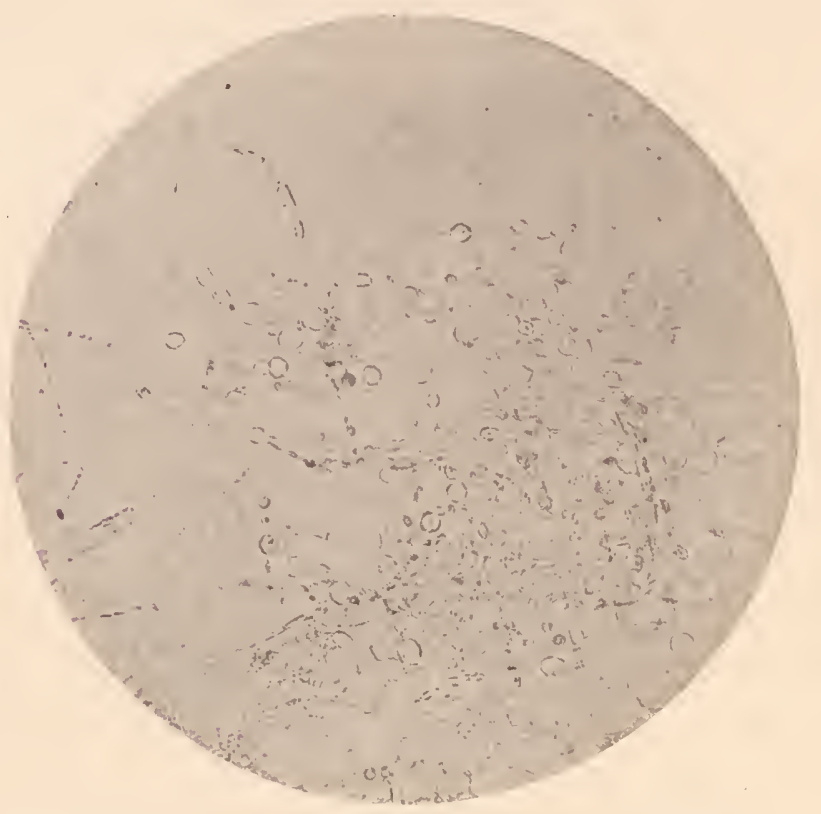

Fig. 144 .

Spores mycélienues do dégénérrscence. Sipores grosses el résjculeuses (gr. 400 diam.).

C'e sont des spores mugéliennes carrées qui rappellent extrèmement

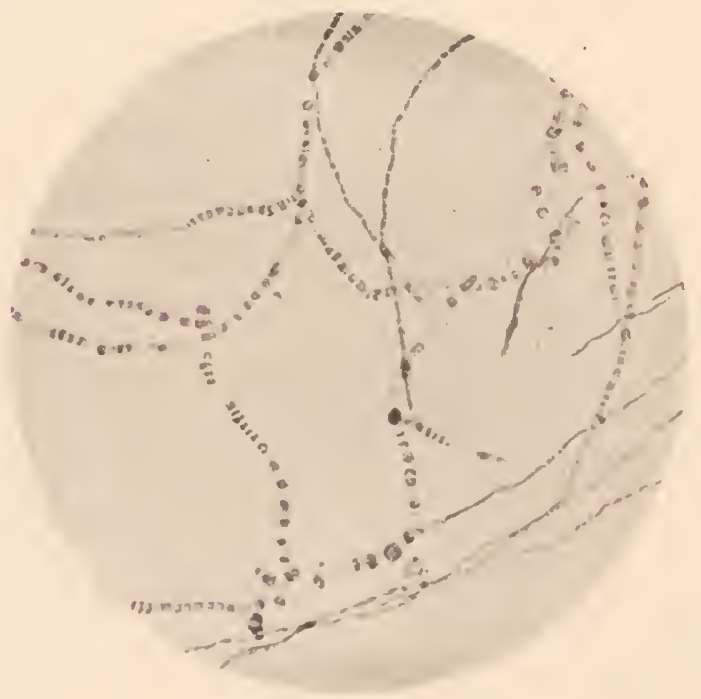

Fig. 145 .

Spores mycéliennes d'adaptation anx milieux azotés (gr. 500 diam.? 


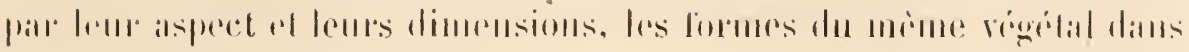

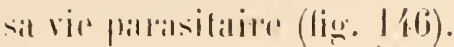

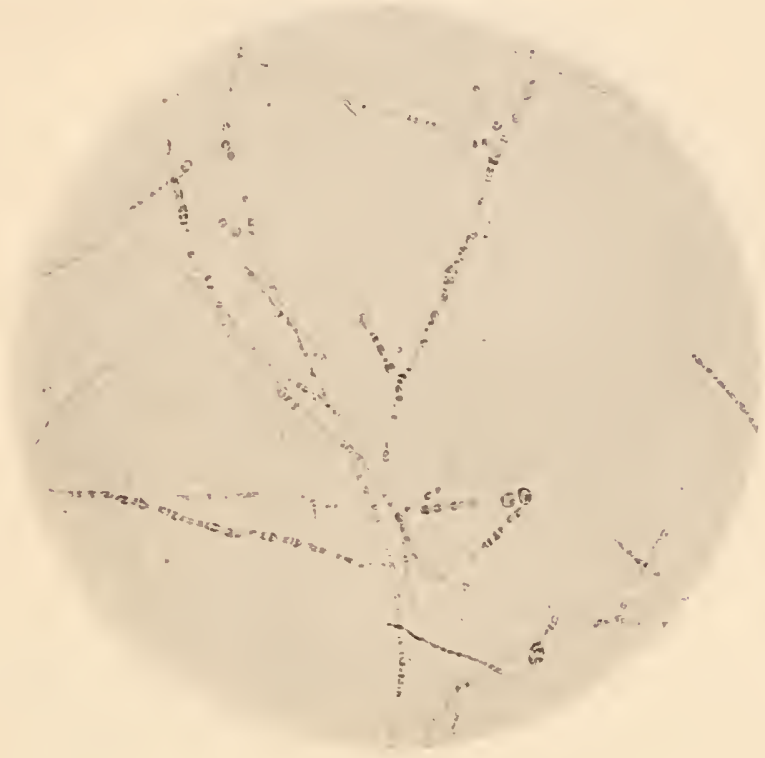

Fig. 1't6.

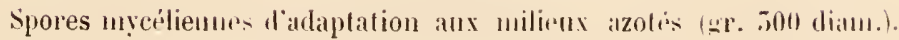

Elles naissent dans les milieux liquides tres azolés. Ce fail mol il rapprocher de la remarque qui précèle, car dans la vie parasitaire, le

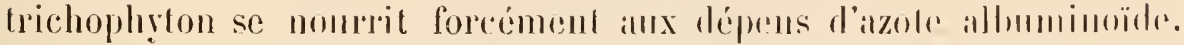

\section{TAXONONIE IISS TRICHOPIIYTONS. - LES BOTRTTIS}

A quelle famille de Hucédinées rapporter les trichophytons? I.eur sporulation exlerne en grappe les rapproche nellenent du groupe des Botrylis dont on connail dëji des représentints silprophỵtes r. parasitaires. (B. tenella, cinerea, Bassiana, elc....)

Le Botrylis Bassiana en culture n’est pals identique anx trichophytons. Son mycélimu est plus din, ses grappes soml composios dr sporrs plus pelites, elc. (fig. 147).

Il est impossible ceprendant de nier l'itroite parente morphologiqur des Trichophytons el des Botrytis. L'agminition des spores en grappr. 


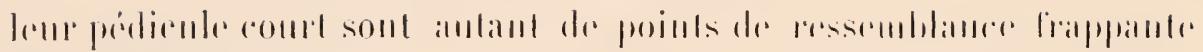

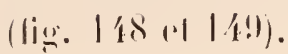

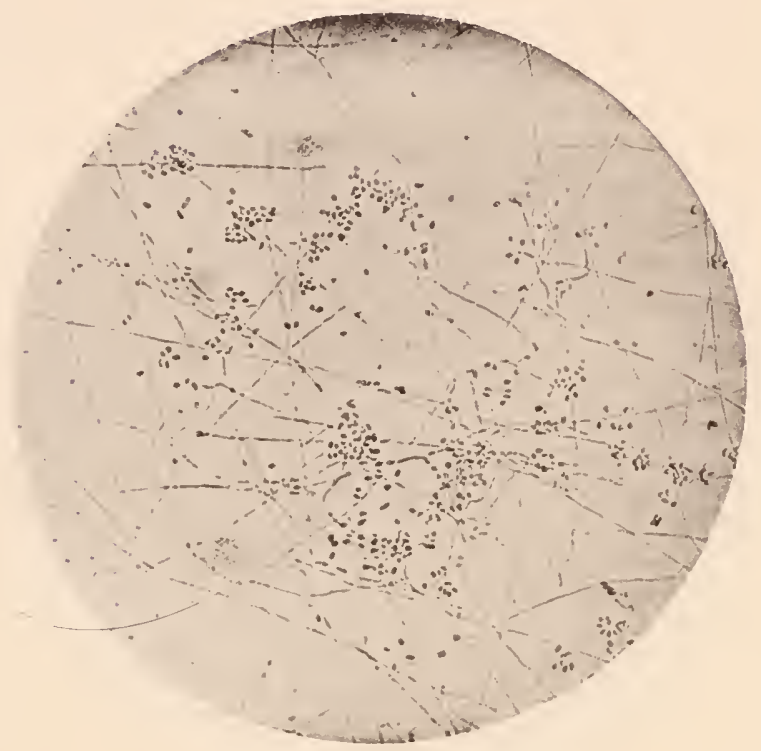

liti. 147 .

Bolvytis Bassiana, culture "ul goulle de 6 jours (ar. 2:il dian.).

Fant-il ajouter que daus sa vie parasitaire le Botrylis de la muns-

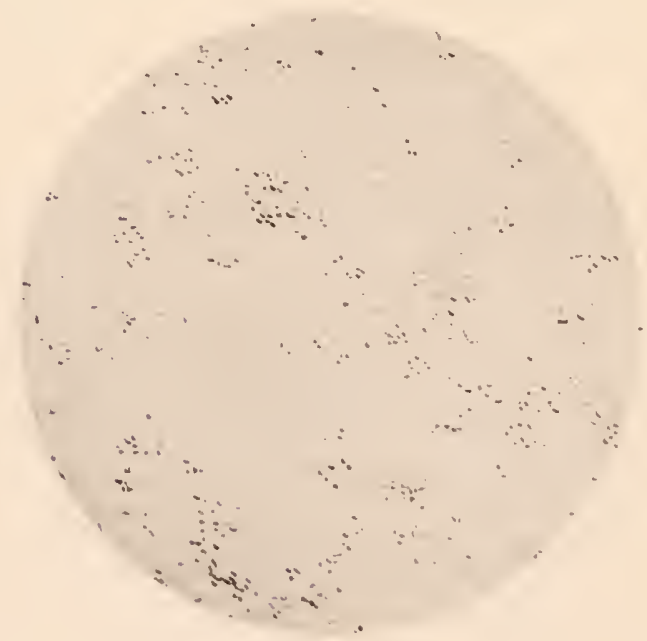

Fig. 148 .

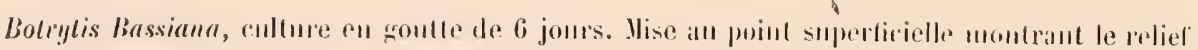
des grajpeses (gr: 230 diam.). 


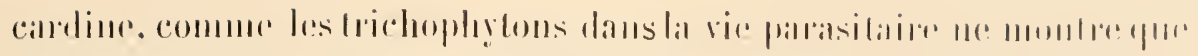

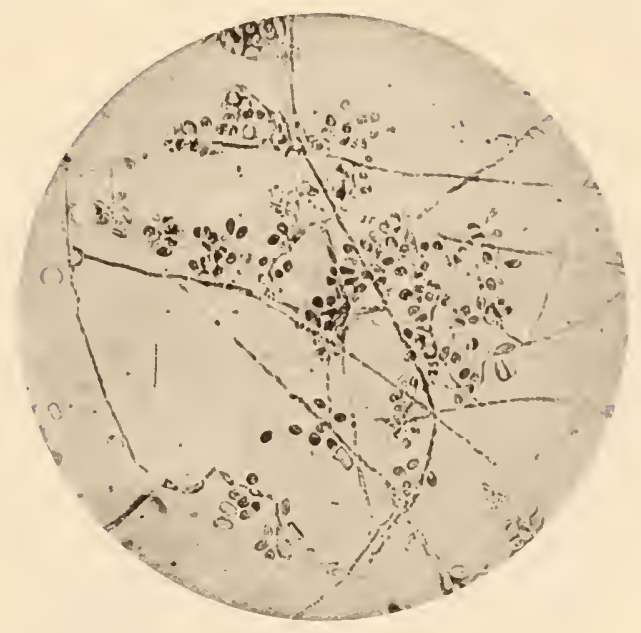

Fig. 149.

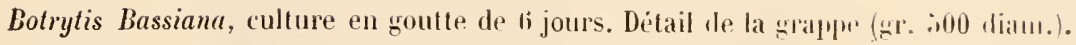

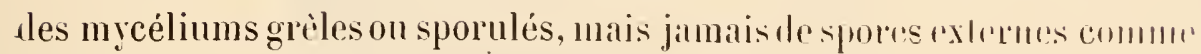

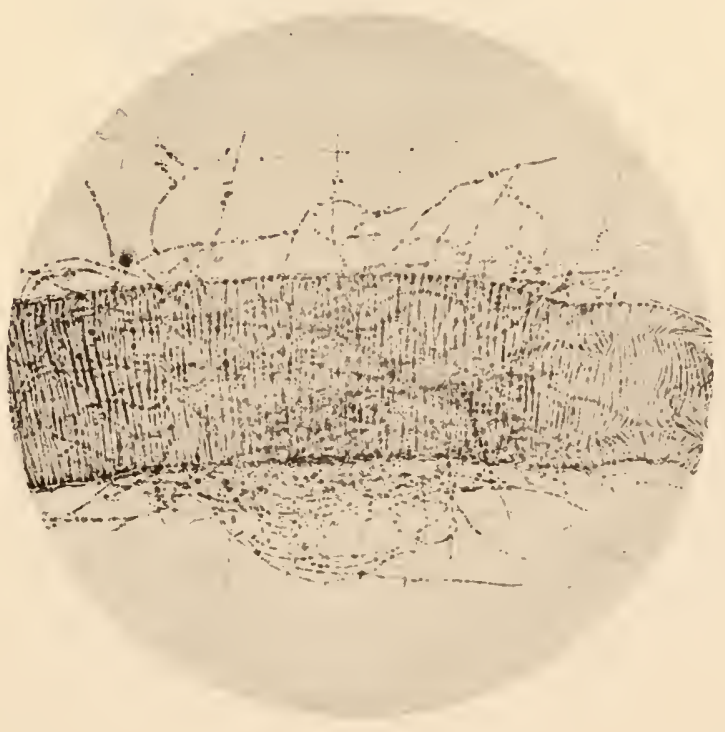

Fig. 150 .

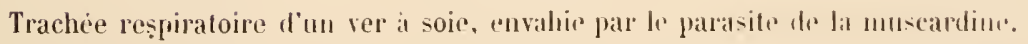

dans la vie en culture. Ainsi le proure cette figure $(150)$ yni montlw

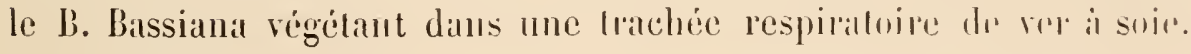




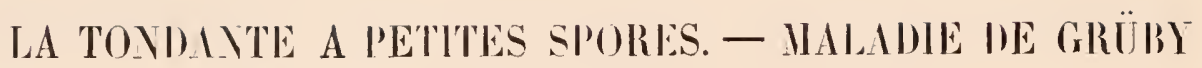 MICROSPORUYY AUDOLIIYT GRÜBY}

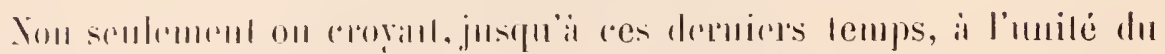

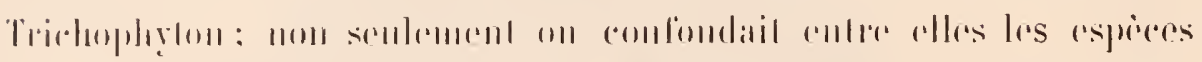

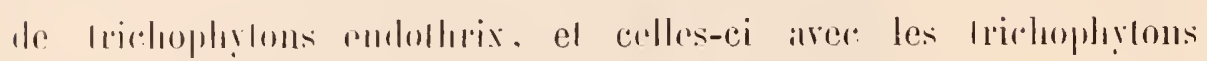

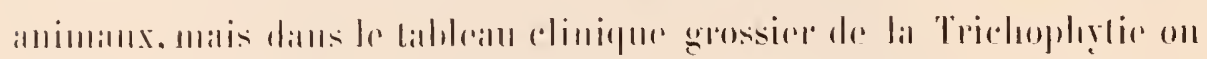

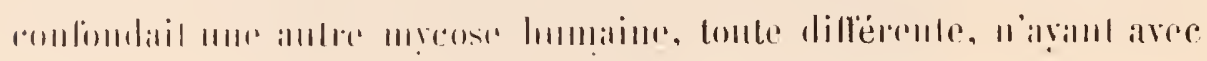

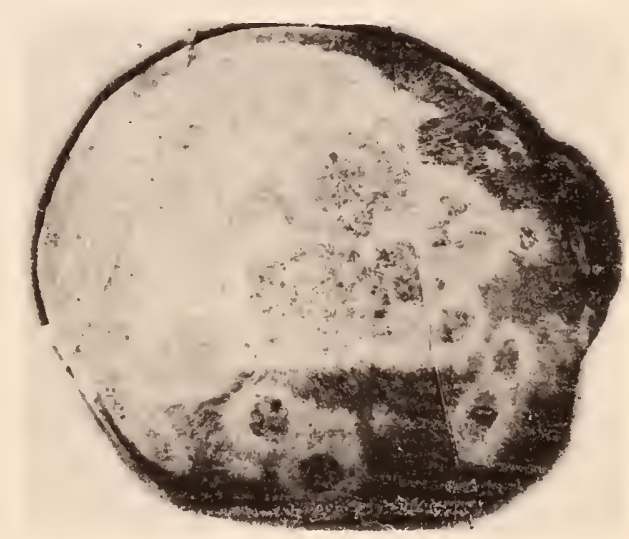

Fir. 1.51 .

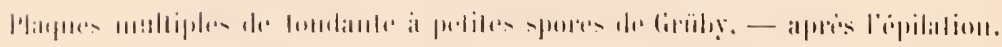

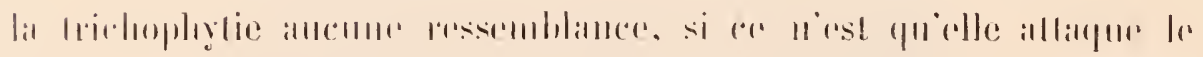

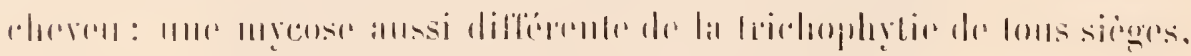

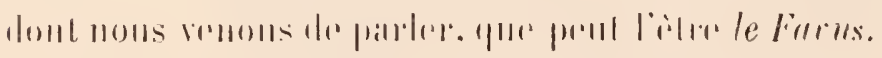

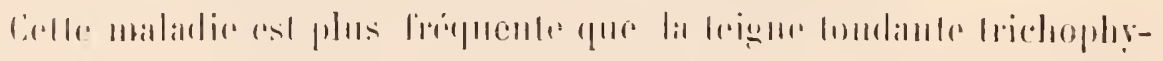

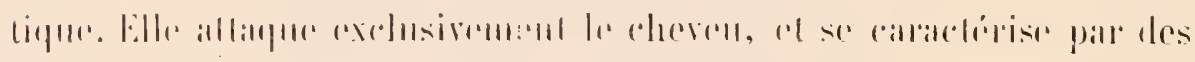

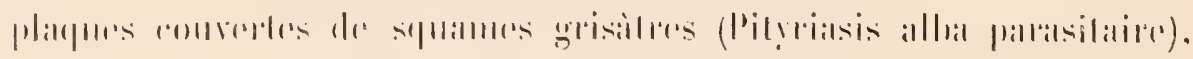

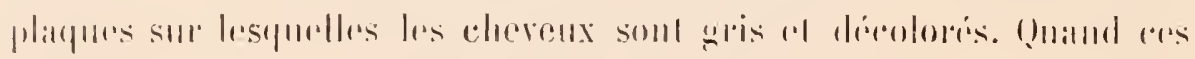

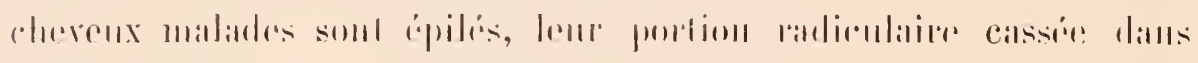

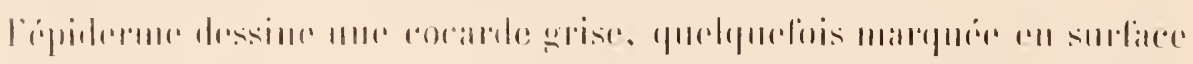

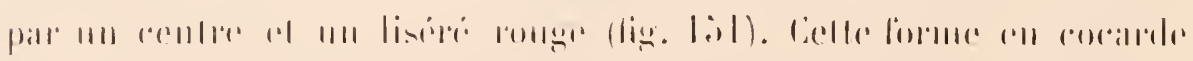

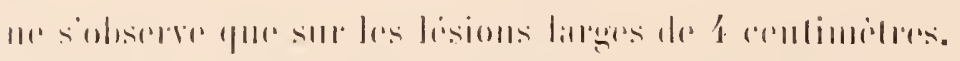

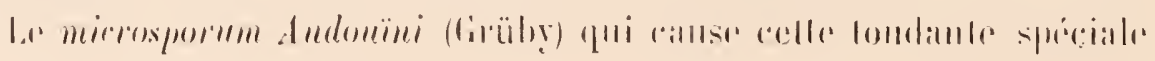




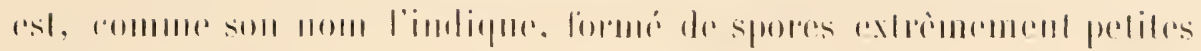

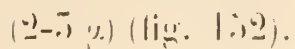

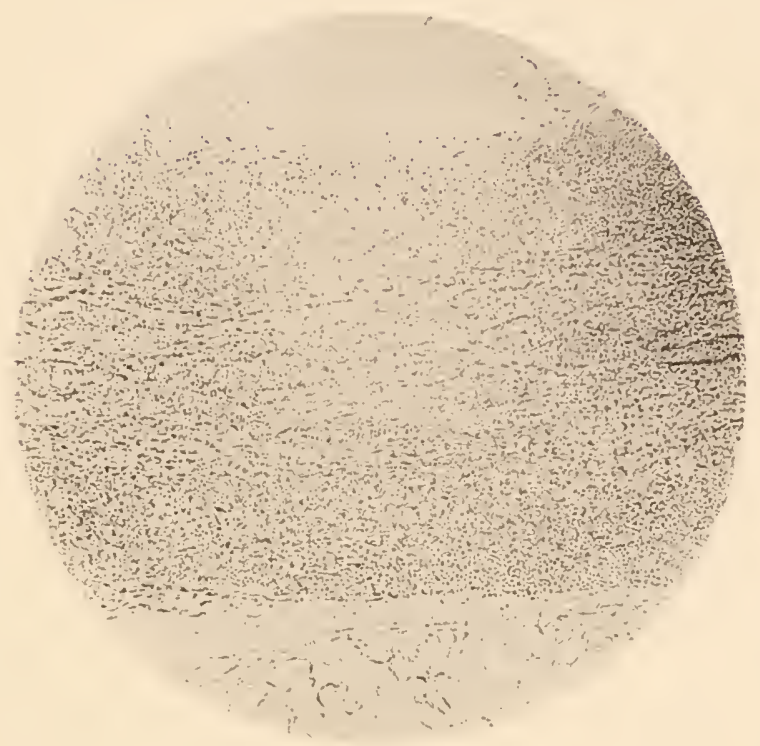

Fit. 1.12

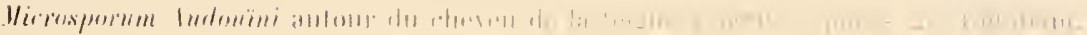

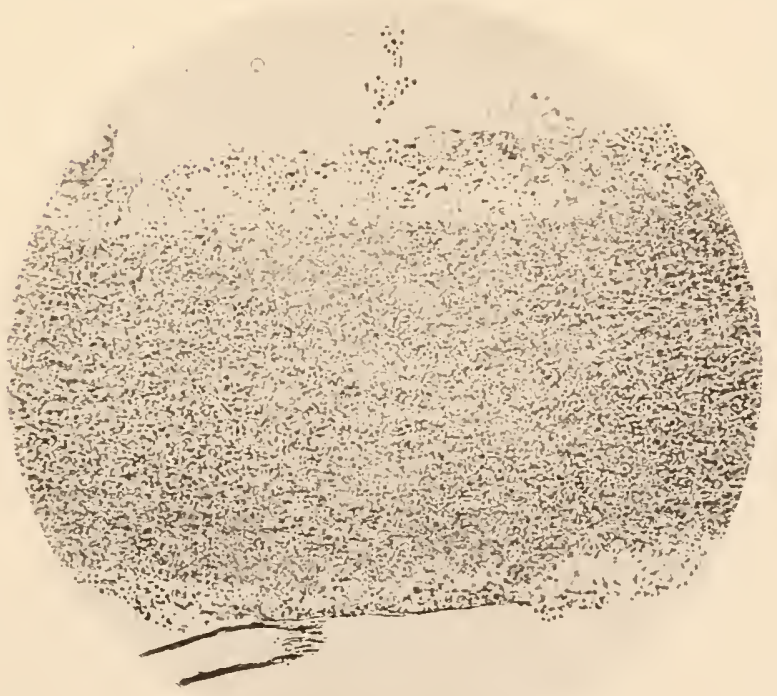

Fili. 19.,

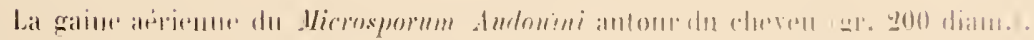

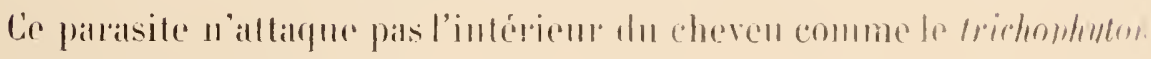


endolhrix, il n’habite pas non plus exelusivement sa gaine folliculaire

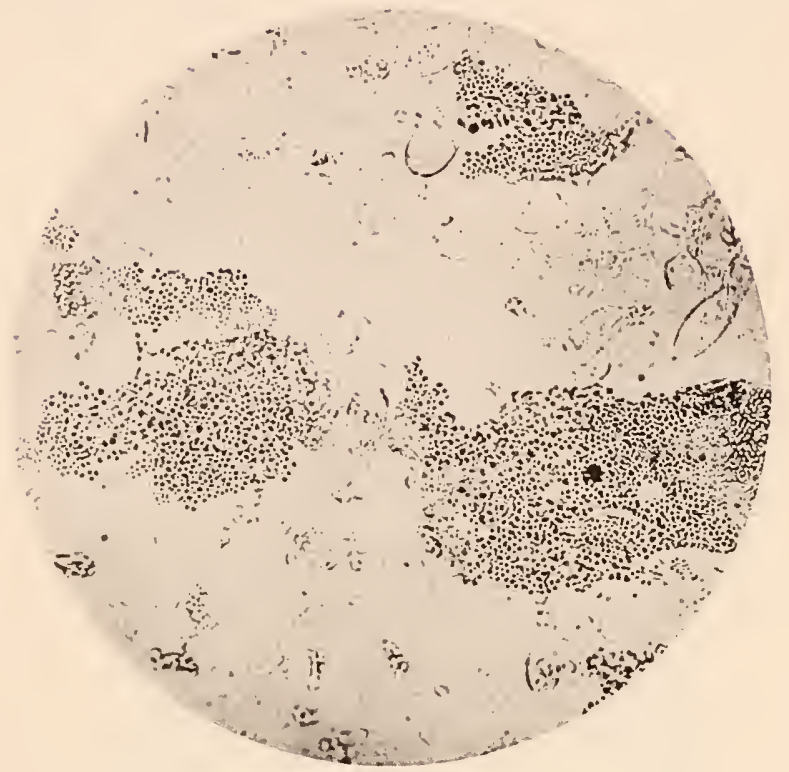

Fig. 154.

L'enveloppe de spores du Microspornu Audoüni après décortication du chereu (gr. 200 dian.).

comme le trichophylon ectothrix; il forme autour de la partie radi-

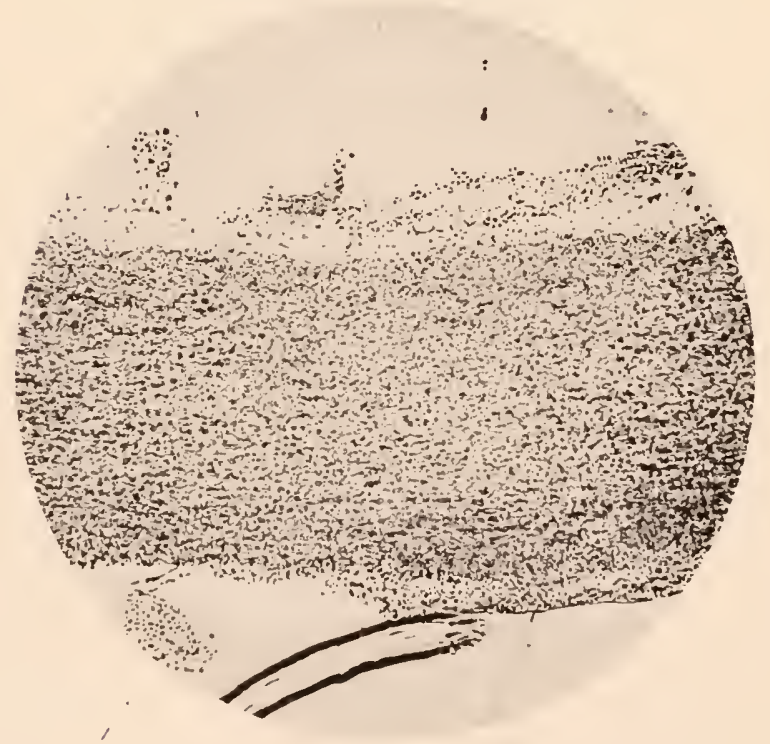

lis. IBi.

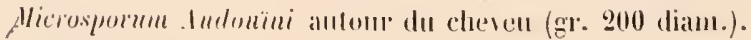




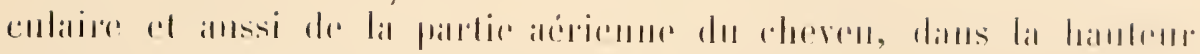

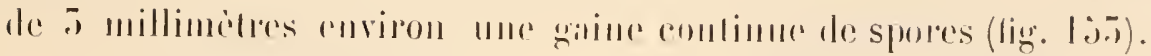

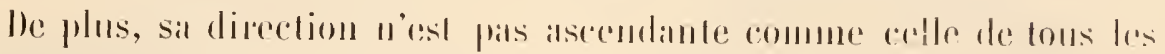

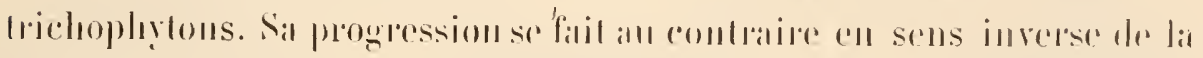

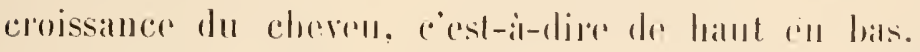

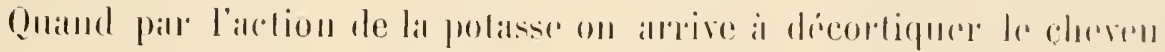

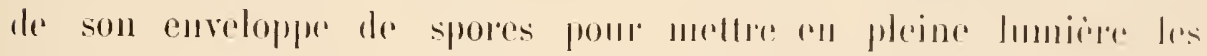

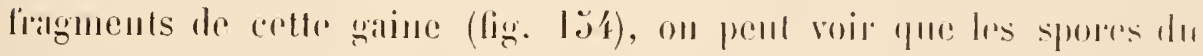

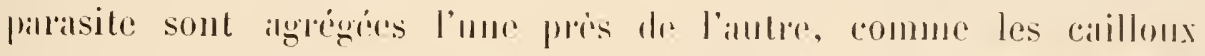
d'une mosiäque, sans former de files arliculées dislinctes (lig. 15' et 153).

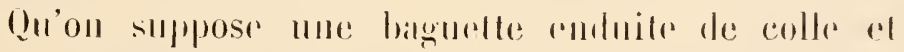

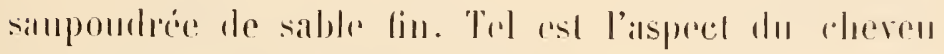
alteint par le microsporum Auloüni.

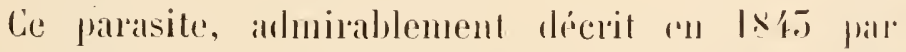

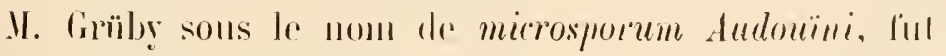

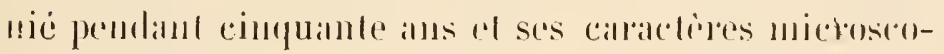

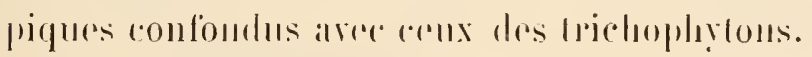

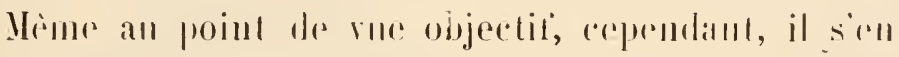
distingue, can sur une lísion non tuatite, le cheren qu’il entoure montre une gaine psendo-iphilermique de 5 millimètres de haut, an-rlessus de l'orilice pilaire. C’est la gaine parasitaire.

Cette malarlie est lat teigne tontante cliniquement commue sous le nom de teigne rebelle. lille n'atteint

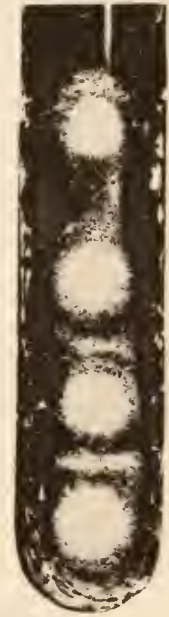

Fiti. liti.

Cullumediredededu

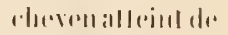
Hicrospormin Alidouini, wilon all motil de hime (2) scmilines). que le cuir chevelu de l'enfint et ne callse jannais ni lésion pilatro de: la barbe chez l'adulte, ni lésion mrecosique dr l'ongle.

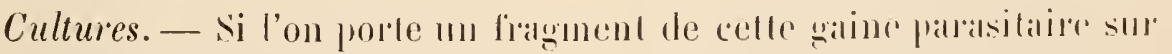
les mèmes milieux de cufture que nous conmaissoms, la culture seral tout antre que celle des trichophỵtons. El d'alhord on pent olutenis. d'embléedessćres de cullures prures en partant du cheren, sans rencon-

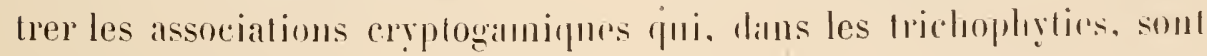
constantes (lig. ligi). 


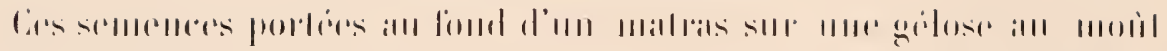

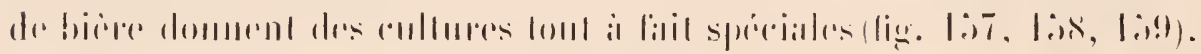

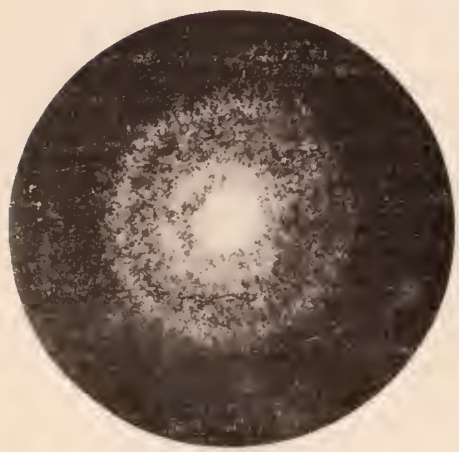

Fig. 1it.

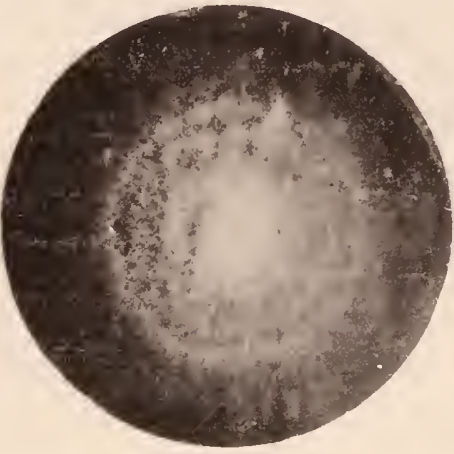

lin, lis.

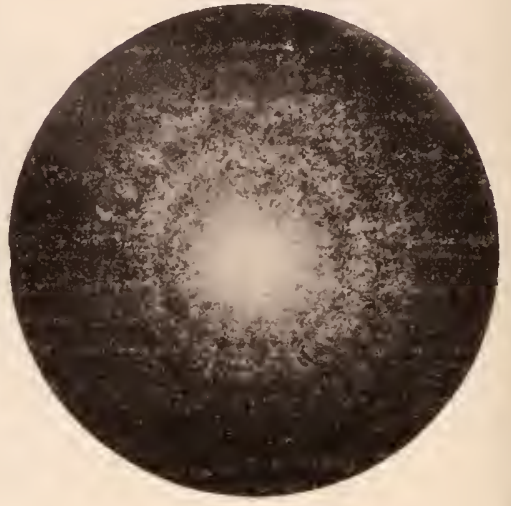

Fig. 1:!.

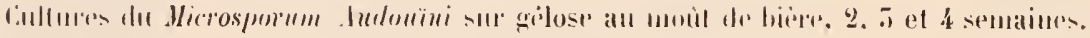

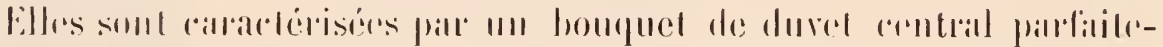

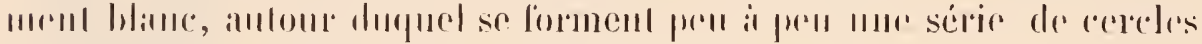

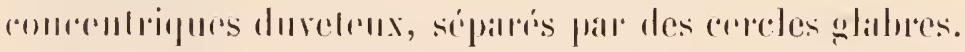

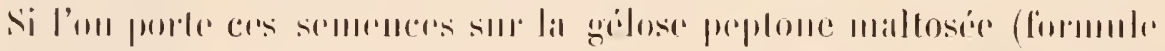

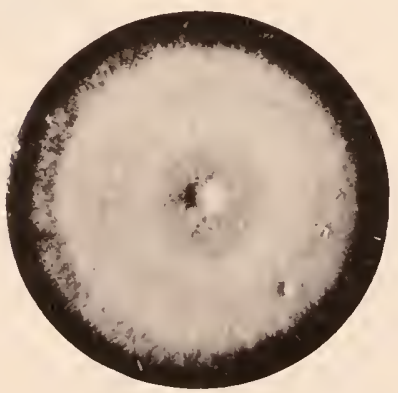

Hig. Itio.

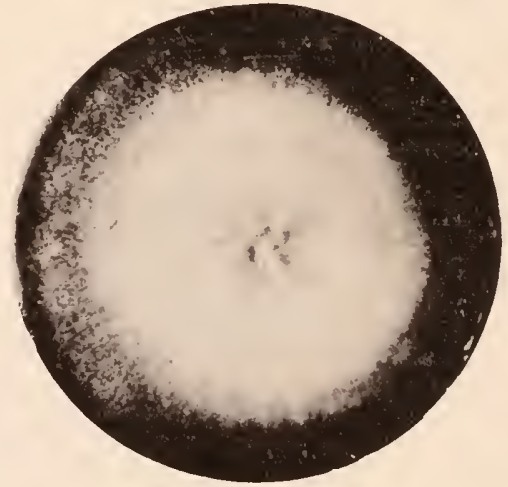

Fig, 161 .

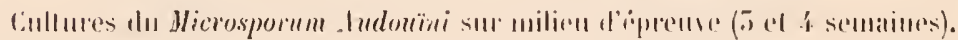

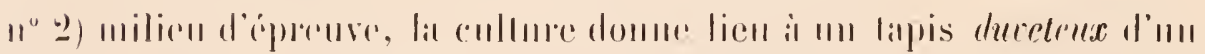

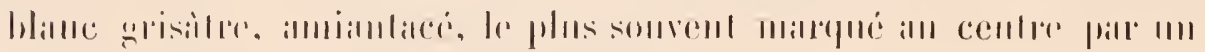

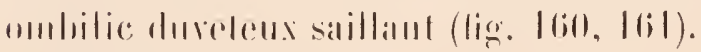

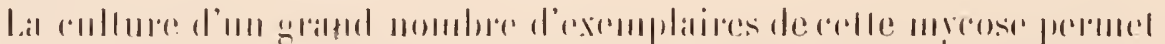

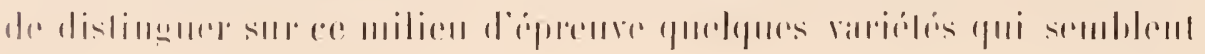




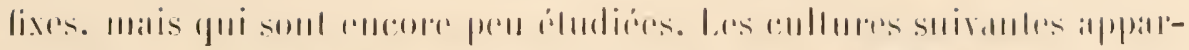

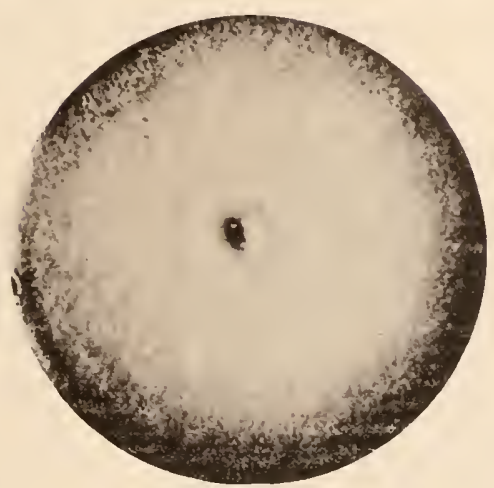

Fig. 162.

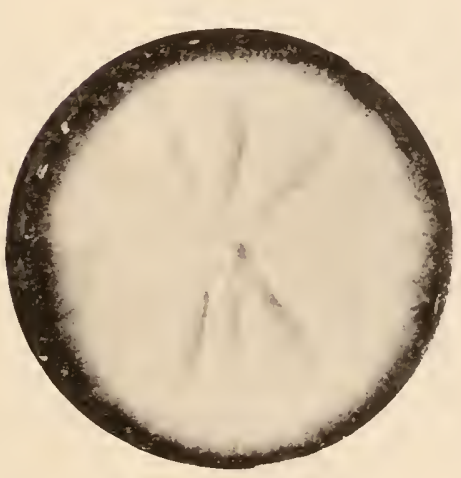

Fig. 164.

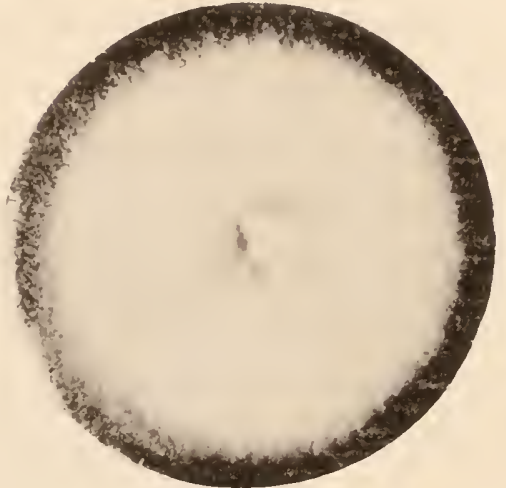

Fig. 163.

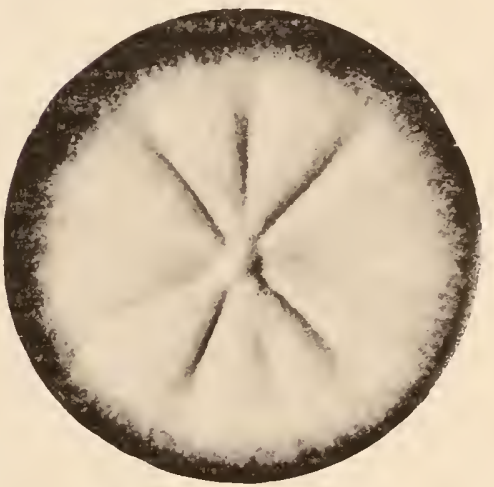

lisg. 1103 .

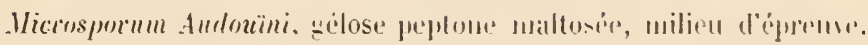

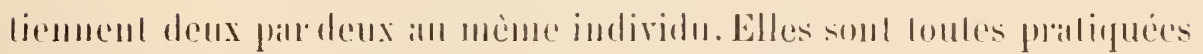

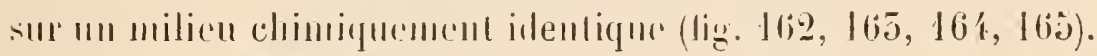

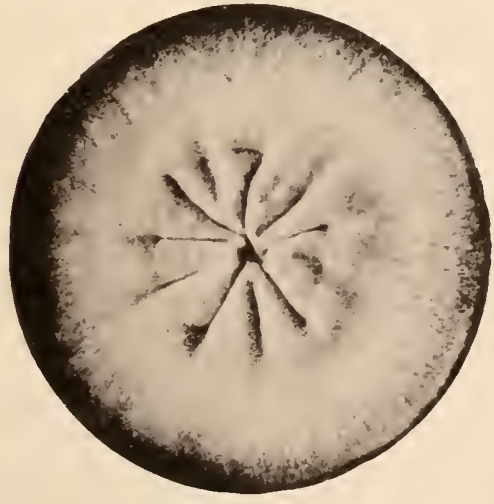

Fig. 1615.

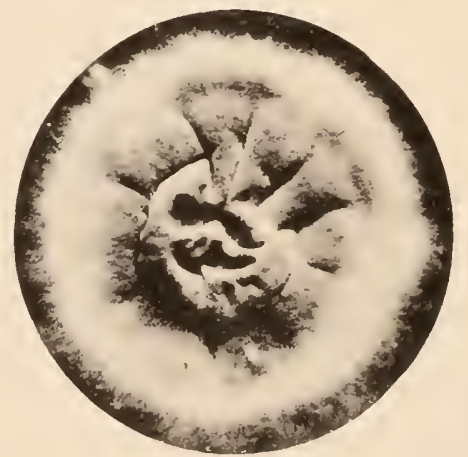

FIG. 167.

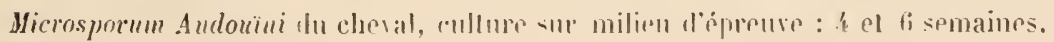


Colle maladie qui ne se rencontre chez l'honume gure daus l'enfance el senlement an cuir cherelu sous la forme de londante, existe anssi char le cheval, el de mime pentant les premiries annies. C'est l'herpris conlagieux vulgaire des poulaims (fig. 166, 1675).

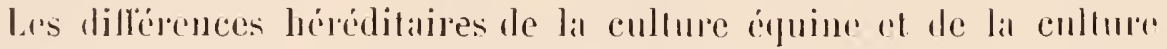
lumbine permettent de croire que ce sont denx esprers distinctes d'un mime gronpe bolaniq̣e. En vicillissant, la culture épuime qui forme

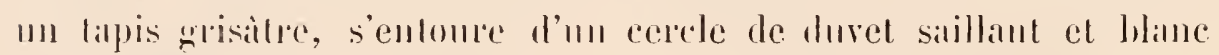
(iig. $16 i \bar{i}$.

\section{Mycologie - Taxonomie}

Iu print de vite botanique, le microsporum Audoüni est albsolument

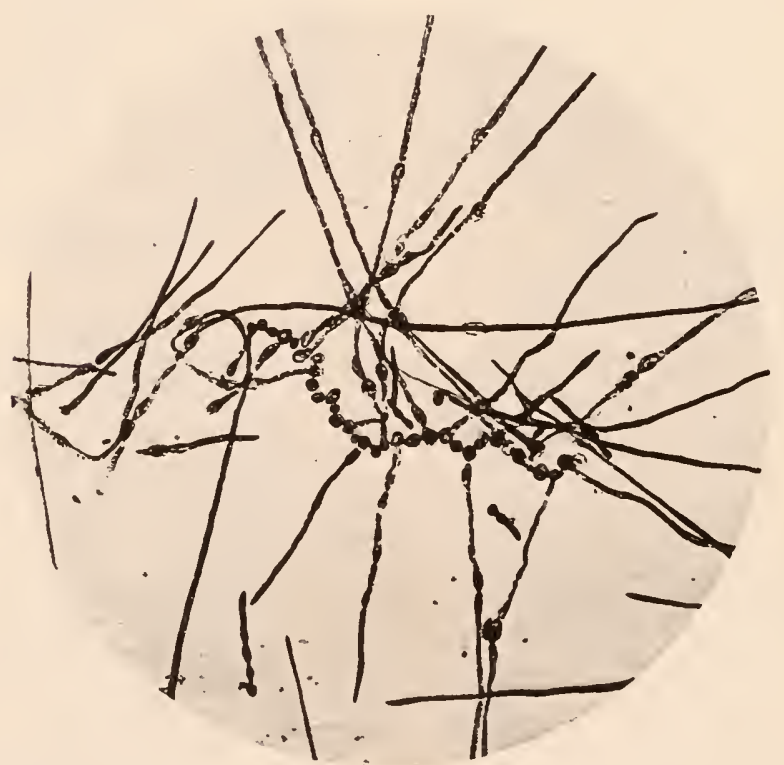

Fig. lis.

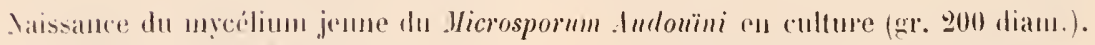

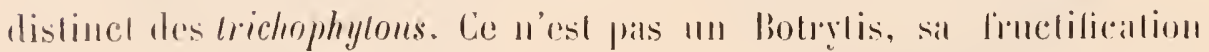
n'est pas la grappe. I'abord son myecélimm nest pas régulier comme rohi des trichophygons, il est fusche el massuri (ligg. 168), chargur

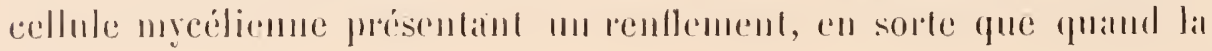




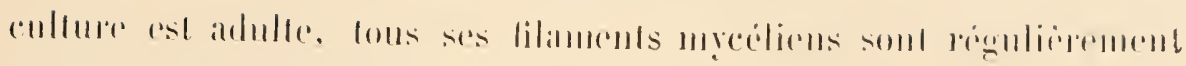
monililoumes (ligg. 169).

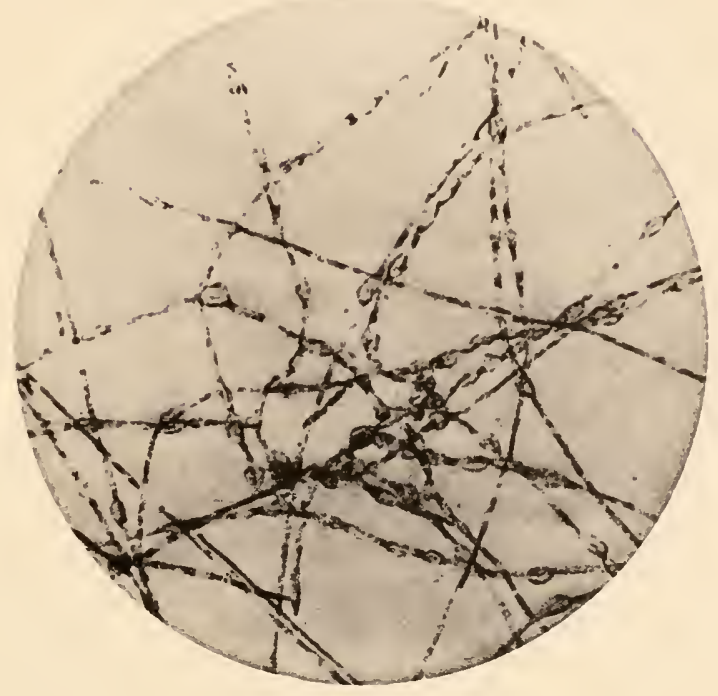

Fig. 169.

Mycélitm adulte du .Hicrosporum Audoüni eu culture (gr. 250 dian.).

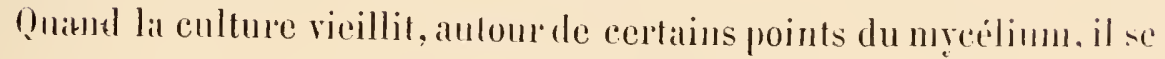

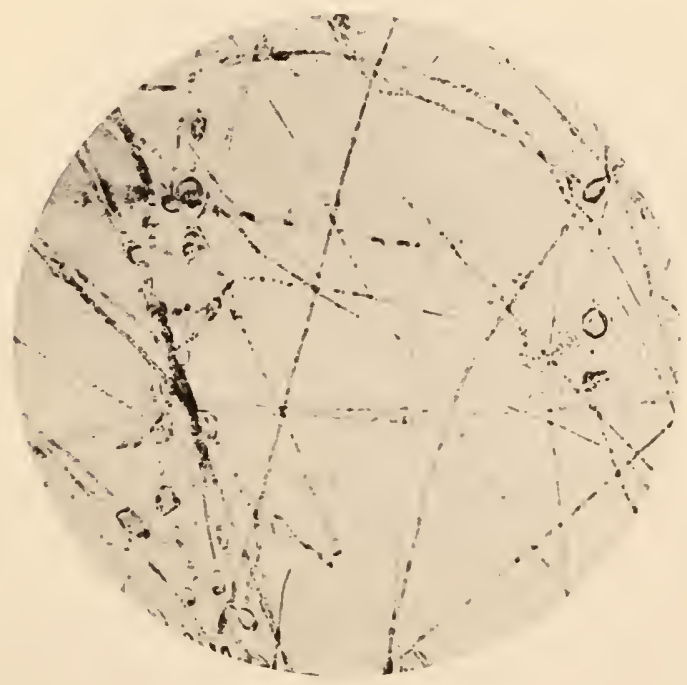

Fig. 170.

Iycélimu virilli du Microspornm (gr. 300 diauı.). 


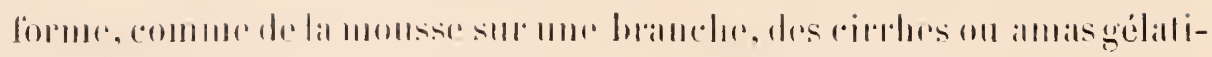

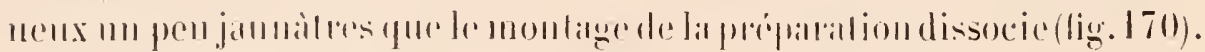

Apres quelynues jomrs si le milien mulrilil de la culture en goulle

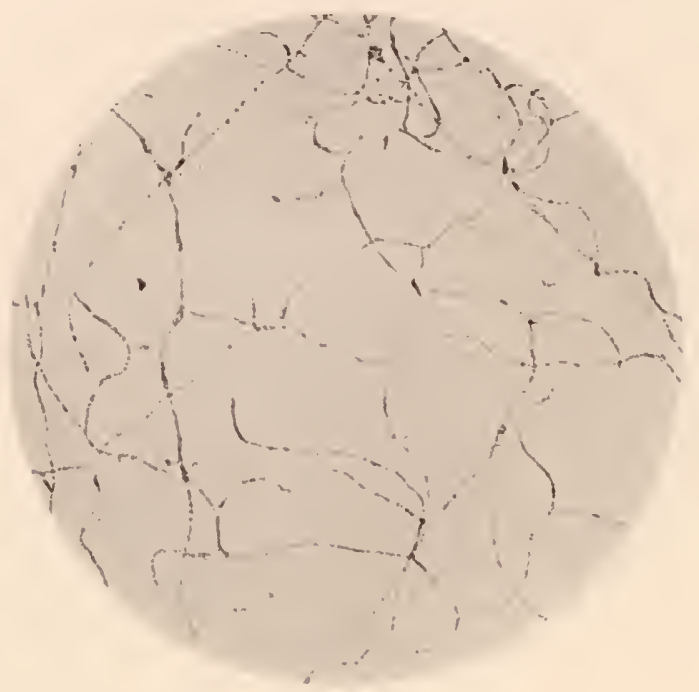

Fin. 171.

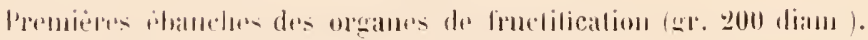

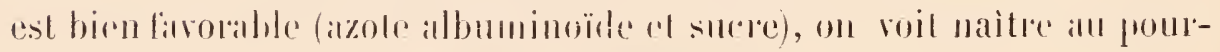

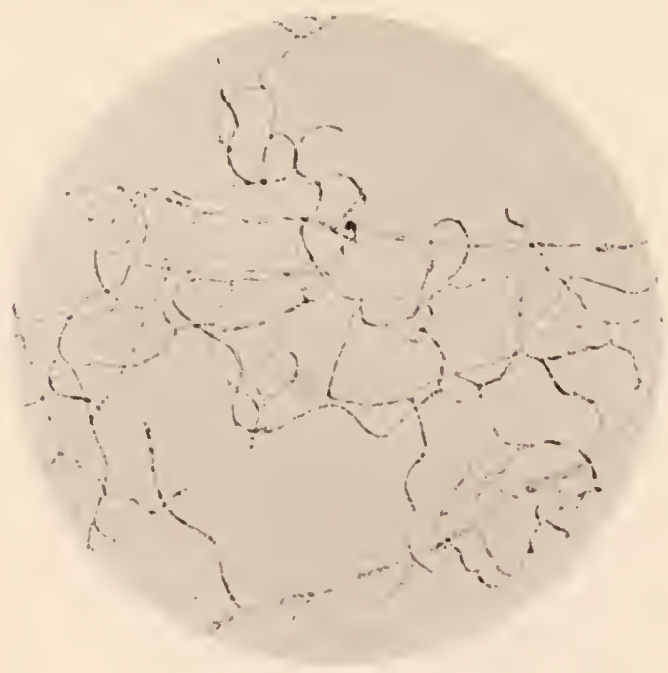

lig. 172.

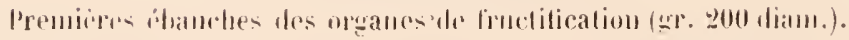

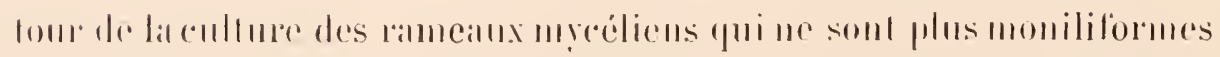

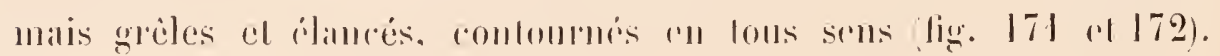




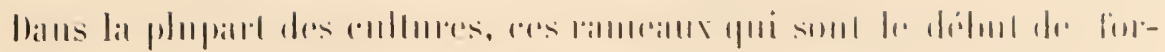

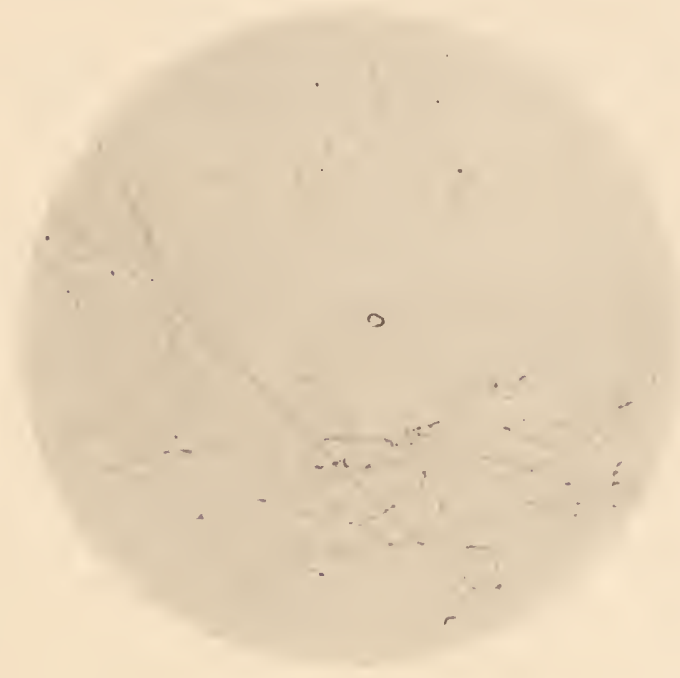

Fig. $17 \pi$.

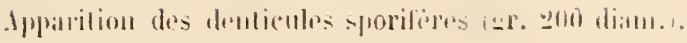

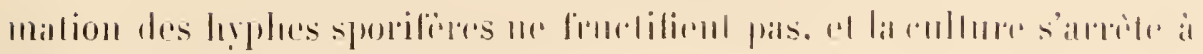
(2) point de sout driveleppement.

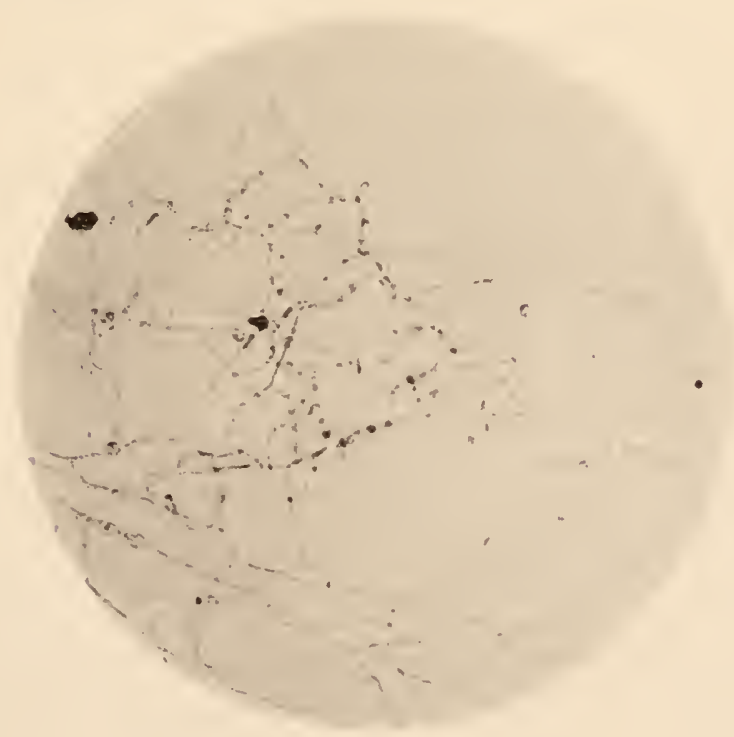

Fir. 17.;

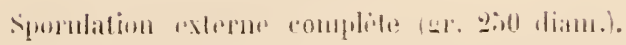

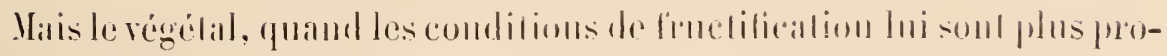

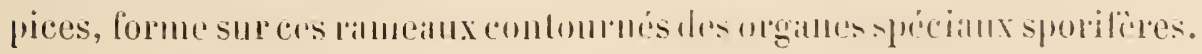




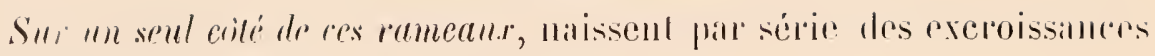

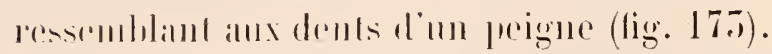

Sur res exroissmees prommont nassance les spores externes, me

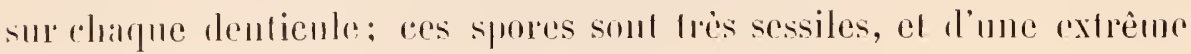
fialgililé (ligg. 17. t).

La plare hotanipue du microspormm Audonïni est diseutable. Je no crois pas (fu'and:an systime analogue (hyphe sporifire pectince) ail rité dreril parmi los Mncédinées. En tous cas celle forme n’a rion do commmu avec la grapper les Trichophytons et des Botrytis.

El rente démonstration botanique appuyant la diflérencialion fondée sur l'examon microseopique et la culture permet de séflarer nettemenI al définilivencut la teigne i petites spores do toules les trichophylies étulióes phus haut. 


\section{LA TEIGNE FAVEUSE}

Le Favus, comme nous l'avons signalé plus haut, a été confondu jusqu'au commencement du siecle avec les maladies les plus diverses du cuir chevelu, sous les noms génériques de Teigne, puis de Porrigo.

La contagiosité de la "Tinea vera " de Lorry fut reconnue bien avant sa nature parasitaire, puisque ce n'est qu'après la découverte du champignon de la Muscardine, le Botrytis Bassiana, en 1855, que Schœnlein et Grüby entrevirent les parasites du Favus (1839) et des Teignes tondantes.

La division des dermatoses en dermatoses simples, ce qui signifie uniquement que la cause en demeure encore inconnue, et en dermatoses parasitaires, permit enfin de consacrer, par la différenciation des parasites, la spécificité du Favus, déjà entrevue cliniquement depuis les travaux d'Alibert et de Biett.

Le Favus, de mème que la Trichophytie, peut atteindre les ongles (onychomycose faveuse) et lès parties glabres.

Comme les Teignes tondantes, il est une maladie de l'enfance,

Nous allons étudier avec le $D^{r}$ Bodin les parasites qu'il a isolés de divers cas de Favus.

L'étude de l'Achorion Schœnleinii, au point de vue morphologiquc, est moins avancée que l'étude du Trichophyton tonsurans.

L'Achorion Schonleinii n'a pas encore sa place désignée dans la classification des infiniment petits.

Les recherches du $D^{r}$ Bodin nous font entrevoir toutefois la solution prochaine de cet intéressant problème : l'Achorion Schœnleinii, loin de demeurer un type unique et indivisible, tend, comme le Trichophyton, à devenir le nom générique de toute une variété de parasites. auxquels correspondraient, chez l'homme et les animaux, autant de Teignes faveuses différentes. 


\section{L'ACHORION SCHCENLEINII}

Dans le cheveu, le parasite du Favus occupe toujour's une étendue assez considérable et se montre composé de mycéliums et de spores mycéliennes.

Le champignon habite l'intéricur même du poil, sans le remplir

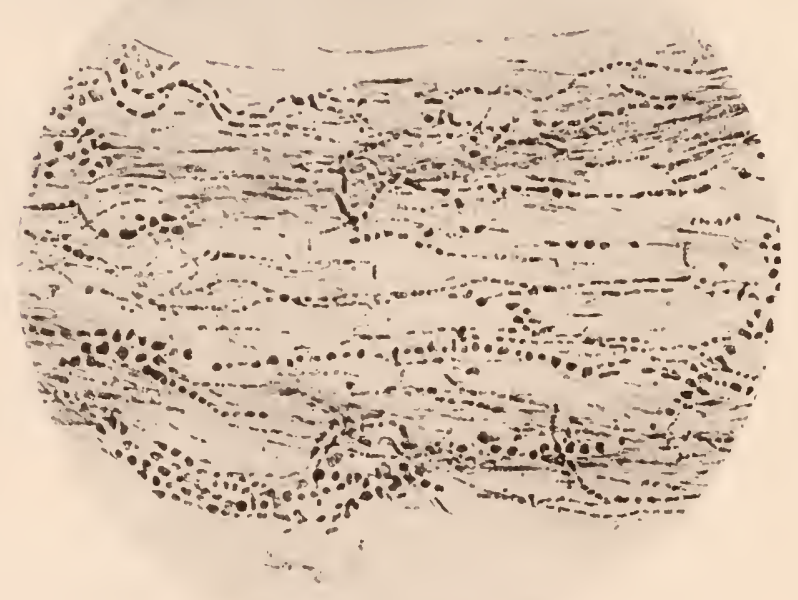

Fig. 175 .

Cheveu favique (gr. 250 diam.).

complètement. La direction générale de ses éléments est celle du cheveu, mais les myeéliums présentent des directions variables et irrégulières et peuvent faire avec l'axe du poil un angle plus ou moins ouvert, qui atteint quelquefois l'angle droit.

Parmi les tubes mycéliens, il en existe de très petits, sans trace de division; les plus nombreux sont assez volumineux et divisés en spores rectangulaires. 
Les spores lorment, soit des chapelets, soit de petits amas irréguliers provenaut de la division des tubes myeéliens.

Elles sont inégales, toutes quadrangulaires ou anguleuses, et ne présentent jamais la forme arrondie. C'e fait est de la plus hante importance et permet de distinguer surement dans le cheveu l'Achorion du Trichophylon.

Le groupement de l'Achorion Schenleinii est trés évident dans la figure 17\%, où l’on remarque combien la répartition en est irrígulière.

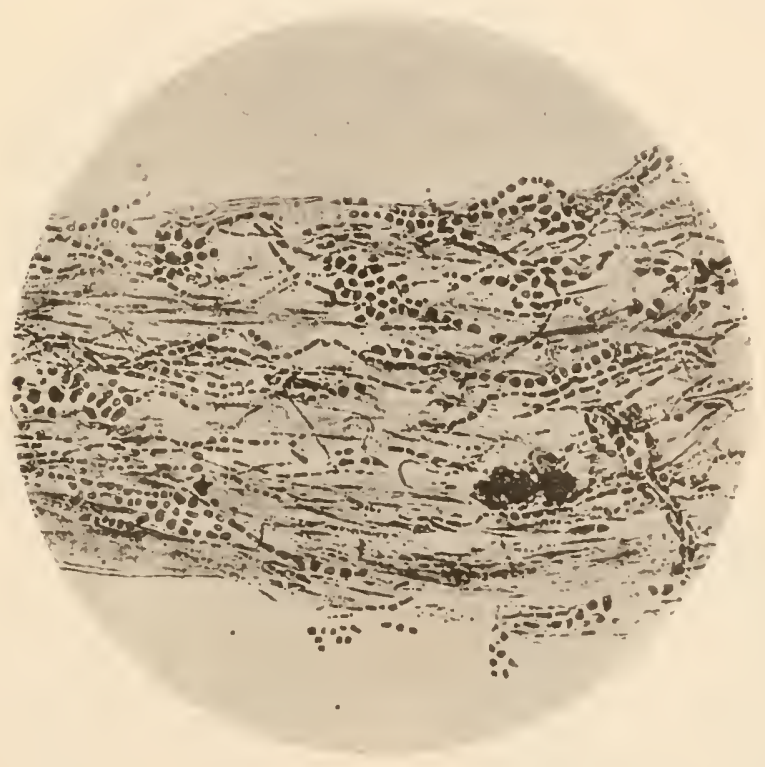

Fic. 176.

Cheveu farique (gr. $250 \mathrm{diam}$. ).

Le cheveu représenté lig. 176 a été mis au point de maniine i bien faire voir le double contour des éléments parasitaires, qui sout, daus cette préparalion, colorés ì l'éosine.

Ja division des inycélimus se fait par tri et tétratomie, de sorte qu'un ramean mẹcélicn, en se divisant, figure grossierenent des tarses.

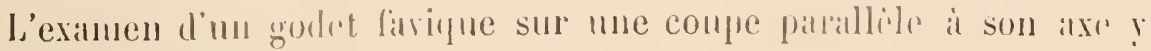
monte les mèmes ciléments. Ils y sont phus lissís yne diuls le 
chereu et présentent une disposition en forme de cone ì sommet inférieur qui, sur une coupe verticale, donne grossièrement la figure d'un éventail (fig. 177).

L'examen microscopique du champignon dans le cheveu et dans le godet ne saurail suffire pour son étude. Il faut donc l'isoler et le cultiver sur des milieux nutritifs artificiels.

Pour faire des cultures d'Achorion Schœnleinii, le premier point est d'avoir un milieu remplissant certaines conditions bien déterminées. II fint aussi qu'on puisse le labriquer toujours d'une façon rigoureu-

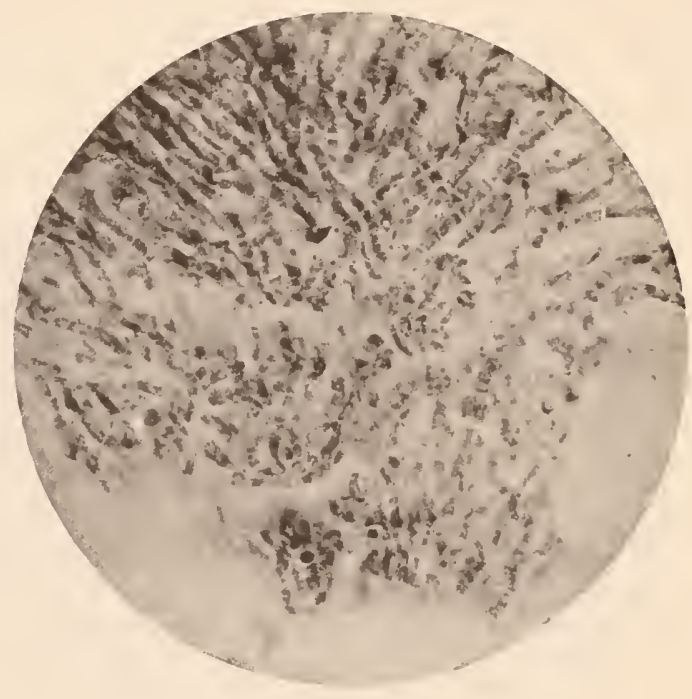

Fig. 177.

Coupe d'un godet favique (gr. 700 diam.).

sement identique. Ce détail est essentiel en raison des variétés d'aspect que rerètent les cultures d'un mème champignon sur des milieux nutritif's présentant des variations qualitatives ou quantitatives mème légères. Il faut, en outre, que ce milieu contienne des éléments nutrilifs favorisant le développement rapide et intense du parasite.

Il est probable que, sur un milieu lui convenant parfaitement, l'Achorion donnerait des formes de reproduction spéciales; mais actuellement ce milieu est encore inconnu.

C'e que l'on sait, c'est que ce champignon utilise surtout les matières a!buminoüdes. C'est aree des milieux nentonisés a fortes doere "un." 
nous avous oblemu les meilleurs résultats. Sur l'agar peptonisé à a) pour 100, et de réaction ligèrement alcaline, les cultures nous ont loujours montré leur maximmm de déreloppement.

Les matières sucrées ne sont ancunement utilisées par le cham-

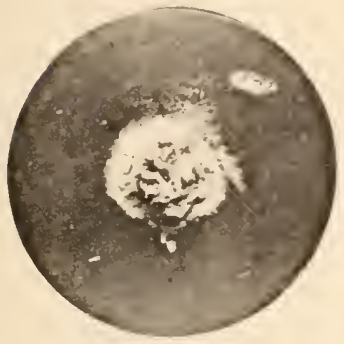

Fig. 178.

Culture d'une variété

d'Achorion

sur agar au moủt de bière.

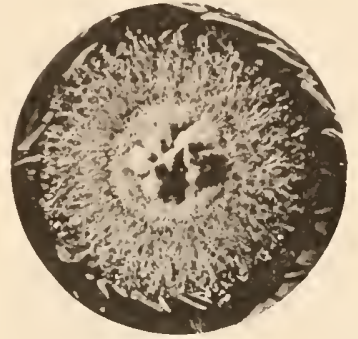

F1G。 179.

Culture d'une variété d'Achorion

sur agar peptonisé à $1 \%$.

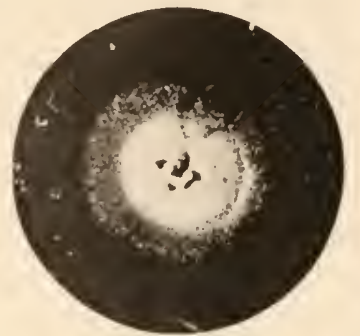

FIG. 180.

Culture d'une autre variété d'Achorion

sur agar peptonisé à $1 \%$.

pignon; leur addition aux milieux de culture est donc inutile. Sur le moùt de bière, par exemple, l'Áchorion végète avec peine.

Il sul'iit, pour constater cette particularité, de comparer la fig. 178

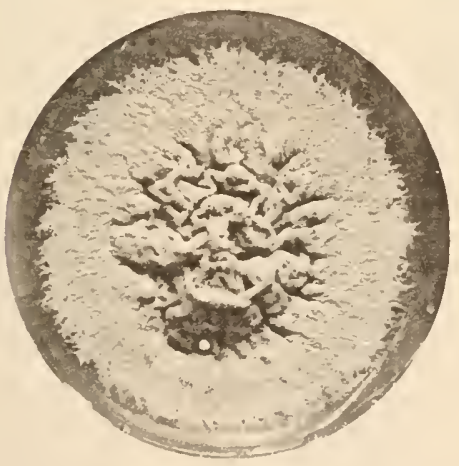

Fig. 181 .

Mème culture que fig. 179, transportée sur agar peptonisé à $5 \%$.

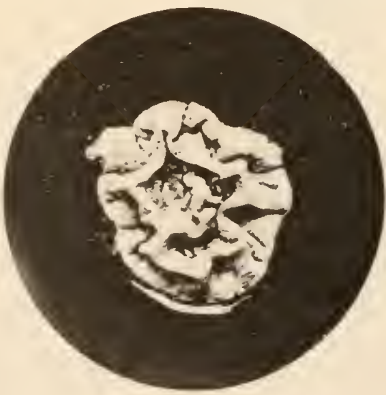

Fig. 182.

Nème culture que fig. 180, transportée sur agar peptonisé à $5 \%$.

(culture sur moût de bière) aux figures 179 et 180 (cultures sur agar peptonisé à $1 \%$ ), et enfin aux cultures les plus vivaces, lig. 181 et 182 (cultures sur agar peptonisé à $5 \%$ ).

Sur la pomme de terre, la culture des diverses espèces d'Achorions est facile; ils s'y développent rapidement et avec abondance. 
Sur l'agaragar peptonisé à $2 \%$ on perit donc obtenir des cultures d'Achorion, mais ces cultures ne demeurent bien vivaces que si on les transplante sur un milieu plus riche.

Les cultures de Favus ne présentent jamais un aspect analogue à celui des cultures des divers Trichophytons. On en jugera en se rapportant au mémoire du $\mathrm{D}^{\mathrm{r}}$ Sabourand et en comparant les figures 183 et 184, qui représentent, sur agar peptonisé à $2 \%$ l'une une cul-

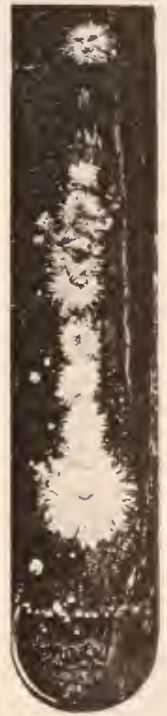

FIG. 183.

Culture directe d'un cas de Sycosis trichophytique phlegmoneux, d'origine équine probable (Doyen).

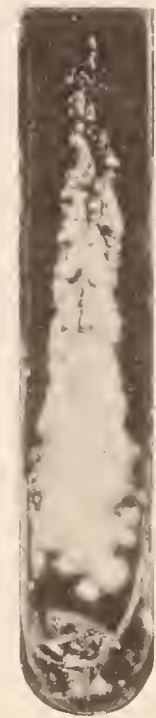

FIG. 184.

Culture comparative du

Favus du Chien (Nocard).

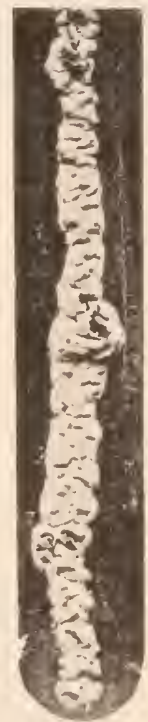

Fic. 185. Culture sur pomine de terre d'un Achorion d'origine humaine.

ture directe d'un Sycosis trichophytique phlegmoneux, culture importante en ce sens qu'elle démontre, chez l'homme, les propriétés pyogènes de ce Trichophyton, d'origine équine probable, l'autre figurant une culture sur le même milieu du Favus du C'hien.

Les cultures en séries nous ont conduit à plusieurs conclusions du plus haut intérêt.

Si l'on étudie plusicurs cas de ravus en faisant des culcures comparatives, on est frappe de deux faits qui ont une analogie remarquable avec ceux que l'on observe pour les Trichophytons : 
$1^{\circ}$ A cot de l'Achorion wegrum; thabitueilement divers commensaux:

zo La duvasicé d'aspect des oulur es on serne d’Achorions de diverses provenances parait correspond th diss especes cryplogamiques différerites

\section{$1^{\circ}$ Associdinans Cirynocogamiques}

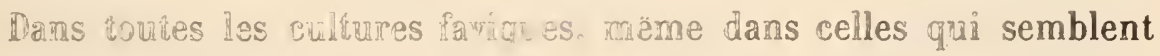

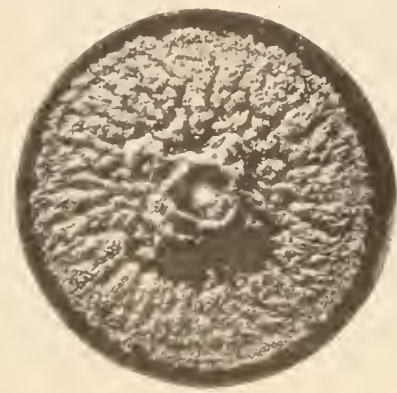

Tine. 186

Fuiture d'Acitorion montrant ie debut du deveroppemen d'un commensal souis forme de rès pelites colonres blanches.

primativemert les plus pures. on yol au bout d'un certain temps, apparaîne des colomies durn champignon différent.

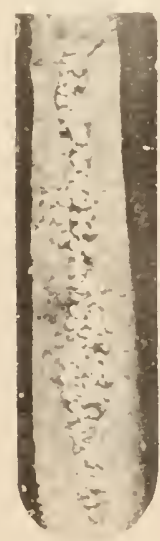

Fic $18 \%$

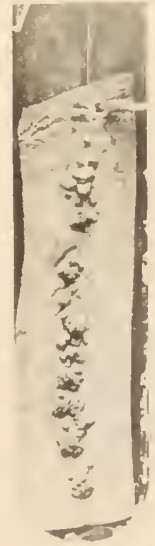

FIG. 188.

Gultures de diverses variètés d'Àchorions sur pomme de terre.

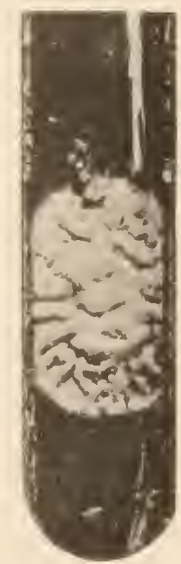

Fig 189 .

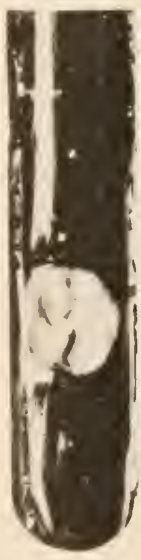

Tig. 190. 7ౌaciécés ae commensaux des cultures A. Aaborion isolès sur agar peptonisé à $\mathbf{1} \%$.

Ce fait, que vient de signaler Kral de Prague, est analogue ả celui 
que l'on observe dans les cultures des Trichophytons à grosses spores.

Les nourelles colonies diffèrent absolument des cultures faviques. Leur aspect est tout autre et leur manière de se comporter vis-à-vis des milieux mutritifs est absolument inverse : sur les milieux suerés ils poussent avec activité, tandis qu'ils végètent sur les milieux

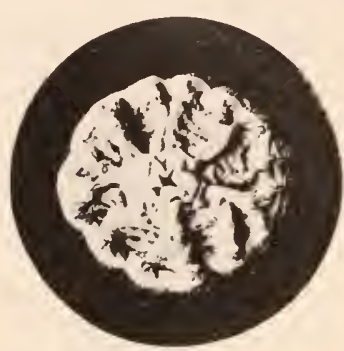

Fig. 191.

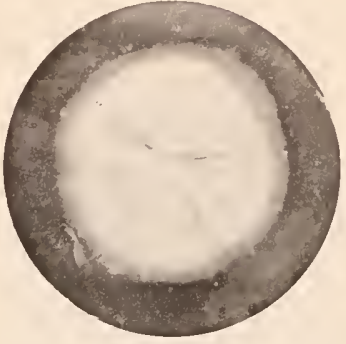

Fig. 192.

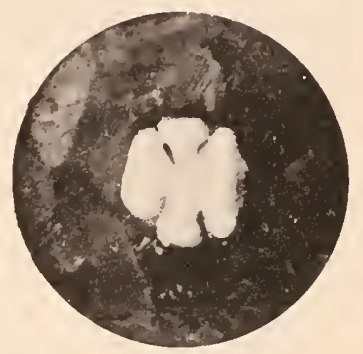

Fig 193.

Commensaldesculturesfaviques Le même, sur agar peptonisẻ Le même, sur agar peptonisé sur agar au moût de biëre. à $1 \%$. à $5 \%$.

azotés et s'y développent d'autant plus mal que la proportion de matière azotée est plus forte (fig. 191, 192 et 195).

(Comparer les cultures d'Achorion, fig. 178 à 182).

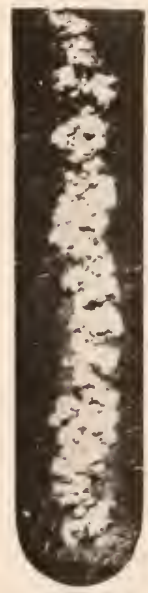

Fig. 194.

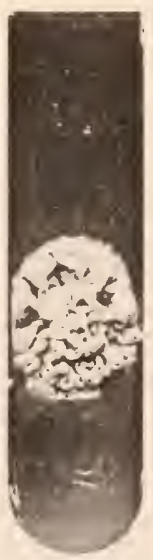

Fig. 195.

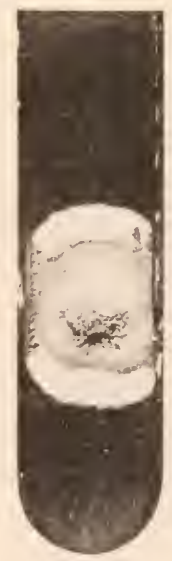

Fig. 196.

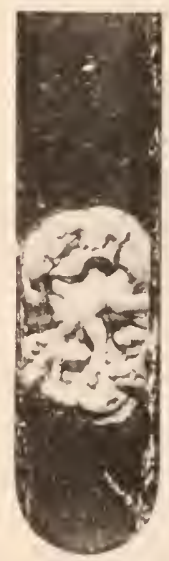

Fig. 197.

Commensal des cultures

faviques sur pomme de terre.

Achorion Schanleinii. Achorion Eulhylrix. Achorion Alutilon

Le rôle de ces champignons est encore complètement inconnu, mais tout porte a croire que ce sont de simples commensaux. 


\section{2" lariciles de Ficus}

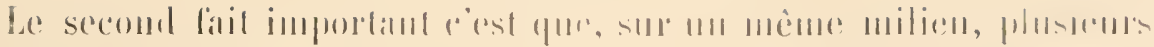

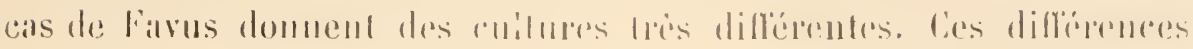

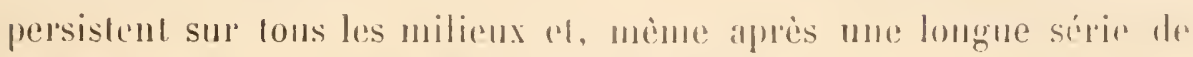

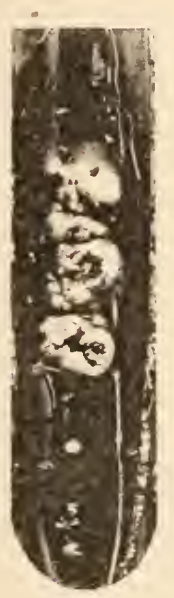

Fig. 198.

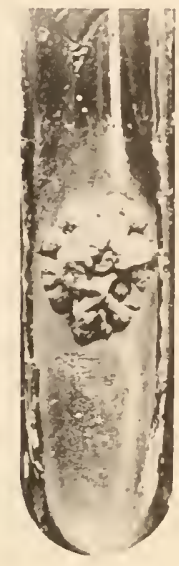

Fig. 199.

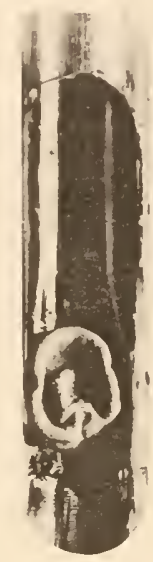

Fig. 200.

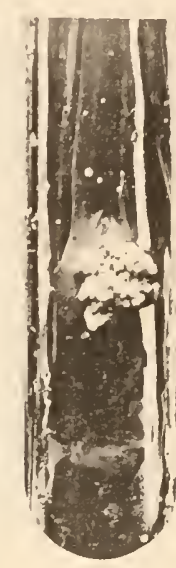

Fig. 201 .

Types de variétés l'ichori sur agar peptonisé à $5 \%$.

passages successifs, demeurent irrédnctibles les unes aux anlres.

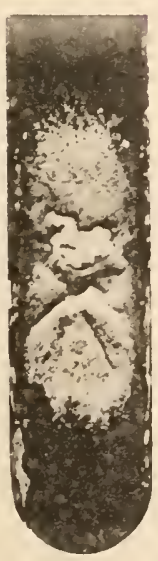

Frg. 202

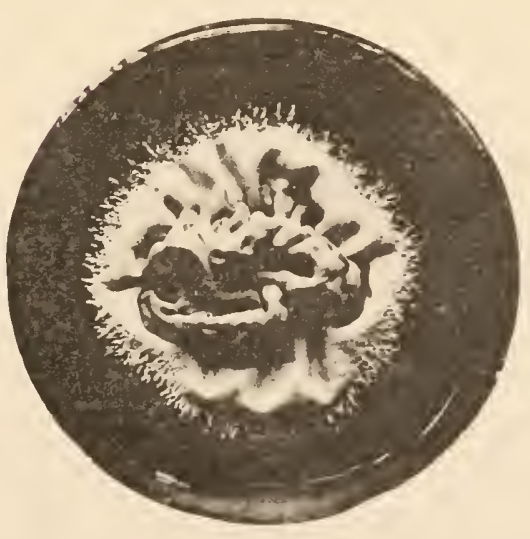

Fic. 203.

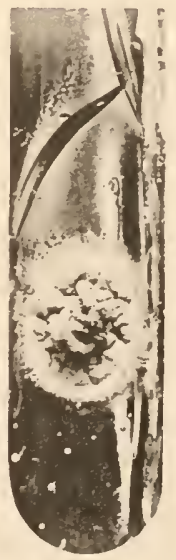

FIG. 204

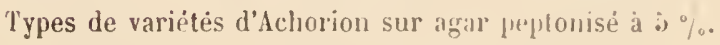

Ces différences caractérisent-elles des espeèces distinctes d'Ichnrion ou bien correspondent-elles simplement à les rariétís l'me mime espèce? La solution de ce problème ne pent encore être donnce d’une manière définitive, mais la similitule des réactions des Adurions 
de provenance variée (Ilomme, Chien, Chat, etc., efe.) sur les milieux nutritifs d'mne part, la ressemblance d'aspect et l'muifin'mité cliniqur des diverses esprices de Farus d'autre part, semblent appurer la première hypothèse.

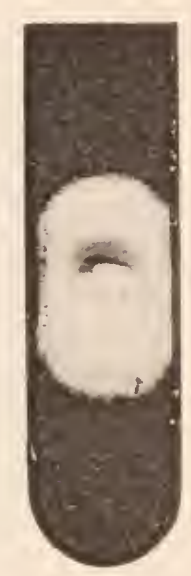

FIG, 205.

Favus de la poule sur agar peptonisé à $5 \%$.

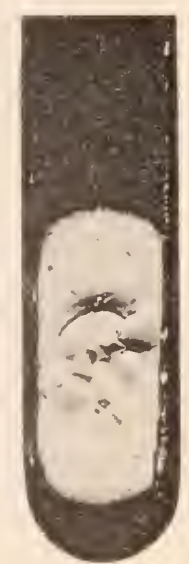

Fig. 206.

Oospora canina (Costantin-Sabrazès) sur agar peptonisé à $5 \%$.

MIN. Unna net Neche ont isolé un certian nombre de variétés d'Achorion et leur ont domné des noms spéciaux. Nous avons reproduit fig. 195, 196 et 197 plusieurs de ces champignons eultivés sur agar peptonisé à วั pour 100. Nous avons pu nous-mème, en étudiant une cinquanlaine de cas de Favus, en isoler quelques-uns dont les principaux types sont représentés page 103 (fig. 198 ì 204).

Enfin, ì coitri des variétís précédentes, il y en a d'autres qui ont reçu une dénominalion spéciale, telle que : Favus du Chicn, Favus de la P'oule, Favus de la Souris, en raison de leur fréquence chez certaines espèces animiles. I. Nociarl, l'úminent Professenr de l’École Vétéri-

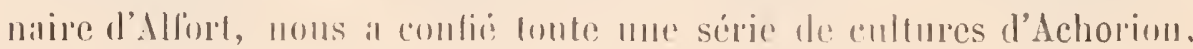
provenanl de sem laboraloire. Le Farns du Chien a élé étudié tout par-

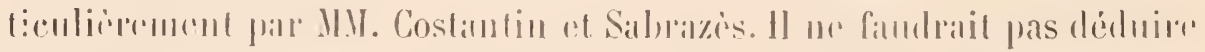

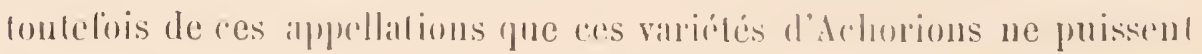

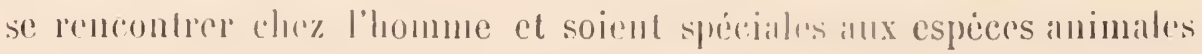
che\% lesquelles on les al primitivement observions. 


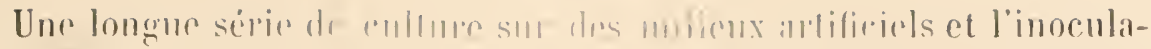

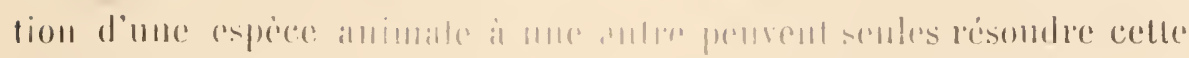

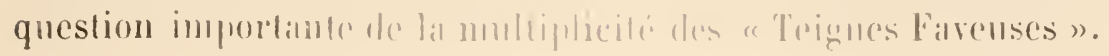

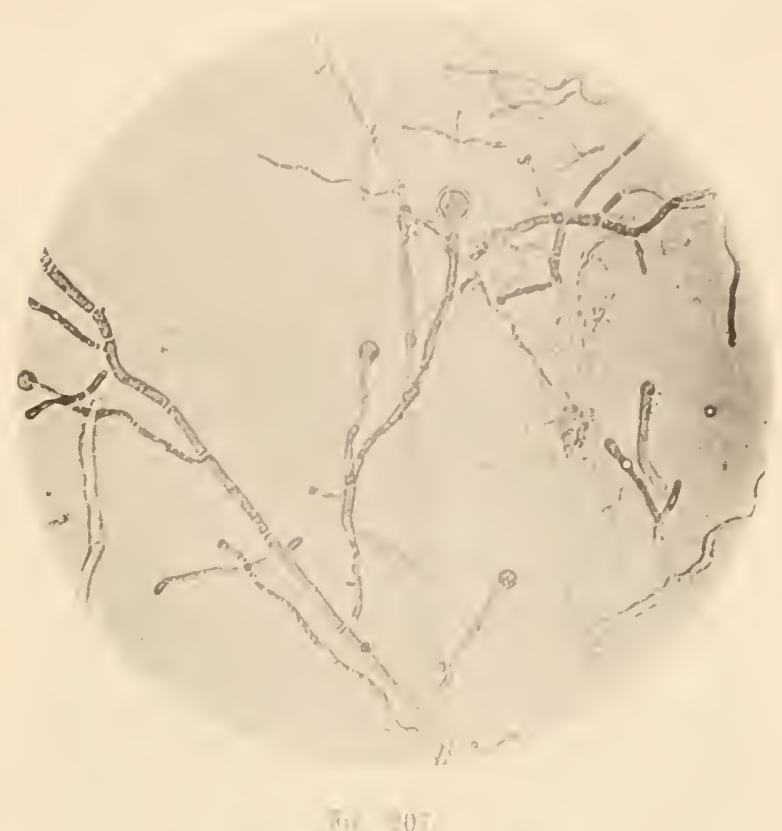

Appareils coniaifns des culfures de Fabus in! 2in) diam.).

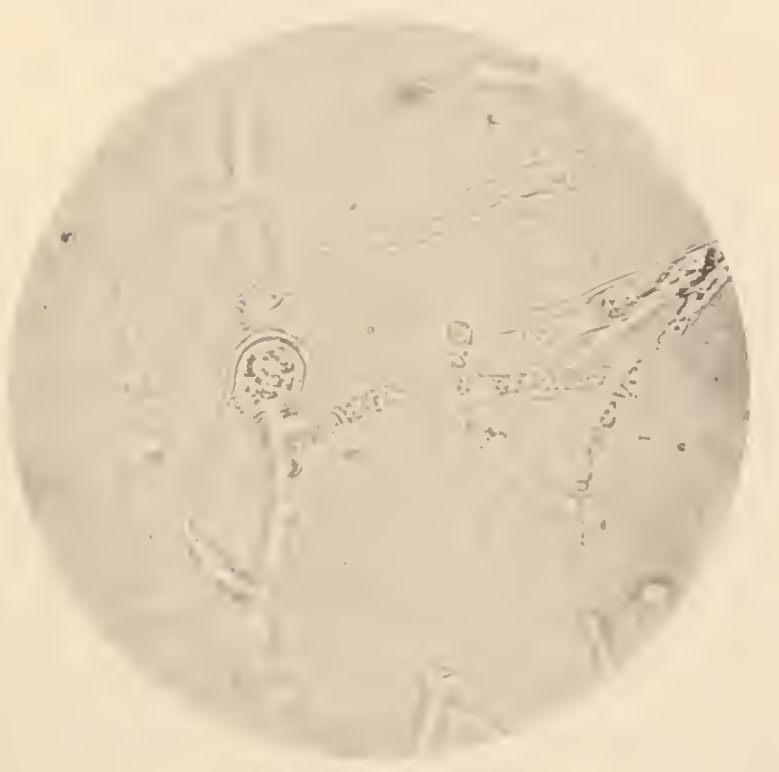

Fig 218.

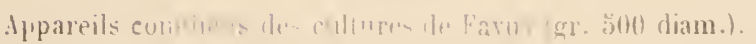


Le mode de reproduction du champignon n'est connu que dans le cheveu et dans l'épaisseur des éléments épidermiques.

Chez les sujets atteints de Teigne Faveuse, l'Achorion Schonleinii se reproduit par spores mycéliennes.

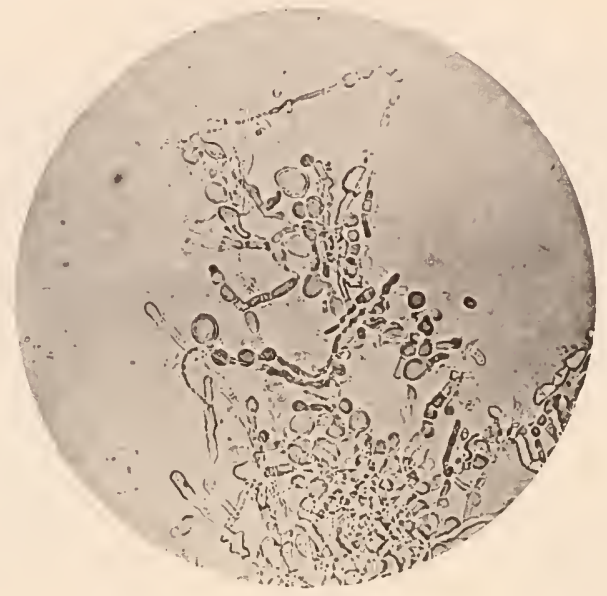

Fig. 209.

Oidies dans une vieille culture de Favus (gr. 300 diam.).

Sur les cultures, on n'observe jamais de ces fructifications externes si remarquables qui ont lait rentrer les Trichophytons dans l'espèce Botrytis.

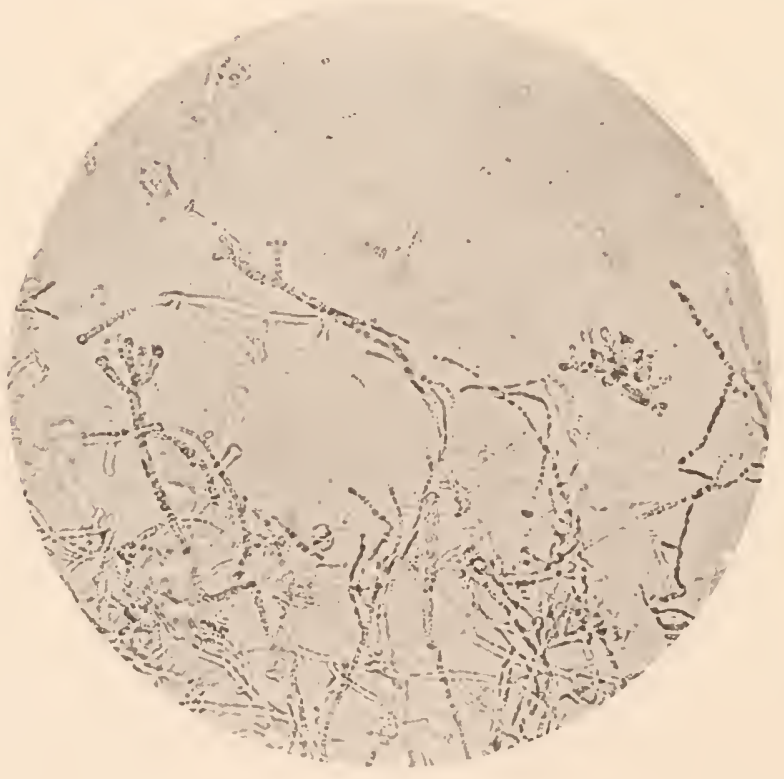

Fig. 210.

Formes de reproduction en houquets de quelques cultures de Favus (gr. 150 diam. 
On constate simplement pendant les premiers jour's une ramification irrégulière du uncélium, puis vers le quatrième jonr on voit se former, ¿ l'extrémité des rameanx terminaux ou sur les tameanx latéraux, des renflements arrondis mrésentant un dumble contour (lig. 207 et 208).

Ces appareils conidiens ne tardent pas à se multiplier.

Si on laisse vieillir les cultures, on ne rencontre plus au bout d'un certain temps que des oïdies arrondies d'un volume variable (fig. 209). Ces éléments se montrent isolés ou bien se groupent bout à bout el forme de chapelets.

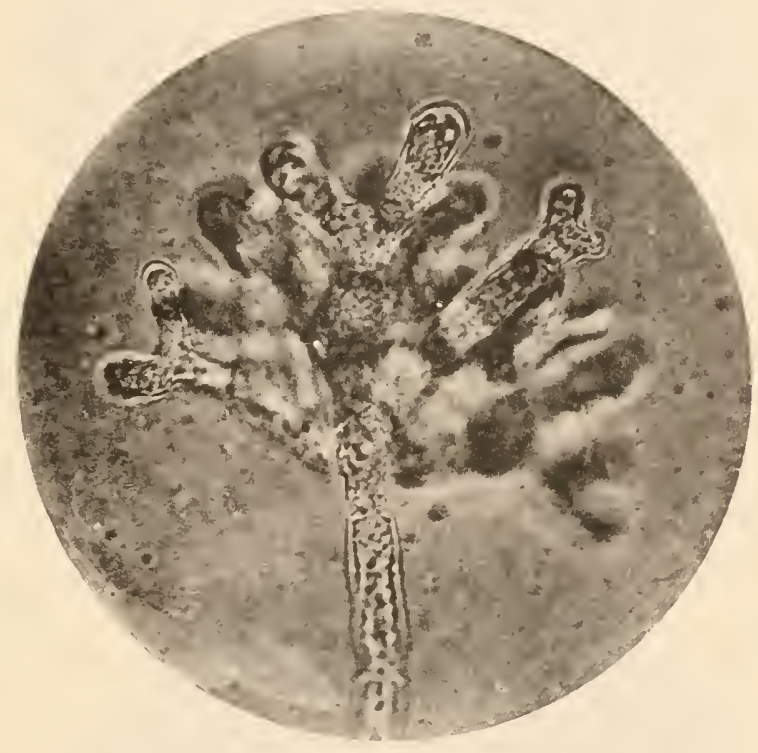

Fig. 211.

Forme de reproduction en bouquet de quelques cultures de Favus (gr. 800 diam.).

Il est évident que les spores mycéliennes et les formes oïdiennes ne constituent pas le mode de reproduction parfait du Favus. La sporulation externe de l'Achorion est encore à découvrir, d'où l'incertitude de sa place définitive dans la classification des champignons.

Il est en effet impossible de considérer comme des organes parfaits de fructification externe les éléments représentés figures 210 el 211.

Ces sortes debouquets, portés par une hyphe terminale, nous semblent être le rudiment d'un appareil reprodncteur externe dont nous n'avons jaınais obtenu le complet développement. 


\section{IPITYRIASIS VERSICOLORE}

Le Pityriasis rersiculore es! une maladie bénigne de la peau qui

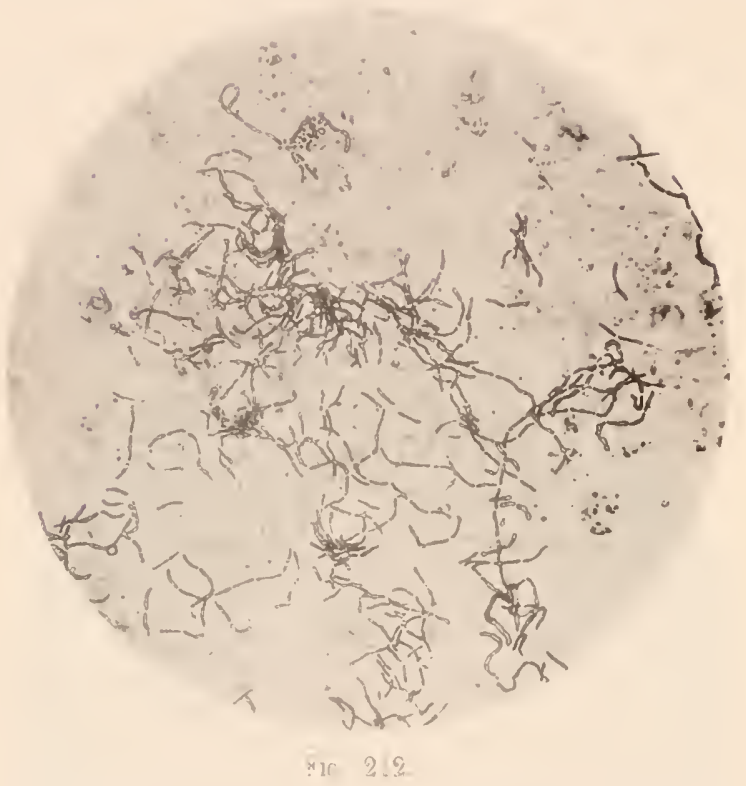

Wicrosporon furfur dans les squanes "piderunigues (mèthode de fraın) (gr. 200 diam.).

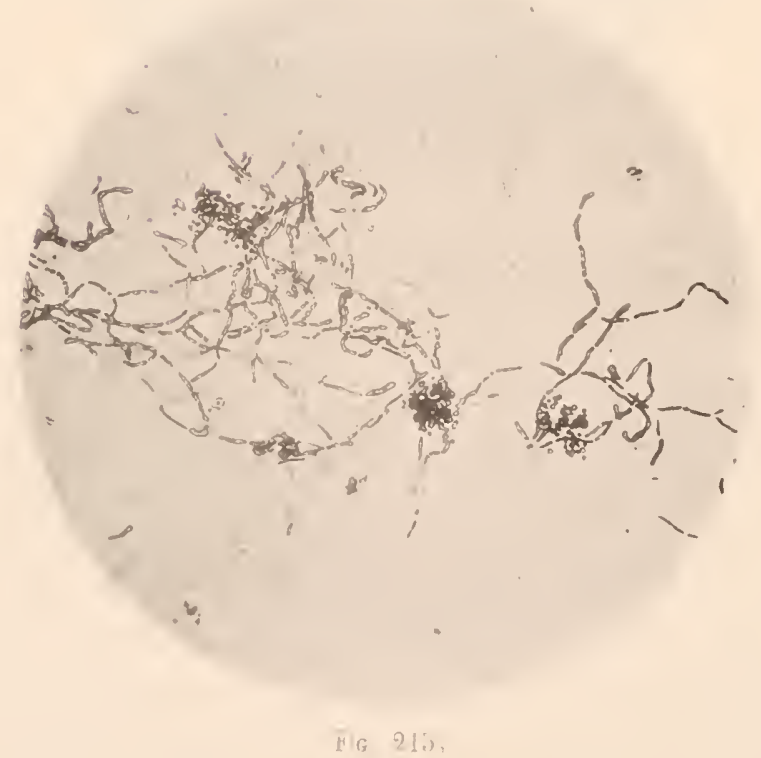

Mirrosporon fur/ur dans les squames piruerinupues (méthorle de Gram) (gr. 500 diam.). 
se caractérise par dés taches jammes on janmr-humn. Cespelites lésions

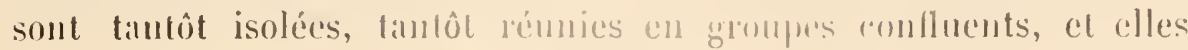

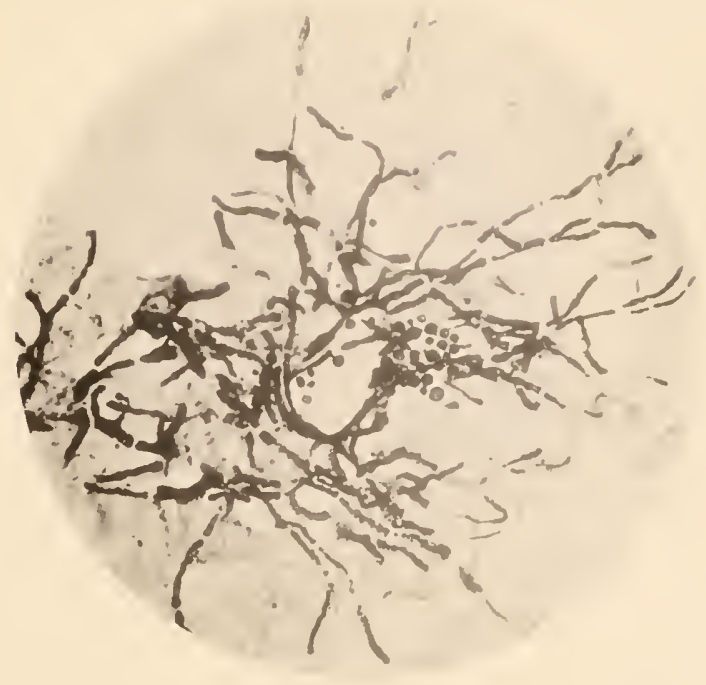

Fic. 214.

Microsporon furfur dans les squaues épider'niques (méthude de Gram) (gr. 500 diam.).

peuvent envahir dans certains cas d'assez larges surfaces sur le thorax, qui est leur sièoe de prédilection.

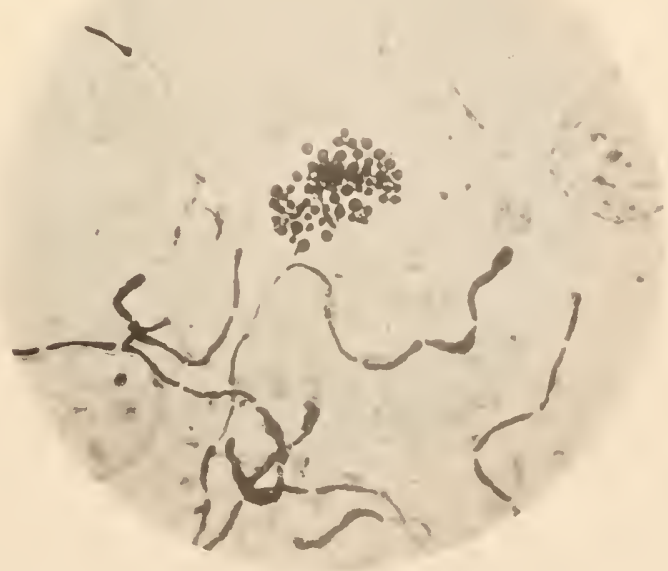

Fig. 215 .

Mid de spores du Microsporon w/ur mothode de Gram) (ert. 500 diam.).

La véritable nature du Patyrinsis cersicolore ne lut connue 
qu'en 1846, époque à laquelle Eischteidt découmit dans les lésions le champignon auquel on domna le nom de Mlicrosporon fur/ur.

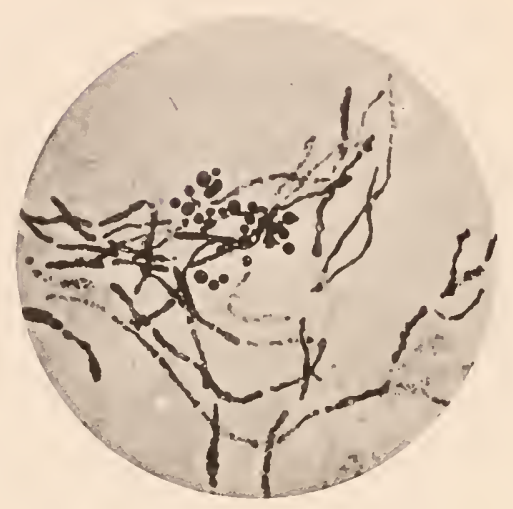

Fig. 216.

Spores et mycéliums du Microsporon furfur (méthode de Gram) (gr. 500 diam.).

Dans les squames épidermiques, qui seules contiennent le parasite, le Microsporon furfur se présente sous la forme de mycéliums et de

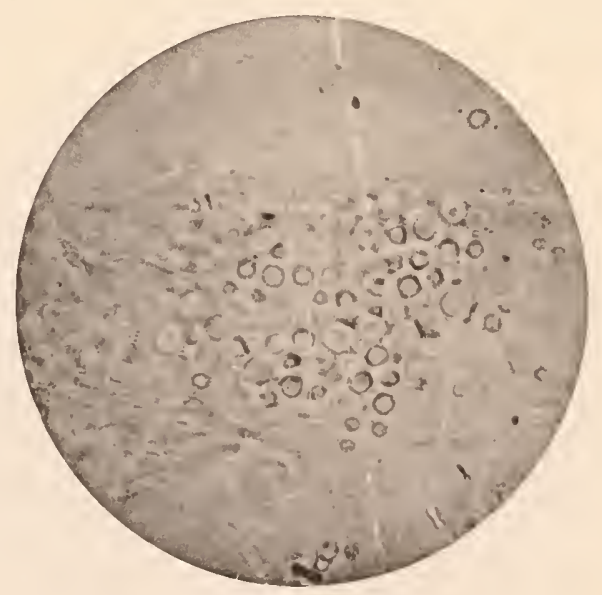

Fig. 217.

Spores du Microsporon furfur colorées à l’éosine (après l'action de la polasse)(gr. 500 diam.).

spores. Ces éléments sont toujour's en tròs grinde abondance, aussi leur recherche est-elle tris aisée. 
Les mycéliums sont courts, irréguliers, dirigés dians tous les sens, peu ramifiés, non segmentés et ne contiennent pas de spores.

Sur les parties latérales ou à l'extrémité des mycéliums se voient des amas ou " nids » de spores.

Ces amas, plus ou moins abondants, sont composés de spores inégales entre elles, mais toutes parfaitement rondes. Elles présentent un double contour très net dans les préparations colorées à l'éosine après chauffage dans la solution de potasse à 40 pour 100 , suivant la méthode de M. Malassez (fig. 217).

Avant de traiter les squames épidermiques par la potasse en solution concentrée, M. Malassez conseille de dissoudre les gouttelettes graisseuses qui les imprègnent par un séjour de plusieurs heures dans un mélange à parties égales d'Éther à $65^{\circ}$ et d'Alcool absolu.

Le Microsporon furfur se colore parfaitement par la méthode bien connue de Gram (fig. 212 à 216). 


\section{ERY THRASIA}

Le champignon de l'Errthrasma (Hicrosporon minutussimum de

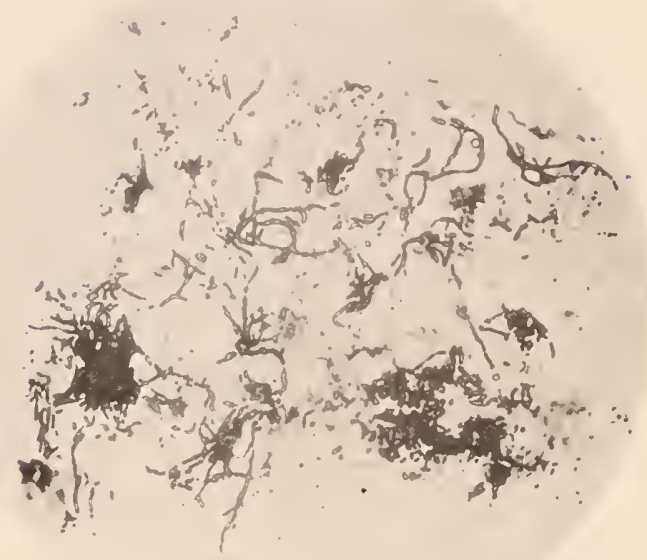

Fig. 218.

Microsporon muntissimum (méthode de Gram) (gr. 800 diam.).

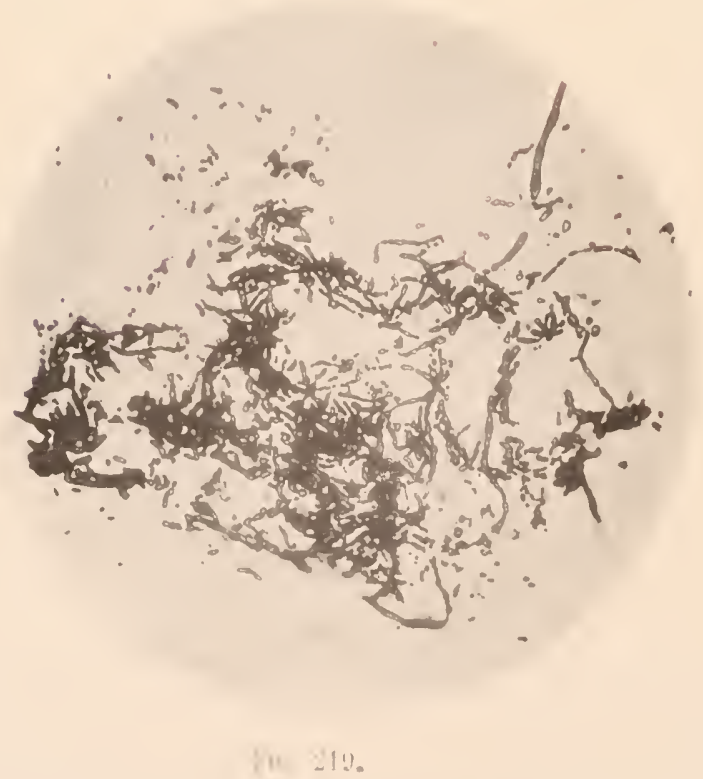

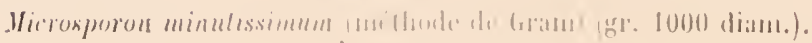


Burchkardi), se montre, dans les squames épidermiques, sous la forme d'éléments extrêmement petits.

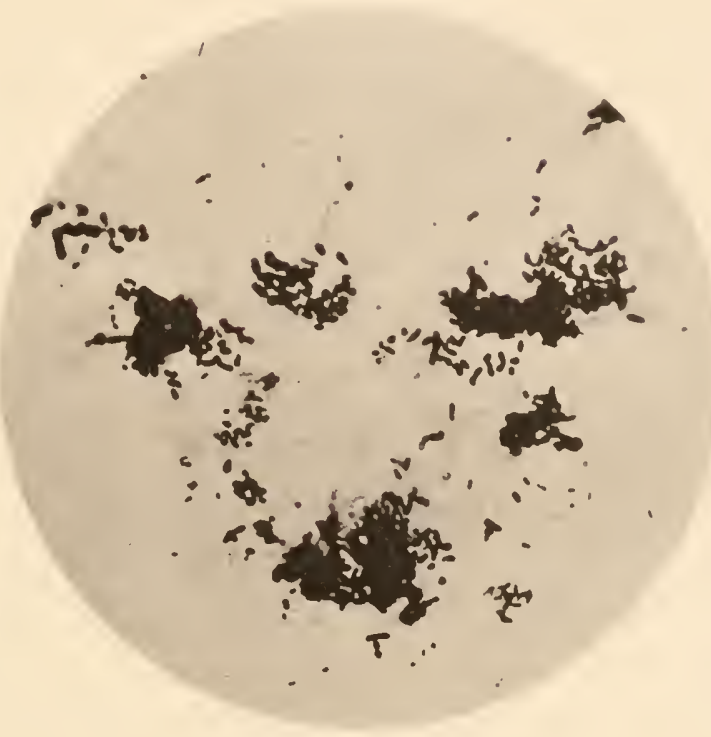

Fig. 220 .

Amas de spores du Microsporon minutissinum (méthode de Gram) (gr. 1000 diam.).

Les mycéliums sont courts, peu ramifiés, dirigés en fous sens comme ceux du Pityriasis versicolore et ne contiennent pas de spores.

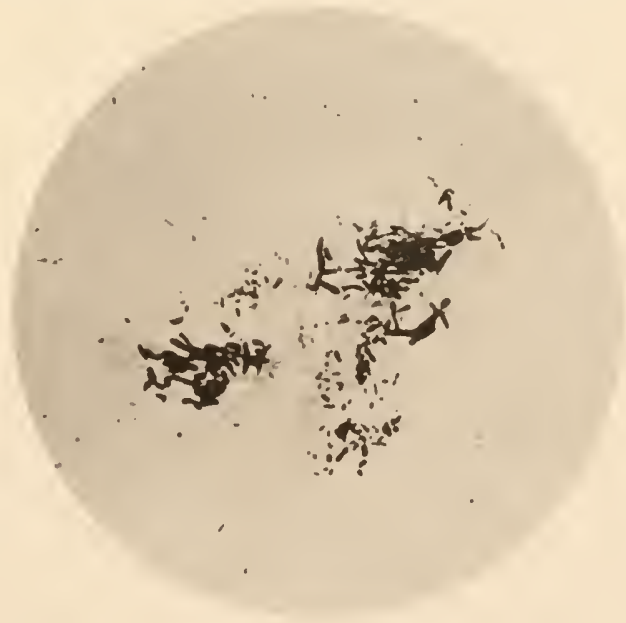

Fig. 221.

Vicrosporon minutissimun dans les squames épidermiques (méthode de Gram) (gr. 1000 diain.).

Ces dernières forment des amas très irréguliers d"aspect ot de dimen- 
sions : elles sont inégales entre elles et n'ont pas toujours la forme arrondie.

La disposition de ces éléments rappelle beaucoup ceỉe que l’on olsserve dans le Pityriasis versicolore, mais il est facile de voir, aux seules dimensions, que le Microsporon minutissimum se distingue nettement du Microsporon furfur.

L'exiguité très graude du parasite exige donc toujours des recherches microscopiques it de forts grossissements.

On trouve aisément et en abondance le Microsporon minutissimum dans les lésions qui constituent la maladie. Ces lésions sont des taches arrondies et à contours bien nets, de couleur rouge pâle ou brun foncé. On les observe tout particulièrement à la face interne des cuisses et dans les plis inguino-scrotaux. C'est une affection beaucoup plus fréquente qu'on ne pourrait le penser, mais d'une bénignité absolue.

Le Microsporon minulissimum, comme le Wicrosporon furfur, se colore par la méthode de Gram. 


\section{OÏDIUM}

Les Ö̈dium sont des chanpignons inférieurs d'une structure très simple. Les microbiologistes ne cultivent guère sur les milicux artificiels que deux espèces d'Ö̈lium : l'Ö̈dium luteum et l'Ö̈dium lartis. Nous décrirons ce dernier en raison de sa diffusion dans la nature.

\section{OIDIUM LACTIS.}

L'Ö̈dium lactis est ainsi nommé parce qu'il est un des Saprophytes

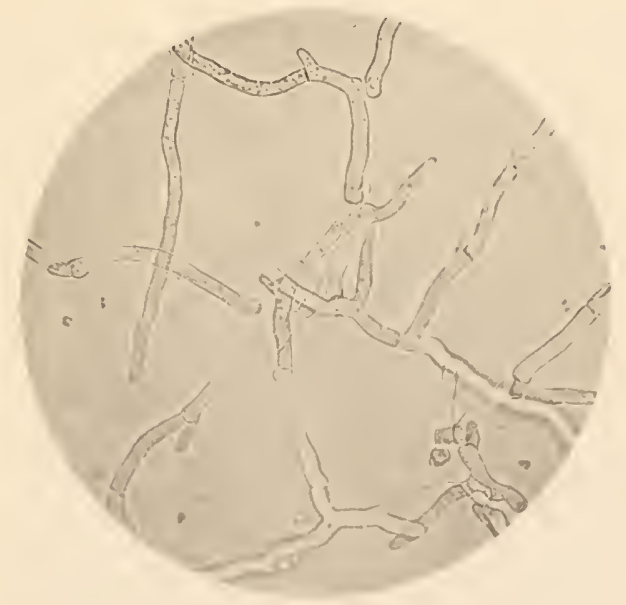

FIG. 222.

Oidium lactis. Culture jeune sur agar-agar (500 diam.).

du lait. Nous représentons figg. 222 le mode de développement des filaments mẹcéliens à la surface d'une plingue d'agar-igar.

Le mycélium présente de nombrenses cloisons et se ramilip ru forme de fourche. Ial croissance de l'Oülium luclis est beaucoup phos rapide sur les milieux liquides.

Les filaments mỵéliens prenneut alor's en vingt-qualre heures w11 développement considérable, et on observe déjil an bout de ce temps 
la production des spores caractéristiques de l'espèce Oidlium.

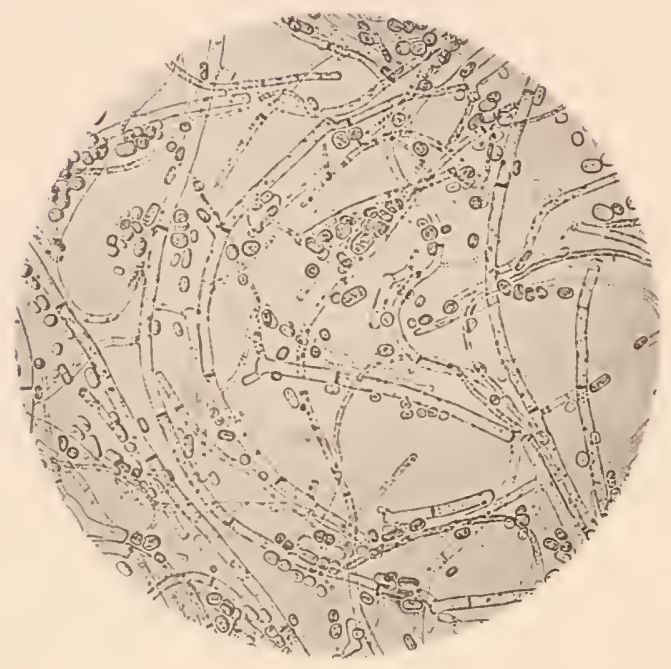

FiG. 223

Ö̈dium laclis. Chambre lumide Culture de 24 heures (400 dian 1.

Les spores, sur la figure 225 , onl été dissociées par la simple application de la lamelle.

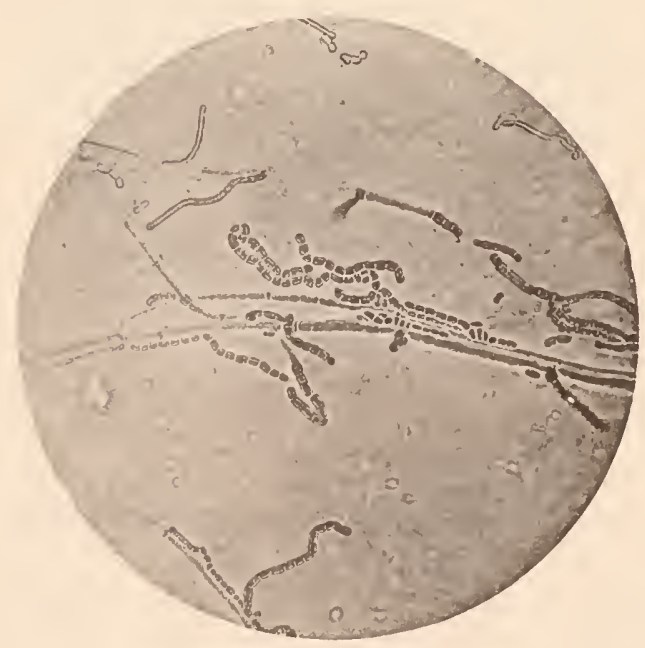

Fig. 22,

Oidium lactis. Culture sur agar-agar (150 diam.).

La figure 224 est destince it faire voir le mode de fructification de l’Oülinm laclis. On y remarque phusieurs ramcanx myeélicus fructiféres qui se terminent chacun par un chapelet de spores rectangulaires. 
()u pent voir la gremination d'une de ees conidies en haut et à droite de la ligure.

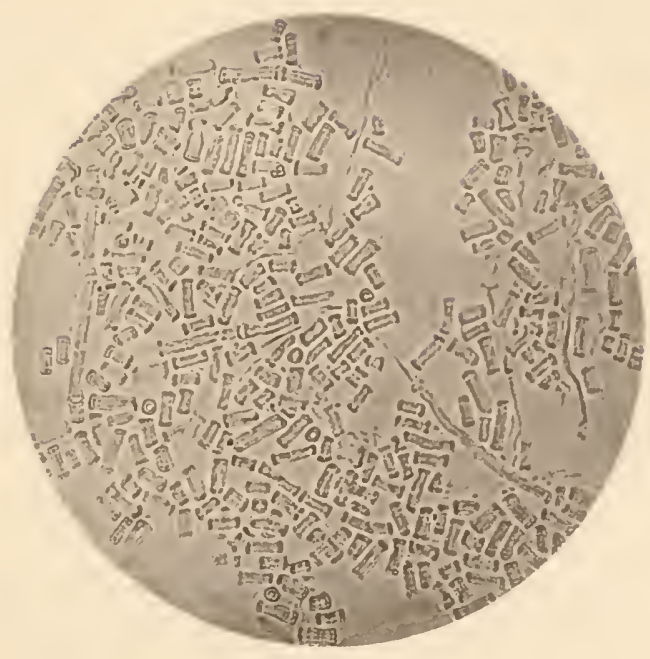

Fig. 225.

Oỉdium lactis. Culture sur agar au moût de biére, âgée de 10 jours (400 diam.).

Les conidies de l'Oidium lacis présentent comme particularité

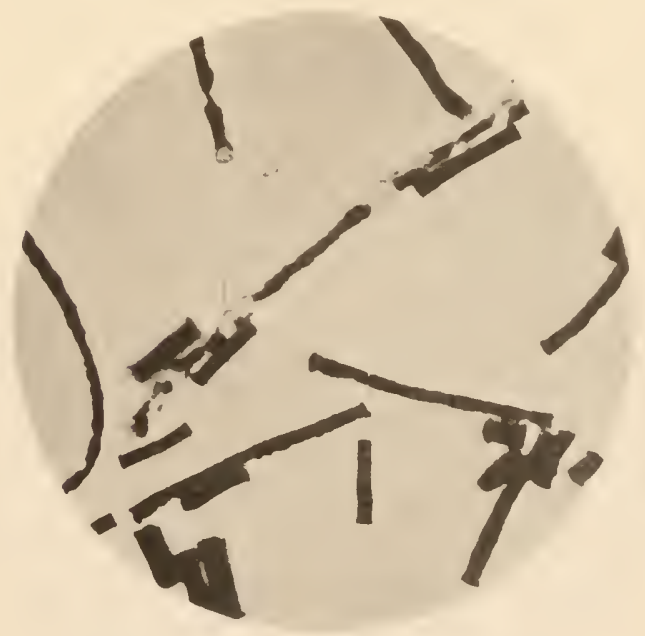

FIG. 226.

Oidium lactis. Culture sur agar (mélnode de Gram) (1000 diam.).

leur aspect rectangulaire, qui est plus ou moins marqué suivant les milieux.

Cette particularité est des plus saillantes sur les fig. 225 ct 226 , qui 
représentent, l'une sans coloration, l'autre, après coloration par la méthode de Gram, des cultures d’Ö̈dium lactis sur agar an moùt de bière et sur agar peptonisé.

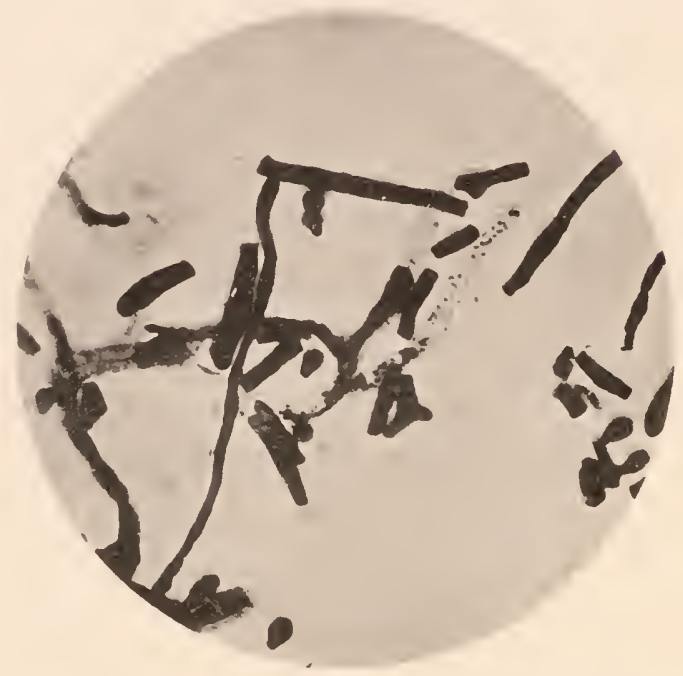

Fig. 227.

Trichophigton du cheval. Culture de 17 jours (méthode de Gram) (1000 diam.).

On sait que l'Ö̈dinm lactis a étélongtemps confondu arec les parasites des teignes.

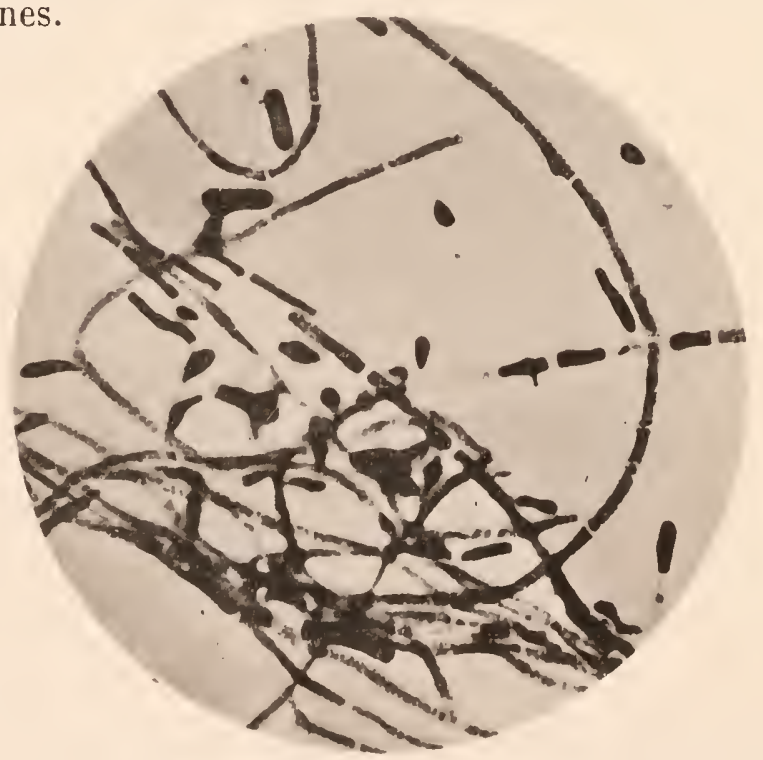

Fic. 228.

Trichophylon de l'homme (méthode de Gram) (1000 diam.).

Quelques auteurs, partisans exagérés du transformisme des espèces, 
ont prétendı que les teignes itaient toutes dues sans distiuction à ce champignon.

Cette analogie n’est pas soutenable, et les simples prépirations colorées par la méthode de Gram démontrent qu'on ne saurait confondre l'Oüdium lactis avec les diverses espèces de Trichophyton et de Favus.

En effet, si les fig. $226,227,228$ et 229 semblent de prime abord offrir une certaine similitude au point de vue de l'aspect des filaments mycéliens et de leur gaine, il en est tout autrement de l'aspect des

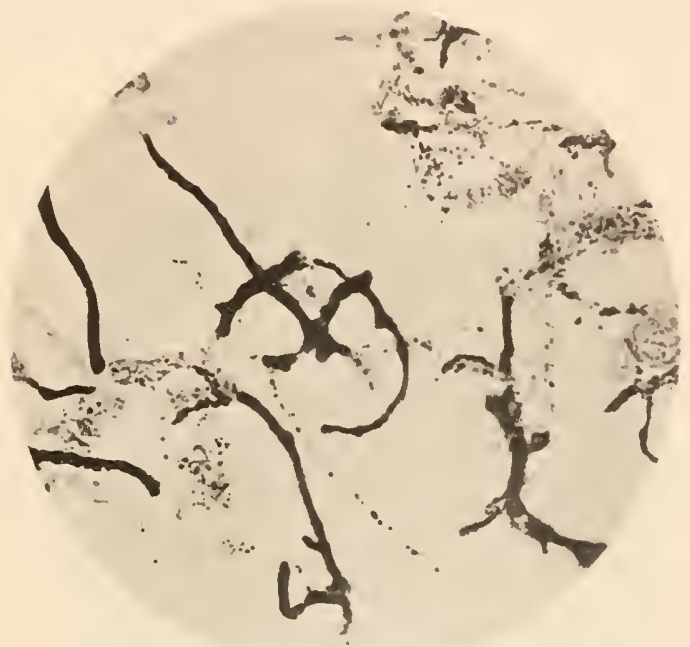

Fig. 229.

Achorion Schœenleinii. Culture sur agar (Préparation par la méthode de Gram) (1000 diam.)

spores. Les conidies de l'Ö̈dium lactis sont rectangulaires (fig. 22j̀ et 226), tandis que celles du Trichophyton sont orales et en forme de larmes (fig. 227, 228).

Quant au Favus, les préparations faites avec les cultures de ce parasite par la méthode de Gram ne donnent qu'un myeilimm irrégulier. mal coloré, et on n'y rencontre aucune trace de spores (fig. 20?!).

\section{ACTION BIOLOGIQUE}

L'Oidium lactis est Saprophỵte; on a prétendu, mais ŝus preures à l’appui, qu’il était un des agents de la fermentation lactipue.

Il peut, en se développant ì la surface de certains liquides sucrés, provoquer une faible fermentation alcoolique. 


\section{BEGGIATOA OU SULFURAIRES}

Les Beggiatoa ou Sulfuraires sont les parasites des eaux minérales sulfureuses. On les trouve aussi parfois dans certaines conduites d'eau douce.

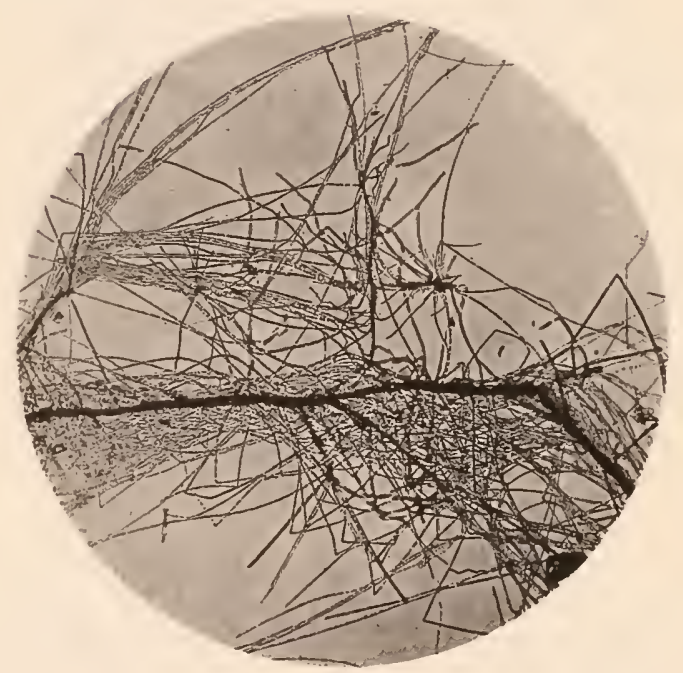

FIG. 230.

Beggiatoa raniana (100 diam).

BEGGIATOA RANIANA

Nous donnons, fig。250, une reproduction au grossissement de 100 diamètres de la Beggiato raniana. On y distingue de nombreux filaments enchevêtrés, composés de petits bâtonnets séparés par des cloisons transversales. 


\section{BEGGIATOA ALBA}

L'une des espèces les plus connues parmi les Sulfuraires est la Beggiatoa alba. Elle se trouve dans les eaux sulfureuses naturelles, froides ou chaudes, dans toutes les eaux impures stagnantes, fréquemment dans les puits et les citernes. Elle y forme des flocons blancs, de consistance muqueuse, el qui peuvent s'étendre en larges colonies.

La Beggiatoa alba prend souvent au début de son développement, comme le montrent les fig. 253,234 et 257 , une disposition rayonnée.

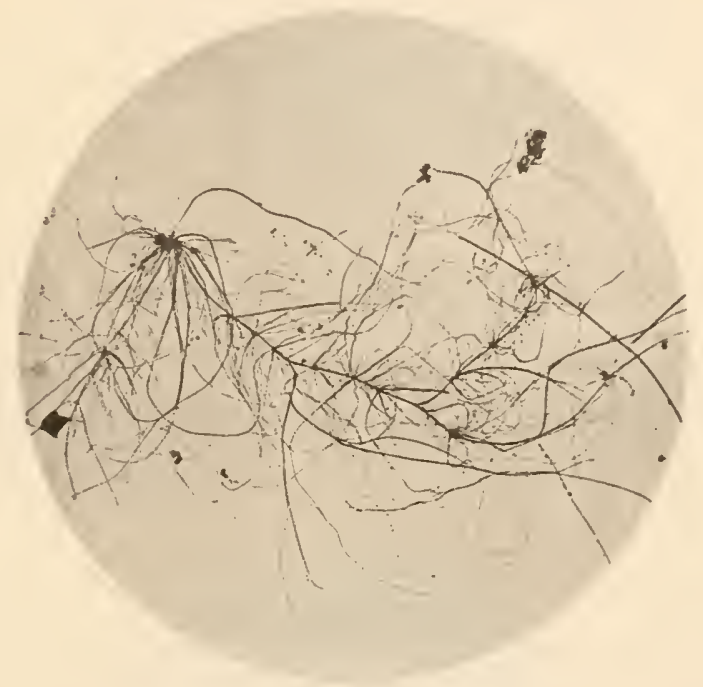

Fig. 231.

Beggiatoa alba (100 diam.)

Dans les colonies plus anciennes, les filaments secondaires divergent en tous sens, et partent d'un nombre variable de centres principaux ou secondaires, disposés le long d'un filament volumineux (fig. 231 et 232).

On observe souvent entre ces filaments des dépôts brunâtres de matières minérales, précipité naturel des eaux oủ se sont développées les Sulfuraires (fig. 232). Nous représentons, fig. 235 à 257, la Beggiatoa alba à un grossissement plus considérable. Les granulations qui existent en général dans les filaments de Beggiatoa ne peuvent être étudiées qu'à 800 ou 1000 diamètres (fig. 235 et 237). 
C'es granulations n'existrnl pas partout, el en certains points ou distingue très bien la struchure des filaments. Ils se emposent diune gaine qui se colore légiprment par la fuchsine et de courts articles

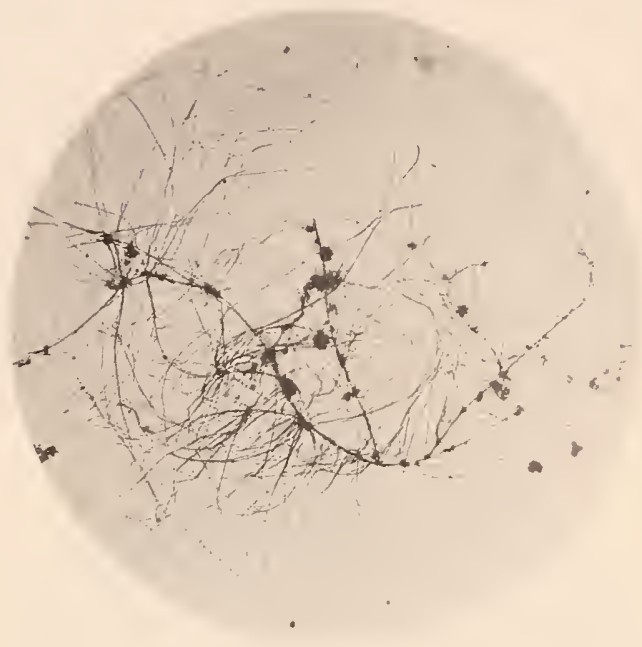

FIG. 232.

Beggiatoa alba (100 diam.).

réunis par un filament axial, d'une ténuité extrème, qu'on peut comparer au cylindre axe des tubes nerveux (fig. 256 et 257 ).

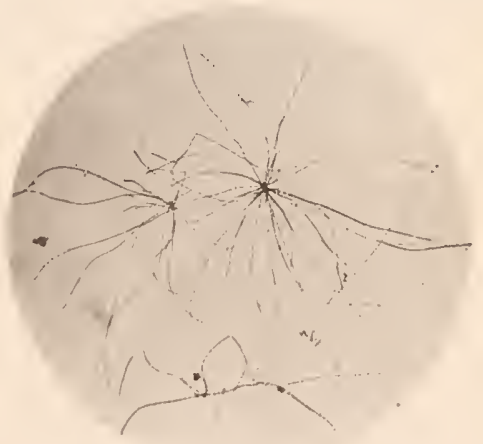

Fig. 253.

Beggiatoa alba (170 diam.).

La fig. 237 représente à un fort grossissement un groupe radié et un filament analognes comme structure à ceux représentés fig. 255 et 256.

liaspect radié, comme nous l'avons signalé plus haml, est bien risible dans les petites colonies de Beggiatoa (fig. 255 et 254). 


\section{PROPRIÉTÉS BIOLOGIQUES}

Les Beggiatoa vivent parliculièrement daus les eaux sulfureuses Ces micro-organismes ont longtemps passé poui joner un grand ròle dans la production de l'hydrogène sulfuré et des sulfures. Il est au

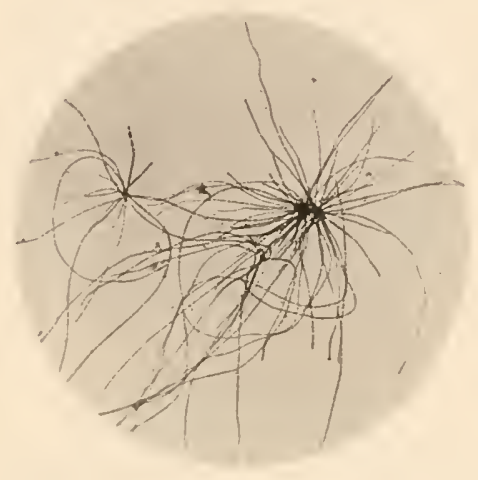

FIG. 234.

Beggiatoa alba (200 diam.).

contraire démontré que les granulations de soufre des Beggiatoa sont empruntées par elles aux eaux minérales, et que, loin de jouer un ròle

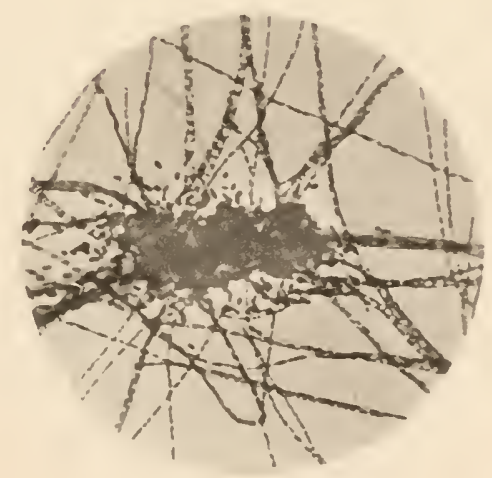

Fig. 235.

Beggictoa alba (1000 diam.).

dans la formation des eaux sulfureuses, elles amoindrissent leur teneur en principes actifs (Nacé). Les Beggiatoa vivent très mal dans 
les eaux pures et leur présence dans une eau potable doit ètre considérée comme l'indice d'unc souillure primitive par des substances orga-

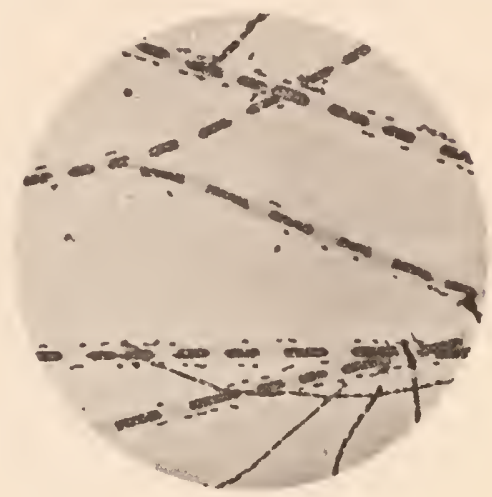

Fig. 236.

Beggiatoa alba (1000 diam.)

niques. Nous en avons observé en quantité considérable, avec MII. Yron et Berlioz, dans certaines conduiles d'eau de la ville de Paris

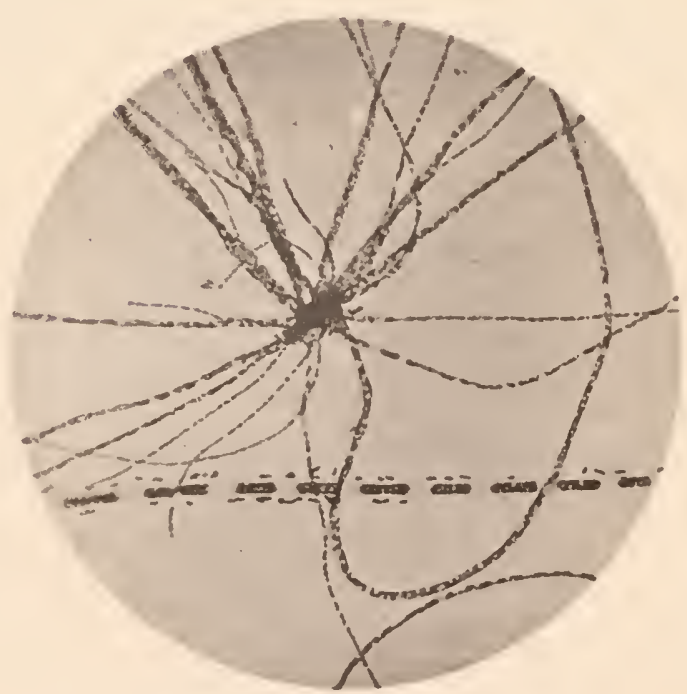

Fig. 257.

Beggialoa alba (1000 diann.).

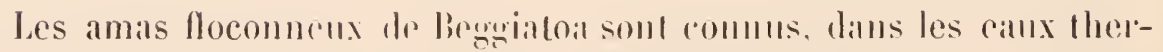
males sulfureuses, sous le nom de glairine on barégine. 


\section{FUSISPORIUII UNCIGERUM}

Le Fusisporium uncigerum ou moschatum, dont la culture exhale une odeur musquée, se développe sur l'argar sons forme d'une épaisse conche rose sammon, très allhérente, et dont on ne peut qu'a grand'peine détacher des parcelles à l'aide de l'aiguille de platine.

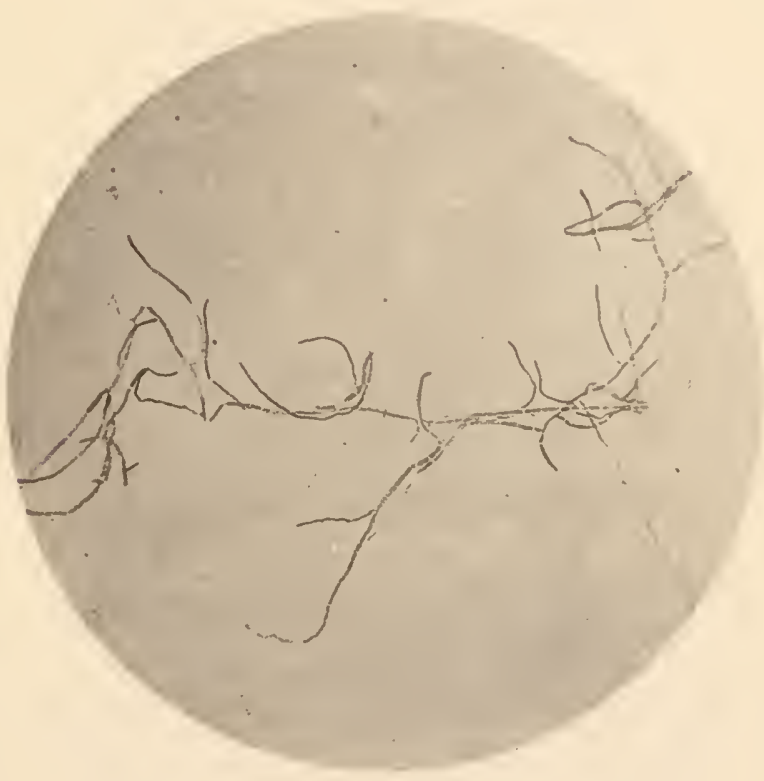

FiG. 258

Fusisporium moschalum. Culture àgée de 36 beures (300 diam

Il faut, pour observer le développement du Fusisporium, étudier des cultures très jeunes sur plaques de gélose (fig. 258 i1 241).

La fig. 238 représente la germination des spores unciformes du Fusisporium, qui poussent un prolongement, point de lépart des filaments mycéliens. On observe le début de la germination d'une de ces spores sur la figure 241. Au bout de 48 heures, les filaments de Fusi- 
sporium forment déjả une épaisse couche enchevêtrée, et sur les bords

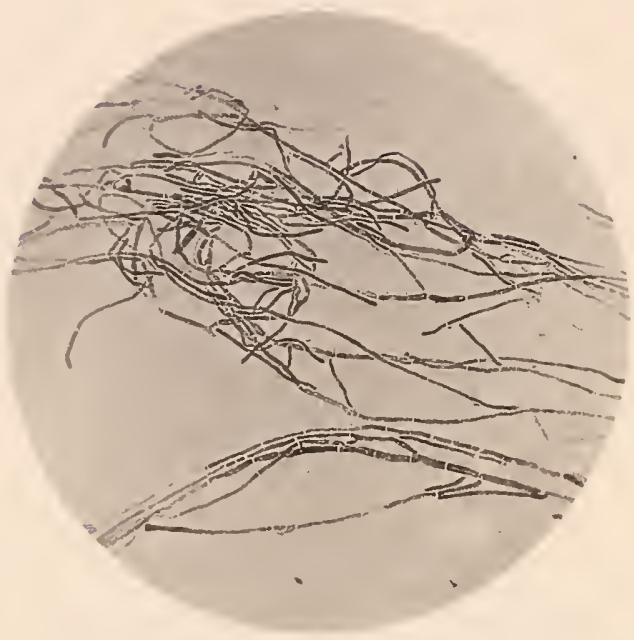

Fig. 239.

Fusisporium moschatum. Culture àgée de 2 jours (400 diam.)

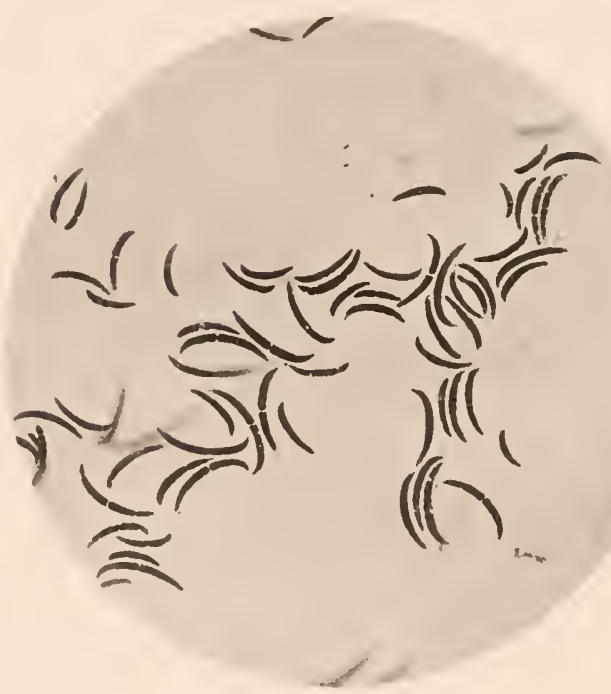

Fig.240.

F'usisporium moschatum. Culture àgée de 12 jours (400 diam.). Basides en forme de croissant.

de la culture on peul constater que ces filaments sont formés 
d'articles séparés, juxtaposés, et présentant des pseudo-ramifications.

Les éléments de reproduction du Fusisporium sont des basides en forme d'ongle ou de crochet et le plus souvent réunies deux par deux, comme le représente la fig. 240.

En d'autres points de la même culture sur gélose, qui est âgée de douze jours (fig. 241), on voit ces éléments insérés sur des filaments adultes par l'une de leurs extrémités. L'un d'eux est en voie de germination.

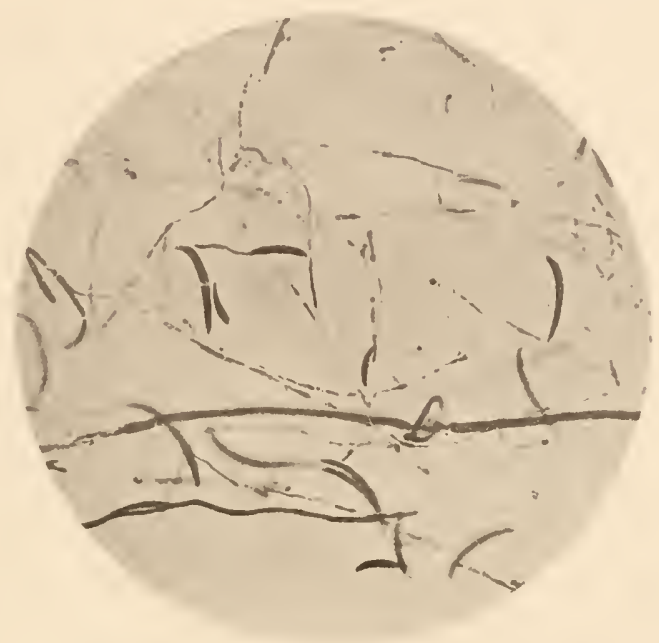

iig. 241.

Fusisporium moschatum. Culture sur agar-agar ( 12 jours) (400 diam.).

Le Fusisporium se colore sur les lamelles, après dessiccation, par la fuchsine alcaline ou par la méthode de Gram.

\section{PROPRIETÉS BIOLOGIQUES}

Le Fusisporium moschatum est un Saprophyte dont l'action est encore assez mal déterminée. 


\section{CLADOTRIX DICHOTOMA}

Les Cladotrix se trouvent dans les eaux impures et stagnantes. Ils régetent sur la carapace de certains animalcules des marais sous forme de touffes filamenteuses pourant donner l'illusion de ramilica. tions; ces pseudo-ramifications ne sont autre chose que l'accolement sous des angles variés de filaments roisins.

I. Metschnikoff nous a fait observer de belles touffes de Cladotrix dichotoma sur les carapaces des cjclopes qui se reproduisent dans les aquariums de l'Institut Pasteur. Nous avons isolé plusieurs colonies de Cladotrix par la dissociation et les avons colorées à la fuchsine.

Les touffes de Cladotrix sont insérées sur la carapace des cyclopes et s'épanouissent en divergeant. Les extrémités des filaments flottent dans le liquide. Après dissociation et coloration, on remarque que les filaments du Cladotrix dichotoma se composent d'une gaine qui fixe faiblement la matière colorante et de cour'ts articles séparés les uns des autres, et donnant assez bien à ces divers filaments l'aspect représenté pour la Beggiatoa alba (fig. 256). Le plus souvent les filaments sont accolés depuis leur point d'insertion; parfois leur gaine semble bifurquée, mais jamais les éléments qui entrent dans la composition des tubes ne se ramifient eux-mêmes. Nos préparations étaient montées dans l'eau; il nous a été impossible de les fixer et de les transporter dans notre laboratoire pour les photographier.

\section{PROPRIETTÉS BIOLOGIQUES}

Le Cladotrix dichotoma se développe dans les eaux stagnantes riches en infusoires. Il est saprophyle. 


\section{STREP'TOTRIX}

Colnt a donnć le nom de Streptotrix à un champignon inférieur Irouvé parr Forster dans des concrétions des canalicules lacrymaux.

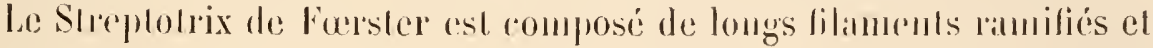
enchevètrés.

Marchand, en 1885, distingna nettement les Streptotrix des Cladotrix d'apres l'ispeet et la disposition de lrurs ramificalions.

Le Cladotrix dichotoma de Cohn esl formé de filinnents juxtaposés; ces filaments sont constitués par des articles contenus dans une sorte de gaine incolore el pen visible, el ne présentent jamais de divisions riribables.

l. Sheptotrix de Ferster "st, an contraire, conslitué parr de longs lilaments dhoits on sinueux, qui se divisenl el se ramifient en tous sens, sinns présenter de segmentillion ippréciable.

La décomserte du streptolrix de fierster devait aroir, en bactériologie, des consíquence inallemdues, fuisque en peu d'aunćes sont venus se grouper sous te mine terme génépique les champignons de toute une sóric de maladies infecticuses : l’Actinomyeose, la P'seudombereulose d'Eppinger, le Farcin du bouf de Nocard. le Pied de Naduria, ele.

Les streplotrix ont été étudiés tout particulièrement par le docteur T. Liossi Ioria, de Rome (1891).

Ipris avoir fait justice de la confusion faite par la plupart des aulcurs cntre le Cladotrix dichotoma et les Streptotrix, l'auteur décrit toute une série de streptolrix nourcaux, de provenance variable, mais dont la plupart ont ábé isolés de l'arir, d'eaux potables on slagnantes, ou de terres de diverse nature.

Depuis cette époque, H. Rossi Doria a poursuivi ses recherches, et nous avons pu roir an congres de Rome, dans son laboratoire, la collection de Streptolrix. la plas complète qüil nous ait élé donné de reneontrer. 
Sur les plaques de gélatine, les Streptotrix saprophytes forment d'habitule des colonies arrondies, mates el analogues a de pelites gonlledrlles de cire ou de stéirine. Les colonies superficielles se déreloppent plus rapidement que les colonies profondes.

Le denxieme el le troisième jour se produit un commenecment de liquéfaction autour de chaque colonie. Quand on essaie de prélever l'une d'elles ì l'aide d'une aiguille de platine, on constate immédiatemenl que lia colonie est formée d'une masse compacte el qui ne se laisse que diflicilement dissocier.

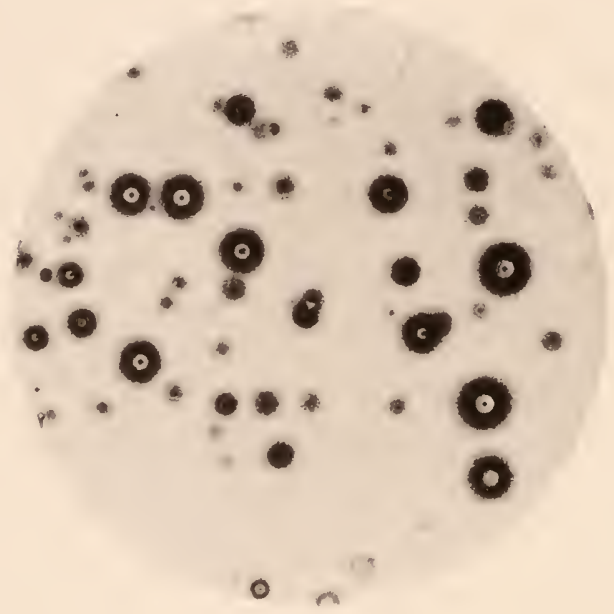

FIG. 242.

Streptotix brunnea. Plaque d'agar. Grandeur naturelle.

Si on lat lransplante sur un tule d'agar-agar, en prenant soin de la fragnenter ch de la frotter énergiquement sur la surface du milien nutritil, on roil an bout de quelques jours se produre une série de colonies mannelonnées el en élanges, saillantes de plusieurs millimitres, a le colorillion rallialle.

C'est anins que le Streplotrix albido-flava denenre d'mne teinte janne pâte al yur le Streptotrix carnea prend en quelques jours une belle

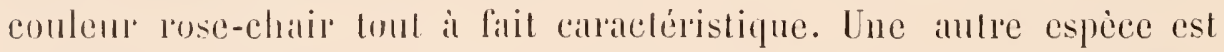
franchement orangée : Iel le Streptotrix nommé jusqu'alors Cladotrix asterioüdes palr Eppinger.

Lal culture du Streptotrix du Pied de Madure offre sur la pomme de terre une teinte d'mu rouge vif. 
I. streptotrix du Furcin du bruf conserve toujours sur la gólose une couleur d'un gris terne.

Le Streptotrix de l'Actinomycose, comme nous le verrons plus loin, prend sourent sur lat pomme de terre nie couleur d'un jaune vif, lappelant celle de la fleur de soufre.

Ontre ces colorations particulicres a diverses especes, certains Streptotrix ont la propriété de délerminer des modilicaltons colvéées dans le substratum nutritil ou ils se déreloppent. C'est allusi que Rossi Doria décrit :

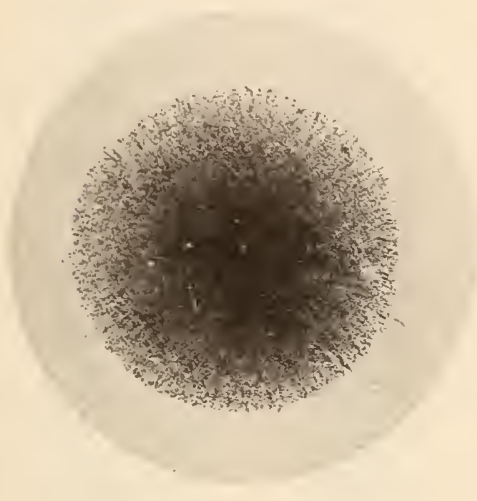

Fig. 243.

Streptotrix brunnea. Colonie jeune sur plaque de gélatine (100 diam.).

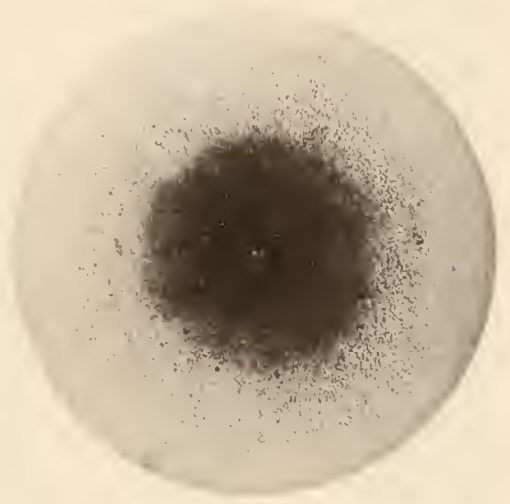

Fig. 244.

Streptotrix brumnea. Colonie superticielle au début de la liquéfaction (70 diam.).

Le Streptotrix brunnea ou migra, dont les colonics s'entomrent rapidement sur agar-agar d'une auréole d’un brun noiritre caractéristique. La figure 242 démontre cette particulariti. Elle représente, grandeur naturelle, un groupe de colonies de Streptotrix nigra sur une plaque d'agar-agar. On remarquera que les plus petiles colonies sonl déjà entourées d’une aréole hrunàtre très calateléristique.

Nous représentons, lig. 20, an grossissentent de lon diamitres, me colonie tris jenne de streptotrix nigret sur planme de gialatine.

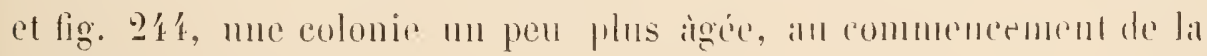
période de liequéfaction.

Le Streptotrix rolucen do hossi Doria détermine dans les milinax mutrilifs la formation d'une teinte violelle loul al lail spreciale. 
Les figures $245,246,247,248$ et 249 représentent les cultures de divers Streptotrix sur l'agar-agar. La fig. 24ว̆ reproduit une culture jeune de Streptotrix albido-flava, provenant du laboratoire de T. Rossi Doria. Les colonies sont cireuses, d'un jaune terne, et le substratum demcure incolore. La culture de Streptotrix violacea (fig. 246) est plus iggée. Les colonies se sont étalées sur le milieu nutritif et se montrent ridéces ì leur surface. Le substratum est coloré, au voisinage des colonies, en violet foncé. Celte teinte violette diffère nettement, tout

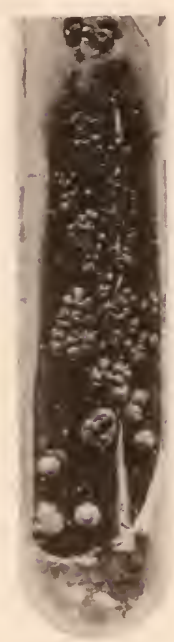

Fig. 245 .

Streptotrix albido-flava. Culture jeune sur agar.

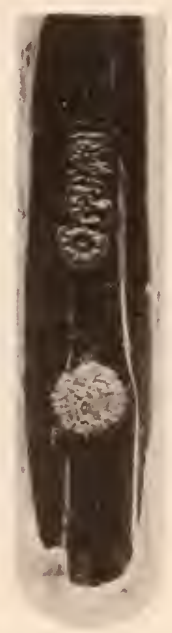

Fig. 246.

Streptotrix violacea. Culture jeune sur agar.

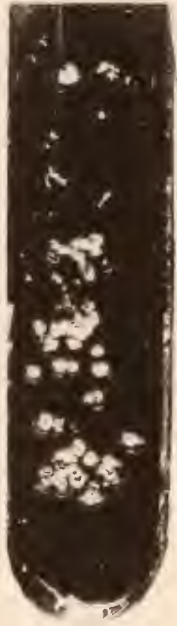

Fig. 247.

Streptotrix nigra.

Culture jeune sur agar.

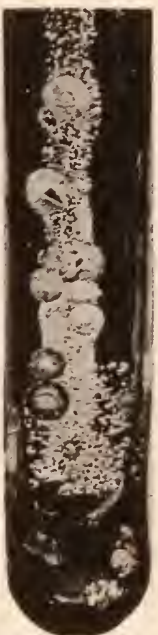

Fie. 248.

Streptotrix alba.

Culture àgée sur agar.

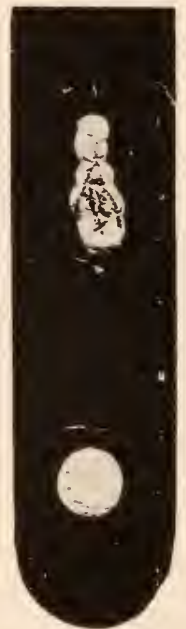

Fig. 249.

Streptotrix nigra.

Culture àgée sur agar.

en présentant arec cette dernière une certaine analogie, de la cóloration des fubes de gélatine on d'agar ensemencés avee le bacille du lait bleu. On remarquera l'aspect saillant. et mimelonné des cultures jeunes (lig. 24ö el 247). Le troisième spécimen (Streptotrix nigra) connucnce ì présentel an centre des colonies une teinte d'un blanc cravenx, qui envalina bienlót toute la surfaee de la culture (fig. 248 el 299). Yous verrons plus loin que cet aspect de la surface des vieilies cultures parait ètre en rapport arec une véritable fructification externe de ces champignons. 
Ces mèmes espèces colorent égalenent les cultures sur gélatine; la gélatine se liquéfie lentement à sal partie supérieure, où se forment les petits flocons caractéristiques du développement des Streptotrix dans les milieux liquides (fig. 250 el $2 \$ 1$ ). La liquéfaction met plusieurs semaines à gagner le foud du lube. Dans le bouillon, on observe le développement rapide de petits flocons blanchîtres sphériques, entourés d'un fin chevelu (fig. 252). Le bouillon reste limpide et les petites sphères se déposent dans la profondeur.

Ces colonies de Streptotrix dans le bouilıon peptonisé offrent une

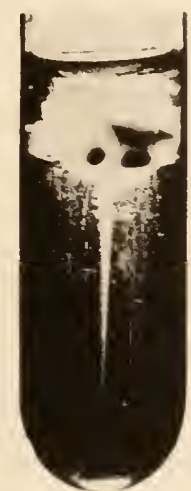

Fig. 250.

Streptotrix alba. Culture sur gélatine. (1 mois.)

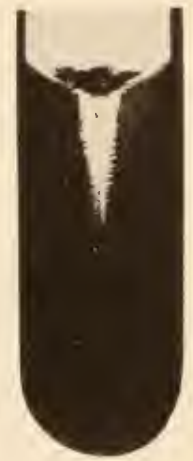

Fig. 251.

Streptotrix asterioüdes. Culture sur gélatine. (1 mois.)

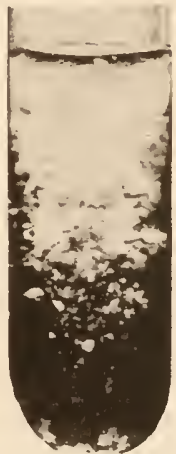

Fig. 252.

Streptotrix brunnea. Culture dans le bouillon. (15 jours.)

grande analogie d'aspect avec les jeunes colonies d'aspergillus ou de mucorinées qui se développent sans f'ructilications externes, et sous forme de petites sphérules blanchâtres et soyeuses, anl lond des flacons remplis d'une solution sucrée. Ces sphérules, trausportées ì la surface d'un milieu approprié, donnent des fruclilications externes telles que nous les avons décrites dans les premiers chipitres de eet Atlas.

Les colonies de Streptotrix, en milieux liquides, domnent naissance, quand on les transplante sur agar-agar ou sur gélatine peptone, à les colonies analogues à celles que représentent les ligg. 2 亿⿺ à 251.

l'étude microscopique des sphérules de Streptotrix liğurées fig. 2\%2 nécessite divers artifices de préparation, dont le principal est de choi- 


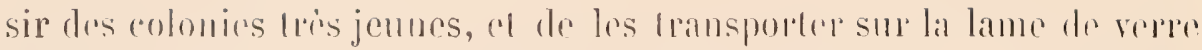

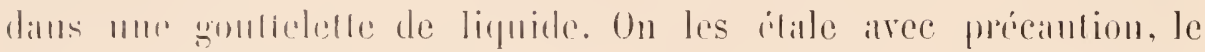

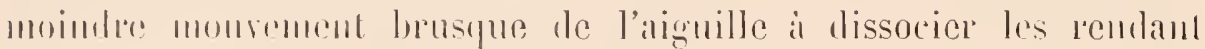
mácommaissibles al les embrouillant comme un lin mycólimm de muror renemusus. Nous figurous plus loin (Aclinomyeose, lanein du berul', l'ied de Mathra) plusients de ces colonies de Streptotrix dans le homillon, montées sur une lanne de rerre el colorées à lat fuchsine ou birn au violel de gentiane.

Qnand on examine an grossissement de 1000 diamètres, après dissociation et coloration par la méthode de Gram, une colonie de

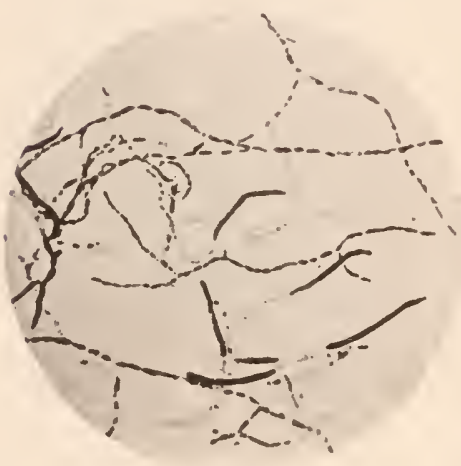

Fig. 250 .

Streplotrix brumea (1000 diam.).

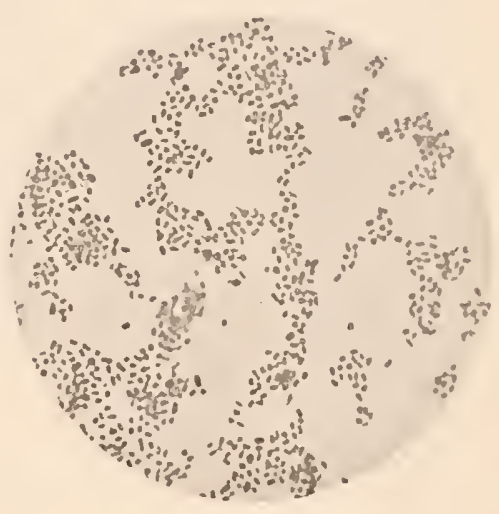

FIg. 234.

Streptotrix alba. Culture d'un mois, surface blanche (100) diallir.).

Streptotrix sur agar-agar, on observe, si la culture est jeunc, de longs liliments oudulés et ramiliés. Quand la culture est plus ancienne, ou remirrque que les filaments ne prement plus la couleur sur toule lemr elendue re paraissent constilues par une gane presque incolore,

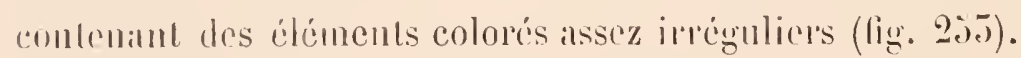

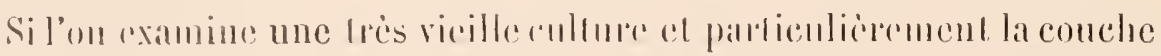

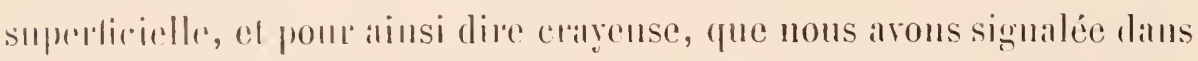

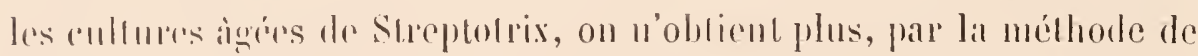

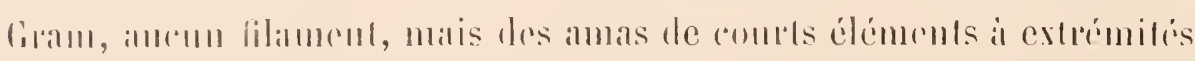
arrondies (lig. 29) 
réritable sporulation externe des Streptotrix. Son ensemencement donne les colonices jemues que mons arons décriles plus lanul.

lien ne justifie la chassilicalion des Streptotrix parmi les Oospor (Siluvagean et Rialdel).

\section{PROPRIÉTÉS BIOLOGIQUES}

Il résulte de ee que nous remons de roir que la pluparl des Streptotrix somt habituellement saprophỵes (Streplotrix allat, allido flavil, carnca, nigra). Toutefois, les propriélés pathogines de certains d'entre eux, mises en lumière depuis les travaux d'tppinger, de Rivollil of Perroncito, de Nocard, de Rossi Iorria, de Gasperini, cle., font rentrer désormais les Streptotrix parmi les espices backériennes les plus intéressantes en pathologie humaine et animale.

\section{AGTION PATHOGÈNE}

Le Streptotrix d'Eppinger (1890), primilivement nommé Cladotrix asterioüdes, qui a été le premier Streptorrix commu, délrmine chrz les animaux l'érolulion d'une pseudo-tubereulose prorlienlicire. II en est de même, d'après Rossi Doria et Gasperini, du Streptotrix violacea et de plusicurs autres.

Bien unieux, Gasperini a démontré récemment (18!9) que, en pratiquanl des séries d'inoculilions sur le chien, on pouvail démpunce

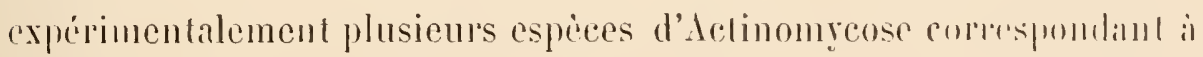
des streptolrix dejji décrils.

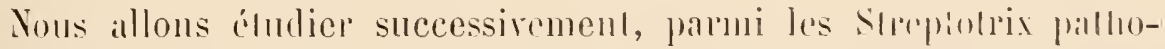
gènes, le Streptotrix de l'Actinumycose, le Streptotrix du fincin du brouf el le streptotrix du Pied de Wadura. 


\section{ACTINOMYCOSE}

L'Aetinomyeose est une maladie infectieuse qui reconnait pour cause la pénćtration dans les lissus d'un parasite végétal, le Streptotrıx Actinomyces.

L'Actinomýcose, très fréquente en Allemagne chez les bovidés, y est également observée chez l'homme. En France, l'Actinomycose de l'homme est cncore me maladie exceptionnelle, bien que les observations l'origine animale ne soient pas tris rares.

lingenbeck, Lebert et Robin furent les premiers auteurs qui étudièrent le pus aclinomỹcosique. Lebert a reconnu et figuré dans son atlas des conidies ou sortes de crosses telles qu'on les représente aujond'lni (18侻, 1871).

Rivolta el Perroneito (1868, 1875), ćtudiant de plus près ce que l'on lésignait sous le nom d" "ostéosarcome de la mâchoire inférieure du bxu|", séparèrent l'Actinomy̧eose du cancer et établirent définitivement lit relation entre le parasite et la maladie.

Bollinger lui donna le nom d'Actinomyces bovis (Champignon rayonné) (de $\dot{\alpha} \approx \tau i \xi-$ rayon).

Isracl fit porter ses recherches sur l'Actinomycose de l'homme et identifia l'Actinomyces du bœuf et celui de l'homme.

Il n'y avait en France qu'une observation depuis celle de Lebert (Nocard), lorsque coup sur coup nous en publiâmes trois cas provenant des environs de Reims (Aeadémie de médecine 1891 - Congrès de Londres 1891). Depuis, nous avons en l'oceasion d'opérer trois nouveaux malades atteints, deux, d'actinomycose de la joue, le dernicr, d'actinomycose thoracique; Netter et Darier en ont rapporté également chacun un cas. Les observations de Guermonprez sont sans valeur scientifique. 
CJiniquement, l'Actinomycose donne lieu chez l'homme à des lésions chroniques qui aboutissent à la suppuration. Chez le bœuf, au contraire, le parasite détermine la production de masses dures qui peuvent, à un examen superficiel, donner lieu à une fausse interprétation et simuler un sarcome.

Chez l'homme, les abcès sont enclarés dans une infiltration dure et lardacée des tissus voisins. lls ne sont pas toujours franchement fluctuants, gràce à la présence de fongosités. Ces foyers finissent par s'ouvrir à la peau en formant de longs trajets simucux, ramifiés, et remplis de fongosités d'aspect violacé et eccḥ̣motique. La zone d'envahissement est la zone périphérique, où l'on trouve quelquefois des abcès fermés et sans communication arec les clapiers fistuleux.

La maladie frappe particulièrement la face (infection buccale), le thorax (infection pulmonaire), l'abdomen (infection intestinale). D'où la classification de Firket : formes cervico-maxillaire, thoracique et lombo-abdominale.

Le parasite est susceptible de s'inoculer dans tous les points de l'économie; l'infection peut rester locale ou se généraliser et donner naissance à des foyers secondaires analogues à ceux de la pyohémie. L'Actinomyeces pénètre dans le sang et forme des embolies septiques comme le staphylocoque doré.

Le pus actinomycosique est caractérisé par la présence, au milieu d'un liquide séreux, séro-sanguinolent ou franchement purulent, de petits grains jaunâtres dont le volume varie d'une graine de pavot à un grain de millet.

Les grains constituent l'élément caractéristique de la maladie. Le grain sphérique peut lui-même être fragmenté et dissocié en un certain nombre de masses secondaires arrondies. On peut reneontrer certains grains qui résistent à l'écrasement et crient sous le scapel : il s'agit en pareil cas de dégénérescence calcaire.

Nous avons réuni, parmi de nombreuses préparations d’Actinomycose du bœuf et de l'homme, celles qui nous paraissaient les plus démonstratives. Nous avons ainsi figuré l'Actinomyces sous ses dif- 
férents aspects: dans les grains, dans les coupes des viseères des animaux et de l'homme, dans le pus, dans les parois des abcès et trajets fistulcux, dans les cullures; nous relaterons enfin les résultats obtenus par l'inoculation aux inimaux.

La méthode la plus simple, la moins parfaite, celle qui a permis cependant aux anciens observateurs, tels que Lebert, de décrire la

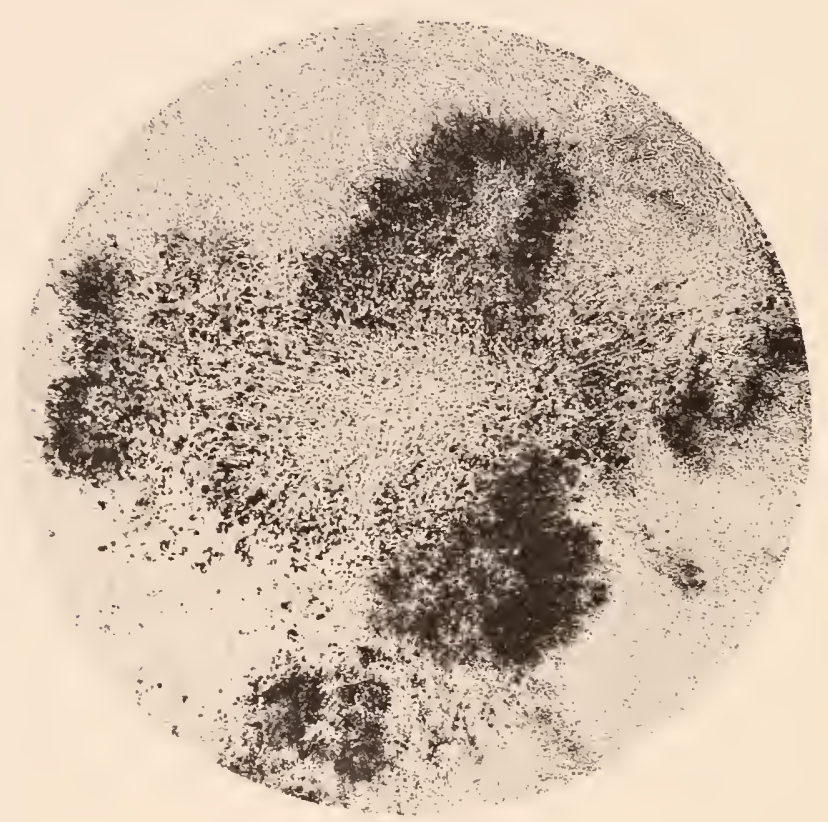

FIG 255 .

Actinomycose de l'homme. Grain préparé par écrasement (gr. 200 diatur.).

maladie, consiste á écraser entre deux lamolles, à l'aide d'une donce pression, un grain frais d'Arlinontycose.

Il est facile, après quelgues essais, de róaliser ainsi une lignure

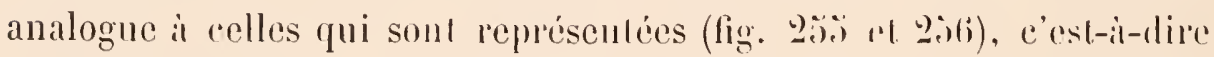
une misse contrale, composée d'un antas incetricable, non alparent à ce grossissement, de filiments entre-croisés. Ce mode de recherche n'établit qu'un senl fatit; la forme sphérique du grain el sa disposition rayonnce : on arrive à soupçonner, à la périphérie des rayons, des formes alrondies, qu'on a appelíes, faute de mieux el sans ìtre fixé sur leur róle, du nom de crosses. 
Tout autour des graius existent des anas cellulaires. Ces collules

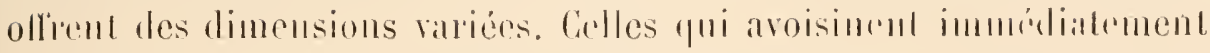

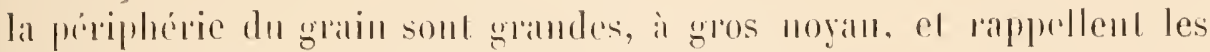
cellules épithétioüles: elles penvent receroir la lerminaison dre cerlaims filamenls mecéliens; mais il fitul se garder de les confondre arec les anses proprement dites.

Plus loin, on rencontre des cellules rondes en grande abondance,

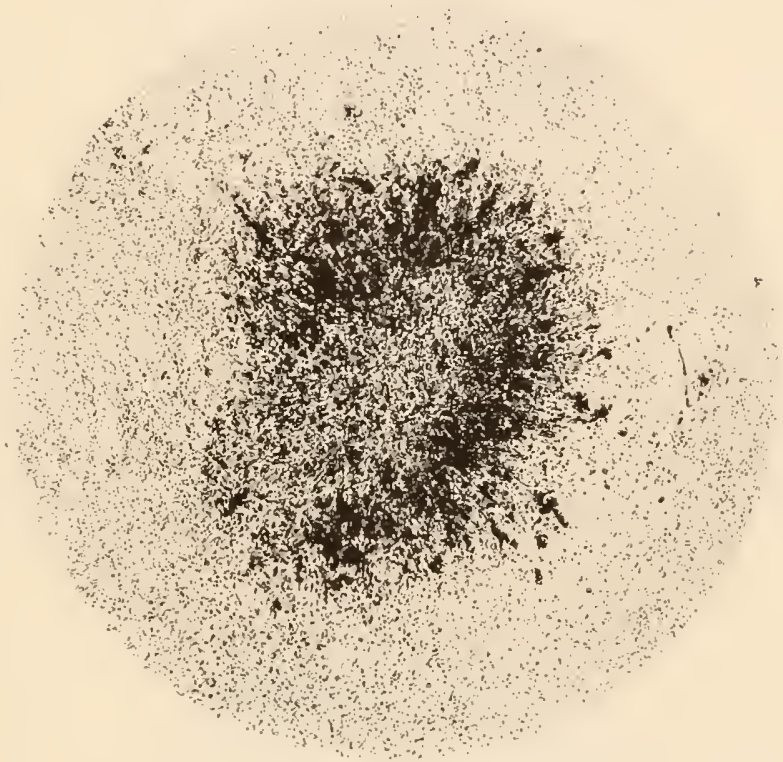

FIG. 256.

Ictinomycose de l'homme. Grain préparé par écrasement (gr. 400 diamètres).

ce qui donne, a un faible grossissement, aux forers actinomycosiques, l'aspeet de foyers luberculeux d'une certaine étendue. Ces amas cellulaires sont rémis entre eux par une gangue librillaire extrimement délicate el lìche : ce qui explique la filcilité avec laquelle on peut énucléer de pelits grains jaunes dans l’actinomycose du bouf, par exemple.

Iais celte méthode rudimentaire a fait place à les procédés techniques plus perfectionnés, dont le plus simple est la dissociation de grains actinomycosiques et leur coloration par le picro-carmin à 
l'état frais, ou mieux à l'aide des couleurs d'aniline après dessicca-

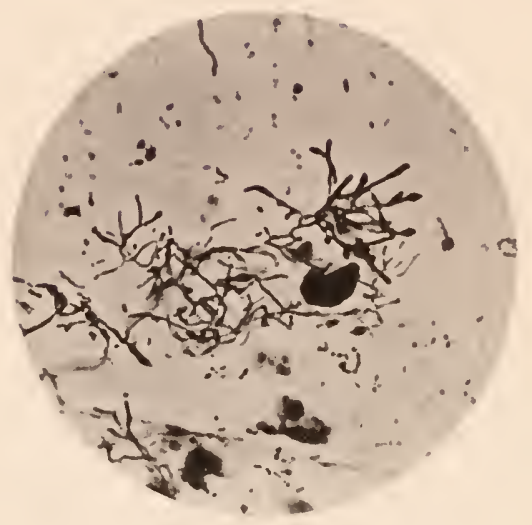

FIG. 257.

Actinomycose du bœuf. Dissociation d'un grain frais (gr. 1000 diam.).

tion sur une lamelle, comme on le pratique pour les autres cxamens bactériologiques.

Les fig. 257 à 260 représentent des dissociations de grains actino-

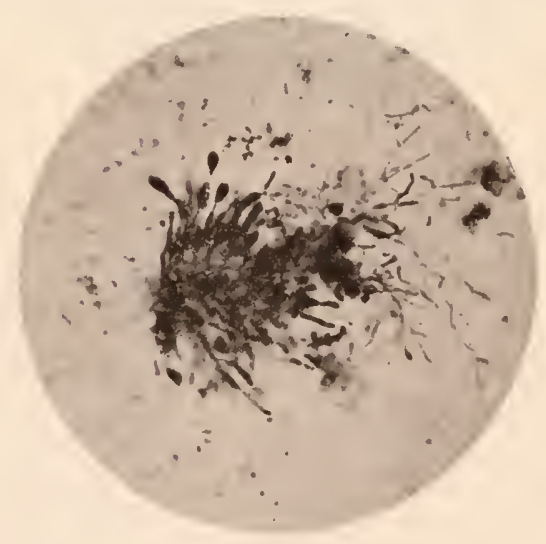

F1G. 258.

Actinomycose du bœuf. Dissociation (gr. 1000 diam.).

mycosiques provenant d'une langue de bouf qu'a bien voulu nous confier le Pr Macé de Nancy. On distingue sur ces diverses préparations 
et parliculicrement sur les fig. 257 el 258 , les ramilications des fila-

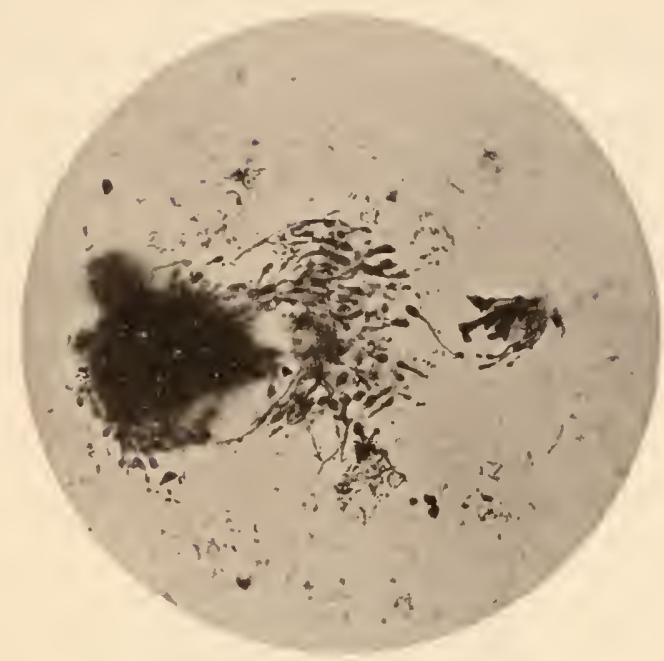

FiG. 259

Actinomycose du bœuf. Dissociation (gr. 700 diam.).

ments actinomycosiques, ramifications analogues a celles des autres Streptotrix. Sur la fig. 25̌7, les crosses sont rudimentaires; on les observe beaucoup plus nettes dans les figures suivantes. Elles se

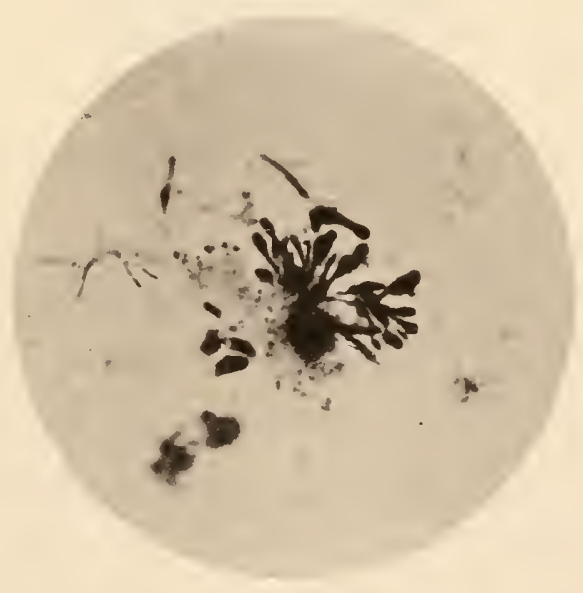

Fig. 260.

Actinomycose du bœuf. Dissociation (gr. 1000 diam.).

monirent parciculièrement volumineuses dans la fig. 260, oủ elles terminent ụ groupe de filaments rayonnés et bifurqués à leur 
extrémilé. Ces quatre préparations ont élé colorées, après dissocialion el dessiccintion sur ume limmelle, pirr lit methorle de Wrigert.

Il peut itre intiressant d'itudier les rapports des filaments ot des conidies. On ublimt a cul oflet des préparalions démonstrallires en

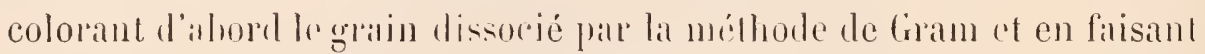
une double coloralion far le carmin on l'éosine. On dislingue alors

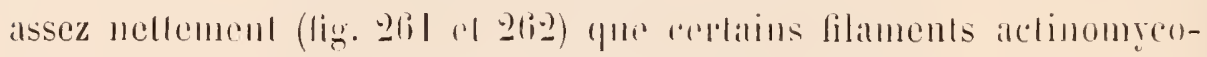
siques se terminent pall un petit renllement coloré en violet loncé,

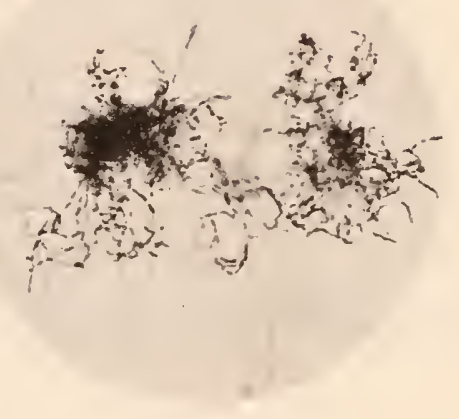

FIG. 261.

Actinomycose du houf. Dissociation (Cornil) (gr. 1000 diam.).

silué an centre d’une erosse assez volumineuse el leintée elle-mème en rose piile.

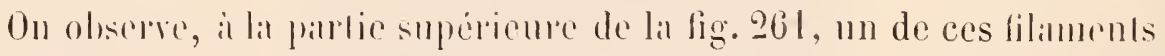

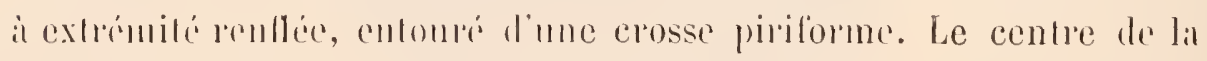

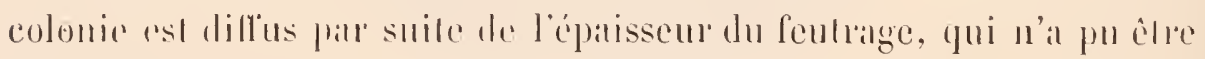
entiementent dissocić.

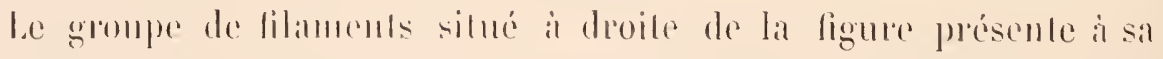

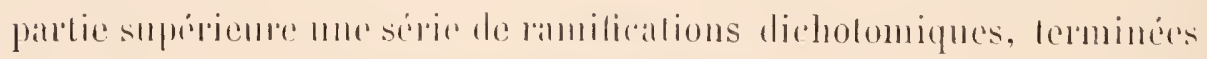

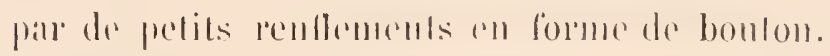

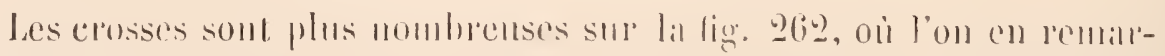

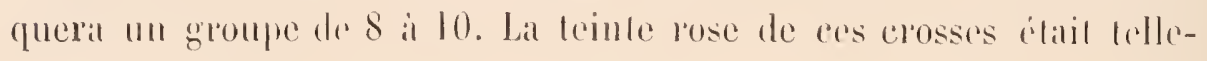


ment pìle qu'il a été impossible de les pholographier aree toute la nelleté de contours désirable.

Il existe ígalement, at ganche de ce groupe tre erosses, quelques terminaisons en bouton de filaments atchonougosiques. L'mn de eas boutons terminatux, le plus rapproché du feulage central de la préparalion, est arrondi, roluminemx el offre la phus grande analogie avec les formes semblables que nous alvous tromres daus l'Aetinomycose de l'homme.

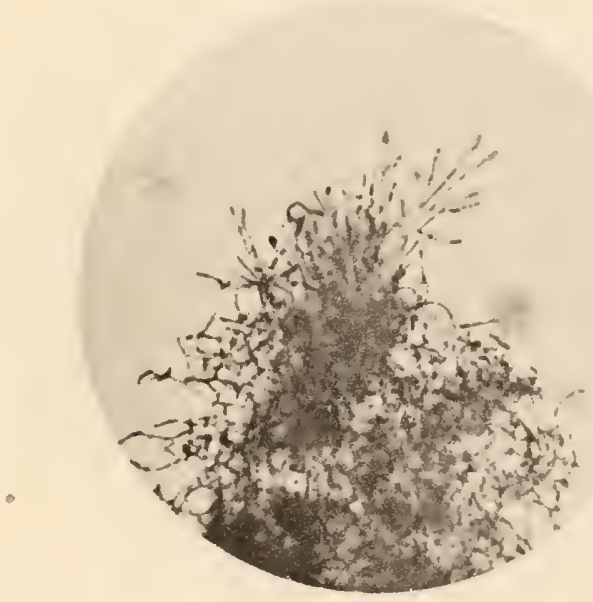

FIG. 262.

Aclinomycose du bœuf. Dissociation (Cornil) (gr. 1000 diam.).

Aucune de ces photographies ne suffit a trancher la question de savoir s'il exisle ou non une membrane d'enveloppe, permellant d'alssimiler définilivement les crosses à des conidies. Les crosses de l'Aclinomyeose offrent en effel aux agents chimiques une résistance que ne comportent pas habituellement les organes de reprodue tion des mucédinćes.

L'élude du grain actinomyeosique ne peut servir quài la démonstration de la nature parasilaire de la maladie gui nous oecupe. Il fiaul étudier les rapports du parasite dans nos lissus pour suive son déreloppement et les désordres qu’il délermine antour de lui. 
Si l'on examine sur une coupe, à un faible grossissement, un cas d'actinomycose de la langue ou d'un viscère tel que le rein, on rencontre généralement, dans les endroits oủ la maladie n’est pas trop avancée, des foyers nettement circohscrits, et tranchant par leur couleur blanc jaunatre sur le fond sombre du tissu sain. Ce sont des sortes d'abcès arrondis - bien enkistés — qui peurent dans la suite devenir confluents, de manière à former de vastes collections suppurées.

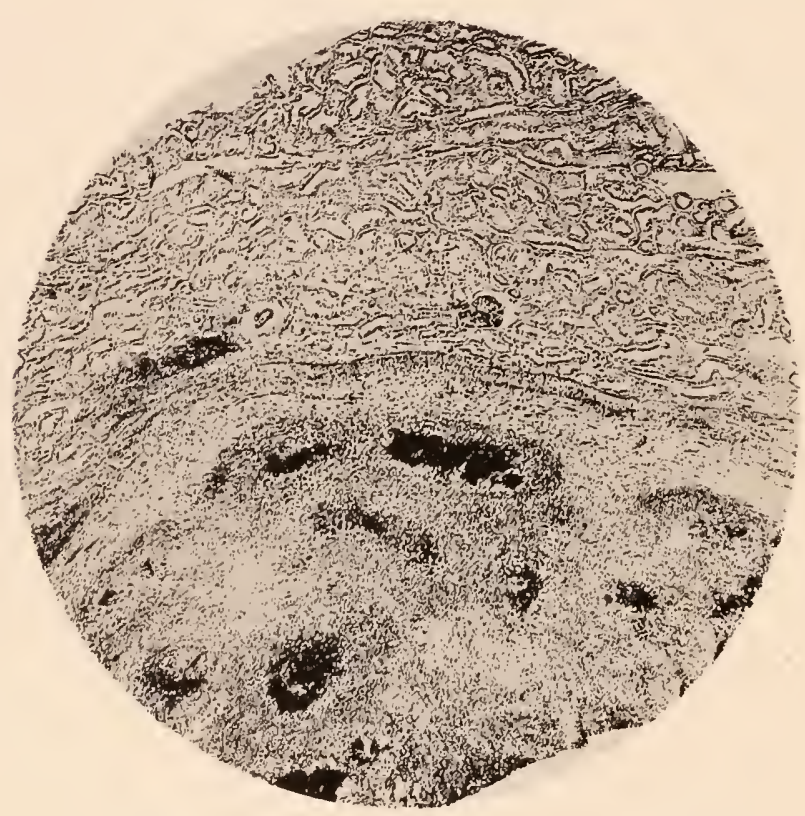

Fig, 263.

Rein de bœuf. Actinomycose (gr. 25 diam.) (Nocard).

L'aspect des foyers actinomycosiques à un faible grossissement ne peut être mieux étudié que sur les belles coupes de rein que nous a confiées le $\mathrm{l}^{\mathrm{pr}}$ Nocard.

Ces coupes sont colorées it la safranine, de telle sorte qu'on peut étudier à la tois les lésions du lissu rénal, glomérules et tubuli, la structure des foyers actinomycosiques, el la disposition des erosses.

Ces dernières, comme nous le verrons plus loin, olfrent sur ces préparations (lig. 266) un aspect tout particulier, et s'y montrent beaucoup moins nettes que dans les coupes de langue actinomycosique (fig. 267 à 270). 
Si nous étudions l'ensemble de ces coupes nous suirrons pas à pas la marele des lésions.

On remarquera, figure $26 \overline{5}$, alu grossissement de 25 diamìtres, $11 n$ fojer actinomyessique émorme, séparé par une zone fibroüde du tissu rénal non encore envahi. Lal délimilalion de ce foỵer infectieux est très nette.

La région des tubes contournés, visible en haut de la préparation, est coupric cemme à l'emporle-piece. Cet aspect dénote un processus

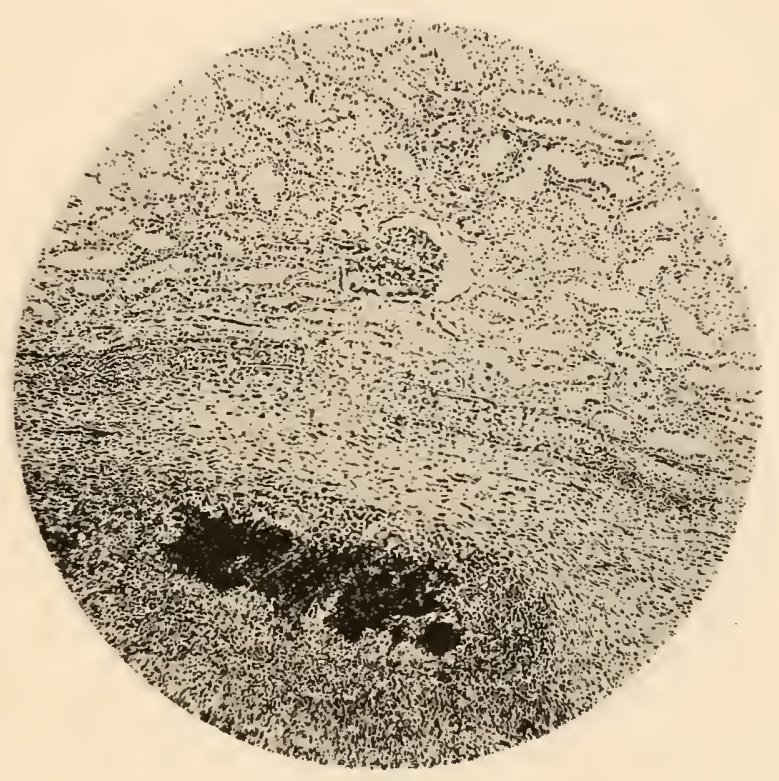

FIG. 264.

Rein de bœuf. Actinomycose (gr. 60 diam.) (Nocard).

destructif à marche lente. L'aspect du tissu rénal atrophié qui forme la coque des gros reins tuberculeux est très analogue.

Les éléments épithéliaux sont comprimés par voisinage. A l'intérieur du foyer principal on remarque une série de foyers secondaires, dont le centre a fixé énergiquement la matière colorante, et qui offrent une certaine analogie avec des amas de follicules tuberculeux en dégénérescence casćeuse.

La figure 264 représente, au grossissement de 60 diamètres, le point central de la figure 263. On y distingue parfaitement les amas de cellules rondes qui forment le centre du foyer. 
La figure 26 montre un point dı mème rein où l'envahissement diffus de la région des glomérules s'étend à distance des foyers centraux.

Il est impossible, à l'aspect de ce point de la préparation, de reconnailre le tissu rénal, dont persistent à peine quelques glomérules déformés et atrophiés. mais non encore entièrement détruits par le tissu inflammatoire.

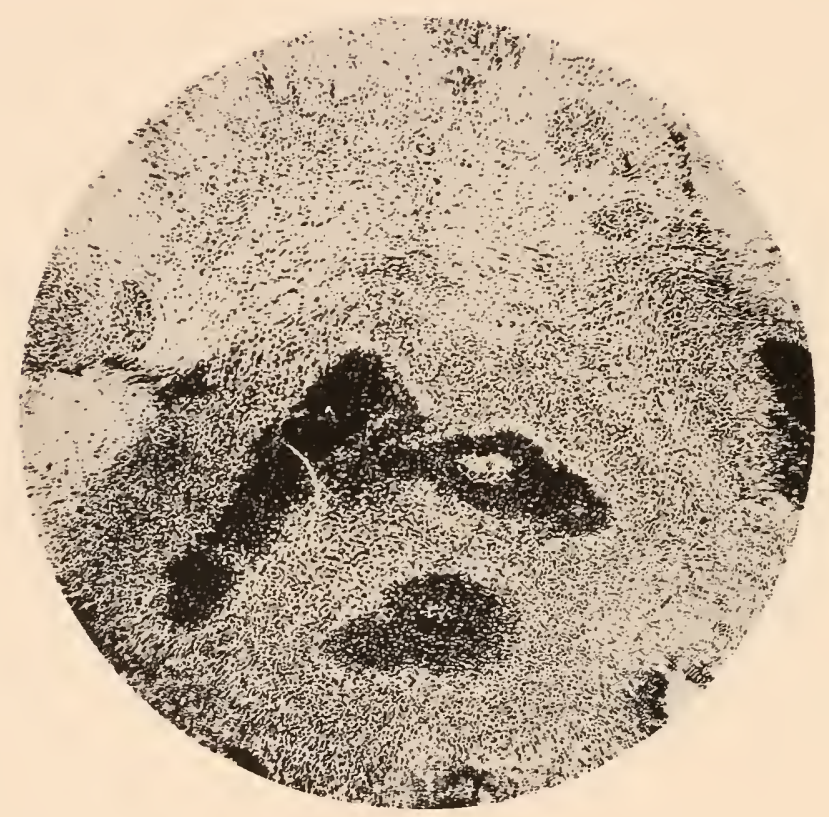

Fเ6. 265.

Reun du bouf. Actinosngcose (gr. 60 diaun.) (Nocard).

Les foyers actinomyensiques de ee rein laissent voir a un plus fort grossissement, aparis colorilion il la salranine, des séries de crosses. Ces crosses correspondent il l'extrémité de: nombreux rancanx mycéliens, qui oceupent le ecutre lles loyers (lig. 266).

Las crosses sont toutefois beancoup plus nettes dans les coupes de langue de beenl", oi elles sont décrlíes frar les réactil's eolorants les plus divers. On obtient alor's, si l'on a des compes très minces, des figures amalugues aux ligures 267 a 270 , qui représentent au grossissement de 700 ì 800 diamitres dilfërents aspects des groupes de crosses ac̀tinomỵcosiques. 
Les crosses offrent presque toujours une disposition ravonnée. Beaucoup d'entre clles, sur cos quatre figures, sont coupées perpendiculairement i leur axe. Ces éléments occupent le centre des tubercules aetinomreosiques.

l'actinomyeose de l'homme diffère notablement de eelle du bouf; cliez ce drrmier en eflet les masses d'aspeet sarcomateux sont tris rares, et le champignon de l'actinomycose détermine plus fréquem-

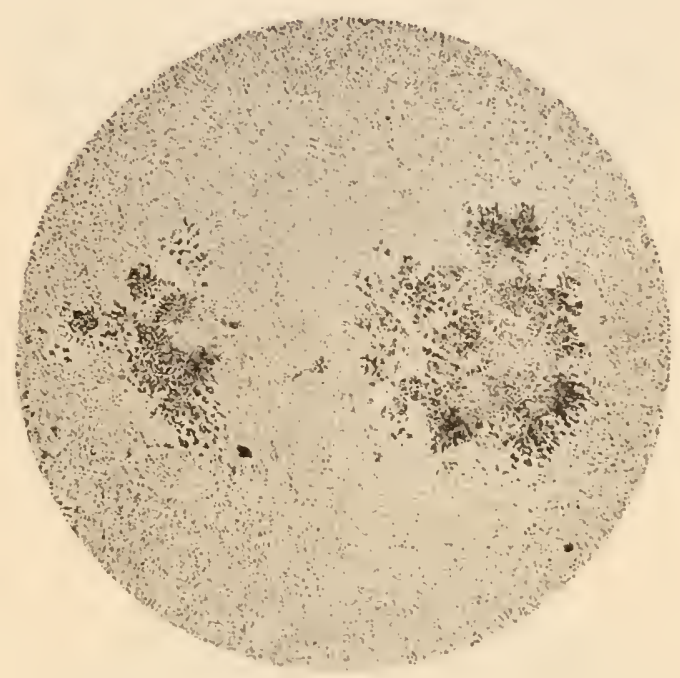

Fig. 266.

Rein de bœuf. Actinomycose (gr. 500 diam.) (Nocard).

Inent le ramollissement des tissus qui l'entourent et la formation d'abcès; l'absence de crosses y cst presque constante. Ces particularités sont évidentes si l'on prend soin de comparer aux figures 257 i 270 (actinonveose des bovidés) les figures 271 à 278 (actinomyeose de l'homme).

Les préparations ont été faites par raclage, écrasement ou dissociation des grains des premier's cas d’actinomyeose que nous avons étudiés ¿l lieims (actinomycose de la joue, actinomycose de la base de la langue, actinomyeose de la plèrre et actinomycose péritonéale et riscérale). La dissociation est ici poussée très loin, les filaments sont nettement

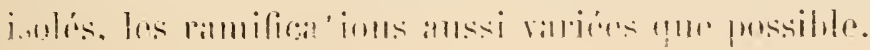




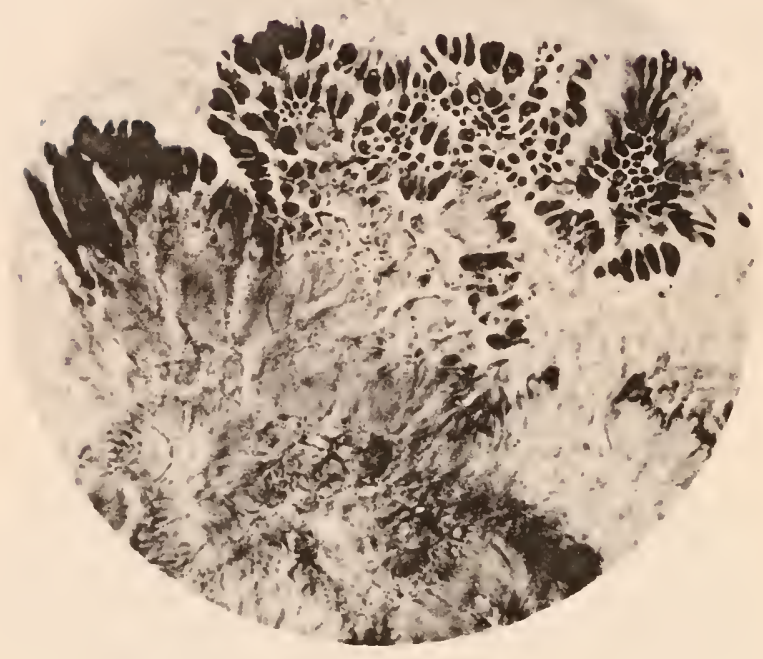

FIG. 267.

Actinomycose. Langue de bœuf (gr. 700 diam.).

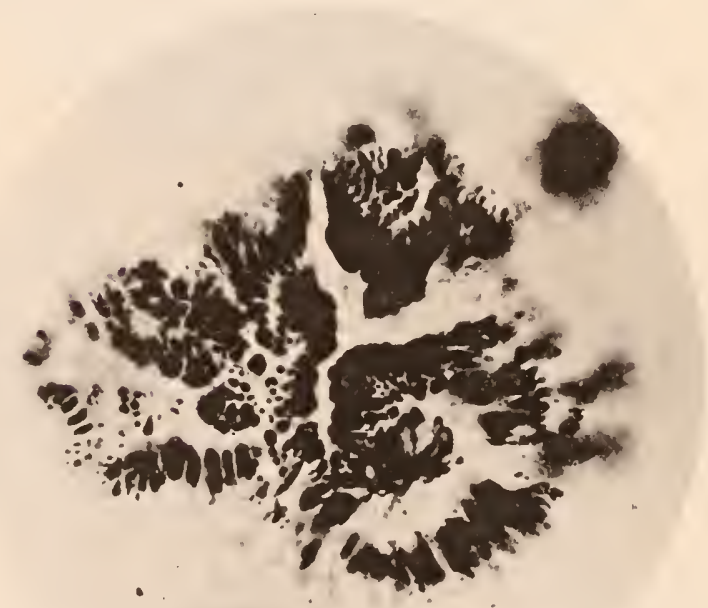

Fig. 268 .

lcinonycose. Langue de bouf (gr. 800 diam.). 


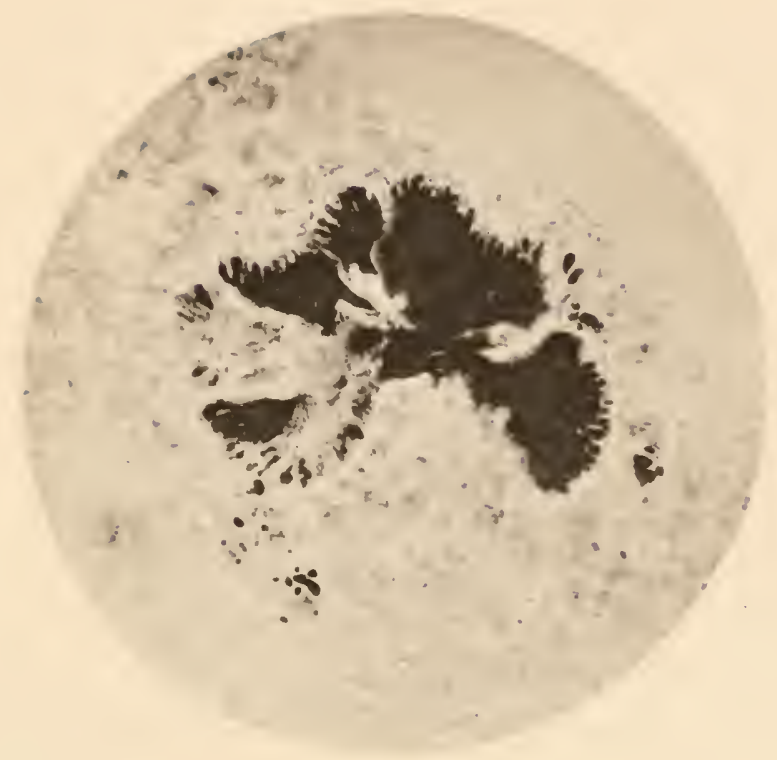

Fic. 269.

Actinomycose. Langue de bœuf (gr. 800 diam.).

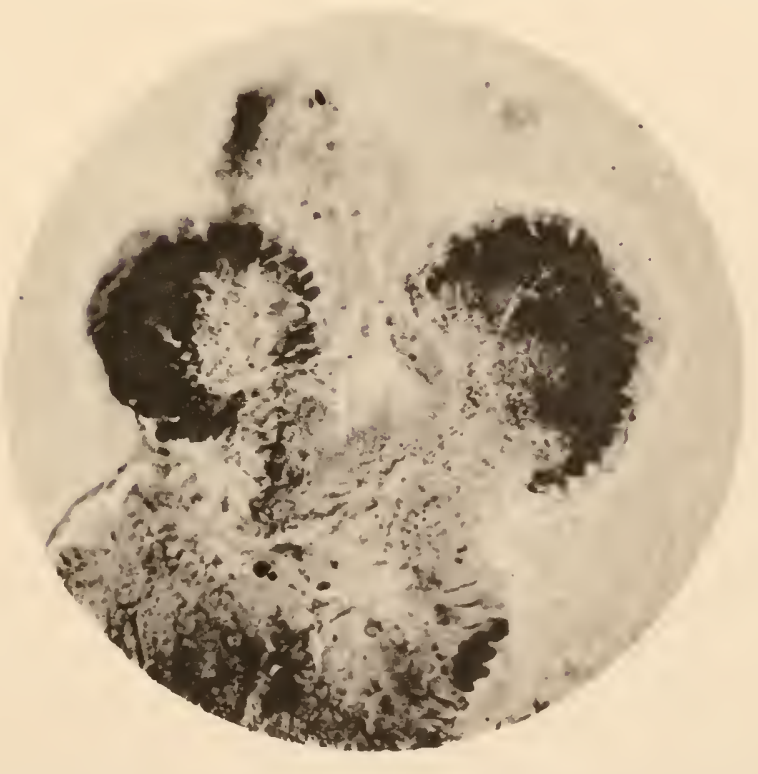

Fig. 270.

Actinomycose. Langue de bœuf (gr. 800 diam.). 
La figure 271 montre, au milieu de mycéliums ramifiés en petit

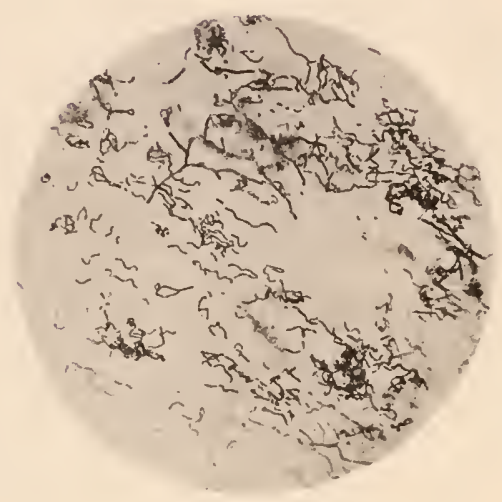

Fig. 271.

Actinomycose de l'homme (abcès de la joue), dissociation d'un grain (gr. 600 diam.).

nombre une quantité de petits bâtonnets, incurvés ou en spirale et non sans analogie avec une culture du choléra asiatique.

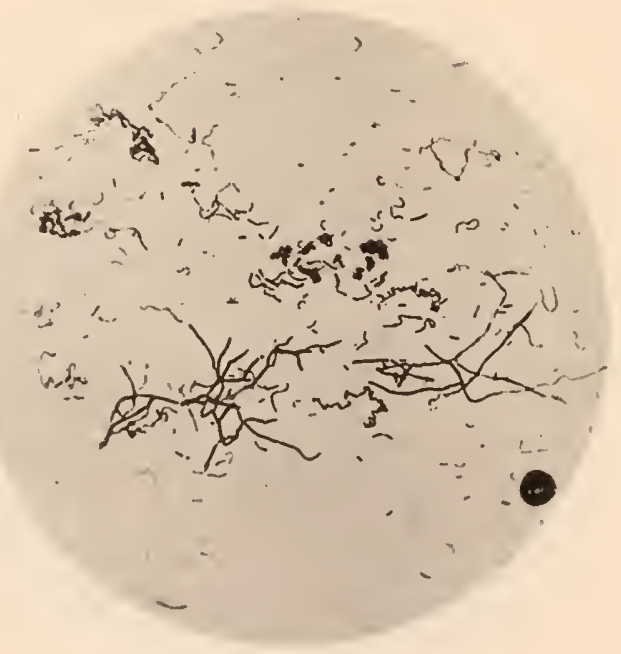

Fig. 272.

Actinomycose de l'homme (abcès de la jouc), dissociation l'un grain (gr. 800 diam.).

I.es ramifications sont plus abondantes dans la figure 272, qui se 
rapporte également ì un cas d'actinomyeose suppurée de la joue che\% l'homme.

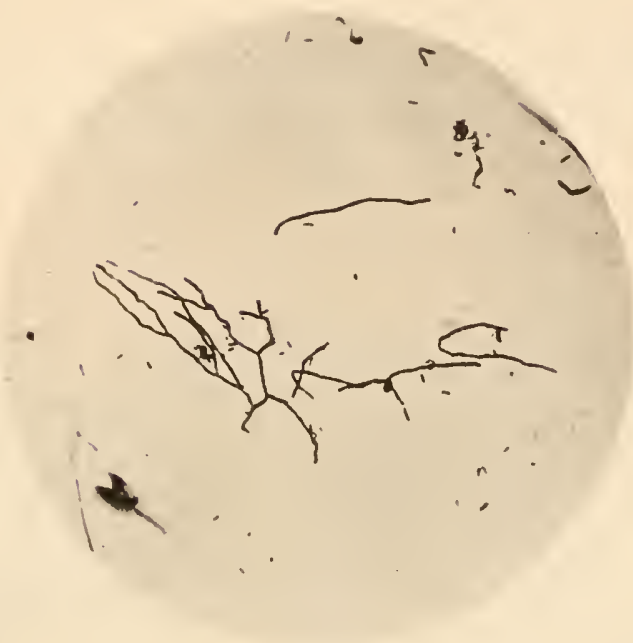

FIG. 273.

Actinomycose de l'homme (alscès de la joue), dissociation d'mu grain (gr. 800 diam.).

Les figures 275 et 274 montrent nettement les ramifications de

Fig. 274.

Actinomycose de l'homme (abcès sub-liugnal, dissociation d'un grain (gr. 1009 diam.). champignon; en aucun point on n'observe de crosses. 
Les figures 275 a 277 représentent au contraire de petites touffes d'éléments très courts provenant d'un cas d'actinomycose viscérale.

On peut se rendre comple, en comparant les planches 271 à 277 , qui proviennent de trois malades différents, que l'actinomỹcose ne se présente pas sous une forme toujours la mime. Le type en reste identique : c'est bien toujours un Actinostreptotrix; mais le volume, l'épaisseur,

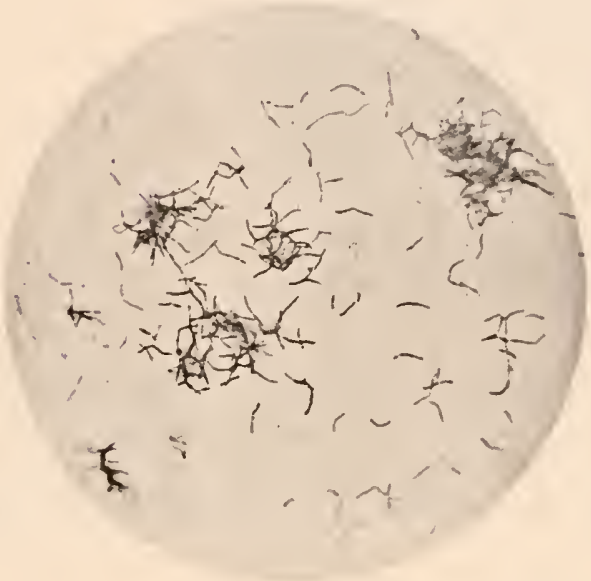

Fic. 275.

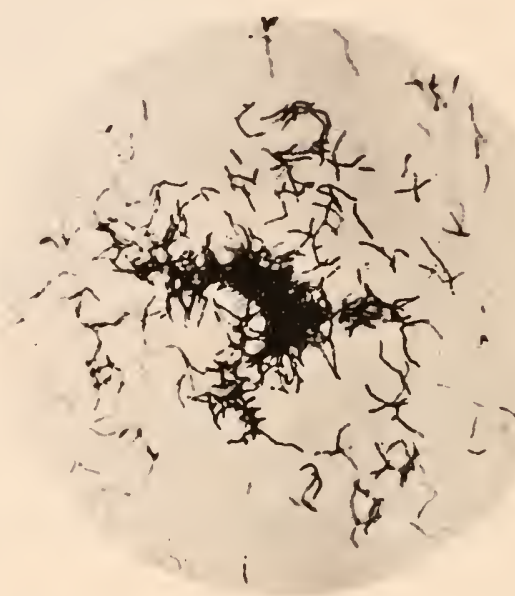

FIG. 276.
Actinomycose de l'homme (abcis pelvien), dissociation d'un grain (gr. 800 diam.).
Actinomycose de l'homme (abcès pelvien), dissociation d'un grain (gr. 1000 diam.).

la longueur des filaments diffërent : ici les filaments sont allongés, rappelant de loin de longs Leptotrix, et les bifurcations se trouvent à des distances très appréciables (fig. 274); là le parasite est ramassé sur lui-même, les branches sont courtes, nombreuses, eondensées autour d'un filament très grêle.

Certains de ces mycéliums, très fragmentés par l'écrasement, rappellent la gracilité et l'incurvation des bacilles tuberculeux. Ces particularités sont restées constantes dans un nombre considérable de préparations.

Nous croyons qu'il n'est pas illogique de conclure qu'il existe entre l'actinomycose de l'homme et celle des animaux des caractères diffè- 
rentiels marqués, que l'actinomycose de l'homme n'est pas une et que des parasites d'espèce très voisine peuvent donner lieu à des manifestations pathologiques identiques, décrites jusqu'ici en bloc sous le nom d'actinomycose.

Ces conclusions, que nous émettions au Congrès d'hygiène de Londres dès 1891 , nous semblent actuellement corroborées par les recherches

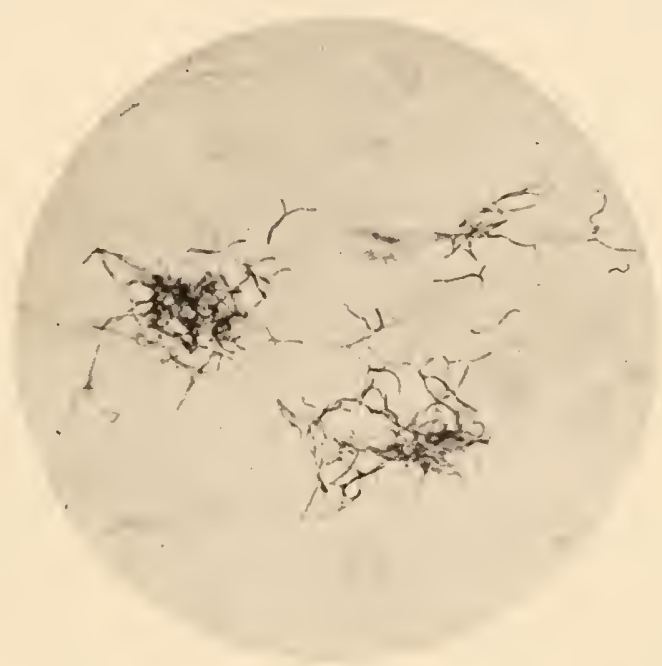

Fig. 277.

Actinomỵcose de l'homme (abcès pelvien), dissociation d'un grain (gr. 1000 diam.).

si remarquables des $D^{\text {rs }}$ Rossi Doria et Gasperini sur les Streptotrix et sur les actinomỵcoses expérimentales déterminées par l'inoculation aux animaux des divers Streptotrix de l'air ou du sol.

Bien plus, le parasite peut être observé à différents stades de son développement, correspondant à des variations de virulence qui nous ont paru incontestables.

Les formes jeunes, à mycéliums courts, comportent, à notre avis, une gravité plus grande, une tendance plus marquée à la généralisation; ce sont elles qui nous ont donné des inoculations positives. Les formes allongées et ramifiées se rencontrent de préférence dans les foyers anciens. 
Nous avons reproduit (fig. 278) une des lares préparations où nous ayons pu déceler la présence de crosses véritables, nous refusant a considérer comme telles les cellules épithéliales ou lymphatiques déformées et arrondies dans lesquelles se terminent certains filitments; ce sont à peu près les seules qui aient été rencontrées dans les préparations de six cas d'actinomycose que nous avons étudiées. Ces crosses sont presque sphériques, en forme de bouton, et moins volumineuses que celles du bœuf.

Nous avons été appelés, peu de temps après la publication de nos

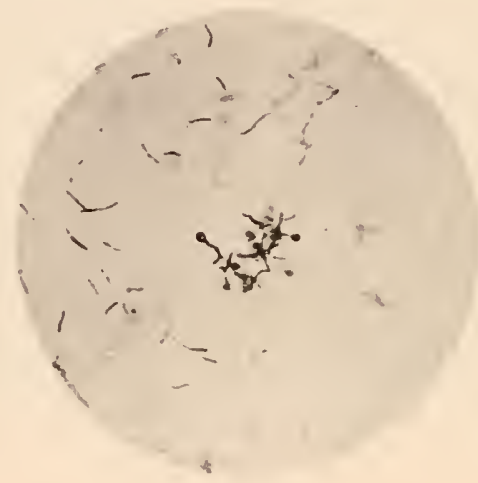

Fig. 278.

Actinomycose de l'homme (abcès pelvien), dissociation d'un grain. Crosses (gr. 1000 diam.).

deux premier's cas d'actinomycose chez l'homme, à donner nos soins à un malade dont l'histoire a été partiellement relatéc au Congrès d'hygiène de Londres, en 1891. Nous pouvons ajouter aujourd'hui à celte observation, alors incomplète, la relation des dernières phases de la maladie, ainsi que le résultat de nos cultures et des inoculations aux animaux.

Il s’agissait d'un individu ayant présenté les sỵmptômes de l'appendicite i rechutes. Après des alternatives de rémission et d'accidents aigus, un phlegmon se développa au niveau de la région iliaque droite el fut incisé parallèlement à lanreale crurale; le pus, cullivé, demeura stipile (novembre 1890). La platie bourgeonna et le malade reprit ses occupalions. Il sulssistait un trijet fistuleux peu étendu sans induration 
manifeste. Étonnés de la duréc de la cicatrisation et mis en éveil par l'observation de nos précédents malades, nous fûmes amenés à recucillir unc gontte du pus, qui suintait d'ailleurs en fort petite quantité de lit fistulc. Ce pus, étalé sur une lame de verre, nous laissa voir leux graains très pelits, qui furent aussitôt examinés. Le diagnostic d’actinomyeose établi, le malade fut tenu en observation. Il accusa, quelques mois plus tard, dans la région de l'aine gauche, des douleurs d'alıord légères, puis très vives, qui aboutirent à la formation d'une volumineuse collection fluctuante, sans rougeur de la peau, ni inflammation notable. On observait cependant une fièvre vive à exacerbation vespérale. L'incision donna issue à un nombre considérable de grains nettement isolés du volume d'une graine de pavot à celui d'une lentille, les uns jaunes, les autres noirs, d'autres enfin grisâtres, en suspension dans un liquide pyo-sanguinolent, qui se coagula aussitôt son émission, en emprisonnant tous les grains dans un réseau abondant de fibrine. Le foyer fut curé, tamponné à ciel ouvert et le malarle se remit assez rapidement de cette rechute.

La guérison complète des fistules ne put être réalisée; et après des alternatives variées et l'ouverture de nouveaux abcès dans la régior lombaire, le malade succomba à la cachexie. A l'autopsie, nous; pûmes constater que le foyer cæcal primitif s'était étendu par propagation à la fosse iliaque gauche : de nombreux trajets à parois grisâtres existaient en avant de la colonne vertébrale et formaient un trait d'union entre les foyers des deux régions inguinales; tout autour, des adhérences péritonéales et une péritonite chronique localisée.

Rien au foie, aux poumons, aux reins, ni à la rate. L'appendice iléo-cæcal fut trouvé augmenté de volume, infiltré, et atteint d'appendicite chronique : la maladie paraît avoir débuté par cet organe.

Nous avons ensemencé les grains sur des tubes d'agar ordinaire, qui restèrent à l'étuve environ trois semaines. Beaucoup se couvrirent de colonies banales de staphyllocoques pyogènes. Les grains restés indemnes furent portés à l'aide d'une aiguille stérilisée sur une lame 
de verre également stérile et dissociés dans un peu d'eau de façon à

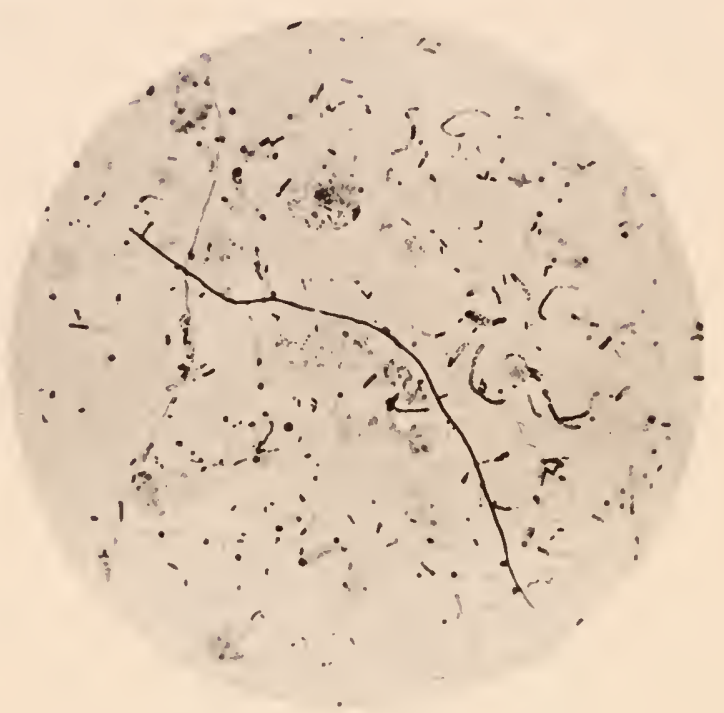

Fic. 279.

Actinomycose de l'homme. Culture dans le bouillon (gr. 1000 diam.).

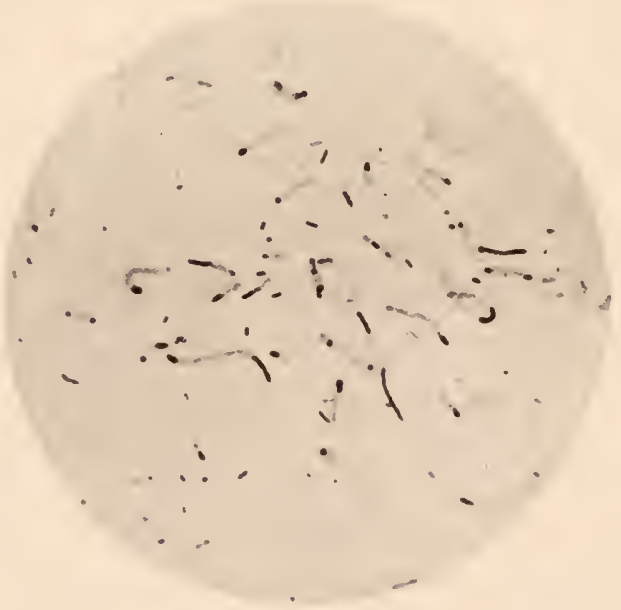

Fig. 280.

Actinomycose de l'homme. Culture dans le bouillon (gr. 1000 diam.).

obtenir une sorte de pâte, qui fut transplantée sur des tubes de sérum gélatinisé. 
Le développement des colonies se montra très lent. Le premier phénomène appréciable fut l'enfoncement des grains qui parurent s'implanter dans le sérum en augmentant de volume et s'entourèrent d'une aréole laiteuse.

Ces premiers rudiments de culture furent transplantés dans des tubes de bouillon et de sérum liquide et donnèrent alors les aspects que représentent les figures 279 et 280 . On ne rencontre guère, en effet,

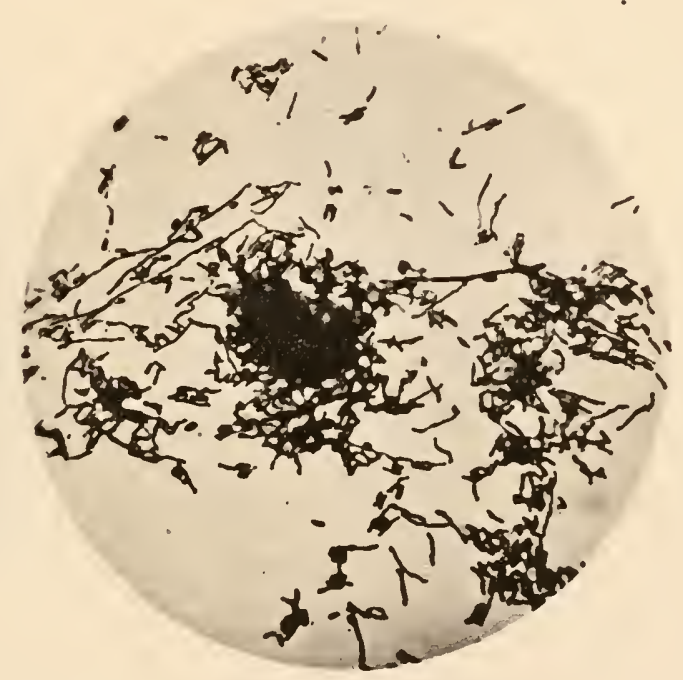

Fig. 281.

Actinomycose de l'homme. Culture dans le bouillen (gr. 1000 diam.).

dans les préparations, que des courts filaments isolés et incurvés de diverses manières, simulant à s'y méprendre de courts spirilles. Nous avons vu que ces aspects s'observaient aussi dans le pus à l'état frais.

Çà et là on rencontre quelques filaments allongés.

Des cultures plus âgées, provenant de notre cas d'actinomycose thoracique, nous ont donné des touffes d'Actino-Streptotrix (fig. 281), touffes analogues à certaines préparations de pus de l'actinomỹcose de l'homme (voir fig. 275 et 276 ). 
Nous arons transplanté ces cultures dans le bouillon sur l'igar et sur le sérum gélatinisé.

Jamais nous n'avons pu oblenir sur les milieux solides ces cultures viraces qui caraclérisen! les culmres des Streptotrix sapropliytes et de l'Actino-Streptotrix du bour.

Ce dernier se développe sur la gélose en formant des cotonies

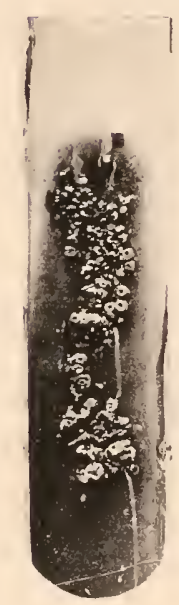

FIG. 282.

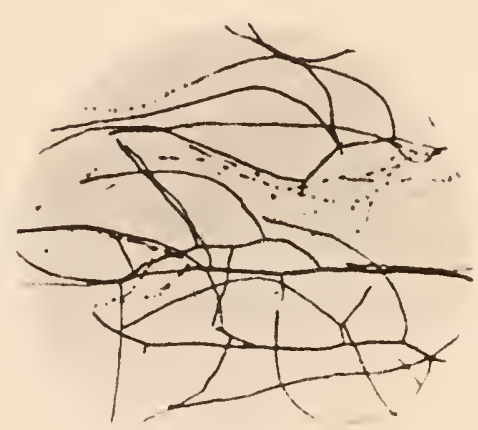

FIG. 283.

Aclinomycose du bouf (Yacé). Actinomycose de l'homme. Culture sur agar. Culture sur agar (hiral). Coloralion par la méthode de Gram (gr. 1000 diam.).

jammatres tris analogues alux colonies des Streptotrix de l'eau. La figme 282 représente une culture de l'aclinonycose du loenf provenant du

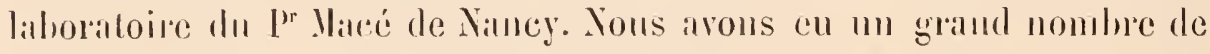
cultures anilogues provenaut du libboratoire de Y. Nocard. Ces culfures, quand alles sout anciennes, blanchissent a lemr surfice el se courrent d'une fine poussirire erayeuse.

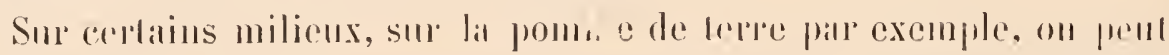
oblenir des cultures exuberantes dont la surface finil par prendre l'aspect l'une conche mine de fleme de soulire. 
La figure 284 représente une culture d'actinomycose de l'homme qui provient du laboratoire de kíal, de Pragne. Celte culture s'est montrée en tous points identique à celle que nous possédions de lakelinomycose du bouf. L'examen de cette culture sur lame de verre doune d'ailleurs, figure 285 , des préparations absolument analogues ì celles des Streptotrix Saprophyles (voir fig. 255).

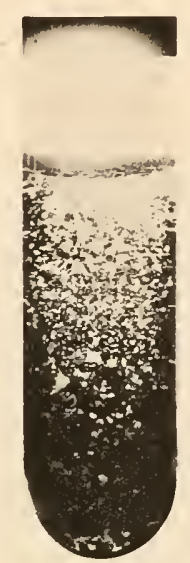

FIG. 285.

Actinomycose de l'homme. Culture dans le bouillon.

Ces différences constantes entre les cultures figurées page 158 et celles que nous avons obtenues de diver's cas d'actinomycose humaine nous domnent à penser que, dans les cas d'actinomycose viscérale qui ont servi de point de départ à nos tentatives de cultures, il s'agissait d’un champignon d'une origine diflérente.

Les cultures de l'actinomyeose de l'homme se déreloppent dans le bonillon sous forme de petits llocons d'un blane jaunitre qui s'entourent d'un fin chevelu (fig. 285), et offrent une certaine analogie arec les cultures de strptotrix sur le mème milieu (voy. fig. 252). le bouillon reste limpide. 


\section{ASSOGIATIONS CRYPTOGAMIQUES DE L'ACTINOMYCOSE}

L'Actinomyeces est assez fréquemment associé, dans les forer's suppurés, à des microles progènes, auprés desquels il se développe libroment. Mais, à còté de cette associalion hilliale de l'itetinomyces et des staphylocoques pyogènes, nous croyons deroir signaler un commensa-

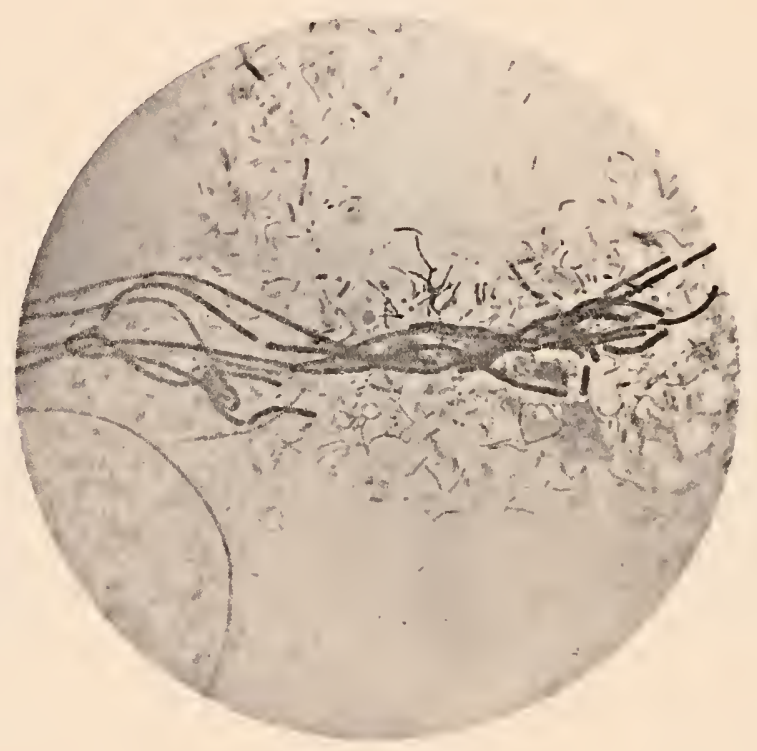

FIG. 286.

Actinomycose de l'homme. Dissociation d'un grain. Leptotrix el Streptotrix (gr. 1000 diam.). lisme plus rare et aussi plus digne d'intérèt, celui du Leptotrix buccalis. Nous l'avons observé chez deux malades différents.

Le premier cas se rapporte a ce malade dont l'histoire est relatée plus haut et qui succomba il une infection actinomycosique viscérale à foyers multiples.

Chez ce sujet, certains foyers contenaient à l'état de pureté l'Actinostreptotrix, tandis que d'autres, ì l'examen des grains, présentiient une série de filaments enroulés en spirale. Ces filaments présentaient parfois une longueur énorme; ailleurs ils se montraient segmentés en 
courts articles (fig. 284). Mais toujours ils demeuraient distincts des Streptotrix actinomycosiques, reconnaissables à leurs dimensions beaucoup plus grêles, auxquels ils se trouvaient mèlés. Ces filaments bactériens étaient souvent enroulés d'une façon très bizarre, comme en témoignent les fig. 287 et 288 .

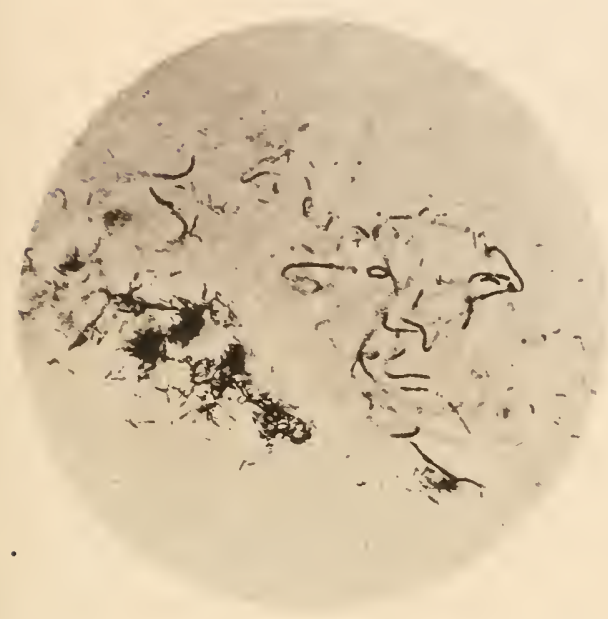

FLG. 287.

Actinomycose abdominale. Actinomyces et Leptotrix (gr. 500 diam.).

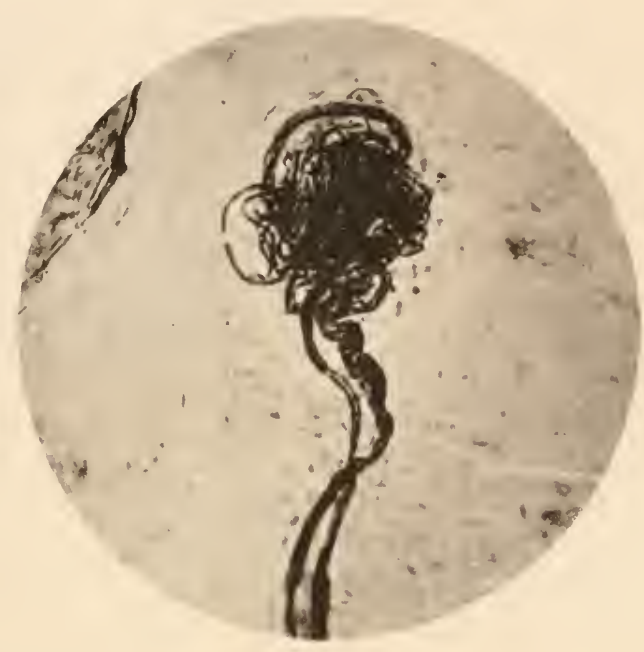

Fig. 288.

Actinomycose de l'homme. Infection mixte. Dissociation d'un grain. Leptotrix enroure en glomérule (gr. 1000 diam.).

Cette dernière figure est particulièrement curieuse, car le Leptoìrix y a pris pour ainsi dire la forme d'un glomérule.

Les dimensions et l'aspect de ces filaments rappelaient assez exactement ceux du Leptotrix buccalis.

Afin d'en déterminer la nature, nous avons cherché a étudier le Leptotrix buccalis.

Nous avons particulièrement rencontré ce champignon dans les produits caséeux des dents cariées et dans les concrétions amygdaliennes. Nous avons obtenu diverses préparations donnant des aspects variables.

Les fig. 289 et 290 montrent, sans coloration, le Leptotrix buccalis au grossissement de 120 et de 400 diamètres. On remarque, dans ces 
préparations, de longs filaments en faisceaux enchevêtrés, sans trace

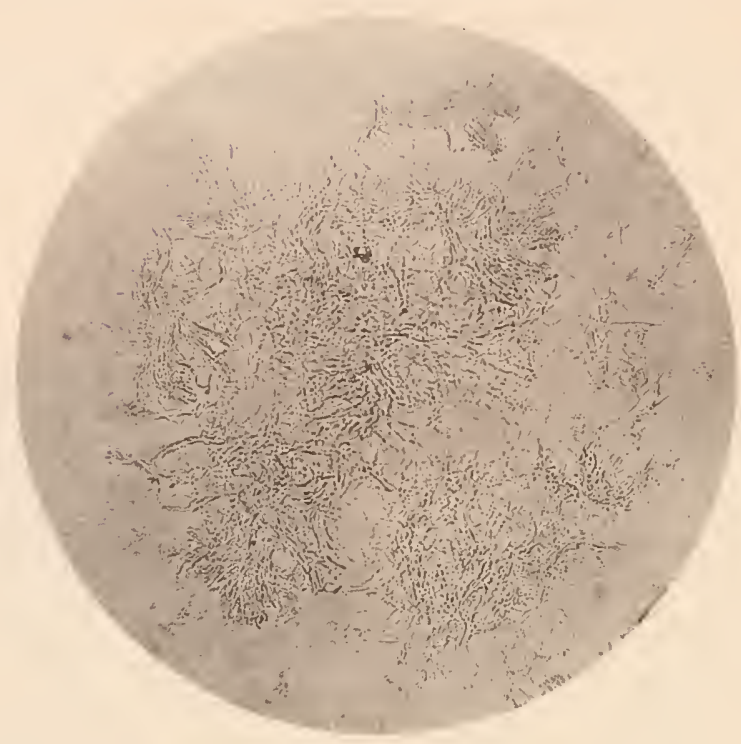

Fig. 289.

Leptotrix buccalis. Dent cariée (gr. 120 diam.).

de ramifications. Il ne faut pas confondre ces Leptotrix avec d'autres

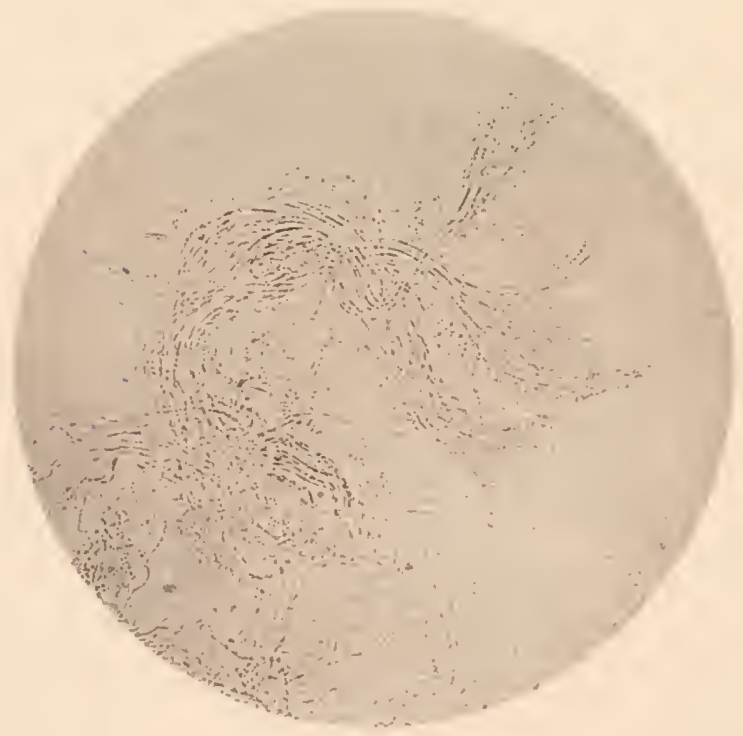

FIg. 290.

Leptotrix buccalis. Carie dentaire (gr. 400 diam.).

parasites que l'on rencontre également dans le tartre dentaire, et 
tels que la colonie représentée fig. 291, au grossissement de

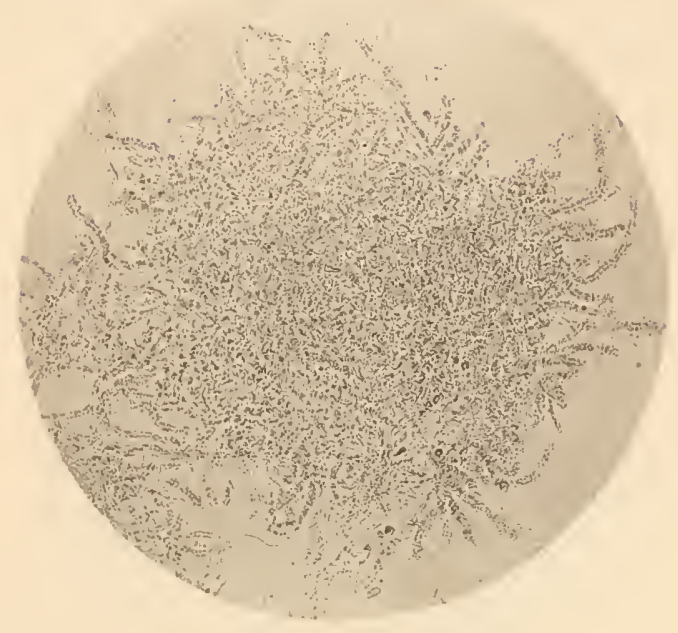

Fig. 291.

Mycose buccale (muguet?) (gr. 200 diam.).

200 diamètres. La préparation n'est pas colorée. Il s'agit d'une moisiṣșure analogue au champignon du muguet.

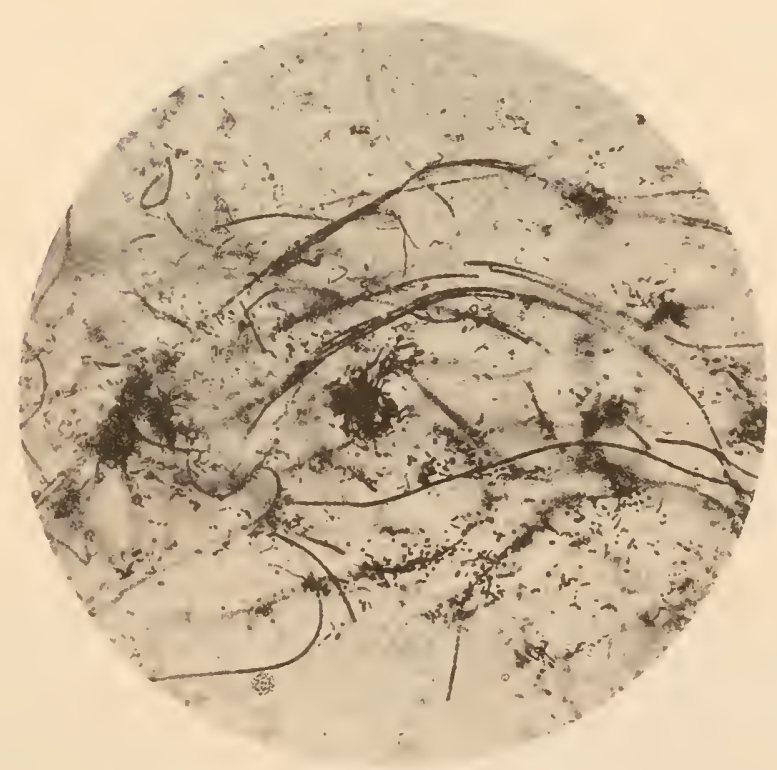

Fig. 292

Mycose pharyngée. Concrétion de l'amygdale. Dissociation (gr. 10190) diam.). 
L'analogic du Leptotrix de provenanec buccale avec le Leptotrix observé dans notre cas d'actinomỵcose abrlominale est particulièreInent frappante quand on colore les préparations par les méthodes de Gram ou de Weigert.

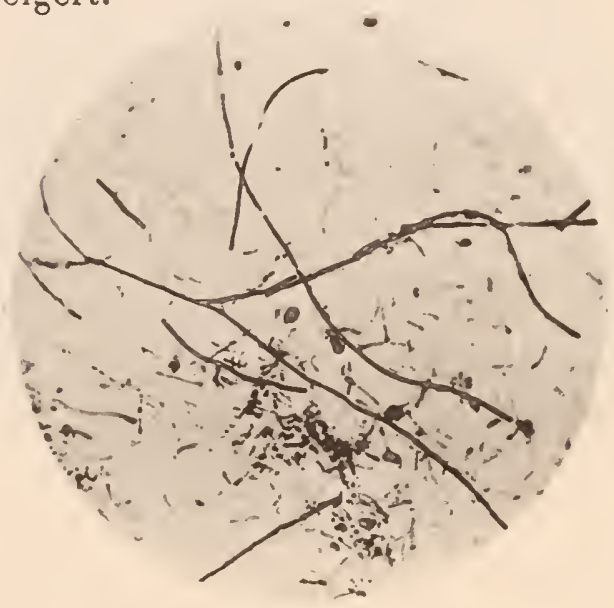

Fig. 293.

Actinomycose de l'homme. Infection mixte. Culture de Leptotrix et de Streptotrix (gr. 1000 diam.).

On obtient alors avec le Leptotrix buccalis des images analogues à

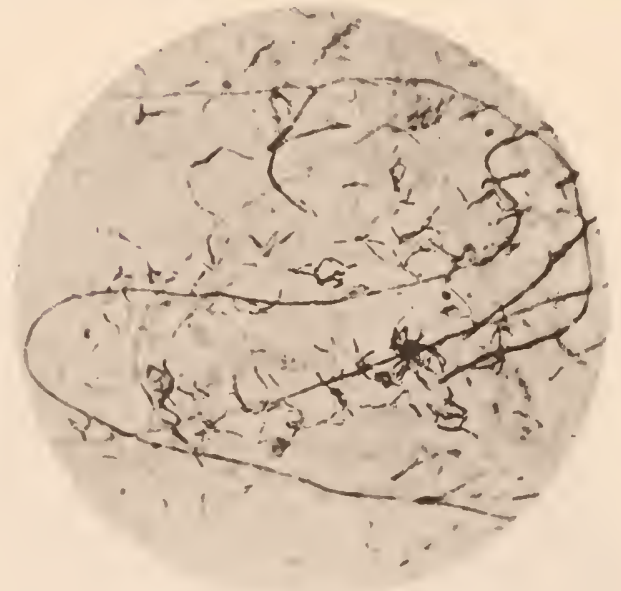

Fic. 294 .

Achmonycose de l'homme. Infection mixte. Culture do Streptulrix et de Leptotrix (gr. 1000 (liamı.).

velle de lat lig. 292, dont les tiliments ollient mue similitude d'aspect

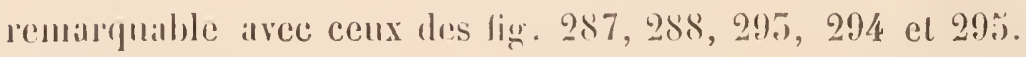

Nous avons cultivé ces granins d'infection mixte comme les grains 
oủ le Streptotrix se trourait ì l'état de purelé, et nous avons obtenu sur le bouillon des cultures où le Leptotrix s'est développé conjointement au Streptotrix (fig. 295 ì 295). Nous alrons mème rúussi à obtenir quelques cultures de Leptotrix sur milieu liquide.

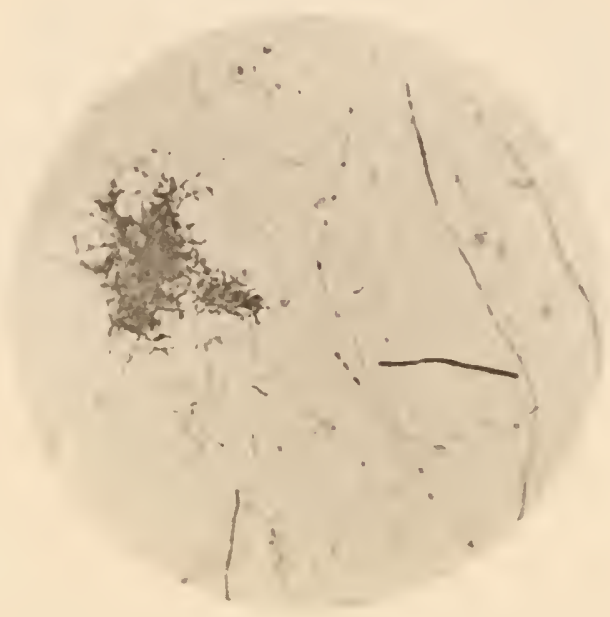

Fic. 295.

Actinomycose de l'homme. Infection mixte. Culture de Streptotrix ef de Leptotrix (gr. 1000 diam.).

\section{NOUVEAU CAS DINFECTION WIXTE (ACTINOMYGES ET LEPTOTRIX)}

Au moment où nous terminions ce chapitre, nous arons observẻ un nouvel abcès de la joue, développé chez une malaule de Charleville, et qui donna à l'incision un pus séro-sanguinolent contenant plusieurs grains. Le diagnostic d'Actinomycose nous sembla probable au premier aspect, d'autant mieux que les parois de l'abcis étaient indurées et se reliaient, par un cordon du volume d'une plume de corbeau, ì la mâchoire supérieure, au voisinage de la seconde grrosse molaire. Le pus fut recueilli dans un tube stérilisé.

La dissociation des grains nous réservait une surprise plus grande encore que celle de notre cas d'Actinomycose abdominalc, car ces grains étaient formés principalement de paquets ẻnormes de l.eptotrix enroulćs comme des nattes de chereux et offrant les dispositions bizarres que représentent à des grossissements variés les figures $\mathbf{2 9 6}$, 
297 et 298 . Ces filaments, qui ne semblent pas ramifiés dichotomique-

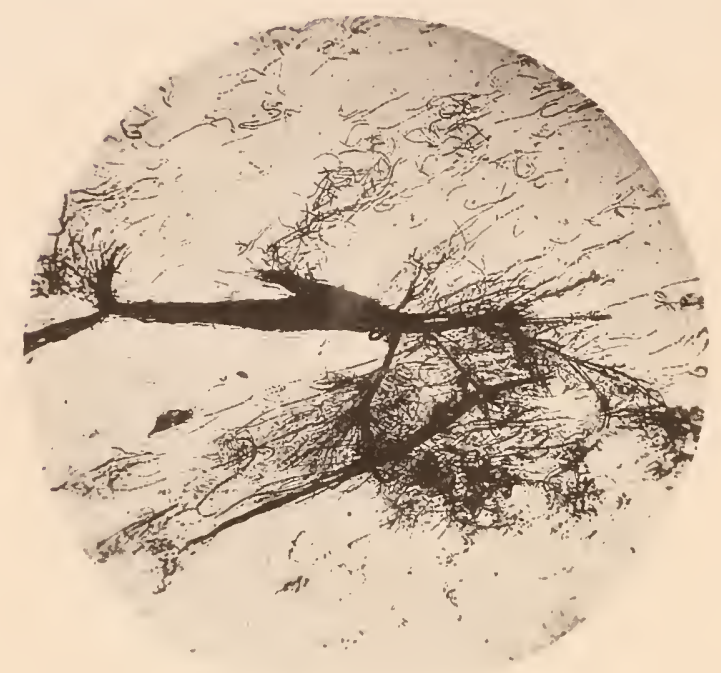

Fro. 296.

Abcès de la joue. Leptotrix en faisceaux (gr. 150 diam.).

ment, sont plus volumineux peut-être que dans le cas signalé plus haut.

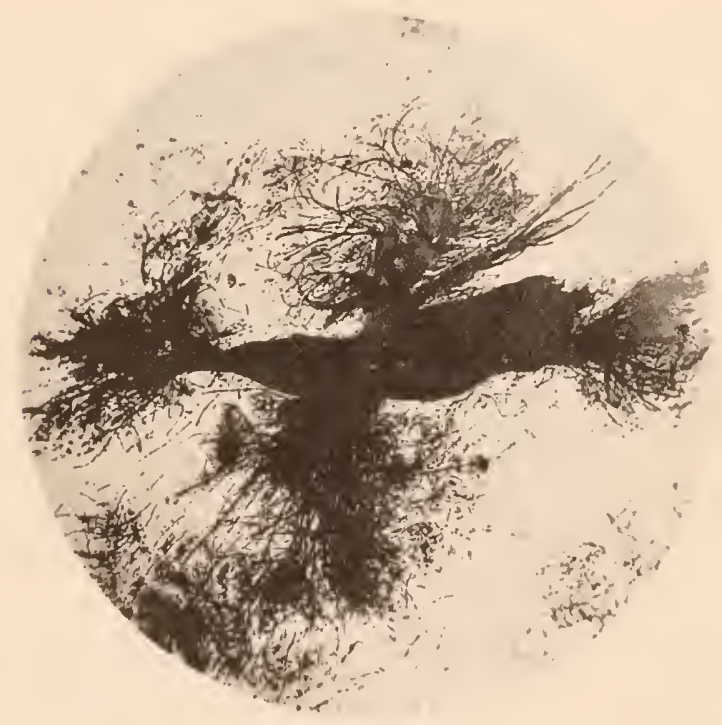

Fig. 297.

Abcès de la joue. Leptotrix en faisceaux (gr. 200 diam.).

A un grossissement de 1000 diamètres on remarque qu'ils sont 
d'épaisscur assez inégale. On observe au milieu d'eux un grand

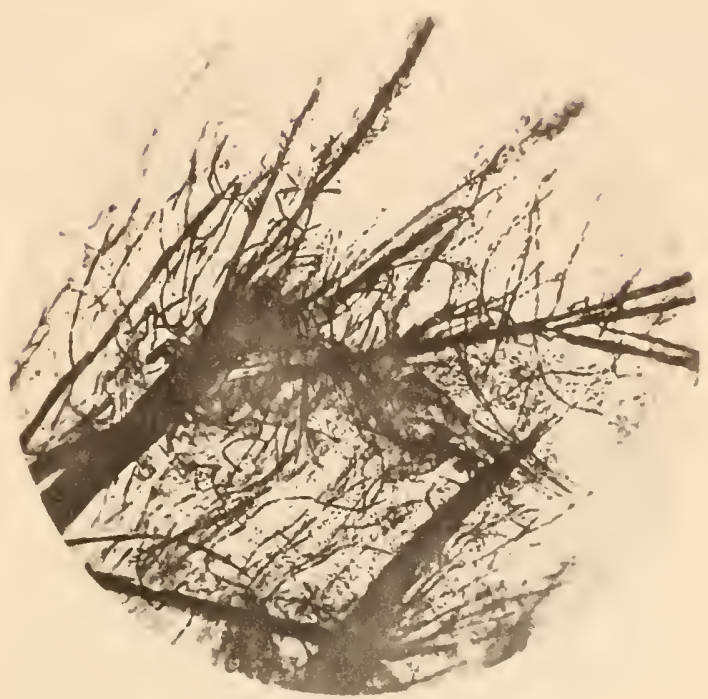

Frg. 298.

Abcès de la joue. Détail d'une touffe de Leptotrix (gr. 600 diam.).

nombre de petits bâtonnets irréguliers qui paraissent être des formes

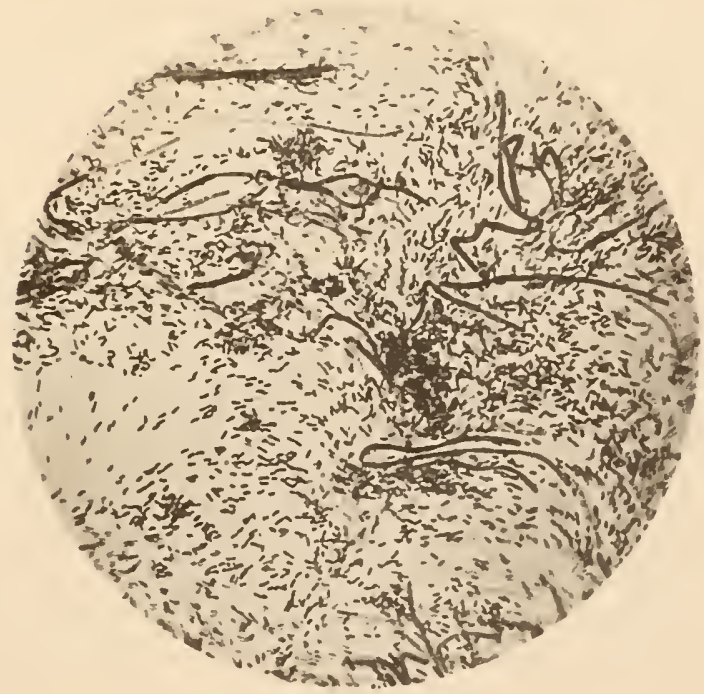

FIG. 299.

Abcès de la joue. Leptotrix et courts filaments (gr. 1000 diam.).

très jeunes d’Actinornyces analogues aux éléments représentés 
plus haut. Les cultures, qui ne sont failes que depuis une quinzaine de jours, ne donnent pas jusqu'ici de développement sur l'agar-agar; elles seront trinsplintées sur le sérum. Ces particulirités témoignent que le pus ne contenail pas de nicrobes pyogènes vulgaires.

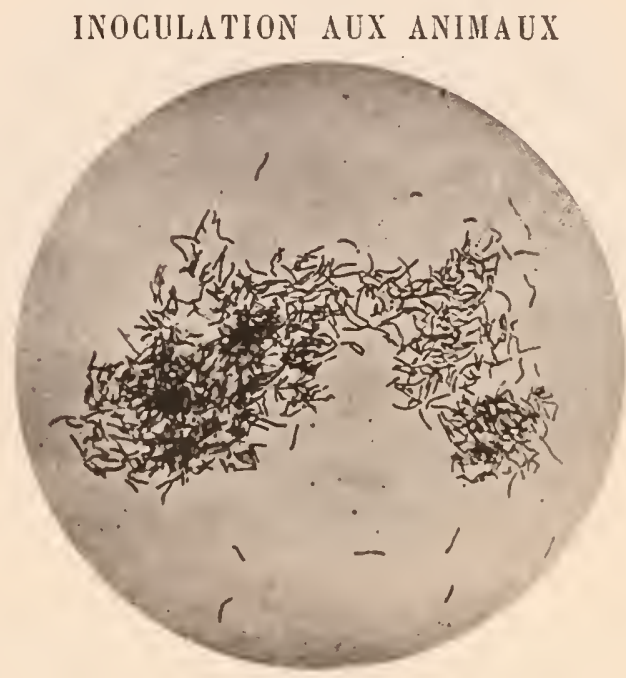

FIG. 300 .

Actinomycose de l'homme. Inoculation du Streptotrix dans le péritoine du lapin (gr. 1000 diam.).

Nous avons fait différentes tentatives d'inoculation aux animaux.

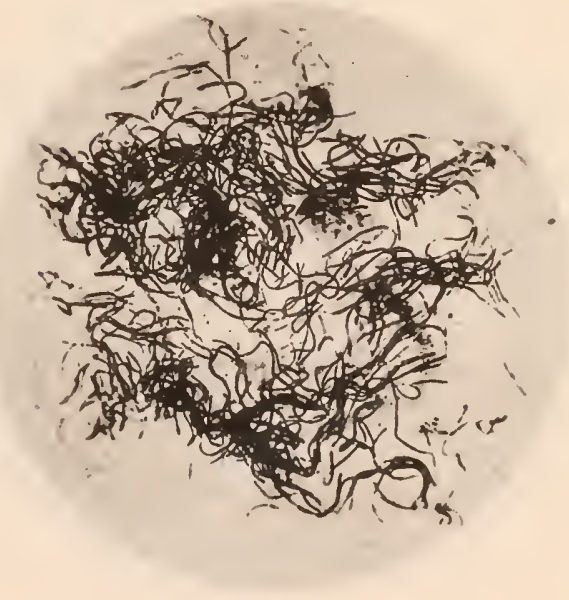

FIG. 301.

Actinomycose de l'homme. Infection mixte. Inoculation du Leptotrix dans le péritoine du lapin (gr. 500 diam.).

Les résultats les plus satisfaisants nous ont été donnés par l'injec- 
tion dans le péritoine des lapins d’une ímulsion de grians frais disconciés et pilés dans de l'cau stririliscé.

Nous sommes ainsi arrivis a démminer dans cerlains cals la production d’une péritonite actinomyesosique allhésive dillisse; le liquide péritonéal foisonnait de courts éléments (fig. 500) amalogues à ceux des cultures dans le bouillon.

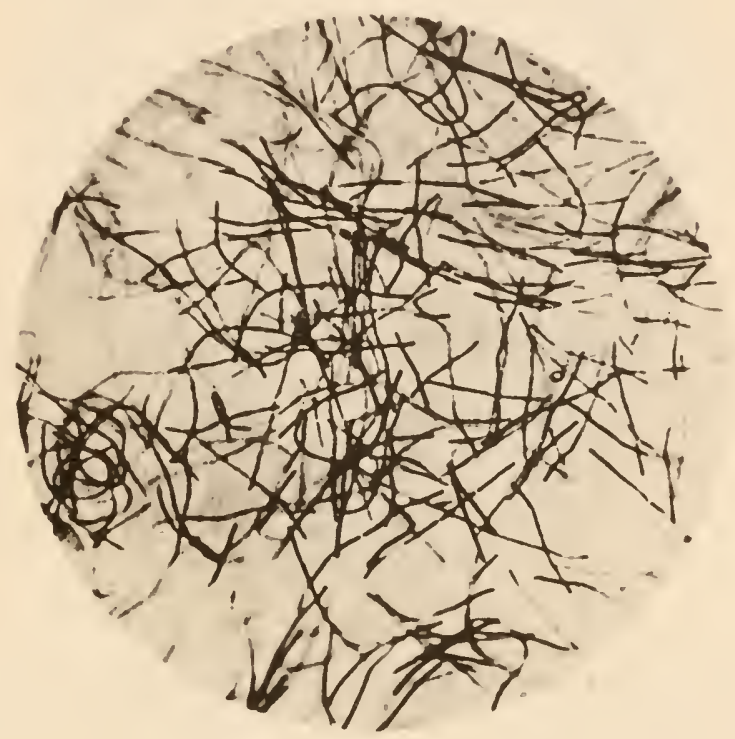

Fic. 302.

Actinomycose de l'homme. Infection mixte. Inoculation du Leptotrix dans le péritoine du lapin (gr. 500 diam.).

Dans d'autres cas il nous est arrivé de déterminer une infection péritonéale pure par le Leptotrix, comme le témoignent les figurcs 301 et 302. Cette action pathogène du Leptotrix extrait du cas d'Actinomycose mixte viscérale que nous venons de signaler est très intéressante; l'inoculation au lapin prouve que, chez notre malade, les accidents obscrvés étaient dus tout aussi bien au Leptotrix, dont l'origine buccale est fort probable, puisqu'il y a eu infection par l'appendice iléo-cæcal, qu'à l'Actinostreptotrix. 


\section{FARGIN DU BOEUF}

Le Farcin du bœuf est une maladie chronique, qui paraît avoir été

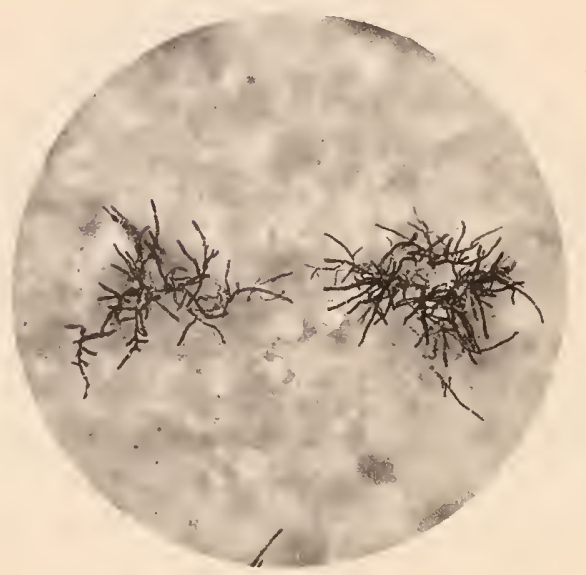

FIG. 503.

Farcin du bœuf. Pus (Nocard). (Gr. 600 diam.)

autrefois fréquente en France, et sévit actuellement à la Guadeloupe.

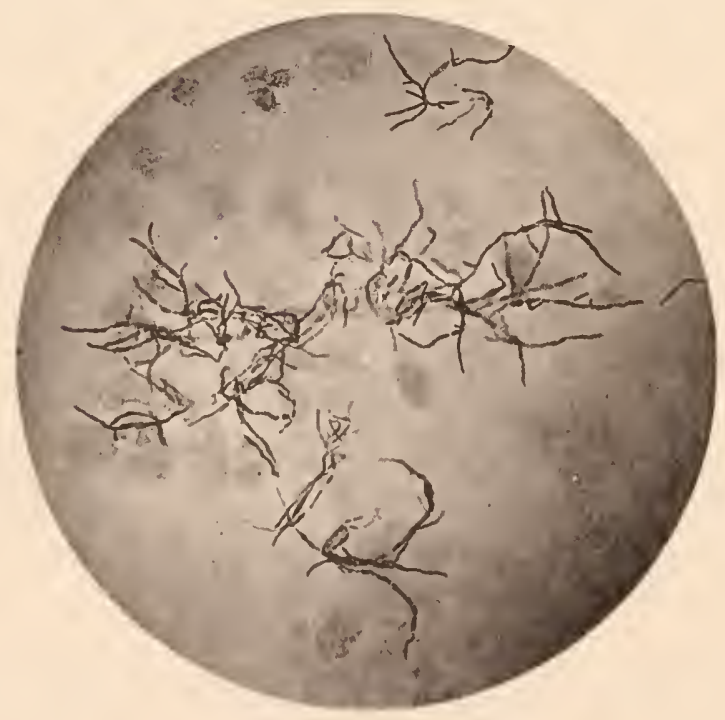

FIG. 304.

Farcin du bœuf. Pus (Nocard). (Gr. 800 diam.) 
Le Farcin du bœuf est caractérisé par une inflammation suppurative des vaisseaux et des ganglions lymphatiques superficiels; cette lym-

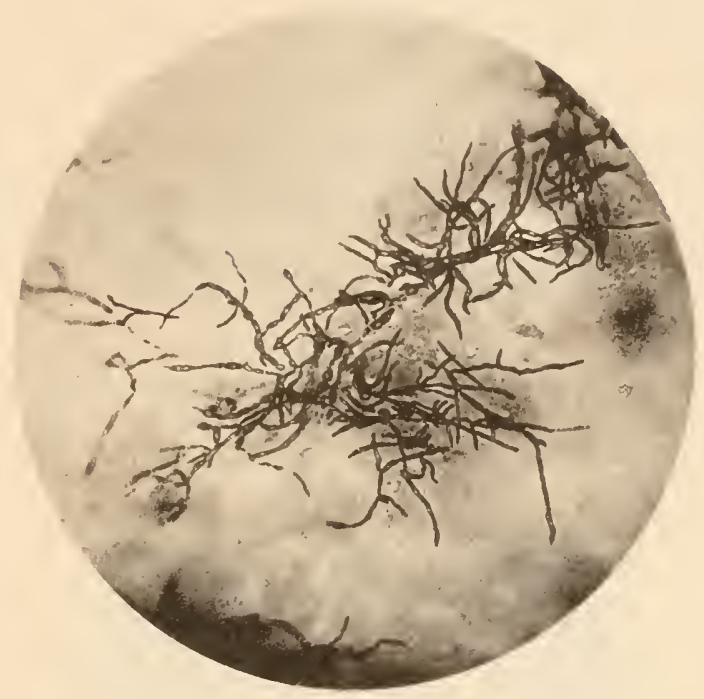

FIG. 305.

Farcin du bœuf. Pus (Nocard). (Gr. 800 diam.)

phangite entraîne rarement la mort, mais se traduit à la longue par des symptômes d'amaigrissement et de phtisie (Cruzel).

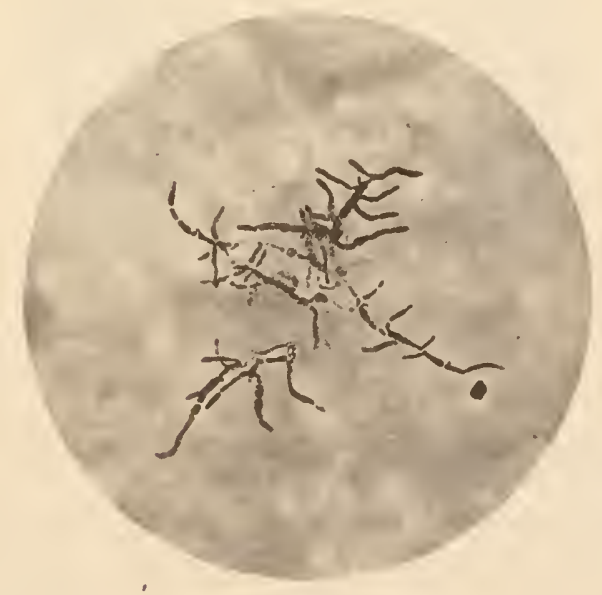

Fig. 306.

Farcin du bœuf. Pus (Nocard). (Gr. 1000 diam.)

Le Farcin du bœuf a été autrefois confondu avec les manifestations farcineuses de la morve et avec la tuberculose. C'est au pr Nocard 
qu'appartient l'honneur d'avoir dénıntré sa spécificité en découvrant chez le bœuf farcineux de la Gradeloupe le parasite de celte maladic.

Le Farcin du bœuf siège ordinairement aux membres et sous le ventre, où il donne lieu à la formation de cordes ou de tumeurs ordinairement dures, quelquefois fluctuantes; ces cordes se dirigent toujours vers les ganglions lymphatiques.

Lorsqu'on ouvre un de ces abcès, il s'en écoule une matière blanchâtre, crémeuse et sans odeur.
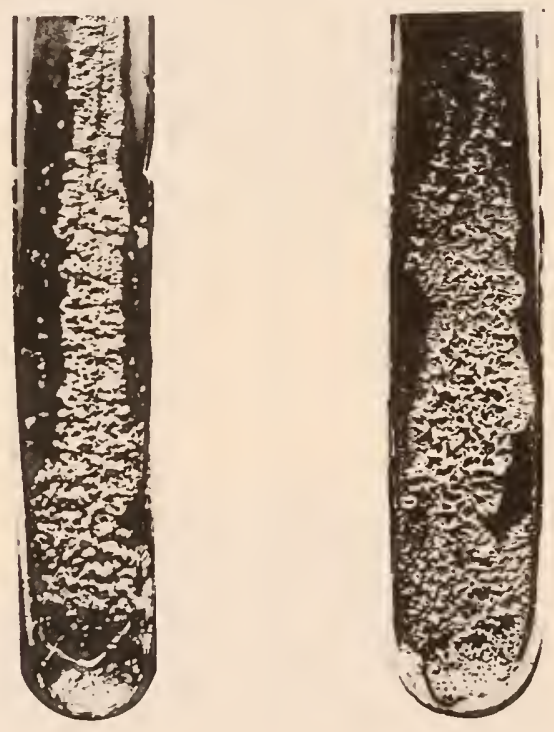

Fig. 307 et 307 bis.

Farcin du bœuf. Cultures sur gẻlose àgées de 5 mois (Nocard). (Grandeur naturelle.)

Quand on pratique l'autopsic, il est de règle de trouver les poumons, le foic, la rate et les ganglions farcis de pseudo-tubercules.

Nocard, colorant par la méthode de Weigert des lamelles de pus desséché que lui avait confiées M. Couzin, découvrit un fiı et long bacille, en amas enchevètrés d'une façon inextricable et ressemblant à des “fagots épineux» (lig. 503 à 506). On remarque très nettement, sur ces quatre préparations, qui nous ont été confiées par le Pr Nocard, 
les caractères du parasite. On l'a depuis classé parmi les Streptotrix.

Les tubercules des viscères, dont le centre est ramolli et liquide, contiennent les mêmes amas bactériens en forme de " broussailles ». La culture du microbe se fait aisément entre 50 et 40 degrés sur tous les milieux.

Sur la gélose (fig. 507) le microbe se développe en petits amas d'une teinte blanc jaunâtre, à surface mamelonnée et poussićreuse. A là longue, ces plaques d'aspect lichénoïde se réunissent et se confondent,

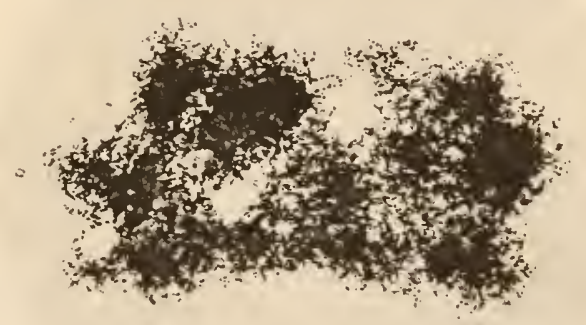

Fig. 308.

Farcin du bœuf. Culiure sur bouillon (Nocaru,. (Gr. 400 diam.)

donnant à l'ensemble de la culture l'apparence d'une membrane épaisse et grossièrement plissée (Nocard).

Sur la pomme de terre la culture est également rapide.

Dans le bouillon, il se produit des amas blanchâtres, dont la plupart tombent au fond du ballon, tandis que d'autres forment une pellicule à la surface du liquide (Nocard). Une de ces colonies, provenant du bouillon, est représentée, après coloration à la fuchsine, fiğ. 508 .

L'examen des cultures, quel que soit le milieu, montre la même disposition que plus haut : amas lilitmenteux samifiés et encherètrés. 


\section{ACTION PATHOGENE}

Le Streptotrix du farcin du bœuf est inoculable, surtout au cobaye et au lapin, dans le péritoine desquels il détermine en 9 à 20 jours une péritonite mortelle. Le péritoine est envahi par des sortes de tubercules au centre desquels pullule le microbe (fig. 309 et 310 ).

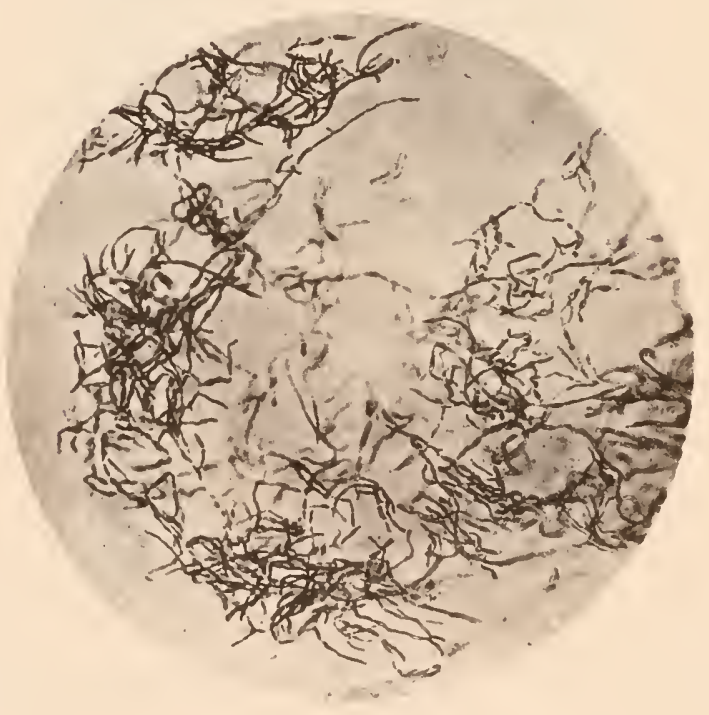

FIG. 309.

Péritonite tarcineuse expérimentale (Lapin). (Nocard.) (Gr. 700 diam.)

L'injection intra-veineuse donne lieu à des lésions simulant la tuherenlose miliaire aiguë. La mort est rapide chez le cobaye.

le houf sucembe rarement. Il en est de mème du mouton. Le chien, le chat ef le cheval sont réfractitires. 
Il se produit cependant chez eux, à la suite de l'inoculation sous-cutanée, des abcès qui se vident et se cicatrisent rapidement.

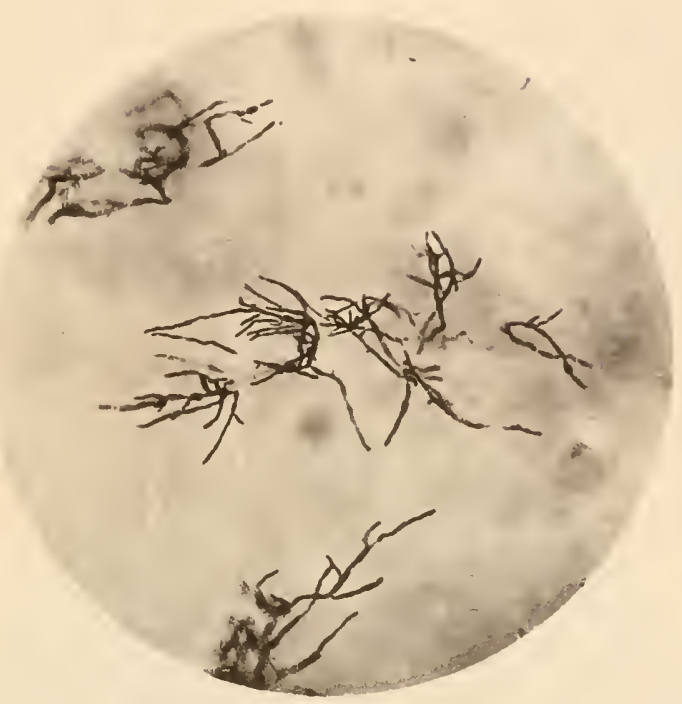

Fig. 310.

Péritonite farcineuse expérimentale. Lapin. (Nocard.) (Gr. 800 diam.)

Chez les animaux non réfractaires, la cicatrisation n'est qu'apparente et l'on observe bientôt une lymphangite progressive et de nouveaux abcès, qui peuvent déterminer une infection mortelle. 


\section{PIED DE MADURA}

L'affection connue sous le nom de Pied de Madura se développe particulièrement dans l'Inde.

Elle est caractérisée par un gonflement indolore et diffus des téguments du pied. Au bout d'un certain temps on voit se développer de petites tumeurs, offrant le volume d'un pois ou d'une noisette.

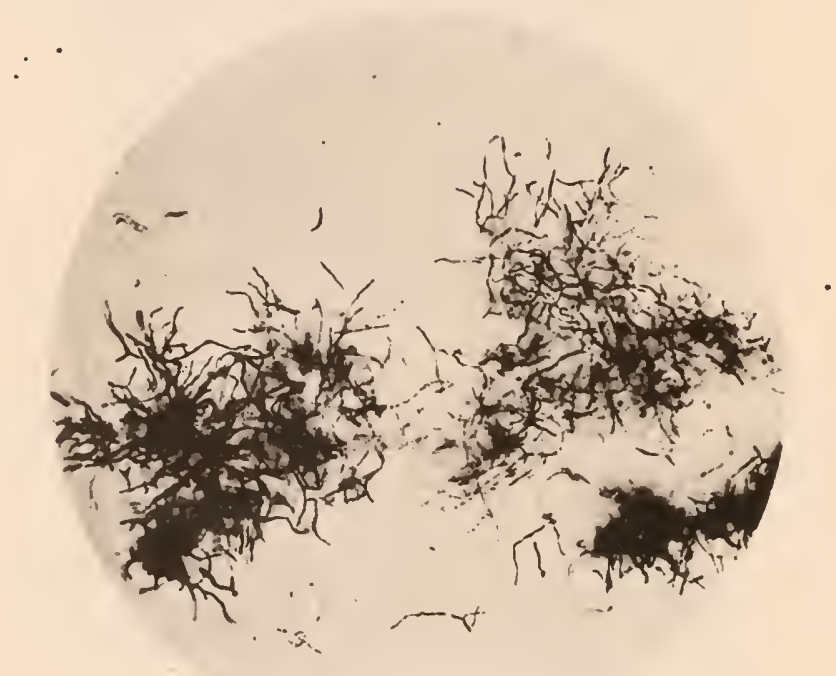

FIG. 311.

Pied de Madura. Pus. Dissociation (Vincent). (Gr. 700 diam.)

Ces nodosités peuvent rester dures ou se ramollir peu à peu. Elles s'abcèdent généralement et donnent issue à un pus contenant de petits grumeaux grisâtres. Le pied continue à grossir, puis se couvre de bulles qui s'ourrent successivement et donnent lieu à des orifices fistuleux multiples. La maladie est incurable. La mort peut survenir par cachexie ou a la suite de complieations infectieuses variables (Érýsipèle, etc.).

Les grumeaux que l'on peut recueillir dans le pus des nodosités ressemblent fort aux grains de l'Athinomycose. Lorsqu'on les soumet 
a l'examen microscopique après avoir étalé en couche mince l'un de ces grains casécux sur unc lamelle, on constate que la presque totalité de la préparation est, à un grossissement de 400 diamètres, parsemée d’innombrables filaments enchevêtrés.

Ces filaments, étudiés de plus près, se montrent sinueux et ramifiés; ils oflrent une disposition rajonnéc comme dans l'Aclinomycose, mais on n'y voit pis de renflements en massue ni de crosses. Vincent a découvert le parasite de la maladie, qu'il a dénommé "Streptotrix Mlulura ». M. Metschnikofl' a cu l'obligeance de nous confier les prépa-

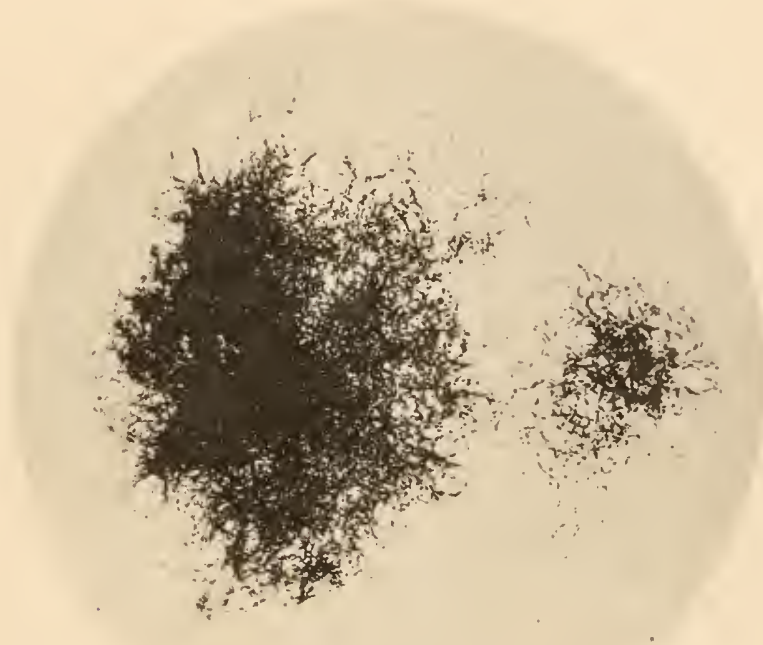

FIG. 312 .

Pied de Madura. Culture sur bouillon (Vincent). (Gr. 100 diam.)

rations de M. Vincent, qui ont été déjà dessinées dans les Annales de l'Institut Pasteur (26 mars 1894 - p. 129).

La figure 511 représente la photographic d'une préparation faite à l'aide d'un grain écrasé.

On voit que les filaments mycéliens ressemblent beaucoup à ceux du Farcin du bœuf et surtout aux filaments de l'Actinomycose. Si l'on remarque qu’il existe dans le Pied de Madura de véritables grains, et non 
pas seulement du pus crémeux, comme dans le Farcin du beuf, on est

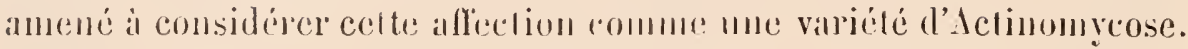

Cultures. - Las premieres culluressolulinment assez dilficilement. Les milieux qui convinnent le mienx sont les influsions régélales légèrement acidres de foin el de pitille additimmées d'un peu de gilycérine et de ghlucose ('́ jour 100).

Sur le bunilon, il se forme des boules minuscules grisitres ou blan-

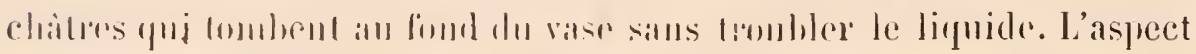

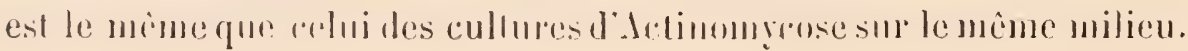

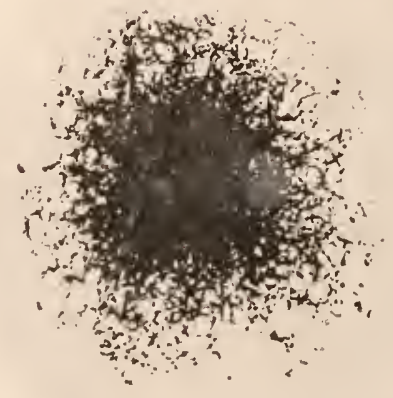

Fis. 315.

Pind de Matlura, Cullure sur benillon (Vincent). (Gr. 250 diam.)

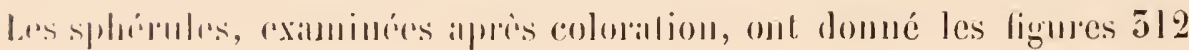
1.151 .5$.

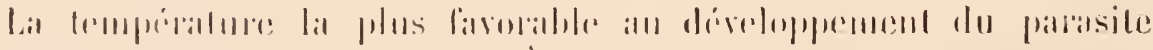

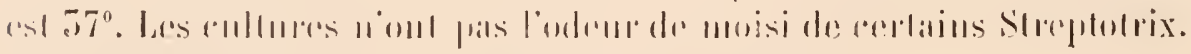

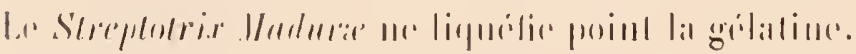

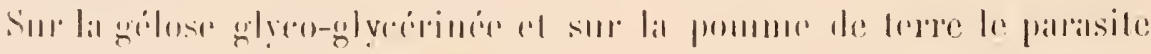

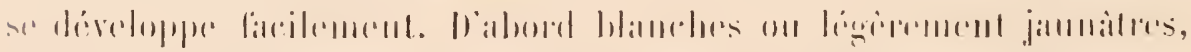

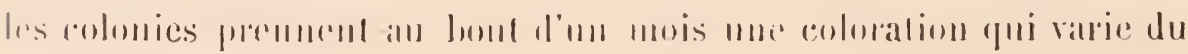
rare all rongere rif.

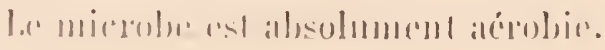


Lorsifue l'on dissocie l'mue des colonies el que l'on en étale une conche mince sur me lamelle, on obtient des filaments offrant des gramulations colories, tels qu’ils sont représentis lignre 51 .

La sporulation est très atche et a lieu spécialement dians les points où le contact arec l'air se fait facilement. Il existe surtont des spores a la surface des cultures sur bonillon on sur pomme de terre. Mais on en trouve également dans le dépôt rassemblé an fond des tubes.

Les spores sont brillantes et se colorent par la méthorle de Gram. Elles sont d'un tiers plus longues que larges.

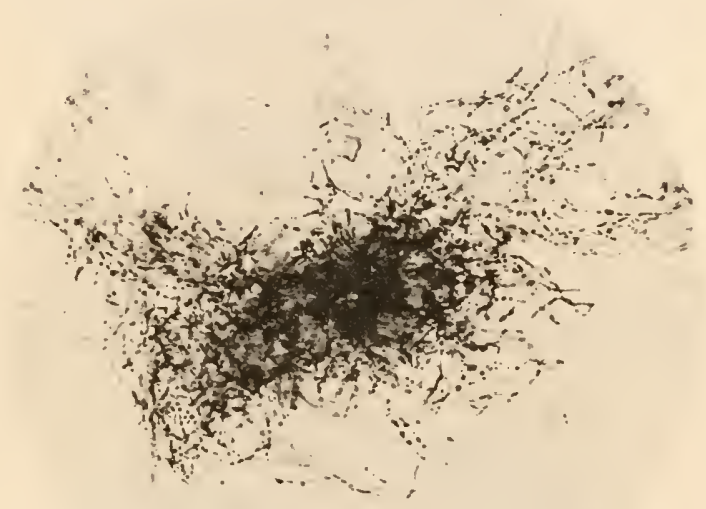

Fig. $31 \%$.

Pied de Madura. Gulture. Bissociation (Vincent). (fir. 700 diam.)

Les inoculations du Streptotrix Hadurx anx animans nout pas donné de résultals positifs.

Si l'on veut étudier les lésions histologirgues produites par le S'trephotrix Madure, il faut exciser des framents culanés alssez volmminenx et en pratiquer des coupes très minces.

Les nodules peuvent ètre comparós à de vériblules fubereules. Au centre on observe le grain proprenent dit, inlillé de filaments mycéliens (fig. 5lö), et antom un anas de cellules cmbryonnaires analogues à celles qu'on remarque au nirean de tont lovgra 
inflammatoire. Cers nodules sont ì leur contre très frialles.

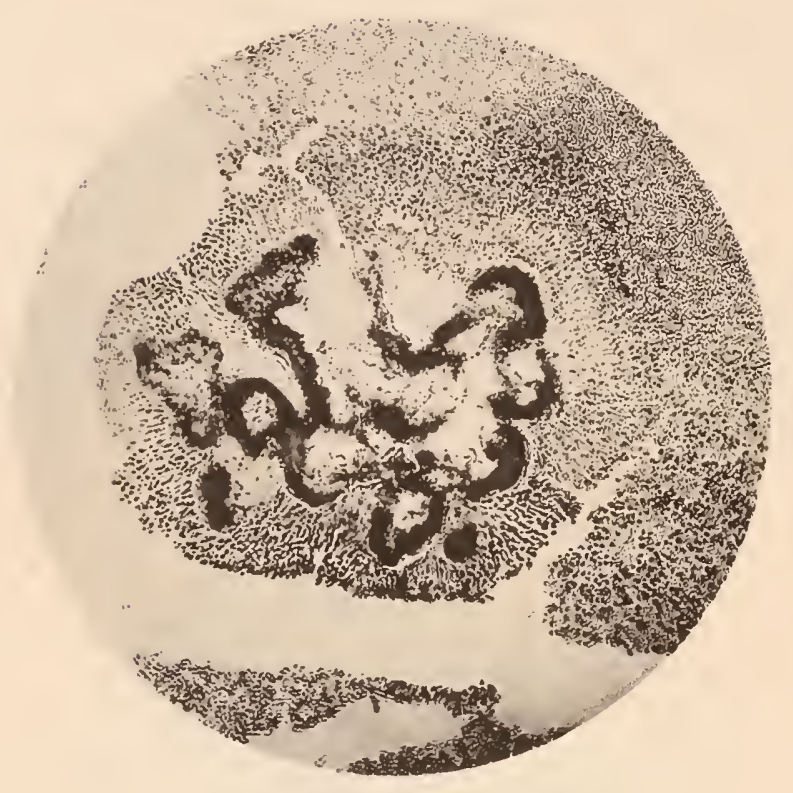

Frg. 315.

Pied. de Yadura. Coupe (Vincent). (Gr. 100 diam.)

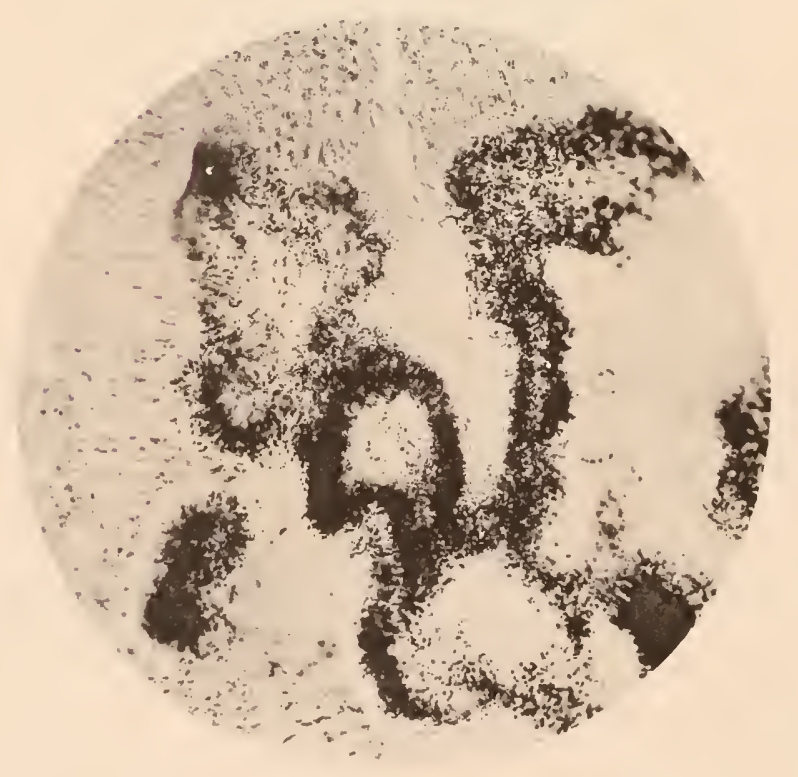

FiG. 510.

Pied de Madura. Conpr (Vincent). (Gr. 225 diam.)

Les cellules deviennent ver's lat périphérie plus espacées et plus volu- 
mineuses. Elles offrent mème une disposition rajonnée et un aspect épithélioïde (fig. 516, 517 et 521).

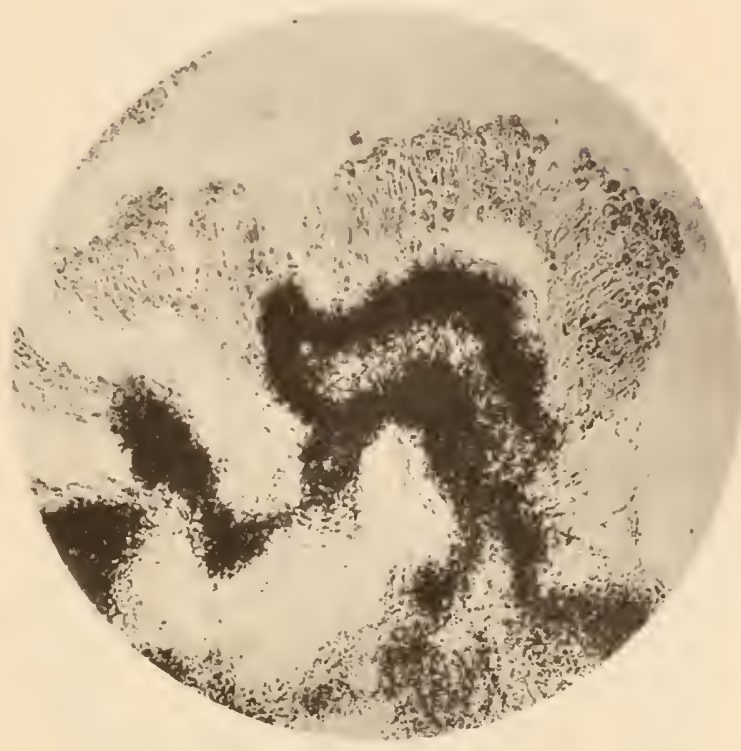

FIG. 317.

Pied de Madura. Coupe (Vincent). (Gr. 250 diam.)

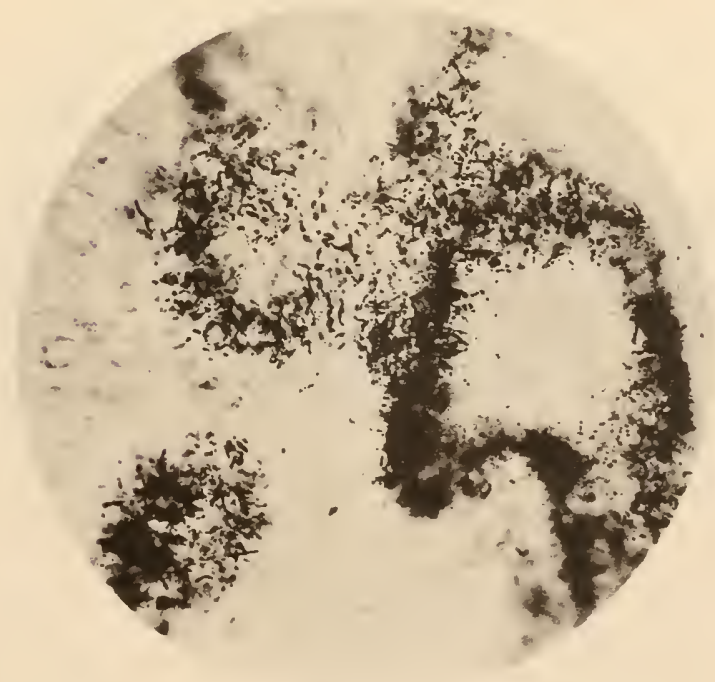

FIG, 318.

Pied de Madura. Coupe (Vincent). (Gr. 500 diam.)

Si l'on examine à un plus fort grossissement (כ00 diamitres par 
exempla) la piere represintéc fig. 5 li, on observe alors très nettement

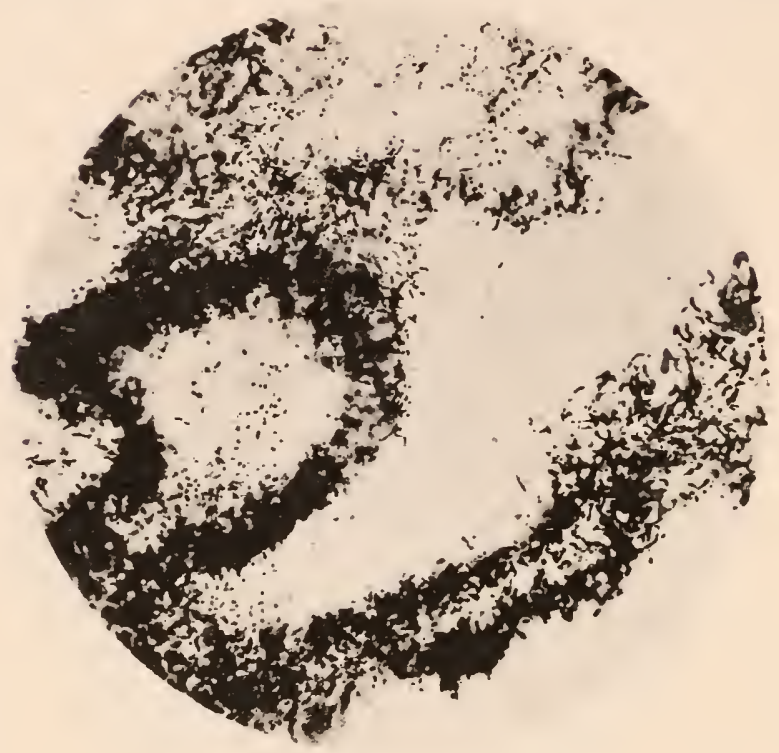

Fic. 319.

Fied de Madura. Coupe (Vincent). (Gr. 500 diam.)

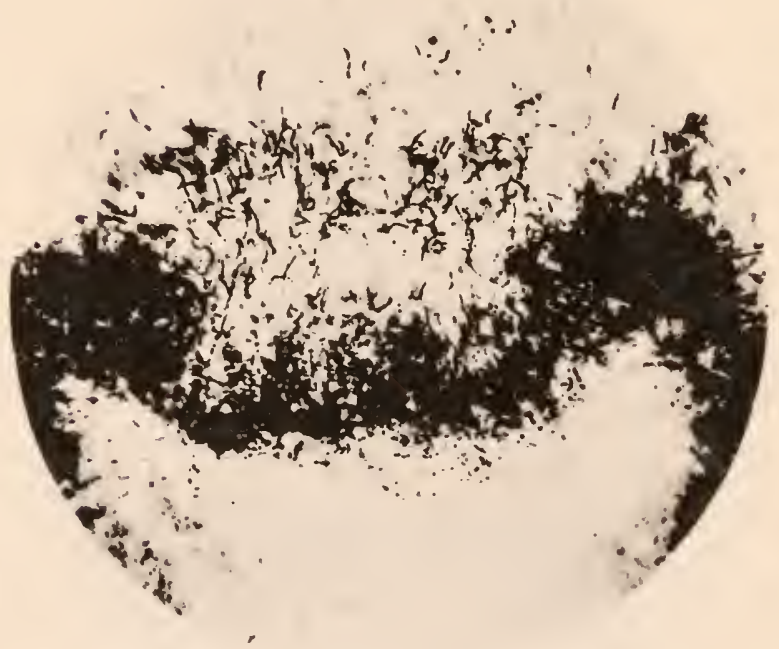

FIเ์. 320.

Fied de Madura. Conpe (Vincent). (Gr. 500 di:um.)

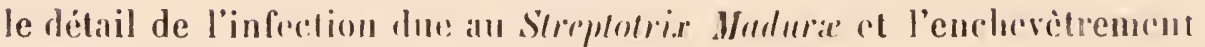
inextricable des fovers mycéliens, ligg. 516 a 521. 
On remarque hilhilucllement, an centre ile chacun des foyers secondaires, des espaces enmmo cascinux et sans traces lu parasite, tandis que celui-ci s'est mulliplie i la périphérie el cntomre ces espaces centraux d'une sorte de comronne irréguliore.

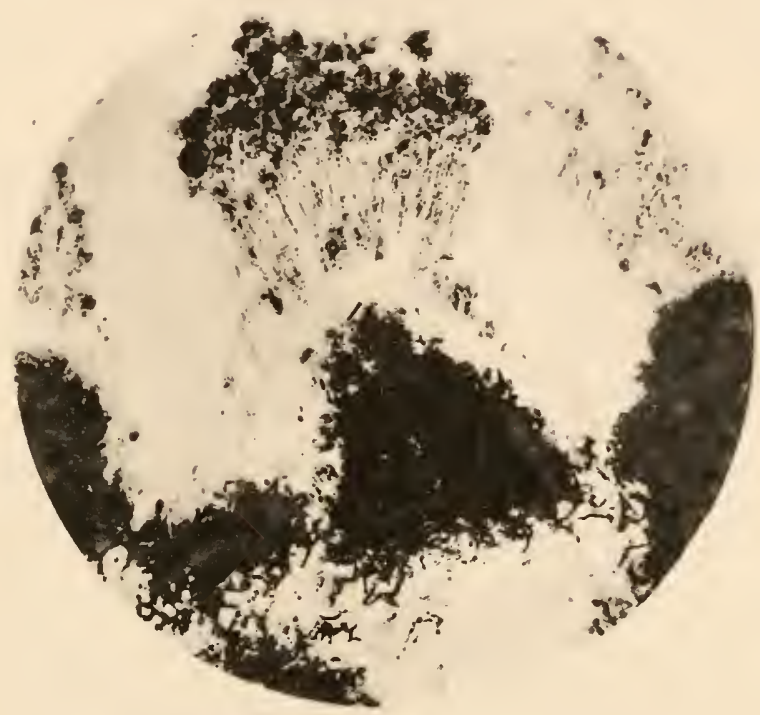

Fig. 321.

Pied de Madura. Coupe (lincent). (Gr. 500 diam.)

Les détails des ramifications du Streptotrix Maluræ sont particulièrement visibles sur la figure 320 .

La fignire 321 est destinće à mieux faire roir les rellules épithélioüles que l'on remarque à un faible grossissement sur les figures 515 et 517 , et qui entourent la plupart des forcers infectieus, cn simulant en quelque sorte l’aspect d’un revêtement épithélial ç̣lindrique. 


\section{LES LEVURES}

\section{SACGHAROMYGÈTES - TORULAS - MYGODERMES}

Les mots " Levure », "ILevain » impliquent l'idée d'une fermentation: levure de vin, levure de bière, levure de distillerie, levain de boulangerie, etc.

On a toutefois réservé le nom de Levure aux ferments analogues d'aspect à ceux que l'on observe dans la transformation des liquicles sucrés ou Fermentation alcoolique.

Ainsi, on n’a jamais classé parmi les “ Levures » les ferments " lactique » ou “ butyrique », qui appartiennent au genre " Bacille ».

Les levures sont des cellules ovales, d'assez gros diamètre, susceptibles de se reproduire par bourgeonnement et de prendre, dans certaines conditions, des formes allongées.

Leuvenhoeck, qui, le premier, les observa en 1680, décrivit leur forme sphérique ou ovalaire, mais méconnut leur nature organisée et les assimila aux grains d'amidon.

Thenard, en 1803, assigna aux levures, en raison de leur teneur en albumine, une place dans le monde organisé.

Cagnard de Latour et Schwann (1856) démontrèrent à leur tour que, sans ces organismes, la fermentation n’a pas lieu.

Le “ bouillage » des moûts sucrés, connu depuis la plus haute antiquité, où l'on faisait usage de boissons fermentées, cessa désormais de demeurer un phénomène inexpliqué. Les progrès de la micrographie permirent bientôt aux savants d'approfondir les phénomènes biologiques si remarquables qu'avaient entrevus Schwann et Cagnard de Latour.

On rencontre des levures, dans la nature, partout où existent des substances fermentescibles.

De nombreuses cellules adhèrent à la surface des fruits sucrés au moment de leur maturité. A côté de ces ferments, on observe les spores des moisissures variées : Aspergillus, Penicillum, Botrytis, ete. 
FERUEATATION ALCOOLIQUE

Si l'on ensemence dans dı moùl de bière un grain de raisin ou bien une parcelle de la surface d'une prune ou d'un abricot qui commence à se craqueler, on obtient en 2 k heures une culture impure, où végètent côte à côte levires, moisissures et bactéries.

Si nous exceptons les bactéries et les moisissures, pour ne nous attacher qu'aux cellules dites Levures, nous isolerons en quelques jours, d’après les méthodes que nons indiquerons plus loin, les espèces les plus variées.

Certaines de ces espèces, transportées en culture pure sur un milieu sucré, déterminent une fermentation alcoolique très nette, avec dégagement de bulles d'acide carbonique.

D’autres végètent comıne de simples Moisissures.

Enfin, les liquides fermentés se recouvrent fréquemment, au contact de l'air, d'une pellicule perlée et d'un blane grisâtre constituéc par de très petites cellules, et sans analogie avec les Levures.

Ce sont des Mycodermes.

Les mêmes liquides sucrés, s'ils sont déjà suffisamment acides, peuvent subir la fermentation acétique, à la suite d'une infection par lc Bacterium aceti ou le Bacterium Pastorianum, qui s'y développent alors ан lieu et place des Micodermes.

L'aspect des Levures proprement dites et de certaines autres espèces saprophytes, à l'état unicellulaire : Dematium pullulans, Monilia candida, Torulas, Mycodermes, etc., est très analogue aux yeux d'un observateur inexpérimenté.

Aussi les premiers savants qui s'attachèrent à l'étude des fermentations se trouvèrent-ils dans l'impossibilité matérielle de distinguer les uns des autres ces organismes microscopiques.

La découverte des cellules de Levure dans les moûts en fermentation demeura ainsi sans portée pratique jusqu'aux recherches de Pasteur. 
Le savant français, après aroir délinitivement runé la théorie de li génération spontanée, appliqua ses recherehes à l'élude des fermentations et contirma ainsi l’idée de Cagnard de Latour et de Schwann, qu'il ne pourait y aroir de fermentation sans l'intervention d'un ferment organisé.

Poursuirant ses éludes sur le vin, la bière, le vinaigre, Pasteur décourrit alors celle loi, que chaque fermentation avait un ferment spécial.

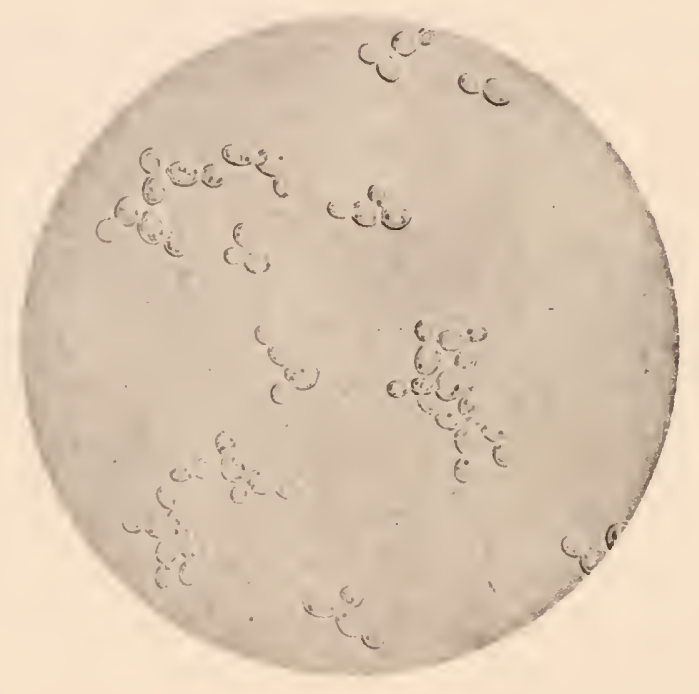

Fig. 322 .

Levure haute (gr. 400 diam.).

L'étude des Levures renait enfin d'entrer dans la période scientifique.

La conséquence directe des recherches de Pasteur fut l'étude des maladies de la bière et du vin.

Pasteur démontra que le vin el la bière malades contienneut d'autres micro-organismes que les Levures (nicrocoques, bactéries, etc.). Nous représentons ci-dessus, fig. 522, une Levure haute de bière, à l'état de culture pure, en voie de bourgeonnement, et, fig. 525, le sédiment d'un vin de Bourgogne atteint de la maladie dite "l'Amertume des vins $»$. 
On y lemarque, nom phus des Levmes, mais des bilommels plus on

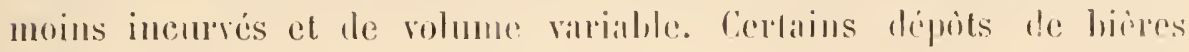
altirées sont assez aualognes d'aspect.

On crogait à celte ípoque qu’il n'existail qu'un sent ferment

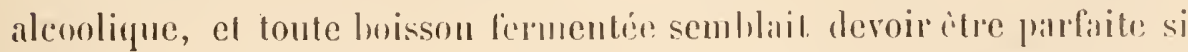

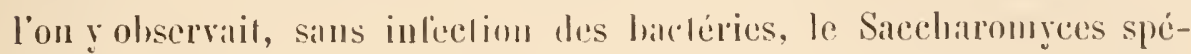
cifique, soit pour le vin le Saccharmmes Ellipsoüdeus et, pour la bière, le Saccharomyces Cerevisia.

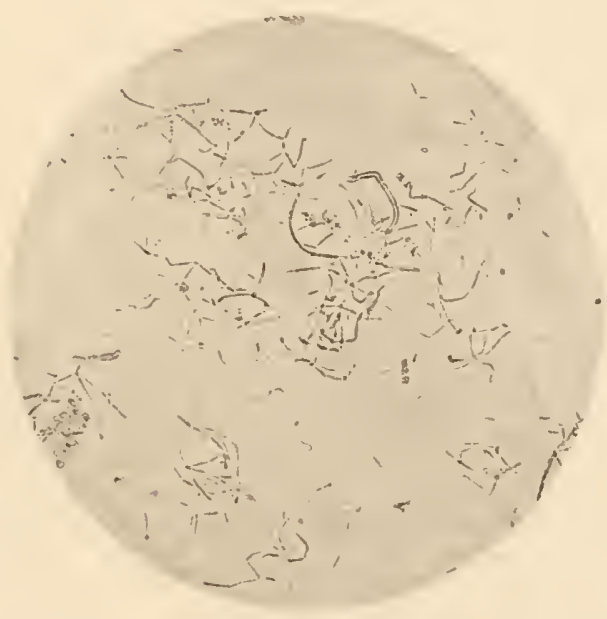

FIG. 323.

Sédiment de vin amer (gr. 400 diam.).

Comme conséquence pratique de ses découvertes, Pasteur proposa a l’industrie des boissons fermentées une série de précanlions destinées à protéger les moîts contre la contannination des hacléries et autles organismes nuisibles.

Il eut également l’idée de stériliser les boissons fermontées et dẹja clarifices, en appliquant scientifiquement les míthodrs driji proposies empiriquement depuis le commencement du sicele par Ippert (IS04) pour la fabrication des comscrres alimentaires.

Le chanflage des vins aux enviroms de $60^{\circ}$ porte, depuis que P'astour l’a recommandé, le nom de Pasteurisation des vins. 
On l'a appliqué également à la conservation de la bière. C'est sur le même principe que sont basées les méthodes de stérilisation du lait actuellement en honneur.

Pasteur fit micux et entrevil, malgré les méthodes imparfaites de recherches dont il disposait alors, la spécificité de certaines espèces de lerures, qu’il décrivit arec soin-d’après leurs caraclères extérieurs.

Bien des points cependant demenraient obscurs dans la science des fermentations, et il n’existail ancun procédé capable de permettre l'isolement à l'état de pureté de tol ou tel ferment bien défini.

Pasteur lui-mème tendait at admettre la transformation possible des ferments, dans des conditions déterminées, et à assimiler les ferments du moût de raisin à des moisissures rulgaires telles que le Dematium pullulans.

Il croyait également que les Levures allongées, dites de forme pastorienne (Saccharomyces Pastorianus) étaient la conséquence d'une transformation des lerures de bière ou de rin (Pasteur. Études sur la bière.).

Il appartenait à Jansen de résoudre cette importante question de la spécificité des Lerures. C'est en 1882 que le savant danois commença, à la brasserie de Carlsberg, les célèbres recherches sur lesquelles il fonda la méthode qui devait si profondément transformer l’industrie des fermentations.

IIansen, rompant avec toutes les méthodes de recherches de ses devanciers, prit comme point de départ l'individu, la cellule mique. S'attachant à connaitre les carratires spécianx à chaque espèce, il arriva à séparer, dins une biire malade, les dillérentes espéces de Levure dont elle étail composée, et it démontrer que les unes procuraient de la bière saine, landis que les autres tomnaient de la bière malade.

La méthode de IIansen fut une rérolution dans l'úlude des ferments que, jusque-lì, persomme n’arait pu isoler ì l'élal de pureté.

Les cellules de Sachinromyciles sonl lellement analognes d'une espece à l'autre, yue leur aspect an microseope est insultisant pour dif- 
férencier les races les plus dissemblablus par leurs propriciés biologicilues.

Une bière troulde el de manvais gonit peut ne contenir, à l'exclusion de loule baclérie, que des cellules de Levure.

llinsen partit ainsi de ee principe que. pour oblunir une race pure

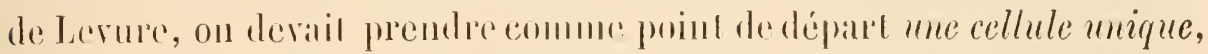
denx celhules roisines, l'ispect identique, pouvinul ètre de race fort diflërente, el donner naissince, fill voisinage, il me seule et mème colonic.

le point délicat élait de perfectionner encore la méthode de Koch - isolement des bacléries par les cullures sur plaques de gélatine - de telle sorte qu'on pùt à coup sûr partir d'une seule cellule.

IIansen, profitant du diamètre assez considérable des cellules de Levure, démontra qu’il étail facile, gràce à l'emploi d'une chambre humide spéciale dont la lamelle porte un quadrillage numéroté, de pointer sur un schı́ma la situation de chaque cellule unique suffisamment distante des cellules les plus roisines, en notant sa situation par rapport aux chiffres qui servent ì numéroter chacune des cases.

Le liquide gélatineux qui est versé sur la lamelle doit donc être assez pauvre en cellules pour qu'il n'en existe guère que 10 à 20 sur toute l'étendue du quadrillage. Chaque cellule, suivie jour par jour, donne naissance à une colonie isolée distante de ses congénères et qu'il est facile de recueillir à la pointe d'une aiguille de platine stérilisée, pour la transporter à l'état de pureté sur un milieu approprié.

Existe-t-il dans le liquide plusieurs races différentes de Levures? Chacunu d'elles peut être isolée, gràce à cette méthode ingénieuse, et reproduite en culture pure.

En possession de cette méthode précise et inatlaquable, Ilansen put conclure avec cerlilude que chaque espèce de Levure présente des caractères distincts, invariables, domne des produits définis, et ne peut se transformer en une autre espèce. 
Bien mieux, poussant presque jusqu’i la perfection l'analỵse batetirologique des mouls en fermentalion, Itansen chercha me méthode calpable de dillërencier chanue ratee de ses congémires.

Il se hasa à cet eflet sur l'étude des cilracleres physiologinues propres at chaque ferment.

L'un des plus précieux est la sporulation.

Les Levures industrielles se reproduisent, dans la pratique, parr bourgeouncentent; mais ce n'est pas lemr seul mode de reproduction;

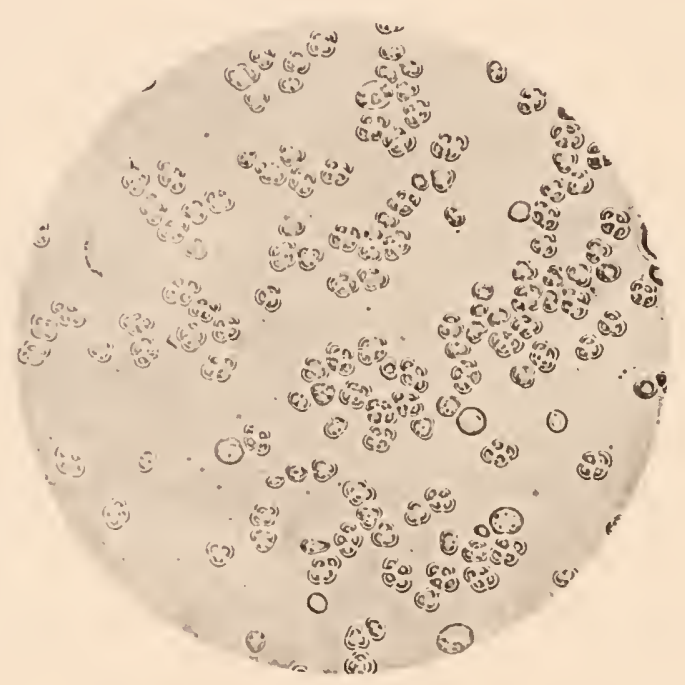

Fic. 324.

Levure de vin de Clampagne en voie de sporulation (gr. 400 diam.)

elles peurent anssi se mulliplier par sporulation : lat cellule-mire, placée dans certaines conditions (libre accés de l'arr, humidité, absence de substrallum mulrilif), forme des spores, e’est-it-dite que smon

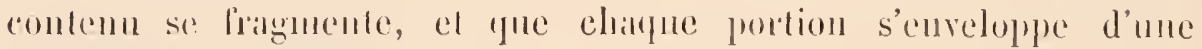
membrane (ligg. 52. 1).

(1), dims les levmes salecharontycotes, les spores apparaissent en

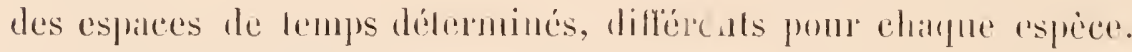

le moyen le plus commorle pour provoquer la lomiation des spores est de porter une on denx gomltes d'un dépôt de levure contenant. des cellules jeunes a rigourenses sur un peiii blen de platre 
préalablement stérilisé. Ce bloc de plitlre est placé diuns une boile de verte converte : on le mainticnt humide en versant de l'ean an fond de lat boite.

T'oules les conditions nécessaires il la lormaltion des spores et signatées plus haut, alecès de l'air, humidité, absence d'éléments nutrilifs, se tronvent ainsi réalisées.

On mole le moment de l'apprarition des rudiments de spores à des tempríatures dillérentes: $15^{\circ}$ et $25^{\circ}$ par cxemple.

Il est exceptionnel que deux races de Levures présentent, à différents degrés de température, les mêmes particularités de sporulation.

Parmi les autres signes capables de permettre la distinction de différentes races de Levures, nous citerons :

$1^{\circ}$ Les caractères extérieurs de la fermentation : fermentation plus ou moins tumultueuse; aspect des écumes; nature et consistance du dépôt, etc.;

$2^{\circ}$ Le degré d'atténuation, c'est-ì-dire la quantité d'alcool formé dans un même moût;

$3^{\circ}$ Le degré d'acidité du moût après fermentation;

$4^{\circ}$ La clarification;

$5^{\circ}$ Le résultat de la dégustation du liquide clarifié; et enfin, l'aspect des voiles et le temps nécessaire à leur formation (voir plus loin).

IIansen divisa en deux groupes les organismes qu'il isola des moûts sucrés en fermentation :

10 Les Levures saccharomycèles, qui présentent comme caractère commun " la sporulation » et comprenuent la presque totalite des levures industriclles : bière, vin, cidre, distillerie, panificalion, cle.;

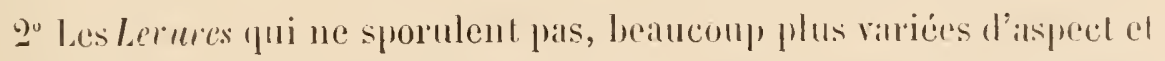
sams gramde imporlance pratique, lelles les Torules de l'ablemr, la Lecure

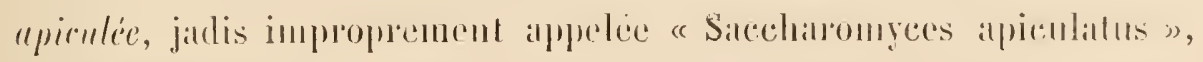

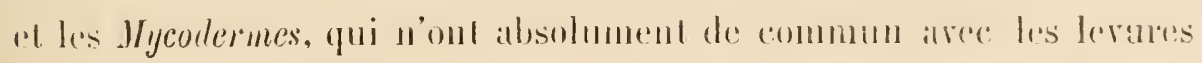

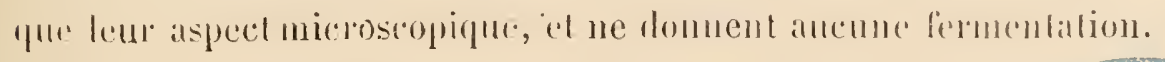




\section{LEVURES VRAIES - SACGIAROMYCETES}

Les Levures saccharomycètes se distinguent des organismes aveclesquels on les a longtemps confondues par deux caractères biologiques principaux :

$1^{\circ}$ Elles sont des agents actifs de fermentation ;

$2^{\circ}$ Elles donnent des spores dans des conditions déterminées.

Nous étudierons tout d'abord les Levures de bière, qui sont actuellement les mieux connues.

\section{LEVURES DE BIÈRE}

\section{FABRICATION DE LA BIÈRE}

La bière est une boisson fermentée produite par l'action des Levures sur une infusion ou décoction de malt et de houblon.

La fabrication de la bière comporte deux opérations bien distinctes:

10 La Saccharification;

$2^{\circ}$ La Fermentation.

\section{I. - SACGIIARIFICATION}

Le moût de bière est un liquide sucré dont l'élément principal est l'extrait d'orge germée ou malt.

La germination de l'orge, qui est provoquée par les conditions voulues d'humirlité et de chaleur, liquéfie l'amidon de la graine et détermine la formation d'un ferment soluble, ladiastase.

L’orge germée ou malt est séchée jusqu’à un degré variable de caramélisation daus des tourailles ou plateaux élagés.

Le touraillage fait sentir son action sur le cachel de la bière suivant qu'il est effectué à une température plus ou moins élevée.

$\mathrm{Au}$ sortir du touraillage, les germes de l'orge sont séprarés de la graine 
par frottement, car leur présence' donnerait au mont une amertume. spéciale fort désagréable et une tencur excessive en matières albuminoïdes, dont l'abondance faciliterait la fermentation putride du liquide.

Le malt touraillé est concassé et réduit en farine, soit à l'état de pureté, soit mélangé à d'autres matières saccharifiables (blé, maïs, riz, etc.).

La farine ainsi préparéc est additionnée d'eau, puis saccharifiée sous l'action lente de la chalcur.

Cette opération, dite brassage, qui a donné aux brasseries leur nom, est de la plus haute importance. Le degré de saccharification, c'est-ì-dire le rapport du sucre formé aux autres matières extractives du malt - dextrines, matic̀res azotées, cendres, etc., dépend de la température du brassin et de la durée d'action de la chaleur.

Le brassin doit être porté par des mojens variables à une température de $55^{\circ}$ à $60^{\circ}$; on l'y maintient pendant trois quarts d'heure à une heure.

Une température exagćrée entrave l'action de la diastase sur le malt:

La saccharification doit être conduite d'une manière déterminée suivant que l'on veut obtenir tel ou tel type de bière, le rapport du sucre. aux matières non saccharifiées ou non saccharifiables influant directement sur la proportion d'alcool et d'extrait du liquide fermenté.

La saccharification terminéc, le moût de bière est additionné de houblon dans des proportions variables et porté à l'ébullition.

L'ébullition du moût en présence du houblon termine l'opération du brassage et donne à ce moût un cachet spécial d'amertume, en même temps qu'elle produit, avec une partic des albuminoïdes du moût, un précipité qui facilite la clarification. Certaines rísines et huiles essentielles se dissolvent sous l'action de la chaleur.

Le moût houblonné présente de ce fait, visoì-vis des bactéries, une résistance antiseptique bien supérieure à celle du moùt non houblonné.

le munit de bière étant franchement acide, l'ébullition a pour effet de le stíriliser. 


\section{II. - FERMENTATION}

Le moût houbionné est mis en fermentation aussitôt après refroidissement.

Les levures de bicre peuvent donner lieu à deux modes de fermentation : la fermeniation haute et la fermentation basse.

La levure haute est ainsi dénommée parce qu’elle est entrainée, pendant le bouillage, à la surface du liquide, que l'on écume.

Au contraire, la levure basse se dépose au fond du récipient.

Le caractère de la levture influe (comme le rapport du sucre au nonsucre) sur le cachet de la bière, et ce sont toutes ces différences qui permettent la fabrication de tant de bières diverses : les types Nunich (brune et peu fermentée), Pilsen (pâle, sèche et alcoolique), pour la fermentation basse; les genres Pale ale, Porter, etc., pour la fermentation haute.

La fermentation haute s'effectue de 12 à 20 degrés. La fermentation basse est provoquée généralement dalls des locaux refroidis par des machiries à glace.

La tempéraiure du moût en fermentation basse varie de 5 à 10 degrés centigrades.

La fermentation haute évolue entre $12^{\circ}$ et $25^{\circ}$ centigrades et dure de 2 à 4 jours: Ia fermentation basse demande au contraire 8 à 15 jours et plus.

Les fermentations haute et basse s'effectuer $\hat{\imath}$ en deux temps : $1^{\circ}$ la fermentation principale ou tumultueuse - pendant liquelle la levure haute se rassemble à la surface du liquide, où on la recueille, tandis que la levtre basse se dépose au fond du récipient; - $2^{\circ}$ la fermentakion secondaire, plus lente, qui se lait en cuve, il la suite de l'oxygénation due au soutirage, dans des fùts on foudres de capacité variabie.

Ial fertuentiation principale est fournie particulierenent par la transformation du sucre, tamdis que, dams la fermentation sccondare, 
ce sont les dextrines et un sucre particulier, l'iso-maltose (Litner), qui se transforment ì leur tour.

Les fùts de garde sont fermés hermétiquement à l'aide d'une bonde avant la fin de la fermentation secondaire, de telle sorte qu'il s'y produit, en vase clos, une véritable prise de mousse, comme on l'observe dans la fabrication des vins de Champayne.

Cette prise de mousse peut être activée par l'addition de bière jeune en pleine fermentation.

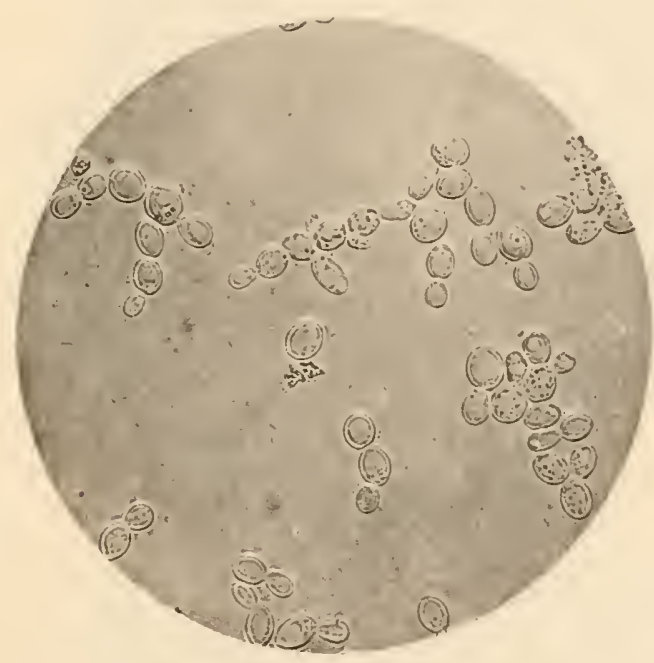

Fig. 325 .

Levure haute en voie de bourgeonnement (gr. 400 diam.).

Le foudre de garde contient ainsi de la bière saturée d'acide carbonique, sous une pression maximum de 1 atmosphère.

On tire cette bière mousseuse, à l'aide d’appareils spéciaux destinés à éviter les pertes de gaz, dans les fûts ou les bouteilles d'expédition.

Nous représentons figures 525 et 526 une levure haute de brasseric en voie de bourgeonnement.

Les levures hautes sont caractérisées par leur développenent en chainetles, chaque bourgeon demeurant altaché à la cellule mère; 
c'est í celte propriété de la levure haute que l'on attribue le phénomine de la fermentation uite "fermentation hante ».

On prétend que les bulles dlacide carbonique ont une prise sur les chainettes de la fermentalion haute, qu'elles entrainent à la surface du liquide, tandis qu'elles restent sans aclion sur les éléments isolés de la levure bisse.

Il est à noter que le dígagem(unt d'acide carluonigue est beaucoup

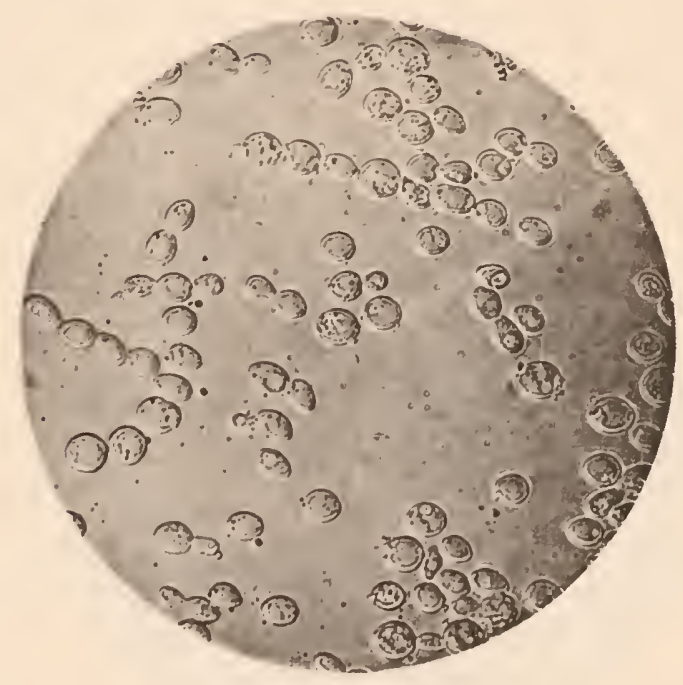

Fic. 326.

Levure haute en voic de bourgeonnement (gr. 400 diam.).

plus énergique dans la fermentation haute, par suite de la température élevée à larpuelle on la provoque.

Le bourgeonnement actif des levures représentées figures 525 et 526 earactérise le délout de la fermentation.

Nons reprodinisons, fig. 527 et 528, les cultures sur milicu solide (agar-igan an nont de biere) de deux types dill'érents de levures l:autes.

Les Jevures basses ne se développent pas en chainettes. Telle la levme dite "levure de Ciurlsherg $1^{\circ} \supseteq$ ", une des deux races de ferments employés a la brasserie de Carlsherg. 
Les figures 529 et 550 représentent cette levure au début de

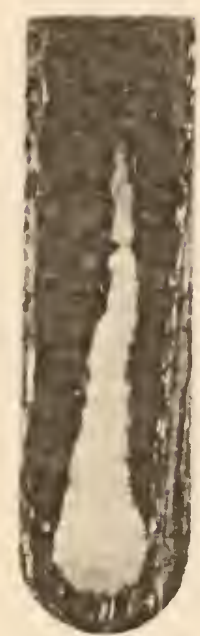

Fig. 327.

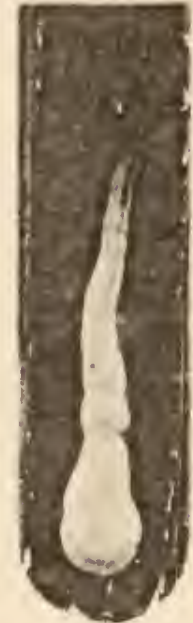

Fig. 328.

Deux levures hautes en culture sur l'agar-agar au moùt de bière (grandeur naturelle).

la fermentation. On remarquera qu'il n'existe sur ces ligures

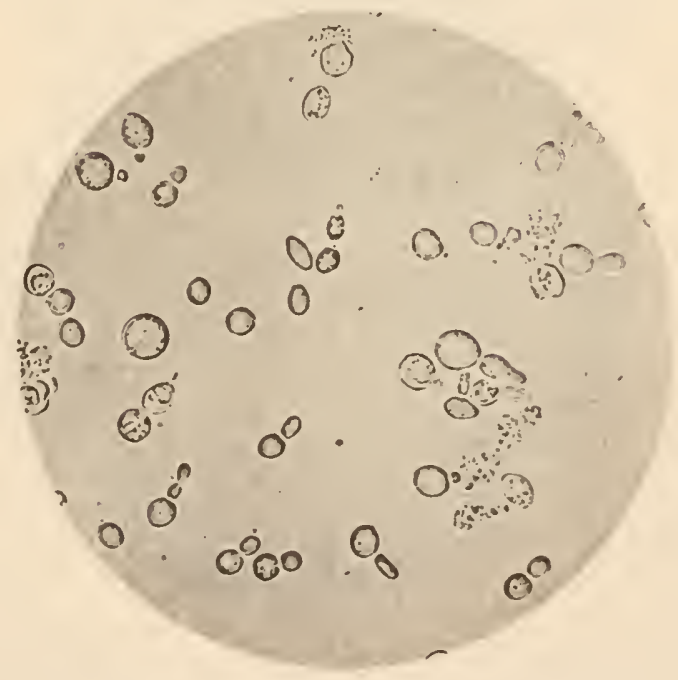

Fig. 329.

Levure basse (Carlsberg II). (Gr. 400 diam.)

aucune des longues chainettes des clichés 325 et 326. 
La figure 351 représente une autre lcvure basse, plus âgée. Cette levure

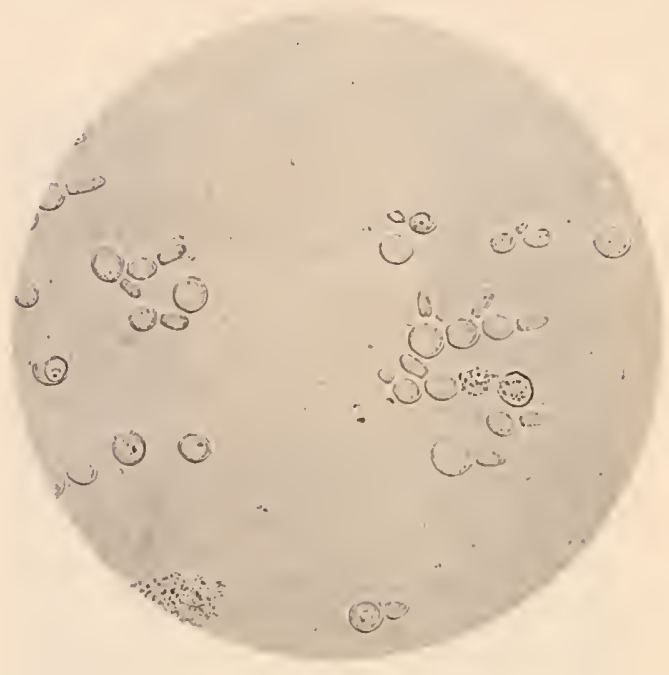

FIG. 330.

Levure basse (Carlsberg II). (Gr. 400 diam.)

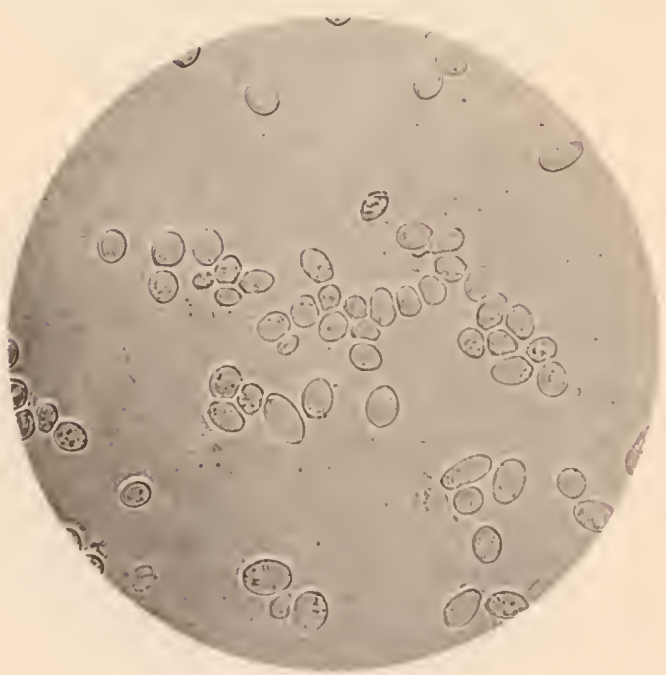

Fig. 351.

Levure basse d'une brasserie de Reins (gr. 400 diam.) (Chazaren.)

n’est plus en hourgeonnement, ce qui indique que la fermentation est à peu près lermincíc. 


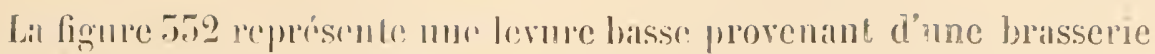
de l’est de la firanee, el en culure tris îgée.

Les cellules, an lien de se montrer liomogrines comme celies des figures 529 et 550 , ne renferment plus dans leur membrane d'enveloppe que des fragments de protoplasma granuleux séparés par des vacuoles.

Cet aspect est toujours un indice de rétusté des ccllules.

Un remarquera figure 552, sur le diamètre vertical es à 20 nilli-

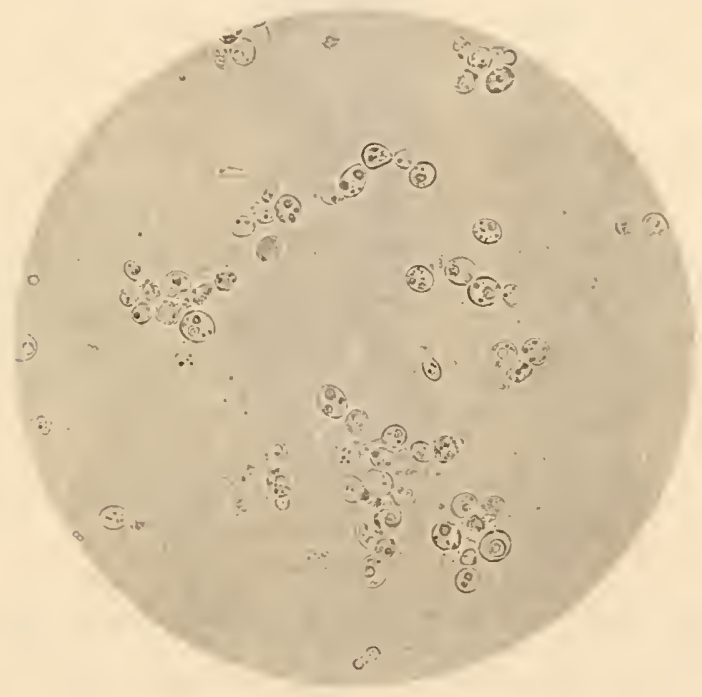

Fig. 332,

Levure basse. Vieille culture sur moût de bière. Cellules de la surface (ğ 100 diam.):

mètres de la circonférence du cliché, au milicu d'une chaînctie horizontale de 5 cellules, une cellule à double contoup, dont le centre rétracté est séparé de la membrane d'enveloppe par un liséré clair.

Cet aspect est celui d'une celiule mortc. On contrôle aisément l'ćtấ de vie ou de mort des cellules de levure en introduisant au bord de la lamelle une goutte de solution aqueuse d'éosine. Les cellules mortes prennent seules la coloration. 


\section{LEVURES DE MALADIE}

Nous avons vu que Pasteur attribuait, au début de ses recherches, les maladies de la bière à des bactéries et croyait l'examen microscopique suffisant pour déceler l'existence de germes nocifs.

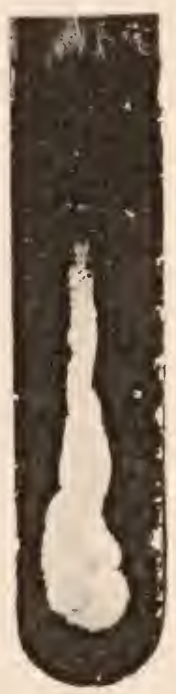

FIG. 333.

Cullure de Sacch. Ellipsoidens I sur agar-agar au moủt de bière.

C'est ainsi que ccrtaines bic̀res malades foisonnent en microcoques, sareines oul bactéries.

Hansen le premier, prenant pour point de départ, comme nous l'avons indiqué, des cultures provenant d'une scule cellule, isola dans une bière trouble et de mauvais goùt où l'examen microscopique ne révélait aucune trace de micro-organismes autres que des levures, plusieurs ferments absolumient semblables a l'examen histologique le plis approfondi, mais entièrement différents par lcurs propriétés biologiques.

Les uns donnaient en fermentation une bière de bonne qualité, les autres une bière trouble et de maurais goùt (amertume, etc.).

Ilansen décrivit ainsi 6 levures différentes dont 4 sont des levures de maladie de la bière. 
Il détermina ces espèces avec une précision absolue par l'étude méthodique de leurs proprićtés au point de vue de la sporulation á diverses températures (de $\check{3}$ a 55 degrés) et de l’époque de formation des voiles, qui, pour certaines espèces, ne se produisent qu'au bout de plusieur's mois.

Ces levures sont : $1^{\circ}$ Saccharomyces C'ercrisix $n^{\circ} 1$, levure haute de brasseric.

$2^{\circ}$ Saccharomyces Ellipsoïdeus $n^{\circ} 1$, levure de vin qu'Hansen a étudićc comparativement aux levures de brasserie, et dont les proprićtés biologiques sont différentes (fig. 555).

$5^{\circ}$ Saccharomyces Ellipsoïdcus $n^{\circ}$ 2, levure de maladie de la bière. Cette levure cst une de celles qui causent dans les brasseries les ravages les plus irrémédiables - trouble de la bière et mauvais goût.

Ce trouble, tout particulicr, ne peut être combattu par aucun des moyens ordinaires : repos, clarifiants, collage, filtration.

$4^{\circ}$ Saccharomyces Pastorianus $n^{\circ} 1$, levure basse caractérisée, ainsi que les deux espèces suivantes, par la forme allongée des éléments. Cette levure donne à la bière un goût amer, une mauvaise odeur et un trouble spécial.

$5^{\circ}$ Saccharomyces Pastorianus $n^{\circ}$ 2, levure de fermentation haute et peu nocive.

$6^{\circ}$ Saccharomyces Pastorianus $n^{\circ} 3$, levure haute, empêchant la clarification.

Depuis la découverte des caractères différentiels de ces premières races de levures, découverte fondamentale qui eut pour effet, comme nous l'avons indiqué plus haut, de métamorphoser en quelques années la fabrication industrielle des boissons fermentées, on a isolé à l'état de pureté une foule de races différentes de Saccharomycètes industriels, jouissant de propriétés distinctes.

\section{SPORUL.ITION}

Nous représentons fignre 554 le Saccharomyces Pastorianus $n^{\circ} \mathbf{3}$, transporté sur bloc de plâtre pour l'apparition des spores. 
On remarquera, dans plusicurs des cellules de Sacrh. Pasto-

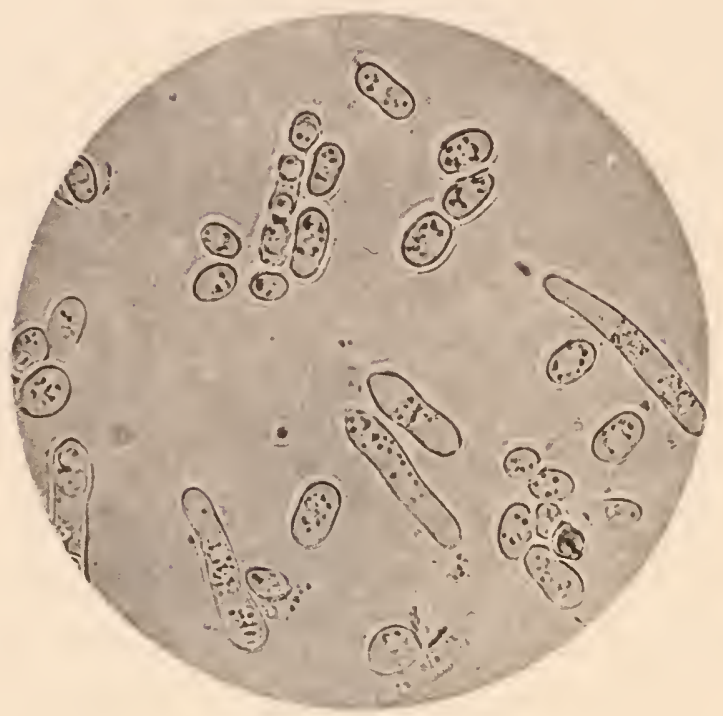

F1G. 554 .

Sacch. Pastorianus III, en voie de sporulation (gr. 1000 diam.).

rianus de la figure 534, notamment en haut de la figure, des spores endo-

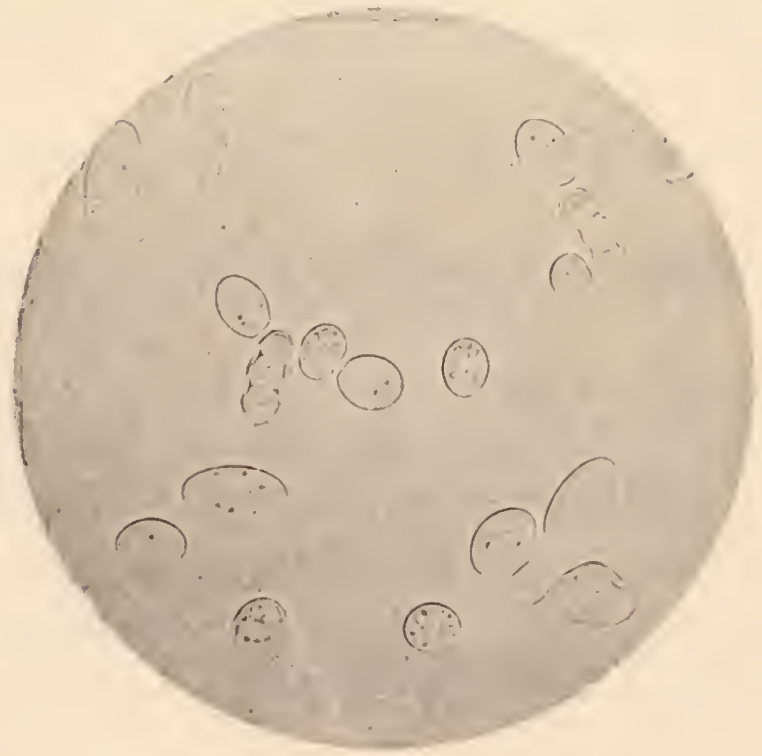

Fig. 355.

Levure de vin. Spornlation sur agar-agar peptonisé le cinqquiène jour (gr. 1000 diam.). gènes bien distinctes, au nombre de qualıe dins le mêne articke. I droite de la figure se frouve un bacille à spore cerninale, infection 
fréquente des cultures sur plâtre oủ lés bactéries, comme les levures, sont placées dans les meilleures conditions pour sporuler.

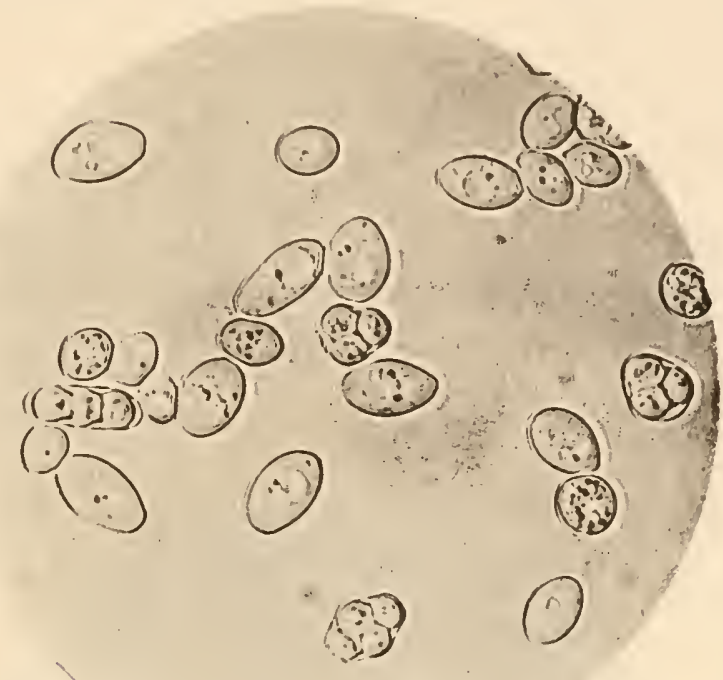

Fig. 356 .

Levure de vin. Sporulation sur milieu solide (gr. 1000 diam.).

Les spores se forment parfois, pour certaines levures au moins, sur

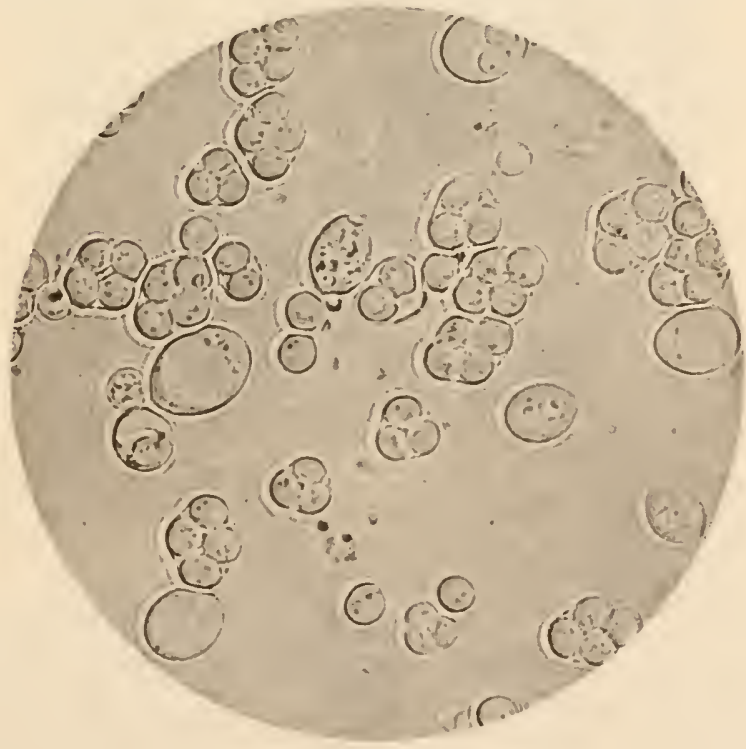

FIG. 357.

Sporulation d'une levure de vin sur bloc de plàtre (gr. 1000 diam.). 
les milieux solides. Telles les spores représentées fig. 555 et 556 , et qui aplartiennent à une levure de vin.

Les spores sont plus nounlıreuses sur plàtre, comme le témoignent les fig. 557 et 558 .

IIansen a saisi daus les particularités de la sporulation un moyen de reconnaitre les levures industrielles des levures de maladie.

Il a, en effet, reconnu qu'en étudiant la sporulation comparative de plusicur's espèces de levures à des tempéralures variant entre 5 et 30 degrés environ, il existe toujours une température où les levures de maladie forment leurs spores plus rapidement que jes levures industrielles.

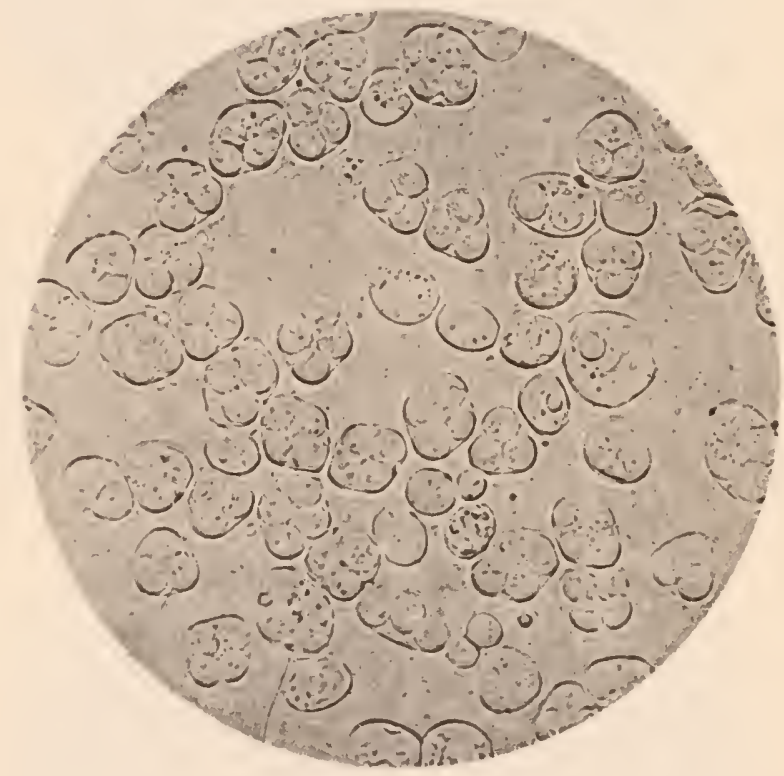

Fig. 538.

Sporulation d'une levure de vin sur bloc de plàtre (gr. 1000 diam.).

Presque toutes ces cellules sont bourrées de spores.

En général il suffit d'étudier la sporulation aux températures de 15 et de 25 degrés.

A 25 degrés, toutes les levures de maladie présentent des rudiments de spores en moins de quarante heures. Il en est de même de presque toutes les levures hautes et de quelques levures basses. Il est donc bien aisé de reconnaître, par la culture sur plàtre à 25 degrés, touies les races de levures basses qui ne présentent à cette température des 
rudiments de spores qu'au delà de quarante heures (de quarante-deux à quarante-cinq heures jusqu'a six à huit jours).

Pour la plupart des levures qui donnent, comme les levures de maladic, les levures hautes et quelques levures basses, leur's spores en moins de quarantc heures à 25 degrés, il faut exposer les blocs de plâtre à une température plus basse. A 15 degrés, par exemple, toutes les levures de maladic donnent des rudiments de spores en moins de soixante-douze lieures, ef toutes les levures industrielles de brasseric, hautes ou basses, en plus de soirante-douze heures.

\section{FORMATION DES VOILES}

Iorsqu'on laisse au repos complet un ballon de moût sucré oûs l'on a ensemencé un saccharomycète, il se produit, plüs vü moins

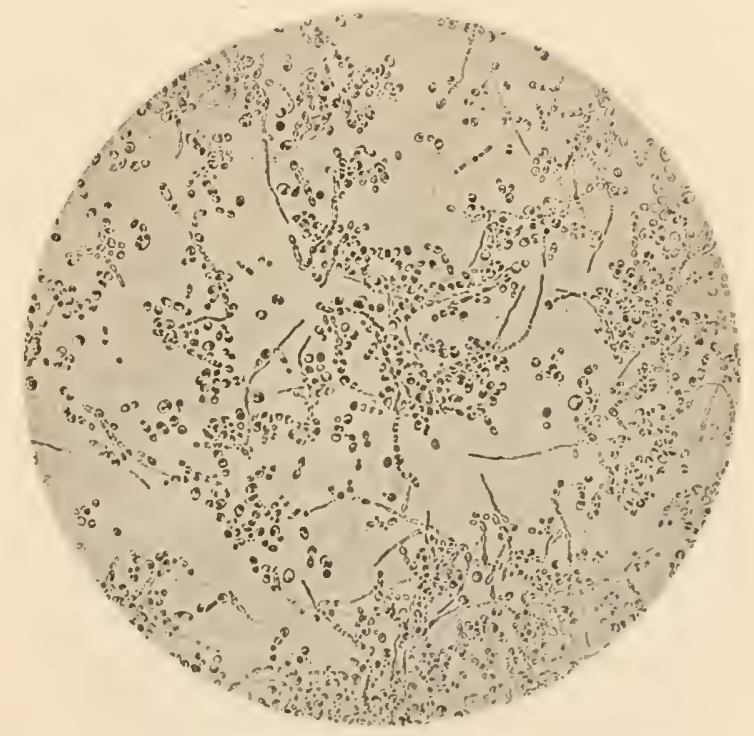

FIG. 339.

Voile jeune du Sacch, cerevisiz I (gr.100 diam.).

longtemps après la cessation complète de la fermentation, à la surface du liquide entièrement clarifié et presque décoloré, une pelliculc mince et à peinc visible, sauf à la lumière réfléchie. Ce voilc pourrait, à un examen superficiel, ètre confonllu avec une infection de 
mycodermes. Il est toutefois beaucoup plus ténu. Si l'on prélève une parcelle de ce voile avec une aiguille stériliséc, et si on l'étudie au

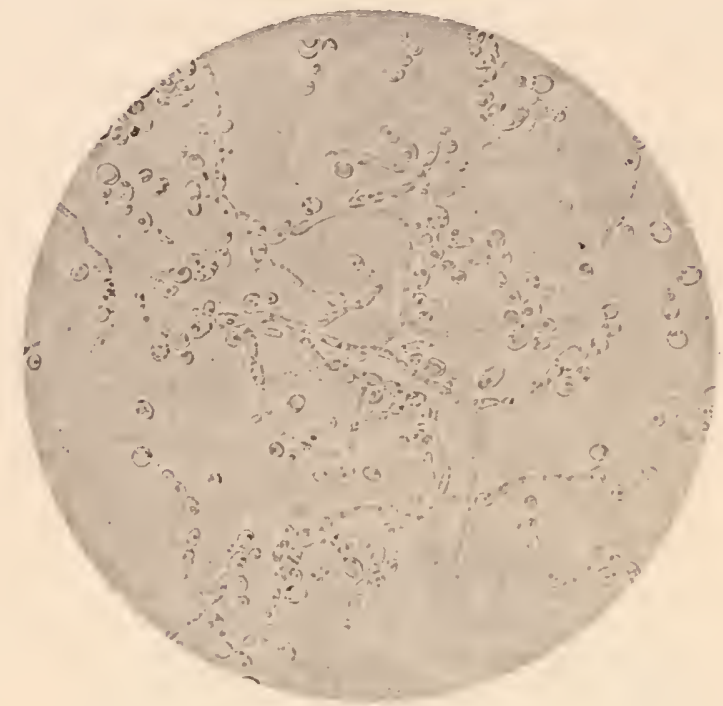

Fig. 340 .

Voile jeune du Sacch. cercvisix I (gr. 400 diam.).

microscope, on remarque que les cellules du voile, au lieu de présenter exclusivement leur forme ovalaire habituelle, donnent, dans la plupart

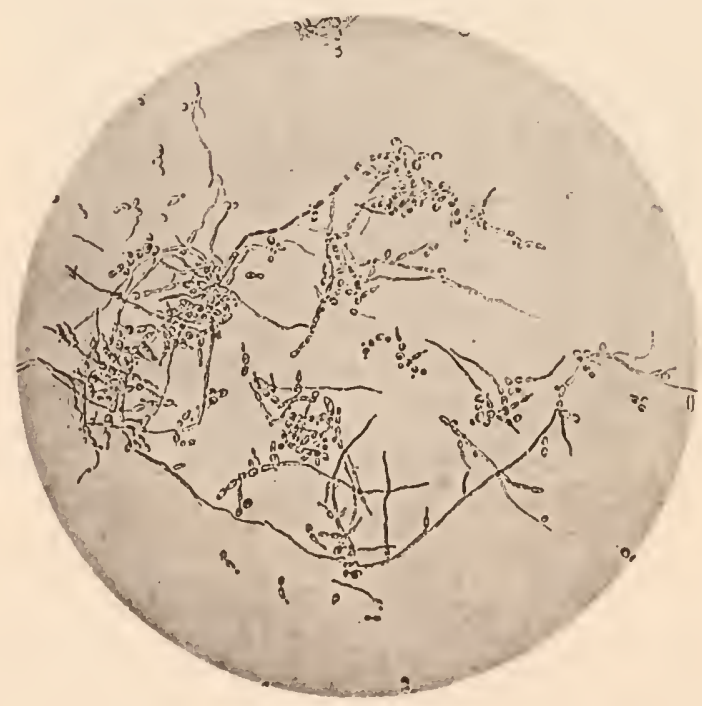

Fig. il1.

Sacch. cerevisix I. - Voile ancien (gr. 200 diam.).

des cas, des prolongements d'aspect mp̣célicn d'alutant plus accentués pour une même espèce que le voile est plus vieux. 
Les fig. 559 ect 540 représentent le début de la formation du voile

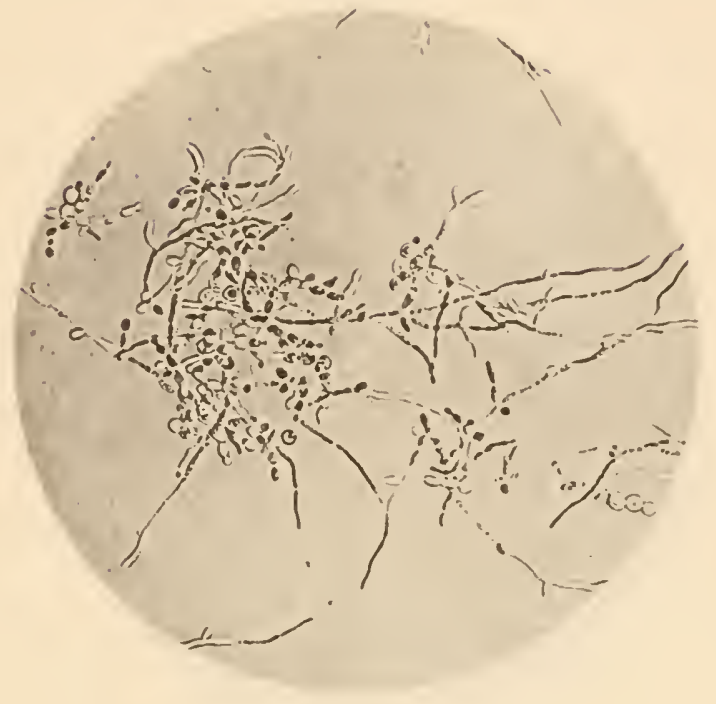

Fig. 5 .4.

Sacch. cerceisix I. Voile ancien (gr. 350 diam.).

d'une culture de Sacch. cerevisix I. On n'y observe encore que peu de

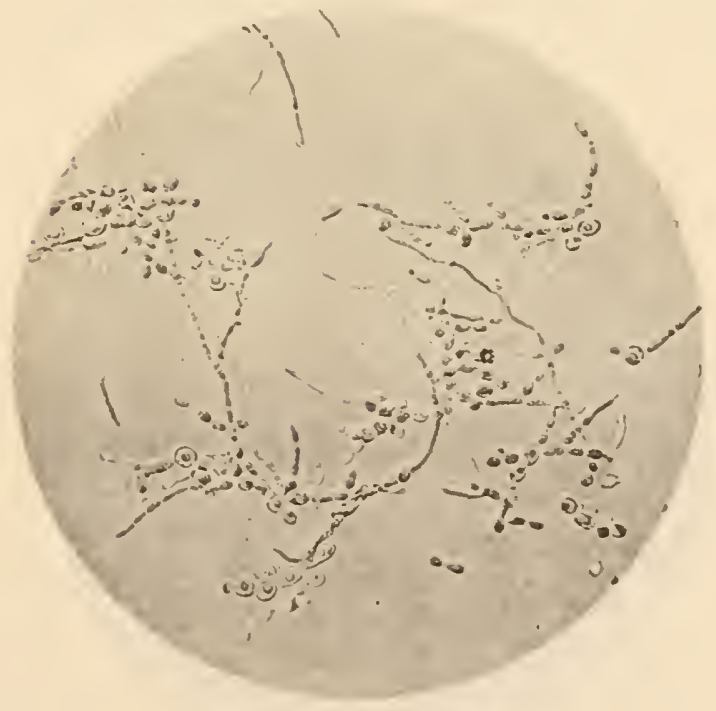

FIG. 345 .

Succh, ccrevisix I. Voile ancien (gr. 400 diann.).

formes mrcélicunes; les fig. 541,5 往 et 545 montrent à des grossissements variables des voiles d'un àge plus avancé. 
Les figures 54 et 545 montrent, à un grossissement de 400 dia-

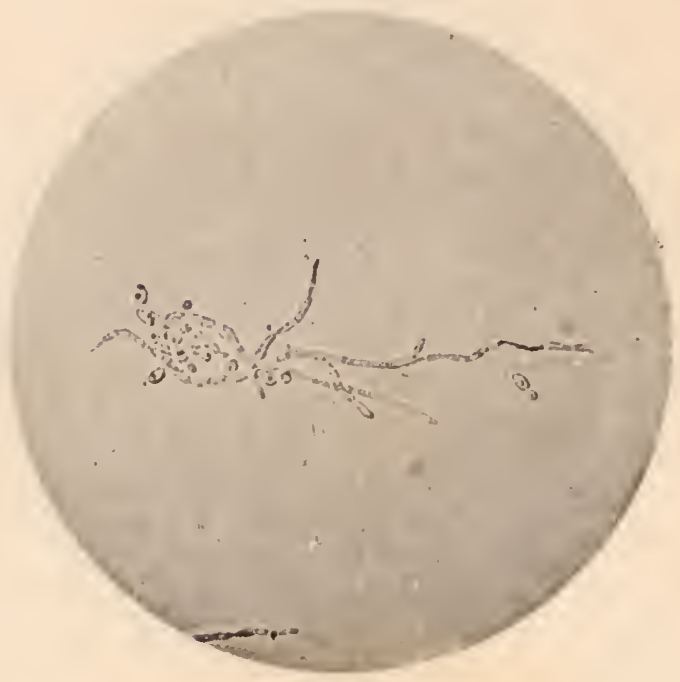

F16. 344.

Voile du Sacch, cerevisiæ I. Colonie isolée (gr. 400 diam.).

mètres, la transformation des éléments ovalaires en éléments mycéliens.

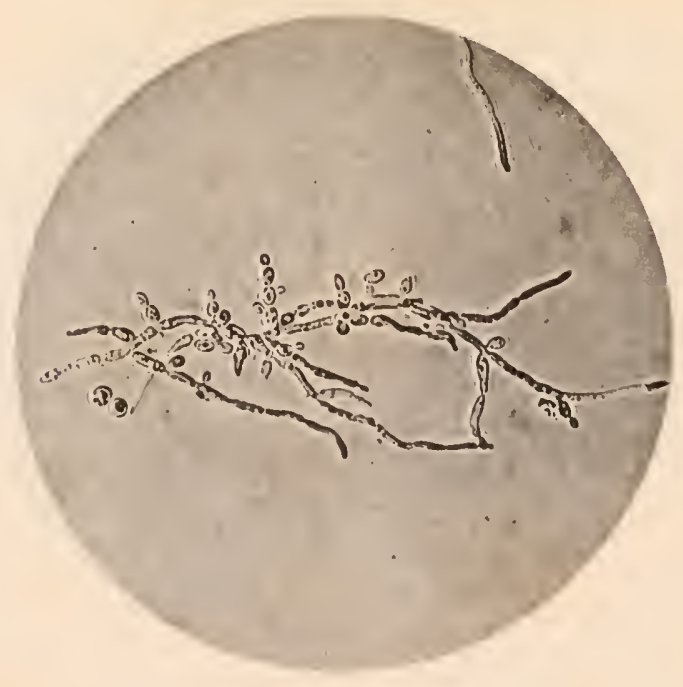

Fig. 345.

Poile du Sncch. cerenisiz I. Colonie isolse (gr. $\$ 00$ diam.).

Cette levure est une levure haute, le Saccharomyces cerevisix I. 
Les figures 546,517 el 548 représentent, it des grossissements diffé-

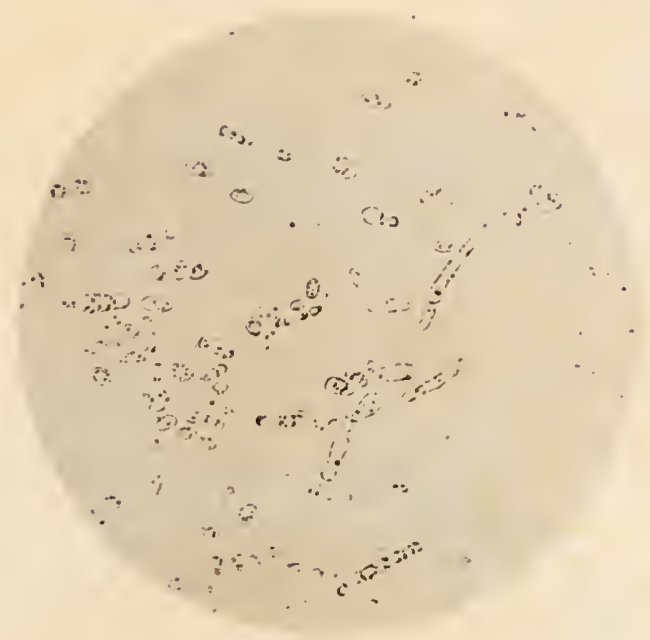

FIG. 346.

Voile jeune de Sacch. Pastorianus IlI. (Gr. 400) diann.)

rents, le roile de la levure de maladie Sacch. Pastorimus Ill. La tlansfor-

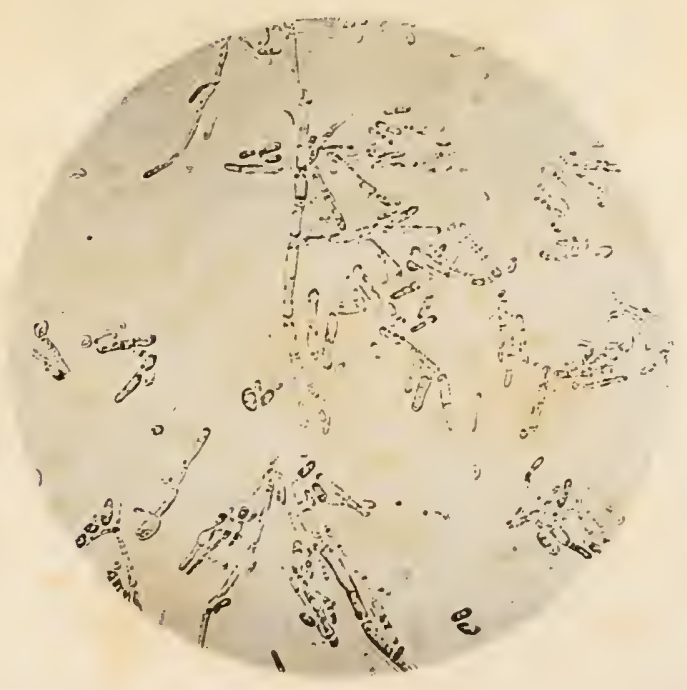

Fig. 347.

Sacch. Pastorianus 11I., Yoile plus ancien. (Gr. 500 dian.)

mation est ici moins éridente que pour le Saccharninyres cerecisix I, en raison de la forme en boudin des articles jeunes. 
On observe néanmoins très nettement dans ces préparations la présence de İongs filarnents.

Certains Saccharomycètes présentent cette particularité, que leurs voiles, tout en étant très caractérisés, ne contiennent pas de cellules allongées. Pour le Sacch. Ellipsoïdeus II, les cellules du voile sont plus arrondies que celles du dépôt, qui se montrent au contraire ovalaires. Le voile du Sacch. Ellips. II est, de tous, celui qui se forme le plus rapidement. Il devient manifeste en cinq à six jours à 25 degrés.

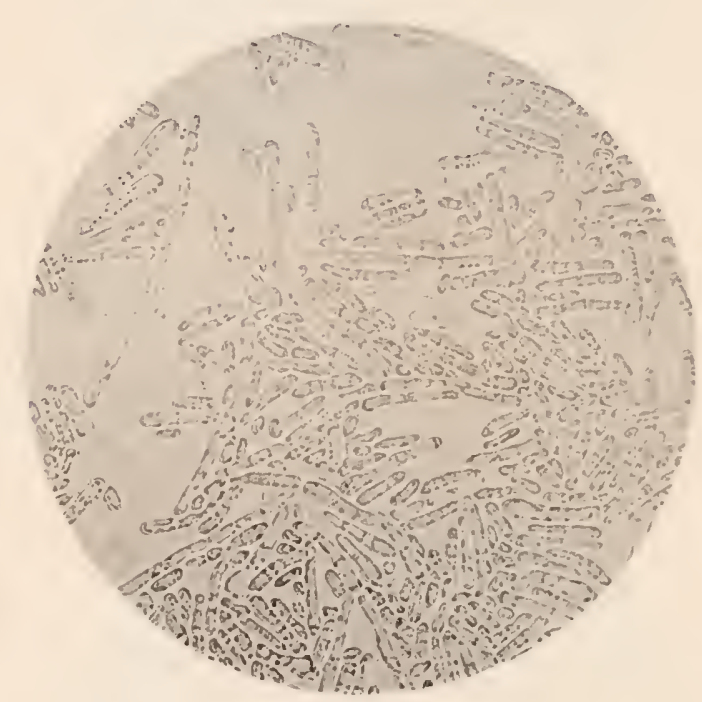

Fig. 348.

Sacch. Pastorianus III. -- Voile ancien. (Gr. 400 diam.)

Comme les spores, les voiles se forment pour une même race de Saccharomycètes et à une mème température en un laps de temps invariable. Ce laps de temps varie suivant les espèces.

Cette particularité s'ajoute aux ciivers moyens d'identification que nous avons signalés plus haut.

Le mérite de cetle décourerte, qui complète celle des caractères spéciliques de la sporulation, et a permis de dilférencier certaines espices de levures cucore mal caractérisées, appartient encore à ilinsen. 


\section{NOYAUX ET RESEALX GELATINEUX}

On a longlemps discuic pour savoir si Ies Sacchitromycètes possédaient un vrai noyau. Les recherches de Jenssen l'ont mis en évidence. Sa méthode est particulièrement hasće sur l’emploi de l’acide osmicue.

On a pu suivre, d'aprìs la méthode de Jenssen, les transformations du noyau des Salcharomycètes an conts de la multiplicillion des cellules par bourgeonnement el par sporulition. Le's ligures de kargokinèse sont toutefois difficiles it olıtenir.

Lorsqu'on abandonne un dépòt de lerure ì l'air libre jusqu'i siccité presque complète, l'examen microscopique révèle l'existenre d’un réseau gélatineux colorable à la fuchsine. Ce réseilu gélalineux des Saccharomyeètes a élé comparé aux masses gèlatincuses qui entourent certains microcoques. 


\section{LEVURES DE VIN}

On pensail, avant les recherehes de llansen al de ses élères, qu il n'existait pour le moût de vin qu’un seul ferment alcoolique, lé Sacsharomyces ellipsoüdeus. Cetle dénomination serait en ious cals impropre, puisqu'on rencontre dims le mout de rin en fermentation des levures de forme très variable, depuis la levure apiculéc (roir plus loin lig. 551 et 552) jusqu’aux formes allongées dites « P'astoriennes ».

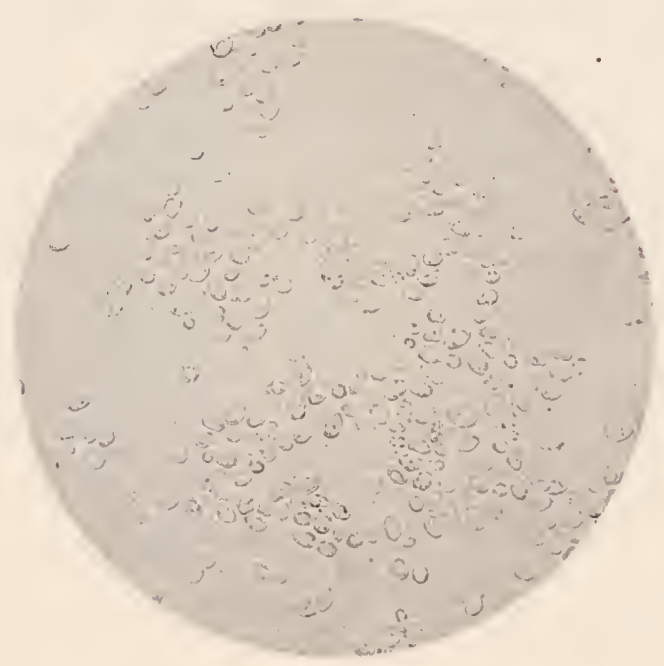

Fic. 349.

Levure de vin de Champagne en culture pure sur milien lifuide (gr. 400 diam.).

Lat plupart des levures de vin sont morphologiquement assez semblables anx levures de bière. Toutefois leur diamètre est généralement plus pelit et leur forme plus irrégulière (fig. 549). P'resque tontes les levures de vin sont des levures basses. Nous n’ en avons observé que de trís rares especes qui donnent en culture pure des phénomènes de fermenlalion haute.

Les levures de vin, sur milien solide, se développent sous forme l'une conche blanche on blane grisithe assez homogenr, comme tous

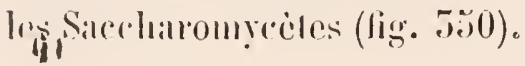




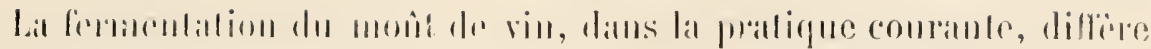

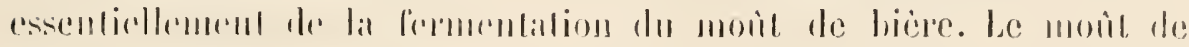

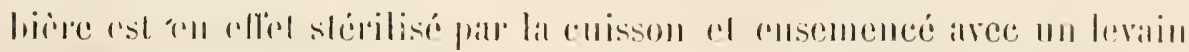

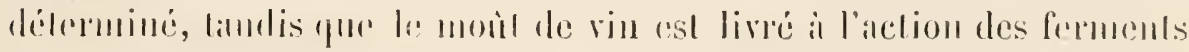

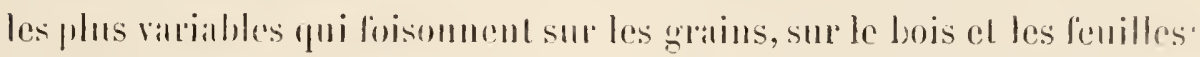

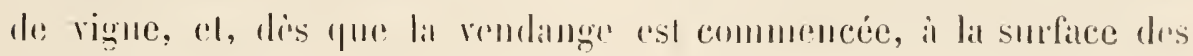

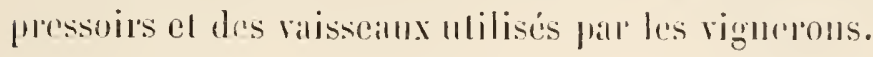

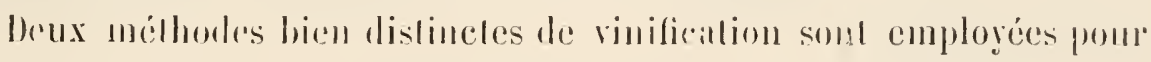
les vims malumels, smivaml yu'il s'agit de vin rouge ou de vin blanc.

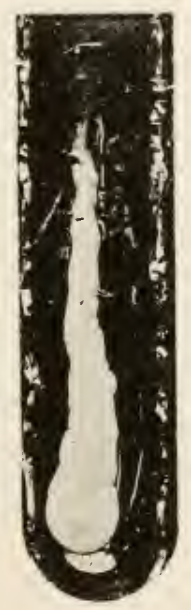

HIG. 550 .

Levure de vin du Rhin. Culture sur nilieu solide.

Pour le vin rouge, les grappes sont versées dans des cures d'un grand volume et écrasées par le foulage. La lermentation se produit bientòt et le vin est soutiré lorsque la presque totalité du sucre a ćlé transformée en alcool. Ensuite les mares sont épuisés sous le pressoil.

Pour le vin blanc, dont le type de fibrication alleint le degré le plus parfait en Champagne, la grappe est atu contraire cucillic salls êlre froissée, transportíe avec soin dans des panicr's d'osicr, et sommise intacte à l'action du pressoir.

Le vin blane de Clampagne est en eflel falurigue en majumere parlie arec du raisin noir, el éest ì ees précintions quon doil de ne pas l'obtenir " rosé » "u, jour mieux dire, " taché ». 
Le pressurage, à cet effet, est mené rapidement. Le premier moût porte le nom de "cuvée ». Il deit ètre limpide et incolore. Le marc est ensuite épuisé et, dans certaines contrées, comme en Champagne, le dernier jus, qui est taché, est mis à part comme étant de qualité inférieure. Le vin blanc peut done être obtenu arec du raisin noir, à condition de faire la cueillette avec soin et de pressurer avant que le grain, meurtri et contus, u'ait subi à sa surface un commencement de fermentation.

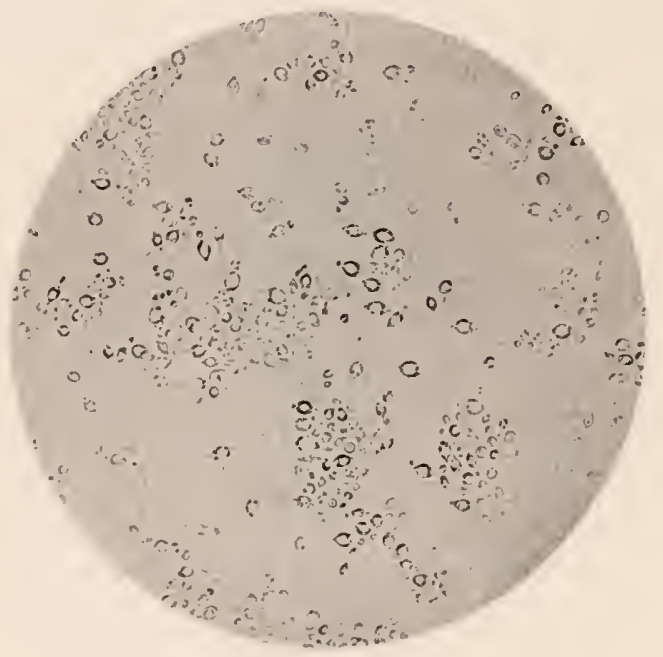

Fig. 351.

Levure apiculée provenant d'un moût de Champagne (Ay). (Gr. 400 diam.)

Dans les années où le raisin est trop mûr, il est difficile d'obtenir avec dụ raisin noir un moût absolument incolore.

Lc moùt au sortir du pressoir, est mis en fùts, où il reste jusqu’à complète fermentation.

Dans la fabrication du vin rouge, la grappe est au contraire écraséc, ou, pour employer le mot technique, "foulée » dans de grandes cures de 10 à 20 hectolitres et plus, et le moût fermente au contact de la grappe, qui lui donne sa couleur.

Dans cerłains pays où le bois de la grappe reste vert, on obtient dı vin ronge de meilleure qualité en pratiquant l'égrenage et en séparant de la grappe elle-mème les grains, qui sont foulés seuls; isolís de la partic ligneuse, et livrés ainsi a la fermentation. 
Qu'il s'agisse de vin blanc ou rouge, diverses levures se succèdent au cours de la vinification.

La levure apiculée, dont nous avons isolè plusicurs espèces (fig. 551 et 552), apparait la première, pour disparaître dès qu’il cxiste une petite proportion d'alcool. Cette levure se trouve également sur les prunes, les abricots et presque tous les fruits sucrés, au moment de leur

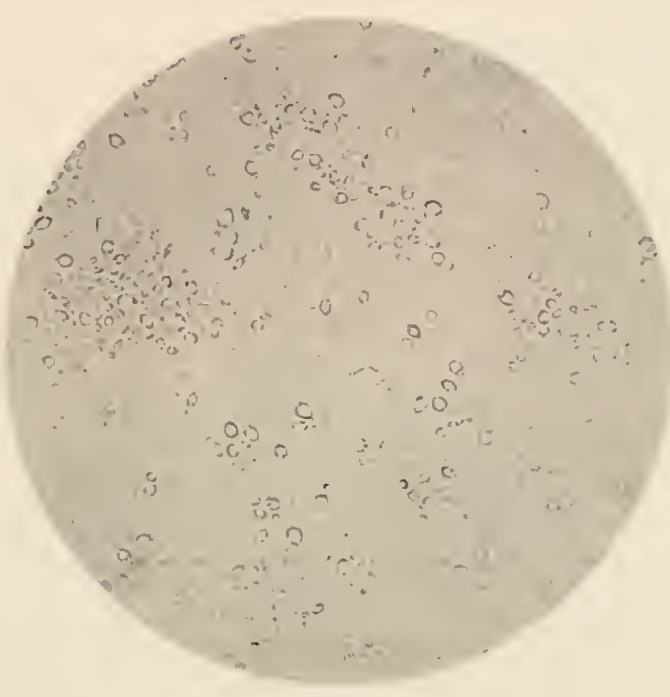

Fic. 352.

Levure apiculée provenant d'un moút de Champagne (Bouzy). (Gr. 400 diam.)

maturité. Les levures apiculées n'ont pas de sporulation connue. Elles n'apparticnnent donc pas au groupe des Saccharonycètes.

Ce sont ces derniers qui sont en général pour le vin, comme pour la bière, les véritables agents de la fermentation alcoolique.

Leur multiplication, d'abord lente, s'accentue rapiaement et est caractérisée par le " bouillage » du moût.

L'analyse bactériologique des moûts de vin en fermentation, faite d'après les méthodes de flansen, démontre que, dans un même cru, végètent côte à côte une multitude d'espèces différentes.

Ces espèces semblent se succéder les unes aux autres au cours de la fermentation, à chacun des stades de laquelle prédemine l'une ou l'autre. 
On comprend done combien est eomplexe l'élude de la vinificalion. Cés parliculariles expliquent égalcuent les ichees multiples qu'ont rencontres les essais d'ensemencenents de moùt de vin arec des culfuress pures, métlode an contraire si remirquable dans la filbricalion le lis biere.

Ijoutons que, pour le moùt de vin, il faul encore envisager, daus le's tentalives d'ensemencement, la concurence des levures naturelles, i) layuelle il est impossible de remédier par la slérilisation du milieu.

Le cardre de cet ourrage ne nous permet pas de décrire ici les méblhorles dont nous disposons pour obrier à ces divers inconvénients.

I coté de la fabrication des vins ronges et blanes naturels se placrent la fabrieation des vins monsseux el la labricalion des vins de sucre ct de raisin sec.

Le's cins merussecux sont obtenus par une seconde fermentation, en vase clos, du vin déji sontiré ol elarifić. On additionne à cet effet le vin on les divers crus mélangés pour obtenir telle oụ telle qualité

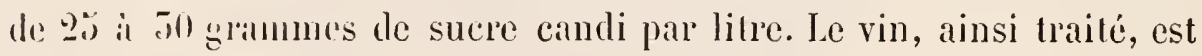
mis ent bouteilles.

liimlôt se développent les lerures naturelles qui restaient en susperssion dans le liquide, et il se produit en vase clos un dégagement l'alcide carbonique qui porte la pression à ơ ou 6 atmosphères.

lies que le vin a pris mousse el que la levure est ramenée à la prulie dielive de la bouteille, maintemue horizontale, celte dernicre esl mise sur prointe, el le clépòt, par diverses manœurres, est amené sur 11. buchon pour ètre expulsé par le " dégorgement».

Le vin est alor's prèt pour l'expédition et dosé de liqueur sucrée en ylimlité variable.

I. ein de sucre est fait avee les aines ou mares, qui doivent alors

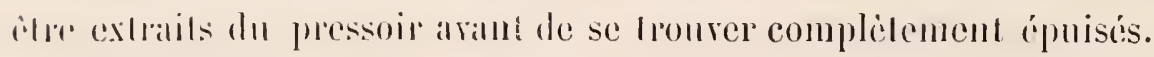

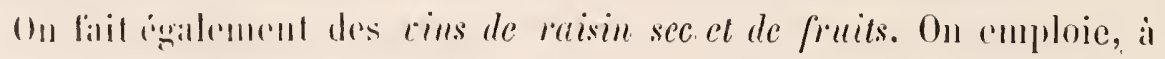

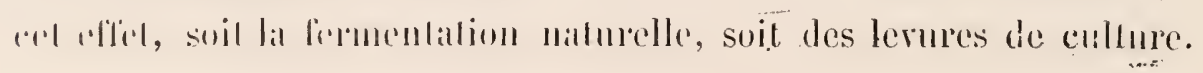




\section{LEVURES DE CIDRE}

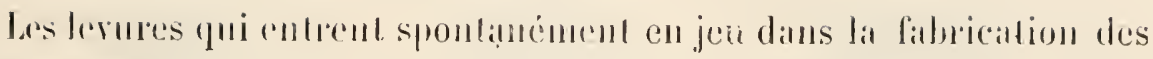
cideres se trouvent, all momant de la recolle despommes el des poires à cidre, à lit surface de ces fruits.

On a isolé des lerures de cidres dont l'ensemencement a donné de bonts résultats.

\section{LEVURES DE DISTILLERE}

Les levures de distillerie (fig. 555) sont des levures industriclles que l’on a choisies parmi les levures de bières susceplibles de donner le plus fort rendement en alcool.

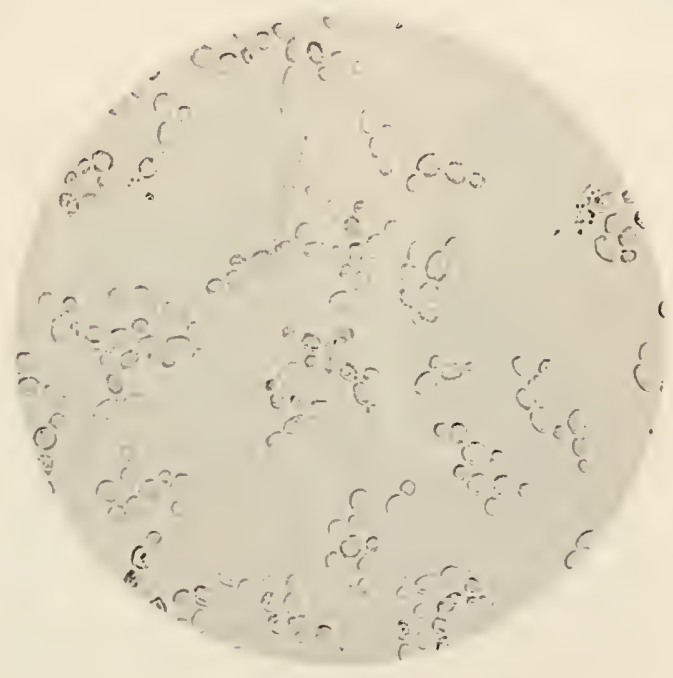

Fig. 555.

Levure de distillerie. Culture jeune (gr. 400 diam.).

Ce haut rendement s'explique par ce fait, que les levures choisies comme lerures industrielles de distillerie sont capables de fermenter non seulement le glucose, le maltose et l'iso-maltose, qui sont directement fermentescibles, mais aussi les produits intermédiaires de la décomposition de l'amidon, tels que les dextrines et les amjloïdes inférieurs. 
La sporulation et la formation des voiles sont pour les levures

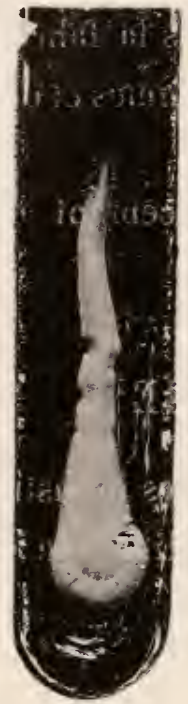

Fig. 354.

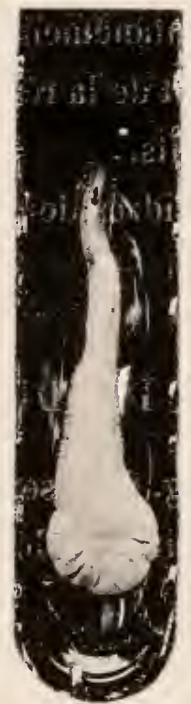

F1G. 355.

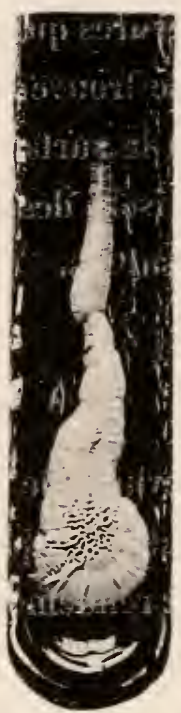

Fig. 356.

Trois levures différentes de distillerie. Cultures sur agar au moût de bière.

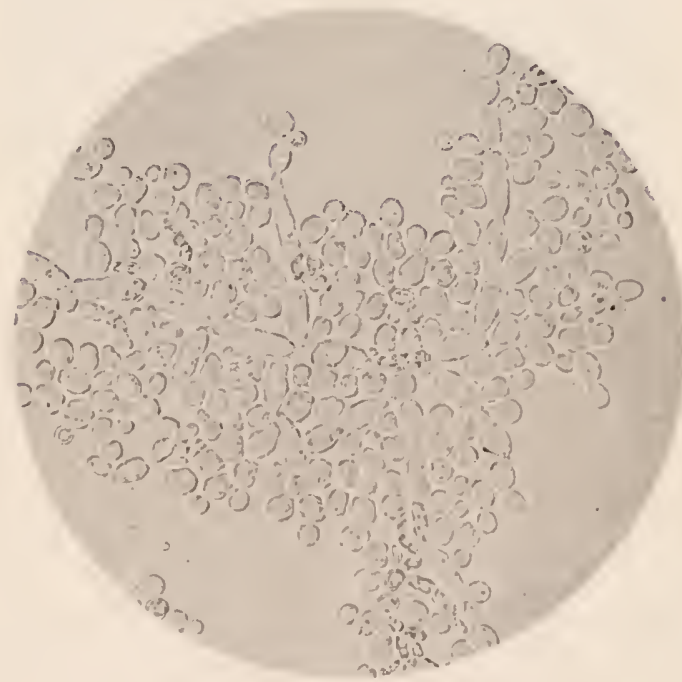

Fis. 357 .

Levure de distillerie. Formes allengćes (gr. 100 diam.).

de distilierie ce que l'on observe pour les autres Saccharonycètes et orit servi au classement des diverses espèces industrielles. 
Nous représentons, fig. $5 \% 4,53 \%$ et 556 , trois levures de distillerie en culture sur milicu solide (agar-agar au mon̂t de bière).

Dans la figure suivante, on remarque quelques formes allongées provenant d'un voile et que l'on rencontre parfois dans le dépôt quand la culture a èté agitée.

Les moùts de distillerie sont en général composés de toute espèce de matières saccharifiables, telles que malt, orge crue, c'est-ì-dire non germée, seigle, riz, maïs, pomme de terre, betterave, etc.

\section{LEVURES DE BOULANGERIE}

Les levures de boulangerie sont des levures hautes de bière. Les levures basses ne donneraient aucun résultat, à moins d'artifices

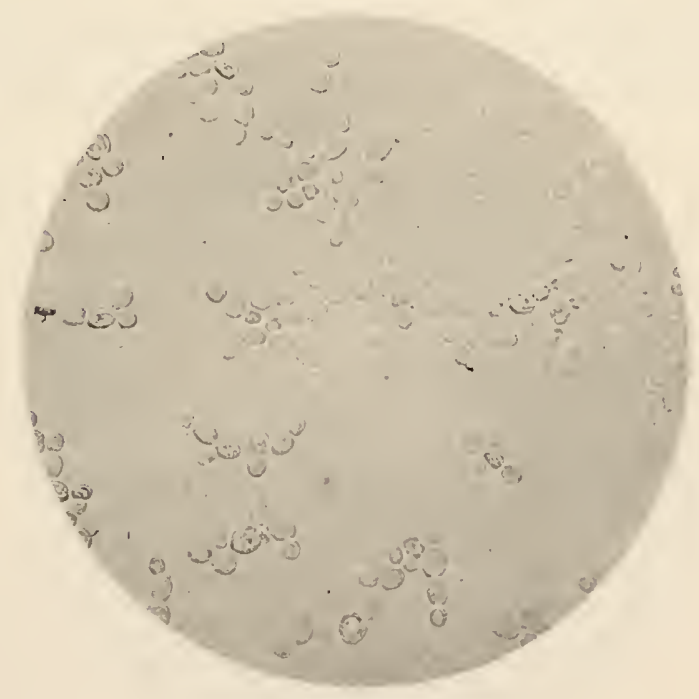

Fig. 358.

Levure de boulangerie (gr. 400 diam.).

spéciaux. On recherche pour la boulangerie les races les plus fertiles, c'est-i-dire celles qui en un temps donné se multiplient le plus vite. On reproduit ces lerures dans des moûts de trèsfaible densité, destinés 
habihellement ì la dislillerie. Le dépôt de levures est recueilli dans des baes ou mieux isolé par la force centrifuge an mogen de lurbines spéciales, puis sommis a l'achion d'une presse, alin d'obtenir des gitteaux fermes, presque sees, et par suite moins altérables.

Ces levures sont expédiées aux boulangers, qui font d'abord un premier levilu en mélangeant a de la farrine une certaine portion d’un gàteau de levure délayé dans de l'eau tiède.

La farrine de blé conlient 2 à 5 pour 100 de sucre, el l'aldlition de levure ajoute une certaine quantité de diastase à la céréilline, diastase naturelle du grain, qui toutes deux transforment en sucre une partic de l'anidon.

Certains boulangers ajoutent même du glucose.

Les cellules de levure, intimement mélangées à la farine humide qui, comme nous renons de le dire, contient naturellement une certaine quantité de sucre ainsi que des matières azotées el des phosphates propres à favoriser leur développenent, y déterminent une véritable fermentation alcoolique.

Les bulles d'acide earbonique se dégagent dans toute l'épaisseur de la pâte, et y restent emprisonnées en la gonflant et en la doublant de volume.

Le pain, ainsi levé, est prêt pour la euisson, qui élimine l’alcool et l'excès d'eau et le rend plus digeste et moins altérable, par suite de la formation d'une croûte dure et sèche. 


\section{LE KEPIIR}

Parmi les boissons fermentées, nous devons encore signaler le

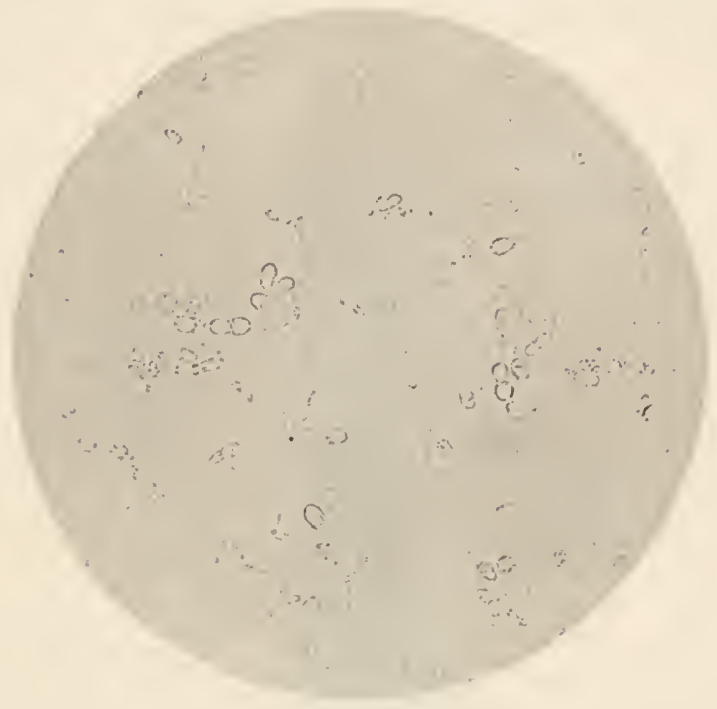

Frg, 509.

Sarchoromyces hephir. Gulture jeune. (Gr. 400 dians.)

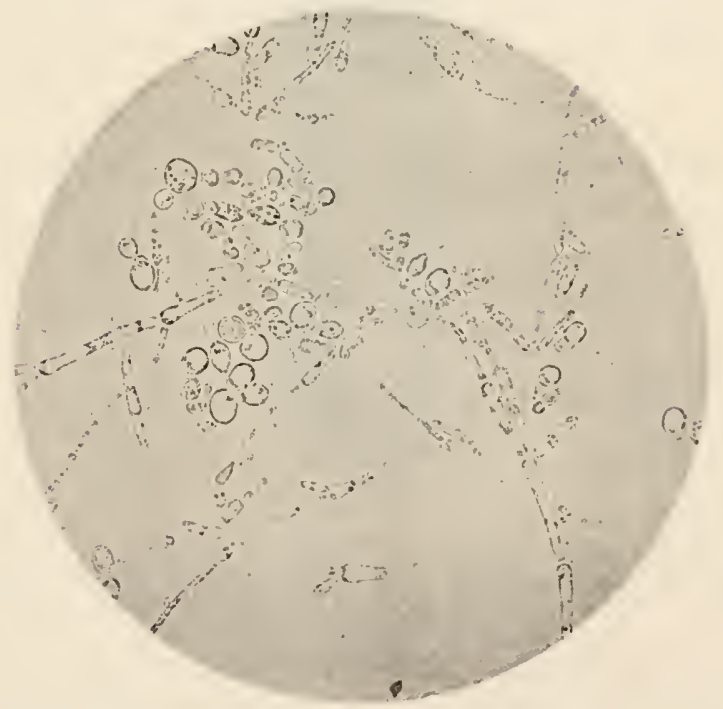

Frg. 560.

Sacharomyecs hephir. Formes de voile. (Gr. 400 diam.)

liéphir du Cantease, qui est une boisson alcoolique fermentée, provenant du lait de vache, de chère ou de brolis. 
Les grains de Képhir, que les habitants du Caucase ajoutent au lait, contiennent, outre d'autres micro-organismes, tels que la bactérie appelée Dispora Caucasica, de véritables Saccharomycètes. Nous représentons en culture pure, fig. 560 et 561, l'un de ces Sacharomycites, isolé au laboratoire de Jörgensen, à Copenhague.

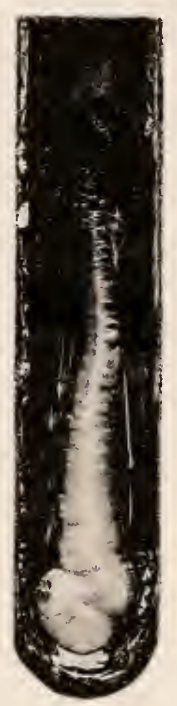

Fig. 561 .

Saccharomyces Kephir. Culture sur agar au moût de bière.

Le lait ainsi fermenté contient jusqu'à 2 pour 100 d'alcool. 


\section{SACGHAROMYCITES NON INDUSTRIELS}

En dehors des lerures industrielles, et parmi les Saccharomycètes, se trouvent un certain nombre d'organismes microscopiques plus ou moins étudiés.

Ces micro-organismes se rencontrent, soit sur les fruits, qu'ils altèrent, soit dans les moûts industriels, oủ ils jouent le rôle d'agents de maladie.

Nous représentons ci-contre la levure nommée par Rees Sacch. exiguus $\mathrm{n}^{\circ} \mathrm{I}$, en culture pure sur l'agar-agar au moût de bière. Cette levure fermente directement le Saccharose.

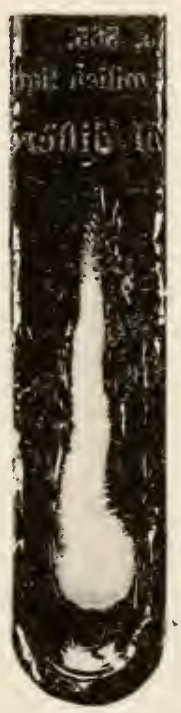

Fig. 362.

Saccharomyces exiguus I. Culture sur agar au moút de bière.

Le Sacch. exiguus II est assez analogue d'aspect.

Ces levures, étudiées par Hansen, ont été isolées d'une levure pressée de boulangeric.

Elles sont toutes deux caractérisées par le petit diamètre des cellules. On remarquera ces particularités en comparant par exemple les 
fig. 565 et 564 (Sacch. exiguus II) aux fig. 526, 529, 550 et 551 (Lerures hautes et basses de brasscric).

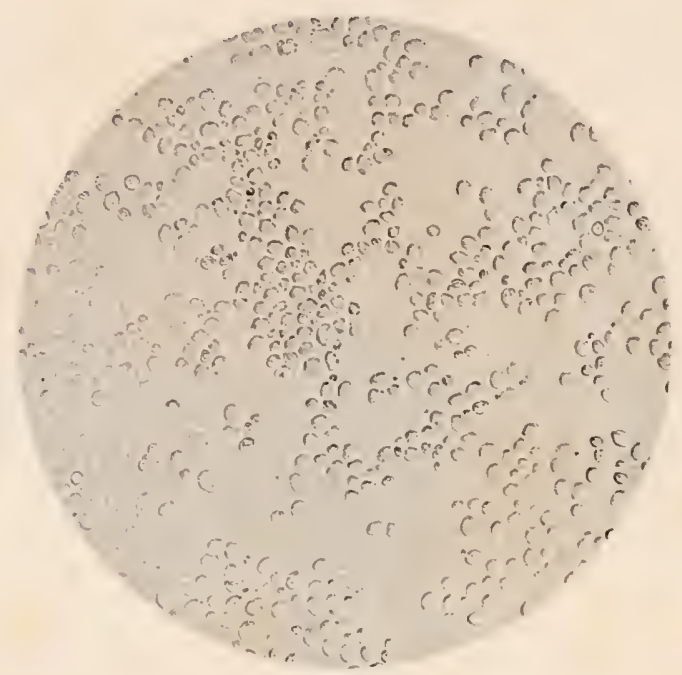

FIG. 565.

Saccharomyces exiguus II. Culture sur milieu liquide (Dextrose). (Gr. 400 diam.)

Le Saccharomyces exigms $n^{\circ}$ II diffère du Sacch. exiguus $n^{\circ}$ I en

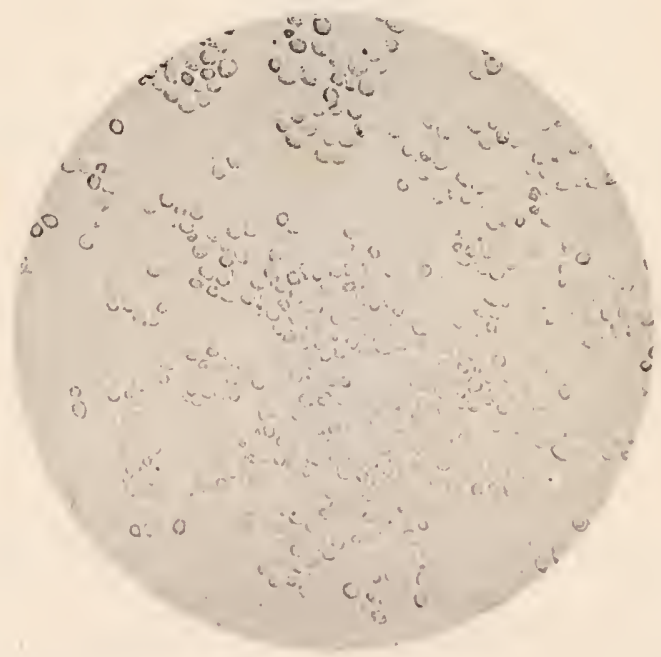

F1G. 564 .

Saccharomyces cxiguus 1I. Culture sur mout de vin. (Gr. 400 diam.)

ce sens, qu’il fermente le saceharose en donnanl de l'invertine, c'est-i-dire après l'aroir hausformé en gilneose. 


\section{S.ICGHAROMYCES ANOMALUS}

Panmi d'autres levures d'un intérêt moins immédiat nous signalerons particulièrement une espèce très curicuse par ses propriétés biologiques et ses formes de reproduction : le Sacch. anomalus.

Ce saccharomycète a été trouvé sur des fruits sucrés. Il se cultive très bien sur le mon̂t de bière. C'est une petite levure (fig. 565), qui donne licu ì une fermentation très active. Nais, phénomène particulier, en mìme temps que se fail la fermentation, il se produit il la surface du

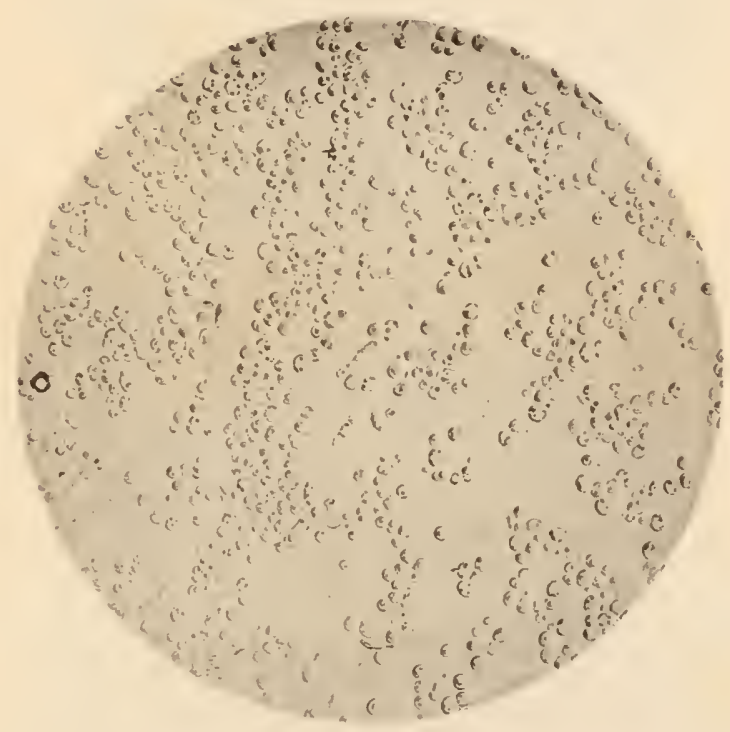

Fic. 365 .

Saccharouyces anomalus (Jörgensen). Culture sur gélatine (gr. 400 diam.).

liquide nutritif un voile très visible, ressemblant quelque peu à une couche de mycodermes, et plus marqué au bout de quelques jours que les voiles ténus de saccharomycètes que l'on n'observe qu'au bout de plusieurs semaines.

Concurremment a la formation de l'alcool, il existe dans les cultures un faible dégagement d'éther acétique. On attribue cette particularité à la présence du voile, où l'alcool s'oxyderait en partie.

La sporulation du Sacch. anomalus, dont on possède aujourd'hui plusieurs variétés, est très bizarre. Comme on peut s'en rendre compte 
sur les figures 566 et 567 , les collules en roie de sporulation devieunent

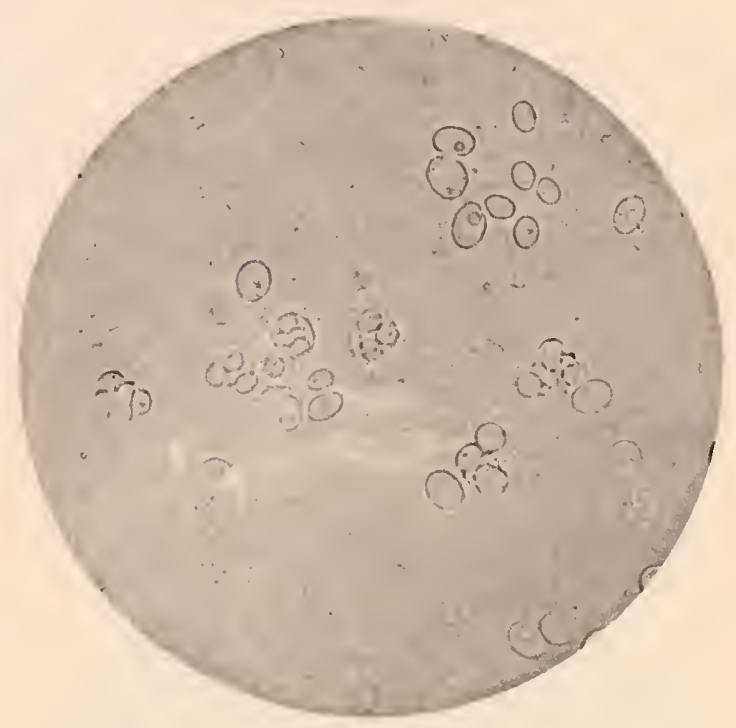

Fig. 566 .

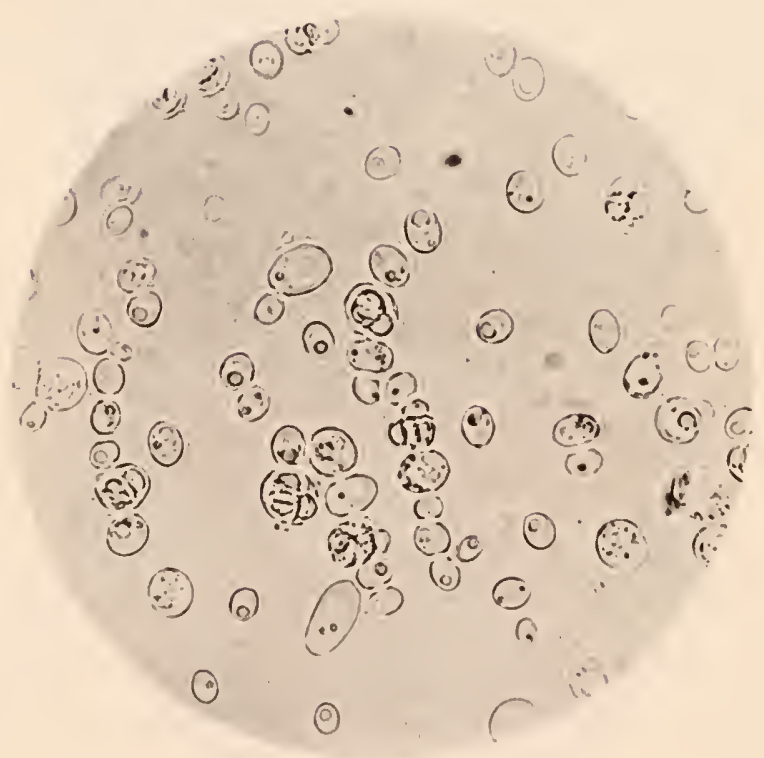

Fii. 317.

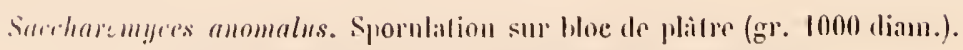
spores cufermies dims leme enveloppo rommmue.

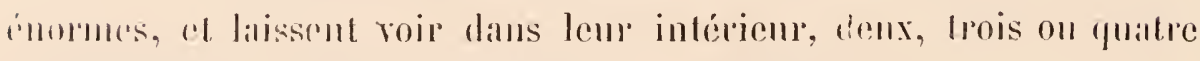

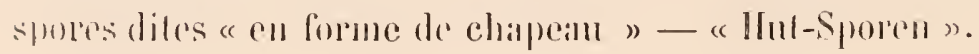




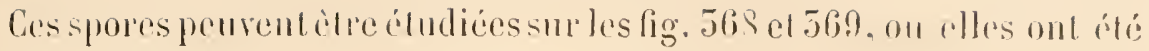

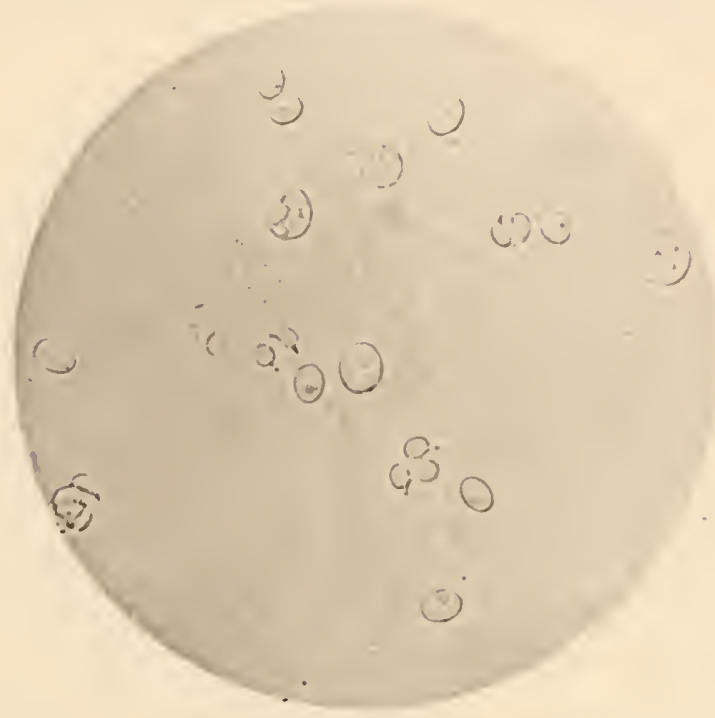

Fif. 568 .

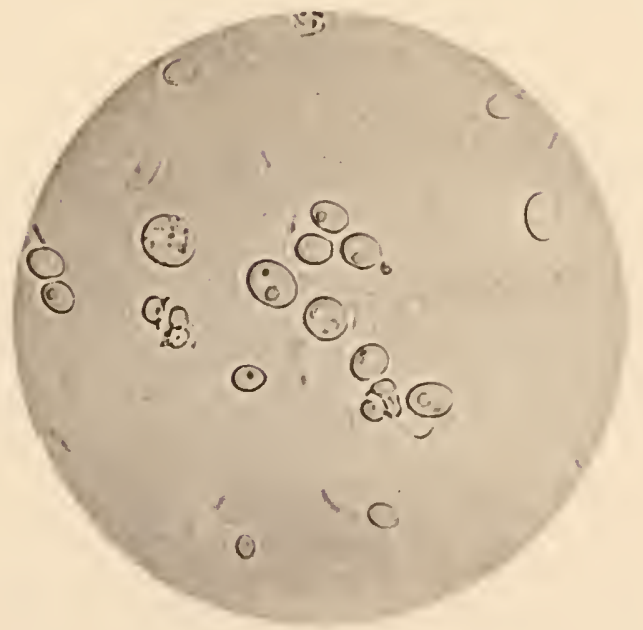

Fig. 369 .

Saccharomyces anomalus (gr. 1000 diam.). Spores mises en liberte.

mises en liberté par suite de la rupture de quelques sacs d'enveloppe. 


\section{LEVURES NE DONNANT PAS DE SPORES}

Les levures de brasserie donnent toutes des spores. Elles appartiennent donc sans exception au genre Saccharomycète.

Parmi les levures de vin, quelques-unes n’ont jamais donné de spores dans les conditions habituelles d'observation.

Hais en général les levures non saccharomycètes ne sont pas des levures industrielles. Tel le Saccharomyces apiculatus, que nous avons cité plus haut (voir fig. 551 et 552), comme apparaissant accessoirement dans le moût de raisin au début de la vinification.

Parmi les levures qui ne donnent pas de spores, nous décrirons les Torulas et les Mycodermes.

\section{TORULAS}

Pasteur a donné le nom de Torulas à toute une série de microorganismes de petites dimensions ayant l'apparence extérieure des levures saccharomycèles, mais ne donnant jamais de spores.

Les Torulas se reproduisent exclusivement par bourgeonnement.

On les rencontre fréquemment dans l'air et sur les fruits sucrés.

\section{TORULA ALBA}

Nous figurons ci-contre, fig. 570, une petite Torula à forme arrondie dont la culture se fiat très bien sur la gélatine peptone ordinaire et 


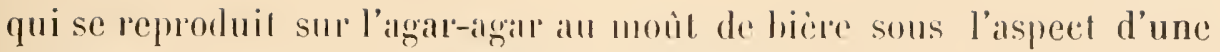
épaisse courlic d’un blanc vif.

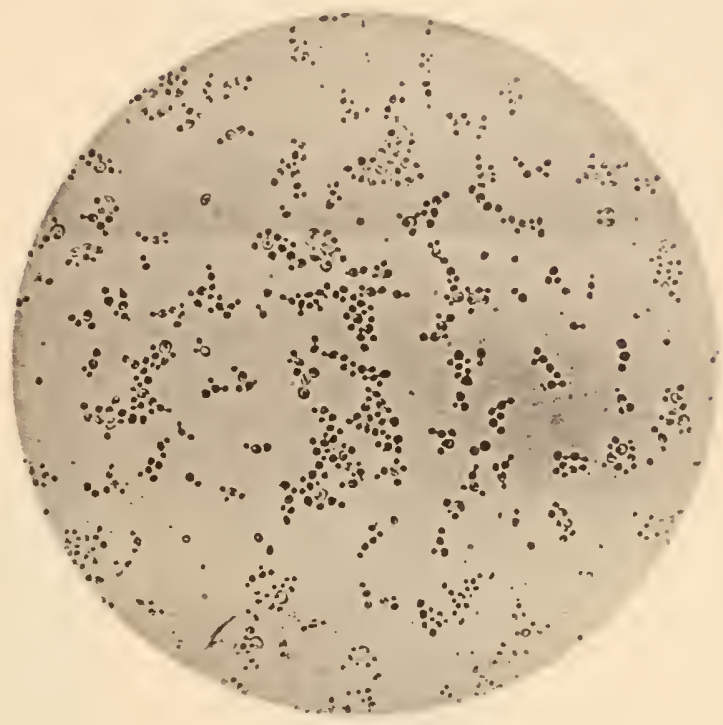

Fic. 570 .

Torula alba (gr. 400 diamı.).

Cette espéce existe en culture dans différents laboratoires sous le terme impropre de Levure blanche ou de Sacchuromyces albus.

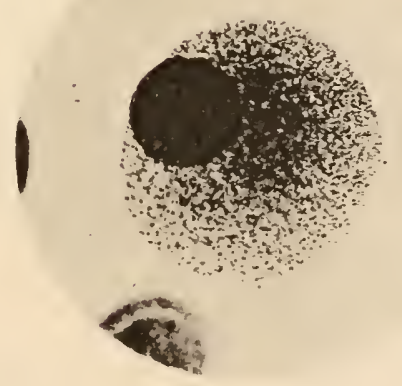

Fig. 571.

Torula alba. Colonie sur plaque de gélatine (gr. 150 diam.).

Nous représentons fig. 571, au grossissement de 150 diam., une colonie de Torula alba sur plaque de gélatine peptone. 


\section{TORULA B}

On cultive au laboratoire de Jörgensen, à Copenhague, une Torula

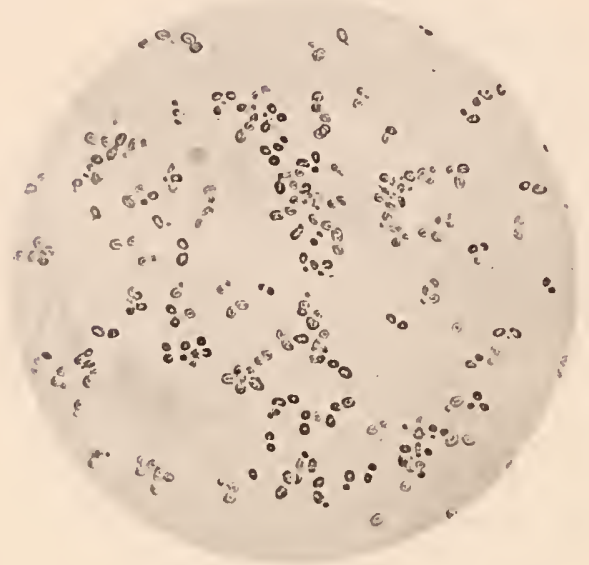

FIG. 572.

Torula B (Jörgensen). (Gr. 400 diam.)

inscrite sous le nom de Torula $B$, et dont nous donnons la photogra-

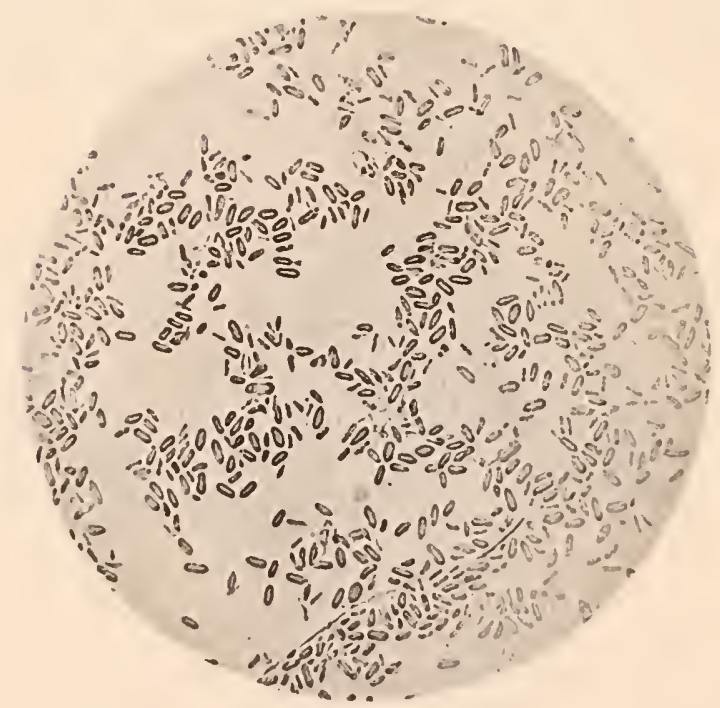

Fig. 575 .

Torula C (T. Rosea). (Gr. 400 diam.)

phic en culture sur milieu liquide (mont. de vin) (fig. 572) et sur agar-agar (fig. 574). 
TORULA C ('Torula liosea)

La Torula $\mathrm{C}$, que nous représentons fig. 375 et $57 \%$, se cultive sur milien liquide (moùt de vin), sons forme d'éléments légèrement allongés, et présente habihellement des vestiges de mỵcélium (fig. 375).

Sur lagar-agar, cette Torula forme une couche rose, ridée it sa surface et assez épaisse.

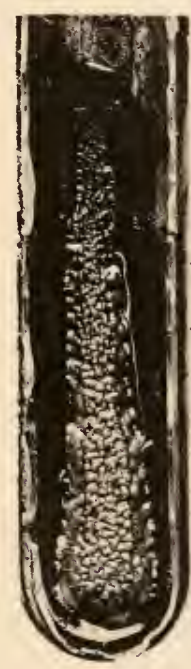

Fig. 374.

Torula B.

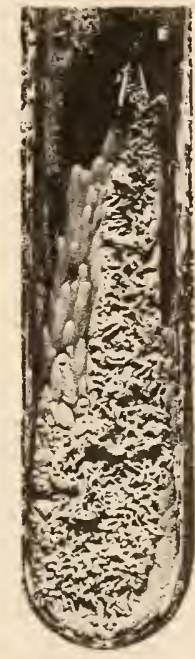

Fig. 375.

Torula C (Rosea)

Cultures sur agar-agar au moût de bierre.

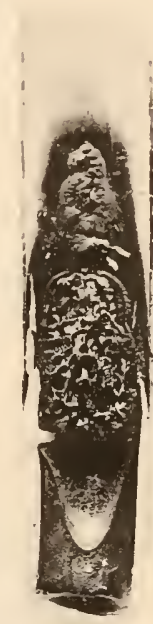

Fig. 376.

Torula nigra.

\section{TORULA NIGRA}

On a décrit sous les noms impropres de Sacch. niger at de Levure noire une torula saprophyte qui se développe sur diflérents inilicux, gélatine peptone, agar-agar peptonisé, et surtout sur le moùt de bière, sous l'aspect d'une épaisse couche noirâtre.

La culture prend un aspect sec et ridé sur l'agar-agar an moùt de bière (fig. 576). 
A l'examen microscopique, on trouve presque toujours, à côlé de très petits éléments qui se colorent à la fuchsine (fig.577), des élé-

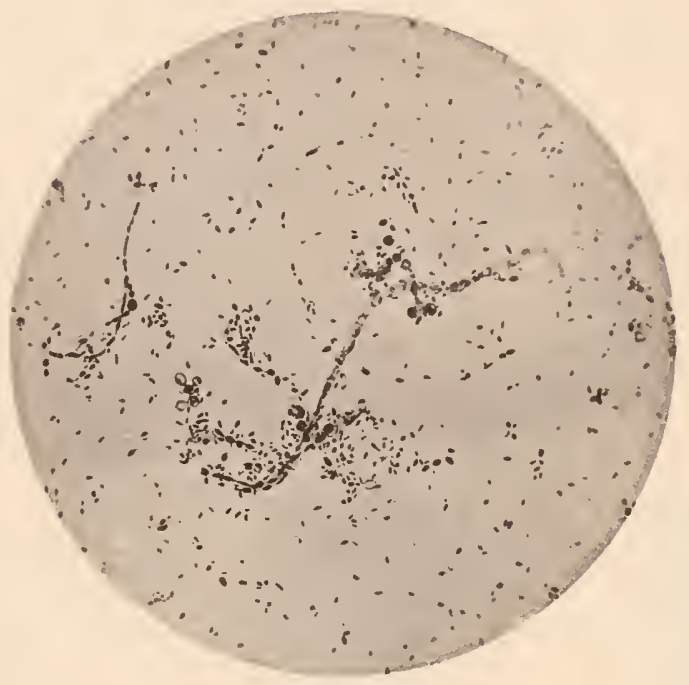

Fig. 577.

Torula nigra. Coloration à la fuchsine (gr. 200 diam.).

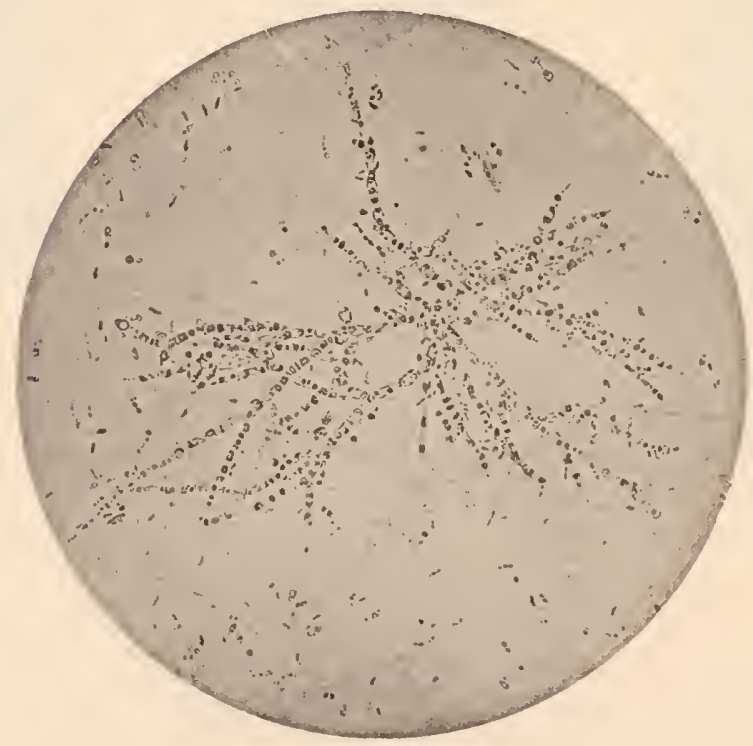

Fig. $57 \mathrm{~s}$.

Torula nigra. Vieille culture (gr. 250 diam.).

ments allongés, groupés en chapelet et ayant grande tendance à la formation de filaments mycéliens (fig. 578, 579 et 580). 
La torula que lou cullive diuns qunelques laboratoires sous les noms

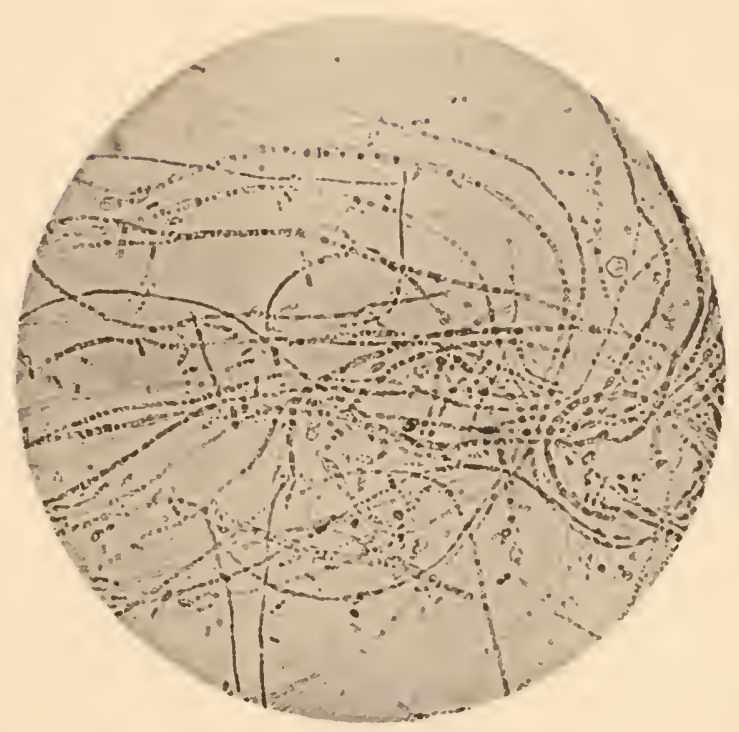

FIG. 579.

Torula nigra. Formes mycéliennes (gr. 250 diam.),

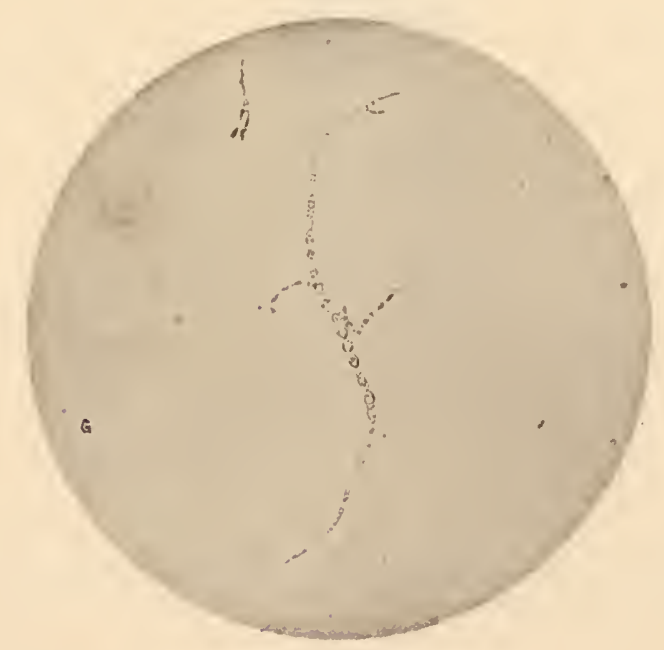

FIG. 580.

Torula nigra. Formes mỵcéliemnes (gr. 250 diam.).

impropres de Levure rose ou Saccharomyces glutinis n'est qu'une torula sans importance. 


\section{MYCODERMES}

Rees a donné le nom de IIycoder ma cerecisia et de Iycodermu vini à de petites levures qui se déreloppent à la surface des liquides faiblement alcooliques, bière ou vin, où ils transforment complitement l'alcool en acide carbonique et en eau.

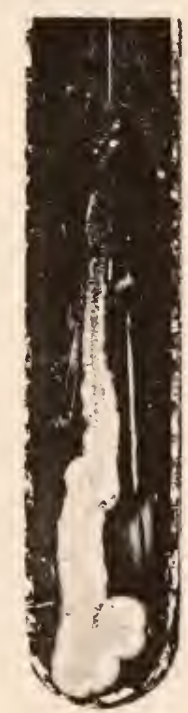

Fic. 581.

Mycoderma cerevisia. Culture sur agar an moût de bière.

Rees a cru que les mycodermes donnaicut des spores. Il n'en est rien. Ils se multiplienl par simple bourgennement.

Nons représentons fig. 381 te Myroderma seretisie. en culture sur agar-agar, ou il forme une conche mince fincment ridée, seche, ressemblant quclque pen i la culture du liacillus mesculericus vulgaris. 
Les figures 282,285 et 284 représentent des cultures pures de

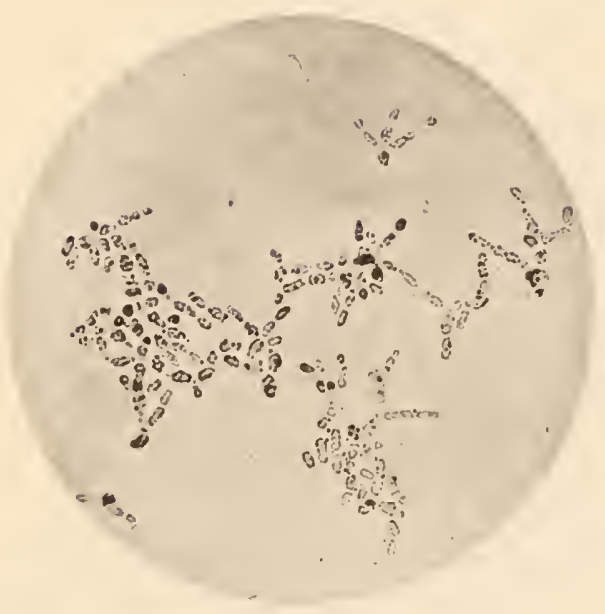

F1G. 582.

Mycoderma cerevisix. Culture sur agar (gr. 400 diam.).

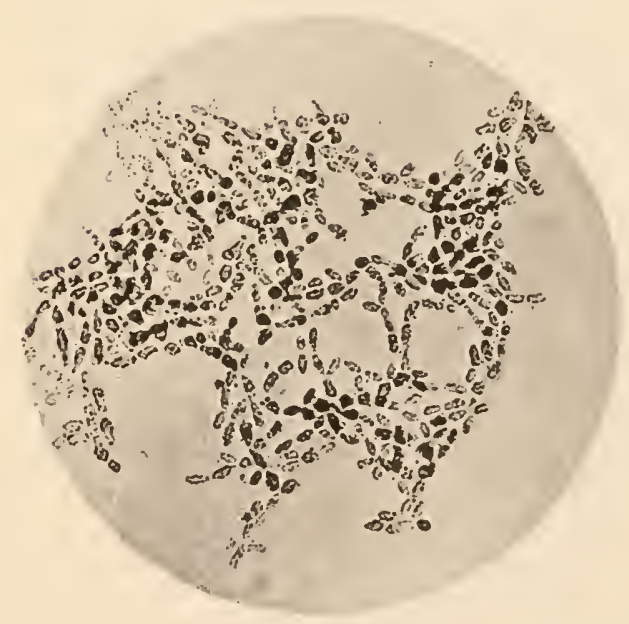

\section{Fig. 585.}

Jycoderma cercvisix. Culture sur milieu liquide (orr. 400 diam.).

Mycoderma cerevisix sur milicu liquide et sur agar-agar, à divers degrés d'ancienneté. 


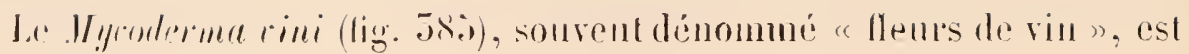

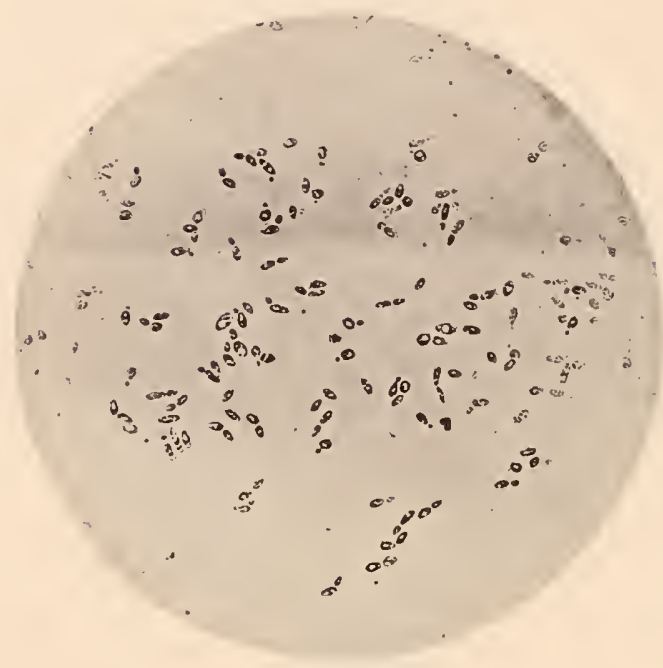

FIG. 584.

Mycoderma cerevisix. Vieille culture sur milieu solide (gr. 400 diam.).

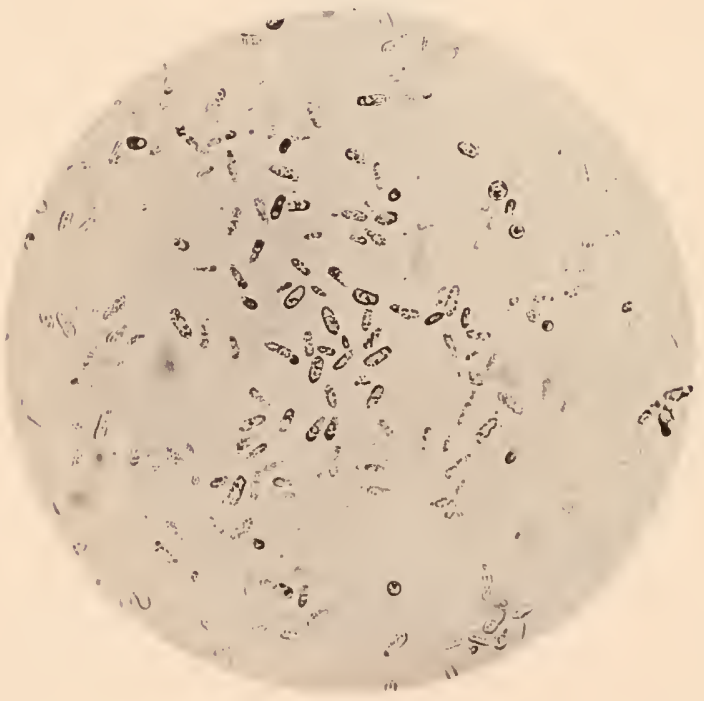

FiG. 385.

Mycoderma vini. Culture jeune (gr. 400 diam.).

assez analogue. On le trouve fréquemment à la surface du vin dans les fûts en vidange. 


\section{MONHIA CANDIMA}

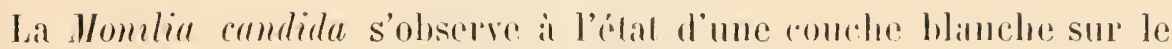
fumier ou sur les fruits suerés.

lille provoque dans le mont de biene mue formentation active, an

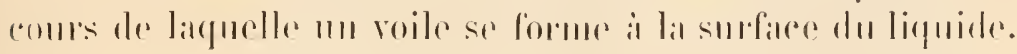

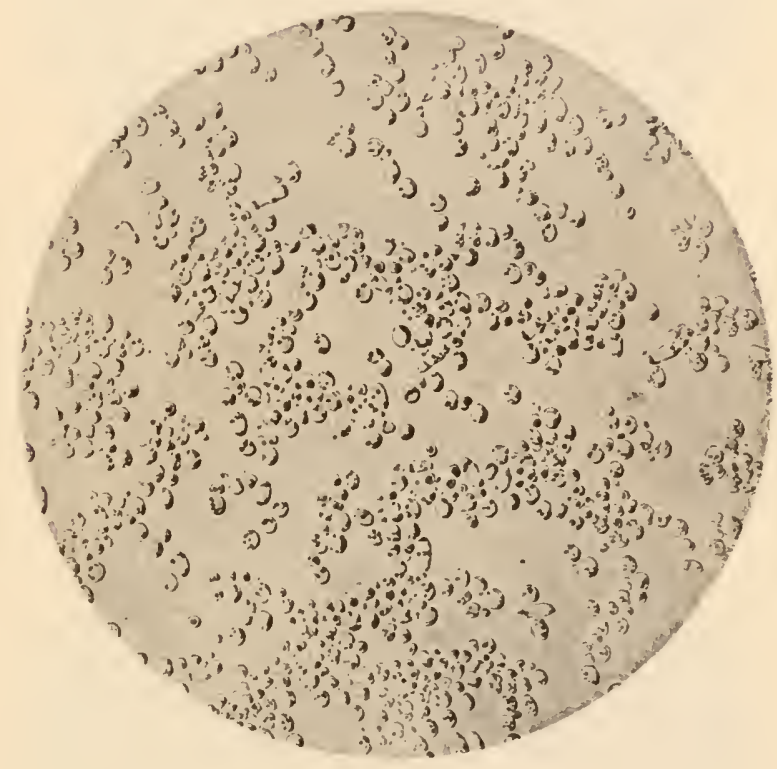

Fis. $\pi 86$.

Monilia cantida. Cultare sur moùt de bière. Formes de dípout (gre qu0 diant.)

Nous domnous lign. 786 l'aspect des cellules du dépôt all cours de celle fermentation.

On les distingne aisément avec quelque habitude des levures proprement dites, dont le protoplasma est plus gramulenx.

Lal figure 387 représente les cellules du voile, au w:onent de sal formation.

Ces éléments sont à per près sphériques.

Leur protoplasma est clair, transparent, et l'on n’̣ observe guẻre 
que des gontlelettes graisseuses el deux ou trois granulations sphériques très réfringentes.

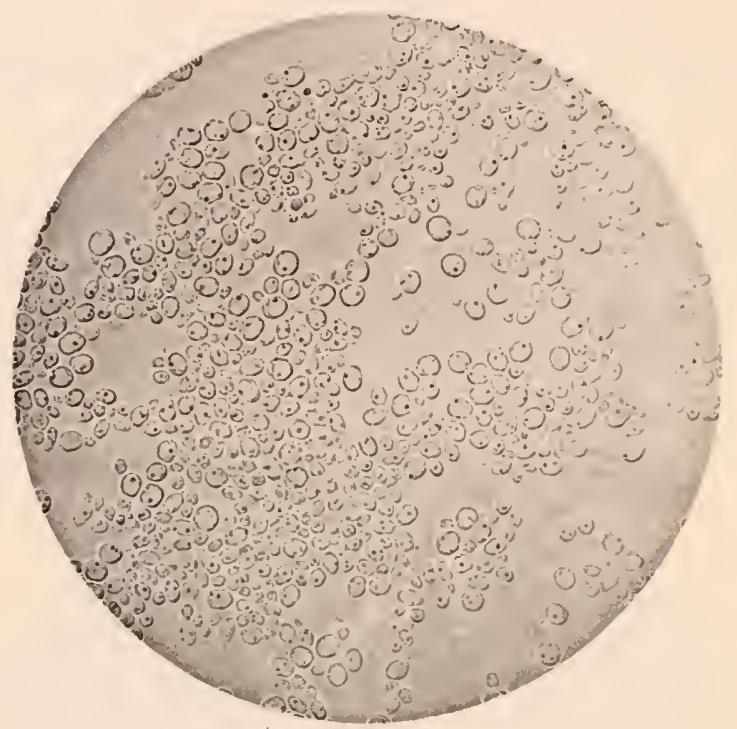

Fig. 587.

Monilia candida. Culture sur mont de bière, Formes jeunes de voile (gr. 400 diam.).

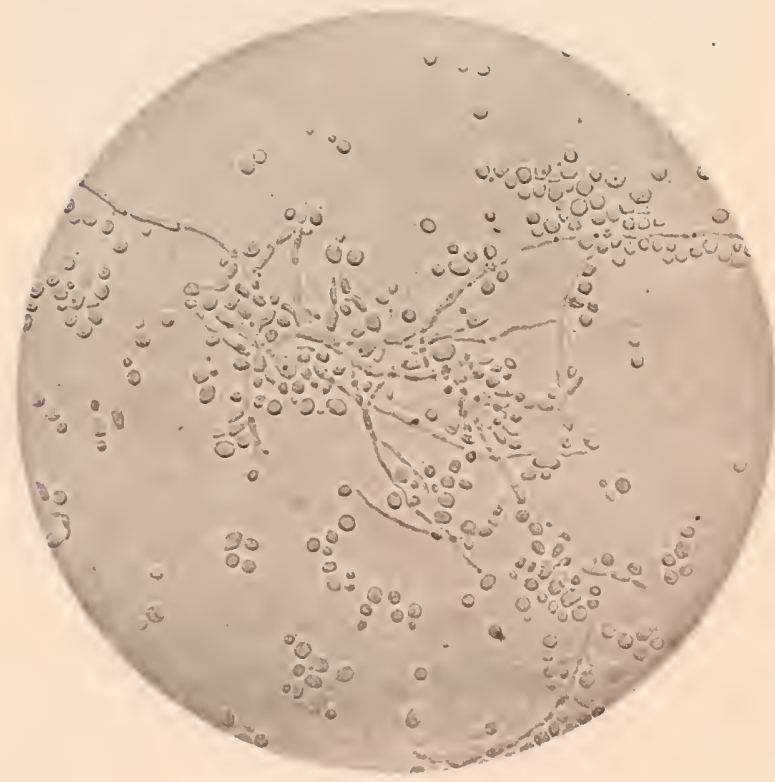

FIG. 588.

Monilin candida. Voile ancien (gr. 400 diam.).

Lorsque le voile vieillit, on roit apparaitre des formes myećliennes, très évidentes daus les ligures 588,589 et 590 . 
Ces voiles sont forl analognes comme caractires microscopiques at

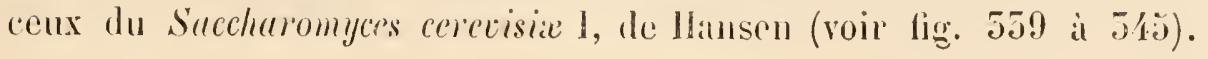

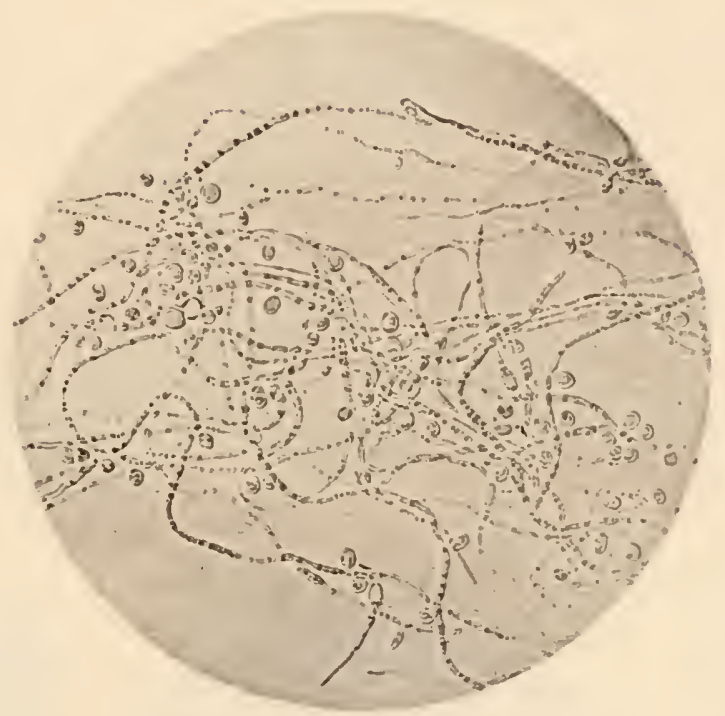

Fig. 589.

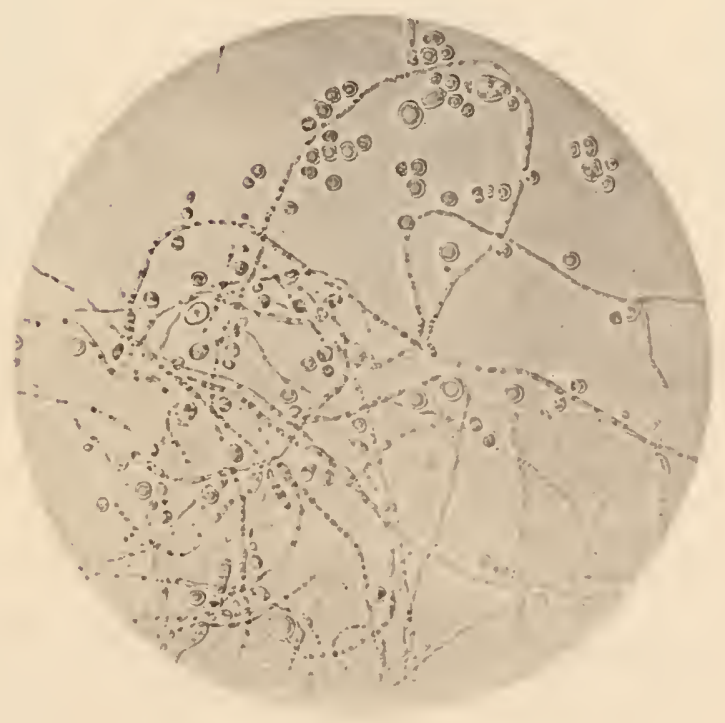

Fifi, 590.

Monilia condida. Woile ancien (gr. 400 diam.).

1 lomil nu ils sont trís dillérents, carr ils se présentent ì la surfice du liquide sous l'aspeet d'une épaisse couche blanchilte, tandis que 
les voiles de Saccharomỹcètes sont très ténus et simplement visibles ì l'examen oblique.

La Monilia candida se cultive aisément sur la gélatine peptone (fig. 291), où l'ensemencement par piquire donne une culture arborescente, assez analogue à certaines cultures de Bacillus Anthraris (voir plus loin).

Sur l'agar au moùt de bière, il se prodluit une culture blanche, épaisse et ridée (fig. 592), très différente de la couche duveteuse qu'offre sur le mème milieu unc moisissure assez analogue, la Chalara Mycoderma (fig. 595), sur laquelle nous n'insisterons pas ici.

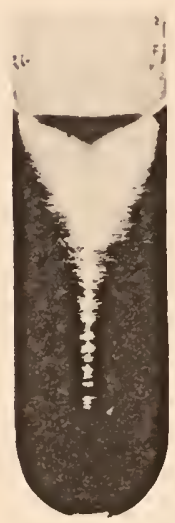

F1G. 591.

Monilia candila. Culture sur gélatine peplone.

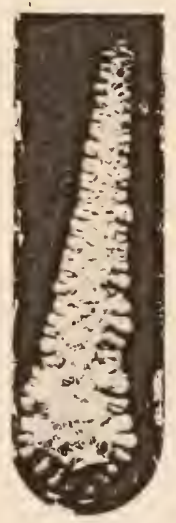

FIG. 592.

Monilia candida. Culture sur agar au mout de biese.

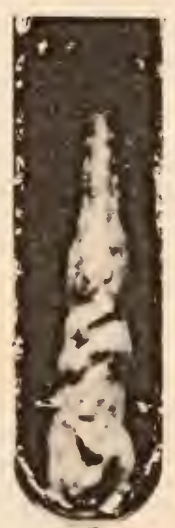

Fig. 595.

Chalara Mycoderma. Culture sur agar-agar.

\section{PROPRIÉTÉS BIOLOGIQUES}

La Monilia candida donne peu d'alcool au début de la fermentation qu'elle détermine, mais la transformation du sucre continue lentement ct, dans les conditions où le Saccharomyces cerevisix I donne en 18 jours to pour 100 d'alcool, la Mlonilia en produit 5 pour 100 an bout de plusicurs mois.

Elle ne sécrète pas d'invertinc et fermente directement le sucre de canne.

Elle ne peut être utilisée comme ferment alcoolique. 


\section{DEMATIUM PULI,ULANS}

Le Dematium pullulans se rencontre sur les fruits, notamment sur les baies de raisin.

Il est caractérisé par un mycélium ramifié d'oủ se détachent des cellules ressemblant à des cellules de levure.

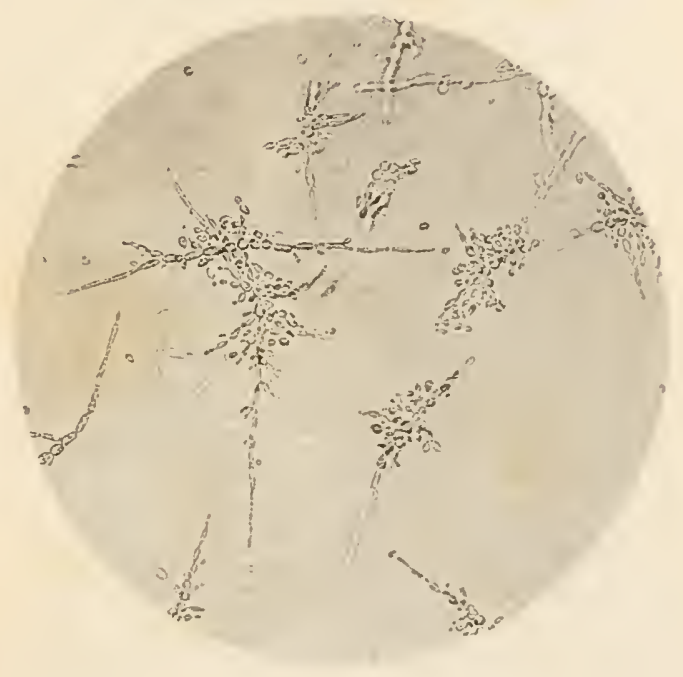

Fig. 394.

Dematium puilulans. Chambre Lumide. Formes jeunes. (gr. 300 diam.).

Ces cellules peuvent bourgeonner ou donner naissance à des filaments mycéliens.

Le Dematium pullulans se rencontrant presque toujours sur le raisin à còté des ceilules de levure, plusieurs auteurs ont été tentés d’identifier les bourgeons du Dematiun et les cellules de Sactharomycètes. Nous représentous (tig. 394 a 397 ) plusieurs colonires de Dematium pullulans sur chamber humide. 
On remarquera su: ces photographies que les éléments ovalaires

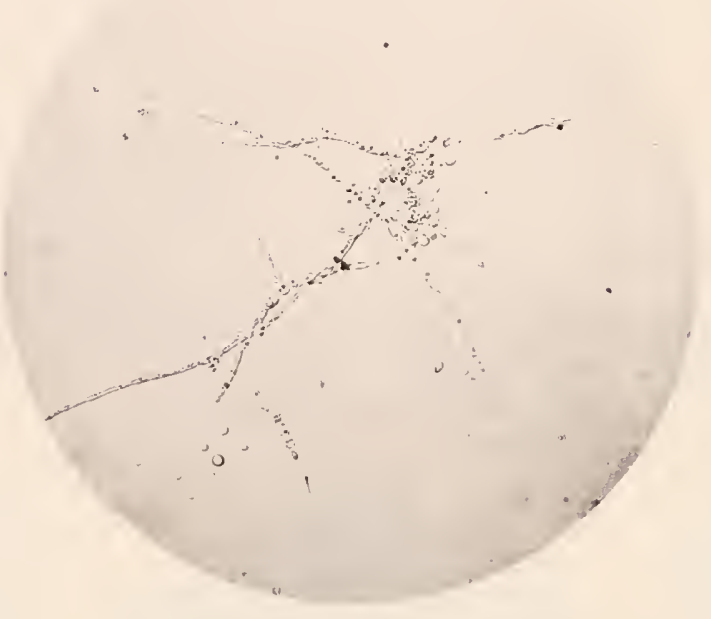

FIG. 395,

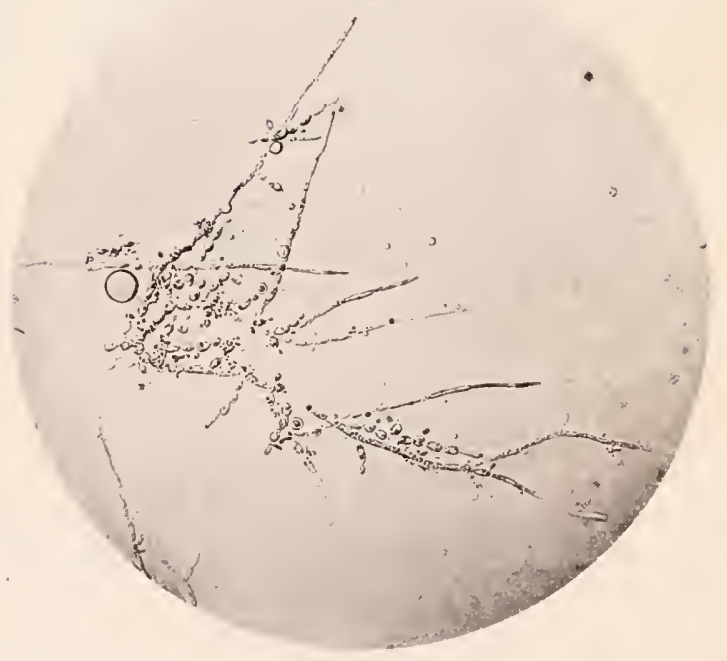

Fig. 396.

Dematium pullulans. Développement du mycélium (gr. 300 diam.).

du Dematium ont une grande analogie d'aspect arec les véritables cellules de levure. 
Le Dematium offre cette particularité, que les formes mrélicnnes appiaraissent des le délut de sa germination, tandis que les levures véritablesne présentent des formes mycélimmes yn'exceptionnellement et dans des conditions bien determinces.

Le Dematium ne donne janais de spores.

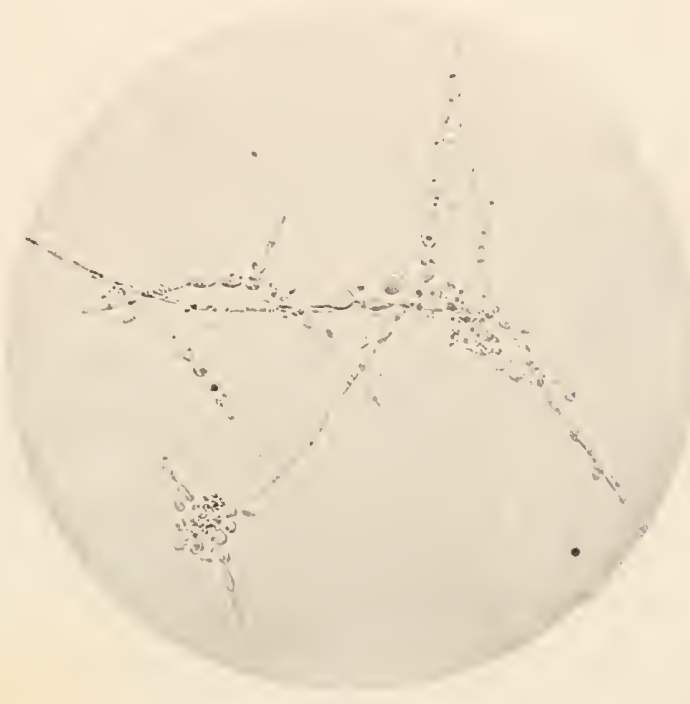

Fig. 397 .

Dematium pullulans. Chambre hunide (gr. 400 dianı.).

\section{PROPRIÉTÉS BIOLOGIQUES}

Le Dematium pulluluns poduit dans l's liquides sucrés une faible fermentation. Il est saprophyte. 


\section{LE MUGUE'I'}

Le muguet, autrefois appelé apha làctamen '(aphte d'allaitement), a porté tour a tour les noms les plus fantaisistes, puisqu'on l'a dénommé, pour n'en citer que quelques-uns : Oïdium albicans (Robin), Syringospora Robinii (Quinquaud), Saccharomyces albicans (Grawitz), Dematium albicans (Laurent).

Nous étudierons le champignon du muguet d'après les intéressantes recherches de notre collègue Achalme, chef de clinique du Pr Jaccoud, et d'après nos recherches personnelles.

l.e munguet se développe en général chez des malades affaiblis, chez le's enfants en bas âge atteints d'athrepsie, ou dans les états cachectiques graves (fièvre typhoïde, paralysie, cancer, etc.).

La maladie débute d'habitude dans la cavité buccale. Quand la muqueuse est envahie par le champignon du muguet, on observe une réaction franchement acide, iémoignant qưil s'esi produit, avant l'apparition du parasite, des fermentations préliminaires susceptibles de lui créer un milieu de culture favorable. C'est ainsi qu'on observe fréquemment chez les jeunes enfants en même temps que lè muguef le hacille de l'acide lactique et un grand nombre d'autres microcoques et bactéries.

Le muguet affectionne les muqueuses à épithélium pavinenteux. II apparait. sur le dos de la langue sous forme de petites colonies arrondies d'un blanc éclatant, qui finissent par l'envelopper d'un enduit membraniforme de plusieurs millimètres d'épaisseur. La face interne des joues, le palais, sont successivement envahis, et, dans des cas assez rares, on a retrouvé à la surface de l'osophage, ou nême de l'estomac et de l'intestin (Parrol), des plaques de couleur marron, dues au champignon du muguet. 
On a rencontré également des plaques de muguel sur les cordes vocales inférieures. Parlois le champignon se dévcloppe an nivean du mamelon, ơ il est apporté par un enfant atteint de mugnt huceal. On l'a observé chez les diabétiques an niveat des organes génitaux.

Si, chez un enfant atteint de muguet, on examine le raclage de la bouche, soit sans coloration, soit par la incthede de ciram, on constate. au milieu de nombreuses cellules épithéliales, un lacis de filanents

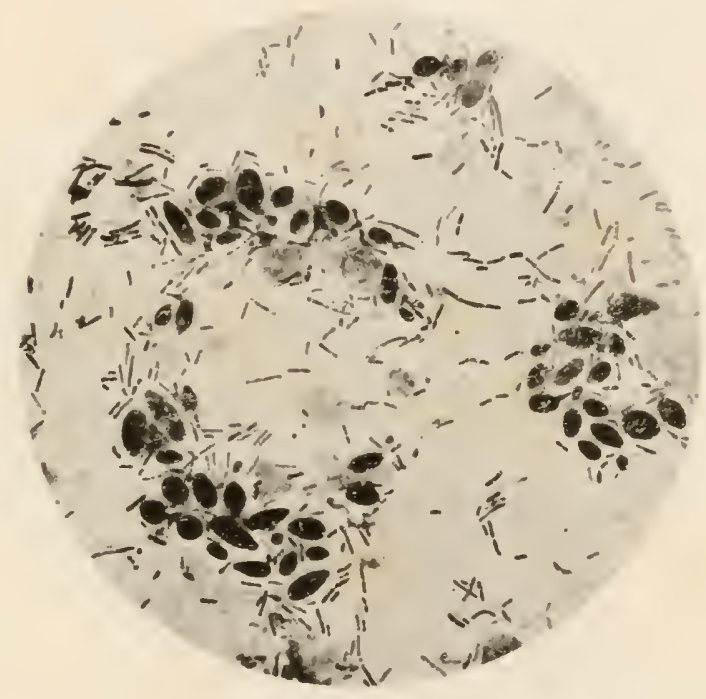

Fig. 398.

Muguet. Apparition du champignon au milieu des bacilles de fermentation laclique. Fornes jeunes el ovalaires (gr. 1000 diam.).

ramifiés, ef dans leurs mailles une quantité de cellules oroïdes allitlogues a des levures. les filamen!s sont d'autant plus abondauls que le muguet est de date plus ancienne.

Tout au début, on n'observe guire que des cellules ovalaires I)ans la fig. 598, les cellules ovalaires se montrent à l'exclusion de tout filament mỵcélien. On remarquera leur association avec le bitcille: de l'acide laclique, qui, dans cette préparation, existe presquie i l'état de pureté à côté du champignon du muğnet, 
Les filaments mỵcéliens, comme nous l'avons signalé, apparaissent dès que la maladie est confirmée.

Ils finissent par former un lacis inextricable, dissocient l'épithélium buccal, pénètreul ses couches profondes et même le derme sous-jacent (Virchow el Parrot). Jans ces cas, comme dans tout processus inflammatoire, on observe dans le chorion de la muqueuse une infiltration embryonnaire.

Pour mettre en évidence le lacis mycrilien du muguet huccal,

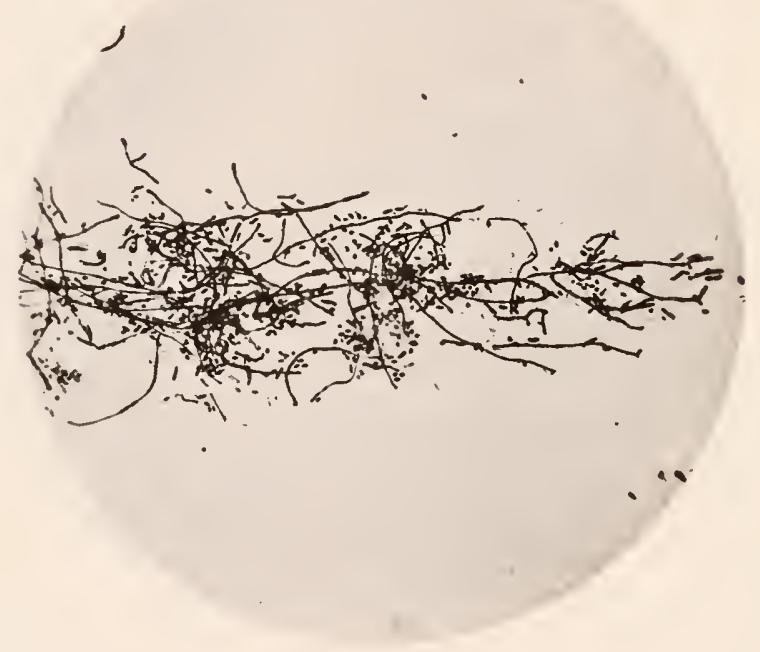

Fic. 399.

Muguet. Formes jeunes et mycéliennes (gr. 150 diam.).

il faut étendre l'enduit blanchître en couche mince sur une lamelle de verre, le fixer par dessiccation à la flamme d'une lampe à alcool, et colorer par la méthode de Gram. C'est ainsi qu'on obtient les préparations les plus démonstratives (fig. 399, 400 et 401 ).

On remarque sur ces trois préparations un lacis inextricable de filaments mỵcélicus, qui, aux grossissements de 200 et 250 diamètres offrent ì peu près les dimensions que présente le Leptotrix buccalis a 1000 dianctres (voir figr. 292).

Les filaments mycéliens sont entremilés de formes jeunes, arrondies ou ovalaires. 
On n’y distingue, a ces faibles grossissements, ni le hacille lactique,

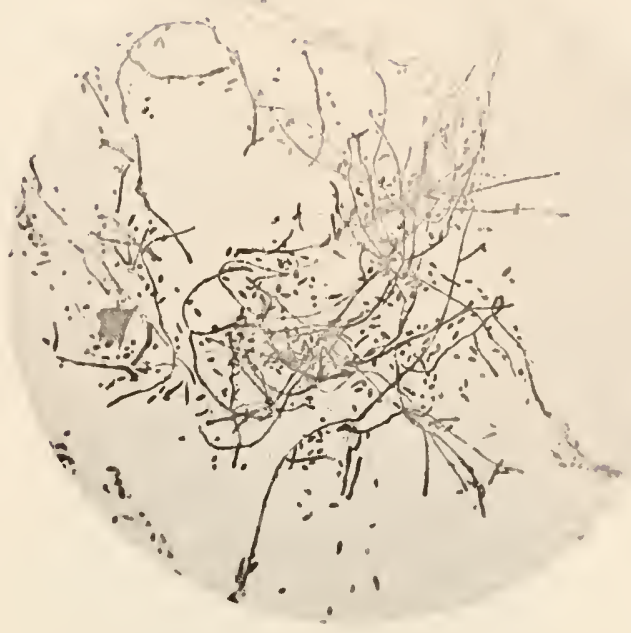

Fig. 400.

Muguet. Paquets mycéliens (gr. 200 diam.).

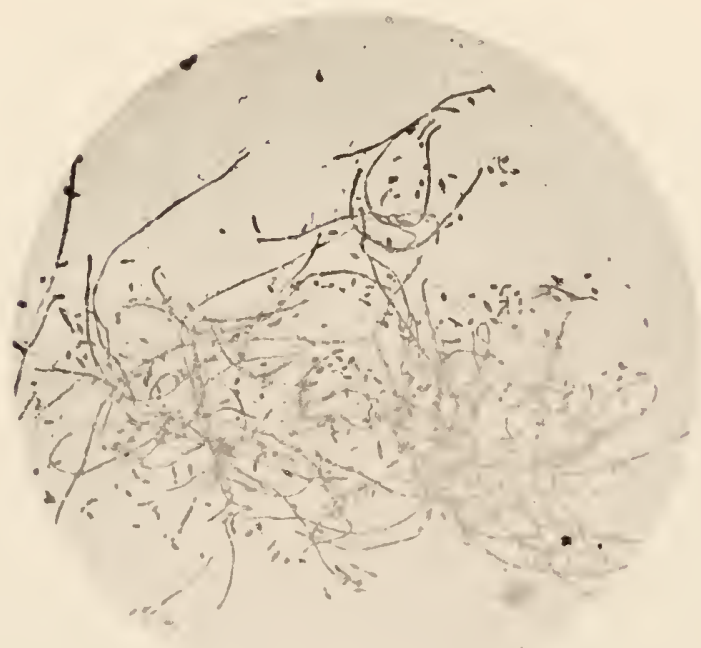

FIG.401.

Yuguet. Filaments nyycéliens (gr. 250 diam.).

seulement visible à 500 ou 1000 diam. (voir figs. 598), ni les antres 


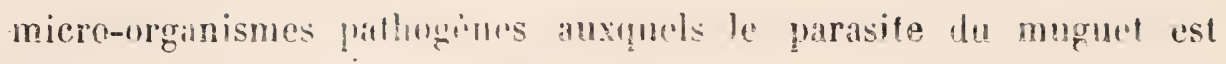

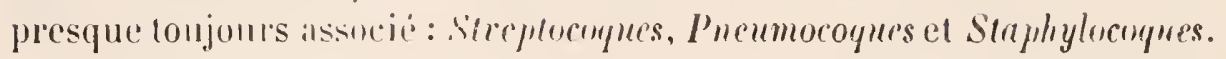

Si nous exciptoms le liacille de l'acide lactique, ces microbes, de

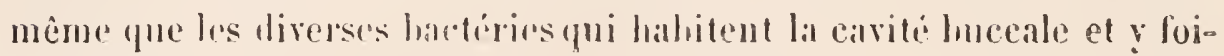
sonnent particulicmumbtians les étits cachectiques, senblent ne jouer aucun rôle dans la pathoginie du mugnet.

On a longtemps contesti que le muzbet puisse envahir la circulation générale el déterminer an loin des foyers dorigine emholique. Virchow

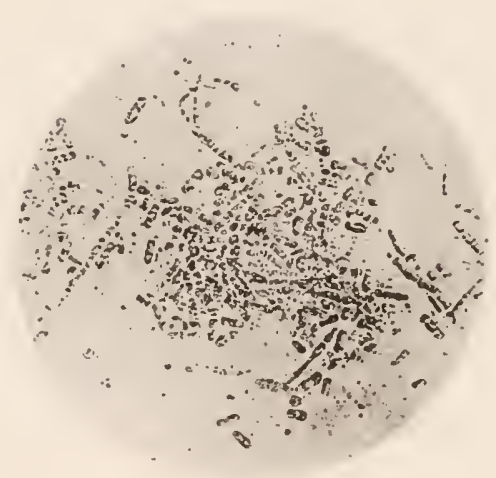

810. 402 。

Mugruet. Culturn inţurr sur agar peptonisé alcalin (gr. 250 diam.).

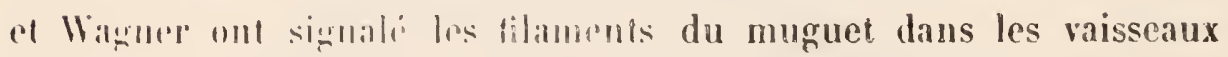

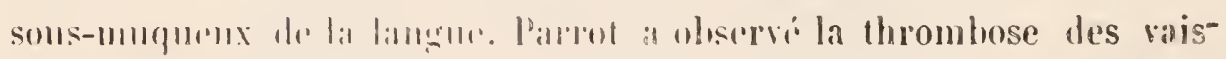

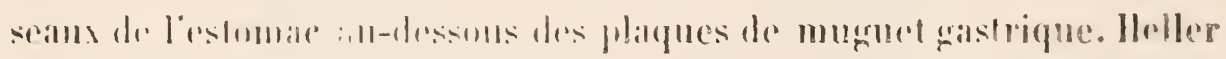

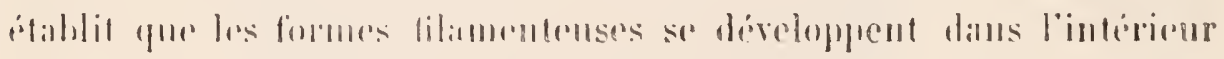

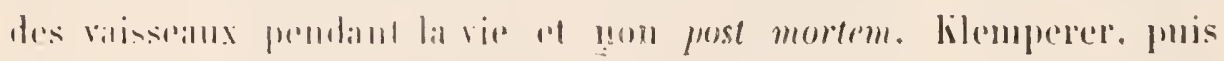

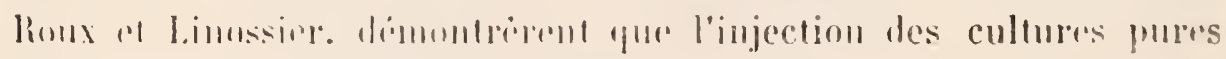

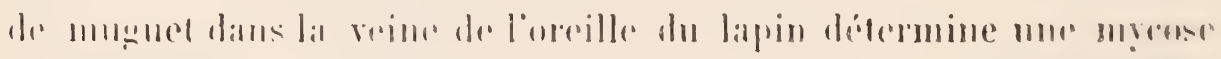

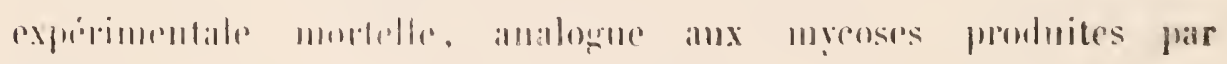

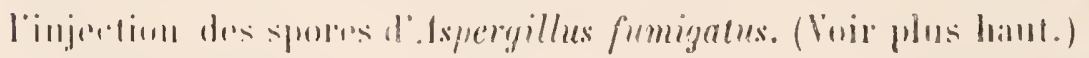

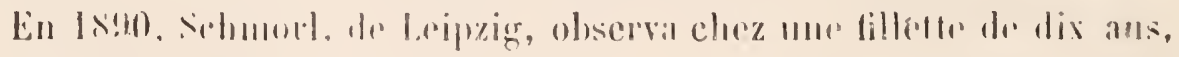

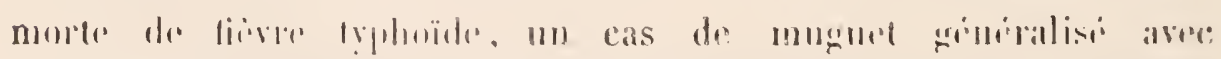

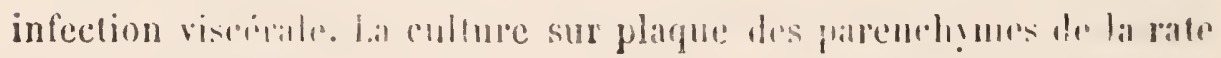

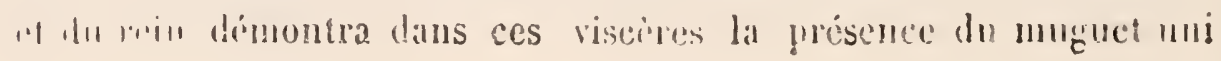


au streptocoque et all staphylocomue pyogrie. Sebmorl retrouva le

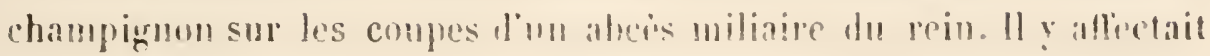

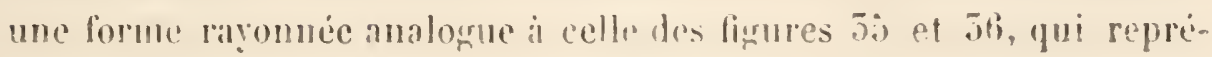
sentent dos abces miliaires asperrillinges.

Le champignon du muguot se cultive partionliopment bien sur les

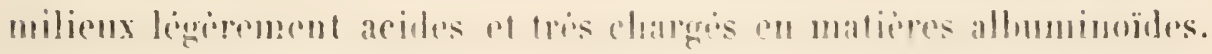

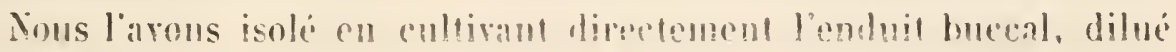
arec de l'eau steriliséc, sur de l'angr pertunise; on ohtient ainsi des

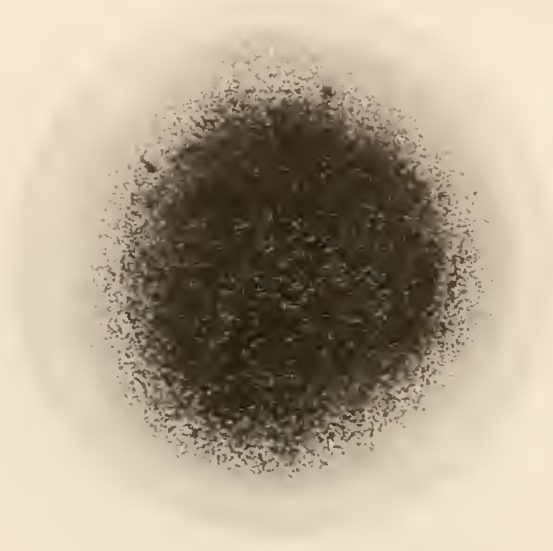

Fic. 603.

Muguel. Colonie superficielle sur plaque de gélatine. - lir. 40 diam.

cultures impures présentant rapidement des formes allongées (fig. 402), puis ou les purifie par la méthode des plaques de gélatine, ou mieux par la mithode de llansen (roir saceharomycites).

La fizure 405 représente une colonie du champignon du muguet sur plaque de félatine prefone. Cette colonic est analogne d'aspert a la plupart des rolonies de silcharomyetes gyue nous arons decrits plus hant.

Nous rornmmandons de laire les culturess sur la gélatine ou l'agar-agar

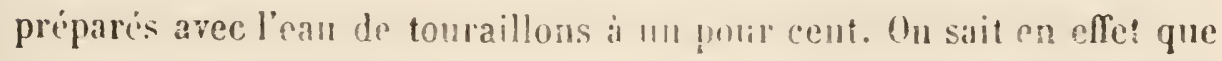
les germes, sejarés de l'orece, comme un te pratique en brasserie, apres lopération du inuaillage, sont d'une richesse exirime en matières albuminoides. 
Les colonies sur ce milieu, qui est naturellement acide, se développent sous forme de petites saillies d'un blanc mat, qui s'étendent bientôt à la surface des plaques. Dans la profondeur elles affectent la forme d'une perite sphère brunâtre d'où partent des prolongements rayonnés (fig. 40k).

Le champignon se cultive également très bien sur les milieux acides riches en peptone; les autres substances azotées lui sont moins favorables. Il peut vivre aux dépens de la mannite et de la dextrine, do même qu'en présence de l'acide lactique et des lactates.

Les milieux sucrés sont moins fertiles.

Fig. 404.

Muguet. Colonie profonde (radièe) sur plaque de gélatine. - Gr. 80 dian.

Comme milieu solide, la carotte stérilisée donne des cultures d'un blanc éclatant très caractéristique.

Le champignon du muguet se différencie des saccharomycètes par ses propriétés biologiques : formation rapide de filaments mycéliens et absence d'action fermentescible sur les liquides sucrés.

L'isolement du parasite se fait toutefois plus aisément sur les milieux acides que sur les milieux alcalins. les premiers étant impropres au développement de bien des bactéries. 
Il parait capable d'oxyder l'alcool et de le transformer en aldéhyde et se montre exclusivement aérobie.

Si l'on étudie au nicroscope l'accroissement des colonies jeunes de inuguet, on conslate un seul morle de reproduction : la scissiparité. Sur les milieux solides, il se produit à la longue de ces formes mycélieunes si earactéristiques à l'examen de l'enduit buccal.

Le parasile du muguet se différencie encore des saccharomycètes par ce fait qu’on n'a jamais pu observer, par les méthodes en usage, la formation d'ascospores analogues à celles des véritables levures. Le muguet rentre donc parmi les moisissures et se classe naturellement à còté du Dematium. Les seules formes durables qu'on ait entrevues seraient, d'après Grawitz, Roux et Linossier, des chlamydospores.

Ces auteurs les ont obtenues en cultivant le muguet sur le liquide sucré minéral de Nageli. Les chlamydospores se développent sous l'aspect d'une sphérule de 14 à $20 \mu$, située à l'extrémité d'un chapelet composé de formes allongées.

Cette sphère est formée d'une miembrane qui peut se rompre sous la pression d'une lamelle de verre, et laisse alors échapper, au milieu d'un grand nombre de granulations, un globule central plus volumineux (Achalme). 


\section{MICROCOQUES}

On a groupé sous le nom générique de Vicrocoques dés micro-organismes de très petite dimension, ie forme sphiérique, qui se développent par bourgeonneinent et n'offrent en général aucune trace de structure intérieure.

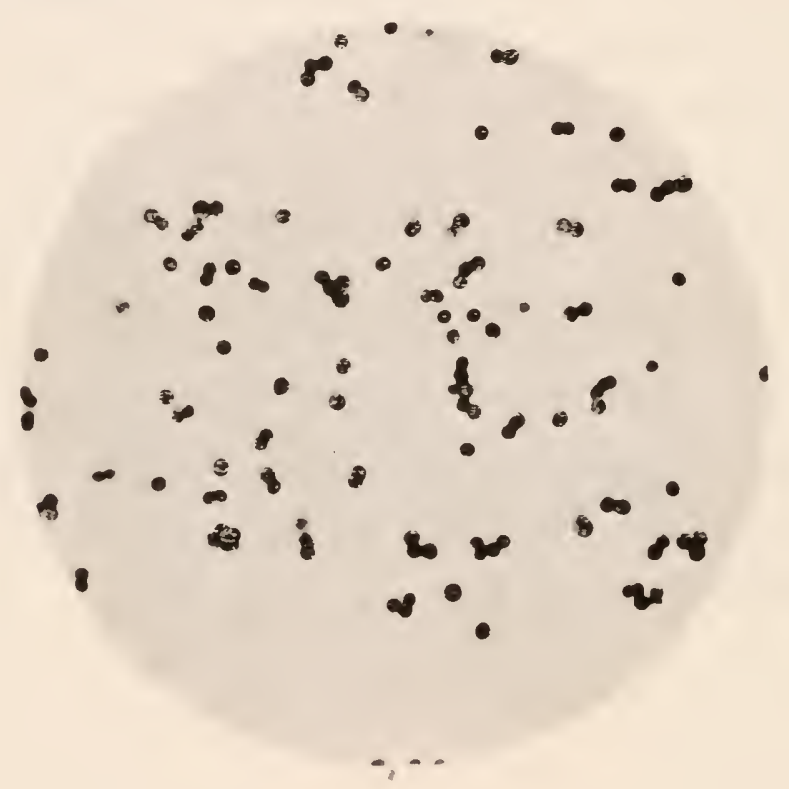

Fig. 405.

Gros microcoques. - Gr. 1000 diam.

Examinée sans coloration, au grossissement de 600 à 1000 diamètres, une culture jeune de microcoques présente, dans le champ de l'objectif, une masse d'éléments sphériques ou légèrement elliptiques, et très réfringents.

En général ces sphérules offrent 6 a 10 millièmes de millimètre de diamètre et sont douées du mouvement brownien.

ll existe des espèces de microcoques de volume bien différent, comme on peut en juger en comparant les figures 405 et 406 . 
Il est très difficile dans bien dè cas de reconnaitre, à l'examen des liquides organiques frais, riches en granulations réfringentes, s'il s'agit de micro-organismes ou d'éléments normaux (sphérules de graisse, albuminoïdes, etc.), et c'est ainsi qu'on a décrit depuis longtemps, sans en avoir pu faire la démonstration vraiment scientifique, des Microcoques dans la variole, la vaccine, le cancer, etc.

La recherche d'éléments parasitaires plus volumineux et doués d'une forme et d'une structure caractéristiques, tels que les champignons des teignes, les groupes radiés de l'actinomycose, les levures,

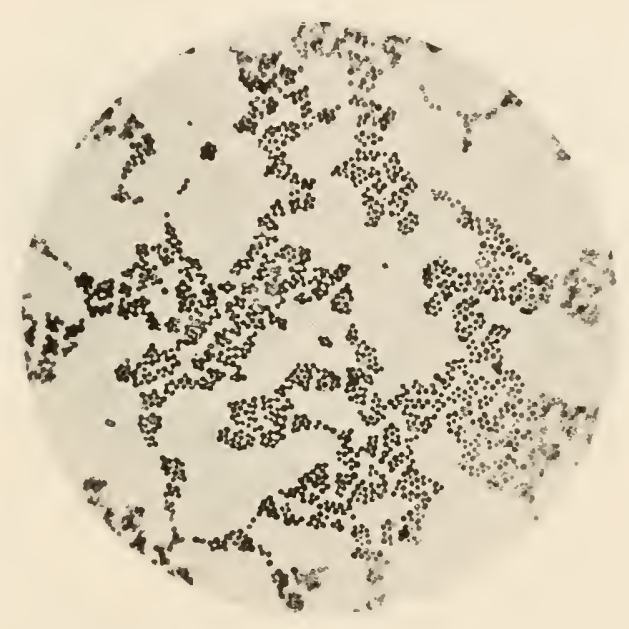

Fre. 406 .

Petits microcoques. - Gr. 1000 diam.

a naturellement précédé la découverte des mierc-organisnes de petit diamètre.

Parmi ceux-ci la bactéridie de Lavaine fut remarquée l'une des prenières (18557). Son abondance dans lé sång des animaux charbonneux, la fréquence à cette époque du charbon chez les animaux et de la pustule inaligne chez l'homme, la facilité de sa recherche à des grossissements faibles, la possibilité de l'inoculation à diverses espèces animales. la découverte enfin par̃ Pasteur de l'inimunisation à la suite d'une alteinte non moltelle de celte maladie, firent du 
bacille charbonneux l'un des micro-organismes les plus typiques et les plus intéressants. - Ce sont d'ailleurs les premières recherches de Pasteur sur cette maladie qui démontrèrent quel profit devait tirer la médecine des études bactériologiques.

La recherche des microcoques était déja plus diflicile en raison de leur forme banale et de leurs faibles dimensions, el jusqu’a la découverte des colorants employés aujourd'hui et particulièrement des couleurs d'aniline, rien n’était plus délicat que de déterminer si les

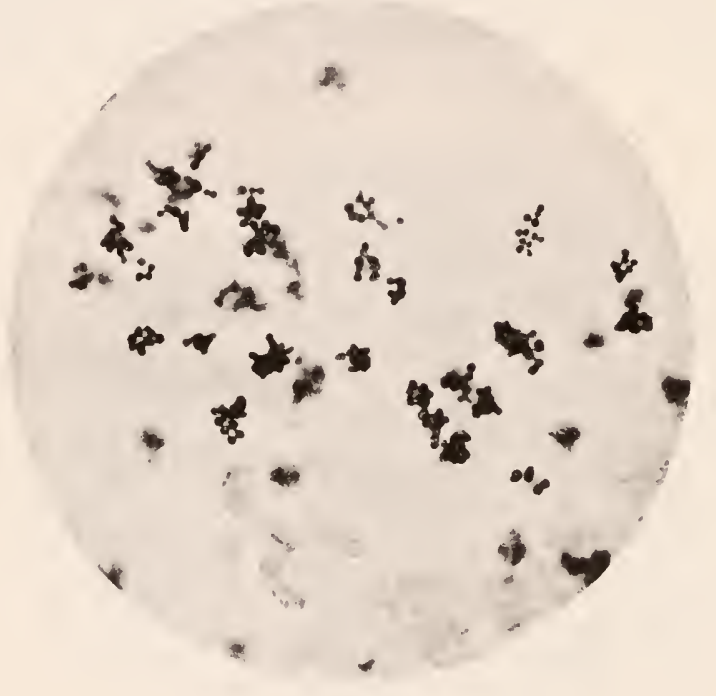

Fig. 407.

Pus phlegmoneux. - Staphylocoque doré. - Gr. 1000 diam.

éléments que l'on croyait pathogènes dans telle ou telle maladie jouissaient d'une forme sphérique ou bacillaire.

On ne connaît donc bien aujourd'hui que les microcoques susceptibles d'ètre colorés par les couleurs d'aniline, capables de se reproduire en culture sur des miliewx artificiels et pouvant ou non donner en pathologie expérimentale des lésions caractéristiques.

Parmi les microcoques, beaucoup semblent ne jouir que de propriétés saprophytes.

Quelques-uns sont chromogènes; tel le Hicrococcus Prodigiosus par exenple, qui présente, en culture jeune, particulièrement sur le pain azyne humide, une belle conleur d'un rouge vif, et fut ainsi l'occasion du miracle des hosties sanglantes. 
D'autres sont pathogenes, tels les microcoques de la suppuration et le streptocoque de l'érisipèle.

Beaucoup enfin doirent ètre encore inconnus, faute d'une méthode de coloration ou de culture capable d'en déceler l'individualité.

Le mode de groupement des Hicrocoques a pernis de les diviser en Staphylocoques, Streptocoques, Tétragènes et Sarcines (fig. 407 à 410 ).

L.es Staphylocoques se développent en groupes irréguliers et donnent des figures analogues à des grappes de raisin (fig. 407).

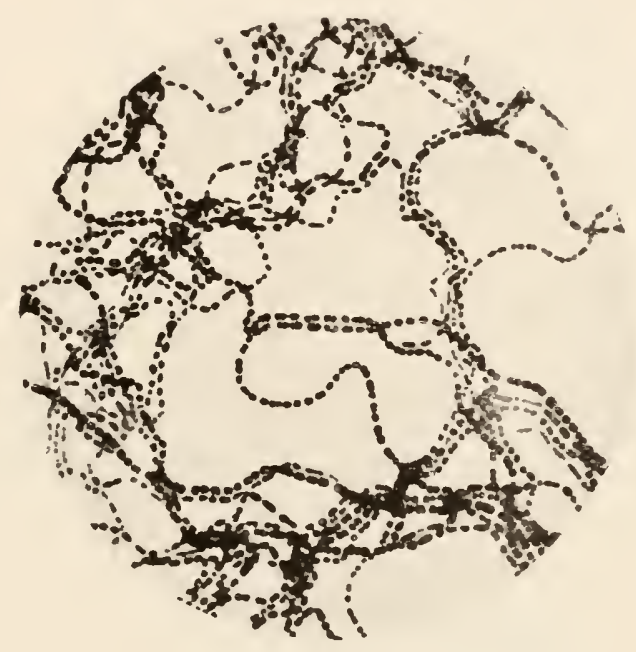

Fig. 408.

Culture de Streptocoques dans le bouillon. - Gr. 1000 diam.

Les Sireptocoques se multiplient dans une seule et même direction, et forment dans certains milieux de longs chapelets (fig. 408).

On donne le nom de Diplocoques à la juxtaposition de deux cocci. Cette disposition est commune aux deux espèces et n'est que le premier stade de la multiplication d'un seul coccus.

La plupart des chainettes de Streptocoques sont formées, comme on le distingue nettement sur la fig. 408, d'une série de diplocoques juxtaposés en longueur.

Certains microcoques se développent par groupes de quatre éléments juxtaposés en carrés ou tétrades. On leur a donné le nom générique de microcoques tétragènes (tig. 409). 
Une de ces espèces au moins est pathogène pour l'homme et peụt se rencontrer dans les abcès chauds (fig. 403).

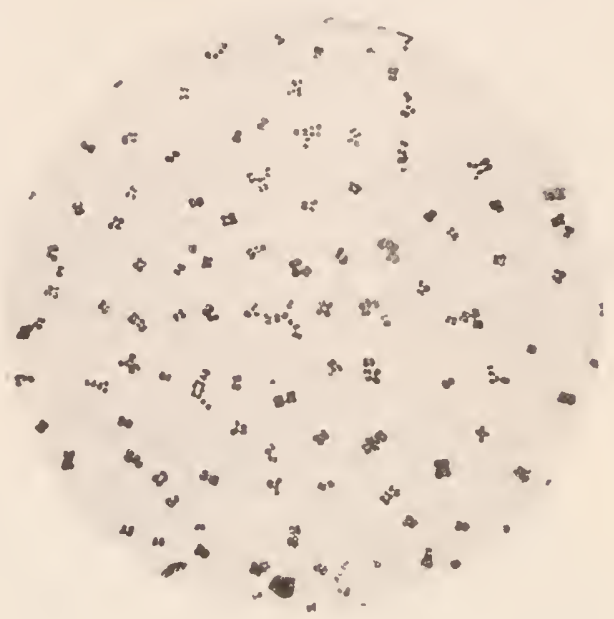

5.1. 409.

Microc. Tetragenus Pyogenes. - Gr。1000 diam.

Les Sarcines enfin se multiplient en forme de cubes, composés de huit éléments ou plusieurs groupes de huit, de manière à former

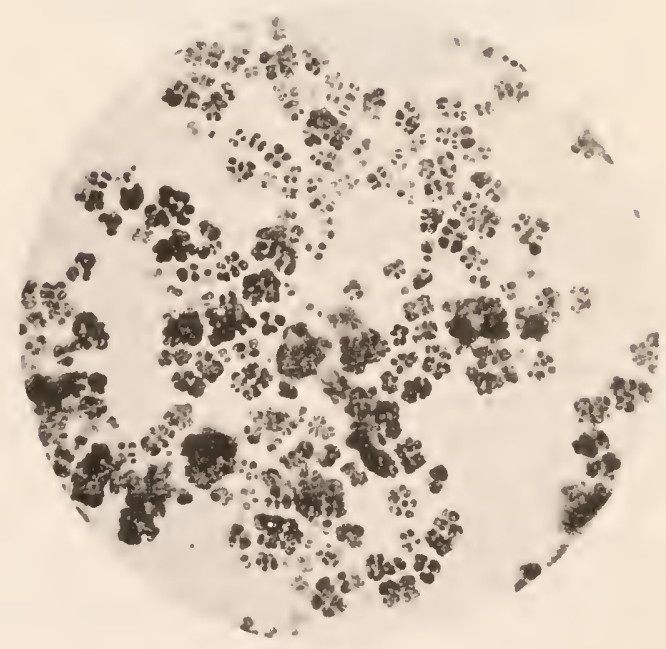

Fig. 410.

Sarcine de lair. - Gr. 1000 diam.

dans certaines conditions d'épaisses masses floconneuses, ou, sur les milieux solides, de larges colonies aux coulcurs variées. 


\section{ANALOGIE DES MICROCOQUES \\ AVEC CERTAINS VÉGÉTAUX INFÉRIEURS}

inelle place faut-il assigner aux microconues dans la matmre?

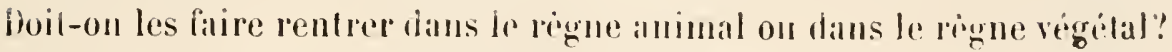
Les premiers histologistes qui olsserverent les micro-oronaismes, Müller,

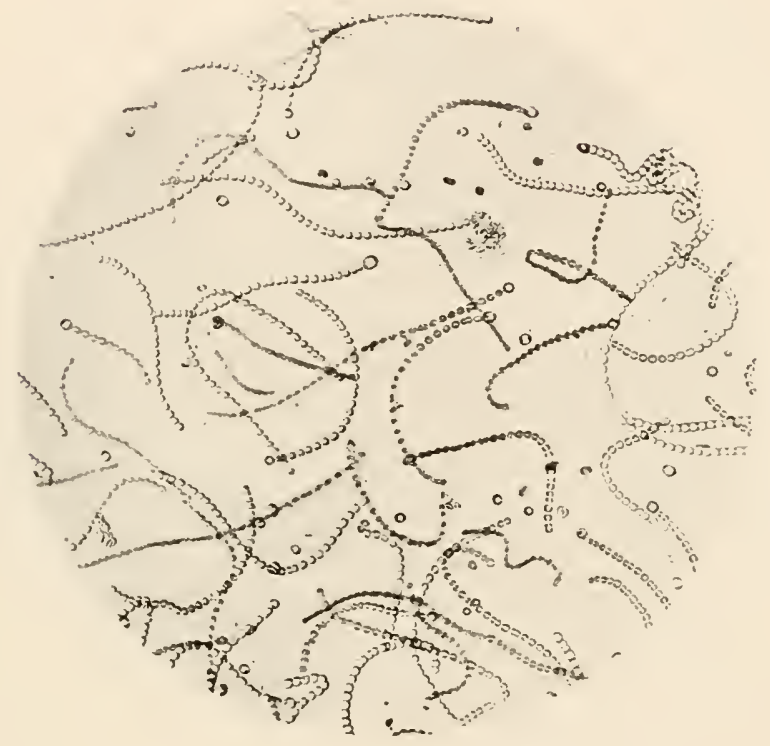

Fi. 11 .

Nostoc commune, Preparation fraiche. - lir. 200 diam.

Ehrenbere, Dujardin, re., furent frappes par ienrs monvements actits et les rlassèrent au degre le plus infime du rogne animal.

Davaine, apros avoir démoutre l’immobilite absolue, a lous les stades de leur existence, de la hacherilie charbommense of d'antres

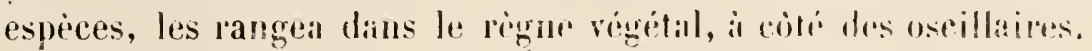

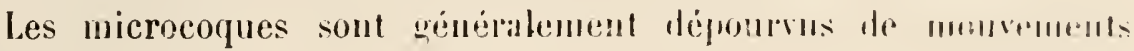
actifs.

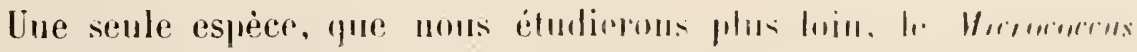

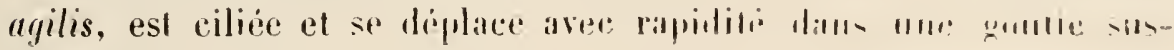
penilue. 


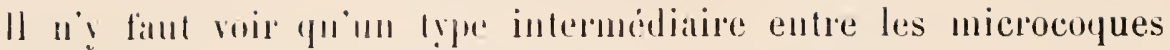
immobiles, qui ne jonsssunt que du monrement brownien, et les batcléries cilices.

las microcoptues se rapprochent tellement de certaines algues et notamment des cyanophreces, qüil serait difficile, sinon impossible sans indieation du grossissentent, de distinguer du . Yostoc commune,

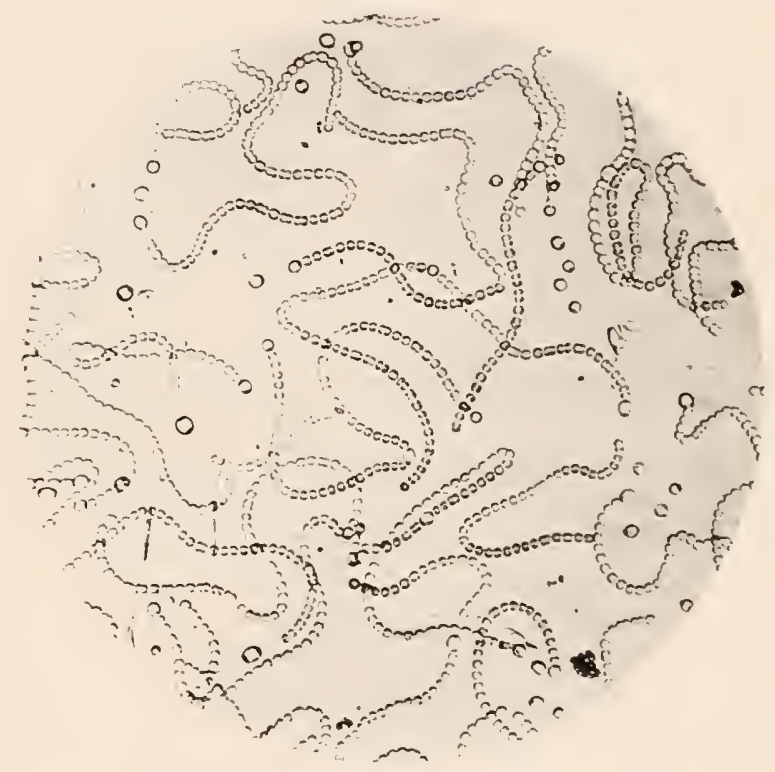

Fig. 412.

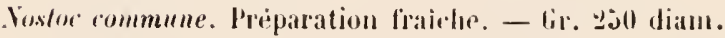

pir exemple, les chainettes du streptocoque pyogène ou du streptocoque de la manmite contagieuse de la vache.

Le Nostoc commune, qui forme assez fréquemment, pendant les saisons chandes et humides, d'épaisses conches verdàtres glaireuses al gélatiniformes sur des matières végétales en putréfaction, est constitué frar des chapelets assez réguliers, présentant, comme les streptocoques, des formes diplococciques, et terminés sonvent à leur extrémité par une cellule vésiculeuse analogue à certains aspects de la Monilia candida. Ces éléments, cinq à six fois plus volumineux que 
les streptocoques pathogenes, contienuent de la chlorophylle et présentent une teinte verdàtre.

Les ehapelets se colorent par les coulenrs d'aniline. C'est à une espece voisine qu'appartient le Leticonostoc mesenteroüdes, agent de la

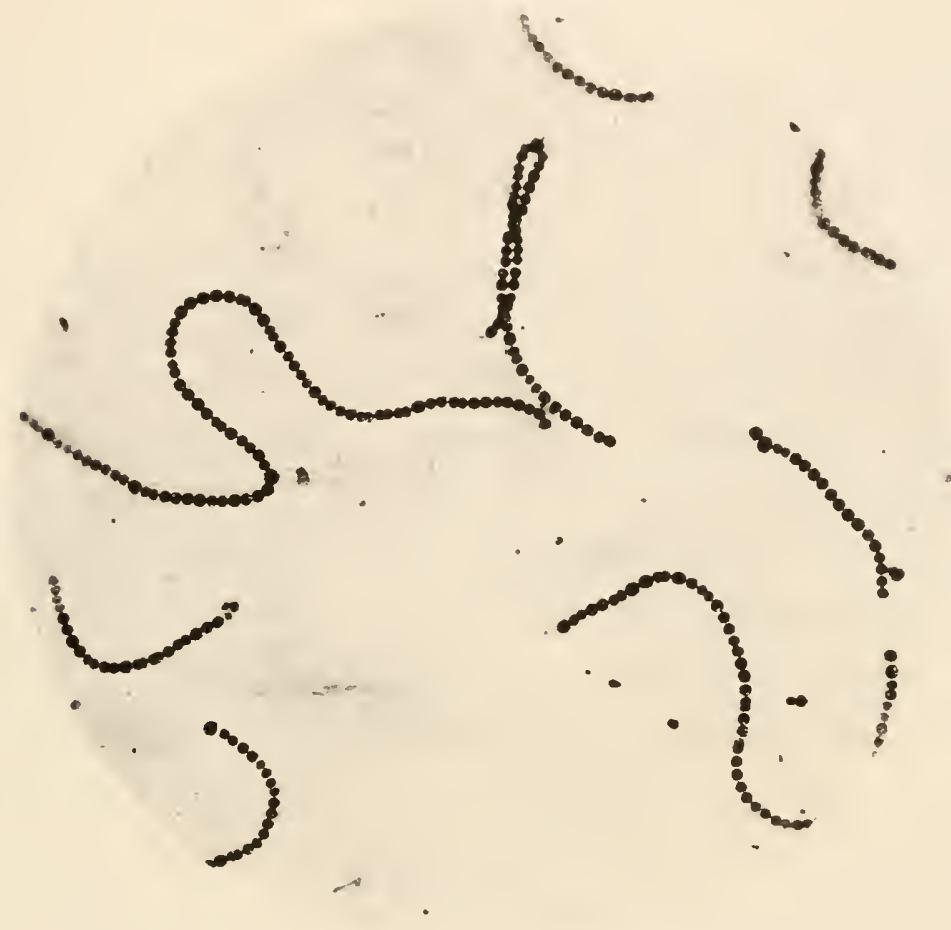

Fig. 413.

Nostoc commune. Préparation colorée. - Gr. 300 diam.

"gomme de sucrerie ", que nous n’avous pas en l'occasion d'üudier. Les fig. 411 et 412 représentent le Nostoc communr à l'íal liais, sans coloration. La préparation colorée pholographiée fig. $11 \bar{j}$ ollipe une analogie encore plus frappante arec critaines préparations de streptocoques.

Nous commencerons l'étude des Nicrocuques par la deseription his espèces pathogènes les plus importantes, et nous passerons ensulte revue les microcoques saprophygtes et chromogènes. 


\section{MICROCOQULS PATHOGiNES}

\section{PYOGEN ̇̀SE}

l'armi les désordres qui peuvent ètre occasionués par les microcoques pathogènes, la suppuration et ses complications présentent en. pathologie génciale une importance capitale. Les accidents si variés produits par ces micro-organismes, depui:; le furonele jusqu’à l’infeclion purulente, leur association anx azents pathogènes des affections les phlus diverses, mberculose, diphtérie, fièvre typhoöle, etc., la fréquence entin des infections secondaires mortelles dans les états eachectiques graves, dont la terminaison fatale se trume aimsi si sourent avancée, rendent lenr éfude inscinarable de tont examen clinique et anatomo-pathologique.

Le premier microcoque pyogene comnu fut celui qui porta plus tard le nom de Staphylocmue pyogene doré. Cette découverte appartient a Pasteur.

l'asteur, en 1880, isola à l'état de pureté, par des cultures daus le bonillon stérilisé, les mierocoques du pus limoneuleux et détermina expérimentalement, par l’injection de ces cultures au lapin, des suppurations étendues.

Ogstom, en 1881, sur.74 abces chauls dont it examina le pus au moment de I incision, a coustamment trouré, apros coloration arre le riolet d'aniline, des microcoques soil en grappe soit en chininettes.

Ogston dillérencia les microcoynes pyogimes dianès leme mode de

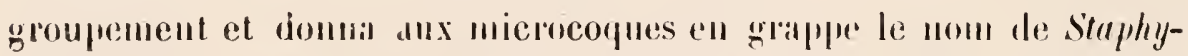
locoques et anx microconues en chapretet le nom de Streptocopues. Cies dénominations sont demenrées chassiques.

Oyston, en injectant des staphylocopues daus lo tissu rollulaido des

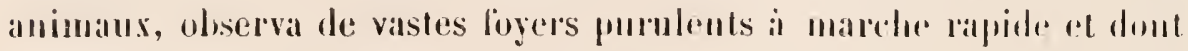

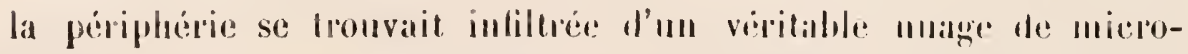

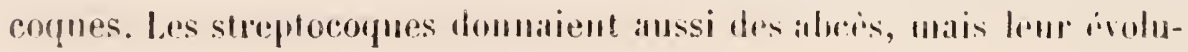


Cion était moins rapiele et lon observait entre les élements anatomigues des farois du foger non plus des amas de microcoques, mais de simples chainettes.

Cornil, en 1885, étudia les micru-organismes do la suppuration dars mue série d'abees chands au moment de l'onverture du foyer. it y observi comme Ogston des microcopurs en graple et en chapelet, tamdis que les abcès froids donnaient un pus moins riche en éléments figurés et dipourvus de tout microbe colorible far les mojens ordinaires.

Comnil cxanina, apiès les métholes de coloration appropriées, des fragments de tissu conjonctif et de peau, prélevés au niveau des foyers suppurés.

Sur les coupes traitées par la fuchsine, les micro-organismes se montrent colorés en rouge vif. Ils sont aboudants vers le centre de l'abcès, qui s'est trouvé ramolli el liquéfié sous l'action peptonisante des microbes. Tout autour, une irritation inflammatoirc, caractérisée par la disteusion des capillaires, dont beaucoup sont thrombosés, et par des amas de cellules lymphatiques, entremclées de fibrilles fibrineuses.

Les hactéries pénètrent daus les cellules lymphatigues ot dans les cellules adipeuses elles-mèmes. Ces divers ćléments sont alteints d’une gangrène moléculaire. l.es cellules lymphatiques épanchées et altérées par les produits solubles d'origine miembienne deviemnent libres au milieu d'un liquide séreux pour constituer le pus el s’éliminer au dehors.

'Tout antour le tissu conjonctif' se uéerose dans unc étenduc variable.

I.es recherches dı Ir Cornil ont été d'une importance eapitale eu anatomie pathologique car, si l’on connaissait déjà l’orignine bactérienne des abcès claauds, on ignorait encore la réaction des tissus en présence des microbes pathogènes. En s'attachant a l'observation des lésions consícutives a l’infection microbienne et en dímontrant que desormais l’étude des altérations histologiques serait inséparable de la recherche des microbes qui les déterminent, Cornil a domué l'ur: des premiers à l'anatomie patlıologique générale l'orientation nou- 
velle qui a éte le point de départ de toutes les grandes déconvertes de ces dernières antrées.

Les collules lymphatiques et les cellules du tissu conjonctif dans le proloplas:na despurlles Cornil a remarqué l'un des premiers la présence des microcoques progénes, n’étaient autres que les cellules microphages et macrophages de Metschnikoft. Nous ítudierons dans le dernier chapitre de ce livre le rôle de ces " phargoeytes » daus la défense de l'ormanisme contre les microbes palhogènes, et nous verrons allors quelle interprétation il faut donner, dans l'étal actuel de nos commaissallees sur l'immunité, de la réaction " pyogène » de l'organuisme virant en prísence le l’inlection par telle on telle espèce bactérienne.

Cornil étudia, en mème temps que la suppuation, l'érysipèle, la lymphangite, la phlébite, le purpura, qui sont au mème titre d’origine microbienne.

Yous arous rérilié nous-mème en 1882, pendant notre internat chez le Dr Lucas-Championnière, les recherehes d'Ugston. L’examen, apres coloration, du pus d'ane série d'abeis chauds el de suppurations variées, phlegmon, ostéonyélite, elc., nous fit constater la présence de stiphylocoques el de streptocoques dans tous les abeès chauds et, dans les cas où l’allection évoluait vers la guérison, ces microcoques se montraient fréquemment inclus dans les cellules lymphatiques. Une seule fois, clicz un allouminurique, il nous est arrivé d'observer une suppuration aiguë purement bacillaire.

L'étude comparlative des abcès froids nous donna des résultats absolument opposés. Le pus de ces abcès ne contenait pas de microbes appinents; mais l'inoculation aux animaux soil dans le tissu cellulaire, soit daus le péritoine, soit dans les articulations de la moelle des os, déterminait non plus des abees locaux, l’infection purulente on! l’ostéomyélite aigü̈, mais des accidents de mbereulose locille on génćlalisée. Sous arous photographié plusieurs de nos premières préparations. Nous les reproduisons plus loin.

Jne de nos compes, datant du mois d'aonit 1882, démontrait, dans un cals de lymphangite des réscaux culanís, la présence d'une quantité de diplocoques dins les pinpilles du derme. le mínoire que nous avions 


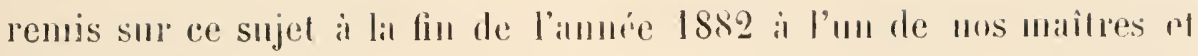
dont nous venons de résumer les conclusions n'a jamais dé publir et

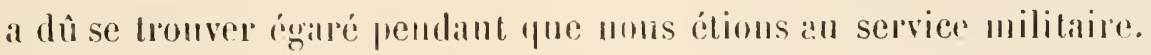

Toutes les recherehes analognes contirmèrent l’importance dans la pathogénie de la suppuration des microhes progenes el drimontripent

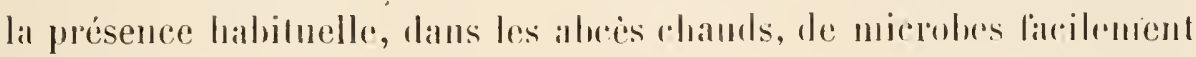
colorables.

\section{SUPPURATION SANS MIGROBES}

Y avait-jl rependant des suppurations saus microbes?

Pasteur démontra des 1878 (Acarl. de méd., 50 avril) que l'on pouvait produire des abcès en introduisant sous lil peau des animaux des fragments de laine stérilisés.

Uskofr en 1881, puis Orthmann en 1882, firent des cxpériences contrarlictoires et n'obtinrent pas de pus en injectant sous la pean de l'eau ou du lait stérilisés. İinjection d'essence de lérbenlhine donnait an contraire un abcès sans microbes.

Councilmann en 1885 arriva an mèue résultat en insérant ces substances sous la pean dans de protites ampoules le rerre seellées, qu’il cassilit après cicatrisation de la plaie.

En 1884, Strauss répéta toutes ces expériences et introduisit sons les téguments de divers animimx, aree des préeantions rignomrensis, des liquides ou des solides stérilisés. Toutes les fois quiun alue ses se prorluisit. le pus, examiné avec les colorants habituels. contenait des microbes. Plus tard Strauss observa a son lumr dı pus sans microbes.

Il est bien démontré anjourd'hni que le pus punt se former sims l'intervention des microbes et que les microbes pyogines n agissent qu’en déterminant une irritation analogue a cellu des irritants chimiques.

Crawitz et de Bary, en 1887, ont domné la preure imrifutable yue certaines ptomaïnes, particnlièrement la cadavérinc, penrent produire chez quelques animanx une suppuration sans microbes, an mime titre pum le nitrate d’argent ou l'essence de térébenthine. 
Choichas (1885) a obtonu de minne la formation de pus dans

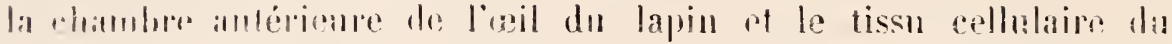

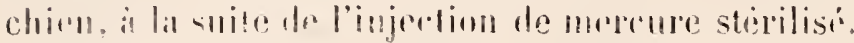

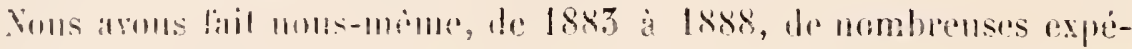

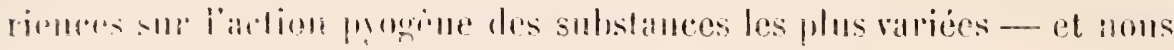

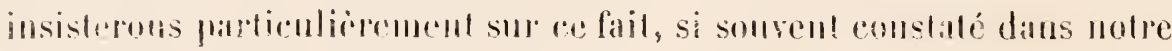

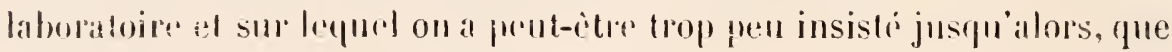

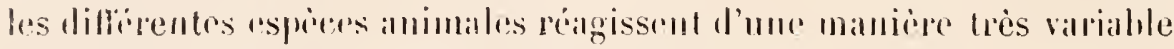

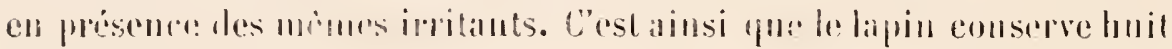

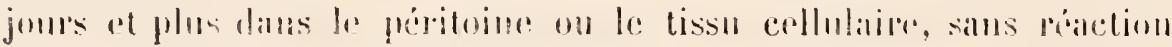

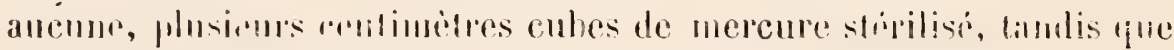

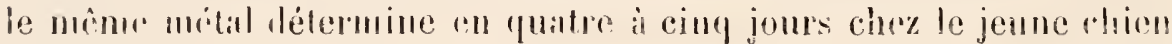
la suppun:alion,

Che\% J'hunmm, le pus sans microbes s'obsene dans deux cas bien distiacts : on hion - I" les buctéries ont cessé de vivre, r’ost ainsi que

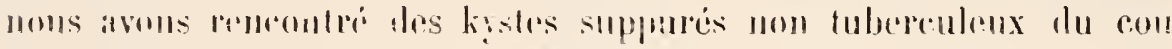

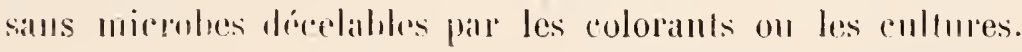

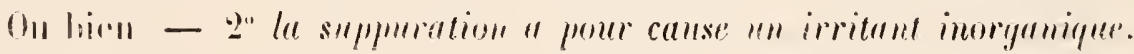
Cos derniches sont les semles riritables suppuralions sans mierobes. les agrouts irritants suserptihles de les frovorgure, chez l'hommo, sont motamment le nitratre d'argente l'essence de térbenthine el l'essence de gonévier.

lafou de licims a produit l'réquemment, lanss un but rérulsil, de

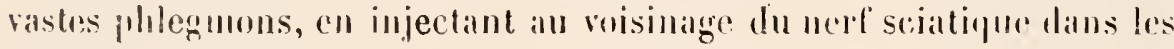
cas do névalgie mue solution de nitrale d’argent.

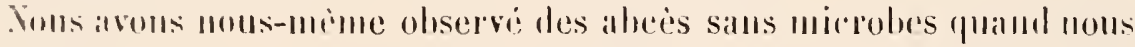

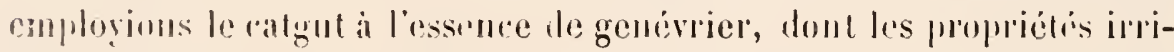
fantess mandifestent chez l'homme comme il arve chez le chien pour l'essentec de léribenthine.

Il existe donc, che\% l'homme, des suppurations sams microbes; cos

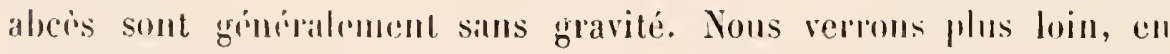

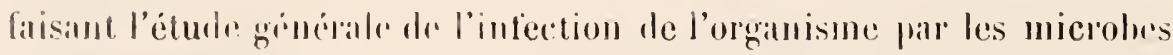
fathogrincs ot du mole dre résistance des cellules virantes, que ces suppuralions sims micrubes et dues à la présence d'irritants chi- 
miques évoluent nu proressins identipur il celui des suppurations inferenesses.

Le mécanisme de la formation dupus est ainsi le mène daus les aloès sans microhes que daus les alocis inferieux, mais, l'agent progene inorganique étant incapable de multiplication, les désurdes lociux qu'il produit ne samaient se mopalger an loin el produire les cas d'infection gralve que déterminent si sonvent les microbes pyogènes.

les premieres recherches sur la pyogenise furent longtemps bien imparfates, l'examen seul du pus après coloration se montrant insuftisant pour permettre d'étiblir les caractires différentiels de diverses espéces.

linsenbach le premier, en appliquant à cetie étude, en 1883, les méthorles de culture de lioch sur les milieux solides, décrivit comme byes bien délinis : les staphỵlocoques doré et blane, les streptocoques لlu pus et de l'érysipièle.

le mode de dévoloppement des cultures dans les tubes de gélatine, lia lị̣néfiction ou lit non liquéfiction du milien, l'aspect ot la coloration des stries sur les tubres inclines llagar-agar, permirent à kosenhach de différencier définitivement le mierobe pyogène vulgaire en chainettes

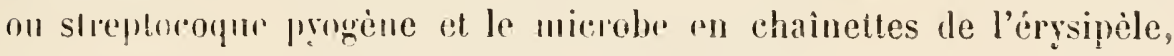
qui ne liqquilient pas la gélatine et offrent sur l'agar-igar une culture très grile, des staphylocoques hlanc et doré, qui liquéfient la gélatine et donnent sur l'igar-agar une végétition abondante.

Il dicrivil aussi lo Vicrococcus pyogenes temuis, qui d'après nos olsepvitions personuelles, semble n'itre autre chose que le Pneumocoque de Talamon el trankel.

P'armi les microcoques panhogènes, nons ćtndierons en premier lieu l's Niaphỵlocoques, qui sont las agents les plus fréquents de la suppuration chez l'homme. 


\section{STAPIIYLOCOQUES}

Rosenbach a décrit les Staphylocoques doré et blanc, qui sout les plus intéressants. Passet et quelques observateurs ont cultivé d’autres espèces pyogènes de microcoques en grappe; ces esprèes ne se dilférencient des deux précédentes que par l'aspect des cultures. Ce sont: les Staphylococci citreus, cereus albus, cereus flavus, etc.

\section{STAPHYLOCOQUE DORÉ}

Le Staphylocoque doré est le trpe des microbes de la suppmralion. Il est le plus répanduet le phus virulent des staphylocoques pathogines. On le rencontre dans l’air, lans l'ran, à la surface de la peau, ou il esl l'agent pyogène des pustules l'acné, sur le pourtour des ongles, sur les poils, les cheveux et la barbe, dins le tartere dentaire, dans les selles, particulièrement en cas de diarhée. On l'y otserve minte eloz les enfants à la mamelle.

Isolé tout d’abord du pus de furoncle et d'ostéontélite frar l'astemr, étudic par Ogston, par Stranss, Rosenbach, l'asset al par nous-mimes de 1881 i 1888, ce mierolse se rencontre dams la plupart des suppurations et en particulier dans le pus du furoncle, de l'antlurix, do l'ostéomyélite, du panaris et dr heaneoup de phlogmons areonscrits ou diflus.

Le Staphyloroque doré présente en rhirmgir mor importance considerable, car c’est à lui seul un associé al d’antres espreces püétail due le plus souvent, avant la volgarisation de l'antisepsie, la suppuralton des plaies opératoires et l’infection purulente lypiqune si reflontie des anciens chirurgiens. Le Streptocoupe pyogine que l'on rencontre fréquemment en pareil cas associé an stepllyglocolue doré peut domer 
igalement lieu i lui seul ì des accidents analogues (phlegmon circonscrit ou diffus, infection purulente).

Préparations colories. - Si uous examinous, après l'avoir étendu et desséché sur une lamelle, le pus l'un furoncle ou d’un anthrax, coloré par la fuchsine ou le violet de méthyle el décoloré par l'alcool, nous remarquons immédiatement dans le champ de la préparation des gronpes de microbes arrondis disposés en forme de grappes. (Fig. 414 et 415.$)$

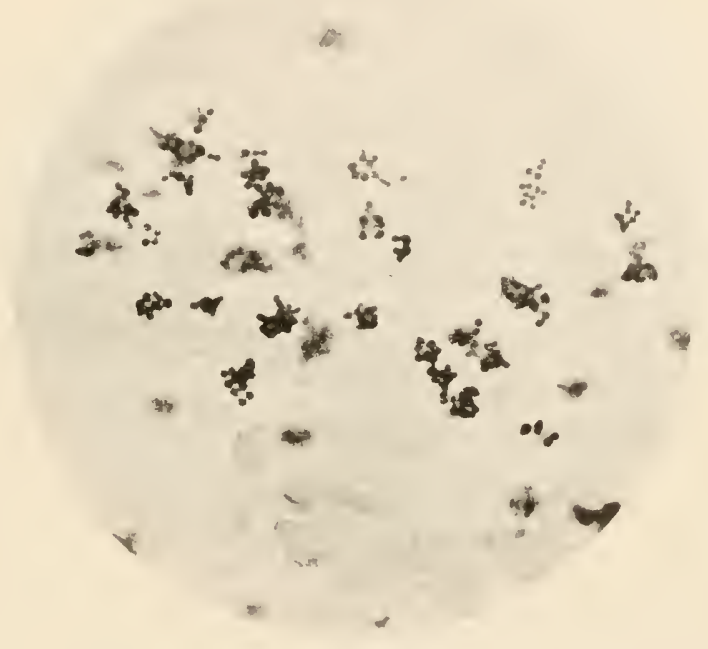

FIG. 414 .

Pus phlegmoneux. Staphylocoque doré. - Gr. 1000 diam.

Ces microcoques, qui oflirent en général de 0 u., 5 à 1 u. de diamètre, sont sphériques ou légirement oralaires et se groupent en petits amas irréguliers. Parfois on n'olıspre des diplocoques, de courtes chainettes de trois a qualre iléments ou des tétrades.

I.es préparations sont particulièrement démonstratives quand on a employé la méthode de Gram, c'est i-dire la coloration avec la solution de violet dans l'eau d'aniline, la double coloration far le brun de Bismarek ou la coccinine et la décoloration par l'essence de girofle après l'action de l'inde. 
Les groupes le microbes tranchent par une teinte d'un bleu intense sur le fond jamne ou rose de la préparation, oủ l’on distingue très bien à leur aspect caractéristique les globules de pus.

L'examen d'une lamelle est suflisant pour reconnititre si le pus d'un abcès chand contient un Staphḷlocopue progène, car les groupes caractéristiques s'y rencontrent en alıondance.

Certaines formes diplococciques (fig. 4l5) pourraient toutefois en imposer pour une infection mixte de slaphylocoques et streptocoques.

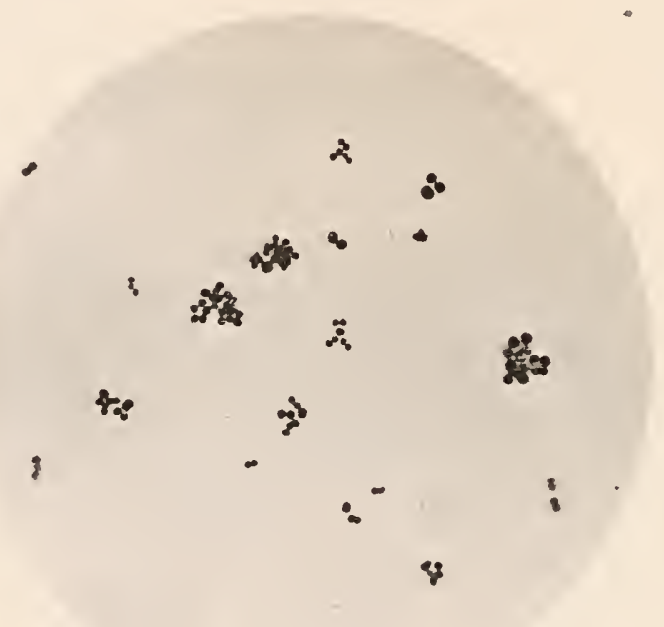

Fia. 415

Pus phlegmoneux. Staphylocoque doré. - Gr. 1000 diam.

Le diagnostic bactériologịue précis ae peut ètre déterminè en pareil cas qu'après l'examen d'une série de eultures fractionnées et très diluées sur des tubes inclinés de gélose.

Cultures. - Si, à l'aide d'ıne aiguille de platine stérilisée, on ensemence une goutte de pus d'un furoncle ou d'ostéomyélite infectiense par piqûre dans un tube de gélatine et en strie à la surface d'un tube d'agar-agar, on observe sur la gélatine une culture en forme de clou qui liquéfie progressivement le milieu, tandis que sur liagar se développe en 24 a 48 heures une large colonic homogine, présintant une teinte jaune d'or des plus accentuces. 
Quelquefois la teinte jannattre n'apparait que le denxirme on le troisieme jour. Quand les cultures sont auriennes, elle devient de moins en moins apparrente, de felle sorte que sur les vicilles cultures il est parfois difficile de recommatre sil s'agit bien dn Staphyloroque dor' ou d'une antre espece très voisine decrite par Rosenbach sous le nom de stuphyloroque blanc.

la coloration des cultures jeunes dépend de la virulence du mierobe

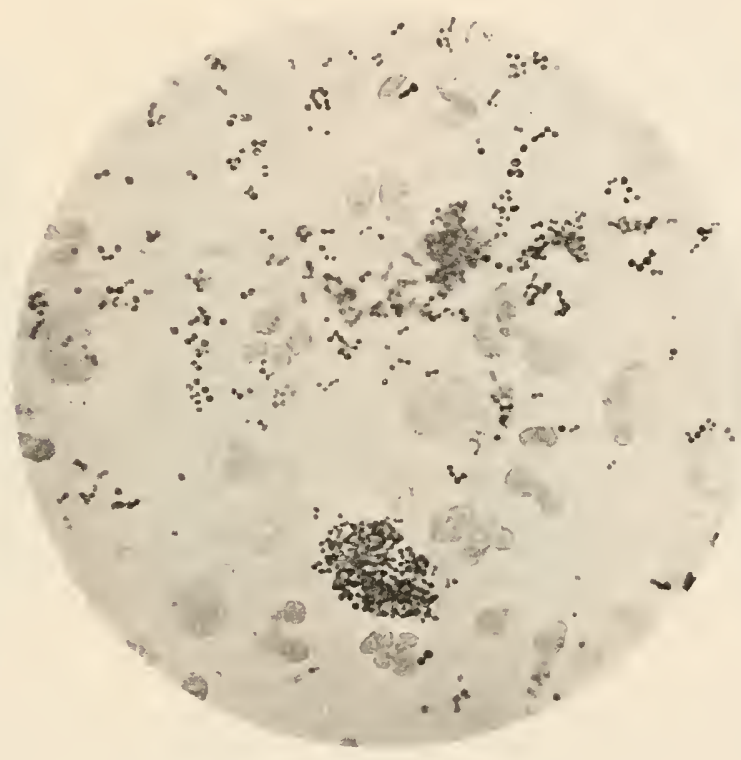

5.G. $\$ 16$.

Pus phtegmoneux. Staphylocounes el Streptocouques. - Gr. 1000 dian.

comme du nilien de culture. La teinte jaune d'or est particulièrement remarquable sur la pomme de terre, qui est d'ailleurs un excellent milien pour tous les microbes chromogènes.

La culture linit par s'étendre au tiers on à la moitié de la surface du tube d’agar. Sur la gélatine, comme l'arons indiqué plus haut, la culture pair piqùre détermine la formation d'une colonie liquéfiante en forme de clou. En quelques semaines, la liquéfaction esl complète, et il se prodnit a la surface du liquide des petits amas crémeux et jannitres composés, ainsi que le sédiment, de Staphylocoques dorés. 
En culture sur plaques de gélatine il se produit assez rapidement de petites colonies qui s'étendent en surface et qui liquéfient lentement le milieu. Mais la recherche du staphyglocoque par la méthode des plaques est rarement utile.

L'aspect des colonies en stries sur l'agar est en effet caractéristique et, s'il y a association avec le Streptocoque, ce dernier est en général mis en évidence dès les premières cultures, à condition qu'elles soient suffisamment fractionnées.

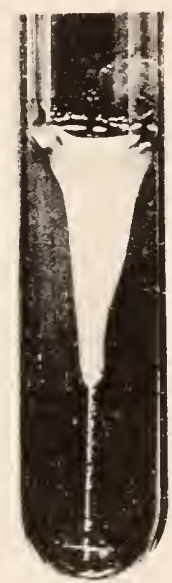

Fig. 417.

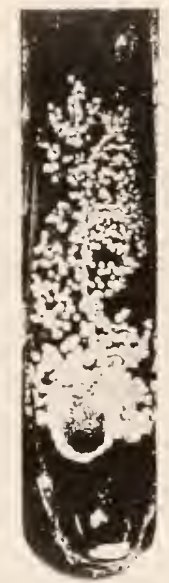

Fig. 418 .

Culture de Staphyl. doré Ostéomyélite ancienne sur gélatine, 3. jour. du radius. $1^{\text {re }}$ culture sur Agar.

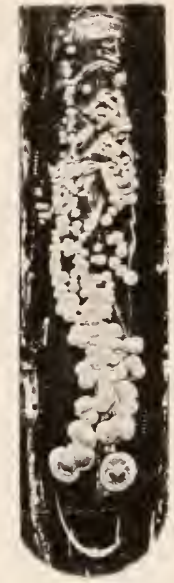

Fic. 419.

Anthrax. Pus : 1'0 culture sur Agar.

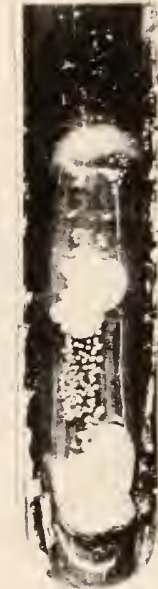

Fic. 420.

$1^{\text {ro }}$ culture de pus conte nant ì la foisle Staph. dore et le Strept. pyogène.

Les Staphylocoques donnant une culture large et épaisse, le pus à examiner doit ètre ensemencé en surface en très petite quantité et l'aiguille doit être essuyée successivement et sans être rechargée sur deux ou trois tubes d'agar-agar incliné. Les colonies de Streptocoques, s'il en existe, apparaissent nettement çà et là entre les larges colonies du Staphylocoque (fig. 419 et 420).

Le Staphylocoque doré se cultive bien sur le sérum, qu’il liquéfie. Les caractères des cultures sur le bouillon sont particulièrement remarquables quand on ensemence des ballons d'un ou deux litres, comme nous l'avons fait pour la recherche des toxines cristallisables ou albuminoïdes. 
Le houillon se trouble dabord en rotalite. Au boul de quelques semaines, le liqunide devient elair el il se produit a la surfice un grand

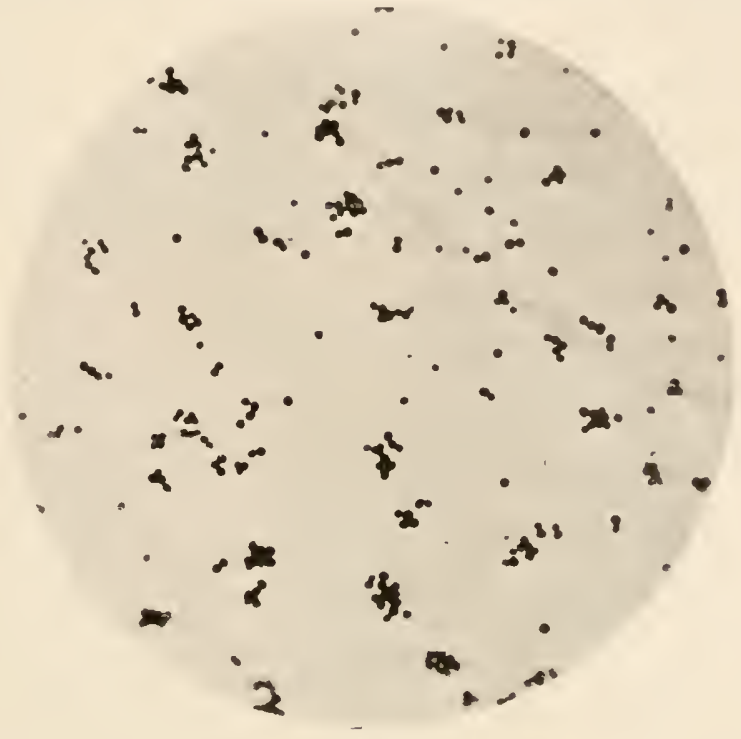

Fig. 421.

Staphylocoque doré. Jeune culture sur milieu liquide.

Les jeunes cultures présentenl souvent de courtes chainetles.

nombre de colonies lenticulaires, tandis que la masse des Staphylo-

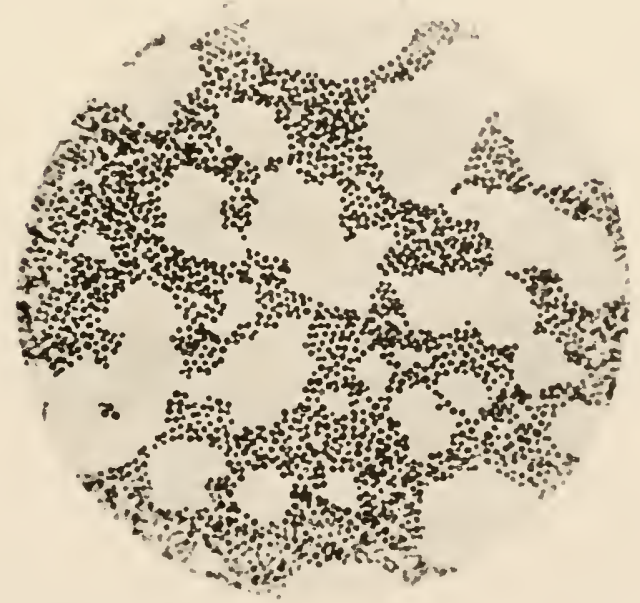

Fig. 422.

Staphylocoque doré. lieille culture sur ggar.

coques vient furmer une couche de plusieurs millimètres d'épaisseur au fond du récipient. 
La virulence du Staphylocoque doré se conserve pendant fort longtemps, ainsi que le prouvent l'inoculation de vieilles cultures d'une part, et d'autre part, comme nous le verrons plus loin, les observations d'ostéomyélite prolongée dans lesquelles, après une période souvent fort longue de guérison apparente (de quelques mois a 15 on mème 17 ans), les accidents locaux ou génératux se manifestent de nouveau.

\section{ACTION PATHOGÈNE}

Lésions locales. - Le Staphylocoque peut donner lieu, comme nous l'avons dit, aux lésions les plus variées, depuis le simple bouton d'acné jusqu'á la septicémie foudroyante; mais si exceptionnellement le Staphylocoque peut tuer par une intoxication générale tellement rapide que le pus n’ait pas eu le temps de se produire, en 18 à 24 heures, par exemple, après une intervention chirurgicale, cette forme grave d'infection est très rare, et l'organisme lumain jouit le plus souvent vis-à-vis de ce microbe d'un certain degré d’immunité.

Les manifestations bénigues de l'infection par le Staplı̣locoque doré sont donc les plus fréquentes. Les boutons d'acné qui se développent autour des poils follets et certaines petites pustules cutanées avec eschare superficielle sont dus ì une inoculation intra-ipidémique du Staphylocoque.

Le furoncle et l'anthrax, qui comme le furoncle, est une lésion suppurative des follicules pilo-sébacés aboulissant à la formation d'un véritable foyer de nécrose sous-rutanée, connu sous te nom de bourbillon, sont dus sims exeeption anl déreloppement d" Staphỵlocoque doré. - L'anthrax est en quelque sorte une rumion de furoneles juxtaposés. Il peur présenter une étendne considálalile, el se montrer envahissant, particulièrement dams les diathreses garres, te diabete. l'albuminurie, el les états cachectiques.

Le Staphylocoque preut eauser a lui seul, sans ancune association microbienne, le phlegmon circonscrit ou dilfus. - liexamen du pus après coloration et par les cultures est alurs imblispensitble pour un diagnostic bateteriologique prieris, ces lisions ponvant itre diterminées par des microbes variés. 
Infertion generale ligere. Lymphumpite et Fibre. - Ces lesions locales

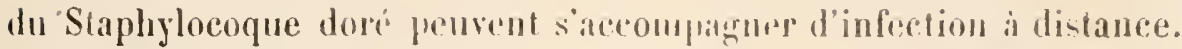
Une simple pustule d'acni, nn furoucle de pelit volume sont en

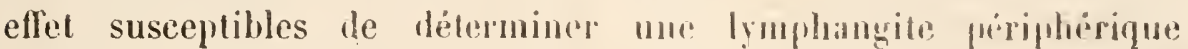
étendue avec adénopalhio donlourense des ganglions vaisins, conne on l'observe si somvent daus les cas de furoncles do la fesse, cluez les cavalier's.

Il existe alors une fieve qui attuint 38, on ou 50 degrés, un alatte-

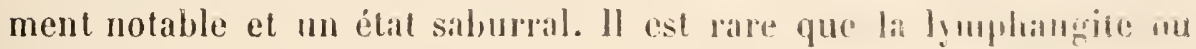
l'adénite dues an staphylocogue suppument. Lal suppurafion des vaisseaux et des ganglions lymphatiques s'observe phus linequenument. comme nous le verrons, dans l’infection streptucoce ique.

Infection générale grave. - Ostéomyélite infectiense. - De merrac quail occasionne des phlegmons et des abces smperficiels, le ciaphyloconpe

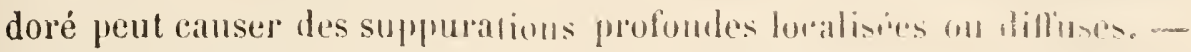

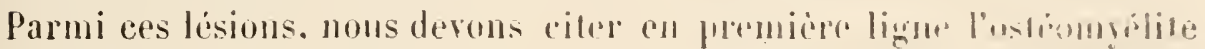

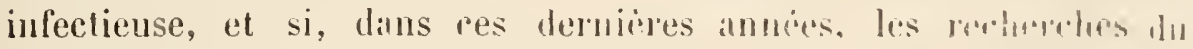

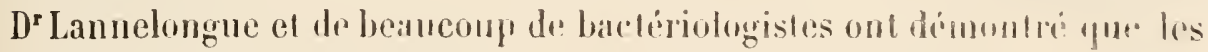

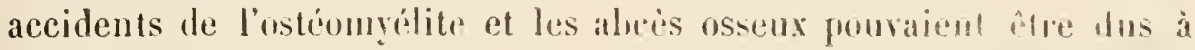
d'autres microbes, particulirement atu Streptocoque on an Jumumu-

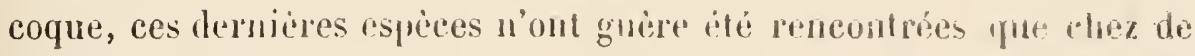
tres jeunes sujets et dans une proporfion très minine (10 pour fon environ). - (Limnelongue.) Le bacille de la fièvre typhoïde a été noté 4 fois sur 90 cas. Nous devons ajouter que le bacille d'kberth et lo Streptocoque ont été principalrment obserrés dans des cas oil l'ostéomyélite était survenue peu après l'évolution d'une searlatin. on d'une fièvre typhoïde.

Ces observations n’infirment donc en rien l'origina staphylococeique habituelle de l'ostéumyedite infoctiense des adoleserents.

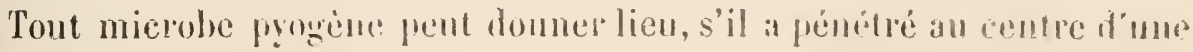
épiphyse ou sous le périoste, à des arceirlents de jériostite un d'usteomýlite, et c’est une loi de pithologire gincialu que le lisste osseux

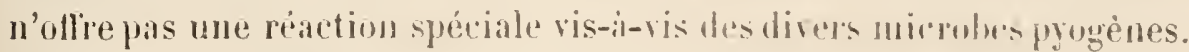

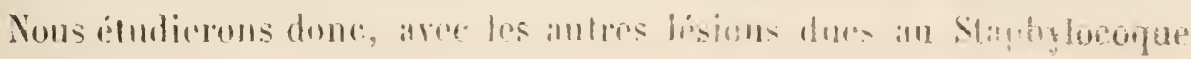


doré, l'ostromrélite tỵpique spontanée des adoleseents, d'autant mieux ynu les osténgélites infeetieuses non staphylococerques ne présentent pars de types cliniques bien distincts et sont de simples curiositis bactiriologiques.

fa Staphylocoque doré ast très répandu dans la nature.

Sous aroms rul qu'il existe tris fréquemment il la surlace de la pran. Il pullule aussi dans les cavilés maturelles. Ce microbe étant III agent prograne d’ume activité tonte spéciale, l’étiologie de l'ostéomyélite alignï dess adolesconts est trís simple.

Tamitis que le furoncle, l'anthrax, le phlegmon circonserit sont presque toujours dus a une inoculation directe d'origine externe, l'ostéomyélitr lypique des aldolescenls se produit d'une manière indirecte et saus que bien souvent on puisse retrouver dans les commémoralils la moindere cause efticiente (traumatisme, etc.).

Nous avons frromnellement renontré le Staphylocoque doré dans l'urine, sans fraces dallumimurie, an cours d'une attaque prolongée de furonculose. Ces observalions prouvent que le staphylocoque, nràce anx propriclés preservalrices bien comnues des cellules lymphatiques et des antres phagocytes, peut traverser le courant sanguin, et mèmr le tissu lénal, sans ! déterminer la mointre lésion appréciable. (Nous verrons plus loin que cette expérience est facile à réaliser chez les animax.) lin enlant dans lo sang duquel eirenient quelques staphylocoques vicut-il a déchirer dans an mourement brusque un carlilage éphiphsalire, il sulfit de la présence d’un seul élément microbien an nivean du point traumalisé pour que, trouvant dans un caillot minuscule un excellent milieu de enitme, ee parasite détermine la mécrose du tissu spongienx roisin, el conséculivement, des desordres intra-osseux el sous-periostiques étendus.

list-il mème nécessiare qu’il ! ait daus tous les cas un trammatisme? II est probahle que, lorsqu'il existe un assez grand nombre de Shaphyloeopues dans lo sang et que l’état géméral est peu satislaisant, l’activite circulatere du tissu ossenx voisin des eppiphyses sultit par y rauser la localisalion bien conme de losténnélite infectiense.

fons representons, lig. 122, motre premiere préparalionde Staphylo- 
coques; cette préparation provient d'un cas d'ostéomyélite opéré en 1882 par le I) Championnière, dont nous étions interne à l'hôpital Tenon.

l'ostéomyélite spontanée se développe le plus souvent aux dépens du tibia, souvent aussi an niveau du fémur. Lannelongue a démontré qu'on peut l'observer daus tous les os de l'économie, même dans les os p'ats et les os courts.

Presque toujours la maladie débute, comme nous l'avons dit, d'une manière insidieuse. L'enfant olfre au niveau de la jambe ou de la cuisse un gonflement dillus. Autrefois on conlondai fréquemment avee une attaque de rhumatisme la période d'invasion de l’ostéomyélite infectieuse. La maladie peut revètir une marche subaiguë et dans certains cas, malgré l'existence de séquestres intra-osseux d'une étendue considérable, il se forme, sans réaction générale violente, un abcès sous-périostique qui s'ouvre spontanément au dehors au bout de plusieur's semaines. C'est ainsi que nons avons v'u venir d'une assez grande distance en boitant, à notre clinique, des enfants présentant d'énormes abcès à Staphylocoques, qui avaient détaché de l'extrémití inférieure du fémur le périoste et les museles adjacents.

Quand on ourre ces abcès, on trouve presque toujours à la face interne du périoste des couches osseuses néoformées. Ces lamelles ossenses d'origine récente sont le premier stade de la formation de la gaine que l'on rencontre autour des anciens séquestres.

L'ostéomvélite alfecte souvent une allure plus alarmante. Plusieurs os peurent être atteints soit simultanément, soit ì des intervalles variables. Entin la maladic peut éroluer d'emblée avec les ș̣mptòmes de l’infection purulente. Dans ces cas, parfois au delà de tonte ressource si l'on ue prévoit en quelque sorte dès les premiers jours la localisation des staplyylocoques, la mort survient en 10 on 15 jours avec un gonflement dillis et parfois pen accentué d'une jambe ou d'une cuisse, mais arec formation rapide d’abeès métaslatiques dans le foic, les reins, la rate, les poumons et parfois le cerveau.

L'ostémyélite peut done se comporter d'une manière hénigne et n'être en quelque sorte, suivant une compraraison inagèce, qu'tin

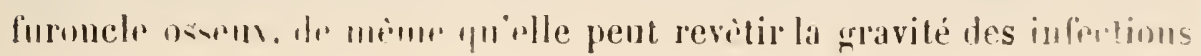


chirurgicales les phus foudrogantes et s'identilier arec l'infection purulente.

Infection purulente. - Le Stiphylocoque est l'un des micro-organismes pathogènes habituels de l'infection purulente typique. L’infection purnknte, caractérisće par la présence de suppurations étendues el d’abeès métastatiques, fut bien longlemps séparée par les Cliniciens de la septicémie, oủ la mort survenait an contraire sans lésions anatomiques grossières. Les études microbiennes ont lait juslice de ces distinetions trop superficielles. Il est prouvé anjourd'hui que le mime microbe peut tuer avec on sims alteces mélastatiques et que la septicémie comme la pyohémie penventètre causćes indilfẻremment par plusienrs especes microbiennes bien distincles.

L’inferlion purulente n’est done, comme l’ostéomyélite, qu’un type clinique dont l’óliologic bartérienne se trouve variable.

Bien mirux il est prouvé, conmune nous venons de te signaler, que la

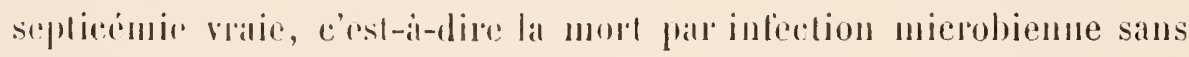
trate de suppunation viscérale on d'abees métastaliques et dont le type se troure par exemple daus le: Charbon, peut ètre réalisée par l'inoculation des especes bactérinues les plus habitucllement progènes. Nous avons vu des malades succomber en dix-huit a vingl heures, sans trace de suppuration focale ou générale, ì la suite d’une inlection par le Staphylucouque doré. Le fromil signalail ces lauts dauns une récente legon el rappelait des observations de mort loudroyante survenant en vingl-pualte heures alnis une infection ehirurgicale ou mème après mne simple piquàre anatomique. It s’agissait tautôt du Staphỵloeoque, tantòt elu streptocoque.

Dans ces cals, la multiplication du mierobe daus le torrent cireulatoire et la production des toxines sont tellement rapides que la mort survient arant que te processus pyogène n'ait eu le temps d'évoluer.

Les alcidents foudroyants peurent dépendre, soit d'un maurais état gíméral du sujet at d’une réceptivité spéciale, soit d'une virulence exagéréc du mierobo. Nous reviendrons phus loin sur ces exaltations remarduables de virulenee anjoud'hui bien commes pour le Streptocoque comme pour le bacille de la Diphtérie depuis les belles recher- 
ches de Roux et de Marmorek, et il est probable qu'con partant de cultures de Staphylocoques provenamt d'un de ces cas de seplicémie foudrovante on arrivera, par les méthoules commes, à la sćrothérapie de l'infection par le Stapliylocoque doré.

Localisations du Staphylocoque dums les cas mortels. - Dans tontes les antopsies que nous arons pratiquées en prenant soin, enmme l'exigent de semblables recherches, de recueillir les malérianx de culture aussitot après la mort, nous avous constati qu'il existe souvent dans le torrent circulatoire, tonjours dans le parrenchyme des prineipanx viscères (foie, rein, rate, moelle des os), de nombreux amas de micro-

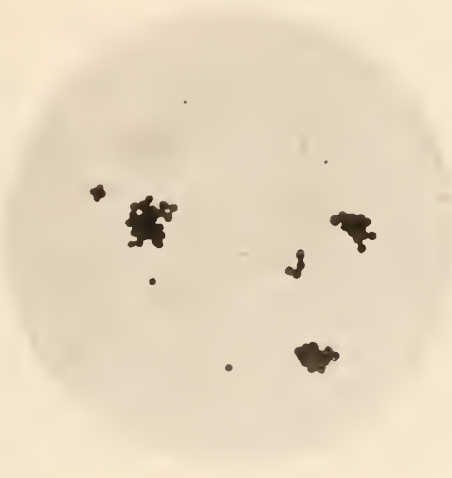

FIG. 423

Ostéonyélite du tibia (1882). Arthrite purulente du genon. Staphylocoques. fir. (1000 dianto.).

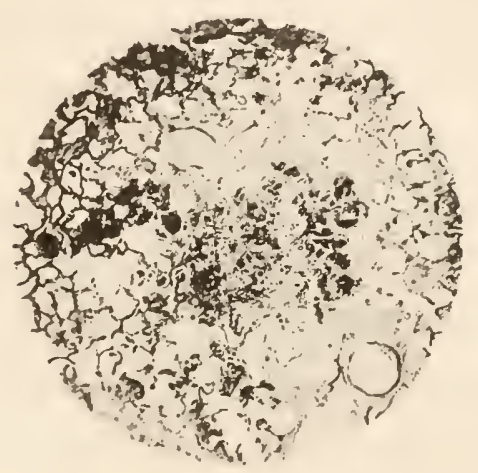

FIG. 424.

Infection purulente par le Slaphylocopne dori.

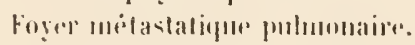
(iir. 2:i dianu.)

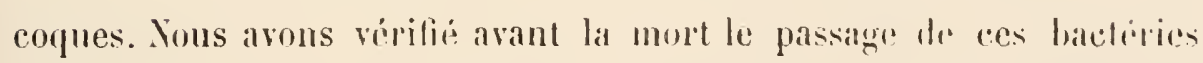
dans l'urine; nous arons observé ce phénomine cher les miliddes pui ont guéri ef nous arons noté que, mème dans ces horniers lais, l'urine, all moment ou la fieve septique était la plus vive of on sa toxicité, comne l'ont si hien démontré le pr Bouchard ot ses chlires, alteignail son maximum, devenail d'acide, neutre el, dans les cas wraves, alcaline.

Xous avons recherehé aver. II. Conttolene, professentr i l'icole professionnelle de lieims, la présence des ptomänes et nous nlabous jamais pun ohtenir ees dernires fu'en tries petite quantité. Les produits les plus toxiques nous ont parn particulièrement ètre des allumnimoïdes, soit précipitables par l'alcool dans les cultures ef le suc des viscères, 
soit dojat peptonisés et solubles, connme toute peptone bien élaborée, daus lalcool concentré.

\section{INOCULATION AUX ANIMAUX}

Nons avons, lios nos premières pecherches en 18\%2, pemlant notre

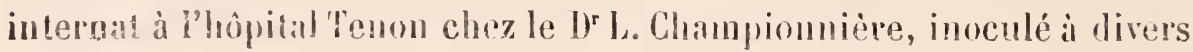
animaux du pus de furoncie el d’ostéonyélite. En 1884, nous avons fait nos prenières cultures de Staphylocogues daus le service du lor Labbé.

L'inoculation de cultures virulentes du Staphylocoque doré présente ce phénomène particulier que l'on n'observe pas le mème lype de suppuration chez les différentes espèces animales 1 , pour ne citer qu'une seule de ces particularités, il est habituel que l'injection au lapin de cultures de Staphylocoques détermine la formalion de véritables abcès caséeux comme il en existe chez l'homme dans certains cas de tuberculose locale.

Ces faits nous ont frappé dès le début de nos expériences. Laction pathogène du Staphylocoque doré étant bien démontrée par l'inoculation dans le tissu conjonclif sous-cutané on daus le péritoine, nous avous cherché à déterminer des ostéomyélites typiques par l'inoculation sous-périostique ou intra-osseuse.

Nous avons obtenu des résultats positifs dès nos premières inoculations. Nous nous sommes alors attaché à obtenir l'ostéonyélite spontanéc chez de jeunes lapins par la simple iuoculation de petites quantités de cultures dans le torrent circulatoire, et c'est aiusi que nous sommes arrivé à provoquer chez un lapiu, daus notre lahoratoire de Reims, sans trammatisme occasionncl, m cas dostromycilite typique avec nécrose de l'extrémité inférieure du fẻmur.

Nous avons également confirmé par nos recherches sur les animanx les observations que nous avons faites chez l'homme sur l'ilimination des staphylocoques par le rein et i ce propos nous avous injecté dans la veine de l'oreille du lapin des microhes vilriés, faeilomont rerommaissables, tels que le staphylocoque doré, le streptocoque, le hacille pyocyanique, le prodigiosus, ete. Ces recherches, répétés mombre de fois, noms ont ameni i cette conclusion que les microbrs mème les plus 
éminemment progènes, et à plus forte raison les microbes indifrérents et non pathogènes, nétaient pas senlenent détruits dins l'organisme par l'action bienfaisante des cellules vivantes, comme l'a démontre II. Vetschnikolf, mais que des microbes étaient éliminés par le rein comme nous l'avions observé chez l'homme, et aussi par le foic, comme il est lacile de te démontrer chez le lapin. L'élimination commence quelques heures après l’injection dans le sang et se montre très évidente pondant deux on trois jours.

Quand il s'agit du staphylocoque pyogène, la présence du microbe dans l'urine et la bile se manifeste hien avant l'apparition des abcès métastatiques du foie et du rein, qui déterminent la mort an bout de quelques jours; pour les microhes non pathoginnes, nous n'avous observé aucune lésion viscérale.

Il est donc démontré l'après ees recherches, d'abord vivement attaquées, puis contròlées depuis par de nombreux bactériologistes et vérifiées notamment pour le foie par nolm ani le lor léticme, que les bactéries en nature, pathogènes ou non, sont susceptibles de traverser le foie et le rein et d'être éliminées par eux comme de simples substances solubles, l'iodure de polassium par exemple.

\section{NÉPHRITE ASCENDANTE A STAPHYLOCOQLES}

Les recherches de Leube (Arch. de Virchow 1885, p. 540), puis de Launois, Clado, Hallé, Albarran et les nôtres (1885-1890), démonlrèrent que la néphrite ascendante était due le plus sourent a la pénétration dans les tubuli et mème jusqu'anx glomérules d’un fin bacille analogue ou identique au Bucterium coli commune. Certains auteurs ont voulu décrire conne un type bien défini un bacille de l’infection urinaire. Nous avons prouvé l'un des premiers que la cystite aiguë infectieuse, dans sa forme bénigne comme daus ses formes les plus graves, et la néphrite ascendante, qui en est la phus terrible complication, penvent être causées mon seulement par plusieurs esperés de bacilles, mais aussi par des microcoques (Société anatonnque, juin 1885).

Souvent mème l’infection est mixte, comme nous l'avons justement 
observé en ISSg su la pirce i laquelle nous faisons allusion ei qui été recueillir dans le service de notre maitre le br Lancereanx.

Xums avons itmdié chez l'homme phusiours cas de evstite et de néphrite ascenlante à Shaphlocorques el it Streptucoques.

Yuus avons provoquí expérimentalement les mimes lísions chez les animaux en injectant dans l'uretire mialidhenrent lic du crili de la vessie une culture de microcornes.

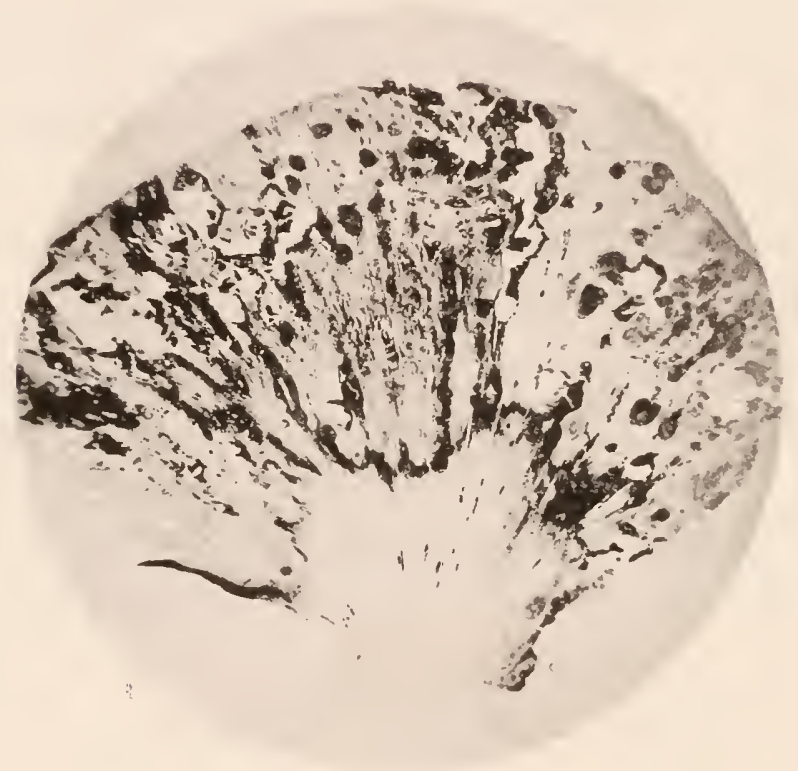

Hiv. 42:5

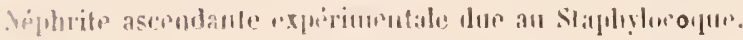

(fir. ¿ ulian.)

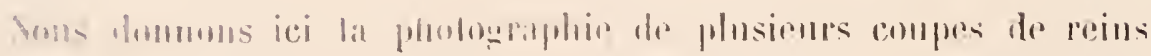

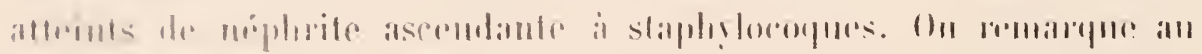

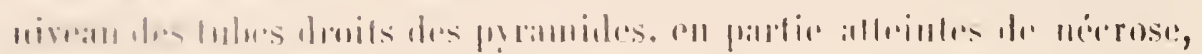

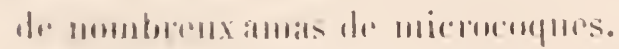

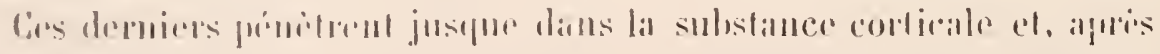

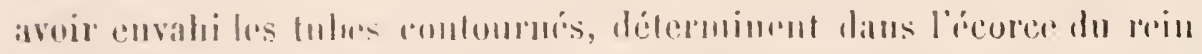

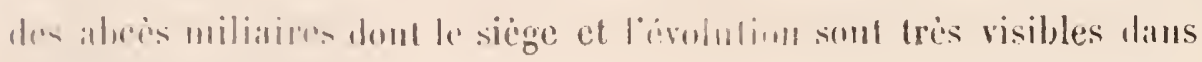

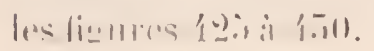




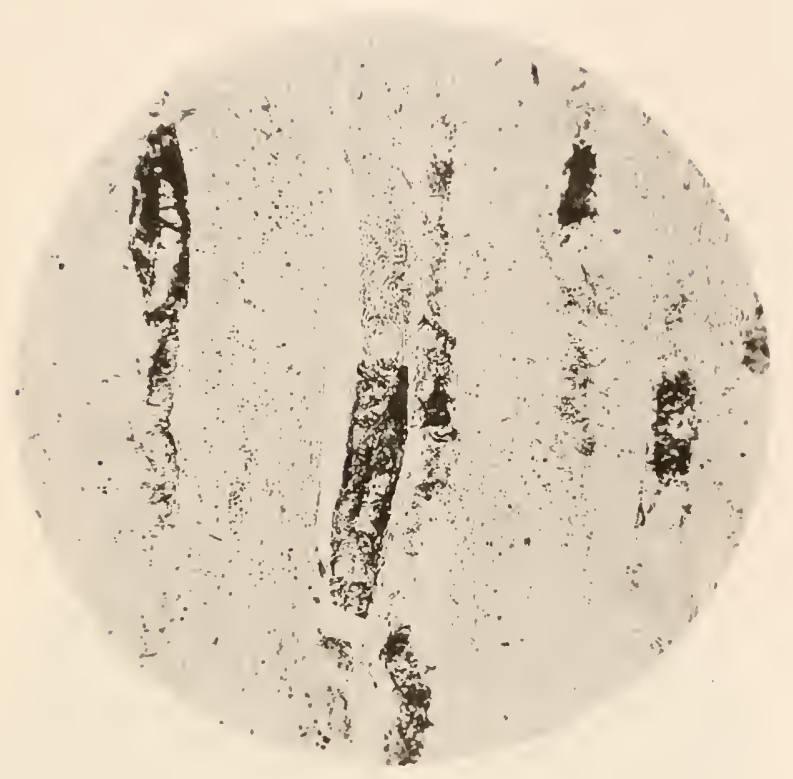

Pic. 426.

Amas de Staphylocoques dans les tubes droits des pyramides. (Gr. 60 diam.)

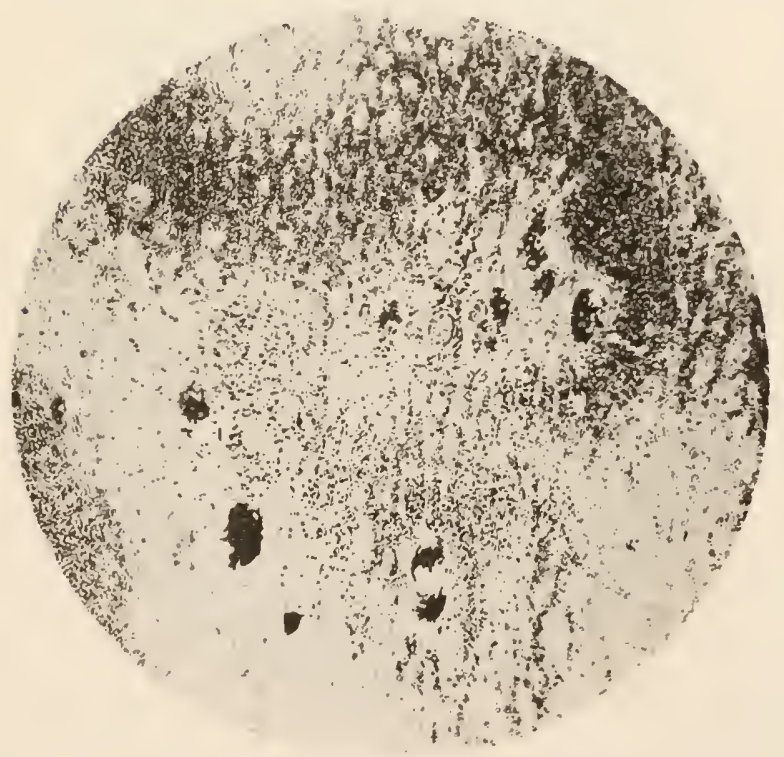

FsG. 427

Lésions suraigues à forme gangréneuse. (Gr. 80 diam.) 


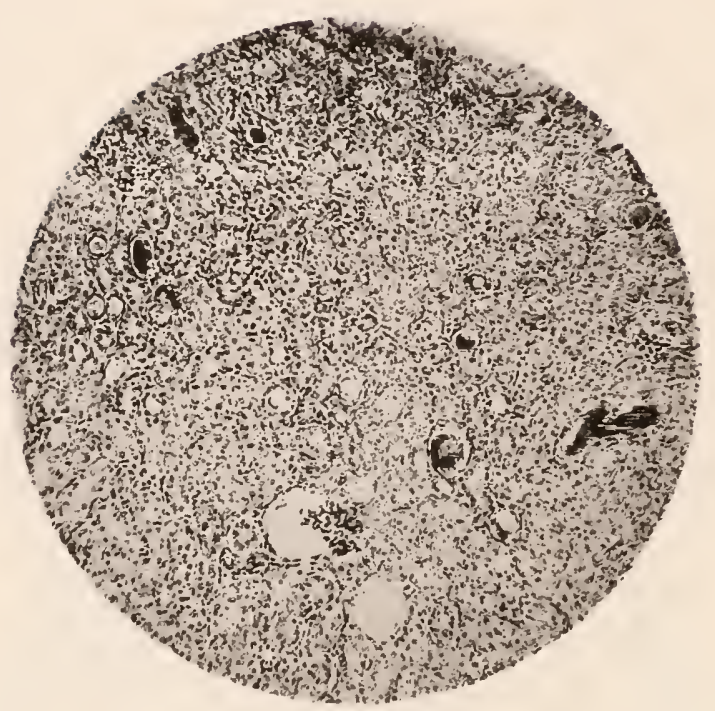

Fig. 428 .

Zooglf́es dans la région corticale. (Gr. 80 dian.)

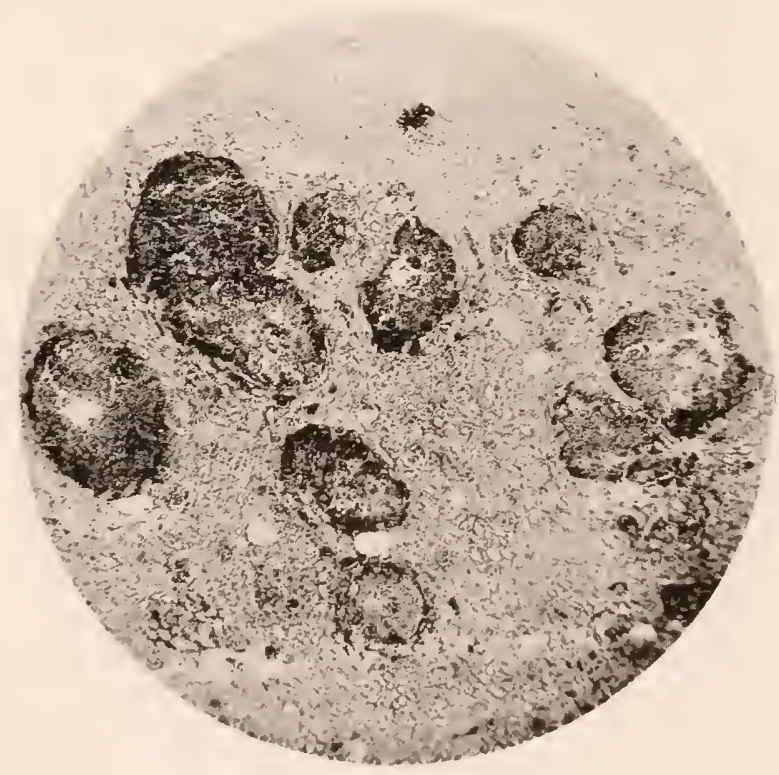

F16. 429

Formation des abcès corticaux. (Gr. 2i diam.) 
On remarque dans la fignle 1.30 , an centre mème do l'abers, nn amas très visible de microcoques. Cotte inlection rénale ascendante est rapidement mortelle chez le lapin on le cobaye, et, quand on inocule un seml rein, il est facile, dams les eas on la mort ne survient pas trop vite, d'observer dans les autres viscères les lésions de l'infection purulente typique les staphylocoques ayant envahi, du rein infecté par voie ascendante, le torrent circulatoire, et ayant déterminé par voie

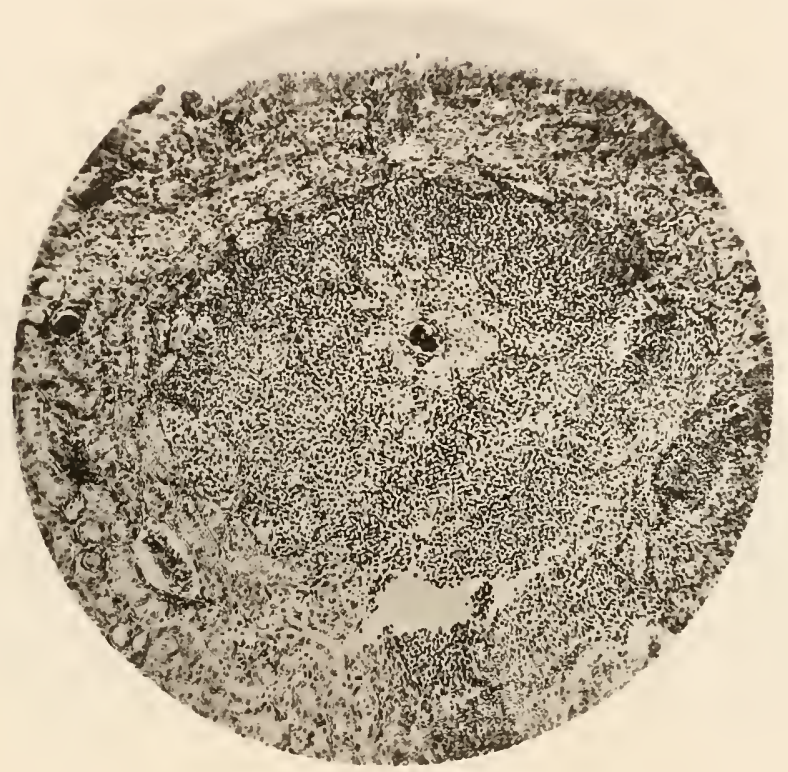

Fic. 430.

Alues cortical avec Zooglée centrale de Staphylocoques. (Gr. 80 diam.)

embolinge daus le foir, le poumon, la rate et le reiu du cóté opposé des abcés mélastatiques. On ohticnt aussi sur le mème animal les deux types de lésions.

De mime que dans la peau on observe deux modes bien différents de suppuration suivant que l'infertion est locale (furoncle, phlegmon circonseric) ou dorigine embolique purpura, abcis métastatiques), de meme ces deux trpes analon!lq̣urs que nous avons appelés, l'un inlicelion parenchymateuse, l'autre inl'ection embolique, s'observent respectivemrnt dans tous les viscires tels que le pounon, le foie, le rein, par 
exemple, où les microbes peuvent pénétrer par l'arbre aérien on les canaux excréteurs (broncho-pneumonte par inhalation, cholécystite infectieuse, néphrite ascendante) ou bien par voie embolique, e'est-idire par le torrent circulatoire, pour déterminer soit une mort foudrovante (septicémie des anciens cliniciens), soit une mort plus lente avec production d'abces métastatiques (infaction purulente), soit senlement, comme nous l'avons démuntré, une sorte d'état infectieux passager et curable au cours duquei les microbes pathogènes sont à la fois détruits par la phagocytose et, comme nous l'avons démontré, éliminés par le foie, le rein et d'autres glandes ( $V^{e}$ Congrès français de Chirurgie, Paris, 1891 ).

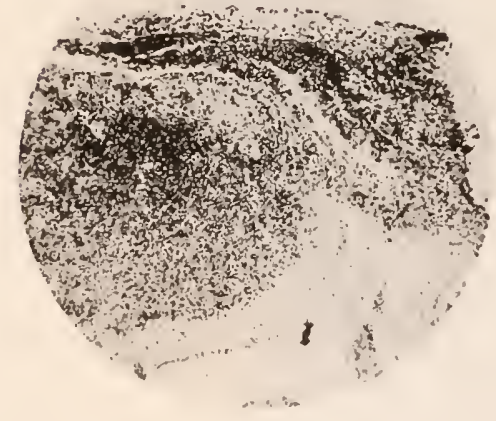

Fic. 4.31 ,

Phlébite de la veine faciale, des sinus de la dure-mere et de la veine sylvienne. Coupe de la veine sylvienne thrombosée.

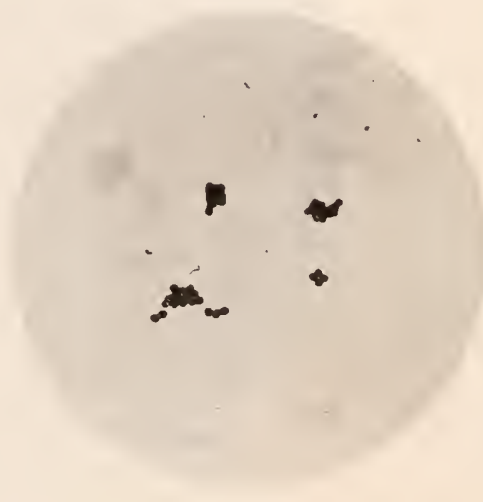

Fic, 432.

Staphyloconues provenant du caillot dune de ces veines.

(I'réparatious faites en 1884.)

\section{PULÉBITE JES SINUS DE LA DURE-MÊRE}

Il n'est pas sans intérit de signaler l'action patlogène du staphylocogue doré sur le systeme veineux. La phlegmatia postpuerpérale, comme l’a bien démontré Widal, est due au streptoconpue. Fidèle à la loi que nous arons donnée a propos do la suppuration ef des divers types d’infection purulente, qui proment relever sans types cliniques bien différents d'esperes microbienues distinctes, le Stiphỵlocoque peut déterminer l'érolution de phlébites progressives i marche straiguie. 
Yous avous observé plusicurs eas de phlébite slaphyglococeique de la reine faciale propagée à lat veine ophtalmique el anx sinus intrateràniens. Ces phléhites évoluent en général à la suite d'un furoncle profond de la lève supérienre ou de l’aile du nez.

l)ans l'une de nos ohservations, une plulébite mortelle s'est installée a la suite d’une simple érosion de l'épiderme de la joue occasionnée ehez une garde par un coup d'ongle d'enfant.

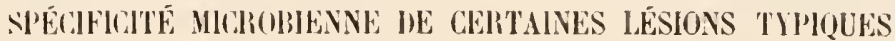

Il résulte de ce qui précède que certaines infections typiques, telles que le furoncle et l'anthrax, sont caractérisées microbiennement par la présence constante d'un seul et mème agent pathogène.

A còté de ces alfections í parasitisme constant et bien déterminé, beaucoup d'antres maladies microbiennes peuvent au contraire revètir un mème lype classique, tout en n’élant pas toujour's causées par le mène micro-organisne (phlegmon, septicémie, infection purulente, choléç̧stite et néphrite ascendinte). Nous retrouverons ces particularités dans toute la bactériologie. Les espèces microbiennes capables de déterminer des lésions analogues au point de rue clinique devront donc être recherchées par l'examen immédiat et les cultures, le moindre phlegmon, lésion banale en apparence, pouvant comporter un pronostic bien variable suivant qu'il s'agit par exemple d'une infection par le Staphlocoque blane, infection presque toujours locale et bénigne, ou bien au contraire d'un cas d'actinomycose, lésion rebelle et envahissante au premier titre.

\section{IMMUNITÉ CONTRE LE STAPHYLOCOQUE DORÉ}

Les infections les plus légères par le Staphylocoque doré, orgeolet, furoncle, pustules sous-épidermiques, s'aceompagnent fréquemment d'un odème intlammatoire étendu avec rougeur, douleur vive, légère élévation de la température, et se compliquent souvent d’adénopathie. Les ganghions enllammés sous l'action du seul staphylocoque suppurent tris rarement.

Ces accidents locaux peuvent se reproduire avec persistance pendant 
plusieurs semaines et plusieurs mois chez un même sujet atteint successivement de dix, vingt, trente furoncles et mème pius. C'est sur un sujet atteint d'me de ces poussées de furonculose que nous avons pu, il y a presque dix ans, démontrer la présence dans l'urine du Staphylocoque doré.

Ayant eu l'occasion d'assister depuis cette époque chez la même personne à diverses manifestations de l'infection locale par le Staphylocoque, provenant parfois d'une inoculation fortuite au cour's d'opérations d'ostéomyélites infectieuses ou de lésions suppurées graves, nous avons remarqué que l'intensité des symptômes inflammatoires diminuait progressivement, et depuis près de deux ans des inocnlations qui avaient provoqué primitivement jusqu’à un phlegmon étendu de la main, des panaris anthracoïdes, etc., déterminent ì peine l'érolution d'une minime vésicule purulente; de mème à la région cervicale se sont développées, en pareil eas, au lieu de furoncles, de petites nodosités infiammatoires qui se sont indurées sans donner une seule goutte de pus. Ces observations nous permettent de penser que l'on découvrira sous peu un moyen d’augmenter la réactiou défensive de nos cellules contre le Staphylocoque et d'atténuer les accidents locaux ou généraux souvent si graves qu'il peut déterminer.

\section{MICROBE DU CLOU DE BISKRA}

Duelaux et Chantemesse ont observé dans le clou de Biskra ou bouton du Nil, bouton d'Alep, etc., des microbes très analogues au staphylocoque pyogène doré.

La gélatine est liquéfiée, les cultures sur agar et pomme de terre ont une belle couleur orangée. Malgré la similitude apparente de ce microbe avec celui du furoncle, il parait que les effets de l'inoculation par frottement à li surface de la peau donnent des lésions un peu différentes de celles produites par le Staphylocoque doré, q̨ui, lui aussi, pénètre aisément dans les follicules pileux et sébacés, et peut déterminer des furoncles et des anthrax avee gangrène de la pean.

Les cultures, comme celles du Staphyglocoque doré. perdent arce l'àge leur belle coloration et diminuent de virulence. La coloration jaune 
redevient manifeste quand les cultures sont rajennies dans le bouillon ou pall phusieurs passages daus le samgo d'animanx non réfractaires.

\section{STAPHYLOCOQUE BLANC}

Rosenbatch a observé dans certains abcès, quile plus souvent étaient survenus salus doulenr vive et sans grande inllammation du voisinage, IIII staphlỵloconpe absolument identique an Staphylocoque doré à l'examen du pus, et qui u'en diffère qu’i l'aspeet des cultures sur agar ou sur pomme de terre, ces cultures étant d'un blanc terne.

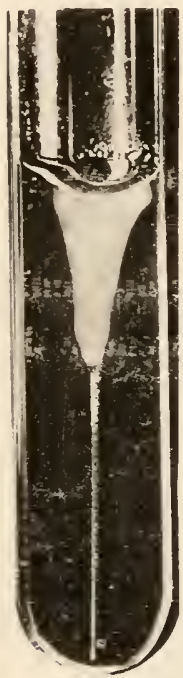

Fig. 435 .

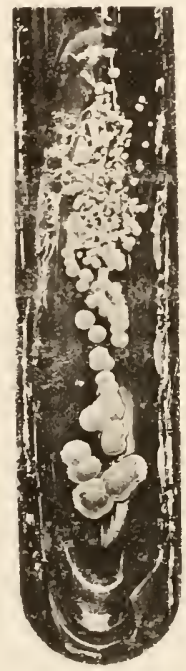

Nig. 4.34.

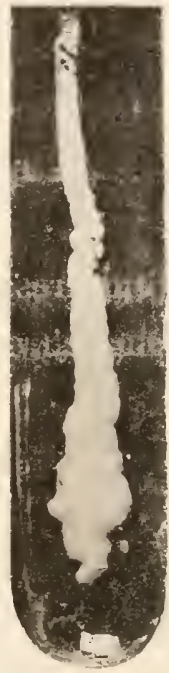

Fis. 435.

Staphylocoque blanc. Citllure sur gélaline ( $3^{e}$ jour).

Staphylocoque blanc (Pus). fre cullure sur agar.
Staphylocoque blanc.

$2^{\circ}$ culture sur agar.

Nous arons fréquemment rencontré le Staphylocoque blanc, et nous citerons particulièrement un abcès péri-anal de 100 grammes de pus survenu chez un enfant de quelques jours et où ce microbe existait à l’état de pureté. Malgré le mauvais état général, la présence exclusive de ce microbe nous parnt comporter un pronostic bénin, et le petit malade guérit en effet en quelques jours.

On a prétendn que ce microbe n’était autre que le staphylocoque doré modifié dans ses propriétés chromogénes et dans sa virulence. Nous répugnons à croire qu’il n'existe pas plusieurs espèces bien déierminces de Staphylocoques, et, dans les cas nombreux où noụs 
avons observé le staphylocoque blane, les cultures présentèrent d'emblée un aspect terne et légèrement grisàtre très caractéristique. Les

Fic. 436 .

Pus d'un phlegmon de la gaine lu psoas. Staphylocoque blanc. (Gr. 1000 diam.)

vieilles cultures de Staphylocoque doré sur la gélose finssent bien par n'être plus chromogènes: mais elles peuvent reprendre leur belle

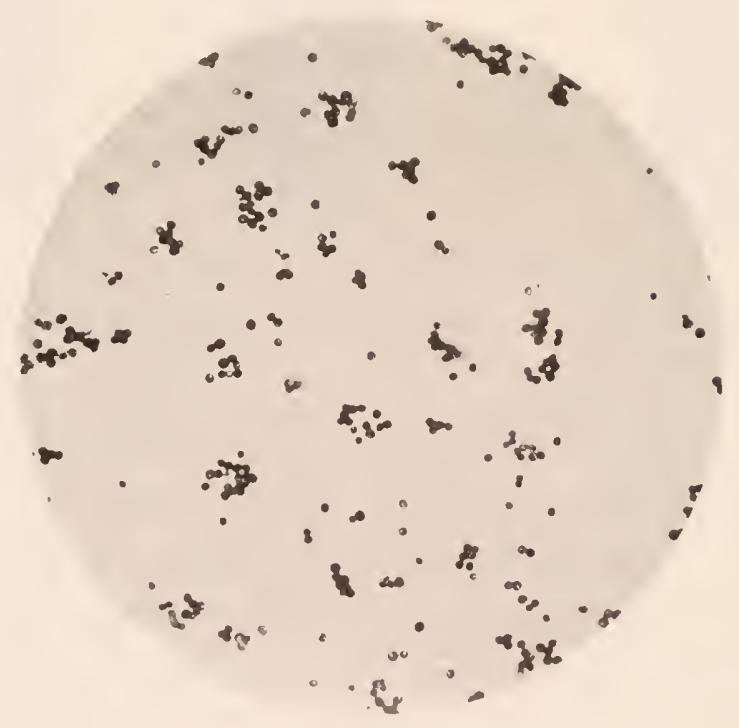

Fig. 437

Jeme culture te Staphylocoque hanc. (Gr. 1000 dian.)

teinte dorée si on leur rend leur virulence palr des inoculations aux animatux. 


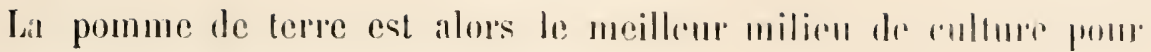
obtenir l'aspect orangé caractiristipur.

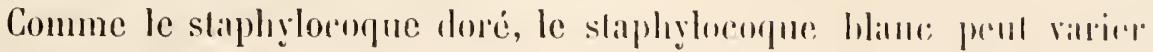
dans sa virulence, el nous arons olscerve un cas de poölis suppurion grave it staphylocoques blancs qui s'est terminc parl lit mult ande; toutes les lésions de l'infection purulente. Jamais nous nomans obtenu sur ces cultures lit moimbe take de pigment mangé.

\section{STAPHYLOCOCCUS CITREUS}

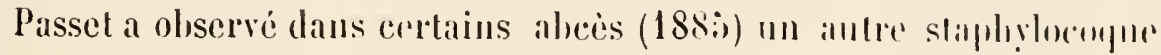

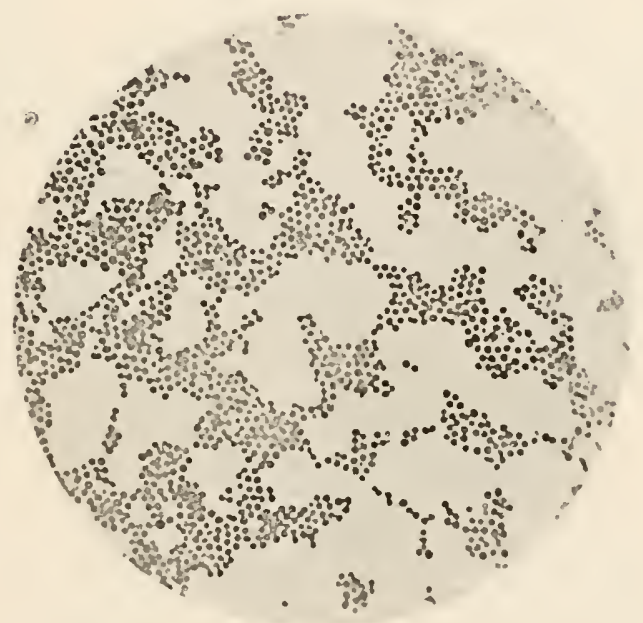

Fig. 458.

Staphyloroccus citrens. (G.r. 11100 liam.)

dont les cultures, tris analogues à celles des deux prédètents, mrumrul une coloration d’un janne citron, très différente de la coloration thu staphylocoque doré. Ce microbe liquélie la gélintine et parail inlermidiaire, an point de vue de la virulence, aux deux precidents.

Lamelongue et Achard (Is:2) onl constalli sil presence dans un

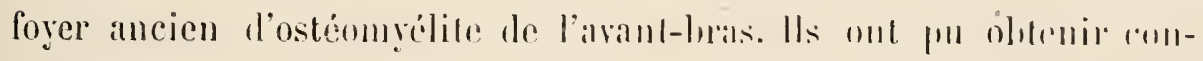

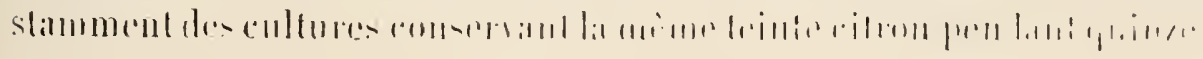


générations sucecssives, et durant sept mois. Ils cousidirent, comme Passet, qu’il s'agit bien d'une espece distincte el non d'un croisement ou d'une transformation des staphylocoyues doré et blane.

\section{STAPHYL. GEREUS ALBUS ET FLA VUS}

Passet a décrit également d'autres microbes pyogènes, notanment les Staphyl. cereus albus et Siaphyl. cereus flacus, qui ne liquéfient pas la gélatine. Ces staphylocoques, conme ceux que nous venons de décrire, se colorent par la méthode de Gram. En culture sur plaque, ils se

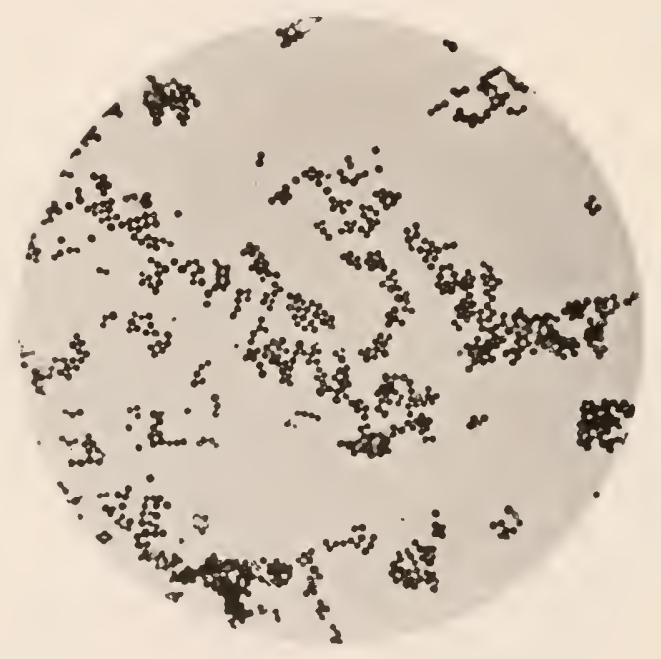

Fig. 459 .

Staphylococcus reveus albus. (Gr. 1000 dian.)

développent sous forne de colonies arrondies, qui s'étalent cn petites taches blanches on jamnitres, ressemblamt a des goullelettes de cire blanche ou jamme.

Ces Aenx espèces se dillërencient tris nellenuml des précédentes,

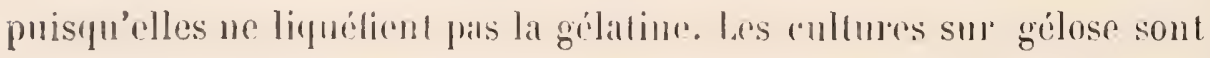
aussi hien distincles; dles ressemblent i mue enthe de cire d'une certaime épaissemr, lamblis que les emlumes des sliphỵlocogues doré, blane el jaune citron, lomment sur l'agar une conche noins épaisse, homogine et humide. 
Les propriéićs progènes de ces espèces sont moins accentuies que celles des staphyiocoques précedenis et he phus sourent on ne les

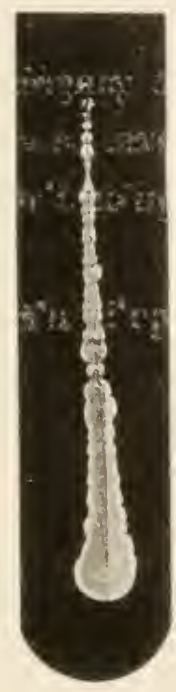

Fig. 440

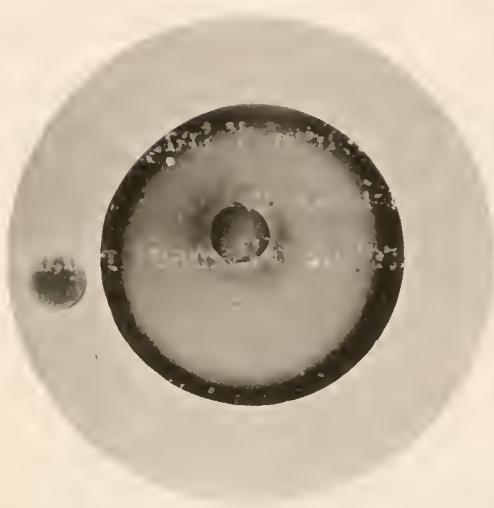

Fig. 14 .

Slaphyl. verens flutus.

Staphyl. ceretls albus. Cuiture sur agar.

Col. sur plaque de gélatine.

(Gr. 20 diam.)

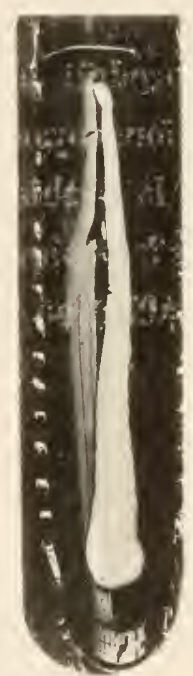

Fig. 4 i2.
Staphyl. cereus flatus. Culture sur agar.

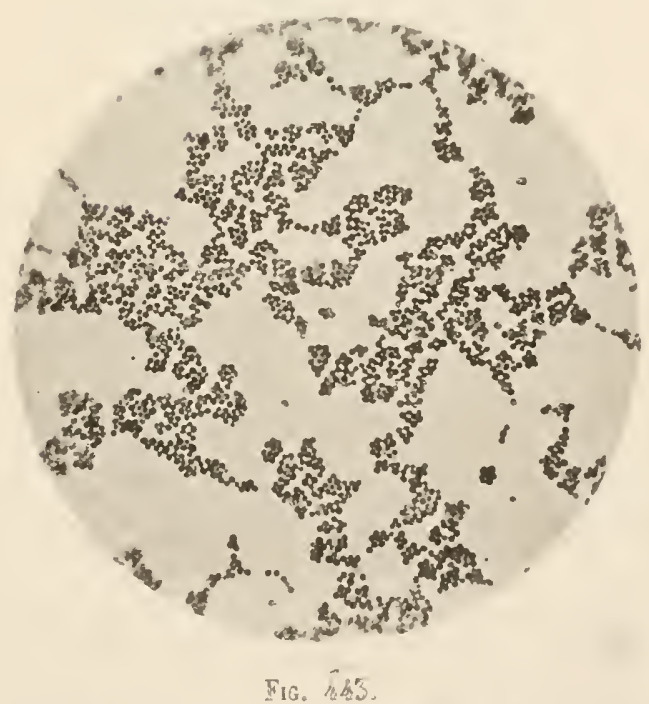

Stripiniococcus co"ens fav:นร。 (fir: 1000 diam.)

poncontre que comme associalion microbienne. Nous les avons

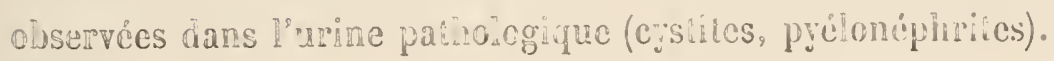




\section{MICROBE DE L'ARAIGNÉE}

\section{MAMMITE GANGRÉNEUSE DES BREBIS LAITIÈRES}

Il se produit parfois chez la brebis une mammite gangréneuse i marche foulroyante et qui peut tuer en 24 et 48 heures. Le " mal de pis » de la brebis a été dénommé l'Araignée, parce qu'on l'attribuait antrefois ì la piqûre de cet insecte.

Cette affection s'est autrefois tellement répandue qu'il n'était pas

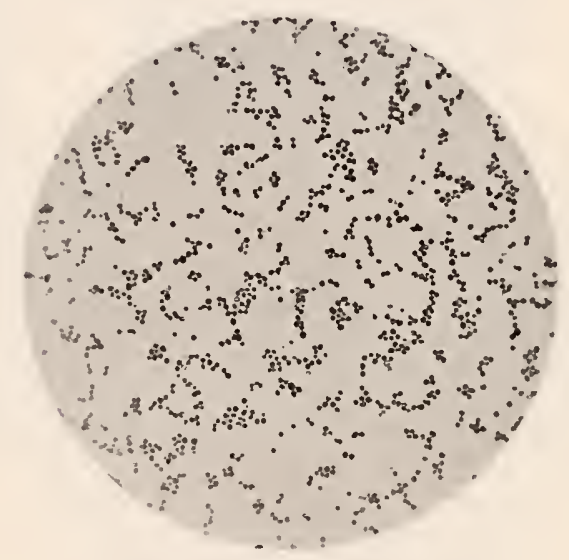

FIG. 444 .

Mammite gangrineuse de la brebis. Culture. (Gr. 1000 diam.)

rare de voir un dixieme des brebis laiticres au moins, dans les tronpeaux infectés, succomber à cette terrible maladie.

La mannelle alteinte s'indure et triple de volume. Elle offre une ciute rouge violacéc.

le mamelon est llétri, flasque et froid. Le tissu ghandulaire se gangrinte.

L’infiluallion sous-culanéc gagne la late interne des cuisses, la rivion ablonimale, et l'animal suecombe.

Xous arous vu que la mort survient, dans les cas suraigus, en

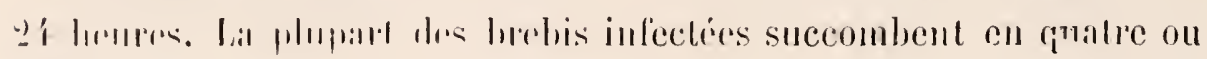


lans les cas asse\% rares on la guérison spontance se produit, les matmelles et les téguments roisins, apmies aroir latissí sumler mur sérusité roussàtre el sanieuse, se fléhissent, se dessiehent et söliminent lentement.

la cicatrisation de ces vastes plaies bourgemnantes exige plusieurs mois.

les rétérinaires ont longtemps considéré cettr malatlie comme une mammite trammatig̨ue. On a recherehé en vain les backéries chanbonneuses. Dans les pays oú le "mal de pis " est fréfnent, ecrlains bergers ont inaginé de fendre dés le délunt le pis en diflërents sens el de traiter les plaies par des lotions détersives.

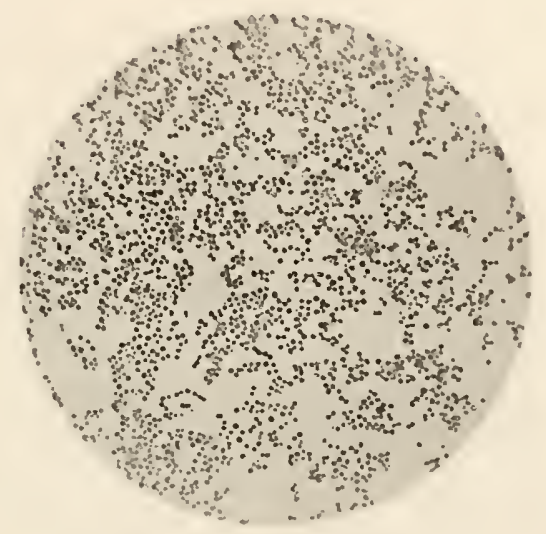

Fig. 445.

Mammite gangréneuse de la brebis. Culture. (Gr. 1000 diam.)

Les recherches du pr Nocard ont confirmé la nature infecticust de l' " araignée ». En mars 1886, examinant le lait extrait pal" lal pression d'une mamelle de brehis indurée, Nocard y observa, apres coluriltion par les couleurs d'aniline et la méthode de Gram, un microcoune extrèmenent petit, en quantité considérabie.

Ce mierocoque est un des plus petits qui existent. On en jugeran par les préparations ci-contre.

Le microbe de lit mammite se enltive aisément dans les bouillons neutres ou alealins, qui, des le premier jour deviement franchement 
acides, moins acides cencndant quaprès ensemencement avec ie stropiocogue de li mammite dles vaches.

Des que le bonillom ac culture est devenu très acide, le microbe pred la propriétedesc reproduire, it moins qu'on n'ajoute, pour le neutraliser, du carbonate de chanx.

Cultive dans du lait de vache on de chève, il y détermine on 24 heures un coagunum rétactile d’une fermeté extraordinaire. Ies bouillons sucrés nentres sont un excellent milieu de culture, l'acidité y apprarait vife et le microcoque meurt si on ne prend soin d'alcaliniser.

Le microbe de l'araignce est un anaćrobic facultatif. Il se cultive bien sur les milieux solides et liquéfie la ge̊latine dès le second jour. Cetre action liquéfiante s'exerce anssi à un moindre degré sur le sćrum grélalinisć.

Sur l'agar-agar il produit en surface une traince opaque, assez épaisse el růi s'ítale peu à peu jusqu'aux parois du tube. Ia culture est d'un blane sale, légèrement grisître, el devient jaunattre aux points les plus épicits.

Nocard démontra expérimentalement, par l'inoculation dans les contrias galactophores d'une brebis saine, que le microcoque qu'il a hicrit est birn l'agent pathogène de la maladic.

I. miclobe de l'araignie n'est nettement pathogène que pour les animaux de l'espicec ovine. Ial chère n'est nullement indisposée; il en est de mime pour le cheral, le vean, le pore, le chien, le chat, la poule, le colnige, a la suite de l'injection soil dans la glande mammaire, soit dans le tissu cellulaire sous-cutané.

l.e mócanisme de la pémithation spontance du microbe dans les conduits gidlatelophores de la brehis domenre assez obseur.

lal prophylaxic seule, par les soins de propreté, est réellement elficalce, et les centilives diujertions antisepriques jusquanx acini ghlamlulaires n’ont pas domme der résultats sillislaisants.

l. Laitement curatif est celui mis en rigneur pall ies bergers,

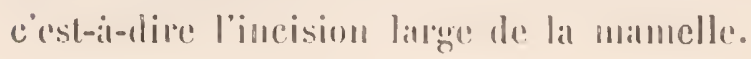




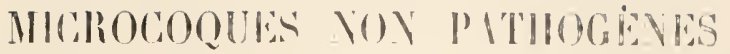

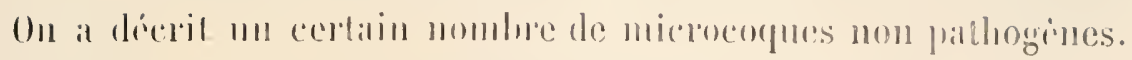

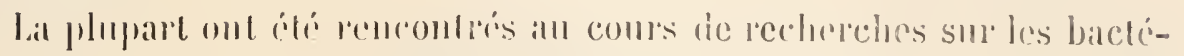
ries de lair el de lean. Nons mentionnenons les plus conmus.

\section{MICROGOGCUS CANDICANS}

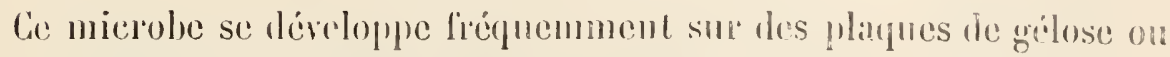
de gélatine exposées a l’alo. Il abonde cigalenent l'ans l'eam.

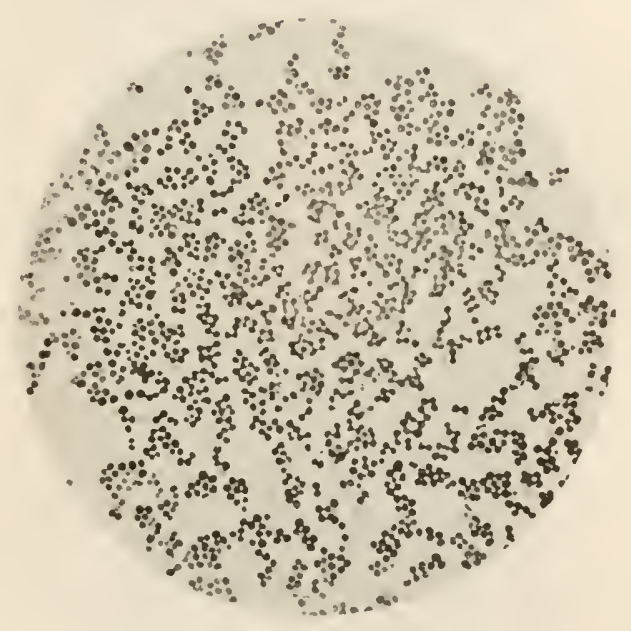

Fiti. Aft.

Mirnococcus candicuns. (Gir. In0n diann.)

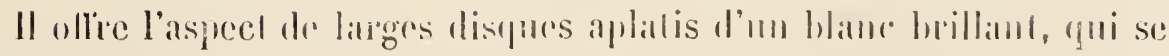

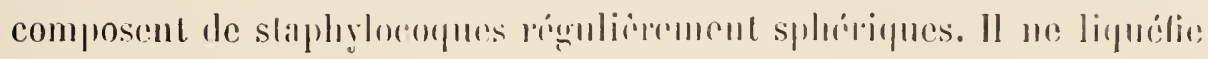

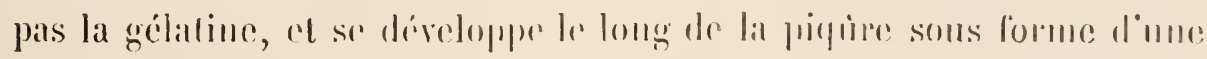

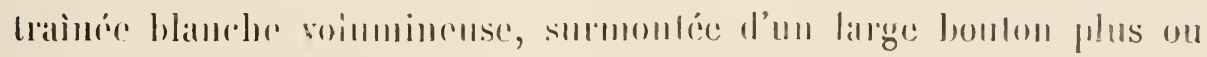
moius hémisphóripur. 


\section{MICROGOCGUS RUGOSUS OLEARIUS}

Nous avons décrit sous ce nom un microcoque qui se trouve fréquemment dans l'air ou dans l'urine exposíe. Ce microbe se déve-

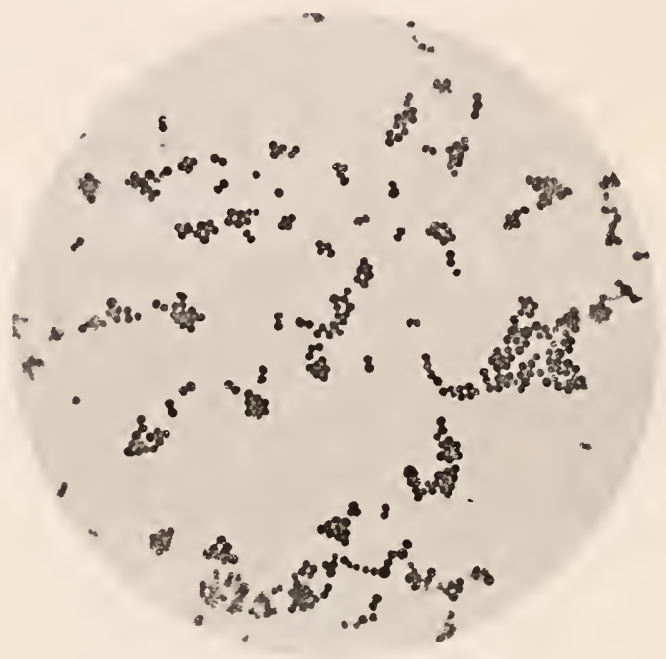

Fig. 417.

Micrococcus rugosus olearius.(Gr. 1000 diam.)

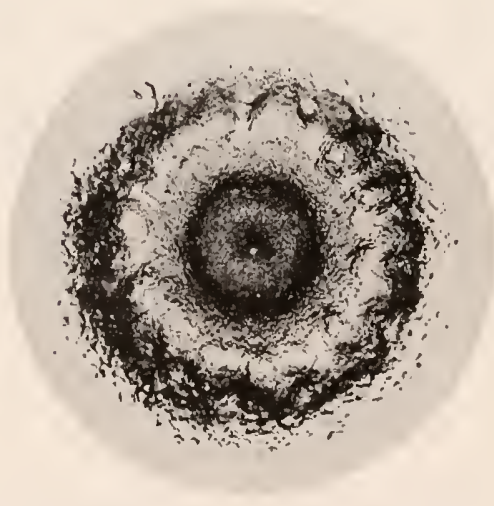

Fig. 48.

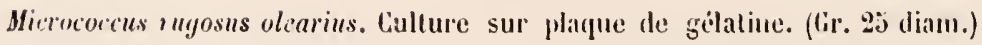

loppe sur l'agar sous forme d'une latrge conche rugueuse et ridee, hanc grisitre, dont l'asprect est intemédiaire it celui des cultures du farcin du bouf et du Bacillus mesentericus culgatus. 
Les tubes de gélatine ensemencés présentent le long de la piquùre une liquéfaction progressive, un peu moins lapide que pour le stiphylocoque doré. Mais la partie liquéfice, an lieu de s'éconler facilenent quand on incline le tube, reste louche et de la consistance d'une huile épaisse.

Cette consistance oléagineuse de la gélatine liquéfiéc est caractéristique. Ce microbe est très résistant et se cultive encore lorșue les tubes de culture sont anciens et presque complètement desséchés. Nos premières cultures datent de 1888 .

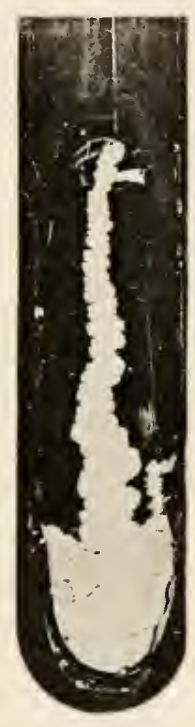

Fig. 449 .

Micrococcus rugosus olearins.

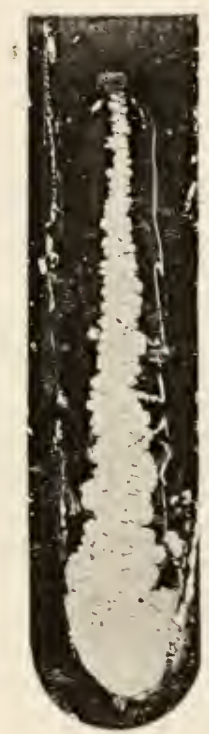

Fig. 430 .

Slicrococcus ruyosus olentius.

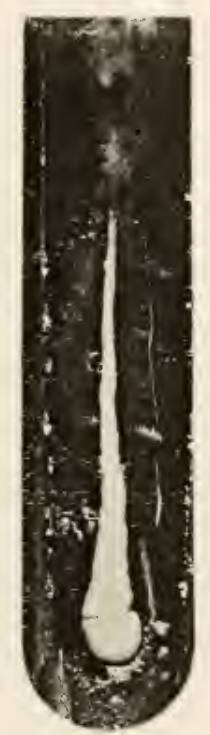

FlG. 451 .

Micrococcus Ravus desielens.

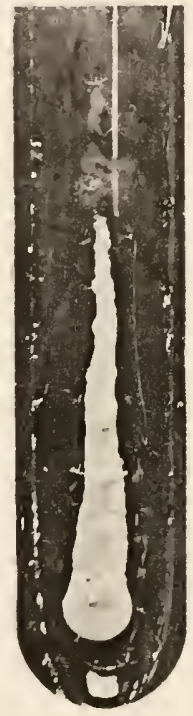

Fเง. 4รั2.

Jicrococcus utrantilucus.

Jeune cult, sur agar. Vieille cult, sur agar. Cullure sur agall. Cullure sur agall.

\section{MICROCOCGUS VERSICOLOR}

Le Micrococcus versicolor provient de l'air et se cultive sur la gélatine sans la liquéfier. Il y forme comme sur l'agar une couche visqueuse d'un jaune verdilte, qui présente il la lumière réfléchic des reflets nacrés. Ce microbe vient souvent contaminer les plaques le gélatine. 


\section{MICROCOCCUS AQUATILIS}

Cie microbe est fréfuent dans les eaux potables. Les colonics se développent dins l'épaissem de la gaibatine avec une apparence mûriforme. A mesure pu'elles se déreloppent, on observe du centre de la eolonic à sa périphérie une série de sillons qui la découpent en petits ilots amalogues inx acini du foic.

\section{MIGROCOCCUS ROSEUS}

Le micrococens rosens est tris conmmn dans l'air et forme sur les

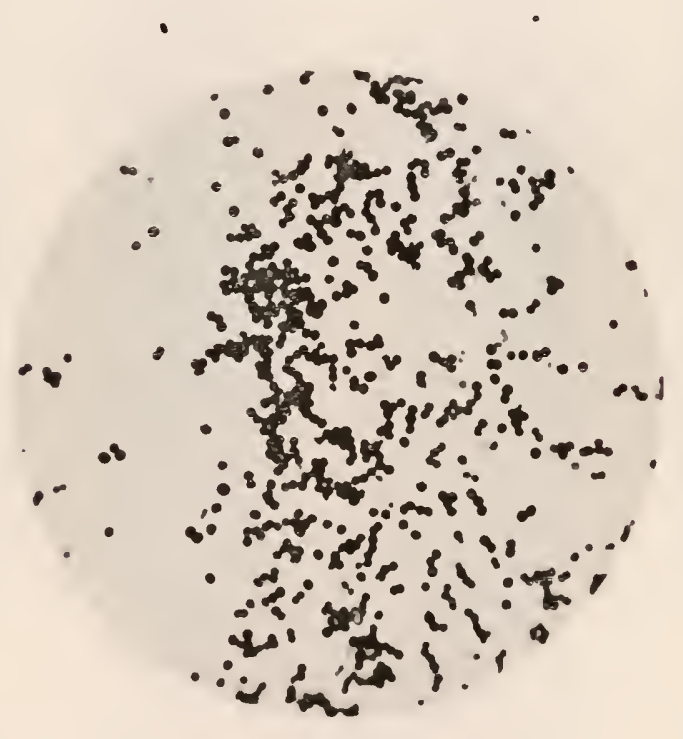

Fig. 俩.

Mirronocrus rosens. linllure. (Gr. 1000 diam.)

panpues de gribline, sams les liquilier, llassez larges colonies humides

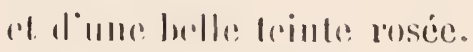

\section{MIGROCOCGUS LUTEUS}

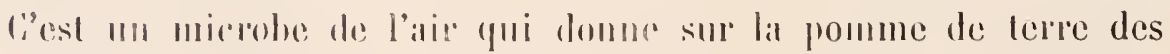
colonies a’un junne citron. II ne liquélic pas la gélatine. 


\section{MICROCOCCUS FLAYUS DESIDENS}

C'est une espèce de l'air. Il se présente sur les plaques sous forme de colonies arrondies à bords sinueux, d'une coloraton jamne. l'aspect des cultures sur gélatine est caractéristique. I.c milieu se ramollit le

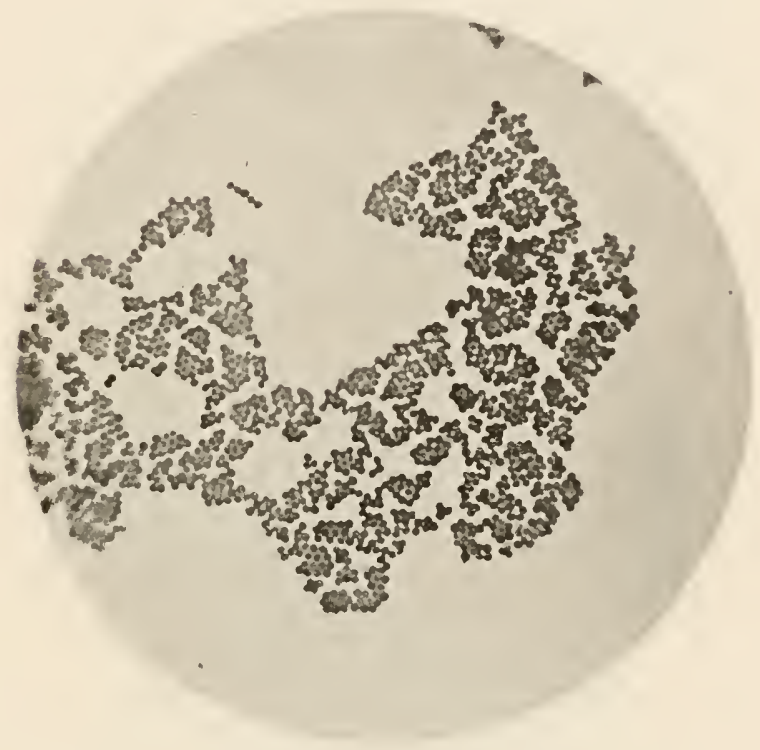

Fig. 454.

Micrococcus fla'us desidens. (Gr. 1000 diam.)

long de la piquire et la colonie s'enfonce dans le substratum en forme d'entomnoir. La liquéfaction est très lente.

\section{MICROCOCCUS FLAVUS OLEARIUS}

Ce microbe, que nous avons isolé de l'urine, nous parait être celui que Prove a dénommé ochroleucus.

Il offre sur l'agar une coloration d'un jaune soufre ou doré et se cultive dans les tubes de gélatine en forme de clou, en ramollissant le milieu, qui devient visqueux et de consistance huileuse. 


\section{MICROCOCCUS FLAVUS LIQUEFACIENS}

Ce microbe, assez analoguc an précédent par la coloration des colonies sur plinues, liquélic rapidement la gélatine. Les éléments sont alssez volumincux.

\section{MICROCOCGUS AURANTIACUS}

Calle espèce, fréquente dans l'air, s’observe sur les milicux de cullure exposis.s. l'espice orangéc, que nous arons rencontrée le plus sourent, oflie comme particularité que les colonies, d'une teinte uniforme,

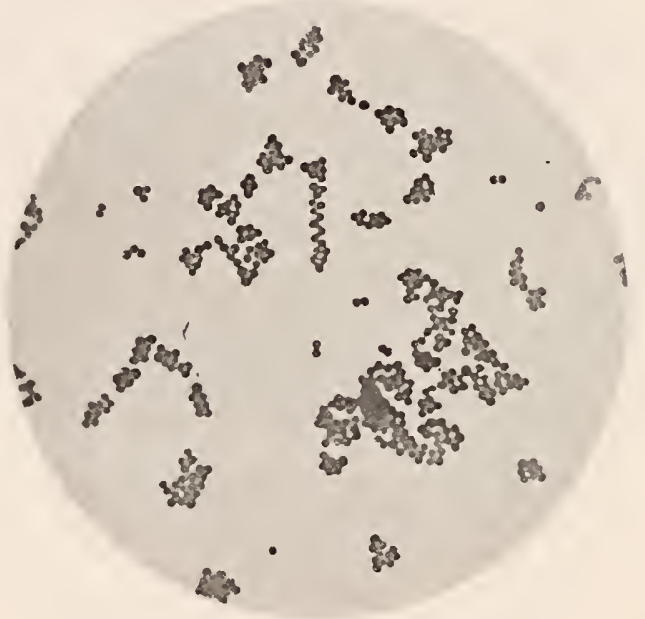

Fis. 455.

Micrococcus aurantiacus. (Gir. 1000 diam.)

s'b́trulent sur l'anall en présentant à leur surface des saillies irrégulires qui lenr domnent un aspreet ridis.

\section{MICROCOCCUS FULVUS}

Cettr espree, ohservie sitr des exeriments de cheval ou de lipin, y

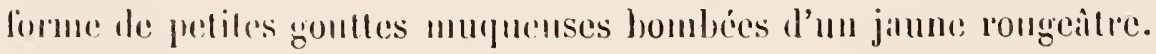

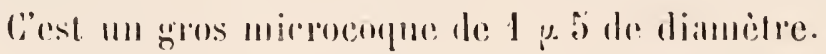

\section{MICROCOCCUS RUBER AGILIS}

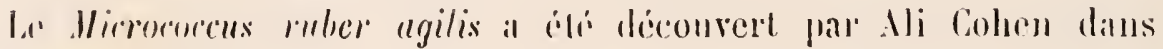
une cill polialle. 
Il se déreloppe bien sur la gélatine, l'agar et la pomme de terre

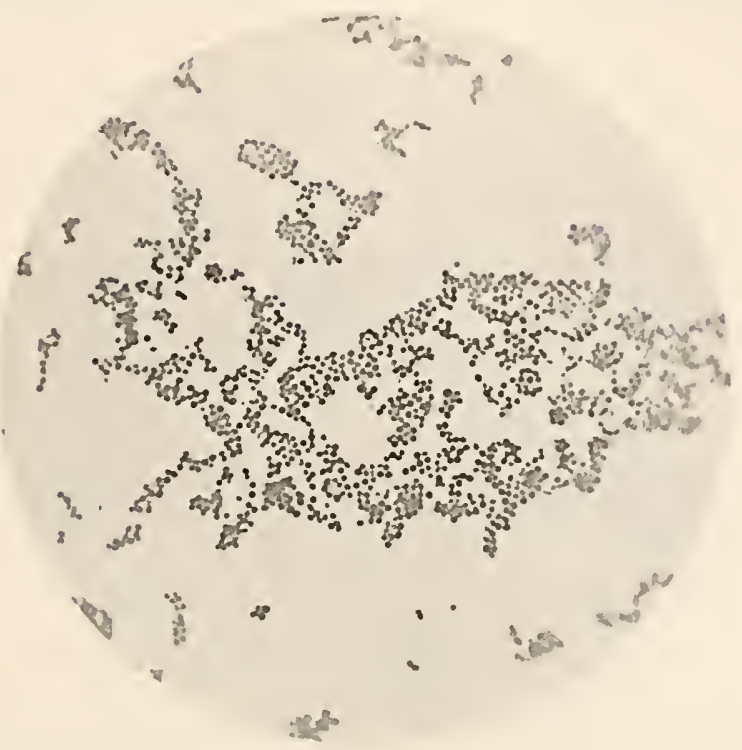

Fic. 456.

Micrococcus ruber agilis. (Gr. 800 diam.)

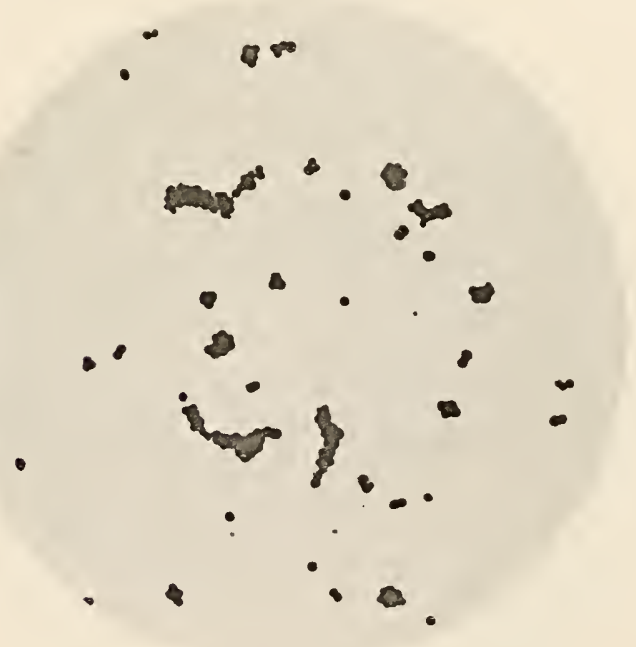

Fig. 4.57.

Micrococcus ruber agilis (cils). (Gr. 1000 diam.)

¿ la température de la chambre, el végète mal au-dessus de 2ö.

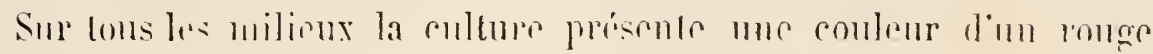


vif. Le Micrococcus agilis présente comme particularité ses mouvements actifs.

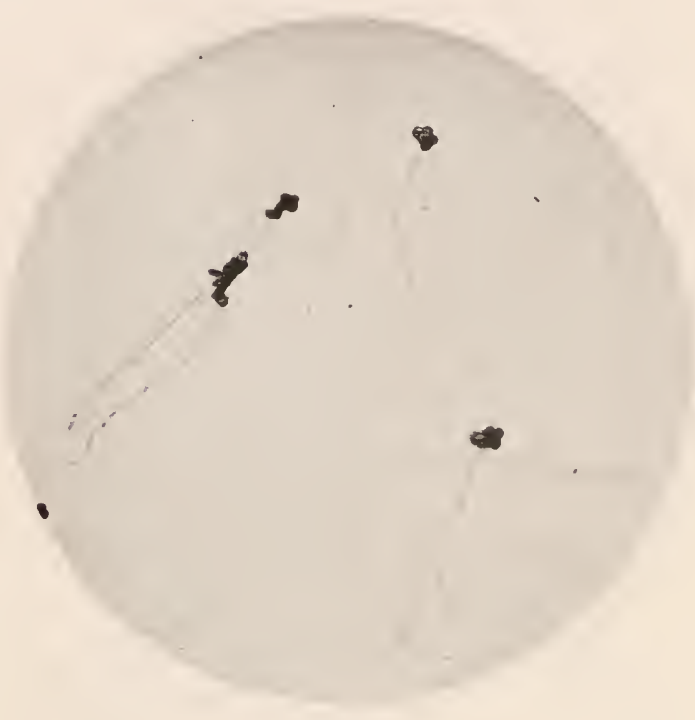

Fig. 458.

Micrococcus ruber agilis (cils). (Gr. 1200 diam.)

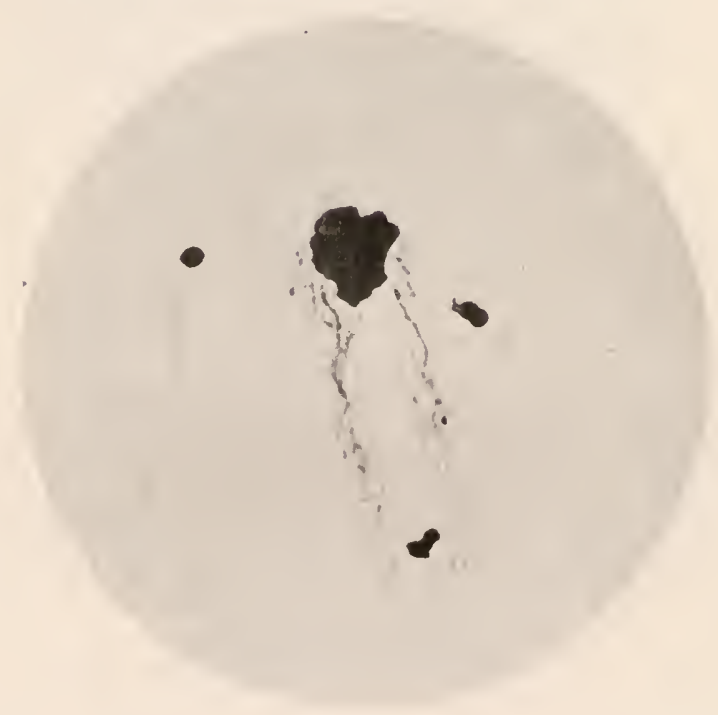

F16. 459.

Micrococeus ruber ag̣ilis (rils). (Gir. 1800 diam.)

Löfler a démontré l'existence de cils longrs et délićs. Nous reproduisons ees cils d'apris une préparation de No Borrel, de l'Institut Pasteur. 
MICROCOCGUS CITREUS AGILIS

lie microcoque, très mobile dans l'eau distillée, donne sur

Fig. 460 .

Micrococcus cilreus agilis. (Gr. 1000 diam.)

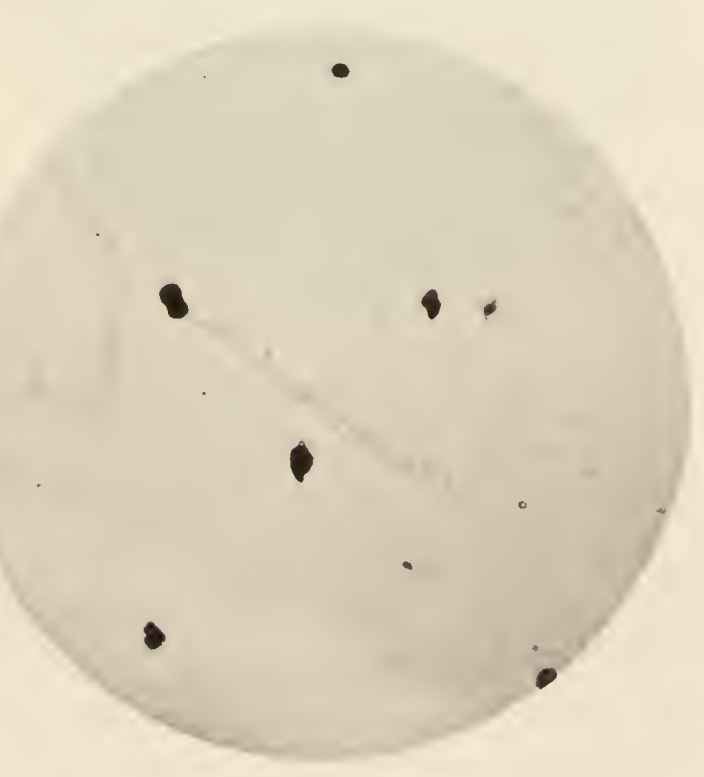

FIG. 461 .

Micrococcus cilreus agilis (cils). (Gir. 2000 diain.)

l'agar une culture crémeuse, de teinte citrine et très visqueuse. 


\section{INFECITON BLENNORRHAGIQUE}

\section{GONOCOQUE}

L'uréthrite blennorrhagique reconnaît pour cause la pénétration au niveau de la muqueuse uréthrale d'un microcoque dont l'aspect et la disposition sont assez particuliers. Il a reçu de Neisser le nom de “Gonocoque »(1879).

Lorsque, chez un malade atteint de blennorrhagie, après avoir désinfecté le méat, on recueille par la pression d'arrière en avant

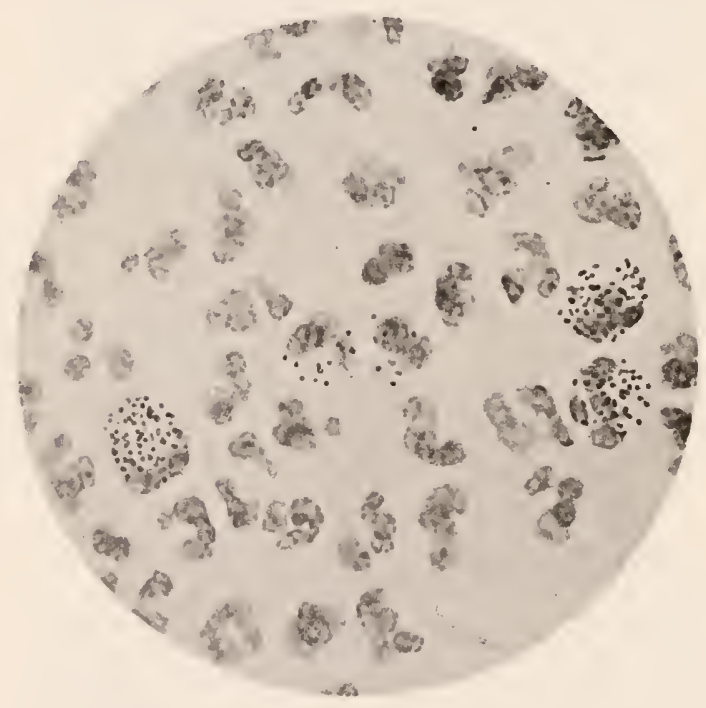

FIg. 462.

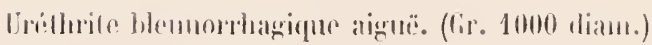

une goulte de pus, pour la soumettre à l'examen microscopique, l'aspect de la préparation varie suirant la date de l'écoulement.

Dins les écoulements récents, de couleur opaline, on constate, après coloration il la fuchsine, la présence de nombreuses cellules d'épithélinm pavimenteux, de grandes dimensions ef de forme pulygo. nale, a d'une assez grande quantite de cellules de pus. Cai et lil on

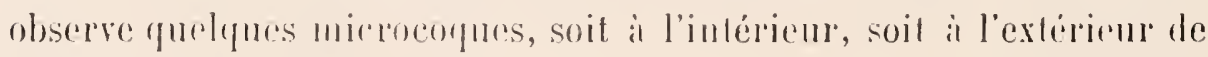

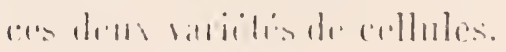


Liaspect des préparations est le phus souvent cirractéristique et permet d’affirmer d'omblie la nature de l'écoulement:

les cellules de pus sont extremement nombreuses, se tonchent et encombrent le champ du microseope; les noyaux sont fortement et uniformément colorés. La disposilion des microbes est toute spéciale : ils se groupent par ilots de dix, de vingt, de cinquantre et plus, soil i l’intérieur des cellules, soil à leur surface ou daus lres respaces qui lr's entourent. Souvent une moitio du groupe est extericure a la crollule. l'autre moitié incluse daus le protoplisimin.

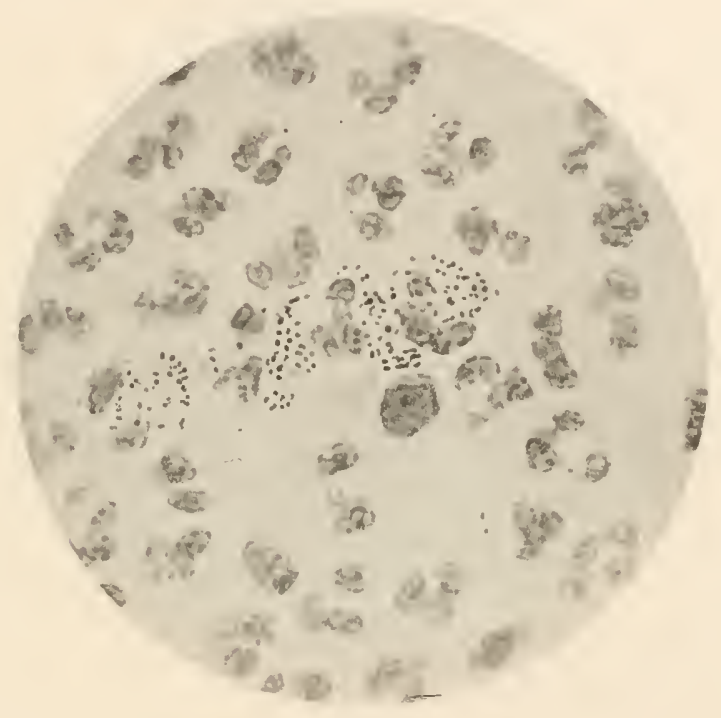

Fig. 405.

Irrithrite blentorrhagique aigü. P'us. (lir. 1000 diam.)

Ces ìlots sont plus ou moins éloignés les uns des autres, et dans leur intervalle on ne voit que rarement des mierocoques isolés.

Enfin la forme du microbe lui-mème est caractíristique. Outre la disposition en diplocoque, l'aspect de chaque élément est colui de deux haricots se regardant par leur face concave. Celte parlicularité est un vestige de la segmentation du microbe, ef lorsqu'on observe, non plus un diplocoque, mais un élément isolé, il se montre absolument arrondi. Le diamètre habituel de chaque élément est de 0 \%. 4 à $0 \mu \mathrm{s}$ 。 
Unamd l'écoulement hennorrhagique est de date plus ancienne, il se produit le plus sonrent, sinon toujours, une infection secondaire. Un peut alors rencontrer dans le pus les microlws les plus divers: mierobes chronogènes généralement jamnes, diplocoques de Legrain, .llicrococeus albicuns de Bumm, microcoques orangés, staphylocoque pyogène doré, ete.

Girode, dans de nombreux examens d'uréthrite chronique, a trouvé le Bacterium coli, les staphylocoques blane et doré, des diplocoques

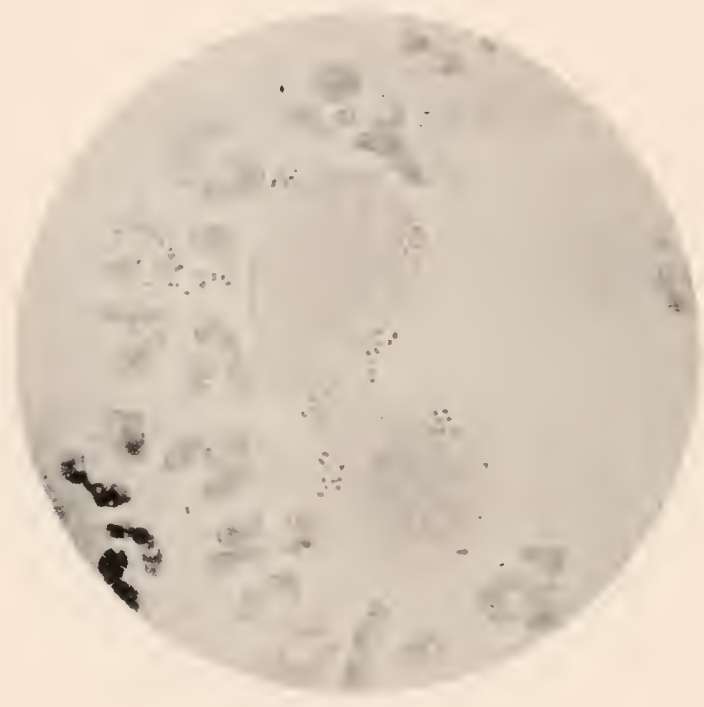

Fig 464 .

Uléthrite blennorrhagique.

Gonocoques libres et à la surface de cellules épilhéliales. (Gr. 1000 diam.)

indéterminés. Ces microbes ont été observés seuls ou en association arec le gonocoque.

Ces diverses espéces bactériennes se rencontrent également chez li femme dans les métrites et pelvi-péritonites elıroniques. Les salpingites suppurées, saul un certain nombre de cas où aucun microorganisme I'a pu itre constalí, reconnaissent souvent pour eause lat présence du gonocoque et sont d'origine blennor rhagique.

Nous arons fait ces conslatilions sur un grand nombre de pièces soumises, après l'hỵstérectomie vaginale tolale, ¿̇ l'examen micro- 
seopique et anx cultures. Sourent anssi fe pus d'origine hemomphatgique est infertile; on 11 ? troure mòme pas de microbes parr lil coloriltion, comme nous l'alvous signalí phus haml.

baus un petit nombre de cars, nous arous rencombe les staphịlu-

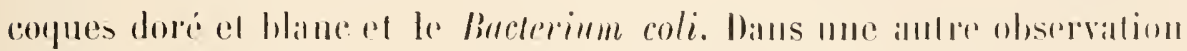
(silpingite suppurée volumineuse), it s'agissait du pnemuntoconpre.

Les streptocoques et le Bacterinm coli sont, daus les silpingilus ancienues, heancoup phus virulents que le gonncoyne ef comportent pmor l’opérée un pronostic plus grave.

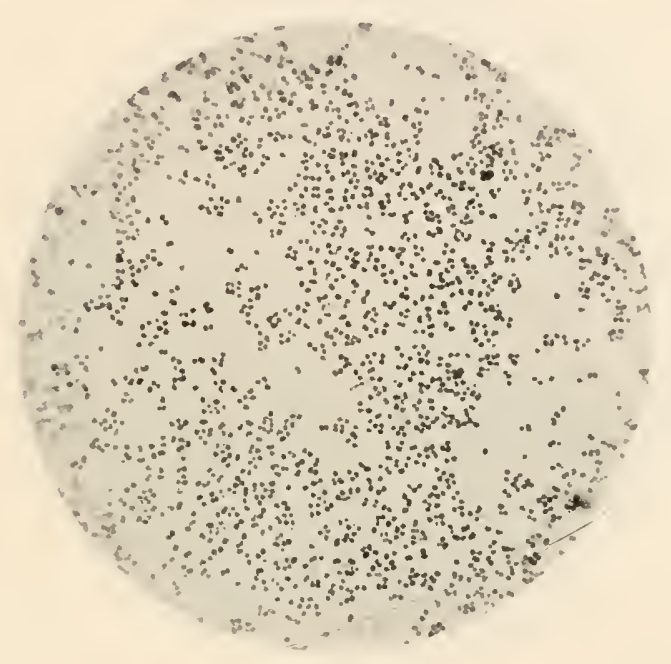

Fig. 465.

Culture pure de gonocoques. (Gr. 1000 di:m.)

Les tentatives faites ponr cultiver le gonocoque ont été longtemps infructueuses. Bumm le premier a obtenu des cultures en ćlalant du sérum humain en couche mince sur des tubes dagar ordinaire. Wertheim emploie un mélange de sérum et d’agar. Au bout de 24 heures, on obtient, sur des plaques de sérum-agar, des saillies punctiformes et transparentes, qui deviennent grosses comme la tète d'une épingle et premnent une teinte blane grisitre.

Turro le cultiva sur l'urine acide stérilisée, puis sur la gélatine peptone acide, qui n'est autre que la gélatine peptone ordinaire 
non alcalinisée. It se forme le long de la piqûre me culture blanche. Lá gélatiue n’est pas liquéliée.

I'après 'Turro, le gonocoque ainsi oblenu est très virulent; il a pu l’inoculer an chien el díterminer chez cet animal des accidents graves.

Ces procúdés ont réalisé de grands progrès, mais il faut reconnaître qu'ils échouent parfois et que la culture du gonocoque n'est pas aussi facile à réaliser que semblerait l'indiquer la description des méthodes que nous venons de dérrire.

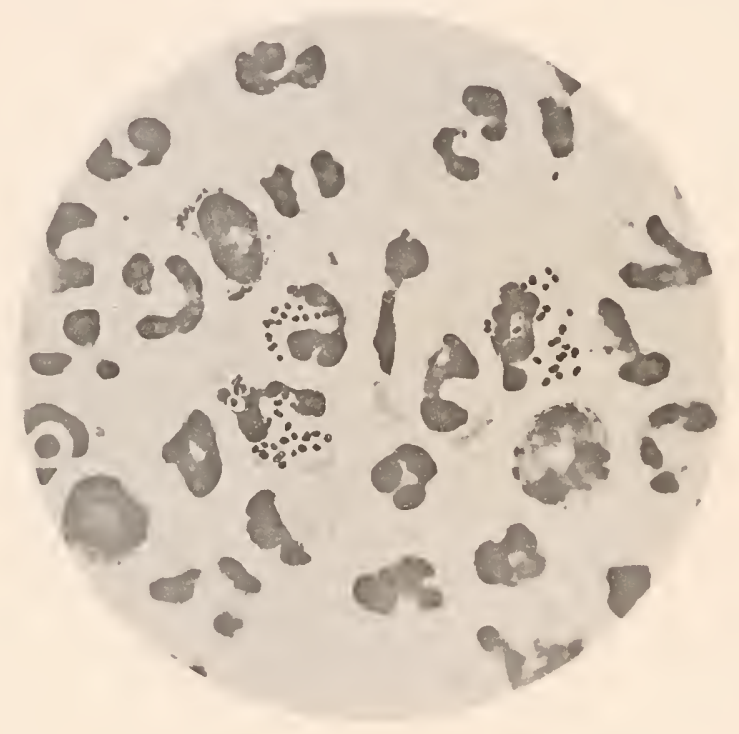

Fig. 466 .

Ophlalunie purulenle du nouveau-né. Leucocytes chargés de gonocoques. (Gi. 1000 diam.)

Les cultures sur des milieux acides sont un excellent procédé pour isoler le gonocoque des lactéries auxquelles il peut se irouver associé, la gélatine acide ćtant un milieu défarorable pour les autres microcoques. On détermine la présence de ceux-ci à l’aicle des plaques de gélaline alcaline ordinaire.

Le gonocoque se décolore par la méchorle de Gram, à moins qu'on ne laisse agir que très peu de temps lia solulion iodée.

On obtient de belles prríparalions, dans les cas d'alssociation microbicune, chl colorint au violet et en traitant pas le Gram avec double 
coloration à la résuvine : les gonocoques et les cellules de pus sont colorés en brun ainsi que cerlains bacilles sur lesquels nous reviendrons it propos de l’infection urineuse, tandis que les autres microbes gardent une leinte hlen loné.

Les inoculations de pus blennorhaginge a l'homme réussissent assez facilement. Los inoculations ì liablu des cullures ont ilomné des résultats positil's dinns un certitin nombre de cas.

On n'a pas encore déterminé exalctement puelle action exereent sur

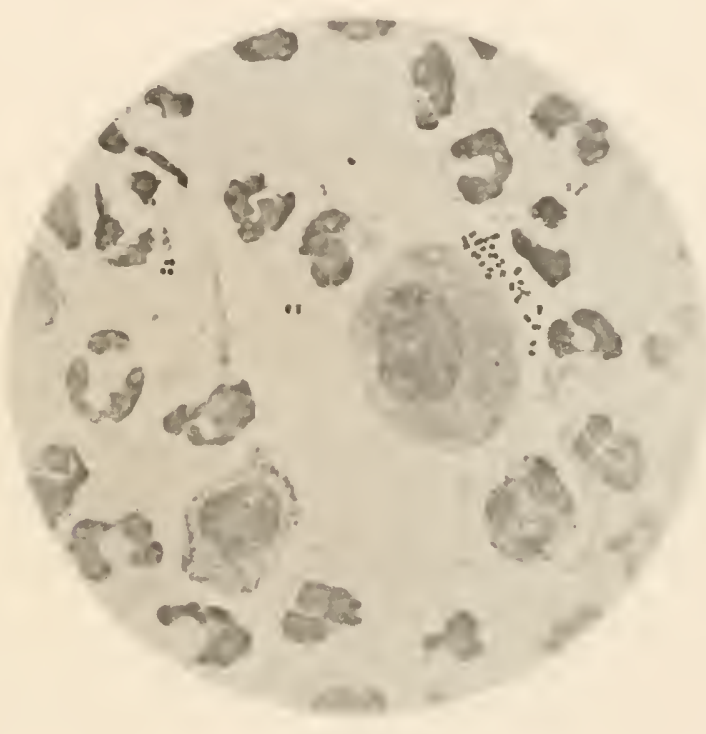

Fig. 467.

ophtalmie purulente du unurean-ne. limneonun's ef cellutes ipitheliales. (lir. 10100 , liam.11.)

la virulence du gonocoque les associalions microhiennes. Toulefois, si

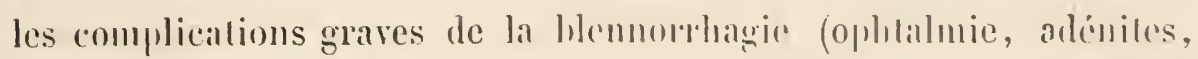

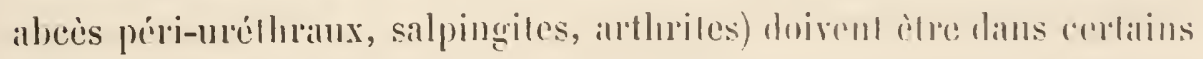

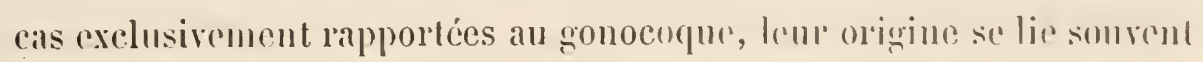

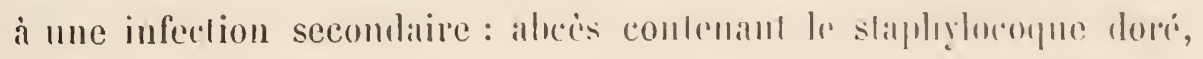

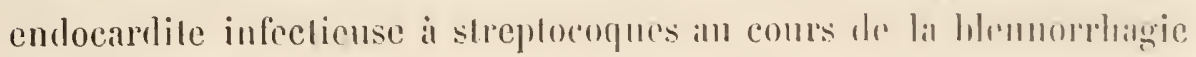

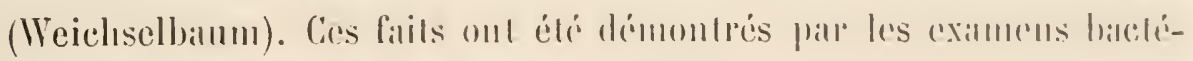
riologiques d’un gramd nombre d'anleurs.

Le gonocoque pent done: it lui senl determiner, comme les antres 
microhes pyogènes, des accidents seplicémiques ou pyohémiques mortels, et particulièrement l'endocardite ulcéreuse (Winterberg). Conncilman a tronvé le gonocoque dans des foyers suppurés du muscle cardiaque.

On a olservé, an cours de la blemnorhagie, cernanes anthrites, daus l'exsulat desquelles il fut impossible de déceler la présence d'ancun microbe. Ces faits méritenl d’ètre rapprochés les cas de pleurésies el de salpingites où, comme nous l'avons vu, l'on ne décourre plus trace de bactéries, soil par la culture, soit par l'examen microseopique.

Expérimentalement ou a produit chez le chien, le lapin el le cobaye, a l'aide de eultures de gonocoques, des arthrites aiguës dont la guérison était rapide. L’inoculation daus le péritoine délermine une péritonite locale rarement mortelle.

Palhogénie. Les baetéries, qui infeetent primilivement le méat, pénitrent entre les cellules épithéliales et alleignent jusqu'au derme de la muqueuse; elles provoquent la ahute de l'épithélium et une migration abondiante de grlobules blancs. La guérison survient soit parce que le milinu derient impropre à la culture du gonocoque (Bumm), soit gràce au roile des cellules lỵmphatiques. Quand la muqueuse a été profimlément altérér, il se produit hallituellement une cicatrice rétractile aboutissant it la formation d'un rétrécissement uréthral.

Truitement. Ia hlennorrhagie el ses eomplieations loeales doivent itre cousidléées comme des suppurations vulgaires. Yous préconisons Jepuis douze ans l'emploi des grandes irrigalions de l'urèllı'e, du vaniu, de la ressie on de la conjonelive avee des solulions trés étendues dr lipuides antisepliques (particulierement de sublime) à la lamperallare de tho centignales. Ces irrigalions se foul aree nure poire de

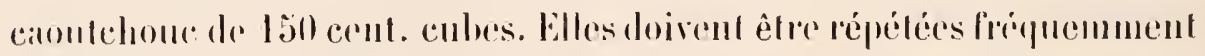
dans les rats graves el surlont daus la conjonctivile des noureall-

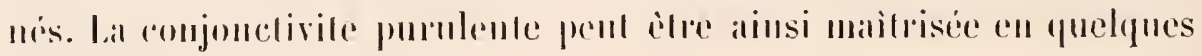
joll's's.

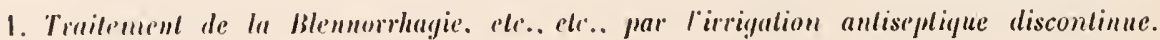
Rurll. P'aris, 189 '. 


\section{HEMOGLOBINURE BACTÉRIENNE DU BOEUF}

L'hémoghlobinure du beul est endémique en Roumanie on elle fait dims eertaines année's des ravages considérables. Les bouls vigourenx suceoulent. Les vathes résistent divantage. Les veaux sont indemnes.

Balbès a éludié cette maladie en Is\$S.

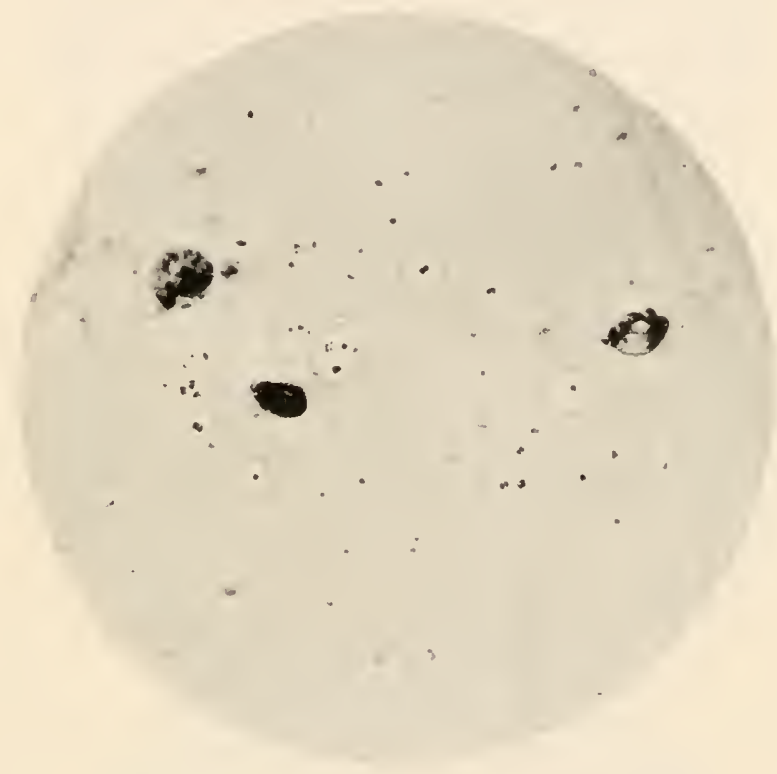

Fig. 468 .

Sierocounes de l'hémoghohinnrie du bernt dans les glohules romges. (Gr. 1000 dian.)

Les animanx atteints perdent l'appétit, présentent de la prostrallinn,

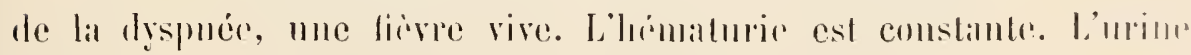

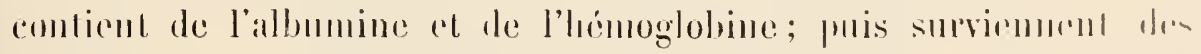
hémorrhiggies sous-cutamées.

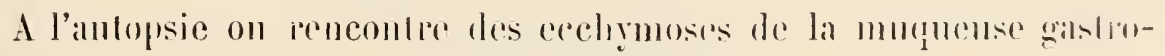

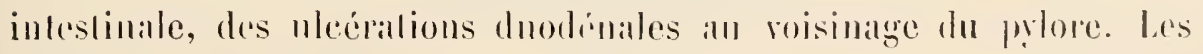
gamplions ablominamx sont engorgés, les reins lyperemiés, la ressir

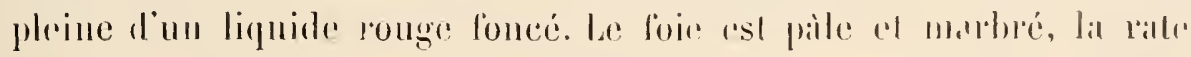
grosse et diflluente. 


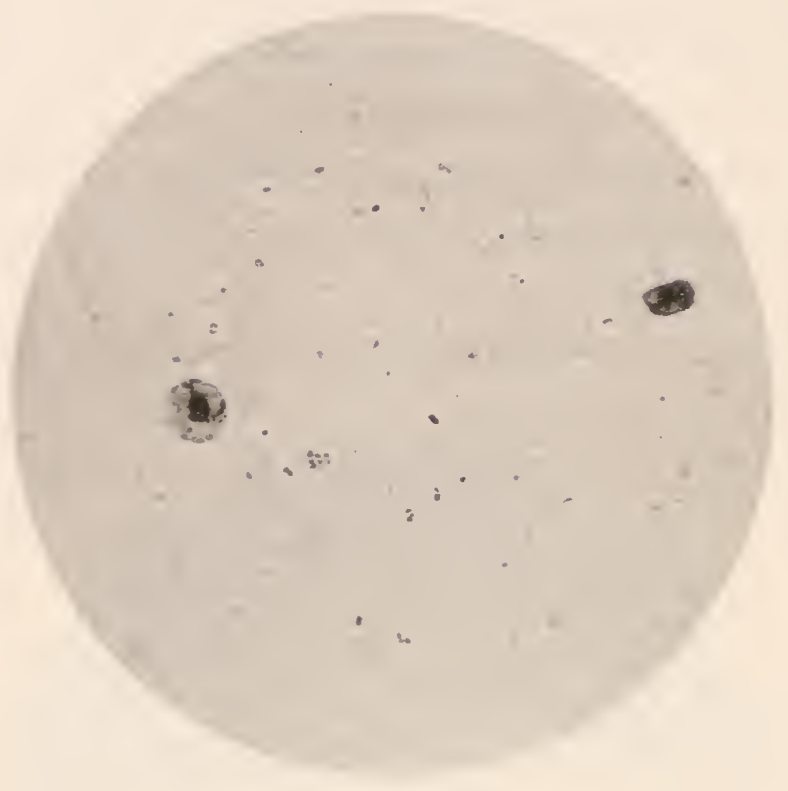

Fis. 469

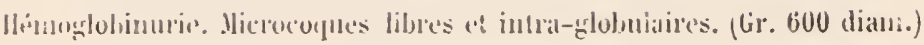

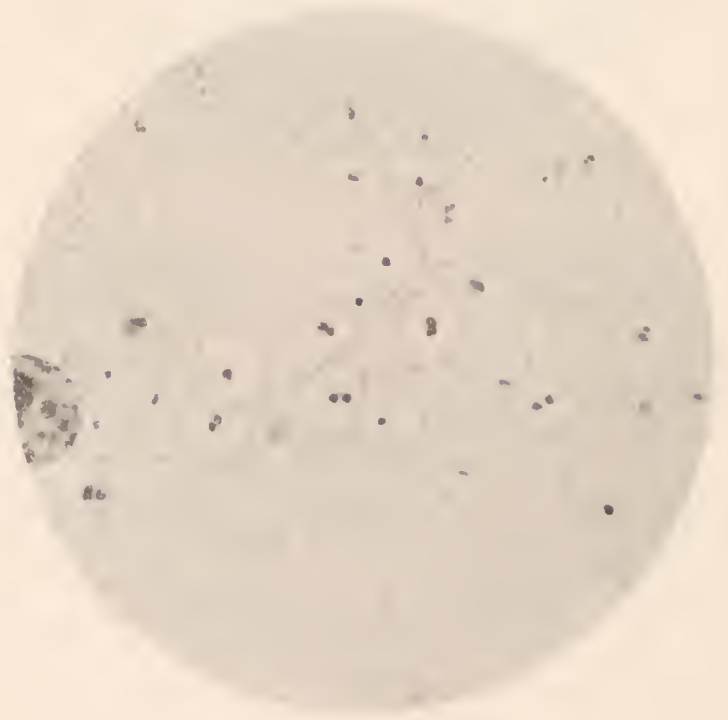

Fiti. 470 .

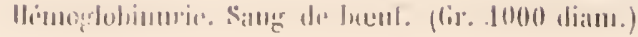


bilnes a décit comme agent pathogine de ectte allection des mi-

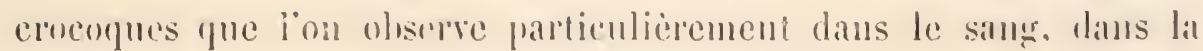
sérosité des platyues arohymotiques el dans le rein.

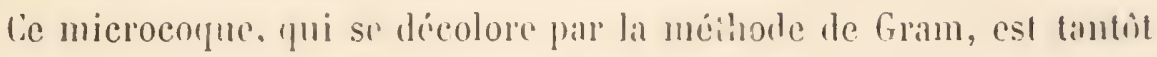

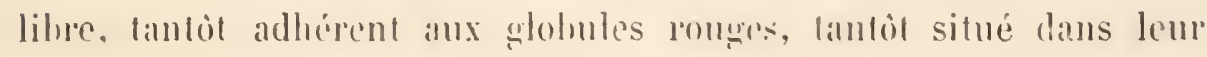
intipirint.

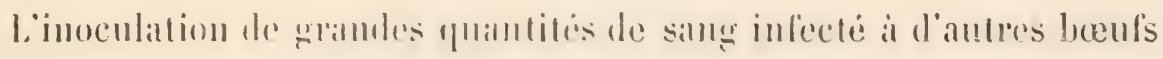
ne leur a pas lamsmis la maladic.

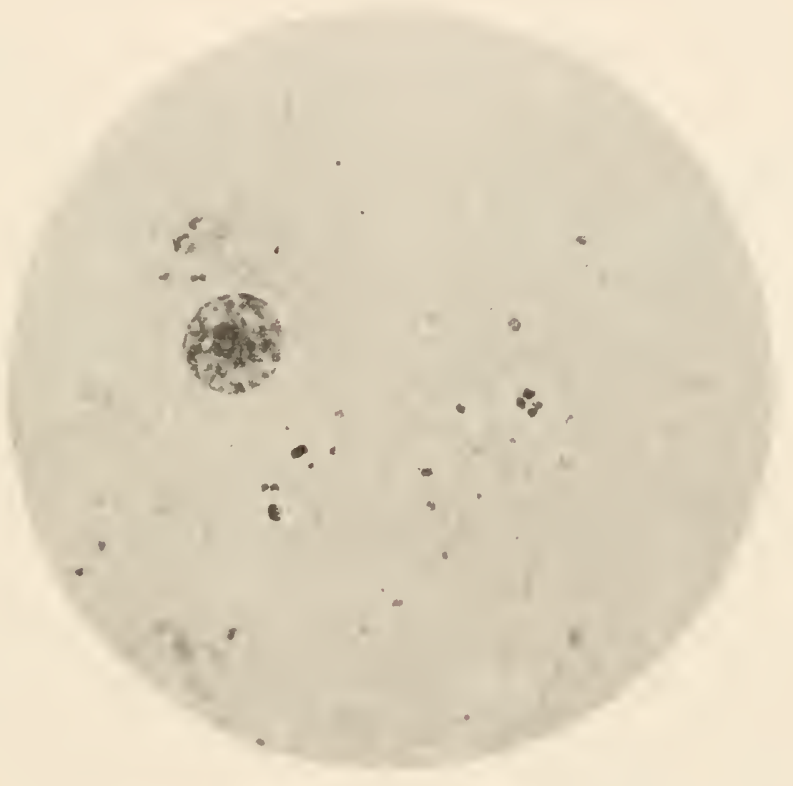

Fici. 711.

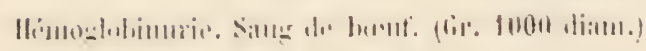

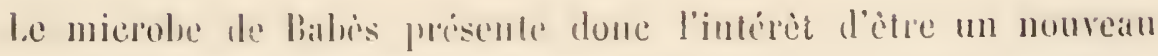
pallasite du sang sans que son alction pathogine comme agent de l’hémoglobinurie soii birn déinontrée.

(In remaregnera sur nos photographies, surtout au grossissement de 1000 diametres, lexistence alatour des parasiles libres on inclus et les

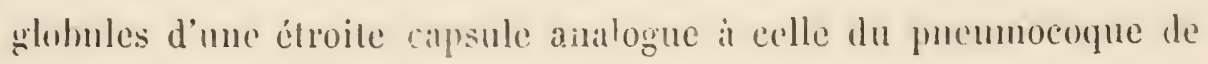
Firinkel. 


\section{STREPTOCOQUES}

Beancoup des espèces que nous venons de décrire présentent dans les cultures, ou mime daus le pus, de comrtes chainettes. Elles ont été classées parmi les Slaphylocoques en raison de leur groupement habituel en petits amas ou en grappes. Le nom de streptocoques est réservé aux mierobes qui, soit naturellement, dans les liquides de l'économie, soit en culture, ef particulièrement dans les milienx liquides, se développent en longues chainettes. Le plus souvent les chainettes sont formées de diplocoques accolés les uns anx autres, comme on pent le remarquer sur les clichés suivants. Un lel aspect ne s'observe jamais daus les comrtes chainettes des cultures de Staphylocorues.

\section{STREPTOCOQUE PYOGENE}

Le Streptocoque pyogène a été décrit dans le pus des abcès chands par Ogston en 1881. Les formes en chainettes avaient déjá été olıservées par Coze et Feltz en 1869 dans la fièvre puerpérale, ainsi que nous le verrous plus loin.

Nous avons fréquemment trouvé le streplocorque au cours de nos rechreches sur les suppurations, dims le service du lor L. Chlomnpionniere en 1882, comme en témoignent les photoghtaphies ei-contre.

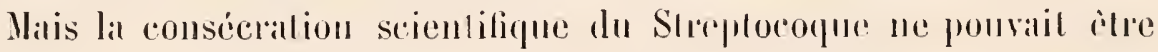
laite lamt que ses canaletères objectil's n’ont pu itre drterminés pall lil cullure sur les milieux solides.

C'est done a Rosenbach qu'appartient le mépite d'avoir dillérencié

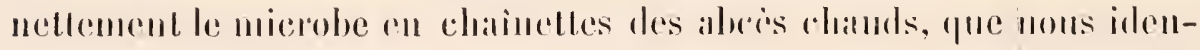

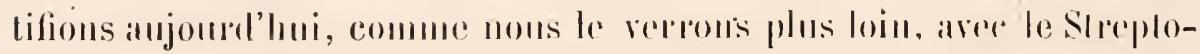

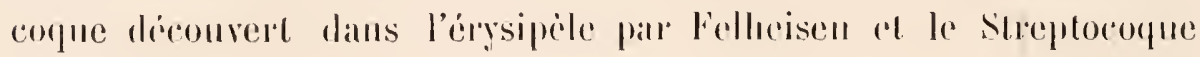
puerpéral. 
Le Streptocoque progène existe dans un grand nombre d'alces chands, daus le phlegmon circonserit on diffus, sans que dans bien des cas il soit possible araut l'examen du pus de prévoir à quel

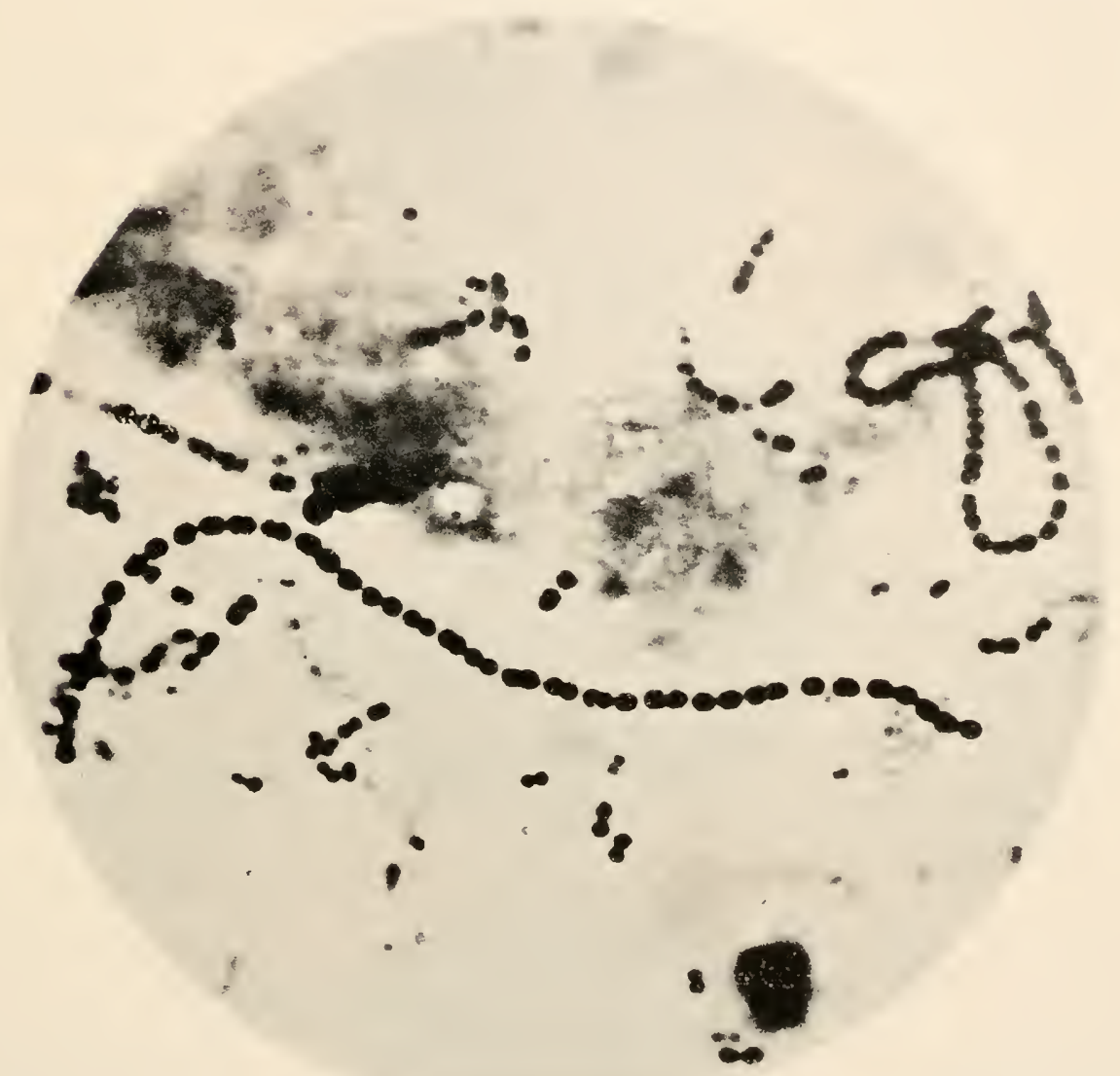

Hili. iT.

P'us phlonmonenx. Sirrptocognes. (Gir. 5000 diann.)

microbe est due l'inllimmation. Nous exceptons naturellement les abeces survenimu an conrs d’une septicémie puerpérale ou de l’ẹrysipèle. 


\section{EXIMLN DU PLS}

Si l'on eximine sans coloration dia pus contenant des Streptocoques, il est en général possible, dans les cas où les chainettes ont quelque longueur, de les aperceroir au milieu des globules blancs. Les gramulations réfringentes qui abondent dans ces derniers pourraient tontefois en imposer pour des microcoques, comme en témoigne la figure 475 , oủ l’on distingue une longue chaînette de Streptocoques, et deux ou trois autres plus petites. Il est préfúrable, comme pour

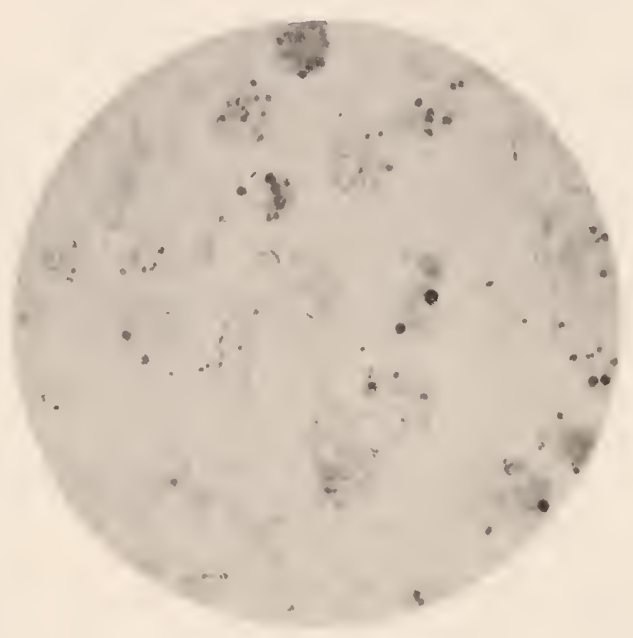

Fiti. 475.

P'us. Fixation par le Jiquide de lilemming. (ir?. 1000 diam.)

la recherehe de tous les microbes susceptibles de prendre les couleurs d'aniline, d'ábler sur une lanelle le pus en conche mince, de sécher la préparation a la flamme d'un hee Bunsen, el de eolorer simplement a l'aide d'une solution ayqueuse de fuchsine, puis de décolorer it l'alcool.

Si l’on veut avoir des préparations encore plus démonstratives, il faul employer la méthode de liram avee domble coloralion.

l'respue torijours, à l'ourerture d'un aheis chand a streptocoques datiml de guelques semaines, on observe dans le pus de longues chainelles. Ces chainelles présentent eefte particularité que les 
éléments sont réunis par groupes de drux, de telle manicre qu’il

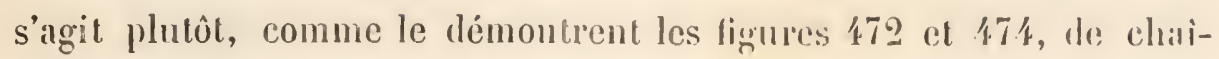
netles de diplocomes en 8 de chiffre. aue de rhainuttes do minn-

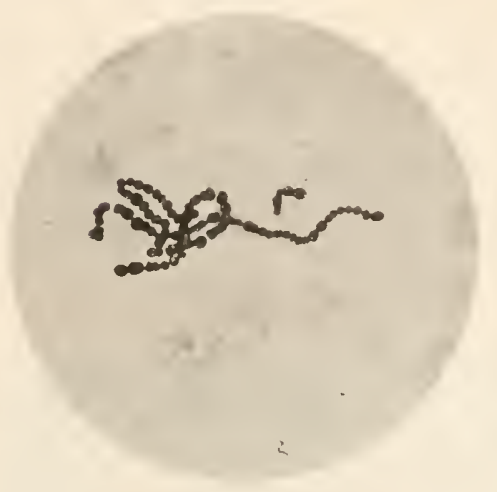

FIg. 474.

Lymphangite phlegmoneuse. - Préparation faite en août 1882.

(Gr. 1000 diam.)

coques. Cet aspect est surtout très caractéristique dans la préparation que nous avons reproduite plus haut au grossissement de 5000 diamètres (fig. 472.)

Quand il s'agit d'une pustule sous-épidermique à évolution très rapide (24 ¿̇ 48 heures après l'infection), on n'observe guère à l'examen

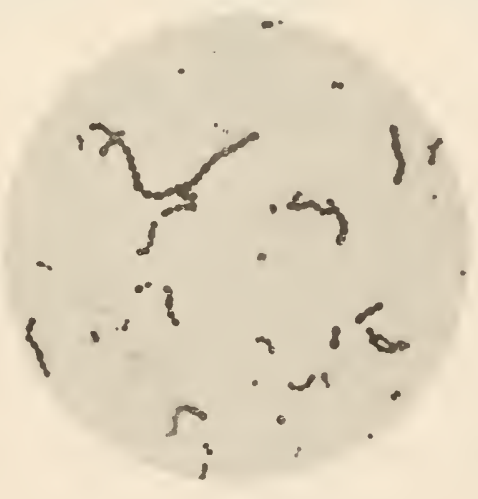

Fig. 475.

Sérosite d'arthrite aiguë. (Gr. 1000 dian.)

du pus que des diplocoques en 8 de chiffre ou de courtes chainettes de trois ou quatre articles, qui ne peuvent être caractérisés que par la culture sur les milieux appropriés (voir fig. 5̆15). 


\section{CLLTCTRS}

Les cultures de streplocopue progene sont font i fait spéciales. Ie Streplocoguc se cultive dans la gélaline au-dessous de 21 degrés; la culture en piquire, quelle provionne directement du pus ou d'mne culture antérienre, donne lien en quarante-lıuit heures, le long de la strie, à une série de pelites sphérules blanchàlres qui déjassent rarement le dianctre de un millimetre. Ces sphérules sont parfois ovalaires; leur volume paraît d'autant plus considérable qu'elles sont

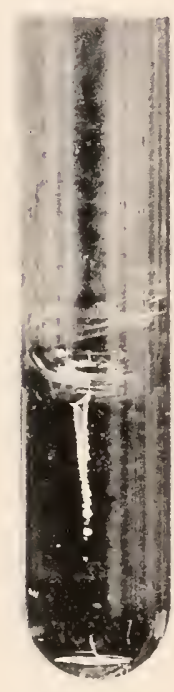

FIG. 476.

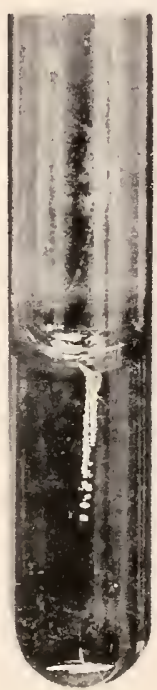

Fig. 477.

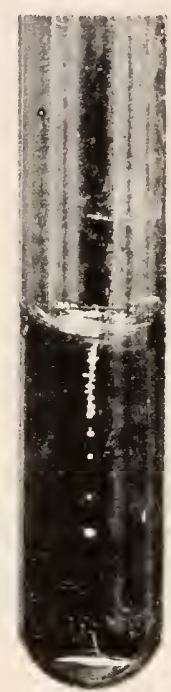

Fig. 478 .

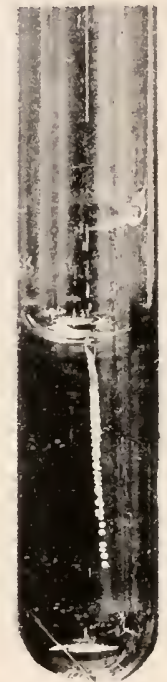

Fig. 479.

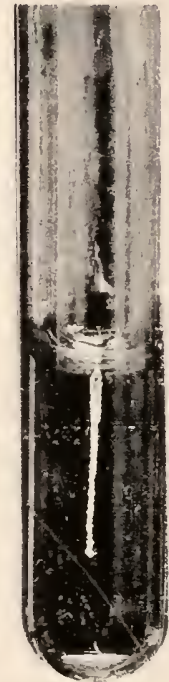

Fig. 480.

Cultures de Streptocoque pyogène sur gélatine peptone.

phus espacées. Les plus volumineuses se trouvent ainsi en général ¿ la partie la plus profonde de la piguire. A la parlie supérieure, l’aiguille a en ellel déposé me plus grinde quantité de Streptocoques et la culture oflie liaspect d'une strie blanchitre, composée d'un grand nombre de lrès petites colonies puneliformes.

La caractéristique des cultures de Streptucopues en piquire dans les tubes de gélaline est que jamais il ne se produit de développenent en surface. Nous u’insisterous pas sur les cullures cu strie stur gélatine inclinée, puisqu'elles ne dillirent gurie de ce quon observe en pareil

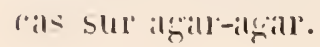


Les eulumes de Stroplecorpues smo agall se font en général sur des tuhes inclinés. On observe alors le diveloppement, le long de la slrie, d'une quantité de petites colonies grèles, s’étendant rarement ì plus de denx on trois millimitres en diamere el caractérisées parre ce litit. anusi que les a décrites Rosenbich, qu’elles sont disprosées en lentasses, c'est-ì-dire qu'autour du centre légèrement surélevé se trouvent deux on trois conromes d'épaisseur décroissante (fig. 482).

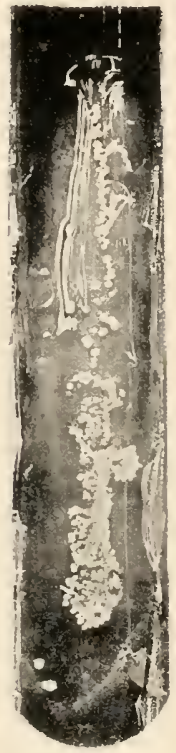

Fig. 481.

$1^{\text {re }}$ culture de pus

a Streptocoques sur agar-agar.

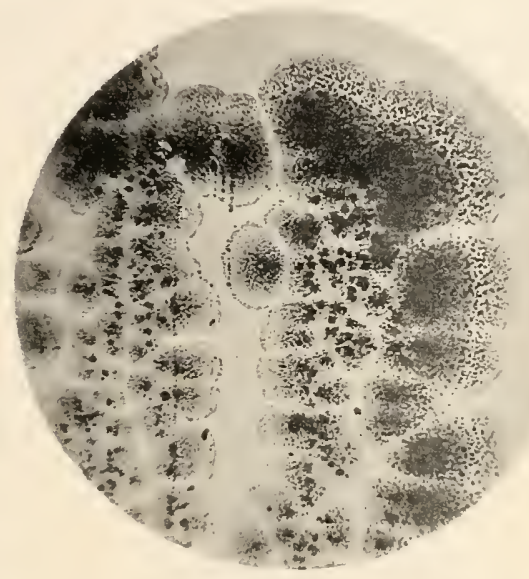

Fig. 482.

llème culture, au grossissemenl de 20 diam.

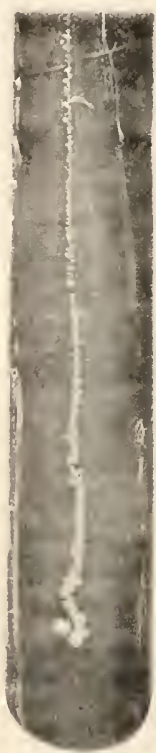

Fig. 483. $2^{\circ}$ culture de Streptocoque sur agar (strie). $\left(2^{\circ}\right.$ jour.)

Les premiers observateurs avaient cru découvrir daus cet aspect un caractère différenciel entre les cultures du Streplocoque de l'érysipèle et celui du Streptocoque pyogène, dont l'identité est aujourd’hui démontrée.

\section{ICTION PATHOGENE}

Le Streptocoque pyogène est susceptible de déterminer, non pas seulement des accidents lociux tels yue le phlegmon circonserit on diffus, mais une infection générale pouvant se terminer par la mort. $1 l$ est donc un des facteurs de l'infection purulente. Yous rerrons 
qu'il peut égalenent, el au même lite que le Staphylocoque doré (roir plus hant), délerminer lis mort pal infection générale arant la production des abees métastaliques, derenant alors lagent de

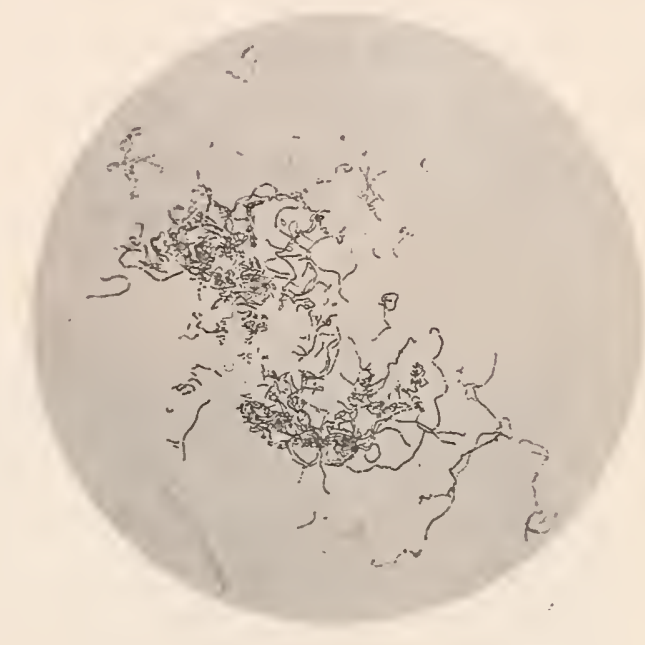

Fig. 48:4.

Pleurisie purulente amciemne a Streplocoques. (Gr. 150 diam.)

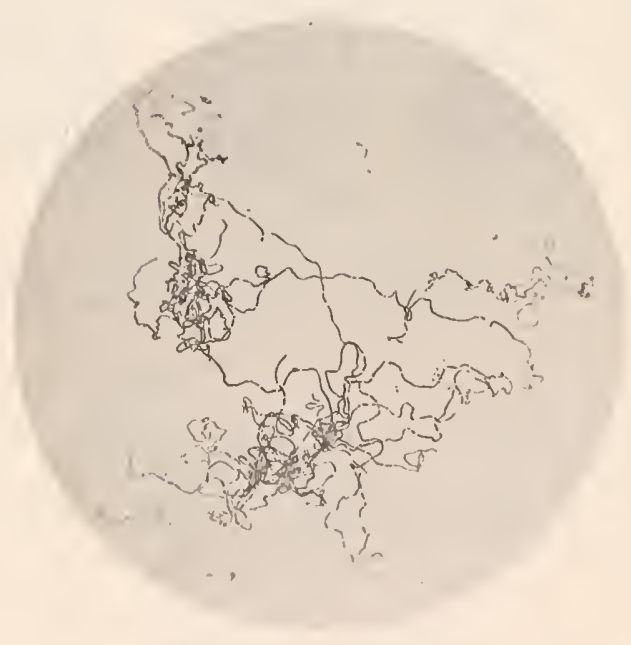

Fig. 485 .

Pleurésie purulente ancienne à Streptococjues.

cette variété d'infection qui portait autrefois ie nom te septicémie.

Quand la mort a lica arec production d'abcès métasiatiques, on observe dars le pus les Streptocoques caracteristiques. Ce pus peut se 


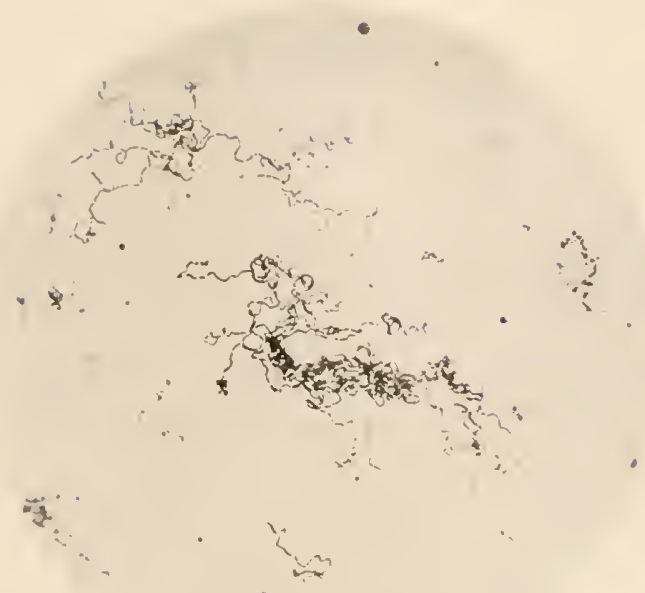

Fif. $4 \times 6$.

Pleurisie purulente à Streplocoques. (Gr. 200 diam.)

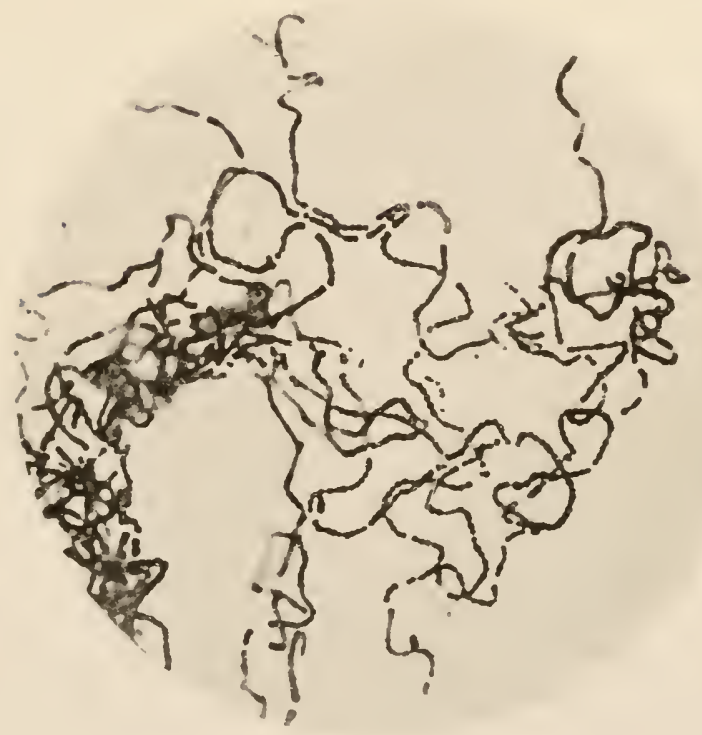

FIr. 187.

Plenresie purulente ì Streptocoques. (Cir. 1000 diam.) 
développer anssi hien daus les antienlations que dans les séreuses viscérales (péritonite, périearditr, pleurésie, méningite).

Dans les cas au contraire où la mort a lieu sans suppuration interstiticlle ou viscérals, il fium pralliquer une recherche méthodique pour dieouvrir la cause de l’iulection. Le meilleur moyen est en pareil cals d’isoler aree soin un fragment des principaux viseères (rein, foie, rate) recucillis tres pen de temps après la mort. Ces fragments doivent ollirir ciny a six centimblres de còlé. On les plonge dans le sublimé il 1/1000; on les plare sur une compresse stérilisée; on y lait une conpe avec un rasoir chaullé au rouge et on prélève à l’aide d'un fort lil de platine recourbé en palette un petit fragment du viscire, qui est ensemeneé dans des tubes à culture.

S’il s'agit du rein on de la rate d'un petit animal, on les plonge entiers dans le sublimé, et on opère ensuite comme précédemment.

Nous décrirons, à propos de la tiève puerpérale et de l’érysipèle, les embolies microbiennes que l'on observe sur les coupes.

Lal culture directe du sue des viscères se fait également bien sur gélatine el sur ayar-agar, et l'aspect d'une première culture suftit en général à un observateur experimenté pour caractériser le Streptocoque pyogène.

Le Streptocoque a élé étudié dans les tissus atteints de lymphangite, dans la paroi des phlegmons, à la surface des séreuses, dans le parenchynue des ganglions lymphatiques et des différents viscères. On l'a également observé daus les parois des veines atteintes de phlébite suppurée ou de phlegmatia alla dolens.

Nous arons obtenu l'un des premiers en 1882, dans un cas de lymphangite septipne suppurée de la jambe et de la cuisse, des coupes des parois de l’abees, intilués de diplocoques jusque dans les papilles du derme; il s'igrissait en elfet d’une infection a marehe extrèmement rapide avec rongeur érysipélateuse mais présentant cette particularité qu'elle est restie localisée a la surface des vastes décollements sous-culanes, au niveau desquels se sont produites plusieurs plaques de gangrène.

Dans les cas ou l'infection est moins rapide on observe, à la base du 
derme, jusque dams le tissu eonjonclif profond, qui est, sur le vivant, alteint d'un ademe dur', une inliltration des lissus palr des diplocopues et des chainelles phus on moins longurs.

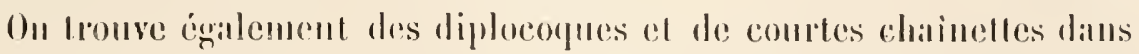
les cellules lymphatiques, accumulées pall diaprédese diuns le lissu conjonelif enllammé. On olserve gai et lia des thromboses vasenlaires. Dans les régions où l’iullatmmation est le plus alerenluée, les strepler-

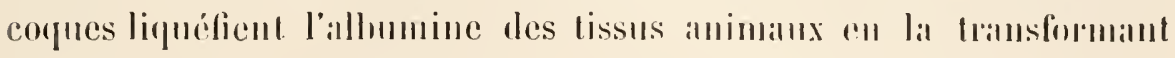
en peprone, el les globules hianes, te mème qua las cellules conjonetives, deviennent libres au milien d'un liquide épais qui prend le nom de pus.

L’inllimmation se limite plus on moins, suivant le degré de virulence du Streptocoque et la résistance du sujet. Quand l’infection est calusíc par un Streptoconpe tris virulent, prespue loujours il se produit alu déhul, et parrois mème arant l'applarition de l'areident local, une poussée fébrile aignë, susceptible minte d'ilhoulir à une mort foudroyante, comme on l'a observé dans cerlains ras de piquinres antatomiques. Inans ces cas, la mort pent survenir salls suppuration, mais on oblient tonjonrs des cultures de Streptocoques du parenchyne du foie, du rein ou de la rite.

D’autres fois, un Streptocoque très virnlent délermine d'emblic le long de tout un membre une rongenr érysipélatense, un empâtement profond, puis un phlegmon diflus; celle particularité sobserve surtout lorsquil y a infection de la gaine des tlćchisseurs du pouce ou du petil doigt.

Il nous est arrivé de ne constater aucune lésion au point l'inoculation (piçûre superficielle à l'extrémité du petit doigl) : ce malade,

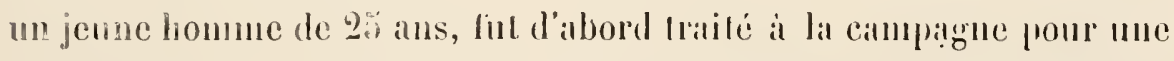
liéve typhoïde. Au bout de trois semaines seulement se manifesta un phlegmon galnglionnatire de l'aisselle, puis apparurent divers phlegmons de la jambe, de la fesse, arec arthrite supjurée dir genon, el la mort survini tardivement par suite d'une méningite suppurce a Streptocogues.

Quand l'inflammation nest pás d'embléc diffuse, l'allitux des eur:o- 


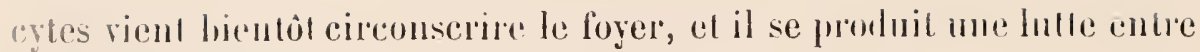
les fireplocoques, qui pullulont a l'ruri et liquéfienf me certane élendue de lissu conjonelif, et lorganisme vivanl qui cherehe i opposer i lenr envahissement une hariere invincible.

le ramollissement des tissus se faif en général de la profondeur vers la superficie et dans les points où il y a le moins de résistance, puis l’abres, s’il a été laissé ì hui-nùme, s'ouve au dehors. La sup-

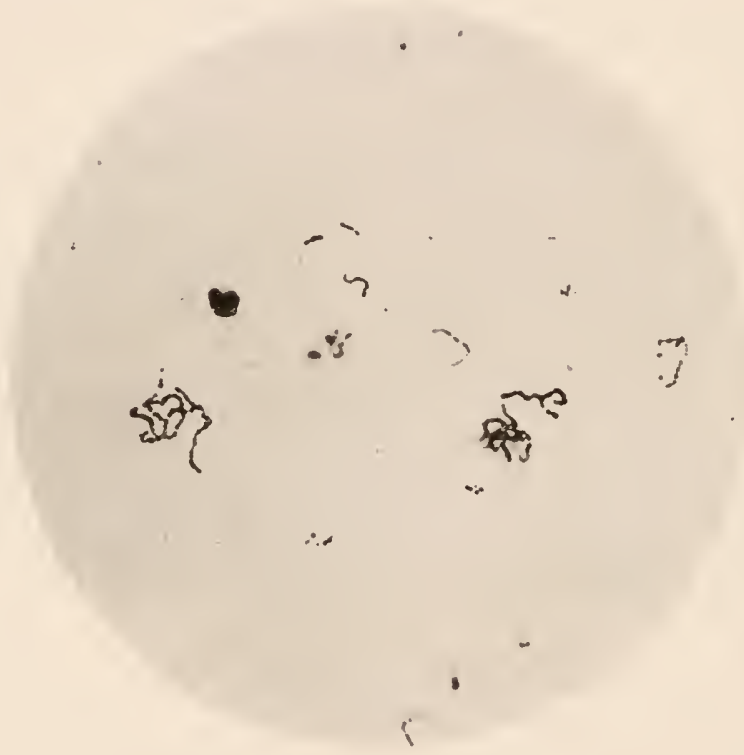

Fig. 48 .

Phlegrmon streplococcipur it marche linto. Streptecouques imelus dans les leucoeytes. (Gr. 700 dian.)

puration continue quelgue temps al la cicatrisation suit son conts.

l.a membrame progénique, à laquelle on allarhail antrefois lanl d’im-

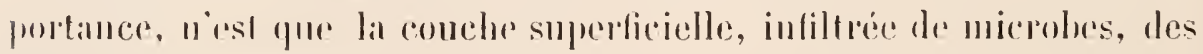

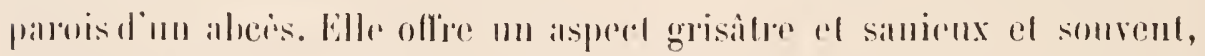
dams le phlegumon dillus particulieroment, de vastes lambeamx de lissu cellulaire nagent dans le pus of sont éliminós all dehors.

(Qnand la combhe grisâtre qui est cn contact avec le pus est élinince, la fruliléralion des cellules du tissu conjonelif et des leucocyles, qui 
ont réussi à opposer à l’inllammation une barritre eflicale, donne atu piarois de l'abces un tout autre aspeet.

Le fond de la plaic est alor's mamelonni, d'un heau rouge vil, el se troure constilué par ce puion appello des bonrorons charmus, commor on le's conslalail autrefois i la surface de toule pline suppurante an roie de gucrison.

Si l'on pratique une coupe au niveau de ces bourgeous charnus, on observe un tissu embryomaire arec de nombreuses anses vasculaires ef

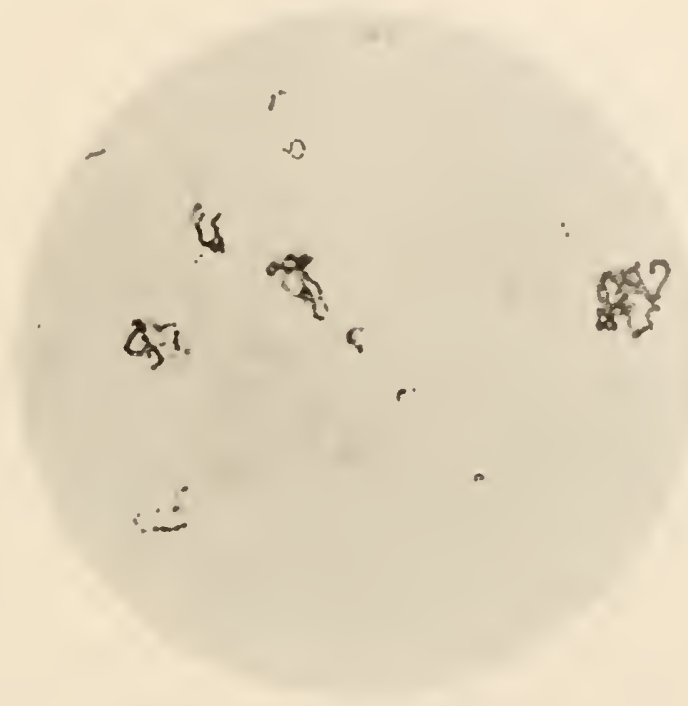

Fig. 489.

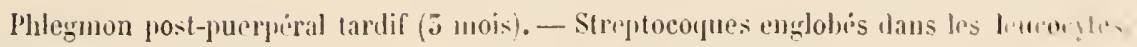
(Gr. 800 diam.)

sins trace de diplocoques dans lá profondeur.

Ces derniers existent à peine en petit nombre an milieu de $1 / 4$ première et de la seconde rangée des plus superlicielles. Les celluls.. embryonnaires remplissent la cavité de l'alucès et aboutissent it une cicatrice fibreuse, en génćral peu rétractile.

Nous avous ru que le streptocoque pyogene est l'agent de la licro pucrpérale proprement dite el de l'érysijuele. Nons consacrerons lontufois a ces deux maladies, en raison de leur importance, un chappitre spécial. 


\section{LA FIEVRE PUERPÉRALE ET L'ÉRYSIPIELE'}

LA FIÈVRE PUERIÉRALE

La fièvre puerpérale, moins commune aujourd'hui par suite de la vulgarisation de l'antisepsie, n'est cependant pas rare dans nos contrées, où bien des cas sporadiques passent inaperçus.

L'étude d'une vingtaine de cas, dont plus de moitié provenaient d'une récente épidémie dans un service hospitalier d'obstétrique, a fourni les matériaux de ce mémoire.

Nous passerons en revue successivement:

$1^{\circ}$ L'anatomie pathologique.

$2^{\circ}$ Les recherches microbiennes.

$3^{\circ}$ Les faits cliniques, envisagés spécialement au point de vue de l'étiologie.

\section{ANATOMIE PATHOLOGIQUE}

Presque toutes les autopsies nous ont donné les mêmes résultats.

L'abdomen contenait 500 à 800 grammes de sérosité purulente, et de nombreuses fausses membranes tirant sur le jaune, comme si l'on y eût dû rencontrer le Staphylocoque doré. Cette sérosité a donné, sans exception, une culture pure de Streptocoques.

Les bases pulmonaires étaient splénisées, partiellement atélectasiées, et leur surface présentait quelques fausses membranes fibrinopurulentes.

Lee foie, jaunâtre, surtout en certains points, pesait jusqu'à $1850 \mathrm{gr}$. Les points jaunes correspondent sur les coupes à de nombreux infarctus microbiens, sans la moindre prolifération cellulaire.

Les reins volumineux, congestionnés, surtout dans la zone des pyramides de Ferein.

La rate lantôt grosse (550 gr.), tantôt de petit volume, sans que son hỵpermégalie présente le moindre rapport avec la marche ou la durée du processus infectieux.

l’utérus mal revenu sur lui-même - presque toujours sanieux par suite de la putréfaction pendant la vie des liquides de sa cavité. -

1. Mémoire présentẻ à l'Académic de médecine de Paris le 13 mars 1888. 
L'incision des cornes montre d'ordinaire une certaine quantité de pus dans les vaisseaux et les trompes. Le pavillon est souvent enflammé. ainsi que les ovaires, qui se montrèrent dans un cas énormes, celématiés et infiltrés de Streptocoques dans tonte leur épaisseur.

Nous signalerons partieulièrement deux eas où la cavité utérine n'exhalait aucune odeur fétide, et le médecin trailant pensait aroir réalisé, en raison de cette particularité, une antisepsie rigonreuse. Jamais nous n'avons trouvé plus de Streptocoques.

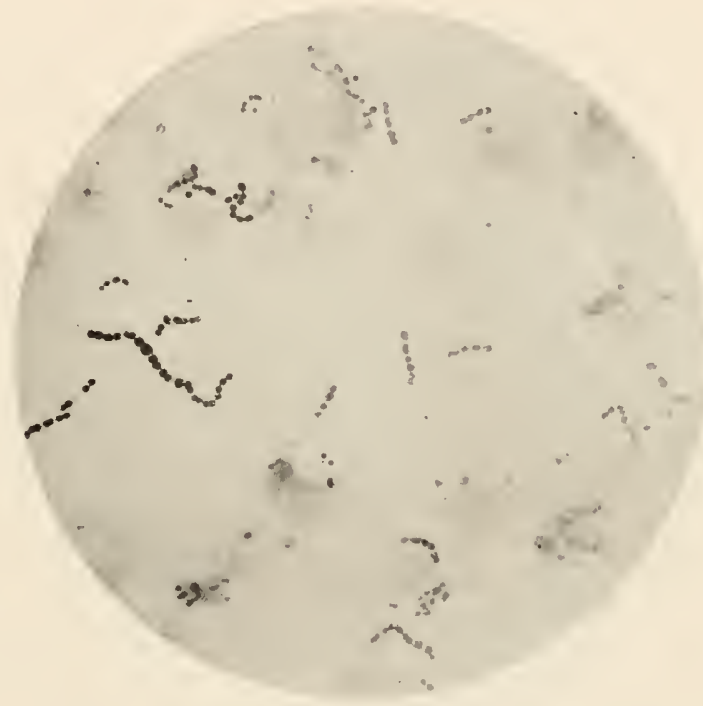

FIG. 490.

Fièvre puerpérale suraiguë. Sérosité péritonéale. (Gr. 1000 diam.

Nous nous sommes d'ailleurs toujours placés dans les meilleures conditions pour éviter toute altération cadavérique et la plupart de nos cultures et examens ont été faits pendant la vic ou inmédiatement après la mort.

RAIPORTS ENTRE LA FIẼVRE PUERPÉRALE, LES ABCES A STREPTOCOQUES ET L'ÉRYSIPELLE

ÉTUDE BACTÉRIOLOGIQUE ET EXPÉRIMENTTILE

A chaque autopsie, nous avons pratiqué la culture immédiate du liquide péritonéal, des parenchỵmes du foie, des reins, de la rate, de l'urine de l'uretère et de la vessic, etc., etc. 
Nous avous recueilli d'iutres cultures sur des malades présentant des formes bénignes de l’inlection puerpérale : abcès multiples pleurésie, etc., etc.

Toujour's et sans exception nous avons obtenu lo mime microbe, répondaut a la description du Streptococcus erysipelatis de Fehleisen et du Streptococcus pyogenes de Rosenbach. - Le pus du péritoine seul nous a dommé des cultures impures dans deux ou trois cas où il avait

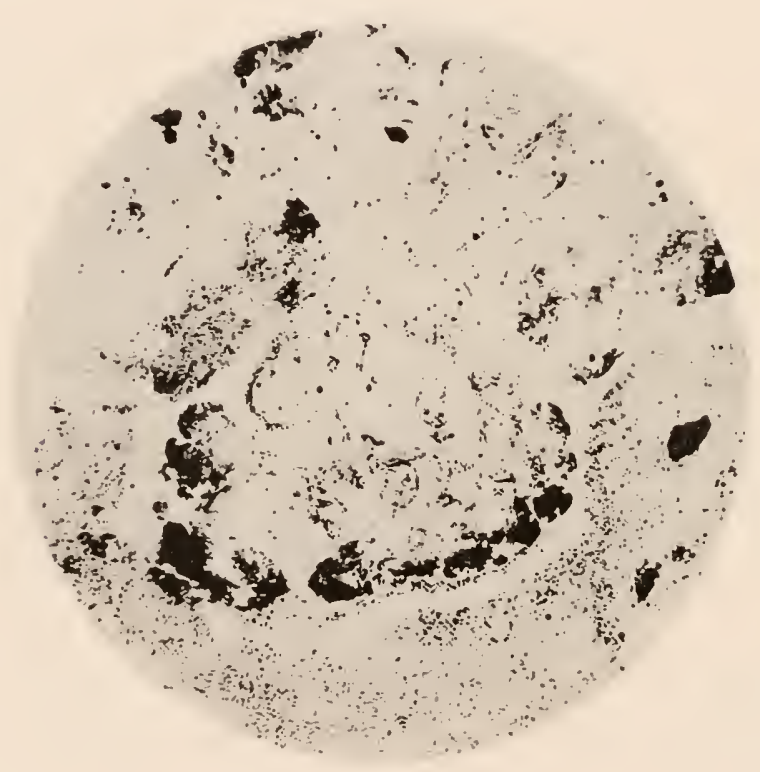

Fig. 491.

Manurite purpoimale à Streptocounes. Acini remplis de zooglées. (Gr. 80 dian.)

áce étudié tardivement, c'est-ii-dire quelques heures après la morl. L'ixumen des coupes a toujours montré des embolies microbiennes cusiderahles dans les cappillaires des principanx visec̀res. Les emholies sont constifnies mniquement par des misses de Streptoconues.

Vuns eitrons partienlicrement une pieve curieuse de suppuralion

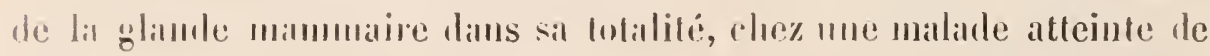

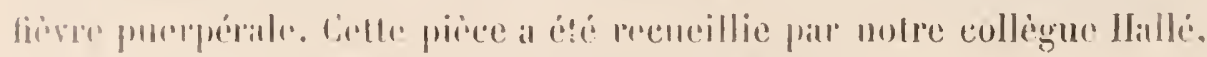

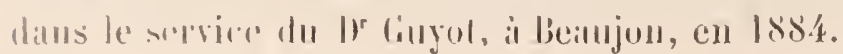


FIG. 492.

Fiève puerpérale suraiguë: Zooglèe du foic ayant domé une culture pure de Streptocoques. (Gr. 800 diam.)

FIG. 493.

Infection streptococenque. - Znoglée de Streptocuques dins le: rein. (Gr. 800 diam.) 
Les coupes de la muqueuse utérine, surtont au niveau de l'insertion placentaire, se montrent criblées de chainettes. Deux fois nous y y avons rencontré en même temps des follicules tuberculeux avec les bacilles caractéristiques, ees derniers en petit nombre.

Nous avons recucilli également des cultures pures du Streptocoque puerpéral dans une pustule sous-épidermique du doigt d'une sagefemme qui venait, après avoir soigné quelques jours avant plusieurs

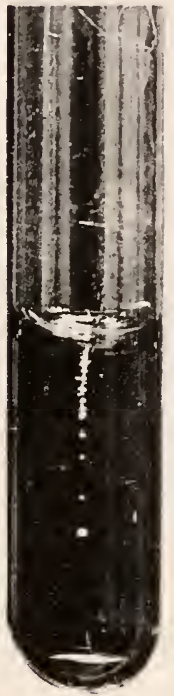

FIG. 494.

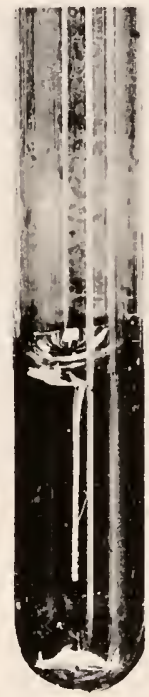

FIE. 495 .

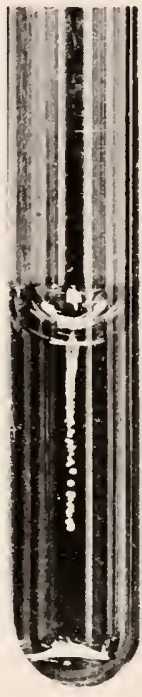

FIG. 496.

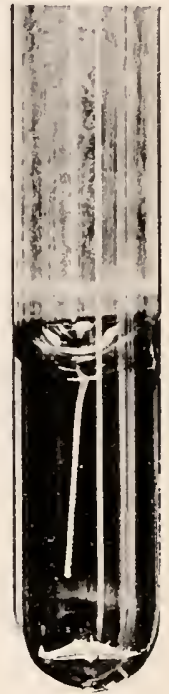

FIG. 497.

Streptocoque pyogène. Streptocoque puerpéral. Streptocoque de l'érysipèle. Cultures sur gélatine.

femmes prêtes à succomber, d'inoculer inconsciemment la fièvre puerpérale à une jeune parturiente de 17 ans (voir fig. 515).

L'analyse bactériologique de tous les cas de fièvre puerpérale mortelle ou d'infection puerpérale bénigne à manifestations variables nous a donc démontré la présence constante et unique d'un même Streptocoque.

Les cultures de ce microbe ressemblent sur tous les milieux à celles du Streptocoque de l'érysipèle et du Streptocoque pyogène; la colonie 
est composéc de petites sphérules d'autant plus grìles qu'clles sont plus tassées. Elles peurent former ne colonic presque contimue (fig. 496 et 497 ).

Les Streptocoques de l'une ou de l'autre provenance sont frappís de mort par la dessiceation el se reproduisent minnement par seissiparité. Ils ne résistent pas a une tempéralture de 60" centigraldes et leurs cultures deviement stériles si on ne prend pas soin de les renoureler tous les deux mois environ.
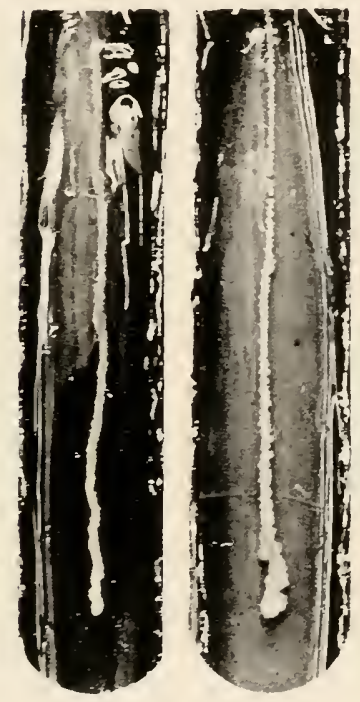

Fig. 498 et 499.

Streplocoque pyogène.

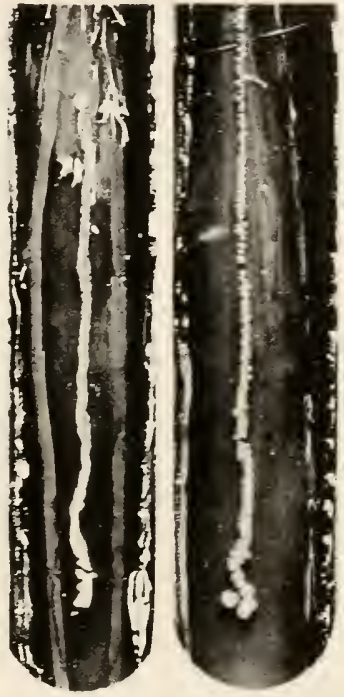

Fig. 500 et 501.
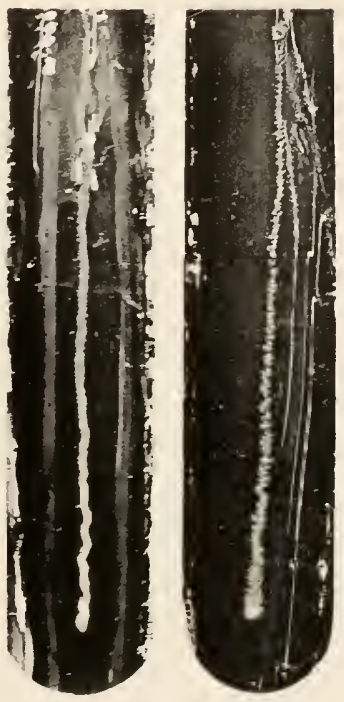

Fig. 502 et 505.

Streptocoque puerpéral. Streptocoque de l'érysipèle.

Cultures sur agar-agar.

Quels rapports existent entre ces trois Streptocoques tellement semblables sur les cultures, que li comparaison impartiale entre une quinzaine de tubes de chaque provenance, dont nous voilions les étiquettes, est toujours restée infructueuse pour la découverte de caractères différentiels bien tranchés et propres it chacun d'cux?

Nous avons pratiqué l'inoculation aux animaux. Afin d'éviter toute lésion mécanique, comme il arrive à la suite de l'injection souscutanée d'une certaine quantité d'un bouillon de culture, nous avons 
procéde de lit firgon snivante: nous pratiquons sous l’épiderme de la litee interne de l'oreille d'un lapin blanc une piqutre oblique arec une

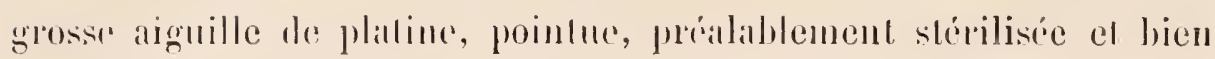
refroillir.

Jussilot nous inlrobluisons an fond de celle plaie minusenle quelques

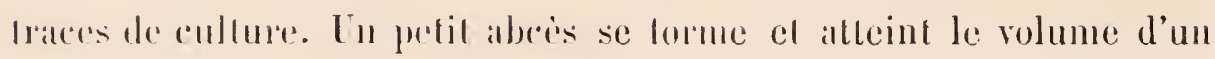
gratin de milled on d'une lenlille.

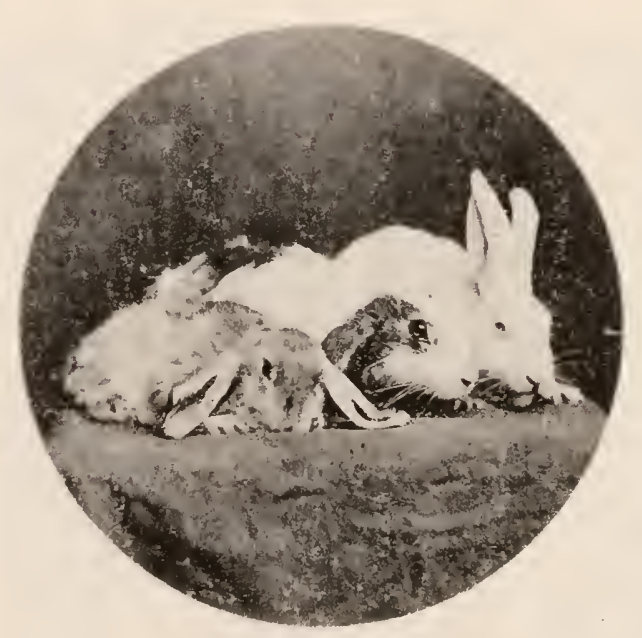

Fig. 50\%.

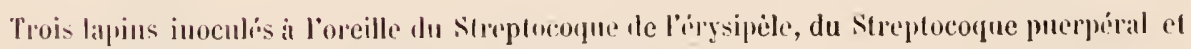

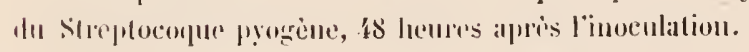

Le premier lapin est monrant (Birysipele infectionx).

l. deuxiène est mort 24 heures plus tird (Fierve puerperale).

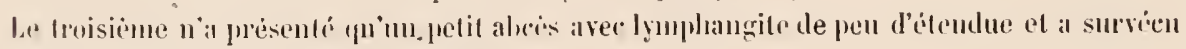

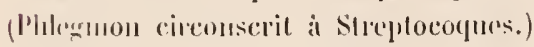

Les cullures d'érysipile nous onl en oulde donné presque toujours l'arsipicle, parfois suivi de mort, aprís un gonflement énome des deux orrilles el de la likle. A l’autopsie: Streptocoyues dans le foice, lat rate, les reins et l’urine.

Cimbines innculalions sont restées infructucuses - en ee sens que

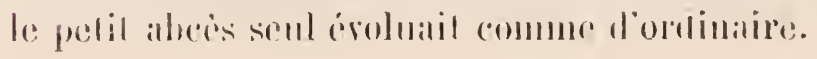


Deux de nos streptocoques, provenant d’érysipriles à forme lyphoüde et suivis de morl, sonl d'une vimulence exceptionnelle. - Inintres donnent des érsipites plus bénins.

Jans les cas gratres, nous arous observe des phlyelines el des platyues gangréneuse's.

L'anatomic palthologique de l'oreille du lipin alleint d'érysipule est identique a celle de la pean de l'homme alteint de la mème maladie.

L'inoculation du Streptocoque pyogène nous a lonjours donné un pelit abcès. Plusieurs fois nous avons obtenu, après l'inoculation de Streptocoques provenant d’abcès chauds, une rougeur érysipélaleuse qui ue s'est pas étendue au delí de quelques centimiolres; d'autres streplocoques de provenance analogne ont déterminé un véritublé érysipèle des deux oreilles, se comportant comme les érsipèles bien caractirisés, mais de forme bénignte.

L'inoculation du Streplocoque puerpéral nous it domné presque tonjours l’érysipèle, et cel érysipèle s'est montré plusieurs fois mortel.

Ces érysipèles du lapin, cinusés parr l’inoculation de Streplocoques provenant indifférenment de l'érysipèle de l'homme, de la fiève pmerpérale, ou des abcis chauds, sont identiques. La dermite inlectiense est simplement plus fiéquente et plus grave quand on inocule les Streptocorucs provenant des deux premières sources, le microbe paraissant jouir en pareil cas d'une virulenee spéciale.

Nous verrons plus loin que ces données sur la virulence varialle du Streptocoque progène, éliblies et démontrées en 1838 dans notre mémoire à l’Académie de médecine, ont resu me pleine el entiore confirmation daus les expériences de Mannorek sur lexallitlon de lia

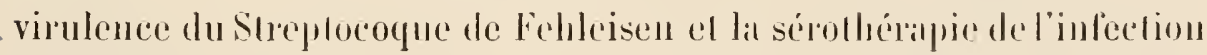
streptococeirue.

\section{ÉTUDE GLINIQUE DE L'INFEGTION STREPTOGOGGIQUE}

Il n’est pas sans intriet de comparer, anx lésons exprírimentales valriables produiles chez le lapin par l'inoculalion de streptocopues sous l'épiderme de la peau de l'oreille, la diversité des manifestilions 
de l’inlection streptococesque che\% l'homme: suppuration simple, suppuralion compliquéce de rongeur írysipélarense, érysipèle frane,

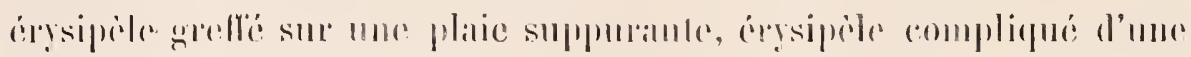

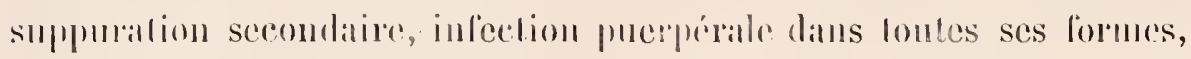

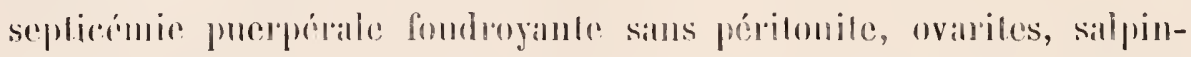

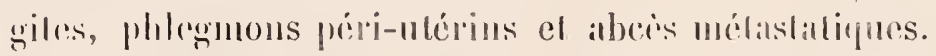

Telles sont les lesions si diverses que peul produire, suivant le point

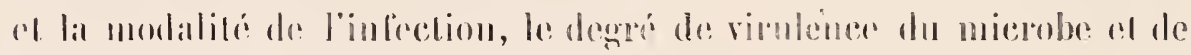

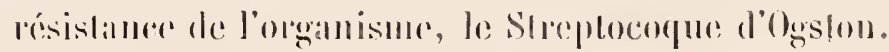

Nons en dommerons qunlques exemples cliniques:

\section{SUPPIIRTIION SIMPHS}

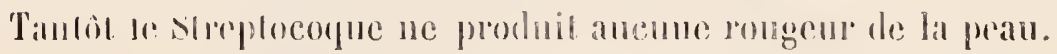

Nons l'arvous ohserve daus ces conditions nombere foris, qu'il s'anisse d’inlerelion sons-culance gannglionnatre on riscérale.

Nons citerous les cals suivants:

lo Aheres gamgliomalne de l'aisselle, apres me plate du pouce.

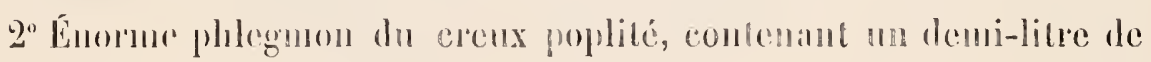
pus et grieri en 12 jour's.

$5^{\circ}$ Alucis ganglionmaire sons-maxillaire.

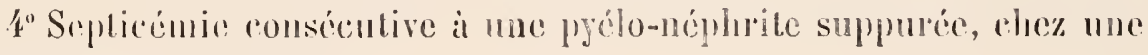
opérée de népluretonie.

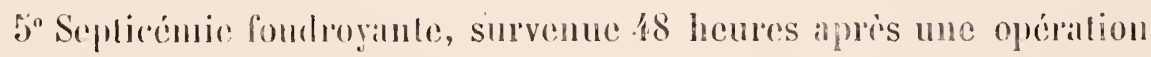
de eance du sein. Le foic contenait de petis noyaux cancéreux. Tous les viscires présentaient des Streptocoques

6" hijstes hydalipues multiples el suppurés da foic.

$7^{0}$ Septicémie a marele leute, à la suite d'une plate insignifiante le l'anriculate. Le sujel ful pris d'un étal byhoüde aree douleurs

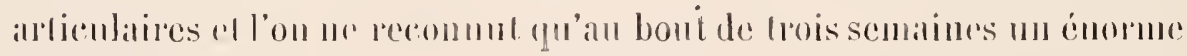

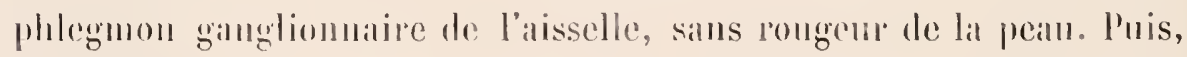
111 phlegrmon de la jambe, me arthrite suppurée des deux genoux, un phlegrinon profond de la fesse ef, an hout de cinq senaines, une méningite suppurée, qui aments la mort. 


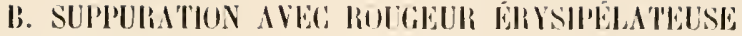

Sonvent an contratic nous arous vu coïnciller avec la présence des Streplocoques daus le pus une lymphangite des phus manguces on bien mo rougenr érysipélaleuse lixe el sims disséminalion loin des loyers suppurés. Nous cilcroms quelques observations :

1" Lymphangite de la cuisse. Abcès comséculif.

20 Plaie du doigl. Iymphamgite. Trois abces sur le trajet des lymphatiques de l'arant-bras.

$5^{\circ}$ Double panaris des gaines tendinenses falnaires compliqué de pustules sous-épidermiques de la région thénar.

$4^{\circ}$ Pantris. P'hlegmon de la gaine palmaire. Lymplangite étendue Adénopalhies multiples.

50 Blessure du doigh. Irmphangite. Phlegmon du dos de la main. Décollenent de la pean dorsale, infiltréc de microbes.

$6^{\circ}$ Phlegnon dillis de la grande gaine palmaire, a la suite d'une plaie de la face dorsale du petit doigt, au niveau de la première articulation phalangiemne, arec arlhrile suppuréc de cette articulation et propagation ì tout l’arant-loxas.

$7^{\circ}$ Abces des ganglions sterno-mastoïdiens et sous-maxillaires avec lymphangite.

8o Abcès de la bourse séreuse olécranienne (Yymphangite.)

$9^{\circ}$ Phlegmon de la fesse avec rougen et gonflement énorme.

$10^{\circ}$ Vaste abeès sous-culané de l'avant-bras, d’apparence érysipélateuse.

$11^{\circ}$ Lymphangite et gangrène des bourses à la suile d'une ponction d'hỵdrocile avec un trocart malpropre.

$12^{\circ}$ Iyymphangite érysipélalense de tont le nuembre inférieur, suivie de phlegmon diffus sous-cutané et d’abećs gangliommane de l’aine.

$15^{\circ}$ Septicémic de cause obscure, aves phlegmon ésysipélaleux de la paroi thoracique ganche et arthrite purulente du poignet gauche, suivie de mort. 


\section{ERYSIILELE SIMPLE}

L'éryipite frane se produit sonvent sans trace de suppuralion. C'est ainsi que, daus la plupart des érysipèles de la face, la platic d'inoculation, minuscule, demenre inaperȩue.

Dans un de ces cas, terminć par la guérison, nous avons obtenu, dès le début de la maladie, par la culture de l'urine recucillie avec toules les précautions de rigueur daus la vessie, et sans complication d'allsuminurie, des Streptocoques à l'état de pureté.
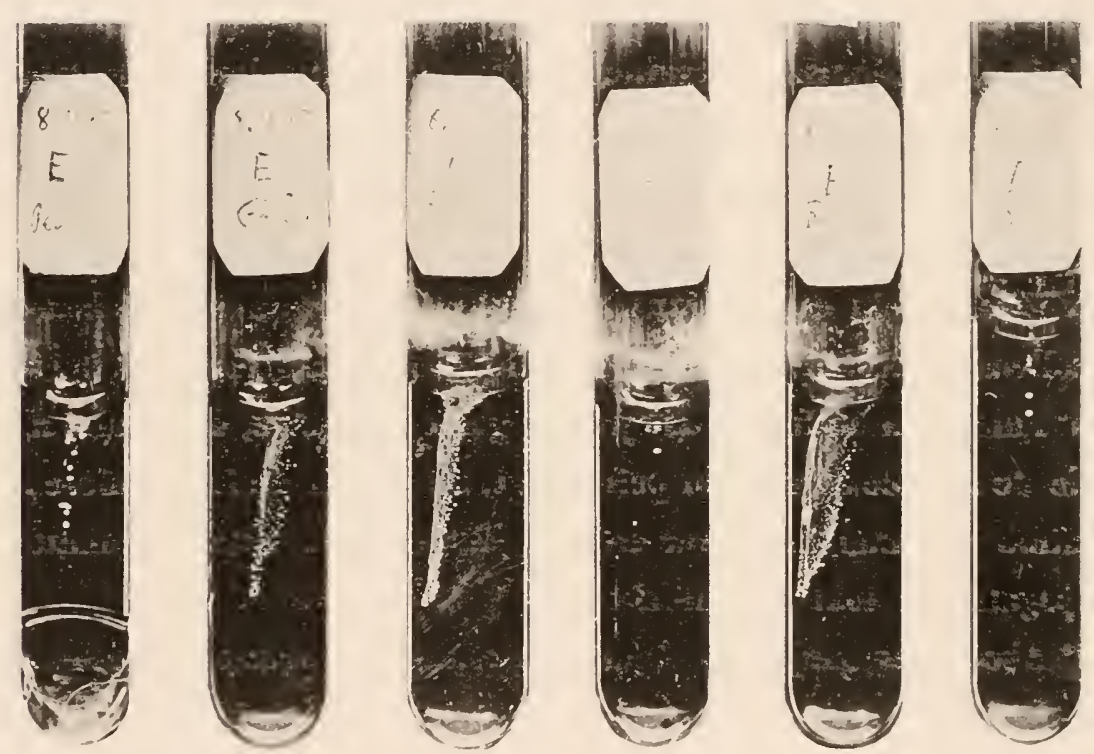

F). 505

Fic. 507

Fig. 508

Fig. 509

Fis. 510

Fug. 505 a 510.

Première culture du sue des visciges ol do l'urine grovmant d'un cas d'irysipèle franc. de: la face, suivi de mort.

Un autre malade, atteint d’un sareome généralisé des os du hassin, a succombe en quelques jours, avec une phlébite infecticuse, à la suite de l'apparition d'un érysipèle te lis firee. Les streptocoques existitient dans tous les viscères, et surtout dans les noyaux cancéreux du foie, dans la bile, dans l’urine des deux uretères et de la vessie? Il n'y avait de pus nulle part. 
f) ER YSIPILE GREFFE SUR UNE PIAL SUPUUANTE

Dans les cas suivants, nous avons ru l'érysipèle se greffer sur une suppuration antérieure :

$1^{\circ}$ Érysipèle à la suite d'une saignée du pli du conde; mort.

$2^{\circ}$ Érysipèle à la suite de l'inflammation d'un ulcère varqueux.

$5^{\circ}$ et $4^{\circ}$ Ieux cas d'érysipèle suivis de unort à la suite d'amputation du sein et ayant débuté après plusieurs jours de suppuration simple.

$5^{\circ}$ Érysipèle de la face et du cuir chevelu, compliqué de phlegmon diffus péri-crânien, oủ coexistaient avec le Streptocoque de l'érysipèle les Staphylocoques doré et blanc. Dans tous les viscères on observait, a l'état de pureté, le Streptocoque de l'érysipèle.

$6^{\circ}$ Érysipèle spontané, survenu chez une femme atteinte de cancer du sein inopérable et de cancer secondaire du foie, ef ayant déterminé la mort avec généralisation des Streptocoques, particulièrement dans les noyaux cancéreux du foie.

La coupe du cancer du sein ulcéré nous a permis de suivre la pénétration des microbes, qui foisonnaient a sa surface et dans les espaces lymphatiques profonds, d'où ils avaient déterminé l'infection générale.

\section{E. ÉRYSIPÈLE SLIVI DE SUPPURATION SECONDAIRE}

Plusieurs fois, l'érysipèle s'est montré, au contraire, l'origine d'une suppuration. Nous insisterons particulièrement sur ces cas, pour démontrer qu'on a rangé á tort le Streptocoque de l'éry̧sipèle parmi les microbes nou pyogènes.

$1^{\circ}$ Érysipèle de la jambe. Trois abeès péri-malléolaires pendant lat convalescence. La peau, examinée, présentait une infiltration embryonnaire profonde du derme, comme dans tous les cas d’érysipèle.

$2^{\circ}$ Érysipèle évoluant autour d'une petite plaie du coude. Phlegmon consécutif de la bourse séreuse olécrânienne et des gainés dorsales du poignet.

$5^{\circ}$ Un homme atteint de cancer de l'estomac, propagé au foie, meurt d'une péritonite séro-purulente à la suite d'un érrsipèle spontané de la face. 
40 En 1885, 111 malande du service de cliniqque de la Pitié menrt de périlonite purulente à Streptoconues, à la suite d’un érysipèle de

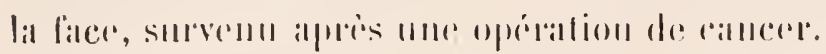

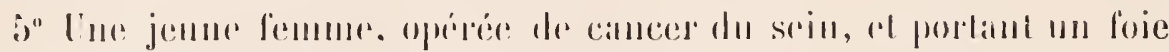
cancérenx méconnu de riny kilogranmmes, munt avee les signes d'une péritonite quatre jours apris l’opéralion. P'eu d'accidents locanx. Partout des streptocoques. Beancoup de liquide séro-purulent dans le péritoine.

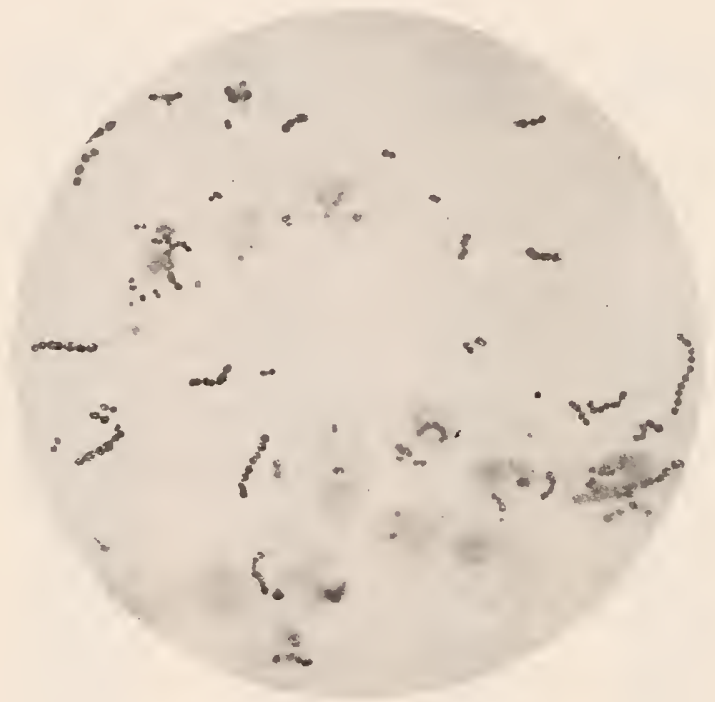

Fic. 511

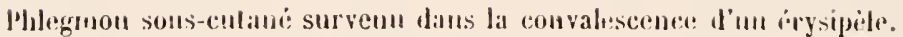
Chathetles incluses dans les lencocyles. (Gr. 1000 diam.).

Dams ces trois cas, nous ue pouvons allirmer si l'aseite préexistait 011 non à l’infection érysipuilatense.

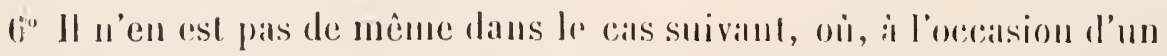
érysipèle, le liquide d’une ascite préexistante s’est trouvé inlecté par les Streptocoques.

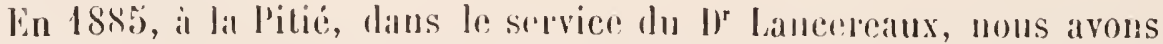
observé un matade alleint de cirhose atrophique avec ascite; le

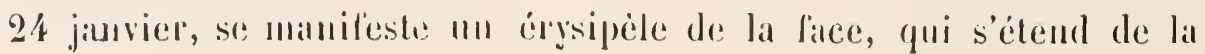


enisse, se.complique de lymphangite tronenlaire el d'alénite ingninale, et tue le palient an bout de six jours aree les signes d'une périlonite.

Le liquide péritonéal, séro-purulent, abonlait en Streptocopues. Le malade présenla également, dans les derniers jours, une arthrite infecticuse du genou.

\section{F. FIÈVRE PUERPÉRAIE}

Passons en revue, à leur tour, nos observalions d'infection puerpérale :

Toute une série, identique par l'anatomie pathologique, ne présente d'intérêt que par la ehronologie. Les dates du 10 juillet 1886 , des 5 et 25 janvier 1887, dı 2 septembre 1887, des 6, 12, 15, 51 janvier 1888 , des $5,11,12,24,25,28$ février 1888, prouvent que la maladie était endémique dans le service hospitalier d'où proviennent tous ces cas.

A part une seule autopsie, remarquable par la présence d'une quantité extrêmement petite de pus dans le petit bassin, tous les cas ont présenté les lésions banales de la péritonite. séro-purulente d’origine utérine, que nous avons décriles plus haut. Les formes anormales sont plus intéressantes au point de vue clinique.

Deux observations, provenant l'une de la ville, l'autre de la campagne, sont remarequables par la coincillence, avee la péritonıte puerpérale, d’un érýthème scarlatiniforme généralisé. Ces deux cas ont été notés par les médecins comme des cas mortels de "Scarlatine» chez des femmes en couches.

Fous avons deux fois observé ces mèmes exanthèmes scarlatiniformes dans les cas de lymphangite infectieuse à Streptocoques, suivie de guérison.

Chez une autre malade atteinte d'infection puerpérale, la mort n'est survenue qu'au bout de quinze joürs, après l'apparition d'un gonflement phlegmoneux d'un bras et d'une arthrite purulente du poignet opposé, compliqués de phlictènes purulentes el de plaques de sphacèie. 
Une autre malade, plus heureuse, a surmonté les accidents d'inCection générale pour ne présenter comme lésion streptococeique grave qu'une pleurésie purulente de quatre litres. Trailie d'emblée par l'opération d'Estlanter, cette femme a parfaitement guéri.

Cette localisation pleurale du Streptocoque d'origine post-puerpérale n'est pas rare, et à la l'itié, en 1881, nous avions déjà constaté clans le service du Dr Bernutz, à l'autopsie d'une jeune femme devenue eachectique à la suite d'une fausse conche, une pleurésie purulente enkystée très limitée provenant d'un pelit abeès métastatique du poumon, et prête à s'ouvrir spontanément en dehors.

Une des femmes citées plus haut, à propos de l'épidémie que nous avons étudiée à l'Hôtel-Dieu de lieims, a présenté pour tout accident une collection purulente énorme de l'épaule, sans rougeur, qui guérit à la suite de trois ponetions aspiratrices, et un phlegmon de la jambe, également sans rougeur, qui dut être incisé.

Une autre personne, atteinte de déchirure du périnée, contracta un érysipèle de la vulve, qui s'étendit jusqu'aux pieds, et présenta, pendant sa convalescence, un phlegmon de la fesse sans rougeur de la peau.

Une troisième fut atteinte d'un phlegmon sus-épineux profond sans lymphangite superficielle.

Nous citerons également une femme atteinte de cancer du sein et du foie, contagionnée manifestement par le Streptocoque puerpéral, et morte avec une péritonite séro-purulente. L'ascite ne s'est manifestée qu'après l'apparition de l'exanthème lhoracique.

Une opérée de cancer du sein présenta au huitième jour une simple gouttelette de pus sur le trajet d'une suture. Bientòt après elle était atteinte d'un érysipèle ambulant du thor:ax, et mourut avec généralisation des Streptocoques dans tous ses viscères.

Rien de plus intéressant au point de vue elinique que les manifestations si variées de l’infection par un mème Streptocorpue, de provenasce unique probable, et qui a tué pendant de longs mois, à l'llòtelDien: de Reins, malades de médecine, de chirurgie el parturientes, se propageảnt de l'un a l'autre par transmission directe dins l'intéricur mème de l'hôpital. 
L'exposé de ces faits confirme les domnées de l'expérimentation e'. prouve :

$1^{\circ}$ Ouc le Streptocoque pyogène de Rosenbach évolue souvent avec une lymphangite ou unc rougeur érýsipélatense.

200 Que le Streptocoque puerpéral peut occasionner, soit la péritonite puerpérale, soit diverses formes d’infection plus bénignes: phlegmons, pleurésie purulente, etc., etc., et même de véritables érysipèles bien caractérisés.

$5^{\circ}$ (Yue le Streptocoque de Fchleisen, tout en étant l'agent de l'érysipèle frane, peut être aussi le point de départ de phlegmons circonscrits, de péritonite ou d'arthrites purulentes.

Chez le lapin, les Streptocoques de ces trois provenances déterminent presque toujours la formation d'un petit abeès, puis un érysipẻle d'une gravité rariable.

On roit lone que les faits cliniques viennent corroborer l'unité presque cerlaine à la suite des simples recherches bactériologiques du Streptocoque progène en tant qu'agent de l'érysipèle et de la fiẻvre puerpéralc.

\section{ETTOLOGIE DE LA FIÈVRE PUERPÉRALE}

Comment se produit la fièvre puerpérale?

Le nicrobe ou bien : $1^{\circ}$ préexiste dans le vagin; $2^{\circ}$ ou bien il est apporté par l'air ; $5^{\circ}$ ou par contagion directe (doigts, instruments, etc.).

Lianalyse hactériologique du mucus vaginal faite dans nombre de cas arant el après l'accouchement, nous a souvent donné le Staphylocoque doré, loujours des bactéries saprogènes, surtout dans les cas de lochies félides, mais jamais le Streptocoque puerpéral. Aucune de ces femmes n'a succombé aux accidents puerpéraux (1887 et 1888).

Au contraire toutes les femmes atteintes d'accidents puerpéraux proprement dits présentaient, au cours de ces accidents, le Streptocoque.

Bien mieux, la muqueuse utérine, chez deux d'entre elles, n'exhalait aucunc odeur fétide.

Les bactéries de putréfaction sont en effet loin d'ètre favorables au développement du Streptocoque, qui souvent se trouve étouffé et 
trappé de mort au milieu d'elles et chez ces deux femmes le Streptocoque pullulait dans l'utérus.

Nous tenons done à affirmer que les accidents puerpéraux proprement dits sont causés par l'inoculation du seul Streptocoque, qui vient se cultiver sur cette surface d'absorption immense, la plaie utérine.

Les autres microbes causent la fétidité des lochies, et cette putréfaction est sans rapport avec l'infection puerpérale proprement dite. Car nous r'cfusons ce nom aux péritonites purulentes à Staphylocoques ou à Bacterium Coli, qu'on a parfois observées à la suite des déchirures de l'utérus ou du vagin chez les parturientes. Ces cas d'infections sont de simples péritonites traumatiques accidentelles.

La fièvre puerpérale est une maladic typique, essentiellement épidémique et contagieuse, et le Streptocoque pyogène est son agent exclusif.

La fétidité simple des lochies occasionne une lièvre plus ou moins durable mais en général bénigne. Le Streptocoque seul tend à déterminer une infection péritonéale rapide.

Les microbes de putréfaction les plus variés se rencontrent dans les lochies fétides; et, parmi eux, on rencontre le plus souvent ces nombreuses variétés de bactéries que nous avons isolées à l'état de pureté de l'urine pathologique et qui, par voisinage, ne peuvent manquer de pulluler dans le vagin et l'utérus des femmes mal soignées.

J'après nos recherches nous croyons exceptionnel que le Streptocoque existe fréquemment daus le vagin avant les couches.

Se propage-t-il par l'air? - Nous ne citerons qu'un seul fait, absolument négatif : tóutes les sages-femmes du service d'obstétrique de l'Hôtel-Dieu de Reims ont été conviées par leur professeur à assister à l'autopsie d'un cas sporadique de fièvre puerpérale : aucune d'elles n'a touché le cadavre ni les pièces.

Il ne s'est produit dans le service, à la suite de cette imprudence, aucun cas de puerpéralité.

Au contraire l'inoculation directe est prouvée par les cas sporadiques ohservés à la campagne. Les exemples abondent :

$1^{\circ}$ Un médecin de l'hôpital d'une petite ville, où il soigne fréquenment des phlegmons et des érysipèles, est appelé pour accoucher 
dans un village une mère de huit enfants. Cette femme succombe à la fièvre puerpérale.

$2^{\circ}$ Un autre médecin inocule la fièvre puerpérale à deux parturientes, et une paysanne qui a lavé, avec des crevasses aux mains, des linges contaminés, succombe peu après à la suite d'un érysipèle phlegmoneux du bras droit.

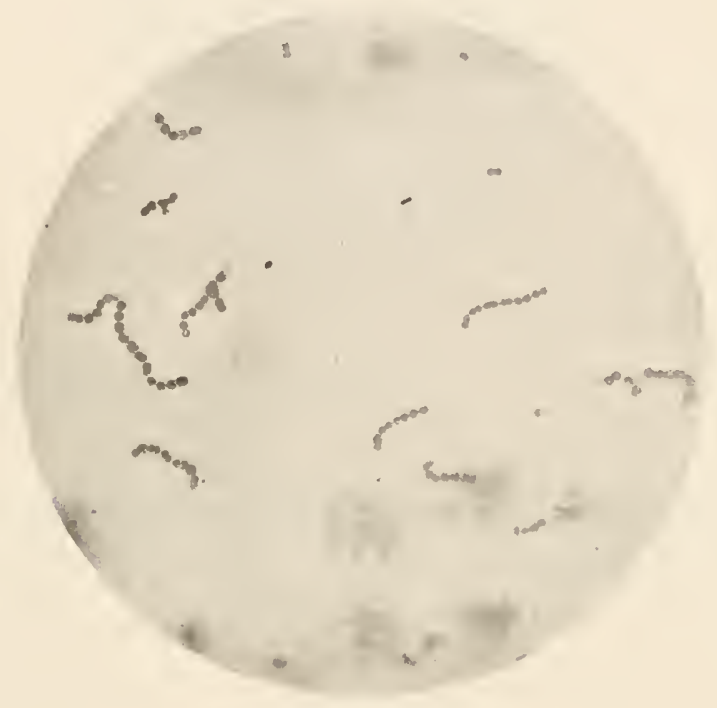

Fir. $51 \%$.

Érysipèle phlegmoneux post-puerpéral. (Gr. 1000 diam.)

$3^{\circ}$ Une sage-femme contracta, en soignant un cas de puerpéralité. une pustule de l'index et un érysipèle ambulant, dont elle mourul Nous avons obtenu dans ce cas, pendant la vie, de la peau de la jamue oủ s’était étendu de proche en proche l'érysipèle, une culture pure.de Streptocoques.

$4^{\circ}$ Une autre sage-femme soignait deux personnes atteintes chacunc de la fièvre puerpérale. Une nouvelle accouchée reçoit les soins de cette personne et tombe malade à son tour. Nous apprenons que la sage-femme est elle-mème souffrante : nous l'examinons et nous con- 
statons qu'elie portait au pouce, sous un cataphasme, une pustule sousépidermique compliquée de lymphangite, et dont le pus nous a donné des cultures plires de Streptocoques.

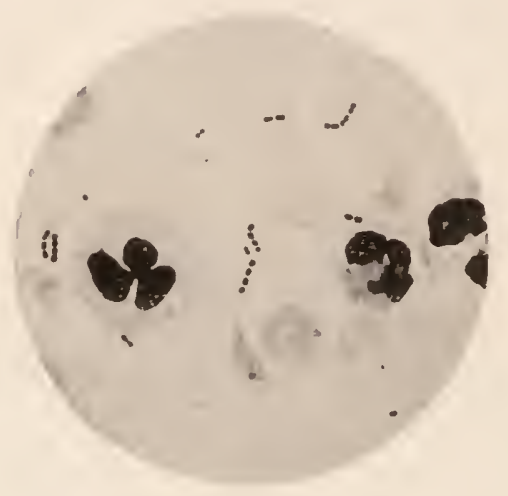

Fig. 515

P'ustule du ponce lluue silge-femmo conlamine. (Gir. 800 diam.).

Lat malheurense, s'exposint dli-mème en soignant sans propreté deux lenmes préalablement contaninćes, arait sans le savoir infecté

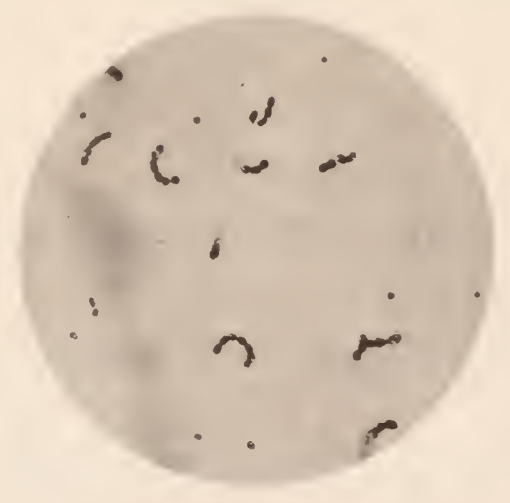

Fig. 514

Sérusité péritonéale d'une des frmmes contaminées par celte sage-femme.

directement une troisième parturiente, a peine âgée de is ans, qui mourut en quelques jours. 
La contagion direcle nous paraît done être la cause réelle de l'infection puerpérale.

Celte maladie est endémique en Europe. Tous les sujets portant des érrsipèles ou des abeés à Streptocoques peuvent la proprager, de mùme qu’ils peuvent également s'infecter eux-mêmes.

L’origine de notre épiciémie parait d’ailleurs avoir été une servante des parturientes, atteinte d'éry̧sipèle à répétition.

l'érysipèle à répélition est en eflet causé par le mème Streptocoque que l'érysipèle commun, et, en examinant avec soin le point de départ habituel de la dermite infecticuse, on trouve toujours une plaque de dermite chronique, qui est, il chaque nouvelle atteinte, le point de départ de l'exanthème.

Nous avons fait dans cinq cas analogues la même observation : Ces éryssipèles à répélition sont curables parr l'application localc prolongée du sullimé ou d'autres antiseptiques.

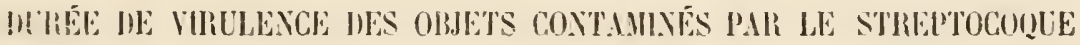

L.e Sireptocorpue peut conserver très longlemps sal virulence. Nous en domnerons quelques exemples probants.

$1^{\circ}$ Une femme meurt d'érysipèle opératoire à l'Hôtel-Dieu de Reims : son lit est souillé de pus.

On désinfecte les draps, mais non la paillasse.

Une autre opérée, couchée dlans le même lit quelques jours après le décès de cette femme, élait déjà en voie de guérison : on oublie de changer son pansement; les liquides de la plaie coulent et viennent s'infecter au contact de la paillasse contaminée; la malade prend un érysipèle et meurt.

$2^{\circ}$ Une jeune femme, épousée en secondes noces, meurt de fièvre puerpérale : elle venait d'accoucher sur le même lit que la première femme du mème mari, norte plus de 18 mois auparavant de la même malidie. - Les Streptocoques, qui exislaient encore à l'état virulent dans le mittelis non désinfecté, s’élatient propagés par les lochics jusque dans la cavité utérine. 
Comment survient la mort dans la fièvre puerpérale? Nos recherches nous ont toujours démontré des embolies microbiennes généralisées.

La lecherche des poisons chimiques produits par le Streptocoque est des plus délicittes.

Les poisons albuminö̈des on toxalbumines nous ont paru jouir d'une importance plus grande que les ptomaines cristallisables.

Toutefois la formation des poisons chimiques est inséparable de la présence au sein même de l'économie des Streptocoques.

\section{PHLÉBITES A STREPTOCOQUES}

Deux mois et demi après notre communication et le dépôt de ce mémoire à l'Acadínie de médecine, notre ami le $\mathrm{D}^{\mathrm{r}}$ Widal faisait présenter à l’Académie, par le professeur Cornil, le résultat de ses recherches, à peu près contemporaines des nôtres.

Widal, en inoculant à l'oreille du lapin des cultures de Strep' ocoques provenant de six cas de puerpéralité, a déterminé indifféremment des plaques érysipélateuses et de petits abcès ${ }^{2}$.

Il a rencontré, chez les malades atteintes de fièvre puerpérale, le Streptocoque dans l'épaisseur du tissu utérin, dans les abcès métastatiques et particulièrement dans les caillots de la phlegmatia alba. dolens dont la forme infectieuse, observèe après l'accouchement, est en relation avec l’infection par le Streptocoque puerpéral.

Les recherches de Widal ont donc confirmé absolument les observations que nous avions faites sur un plus grand nombre de malades.

Le microbe en chaînettes, décrit par Coze et Feltz en 1869 dans les cas de fièvre puerpérale, puis par Recklinghausen 1871, Valdeçer, Orth, Pasteur en 1879, est donc bien le seul microbe de l'infection puerpérale type. C'est le Streptocoque de 0gston.

On a prétendu, à l'exemple de Doléris (1880) que la fièvre puerpérale évoluait avec des formes variables suivant le microbe pathogène Le microbe en chaînettes produirait d'après lui une pyohémie lente: Le diplocoque, des suppurations dites rapides. Les bacilles, une septicémie foudroyante évoluant presque sans suppuration.

1. Bull. Acad. méd. 27 mai 1888. 
Fränkel en 1884, et quelques autres auteurs, tels que Brieger, en 1888, prétendent avoir observé des cas d'infection puerpérale dus à une bactérie progène.

Les conditions spéciales dans lesquelles nous avons pratiqué nos autopsies, presque toutes nos observations ayant été faites pendiut la vie ou aussitôt après la mort, nous permettent d'affirmer, conme nous l'avons signalé plus haut, que, dans les eas d'infection puerpérale type, le seul organisme pathogène est le Streptocoque.

Cette origine streptococcique pure de la fièvre puerpérale proprement dite vient d'ètre vérifiée cette année mème par notre ami le $D^{r}$ Marcotte, dans un grand service d'accouchements.

La condition essentielle est d'éviter toute invasion de la flore microbienne cadavérique.

Si l'on fait l'autopsie vingt-quatre heures après la mort, on trouve en effet le plus fréquemment dans le péritoine, à côté du Streptocoque, des bacilles qui ont émigré de la cavité intestinale et déterminé la putréfaction conte.ue dans la séreuse.

Le liquide péritonéal que l'on peut extraire par ponction pendant la vie ou bien an moment de la mort chez une malade qui succombe à la fièvre puerpérale est bien différent du liquide recueilli à l'autopsie au bout de vingt-quatre heures. Au moment de la mort le péritoine contient une sérosité louche et sans odeur où nagent un certain nombre de fausses membranes fibrineuses purulentes.

Plus tard, on rencontre un liquide sanieux et d'une fétidité remarquable, infecté par divers bacilles, notamment par le Bacterium coli commune.

Il n'est pas inutile de rappeler ici que dans plusieurs eas de fièvre puerpérale, terminés par la mort et où le médecin traitant croyait avoir pratiqué l'anísepsie vagino-utérine, nous avons trouvé des Streptocoques à l'état de pureté dans toute l'épaisseur du tissu utérin, dans le péritoine et dans les viseères. Dans ces cas types, la cavité utérine n'exhalait aucune odeur désagréable.

Ces faits sont importants à signaler pour permettre aux eliniciens d'éviter cette erreur qui consiste à attribuer à la soi-disant fièvre 
de lait, sous prétexte qu'il n'existe pas de fétidité de l'écoulement vaginal, une élévation de température qui est trop souvent un début menaçant d'infection puerpérale.

I'infection puerpérale est donc sans rapport avec la fétidité des lochies. Le Streptocoque à l'état de pureté ne donne aucune odeur, bien que lui seul se montre réellement nocif.

Jes femmes malpropres et accouchées sans les moindres précautions antiseptiques guérissent au contraire sans encombre avec des lochies d'une abondance et d'une fétidité extrême, quand le vagin n’est infecté que de rnicrobes saprophytes.

La fièvre puerpérale est une au point de vue bactériologique.

Les cas où l'on a observé, comme Fränkel et d'autres auteurs, des Staphylocoques et des Bacilles chez des femmes atteintes de péritonite puerpérale mortelle, se rapportent à des infections multiples ayant pour origine des déchirures cervicales, vaginales ou vulvaires, oủ végétaient les microbes les plus variés.

la fièvre puerpérale typique, celle qui survient après un accouchement simple et se montre épidémique, est due à la propagation exclusive du Streptocoque.

\section{AUTRES SEPTIGEHIES A STREPTOGOQUES}

$1^{\circ}$ NÉPHRITE ASCENDANTE A STREPTOCOQUES

Nous avons déjà signalé, à propos du Staphylocoque doré, la néphrite ascendante spontanée et expérimentale due à ce micro-organisme.

La néphrite ascendante peut avoir également comme agent pathogène le Streptocoque, soit seul, soit associé aux divers bacilles que nous décrirons plus loin. Nous donnons ci-contre la photographie d'une colonie de Streptocoques dans le rein de l'homme, à la suite de l'évolution d'une néphrite ascendante bi-latérale.

$2^{\circ}$ ANGINE DE LUDWIG

Parmi les autres formes rapidernent mortelles de l'infection par le Streptocoque pyogène, nous citerons particulièrement l'Angine de Ludwig. 
Cette affection, comnue depuis la description clinique faite par Ludwig en 1856, est une sorte d'érşipète phlegmoneux du pharynx et de la région sous-maxillaire. - Les Streptocoques obtenus des cas mortels sont d'une virulence extrème. - La mort survient d'ailleurs le plus souvent en 24 heures, avec ume dureté ligneuse du pharynx et du plancher buceal, compliquée d’infection générale, d'albuminurie et souvent d'œème de la glotte.

Cette affection n'est donc qu'une manifestation de l'infection générale par le Streptocoque avec point de départ pharyngé. L’importance des angines à Streptocoques a été mise en lumière dans ces dernières

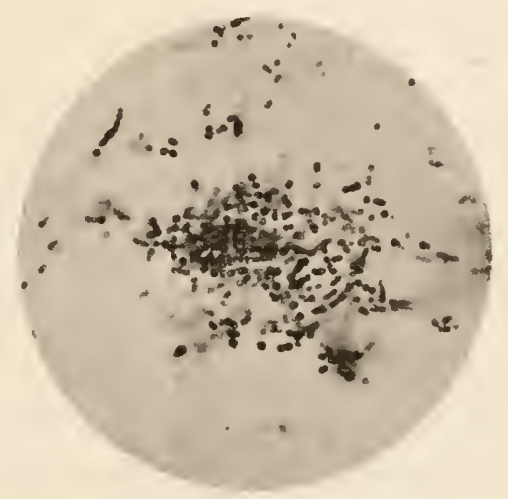

FIG. 515 .

Néphrite ascendante. Zooglée de Streptocoques dans le rein. (Gr. 800 diam.)

années par les recherches bactériologiques faites dans les cas de diphtérie scarlatineuse on vulgaire.

Il est prouvé aujourd'hui que la diphtérie scarlatineuse et la plupart des complications infectieuses de la scarlatine sont dues a la pénétration dans le torrent circulatoiré du Streptocoque progène.

Les recherches de Klein et des autres auteurs qui ont prétendu aroir isolé de la scarlatine un Streptocoque spécial n’ont pas été confirmées.

L'angine pseudo-membraneuse de la scarlatine peut ètre suivie de mort comme l'angine de Ludwig. Löffler a observé dans différents cas 
d'angine scarlatineuse le bacille de la diphtérie uni au Streptocoque pjogène.

L'association dans l’angine diphtérique vraie du Streptocoque pyogène an bacille de Löfller est fréquente. L'importance de celte association microbienne est particulièrement comne depuis l'emploi du sérum de Roux pour la guérison de la diphtérie.

La présence du Streptocoque au cours de la diphtérie est une complication grave et c'est a l'infection streptococcique pure que l'on doit attribuer', comme l'ont démontré Grancher, Roux, Marmorek, etc., un certain nombre de cas mortels où l'on a trouvé, après disparilion des fausses membranes et guérison de l'angine, des Streptocoques daus les viscères et dans le sang.

\section{SÉROTHÉRAPIE DE L'INFEGTION STREPTOGOGGIQUE}

La déconverte du sérum anti-streptococcique appartient à Narmorek et à Roux, qui appliquèrent contre le Streptocoque la méthode d'immunisation par les injections de sérum anti-toxique réalisée dans la diphtérie.

Nous passons en effet sous silence les mélhodes d'immunisation basées sur l’injection de cultures stériliscées à 120 degrés dans l'autoclave, la température très inférieure de 58 degrés suffisant déjil pour altérer les poisons albuminö̈des et clénaturer entièrement le liquide.

Marmorek et Roux ont pris, lien an contraire, comme point de départ, l'injection au cheral de cultures rivaces et tellement actires, qu'un rent-nulliandiène de centimètre cube, c'est-it-dire une quantité de bouillon actif tellement faible qu'on n'y reneontre par lose qu'm seul grain de streplocoque, lue ì coup sù mu lipin adulte.

Celte virulence extrime du Streptocopue soblient en cultirant un Streptocoque provenamt d'un cas d'infection grave chez l'homme dans du sérum de sang humain mélangé d'un tiers de bouillon de heul' peptonisé à 1 pour 100 et en réalisant des passages successifs, avec cultures intermédiaires, diuns le sang du lippin.

Le sérum humain est reliré, dans les services d'alcouchement, du sang qui s'écoule du placenla après la ligature du cordon. 


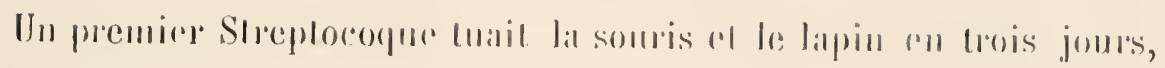

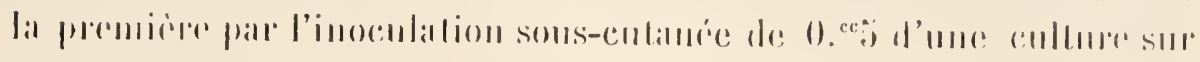

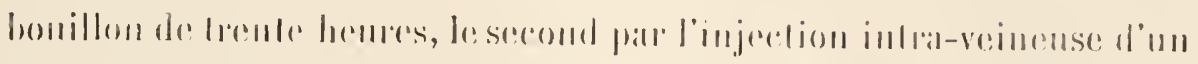

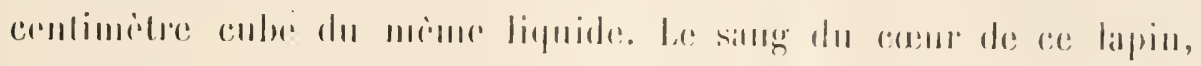

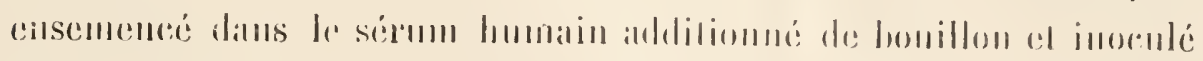

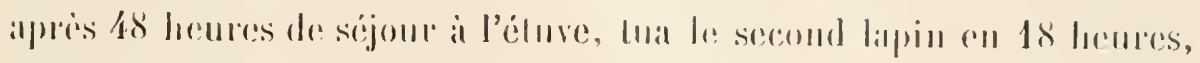
a dose moilic moindere, alinsi de suite.

Pour immuniser un cheval on injecte sous la pean environ $75^{\mathrm{cr}}$ d'ane

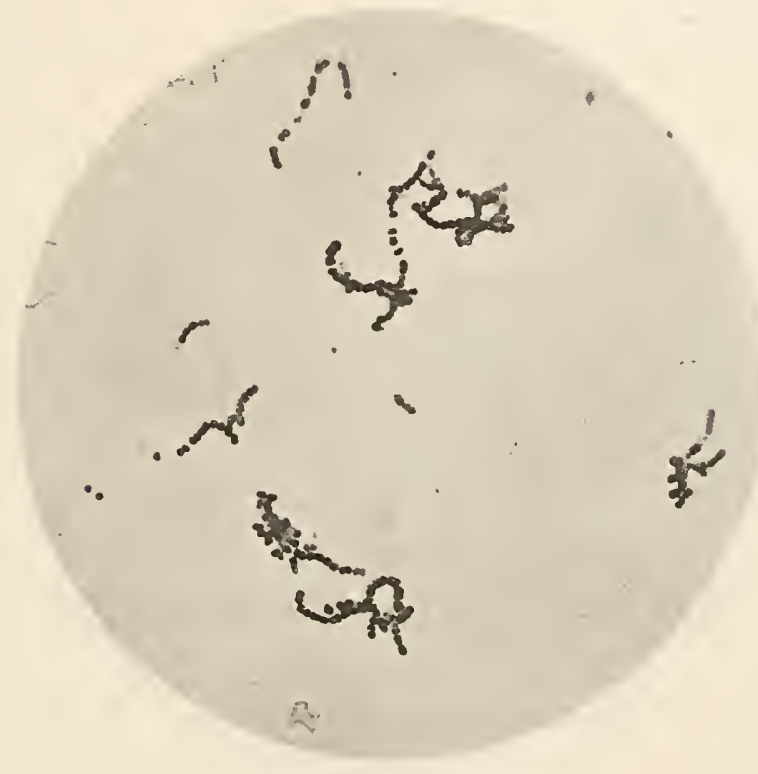

fig. $\$ 16$

Jeune culture de Streptocopue pyogèur sur le milion de Marmorek. (Gr. 900 daun.)

cullure tres virulente. La tenupralure monte a 59 degres. Au hout de quelques jours on injecte mone seconde dose un pen plus lorte el ainsi

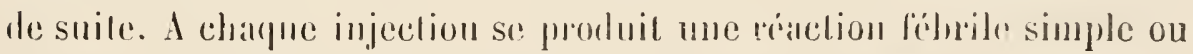

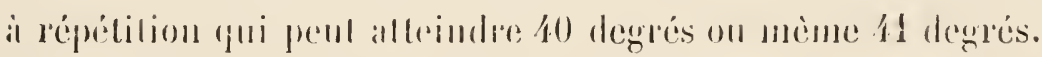

Il est mécessilire, pomr que de serrum soil très ellicilee, de provoquer des réalions lrés énergiques.

Les injections sont lates an nombere de trois ou quatre par mois. On arrive ainsi à oblenir des animanx qui, apres avoir regu, en un certain nombre d'injections, deux litres de culture virulente el plus, fournis- 
sent un sérum assez anti-toxique pour préserver le lapin contre les cultures les plus virulentes.

Les animaux en expérience ne doivent servir à un traitement antitoxique que quatre semaines après la dernière injection.

Jusqu’à la troisième semaine, le sérum demeure toxique et ce phénomène s’observe ì chaque période fébrile chez un cheval déjả bien immunisé. Au début de la troisième semaine, l’injection détermine un gonflement local douloureux et un empâtement qui peut être suivi d'abcès. Au bout de quatre semaines cet accident n'est plus à craindre.

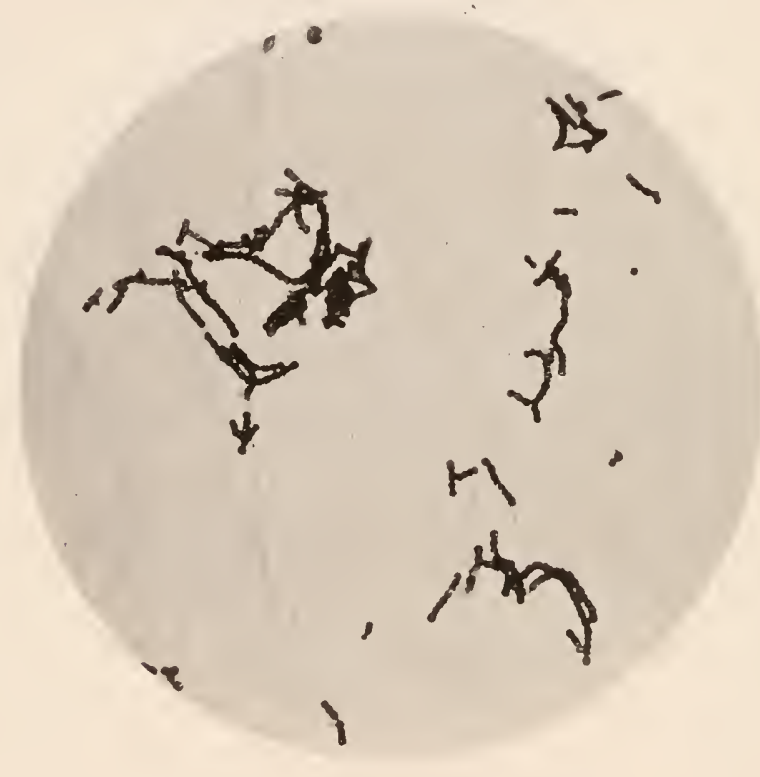

FIG. 517

Culture ancienne de Streptocoque sur le même milieu. (Gr. 1000 diam.)

Il faut environ un an pour préparer un cheval à domner un antitoxine streptococcique réellement efficace.

Le pouvoir antitoxique du sérum est mesuré en injeclaul il des lapins d'un poids délerminé des doses variables de sérum antitoxique 0 ce, 1 par exemple et $0^{\text {ce }}, 2$ pour des lapins de 1500 grammes.

Douze à dix-huit heures après cette injection on leur inocule sous la peau un millionième de centimètre cube d'une culture, c'est-ì-dire une dose dix fois mortelie. 


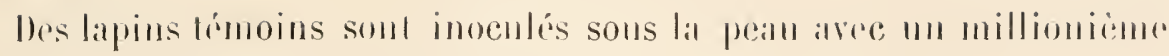

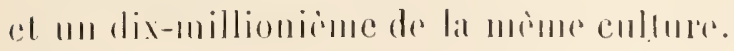

liente hemles apres, les lémoins sont molts.

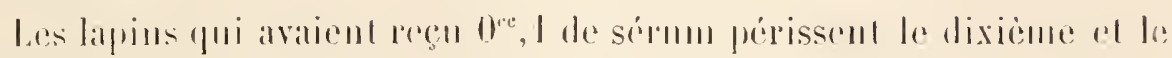

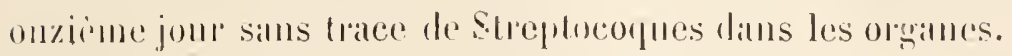

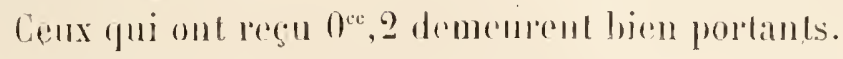

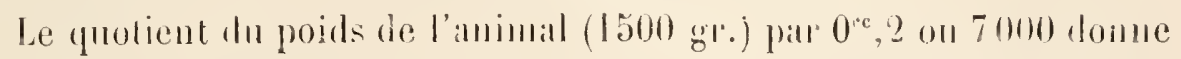
le litre llu pouvoir préservatil. Celle dose, éfuivalenle i la 7000" parlie de lenr poids, anrait dù naturellement ètre phos áleve si l'on avait introduit äumoment de l'inoculation mue plus forte quantité de enllure ultra-virulente.

Le sírum de Marmorek a été injecté chez l’homme dans les cas les plus variables. Erysipèle avec ou sans albuminurie, lièrre puerpérale, angines graves, scarlatine, phlegmons a streptocoques, infections postopératoires. Jans les cas graves il faul injecter d'emblée $20^{\text {ce }}$ de sérum ef 24 heures après 10 autres.

L’ér’̧sipèle pris au début peut s'atténuer trois heures seulement apres l’injection. La despuamation est rapide et se fail par grands lambeaux. L'albuminure si ẹle existe disparait en vingl-fualre à quarante-huit heures. Dans l’infection puerpérale vraic, qui, comme mons l'avons démontré, eśs toujours streptococeique, les injections de sérun de Marmorek ont donné quelques résultats posilifs.

Dans la scarlatine, l’angine streptococeiqur disparait et l’élat góné-

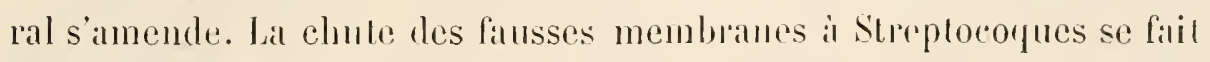
aussi vite que celle de l'exsudat diphléripue sous l’influence alu sévinu de lionx.

Vlarnorek ef houx ont mème immunisé contre le Streptocoque afin d'obtenir un sérum domblement actil des chevanx déjä immunisés contre le bacille de Löfler. Les phlegmons dillus ì Streptocoques s'allinissent el se résorbent quand il n'y a pas de pus collecto. S’il existe un foger purulent, il faut l'ourrir ot il se tarit immidiatement. Le sírum de Varmorek serait entin indiqur dams beaucoup de complicalions post-opéraloires, celles an moins or lestreptocorpe pyogène se tromre ètre le seul agent inlectieux. 


\section{L'ANASARQUE INFEGTIEUSE DU CHEVAL}

\section{ACTION CCRATIVE DU SÉRUN DE MARMOREK}

On a domné le nom d'anasarque active ou essentielle du cheval (fièvre pétíchiale des Allemands) à une affection presque toujours mortelle rt caractérisée par l'apparition de tumeurs œedémateuses à marche rapide et progressive au niveau des membres ou de la partie inférieure de la tète.

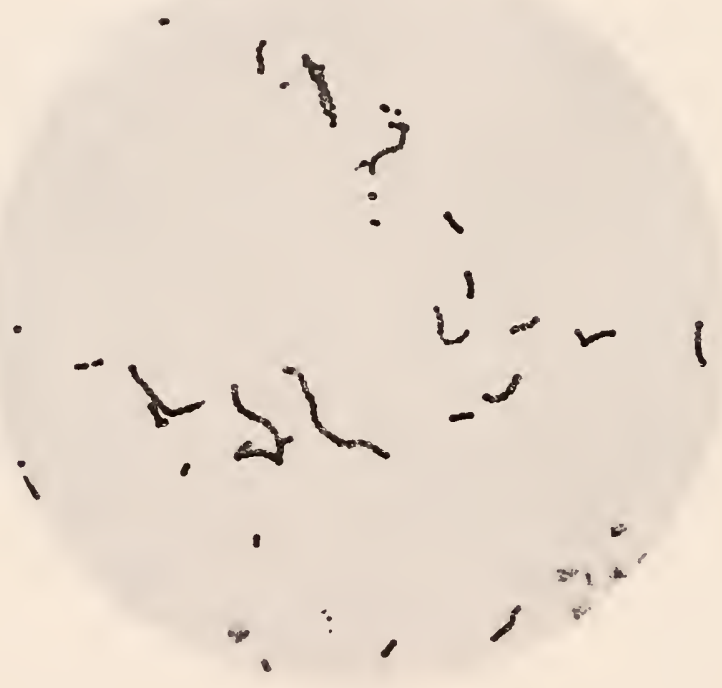

FIg. 518.

Streptocoine de l'anasarque du cheval. (Gr. 1000 diam.)

L’anasarque aiguë peut ètre secondaire et survenir au cours de maladies infectieuses, telles que la gourme, la morve, les suppurations traumaliques ou viscérales; dans d'atutres cas au contraire, celte affection évolue en dehors de toute lésion antérieure el survient inopinément.

Lignières, étudiant l'éliologie d'une série de cas graves d'anasárque aiguë et rapidement mortelle, isoliı par diverses méthodes, du sang et des viscires, un Streptocoque identique au Streptocoque de Rosenbach et Vehleisen. 
Lignicres ent l'idée d'éludier d'abord chè les animanx imoculés, puis elez le cheval, l'action immunisante et curalive du sérom de Marmorek.

Tes expériences furent eomronnées d'un plein succis. Chez lat somris, l'injection du sćrum de Harmorek prévient les accidents habilnellement mortels de l'inocilation du Streptocoque de l'anasirepue du chevat. Le mème sérum est au contraire sans action contre l’infection par le Streptocoque de la gourne de Schulz; il en est de même chez le cheval.

lignières a démontré par une longue série d’expérienees que l’anitsarque infectieuse, traitée à temps par les injections du sérum de 1/armorek, amène une prompte déferreseence.

Des animaux atteints de tumeurs cedémateuses unultiples et présentant des pétéchies hémorrhagiques de la muqueuse pituitaire, avec jetage sanguinolent, avé température de 40 degrés, dyspuće et prostration, ont été guéris en quelques jours.

La mortalité considérable de l'anasarque est réduite dans des proportions presque inespérées. Le rétablissement complet et la remisc: au travail suivent de quelques jours le début du traitement.

Ces résultats thérapeutiques prouvent qu'il y a une grande analogic, sinon parfaite identité, entre le Streptocoque de l'anasarqua ef le Streptocoque de l'érysipèle de l'homme.

L'activité remarquable du sérum de Marmorek contre l’infectiou streptococeique du cheval, où il se montre plus efficace peut-ètre que ehez l'homme, est vaisemblablement en rapport arec l'origine équine du liquide actif.

Les résultats acquis sont donc aujourd'hui suffisants pour que la préparation en grand du sérum de Marmorek s'imp̣ose désormais comme la préparaion des sérums anlitétanique et antịdiphtérique. 


\section{STREPTOCOCGUS HOMINIS GRASSUS}

Nous avous observé à diverses reprises un Streplocoque particulier qui se distingue du Streplocoque pyogène commun par des caractères dilfëreutiels constants.

Ce Streplocoque, très analogue au premier sur les préparations colorées et dans les cultures sur le bouillon, ne liquéfie pas la gélatine

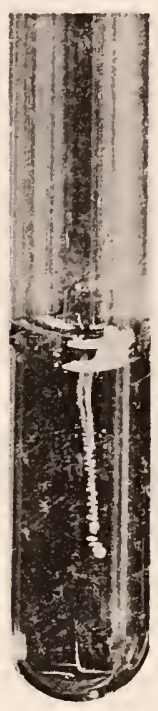

FIG. วิเง.

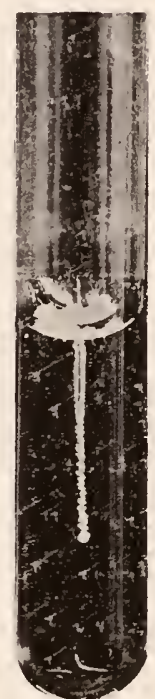

Fic. 520.

Streplococcus pyogenes Crassis. Culture sur gélatine.

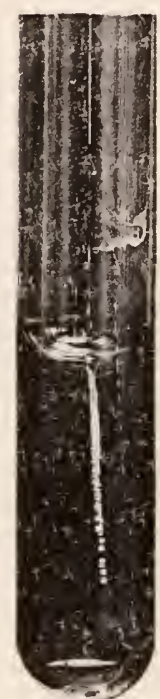

Fic. 521 .

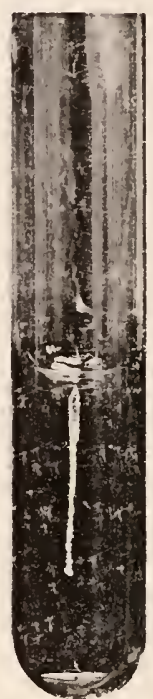

Fig. 522.
Streptococcus pyogenes Communis. Cullure sur gélatine.

et s'y développe le iong de la piqûre sous forme cl'une trainée plus épaisse que celle du Streptocoque pyogène. Quand l'aiguille a ćté essuyée dans un premier tube, il se produit dans le second mue chaine de petites colonies sphériques ou lenticulaires un peú plus volumineuses, et sans execption la culture s'étend à la surface du lube sous forme d'un bouton aplati de phusieurs millimètres de diamètre.

Cette parlicularité ne s'observe janais pour le Streptocoque d'Ogston, Rosenhach el Fehleisen, qui se déreloppe exclusivement, après ensemencentent par piquire, le long du passage de l'aiguille. 
Sur l'agar la colonie est tonjours plus grasse et plus large que celle du Streptocoque de Rosenbich.

Un antre caractire diflérentiel constant est ce fait que les cultures de notre Streptocoque peuvent ère frausplautíes au bout d'un an et plus, parfaitement vivaces, d'un vieux tulbe de gélose desscéché sur un tube nourellement prépare, tandis que dans les mêmes conditions et sur le mème milieu, au bout de deux mois à deux mois el demi seulement, le Streptocoque pyogene de Rosenbach demeure infertile a moins qu'on ne prenne, à l'exemple de Marmorek, la précaution de

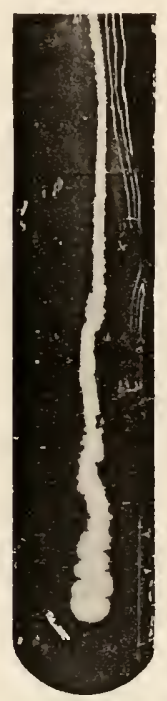

Fig. 523.

Streptococcus pyogenes Crassus. Culture sur agar.

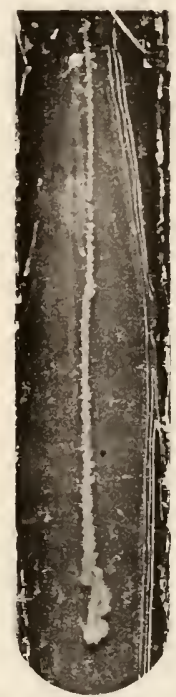

Fic. 525.

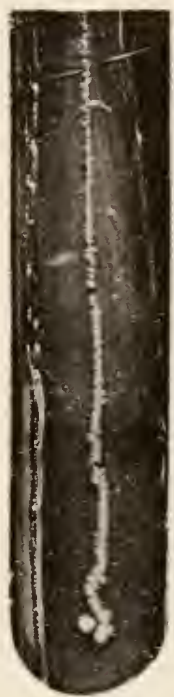

Fig. 526.
Streptococcus pyogenes Communis. Culture sur agar.

revivifier la vieille culture en versant à sa surface un peu de sérum humain additionné de bouillon.

Nous arons rencontré le Streptocoque que nous décrivons ici dans divers cas de phlegmons sous-cutanés, dans un kyste de l'ovatire suppuré, et dans trois cas d'accidents puerpéraux à marche lenle qui ont déterminé la mort au bout de quatre à cinq senaines, en dépit d'une désinfection utérine aussi parfaite que possible et sans trace de piritonite purulente. Nous conservons depuis 7 a 8 ans toute notre série de cultures absolument vivaces. 


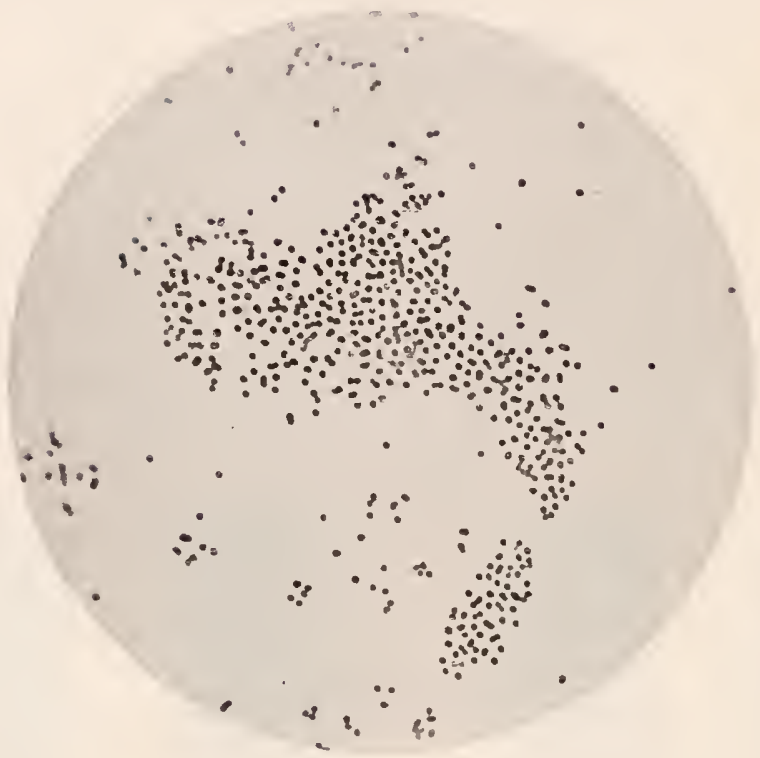

FIG. 527.

Streplococeus pyogenes crassus. (Culture sur agar). (Gr. 1000 dian.)

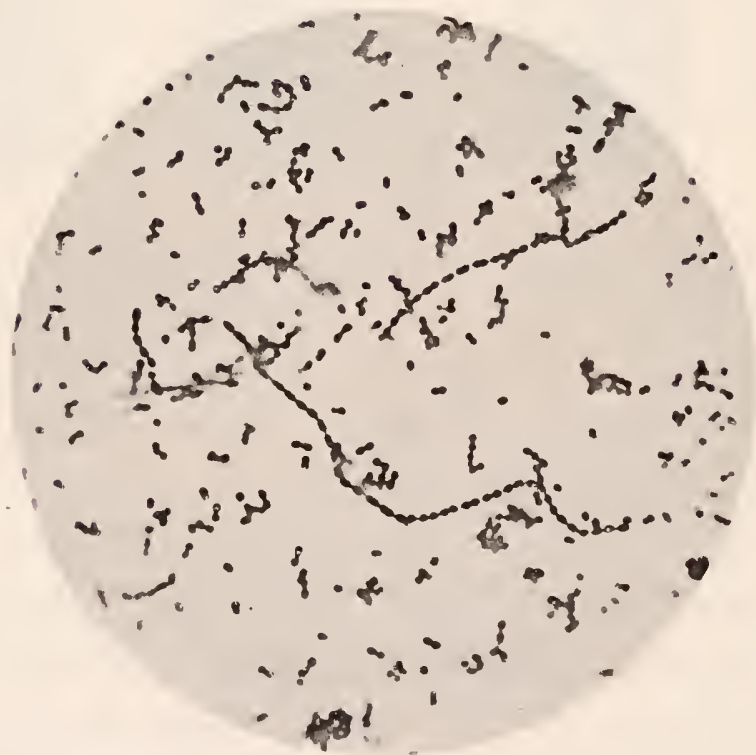

Fic. วิ28.

Striptococcus myogenes crassus. (Culture sur bouillon). (Gr. 1000 diam.) 
L'inoculation de eultures virulentes à l'oreille du lapin, que nous avons pratiquée parallèlement ì l’inculation du Streptocoque progène provenant d'abè̀s, de fiève puerpérale, ou d'érşsipile n’a jamais déterminé de rougeur érỵsipélateuse, mais un simple abeès.

Cs Streprocoque est donc capable au inème titre que le Streptocoque pyogène de déterminer la suppuration locale simple, la septicémic ou la pyohémie, mais ne présente aucun rapport avec l’érysipèle.

\section{STREPTOGOGGUS HOMINIS LIQUEFAGIENS}

Au cours de nos recherches sur la pyogenèse et la fièvre puerpérale nous avons isolé dans un cas de septicémie post partum à marche lente

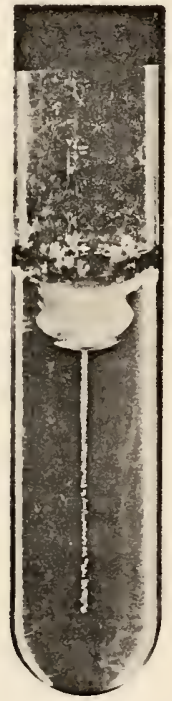

Fig. 529.

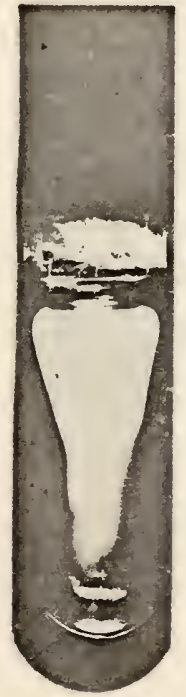

Fig. 530.

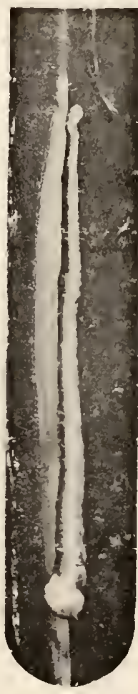

Fig. 531.

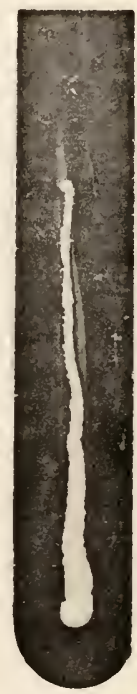

FIG. 552 .

Streptococcus pyogenes liquefaciens. (Culture sur gélatine.)

Streptococcus pyogenes liquefaciens. (Culture sur agar.)

et mortelle un Streptocoque identique au précédent par ses cultures sur l'agar, mais qui liquéfie la gélatine aussi vite que le Staphylocoque blanc ou doré.

Les cultures sur agar comme sur gélatine sont incolores. Cette liquéfartion rapide de la gélatine nous a causé au début quelque étonncment et nous avons cru nos cultures impures. Après une súrie de 
rechicrches méthodiques au cours desquelles nous avons rencontré une seconde fois le même microbe, nous avons pu le déterminer nettement comme un streptocoque pathogène pour l'homme el liquéfiant la gélatine.

Les proprictés pathogines du Streptocorcus lequefaciens sont idenliques il celles du Streplococus pyogenes rrassus.

Cies sireplocoques, le sitreplncoccus hominis crassus el le Streptococcus heminis liquefaciens, seront d'ici peu l'objet d'une série de

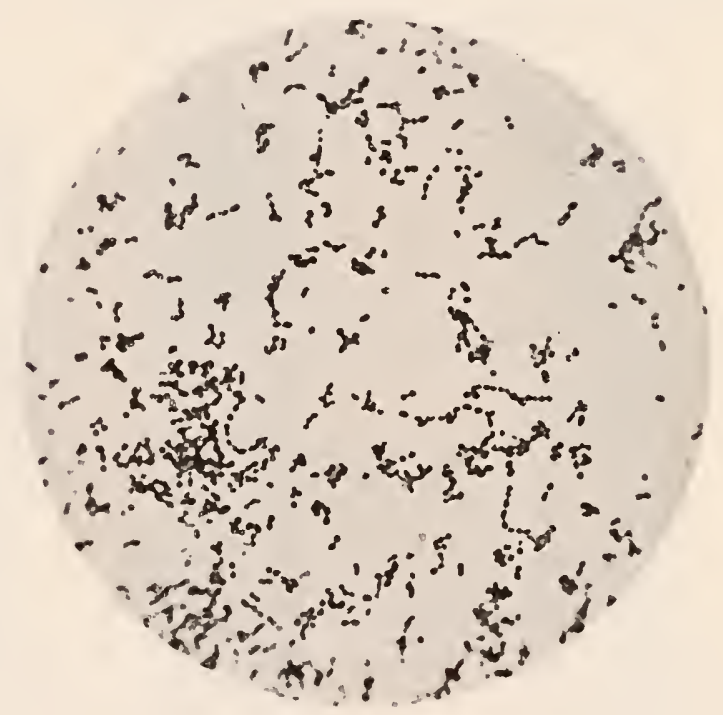

Fic. $55 \%$.

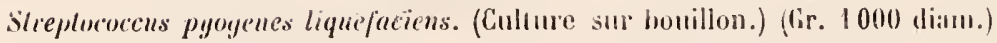

reeherehes expérimentales. Nous arous vo que leur iunoculation it

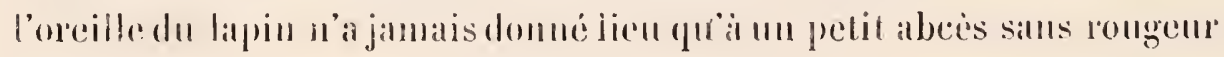
sprsipidallolsse.

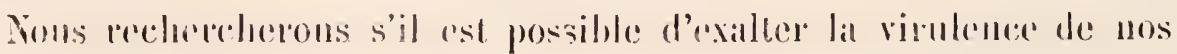

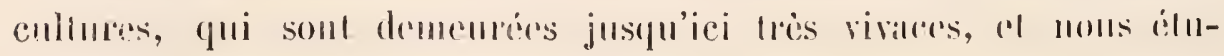
dierous chez les animan inoculés l'aclion du sérum de Marmorek. 


\section{STREPTOGOQUE DE L'IMPÉTIGO}

Leroux (189) a déerit dans l'impéligo un Streptocoque qui parait otre cartactéristique de celte allection éminemment contagiense,

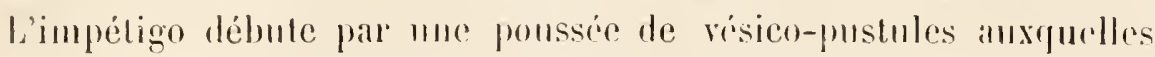
suceident des crontes jaunitres, mellithentes ou verdilres, qui recouvrent bientòt les téguments atteints.

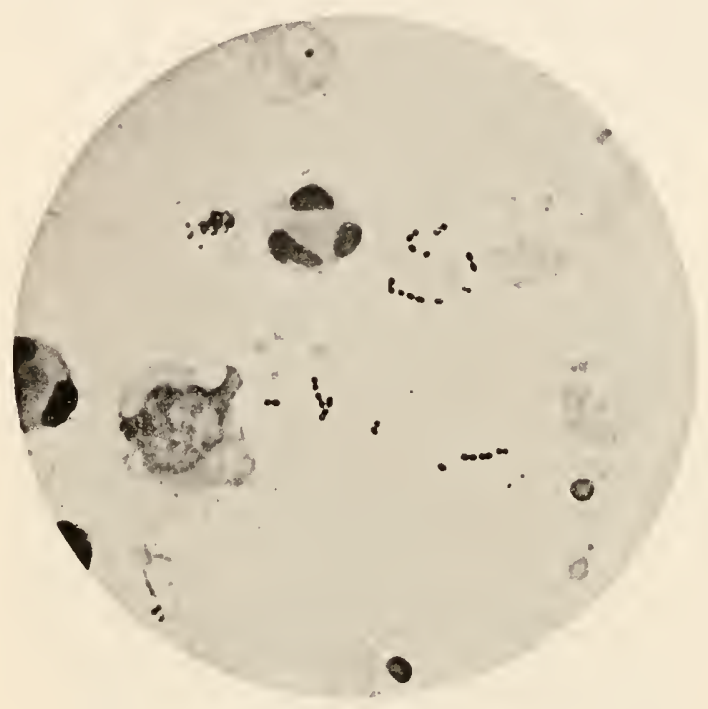

Fig. 554 .

Inpétigo. - Liquide d'une vésicule récente (Leroux). (fir. 1000 dian.)

Il existe souvent mo zone intlammatoire ronge à la périphérie. Le lerme est tumcitie et les ganglions voisins engorgís et doulomreux.

Limpéligo prut présenter une tendauce à la chronicité el se montrer tris rebelle.

la démonstration clinique de la contagiosité de l’impétigo est depuis longtemps acquise. En raison de la bénignité de l’affection, le lor leroux a tenté de nounbrenses expéricues d'inoculations soit simples, soit en séries. Lies inncublations ont áté presque tontes snivies le sulceis. 


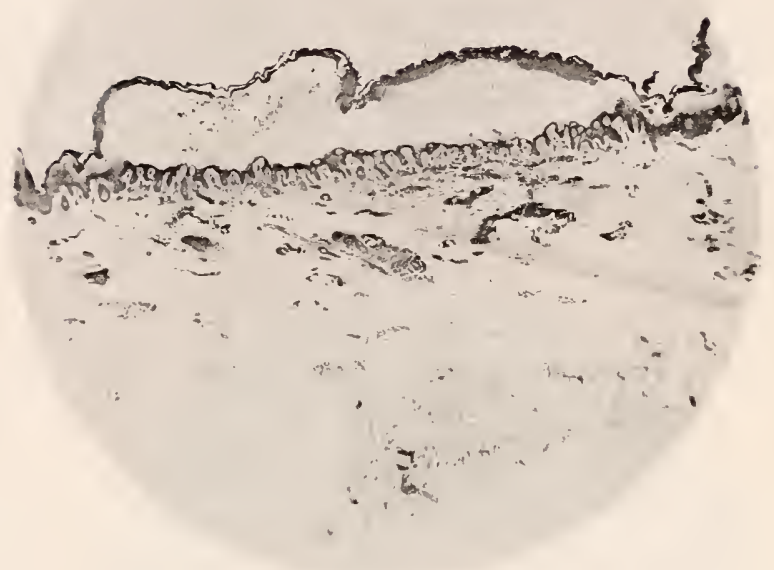

Fig. 555.

Variole. Vésicule jeune. (Gr. 8 diam.)

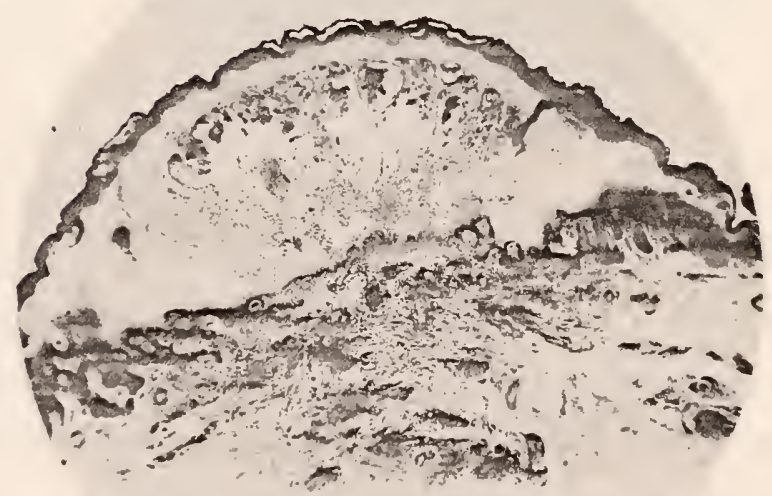

FIG. 536 .

Variole. Jébut de la période de suppuration. Le derme est envalii. (Gr. 20 diam.) 
L'examen bactériologique des croùtes et du liquide sous-jacent domne le plus souvent des cultures de Staphylocoques et des autres microbes fréquents a la surface de la peau.

I.e Staphylocoque doré prédomine habituellement et l'on observe de très rares chainettes. Leroux a eı l'excellente idée de pratiquer ces recherches sur les sujets atteints d'impétigo expérimental et avant la rupture de la vésicule. A ce moment on observe de nombreux diplocoques réunis ou non en chainettes.

Nous représentonis fig. 553 et 556 le mode de formation des vésicopustules cutancies. Nous avous pris pour type des pièces provenant d'un eas de variole.

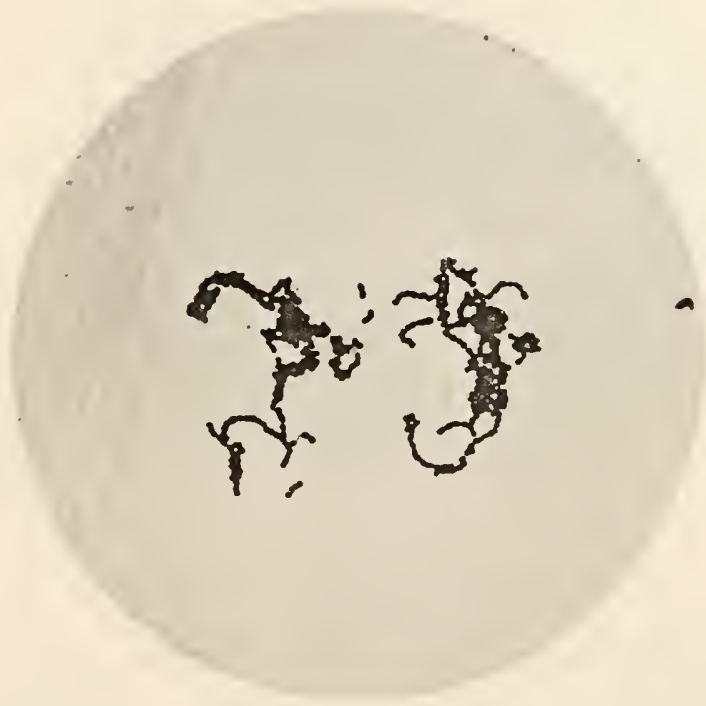

Fig. 557.

Streptocoque de l'mpétigo. Ciulture sur bouillon (Leroux). (Gr. 1000 diam.)

Si l'on ensemence ce liquide dauns des milieux appropriés, il se forme sur la gélatine, le long de la piquire, des colonies ponctuées analogues à celles du streptocoque pyogène, sur l'agar des coloniés fines en forme de trèfle, et lans le bouillon des chaincttes de longueur varialble. 
Sur quinze inoculations faites avec des cultures récentes, Leroux a obtenu qualre fois des résultats positifs pouvant se reproduire en séries. Il a observé le.mène mierobe dans l'impétigo secondaire des enfants, c'ust-it-lire an nirean des iruptions discrites ou confluentes qui se produisent sur le cou, les épaules ou les fesses par graltage. On troure en grinéral dans cos rígions la trate des ongles. Ces enfants présentent fréquemmont a l'extrémité des doigts des tomrnioles qui peuvent ahoutir a lat chute de l'ongle.

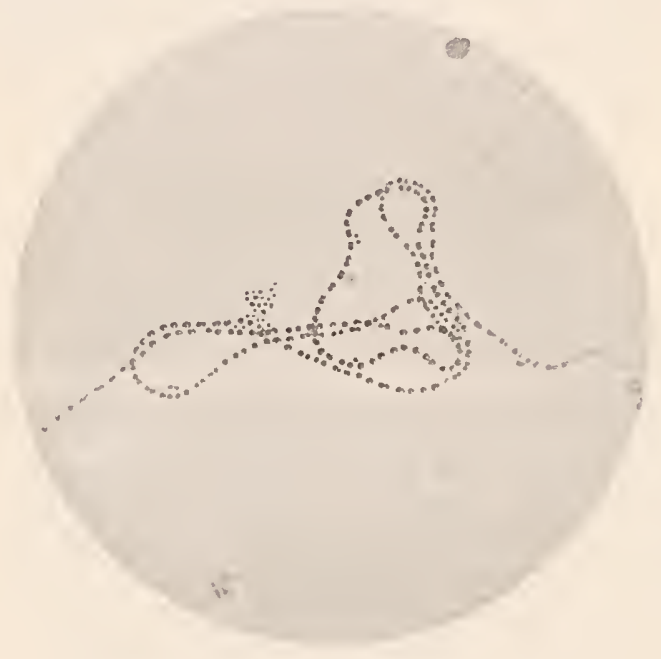

Fig. $5 \overline{8} 8$.

lmpéligo. Culture sur bouillon (Leroux). Longue chainetle. (Gr. 1000 diam.)

Il peut se produire d'autres manifestations corollaires : conjonctivite purulemle, kiratite, vulvite et stomatite impétigineuse, celte dernière olserve par Bergeron, Comby, Serestre et calactérisée par la coüncidence dr aroùles fondillées d’impéligo sur la face exposér des lèvres ou des commissures aree des pseudo-membranes diphteroüdes superficielies sur leur face interne ot la mugucuse bucale.

Les aténites profondes du con et les adéno-phlegmons en sont la conséquence fréquente. Lammelongne a décrit des cas d’ostéomyélite survenus chez des enfauts atteints de gourme. 


\section{ASSOCIATION D'UN STREPTOCOQUE}

\section{ET DE LA BACTÉRIDIE CHARBONNEUSE}

C'est unt Streptocoque antalogue qui a été décrit sons la dénomination bizarre de microbe de la soplicémie conséculive au chanbon. Nous arons en eflet conslaté en 1884, dims des cultures de charbon qui nous avaient été domnées conme pures, mne végétation de vitreptoeoques pyogines ì còté des bactéridies charbonnenses.

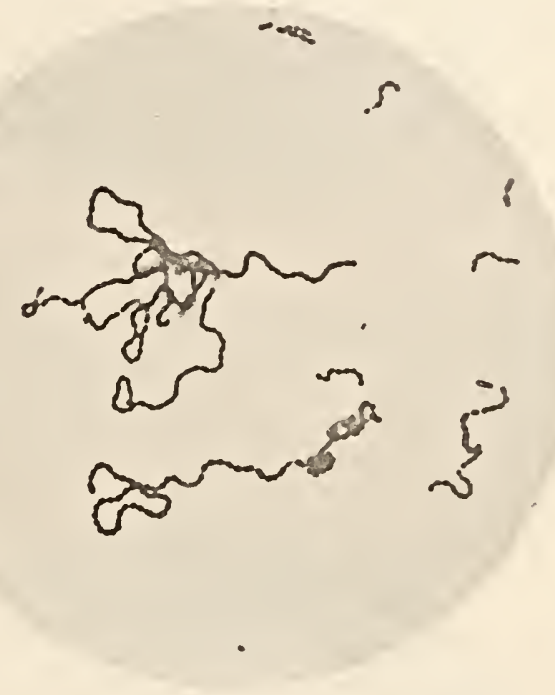

Fig. 55!.

Streplocoques et bactéridies associés dans une culture impure. (Gr. 800 dian.)

Sur les carlarres de lapins inoculés arec ces cultures impures, les Streptocoques seuls se montrent virulents si l'autopsie est faite un cerlain temps après la mort.

Nous avons rencontré plus tard le nème Streptocoque dans un raccin impur. Il se développe dans le bonillon charbonneux virulent ou vaccinal, sims en altérer sensiblement la transpinence. Cette assuciation microbieme pourrail expliquer certains cas de mort apres vaccination anticharbonneuse. 


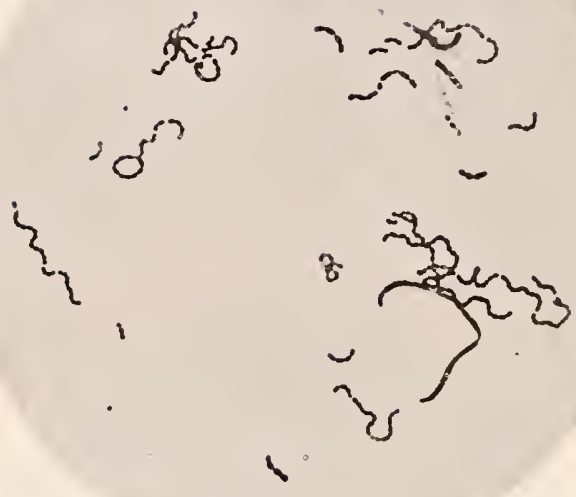

F1G. 540.

Streptocoques et bactéridies associés dans un vaccin impur. (Gir. 800 diam.)

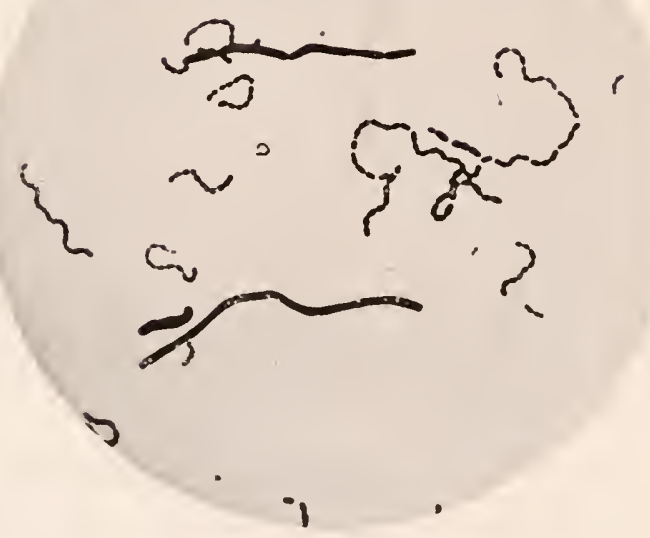

Fig. 541.

Streptocoques d'une culture impure de Charbon sur bonillon. (Gr. 1000 (liam.) 
Le Streptocoque que nous venons de décrire comme observation mierobienne avec la bactéridie charbonneuse, nous parait analogue au Streptococcus pyoyenes crassus. Son action pathogène sur le lapin l'en rapproche tout particulièrement. Nous pouvons donc dès lors affirmer qu'il existe au moins trois types distincts de Streptocoques pathogènes pour l'homme.

$1^{\circ}$ Le Streptocoque d'Ogston, Rosenbach et Fehleisen, que l'on pourrait nommer, à eause de sa fréquence, Streptococcus communis. Ce Streptocoque est l'agent pathogène de l'anasarque du cheval.

$2^{\circ}$ Le Streptococcus hominis major ou crassus, d'un diamètre un peu plus considérable et dont les cultures sont plus luxuriantes.

$5^{\circ}$ Le Streptococcus hominis liquefaciens, identique au second, en stries sur l'agar-agar, mais jouissant de la propriété de liquéfier rapidement la gélatine. 



\section{TABLE DES IATIERES}

P'RÉFick.

\section{IIGOHIVElEs}

Pliycomyces nilms . . . . . . . . . . . . . . . . . . 8

Mucor spinosus . . . . . . . . . . . . . . . . . . 10

Mncor racemosus . . . . . . . . . . . . . . . . . . . 11

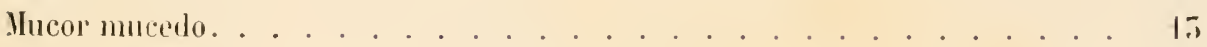

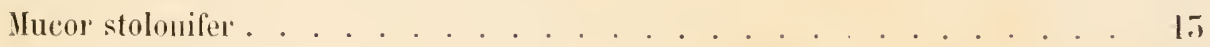

Thamnidium elegans. . . . . . . . . . . . . . . . . . 16

Propriélés biologiques des mucorinèes. . . . . . . . . . 18

\section{MOLSESURE}

Ispergillus niger. . . . . . . . . . . . . . . . . . . . . . . . . 19

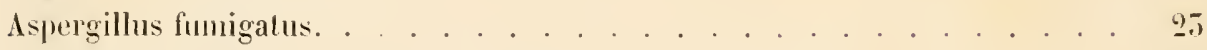

Aspergillus orizie. . . . . . . . . . . . . . . . . . . . . . . . . 93

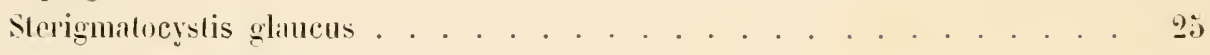

Propriétés biologiques des aspergillıs. . . . . . . . . . . 27

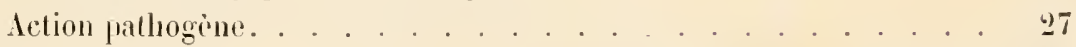

Penicillum. . . . . . . . . . . . . . . . . . . . 51

l'roprictés biolugignes des penicillum. . . . . . . . . . . 55

MYCOSES EXTERIE WE L IIOUME ET IES I MUAT

Trichophylies, Favus, Pityriasis versicolore, Erylumsma . . . . . . . . . Ji

LES TELINES

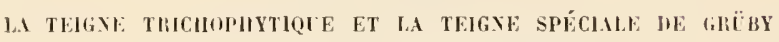

\section{LES TRICHOPHYTIES}

$I^{\circ}$ Influence de la composition chimique du milieu de culture sur la forme des cultures eryplogamiques . . . . . . . . . . . . . . . 59

20 Les associations eryplogamiques dans les lrichophlylies. . . . 42

Les trichophyties diorigine humaine. . . . . . . . . . . . . . . 14

Les trichophyties animales transporties sur l'lonnme. . . . . . . . . . of

Les trichophyties de la barbe. . . . . . . . . . . . . . . . . . . . lis

Les trichophyties exotiques. . . . . . . . . . . . . . . . . 70

Étude mycologique des Trichophytons. . . . . . . . . . . . . . . . 75

Taxonomie des Trichopliytons. Les Botrvlis... . . . . ... . . . . . . 78

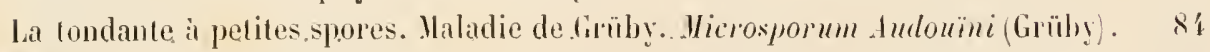

Mycologie. Taxomonie . . . . . . . . . . . . . . . . . . . . 901

\section{LA TEIGNE FA VEUSE}

Lidchorion Schenleinii . . . . . . . . . . . . . . . 96

fo Associations eryploganique's. . . . . . . . . . . . . 101

2. Variétés de Favus. . . . . . . . . . . . . 100 
Ö̈dium lactis

Action biologique

\section{BEGGIATOA OU SULFURAIRES}

Beggiatoa Ramiana.

Beggiatoa alba.

Propriétés biologiques

Propriétés biologiques.

Propriétés biologiques.

\section{STREPTOTRIX}

Streptotrix allat

Streptotrix nigra.

Streptotrix violacea.

Streptotrix albido llava

Propriétés biologiques.

Action pathogène.

ACTINOMYCOSE. . . . . . . . 156

Actinomycose du beruf. . . . . . . . . . . . . . . . . 140

Actinonyeose de l'homme. . . . . . . . . . . . . . . 150

Cullures de l'Actinomyces . . . . . . . . . . . . . . 156

Associations cryploganiques de lactinomycose . . . . . . . . . . . 160

Nonveau cas d'infection mixte (Actinomyces et Leptotrix). . . . . . . . . 165

Inoculation aux aninaux. . . . . . . . . . . . . . . . 168

FARGIN DU BCEUF. . . . . . . . 170

Action pathogène . . . . . . . . . . . . . . . . 174

PIED DE MADURA. . . . . . . 176

LES LEVIRES

Sacharonycètes. Torulas. Hycodemes . . . . . . . . . . 18.4

Fermentation alconlique. . . . . . . . . . . . . . . . 185

\section{IEVTRES VRIIES SICCHMOUMCETES}

LEVURES DE BIÈRE. . . . . . . . . 192

labrication de la bière . . . . . . . . . . . . . [92

I. Sacharification............... . . 192

II. Fermentation. . . . . . . . . . . . . 194

Levures de maladic. . . . . . . . . . . . . . . 200

Sporulation . . . . . . . . . . . . . . . 201

Formalion des voiles. . . . . . . . . . . . . . . 20)

Noyaux et réseaux gélatineux: . . . . . . . . . . . . . 211

LEVURES DE VIN. . . . . . . 212

LEVURES DE GIDRE. . . . . . . 217 
LEVURES DE DISTILLERIE.

LEVURES DE BOULANGERIE.

SACCIAROHCETES VUN INUUSTRIELS.

Saccharomyces anomilus .

LEWTRES NE MONNANT PIS WE SMMES.

TORULAS.

Torula Albil.

Torula B:

250

Torula C (Torula Rosea).

2.1

Torula nigra.

MYCODERMES.

22.1

MONILIA CANDIDA. . . . . . . . . . 257

Propriétés biologiques

Proprietes liologiques.

Suppuration sans microbes

\section{ST APH YLOGOQUES}

Staphylocoque doré. . . . . . . . . . . . . . . . . . . 266

Préparations colorées. . . . . . . . . . . . . . . 267

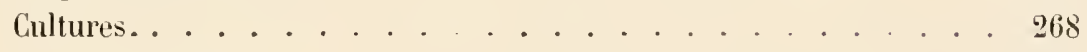

Action pathogène . . . . . . . . . . . . . . 272

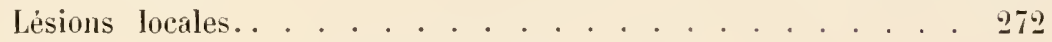

Infection générale légère. Lymphangite et tiève. . . . . . . 275

Infection générale grave. Ostéonyélite infectieuse. . . . . . . 973

Infection purulente. . . . . . . . . . . . . . . 276

Localisations du Staphylocoque daus les cas mortels.. . . . . . . 277

Inoculation aux antmaux . . . . . . . . . . . . . . 278

Néphrite ascendante à Staphlylocoques. . . . . . . . . . . . 979

Phlébite des sinus de la dure-mère. . . . . . . . . . . . . . . 284

Spécificité microbienne de certaines lésions typinues. . . . . . . 285

Inmmunite contre le staphylocoque doré . . . . . . . . . . . 985

Nicrobe du clou de Biskra. . . . . . . . . . . . . . . . . . . 286

Staphylocoque blanc . . . . . . . . . . . . . . . . . . . 287

Staphylococcus citreus . . . . . . . . . . . . . . . . . . 289

Staphylococcus cereus albus et flaxus. . . . . . . . . . . . . . . . 290

MICROBE DE L'ARAIGNÉE

Hammite gangréneuse des brebis laitières . . . . . . . . . . 292

MHCROCOQUES NON PATHOGẼNES

Micrococcus candicans ................ . . 295

Mierococeus rugosus vlearius . . . . . . . . . . . . . . . 296 
Micrococens versicolore. . . . . . . . . . . . . . . 297

Vicrococens aquatilis . . . . . . . . . . . . . . . . . . 298

Hicrococcus roseus (llügge). . . . . . . . . . . . . . . . . . . . 298

Micrococcus Iuteus. . . . . . . . . . . . . . . . . . . . . 298

Micrococcus flavus desidens . . . . . . . . . . . . . . 99!

Jicrococens flavus oleirius . . . . . . . . . . . . . . . . . . 299

Hicrococens flavas liquefaciens. . . . . . . . . . . . . . . . . . 500

Micrococcus anrantiacus. . . . . . . . . . . . . . . . . 510

Micrococcus fulvus (Cohu). . . . . . . . . . . . . . . 300

Micrococeus ruber agilis . . . . . . . . . . . . . . . . 501

Micrococcus citreus agilis. . . . . . . . . . . . . . . . . 50 J

INFECTION BLENNORRHAGIQUE

Gonocoque . . . . . . . . . . . 504

HÉMOGLOBINURIE BACTÉRIENNE DU BCEUF. . . 引l STREPTOCOQUES

Streptocorpe pyogène . . . . . . . . . . . . . . . 5lt

Examen du pus . . . . . . . . . . . . . . . . . . . . . . . 516

Cultures . . . . . . . . . . . . . . 518

Ietion pathogine . . . . . . . . . . . . . . . 519

L. FIETRE PUER'ERMLE ET L'ERTSIPÈLE

1. La Fièvre puerpérale.

Anatomic pathologifue

\section{3. - F apports entre la fièvre puerpérale, les abcès ì Streptocoques et l'érysipèle.}

Étude baclériologigue et expérimentile . . . . . . . . . . . . . . . .ez

Eifude clinique de linfection streptococcipue. . . . . . . . . . . . . 55̃

1. - Suppuration simple... . . . . . . . . . . . . . $5 \overline{\text { s. }}$

B. - Supntration avec rougent érysipélatense . . . . . . . . . . 555

C. - Erysipète simple . . . . . . . . . . . . . . . . . . . . . . 550

1). - Érysipèle greffe sur me ploie suppuramle. . . . . . . . . . . . 557

E. - Erysipèle suivi de suppuration secondaire. . . . . . . . . . . . 557

I. - Fierre puerpérale. . . . . . . . . . . . . . . . . . 559

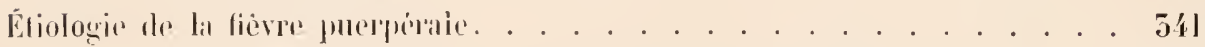

Durée de vinulence des objets contaminés par le streplocoque . . . . 5.15

Phlebites it streptoconues. . . . . . . . . . . . . 546

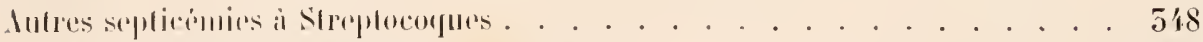

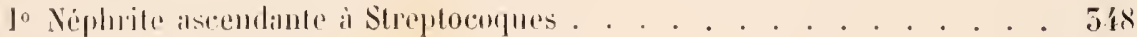

20 lugine de ludwig. . . . . . . . . . . . . . . 5 . . . . . . . . . . . . .

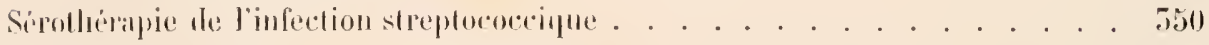

Streplococcus hominis crassus. . . . . . . . . . . . . . . Tint

Streptocoecus hominis lingefaciens . . . . . . . . . . . . . . . 5id?

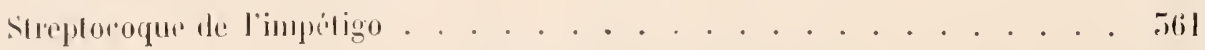

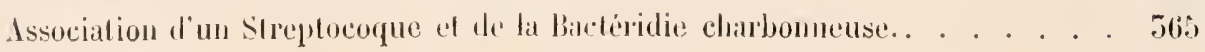




\section{TABLE IIES FIGURES}

\section{MUCOLINEES}

Pis. I Phycomyes milens (grandeur naturelle). . . . . . . . . . 8

2 Sporanges de Rhygemyees nitens (gr. d0 dian.). . . . . . . . . . 9 9

5 Sporange de Phycomyces nitens (gr. 180 dian.). . . . . . . . . 9

4 Spores de Phyromyer's miterns (gr. 400 diant.). . . . . . . . . 10

5 Colonie de Hneor spinosus (gr. 20 diam.). . . . . . . . . . . 10

6 Sinoranges de Vucor spinosus (gr. 150 dianı.). . . . . . . . . . 11

7 Sporange jeune de Hucor spinosus (gr. for) dian.). . . . . . . . I2

\& Sporinges de Vucor racemosus (gr. 200 diam.). . . . . . . . . 16

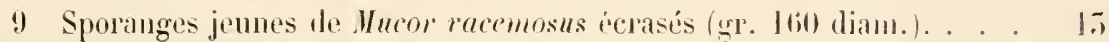

10) Hucor mue do (gr. 160 diant.). . . . . . . . . . . . . 1'

11 Rhisopus nigricuns (Hucor stolonifer) (gr.. diann.). . . . . . . . I'

12 Ciroupe de Hucor stolonifer (gr. 1: diam.). . . . . . . . . . lis

1.5 Déhiscence de Mucor stolonifer (gr. 200 diam.). . . . . . . . . 15

14 Thamnilinn elegans (gr. 70 dian.). . . . . . . . . . . . . . . 16

15 Groupe de Thamnidium elegans (gr. 70 diam.). . . . . . . . . 17

li Sporangiole de Thamuidium elegans (gr. 100 diam.). . . . . . . . 17

17 Sporangiole de Thamnidium eleyans (gr. 180 dian.). . . . . . . . I8

\section{OISISSIRES}

\section{ASPERGILLUS}

I8 Ciemination des spores de l'Asperyillus myer (gr. 250 dian.). . . I9

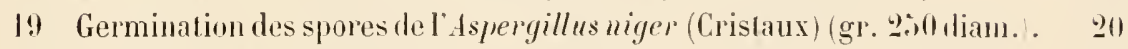

20 Colonie d'Aspergillus niger (gr. 7 dianr.). . . . . . . . . 20

21 Aspergillus niger à diver's degrés de maturité (gr. 200 dian.). . . . -

2.2 Aspergillus niger. Sterigmates principaux (gr. 3is) diam.). . . . . 21

9-) Aspergillus niger. Sterigmates secombires (gr. 400 diam.). . . . . 29

24 Aspergillus niger. Naissance des spores (gr. 800 dianr.). . . . . . 29

25 Aspergillus fumigatus (gr. 1000 diam.). . . . . . . . . . . פ.

26. Aspergillus orize (ar 1000 diann.). . . . . . . . . . . y4

27 Structure diun stérigmatorvste (gr. 1000 diam.). . . . . . . . 29

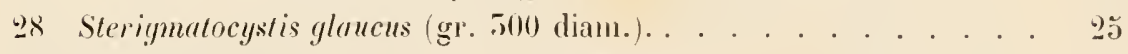

29) Sterigmatocystis glaucus (gr. 180 diam.). . . . . . . . . . . . 26

50) Sterigmatocystis glancus (gr. iiso diam.). . . . . . . . . . . . 20

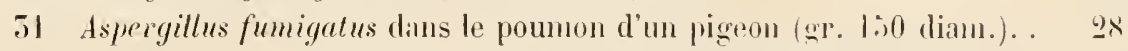

52. Alvéole pulnonaire du canard (dspergillus fumigalus) (gr. 2.)0 dian.).

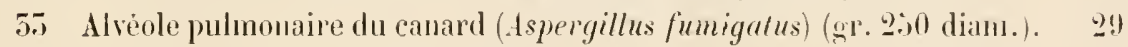

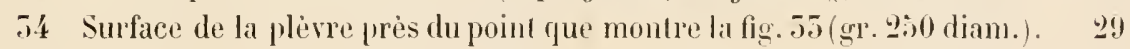


Fıg. 5i. Tuberculepulmonaire du pigeon (Aspergillus fumigatus) (gr. 800 diam.). $\quad \begin{aligned} & \text { Pages. } \\ & \mathbf{5 0}\end{aligned}$

56 Tubercule pulmonaire du pigeon (Aspergillus fumigatus) (gr. 800 diam.). $\quad 50$

\section{PENIGILLUM}

57 Colonies de Penicillum ylaucum sur agar-agar (grandeur naturelle). .

58 Groupe de pinceanx fructifères du Penicillnu glaucum (gr. 200 diam.).. 31

59 Penicillum glaucum. Détail des organes de fruclification. . . . . .

40 Penicillnm glaucum. Pinceaux fructifères (gr. 500 diam.). . . . .

\section{LES TEIGIES \\ LES TRICHOPHYTIES}

MHLIXX HE COLTLRE. - COMMENSALISME

41 et 12 Trichophyton d'origine humaine, culture adulte ( 1 mois) sur le milieu de la formule $\mathrm{N}^{0} \mathrm{l}$. . . . . . . . . . .

45, 44 of 45 Vême espèce que fig. Al et 42 , cultures adultes. Milieu

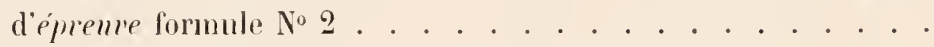

46,77 et 48 llême espèce rne fig. $41,42,45$, ete. cullures adultes. Milieu

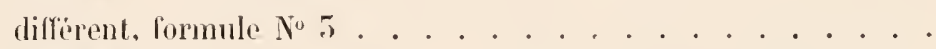

49, 50 et ذا Variations de formes d'une même espèce trichophytique suivant le milieu de culture . . . . . . . . . . . .

52 et $\mathrm{i}$ Commensalisme parasitaire dans les culıures trichoplıytiques. Colonies isolies. . . . . . . . . . . . . . . . 42

54 duxtaposition totale dn Trichophyton et de son commensal . . . . 42

5.) Le même Trichophyton séparé de son commensal. . . . . . . . . 42

si et 57 Henx commensanx du Trichophyton lans sa lísion. . . . . . 4.5

is, 59, 60 ef 61 thenx antres commensaux des Trichophytons dans leur lésion. Les fig. ¿8-ă! et (\$0-61) représentent deux à deux le même champignon .

62 Commensal ayant pris la place d'un Trichophyton dans la culture Irichophylique primilive (gr. 200 diam.) .

6.) Commensal ayant pris la place d'un Trichophyton dans la cullure trichophylique primilive (gr. 400 diam.) . . . . . . . .

TRMHOHIYTIES H'ORGIM: HUM.MNE

6' Forme de Trichophylon dans le cheven (chaine mycélienne sporulée) (gr. 1000 dianı.). . . . . . . . . . . . . . .

6.) Trichophylon endolhrix dans le cheren de la teigne tondante (gr. loil diam.). . . . . . . . . . . . . . 45

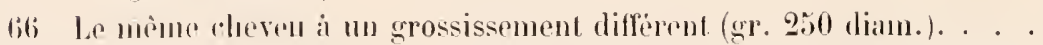

6i Cheven trichophytipue. Les filaments du parasite sont plus distinels pres du boril meme du cheveu (gr. 200 diam.) . . . . . . . . 46

bs Trichophytou ondothrix, cheven complitement ouvahi (gr. 280 diam.).

69) Choven dissocio par laclion de la polasse. Les filanents mycéliens Jestent entiers (gr. 280 diam.) . . . . . . . . . . . .

70 Mise en liberte dn Trichophyton par la complete dissolution du cheren (gr. 280 diam.) . . . . . . . . . . . . . 48

il Même préparation (gr. 1000 liam.). . . . . . . . . 48 
Frg. 72 Culture direros sur mont de biere d'un cluven alteint de Trichophylon emdolhrier a m.grélimm resistaml . . . . . . . . . . . . . . 19

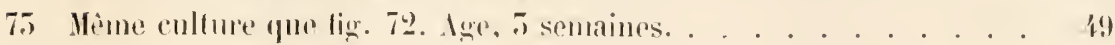

7' Mème collure que fig. 72. Ige, 亿 semanos. . . . . . . . . . 49

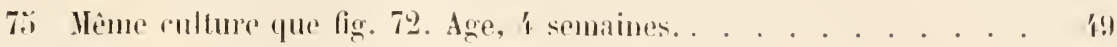

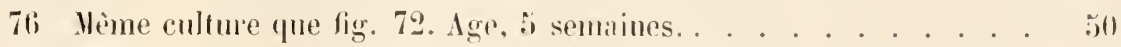

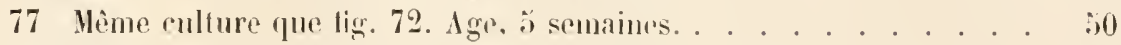

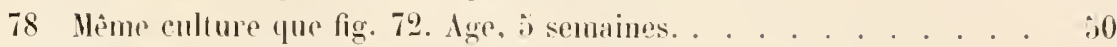

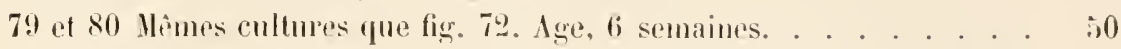

81.82 et 85 llimes cultures trichophytipues portées sur milieu d'épreuve. (cullumes cratériformes) à comparer amx cultures du T. à mycolium

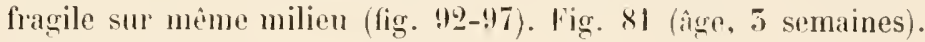
fíg. 82 et 8.5 (àge 4 et 5 semaines). . . . . . . . . . 50

84 Triehophyton entothrix a mycélium fragile (gr. 250 dian.). . . . 5

85 Même cheveu aprés l'action de la potasse (gr. 200 diam.). . . . . il

86 Jème cheveu ierasé sous la lamelle (200 diam.). . . . . . . . . .2

87 Même cheveu. Les spores sont entièrement mises en liberté

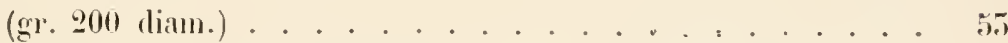

88, 89 et 90 Cultures du Trichophyton endothrix à mycélium fragile sur gélose an mont de bière. Comparer aux cultures de Trichophytons à mycélium résistant sur le même milieu. . . . . . . . . . . 5. . .

91 Nime culture. Age, 5 semaines. . . . . . . . . . . . . . 54

92, 95̃ et 9.' Culfures du T'. à mycélium fragile sur milieu d’épreuve. Cultures acuminces (Voil fig. 81, 82 et 85). Age, 5 et 4 semaines. 54

95 , 96 et 97 Mèmes cultures. Age. 5 et 6 semaines. . . . . . . . . .

98 Culture d'un T. endothrix (rare) sur mont de licie. . . . . . . . . .5

99 La même sur milieu d'ípreuve. . . . . . . . . . . . . . . 5ว

TRICHOPHYTIES DOORIGINE ATIMLLE

100 Autre espèce rare de T. endothrix (milieu d'ipreuve).. . . . . . . 56

101 T. ectothrix d'origine animale, cheveu de l'lomme (gr. 100 diam.). 56

102 Racine d'un poil envahi (gr. 180 diam.). . . . . . . . . . 57

105 Spores mycéliennes nucléces d'un T. ectothrix (gr. 1000 diam.). . 58

104 Epiderme folliculaire autour de la racine d'un poil malarle. . . . 58

105 Poil follet atteint par un T. ectothrix (gr. 150 diam.). . . . . . . 59

106 llerpès iris vésiculeux de Biett. T. ectothrix du chat. . . . . . . 60

107 T. ectothrix du chat. Culture directe de la lésion sur tube de moût de bière gélosé . . . . . . . . . . . . . . . 60

108 T. ectothrix du chat. Culture faite avec le pus de la même lésion. . . 60

109 Culture de Trichophyton du chat après 5 semaines (moùt de bière gélosí) . . . . . . . . . . . . . 61

110 Le sycosis. Périfolliculite. Trichophỵton du cheval. . . . . . . . 61

111 Culture du Trichophyton de cheval après 5 semaines (mont de bière gélosí) . . . . . . . . . . . . . . . 62

112 T. ectotluix du cheval. Culture sur pomme de terre. Age, 5 semaines. 65 
Fig. 115 T. ectothrix du chat. Même espece que la fiğ. 109. Culture de 10 semaines sur gèlose au mon̂t de bière au 1/10 . . . . . .

114 T. ectothrix du cheval. Mème esprice que la lig. 111. Culture de

114 T. ectothrix du cheval. Nême espice que la lig. 111. Culture de
10 semaines sur gélose au moùt de biere au $1 / 10^{\circ} . . . . .$.

11:) T. ectothrix du cheval. Mème espéce que les fig. 111 i 114 . Culture le 7 semaines sur gélose an moût de bière au $1 / 3{ }^{c}$. . . . . . 6i

116 T. ectothrix du veau. Même milieu que liı figure précédente. Ilème âge.

117 Trichophỵton du porc. Hène milieu que la figure 115. Mème âge.

118 T. du même groupe, mais dont l'animal d'origine est inconnu. . . . $\quad$ 6i6

119 Autre Trichoplạton du même groupe, d'origine inconnue.. . . . . 67

120 Culture du Trichophỵton du cheval (fig. 111) sur la feuille du mùrier.

$12 \mathrm{I}$ T. ectothrix à culture jaune (2e espèce d'origine équine), sur moût de bière gélosi. . . . . . . . . . . . . . . . . . . . . . 68

122 T. ectothrix à culture jaune. Culture to 4 semaines en matras, sur moûl de bière gélosé. . . . . . . . . . . . . . . . 68

125 T. ectothrix à culture jame. Culture de 4 semaines en matras (mème milieu). . . . . . . . . . . . . . .

124 et 125 Culture dı même Trich. sur milieu d’èpreuve, 4 semaines. Cultures craquelées vermiculaires, jaunes . . . . . . . . .

126 Espèce de Trich. ectothrix d'origine ariaire (?). Cultures roses sur moût de bière gélosé (6 semaines). . . . . . . . . .

127 et 128 lême espèce. Culture de six semaines sur milien d'ípreuve.

(Formule $\mathrm{n}^{\circ} 2$ ) . . . . . . . . . . . . . . . 70

THCHOPHYTLS EXOTIQCLS

129 Teigne imbrique de Patrick Nanson . . . . . . . . . . . . 71

150 Teigne imbriłnée tle Patrick Hanson . . . . . . . . . . . 72

151 Squane de teigne imbriquec. . . . . . . . . . . . 79

ÉTLDE MYCOLOGlQLe DES THCHOPHYTOXS

152 Culture trichophytique jeune. Sporulation externe commencinte (gr. 250 dianr.). . . . . . . . . . . . . . . . 75

155 Culture trichophytique adulte (gr. 250 dian.). . . . . . . . 74

154 Spores accessoires, porties directement sur le mycélium (gr. lion diant.). . . . . . . . . . . . . . . .

155 Sporulation exterue disséminée. Trich. à mycélium fragile (gr. 500 dianı.). . . . . . . . . . . . . . . . . .

156 Sporublion exterme. Tentance ả l'agnination en grappe (gr. 200 diam).

157 Sporulation externe en milien pauver. Les spores externes redeviennent solitaires (gr. 250 dianr.) . . . . . . . . . . .

158 Sportation par grappe. L'hyplse sporifiere se dillërencie des filantents non fruclifere's (gr. 1000 diam.). . . . . . . . . . . . . . 76

15!) Chlamylaspores des especes it cultures blanches (gr. 850 dianı.) . . 77

I h) Chlamydospores à éperon saillant. Forme chlamydospore supportant deux graples (gr. 800 diam.). . . . . . . . . . . . . . 77

1 li Chlamydespore terminale (gr. 500 diam.). . . . . . . . . . 78

142 Filanents myceliens terminatux steriles (gr. 200 diam.) . . . . . . 7!) 


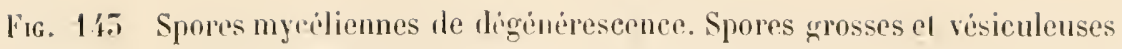
(gr. 400 diam.). . . . . . . . . . . . . . . . . . 79

1.' Spores mycéliennes de tégínirescence. Spores grosses et résiculeuses (gr. 400 dian.) . . . . . . . . . . . . . 80

145. Spores mycóliennes d'adiptation aux milieux azotés. . . . . . . . 80

146 Spores myceliennes dadaptation aux milienx azotis (gr. .700 dian.). 81

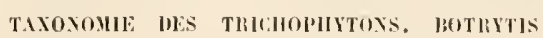

147 Botrytis Bassiana, rulture en goutle de 6 jours (gr. 250 diam.) . .

148 Botrytis Bassiana, culture en goutle de 6 jours. Mlise au point superficielle montrant le relief des grappes (gr. 250 diam.). . . . . .

149 Botrytis Bassiana, culture en goulte de 6 jours. Détail de la grappe (gr. 500 diam.).

150 Trachée respiratoire d'un ver à soie, envalie par le parasite de la muscardine . . . . . . . . . . . . .

\section{LA TEIGNE TONDANTE A PETITES SPORES}

151 Plaques multiples de tondante à petites spores de Grüby après l'épilation. . . . . . . . . . . . .

152 Microsporum Audoüni antour du cheveu de la teigne à petites spores (gr. 150 diam.). . . . . . . . . . . . .

155 La gaine aérienne du Vicrosporum Audoüni autour du cheveu (gr. 200 diam.) . . . . . . . . . . . . . . . . . . .

154 Lienveloppe de spores du Microsporum Audoüni après décortication du cheveu (gr. 200 diam.). . . . . . . . . . . . . . . 86

155 Jicrosporum Audonïn autour du cheveu (gr. 200 diam.) . . . . . 86

156 Culture directe dn cheveu atteint de Microsporum Audoüni, gélose au moùt de bière (2 semaines). . . . . . . . . . . . .

157, 158 et 159 Culture du Kicrosporum Audoüni sur gélose au moùt de bière $(2,5$ et 4 semaines $)$. . . . . . . . . . . .

160 et 161 Cultures du Microsporum Audoüni sur milieu d'éprenve (5 et 4 semaines) . . . . . . . . . . . . . . 88

162, 165, 164 et 165 Microsporum Audoü̈i, gèlose peptone maltosée, milieu d'èpreuve . . . . . . . . . . . . . . . . . 89

166 et 167 Ificrosporum Audoüni du cheval, culture sur milieu d'épreuve 4 et 6 semaines. . . . . . . . . . . . . . . . . . .

lis Naissance du mycélium jeune du Microsporum Audorïni en culture (gr. 200 diam.). . . . . . . . . . . . . . . . . . . 90

169 Nycélium adulte du Nicrosporum Audoüni en culture (gr. 250 diam.). 91

170 Mrcélium vieilli du llicrosporum (gr. 500 diam.). . . . . . . . 91

171 Premières ébauches des organes de fructification (gr. 200 diam.) . . 92

172 Premieres ébanches des organes de fructification (gr. 200 diam.) . . 92

17.5 Apparition des denticules sporifères (gr. 200 diam.) . . . . . 95

174 Sporulation externe complite (gr. 250 diam.) . . . . . . . . . . 95 


\section{LA TEIGNE FAVEUSE}

Pages.

Fis. 175 Cheveu favique (gr. 250 diam.) . . . . . . . . . . . . . . 96

176 Chereu favique (gr. 250 diam.). . . . . . . . . . . 97

177 Conpe d'un godet favique (gr. 700 diam.). . . . . . . . . . 98

178 Culture d'une variéti d'Achorion sur agar an mon̂t de bière. . . . 99

179 Culture d'une variété d'Achorion sur agar peptonisé à 1 pour 100. . 99

180 Culture d'une autre variété d'lchorion sur agar peptonisé à 1 pour

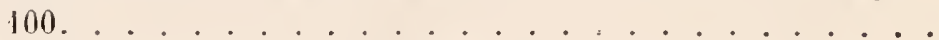

181 Même culture que fig. 179, transportíe sur agar peptonisé à 5 pour

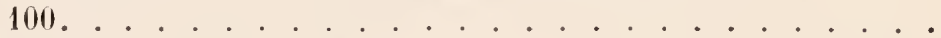

182 Mime culture que fig. 181, transpottée sur agar peptonisé à 5 pour 100. . . . . . . . . . . . .

185 Culture directe d'un cas de sycosis trichophytique phlegmoneux, d’origine équine probable (Boyen). . . . . . . . . . . 100

184 Culture comparative du lavus du chien (Nocard). . . . . . . . . 100

185 Culture sur fonnme de terre d'un Achorion d'origine humaine . . 100

186 Culture d'Achorion montrant le début du développenent d'un commensal sous forme de très petites colonies blanches. . . . . . . 101

187 et 188 Cultures de liverses variétés d'Achorions sur pomme de terre. 101

189 et 190 Varietés de commensaux des cultures d'Achorion isolés sur agar peptonisé à 1 pour 100. . . . . . . . . . . 101

191 Commensal des cultures faviques sur agar au moùt de biere . . . . 102

192 Le même, sur agar peptonisé à 1 pour 100 . . . . . . . . . . 102

195 Le même, sur agar peptonisé à ¿̀ pour 100 . . . . . . . . . . . 102

194 Commensal des cultures fariques sur pomme de terre. . . . . 102

195 Achorion Schronleinii . . . . . . . . . . . . . . 102

196 Achorion Euthytrix . . . . . . . . . . . . . . . . . . 102

197 Achorion Ataliton . . . . . . . . . . . . . . . . . . 102

198, 199, 200 et 201 Týpes de variétés d'Achorion sur agar peptonisé à

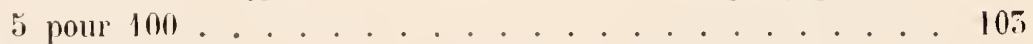

202. $20 \pi$ ef 20 'Types de variétés d'Achorion sur agar peptonisé a $\vdots t$ pour

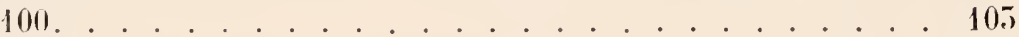

20.) Favus de la poule sur agar peptonise à 5 pour 100. . . . . . . . 104

206 Oospora caniua (Costantin Sahrazes) sur agar peptonise à i) pour 100. 10.4

207 Appareils conidiens des cultures de Favus (gr. 250 diam.). . . . . 106

208 Appareils conidiens des cullures de Favus (gr. 500 diam.). . . . . 105

209) Oïdies dians une vieille culture de lavus (gr. 500 diam.) . . . . . 106

210 Formes de reproduction en houquets de quelques cultures de Favus (gr. 1:0 diam.). . . . . . . . . . . . . . 106

211 Forme de reproduction en bouquet de quelques cultures de Farus (gr. 8001 diam.) . . . . . . . . . . . . . 107

\section{PITYRIASIS VERSIGOLORE}

212 Microsporon furfur diuns les słuames épidermiques (méthorle de Gram) (gr. 200 dian.). . . . . . . . . . . 108 
Fir. 215 Microsporon furfur dans les squames épidermiques (merhode de (iram) (gr. . 800 diatur.).

214 Mirrosporon furfur dans tes squanes ipidermigues (methode de (il:mul) (crr. 500 dianr.).

$10 !$

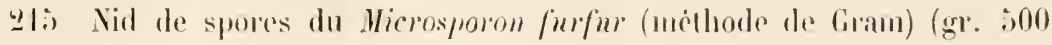
dianı.) . . . . . . . . . . . . 1119

2If Spores el mycélimus du Vicrosporon furfur (méthode de Grant) (gr. iolo dians.).

217 Spores du Microsporm furfur colories à l'óosine (après l'action de la polasse) (gr. bou diam.)

\section{ERYTHRASMA}

218 Microsponon minulissimum (méthode de Gram) (gr. s00 diam.). . 112

219 Microsporon minutissimum (méthode do Grans) (gr. foun diam.). . 112

220 Imas de spores du Microsporon minutissimnm (méthode de Gram) (gr. 1000 dianı.).

221 Vicrosporon minntisimum dans les squames ipidermiques (méthode de Gran) (gr. 1000 dian.)..

\section{OIDIUM}

222 Oidlum lactis. Culture jeune sur agar-agar (500 diam.) . . . . . . 11

225 Ö̈dium laclis. Chambe humide. Culture de 2 't henres (400 diam.). 116

29.4 Ö̈dium lactis. Culture sur agar-agar (150 diam.). . . . . . . . 116

22:) Ö̈dium lactis. Cullure sur agar au moùt de bière, àgée de 10 jours (400 diam.) . . . . . . . . . . . . . . . . . . 117

226 Ö̈dium lactis. Culture sur agar (méthode de Gran) (1000 diam.) . . 117

227 Trichophyton du cheral. Culture de 17 jours (méthode de Gram) 1000 dian.)................ 118

228 Trichophulon de l'homme (méthode de Gram) (1000 diam.). . . . 118 229) Achorion Schonleinii. Culture sur agar (Préparation par la méthode de Gram) (10000 diam.) . . . . . . . . . . . 119

\section{BEGGIATOA OU SULFURAIRES}

250 Beggiatoa raniana (100 diam.). . . . . . . . . . . 120

2.) Beggiatoa alba (I00 diam.). . . . . . . . . . . . . . 121

252 Beggiatoa alba (100 diam.). . . . . . . . . . . . . . . . . . 122

2.5 Beggiatoa alba $(170$ diam.). . . . . . . . . . . . . . . . . . 122

2.4 Beggiatoa alba (200 diam.). . . . . . . . . . . . . . . . . . 125

2.5 Beggiatoa alba (1000 diam.). . . . . . . . . . . . . . . . 125

25ti Beggiatoa alba (I000 diam.). . . . . . . . . . . . . . . 124

257 Beggiatoa alba (1000 diam.). . . . . . . . . . . . . 124

\section{FUSISPORIUM UNCIGERUM}

258 Fusisporinm moschatum. Culture âgée de 56 heures (500 diam.) . . 125

259. Fusisporium moschatum. Culture âgée de 2 jours (400 diam.) . . . 126

240 Fusisporium moschatum. Culture àgée de 12 jours ('400 diam.). Basides en forme de croissant . . . . . . . . . . . . . 126

241 Fusisporium moschatum. Culture sur agar-agar (12 jours) (400 diam.). 


\section{STREPTOTRIX}

Fıg. 242 Streptotrix brumea. Plaque d'agar. Grandeur naturelle . . . . . Бо

2'.' Streptotrix brumea. Colonie jeune sur plarue de gélatine 100 diam.).

24't Streptotrix brunnea. Colonie superficielle au début de la liquéfaction $(70$ diam.). . . . . . . . . . . . . 151

2.45 Streptotrix albilo-flar'c. Culture jeune sur agar . . . . . . . . 152

246 Streptotrix violacea. Culture jeune sur agar. . . . . . . . . . 152

2.4 Streplotrix nigra. Culture jeune sur agar. . . . . . . . . . . . 152

2 48 Streptotrix alba. Culture âgée sur agar. . . . . . . . . . . 152

2.49 Streptotrix nigra. Culture âgée sur agar . . . . . . . . . . 15e

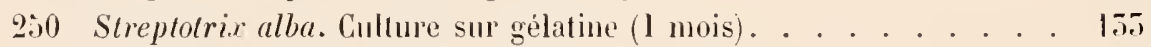

251 Streptotrix asterioüdes. Culture sur gélatine (1 110is). . . . . . . 155

252 Streptotrix brunnea. Culture dans le bouillon (lij jours) . . . . 155

255 Streptotrix brumea. (1000 dian.). . . . . . . . . . Tít

25.4 Streptotrix alba. Culture d'un mois, surface blanche (100 dianı.). . 554

\section{ACT INOM YGOSE}

2.;.) Actinomycose de l'homme. Grain préparé par écrasement (gr.900d.). 158

256 Actinomycose de l'homme. Grain préparé par écrasement (gl. 400 (liam.). . . . . . . . . . . . . . . . 179

257 Actinomycose du buenf. bissociation d'un grain frais (gr. 1004 diam.). 140

258 Aetinomycose du bouf. J)issociation (gr. 1000 dian.). . . . . . 140

259 Actinomycose du bouf. Dissociation (gr. 700 diam.). . . . . . . 141

260 Actinonycose du breuf. Ibissociation (gr. 1000 diam.) . . . . . 141

261 Actinomycose du beruf. Itissocialion (Cornit) (gr. 1000 dian.) . . . 142

262 Actinomycose du bouf. Dissociation (Cornil) (gr. 1000 dimm.). . . 145

265 Rein de bouf. Actinomyeose (gr. 25 clian.) (Nocard). . . . . . 144

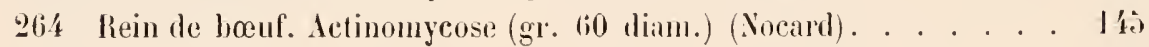

26̧ liein de bouf. Actinomyeose (gr. 60 dian.) (Nocard). . . . . . . 146

g6ti Rein de bouf. Aclinomyeose (gr. 700 diam.) (Nocard) . . . . . 1 1 1

267 Actinonycose. Langue de boruf (gr. 700 dian.). . . . . . . . . 148

268 Actinonycose. Langue de bouf (gr. 800 dian.) . . . . . . . . 1 is

269 Actinomycose. Langue de bouf (gr. $8(30$ dian.) . . . . . . . . . I 19

270 Aclinomycose. Langue de bouf (gr. 800 dian.) . . . . . . . . . 1.99

971 Actinomycose de l'homme (abci's de la jone), dissocialion d'un grain (gr. 600 dianr.). . . . . . . . . . . . . . . . . lo0

272 Actinomycose de l'homme (abcis de la joue), dissociation d'un grain (gr. 800 diam.) . . . . . . . . . . . . . . 150

275 Actinomycose de l'homme (abres de la junn) dissocialion diun grain (gr. 800 dian.). . . . . . . . . . . . . . . 1 . . . .

27.4 Actinomycose de l'homme (abres sub-lingnal), dissocialion d'un grain (gr 1000 dian.). . . . . . . . . . . . . . . 151

27. Actinomycose de l'homme (abees pelvien), dissociation d'un grain (gr. 800 dian.). . . . . . . . . . . . . . 152 
Fic. 27i Aclinomycose de l'homme (abees pelvion), dissociation d'un grain (gl. 1000 dian1.).

27i Actinomycose le l'homme (abces pelvien) dissociation d'un grain (gl' lol)1 diam.). . . . . . . . . . . . . . . .

gis Actinomyeose de lhomme (abces pelvien) dissociation d'un grain. Crosses (gr 1000 diam.) . . . . . . . . . . . 154

27!) Actinomyeoso de l'homme. Cullure dans le bonillon (gr. 1000 diam.). List

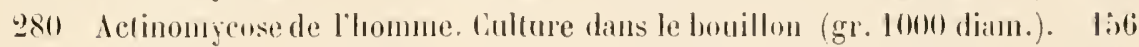

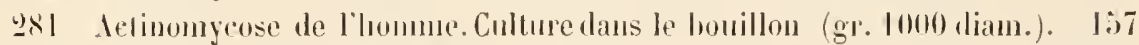

282 Ielinonycose du bœuf (Macé). Cullure sur agir . . . . . . . . . 1;88

285. Aetinomyeose de l'homme. Culture sur agar (liral) Cololition part la methode de Gran (gr. 1000 diam.) . . . . . . . . 158

28' Actinomyeose de l'lomme. Culture sur agar (Kral) . . . . . . . lis

2x5 Actinomyeose de lhomme. Culture dans le bouillon . . . . . . J J!!

ASSOCIATONS CRYPTUGMUOCE I)E L'ACTINOMYCOSE

286 Actinomyeose de l'homme. Dissociation d'un grain. Leptotrix et Streptotrix (gr. 1000 diam.). . . . . . . . . . . . . 160

2xt Actinomycose abdominale. Ictinomyces et Leptotrix (gl. 500 diam.). 161

QSA Actinomycose de l'homme. Infection mixte. Dissociation d'un grain.

Leptotrix enroule en glomérule (gr. 1000 dian.). . . . . . . . 161

289 Leptotrix bucealis. thent cariée (gr. 120 dian.). . . . . . . . . . 162

290 Leptotrix loncealis. Carie dentaire (gr. 400 diam.) . . . . . . . 169

291 Mycose bnccale (muguet?) (gr.200 diam.). . . . . . . . . . . . I6i

292 Ircose pharyngée. Concrétion de lanygdale. bissocialion (gr. 1000 diam.). . . . . . . . . . . . . . 16 . . . . .

295- Actinomycose de l'homme. Infection mixte. Cullure de Leptotrix el de Streptotrix (gr. 1000 diam.) . . . . . . . . . . . . .

29' Actinomycose de l'homme. Infection mixte. Culture de Streptotrix et de Leptotrix (gr. 1000 dian.) . . . . . . . . . . . l lí

295 Actinomycose de I'homme. Infection mixte. Culture de Streptotrix et de Leptotrix (gr. 1000 diam.) . . . . . . . . . . . . 16аั

296 . Mces de la joue. Leptotrix en faisceaux (gr. ibll diam.) . . . . . 166

297 Abcès de la joue. Leptotrix en faisceaux (gr. 200 dian.) . . . . . 166

298 Abcès de la joue, Iétail d'une touffe de Leptotrix (gr. 600 diam.). . 167

299 Abcés de la jone. Leplotrix et courts filaments (gr. 1000 diam.) . J6i

500) Actinomyeose de l'homme. Inoculation du Streptotrix dans le péritoine du lapin (gr. 1000 dian.) . . . . . . . . . . . . 168

501 Actinomycose de l'homme. Infection mixte. Inoculation du Leptotrix dans le péritoine du lapin (gr. 500 diam.) . . . . . . . . . 16s

502 Ictinomycose de l'homme. Infection mixte. Inoculation du Leptotrix dans le péritoine du lapin (gr. 500 dian.). . . . . . . . . 169 
Pages.

\section{FARCIN DU BEUF}

Fig. 505 Farcin du bœuf. Pus (Nocard) (gr. 600 diam.) . . . . . . . 170

504 Farein du bouf. Pus (Nocard) (gr. 800 diam.) . . . . . . . . . . 170

505 Farcin du bœuf. Pus (Nocard) (gr. 800 diam.). . . . . . . . 171

506 Farein du bouf. Pus (Nocard) (gr. 1000 diam.) . . . . . . . . . 171

507 et 507 bis. Farcin du bouf. Cultures sur gélose àgées de j mois

(Nocard) (grandeur naturelle). . . . . . . . . . . 172

308 Farcin du bouf. Culture sur bouillon (Nocard) (gr. 400 diam.). . . 175

509 Péritonite farcineuse expérimentale (lapin) (Nocard) (gr. 700 diam.). 174

510 l'éritonite farcineuse expérinentale (lapin) (Nocard) (gr. 800 diam.). 175

\section{PIED DE MADURA}

511 Pied de Madura. Pus. Dissociation (Vincent) (gr. 700 diam.). . . . 176

512 Pied de Madura. Culture sur bouillon (Vincent) (gr. 100 diam.). . . 178

515 Pied de Madura. Culture sur bouillon (Vincent) (gr. 290 diam.). . . 178

514 Pied de Vadura. Culture. Dissociation (Vincent) (gr'. 700 diam.) . . 179

315 Pied de Madura. Coupe (Vincent) (gr. 100 diam.) . . . . . . . . 180

316 Pied de Madura. Coupe (Vincent) (gr. 225 diam.). . . . . . . . . 180

517 Pied de Jadura. Coupe (Vincent) (gr. 950 diam.) . . . . . . . . . 181

518 Pied de Madura. Coupe (Vincent) (gr. 500 diam.) . . . . . . . . 181

51! Pied de Madura. Coupe (Vincent) (gr. 500 diam.). . . . . . . . . 182

520 l'ied de lladura. Coupe (Vincent) (gr. 500 diam.) . . . . . . 182

521 Pied de Madura. Coupe (Vincent) (gr. 500 diam.) . . . . . . 185

\section{LEILRES \\ A. SAGGHAROMYGÈTES INDUSTRIELS}

522 Levure haute (gr. 400 dian). . . . . . . . . . . . 186

525 Sédiment de vin aner (gr. 400 diam.). . . . . . . . . . . . . 187

524 Levure de vin de Champague en voie de sporulation (gr. 400 dian.). 190

\section{LEVURES DE BIÈRE}

325 Levure hante en voie de bourgeonnement (gr. 400 dianı.) . . . . 195

326 Levure haute en voie de bourgeonnement (gr. 400 diam.). . . . . 196

527 et 328 Deux levures hautes en culture sur l'agar-agar au moùt de bière (grandeur naturelle) . . . . . . . . . 197

529 Levure basse (Carlsberg II) (gr. 400 dian.) . . . . . . . . . . . 197

550 Levure basse (Carslsberg II) (gr. 400 diam.) . . . . . . . . . . 198

551 Levure basse dinne brasserie de Reims (gr. 400 dimm.) . . . . . . 198

552 Levure basse. Vieille culture sur moùt de bière. Cellules de la surface (gr. 400 dian.). . . . . . . . . . . . . 199

LEVTLES ILE MALAUHE

555 Culture de Sacch. Ellipsoïleus $I$ sur agar-agar au moùt de bière . . 200

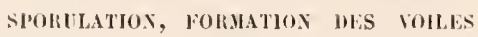

55.4 Sacch. P'ustorianus /II, en voie de sporulation (gr. 1000 diam.) . . ㄴo2

355 Levure de vin. Sportulation sur agar-agar peptonisé, le einquieme jour (gr. 1000 diam.). . . . . . . . . . . . 202 


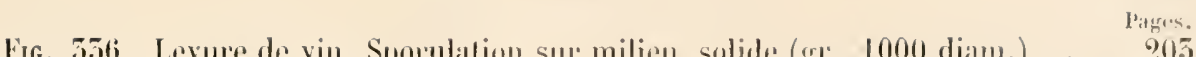

557 Spormation d'une levare de vinsur bloe de plitre (gre 11000 diam.). 205

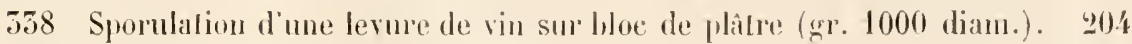

359 Voile jente rlu Sach. cerevisie I (gr. I00 rlianı) . . . . . . . 205

5.90 Voile jeune du Sacch. cerevisiar I (gr. 100 dian.) . . . . . . . . 206

341 Sarch. cerevisia I. Voile ancien (gr. 2016 dian.). . . . . . . 206

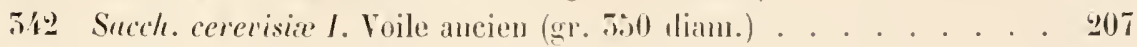

5.5.) Sacch. erevisie I. Voile ancien (gr. 4010 llian.) . . . . . . . . 207

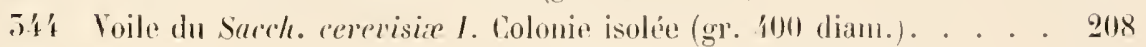

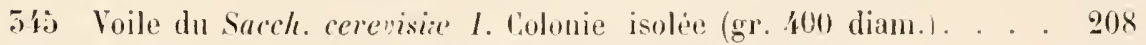

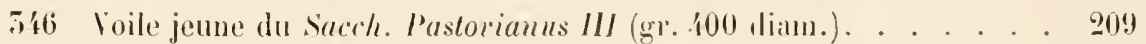

5.7 Sacch. I'asloviamus /II. Voile plus ancien (gr. 50) diam.) . . . . . 209

348 Sacch. l'aslorianus III. Voile plus ancien (gr'. 4l10 dian.) . . . . 210

\section{LEVURES DE VIN}

549 Levure de vin de Clampagne en culture pure su' milien liguide (gr. 400 diam.). . . . . . . . . . . . . . . . 212

550 Levare de vin du Rlun. Culture sur milieu solide . . . . . . . 215

551 Levure apiculée provenant d'un moùt de champagne (Ay) (gr. 400 dianı.) . . . . . . . . . . . . . . . . 21.4

552 Levure apiculée provenant d'un mont de champagne (Bouzy) (400 diam.) . . . . . . . . . . . . 2 215

\section{LEVURES DE GIDRE ET DE DISTILLERIE}

555 Levure de distillerie. Culture jeme (gr. 400 diam.).

$554,5 \%$ et 556 Trois levures diffërentes de distillerie. Cultures sur agar au moût de bière. . . . . . . . . . . . . . . 218

357 Levure de distillerie. Formes allongées (gr. 400 diam.). . . . . . 218

\section{LEVURES DE BOULANGERIE}

53 Levure de boulangerie (gr. 400 diam.) . . . . . . . . . . . 219

\section{KÉPHIR}

559 et 560 Saccharomyces Képhir. Formes de voile (gr. 100 diam.). . . 221

561 Saccharonyces Képhir. Culture sur agar au mont de bière. . . . . 222

562 Saccharomices exigums $I$. Culture sur agar an mont de bière. . . . 225

365 Saccharomices exigums II. Culture sur milieu liquide (Dextrose) (gr. 400 diann.). . . . . . . . . . . . . . 29

\section{B. SACGHAROMYGÈTES NON INDUSTRIELS}

564 Sacchuromyces exigums II. Culture sur mont de vin (gI'. 400 diant.). 224

565 Saccharomyces anomalus(Jörgensen). Cullure surgélatine (gr . 400 d.). 295

566 et 567 Saccharomyces anomalıs. Sporulation sur bloc de plâtre (gr. 1000 diam.). . . . . . . . . . . . . . 226

568 et569 Saccharomyces anomalus.Spores misasenliberlej jor.1000 dian.). 227 LEVLliES TE DOSTANT PAS ILE SPURES

\section{TORULAS}

370 Torula alba (gr. 400 diam.). . . . . . . . . . . . . . 229

371 Torula alba. Colonie sur plaque de gélatine (gr. 150 diam.) . . . . 229 
Fıg. 372 Tornla B. (Jörgensen) (gr. 400 diam.). . . . . . . . . . . . 250

375 Torula C. (T. Rosea) (gr'. 400 diam.). . . . . . . . . . . . 250

574 Torula B. Culture sur agar au moùt de bière . . . . . . . . . . 251

57 Torula C. Culture sur agar au moût de bière. . . . . . . . . . . 251

576 Torula nigra. Culture sur agar au moint de bière. . . . . . . . 251

577 Torula nigra. Coloration à la fuclısine (gr. 200 diam.). . . . . . 252

578 Torula nigra. Vieille cullure (gr. 250 diam.) . . . . . . . . . 252

579 Torula nigra. Formes myceiliennes (gr. 250 diam.). . . . . . . . 255

580 Torula nigra. Formes mycéliennes (gr. 250 diam.) . . . . . . . . 955

\section{MYCODERMES}

581 Nycorlerma cererisice. Culture sur agar au moùt de biere. . . . 25't

582 Hycoderma cerevisire. Culture sur agar (gr. 400 diam.). . . . . . 250

585 Hycoderma cerevisia. Cullure sur milieu liquide (gr. 400 diam.). . 275

58.' Hycoderma cererisir. Vieille culture sur milieu solide (gr. 400 diam.). $\mathbf{2 5 6}$

585 Iycoderma nini. Culture jeune (gr. 400 diam.) . . . . . . . 256

\section{MONILIA GANDIDA}

786 Monilia candida. Culture sur moǹt de bière. Formes de dépòt (gr. 400 dian.) . . . . . . . . . . . . . . . .

587 IIonilia candida. Culture sur mont de bière, Formes jennes de voile (gr. 400 dian.) . . . . . . . . . . . . 258

.88 Monilia candida. Voile ancien (gr. 400 diam.). . . . . . . . 958

589 et 590 Monilia camlida. Voile ancien (gr. 400 diam.). . . . . . . 259

591 Uonilia camlida. Culture sur gélatine peptone. . . . . . . . 290

592 Monilia candicla. Culture sur agar au moût de bière . . . . . . . 9.90

59.7 Chalara-llycolerma. Culture sur agar-agar. . . . . . . . . . 240

\section{DEMATIUM PULLULANS}

59' Dematium fmullulans. Chambre hunide. Formes jeunes (gr. 500 dianı.). 241

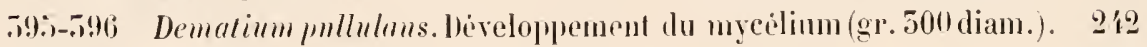

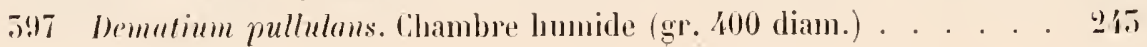

\section{LE MUGUET}

798 Muguet. Apparition du champignon an milieu des bacilles de furmenlation lactipne. Formes jemmes of ovalaires (gr. 1000 diam.) . . . 945

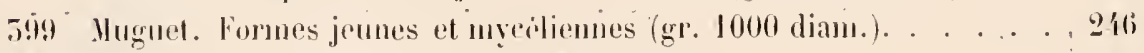

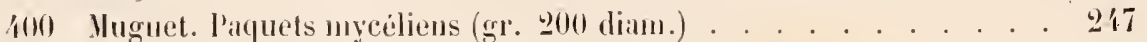

401 Muguet Filaments mp̣éliens (gr. 250 diam.). . . . . . . . . 247

402 Mugnet. Culture impure sur agar peptonise alcaliu (gr. 250 diam.). 2.48

40.5 Dugnet. Colonie superfieielle sur plaque rle gélatine (gr. ł0 diam.) . 2.19

404 Muguet. Colonie profonde (radièe) sur plaque de gélatine (gr.80 dianr.). 250 


\section{MIROCOOUES}

Fig. $\{0$; diros microcoques (gr. 11000 diant.). . . . . . . . . . . 2:2

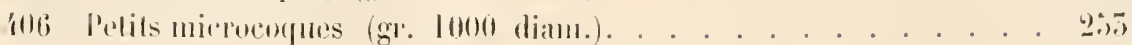

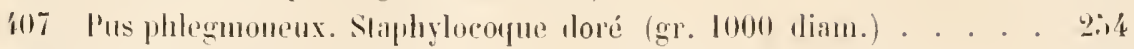

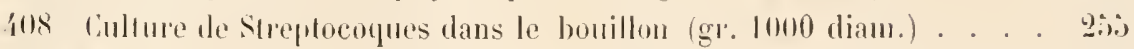

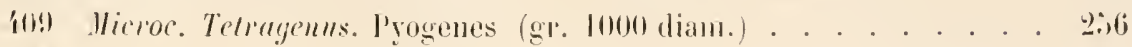

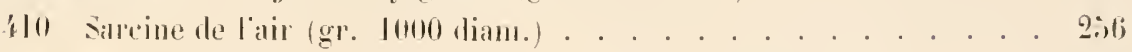

1ll Vostoe commume. I'reparation fratche (gr. 200 d liant.) . . . . . 957

19 Vostoc commune. I'réparation fraiche (gr. 250 diam.). . . . . 258

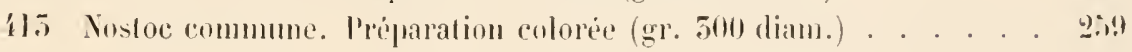

\section{MCROCOQLES PATHOGEVES}

\section{STAPHYLOGOQUE DORÉ}

41.' I’us phlegmoneux. Staphylocoque doré (gr. 700 diam.) . . . . . 267

1l: I'us phlegmoneux. Staphyloroque doré (gr. lono diam.) . . . . 268

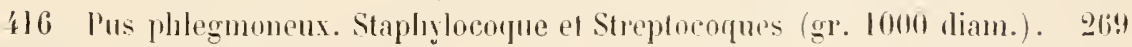

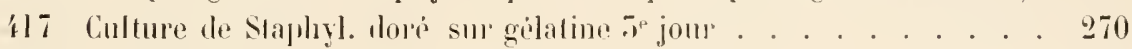

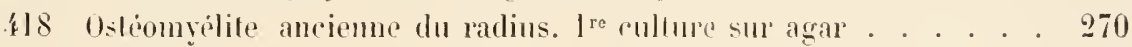

1l9 Anthrax. Pus : fre culture sur agar . . . . . . . . . .

120 Ie culture de pus contenant à la fuis le staph. doré et le Strept. pyogene. . . . . . . . . . . . . . 270

421 Staphylocoque doré. Jeune culture sur milieu liquide. . . . . 271

122 Staphylocoque doré. Vieille culture sur agar . . . . . . . . 271

425 Ostéomyélite du tibia (1882). Irthrite purulente du genou. Staphyloeoques (gr. 1000 diam.) . . . . . . . . . . 274

494 Infection purulente par le Stapliylocoque doré, foyer métastatique pulmonaire (gr. 25 diam) . . . . . . . . . . . . . . 277

425 Xeplrite ascendante expérimentale due au Staphylocoque (gr. 5 diam.). 280

426 Amas de staphylocoques dans les tules druits dos pyramides (gr. 60 ,liam.). . . . . . . . . . . . . . . . 281

427 Lésions suraiguès à forme gangréneuse (gr. 81 diam.). . . . . . . 281

428 Zooglíes daas la région corticale (gr. 811 diam.) . . . . . . . . . 982

49!) Formation des abcès corticaux (gr. 2. dian.) . . . . . . . . . . 282

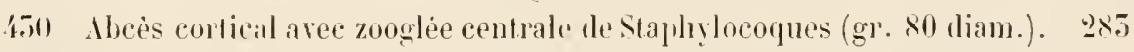

451 Phlébite de la veine fariale, des sinus de la dure-mère et de la veine sylvieme. Coupe de la veine sylvieme thrombose . . . . . . 28.4

452 Staphylocoupes provenant du caillot d'une de ces reines. . . . . 28 i

\section{ST APHYLOCOQUE BLANC}

155. Staphylocoque blanc. Culture sur gélatine 5 jour . . . . . . . 287

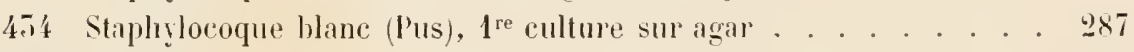

f.jo Staphlylocoque blanc, ge culture sur agar. . . . . . . . . . 287

456 Pus diun phlegmon de la gaine du psoas. Staphylocoque blanc (gr. 1000 diam.) . . . . . . . . . . . . . . 288.

457 Jeune culture de Staphyglocorge blanc (gr. 1000 dianr.). . . . . . 288 


\section{STAPHYLOGOGGUS GEREUS ALBUS ET FLAVUS}

\section{MIGROBE DE L'ARAIGNÉE}

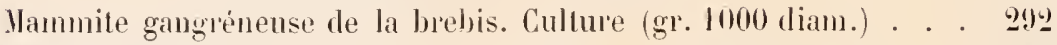

Nammite gangrenense de la brebis. Culture (gr. 1000 diam.) . . . 295

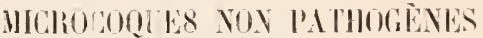

Micrococens condicans (g1. I 1100 diam.). . . . . . . . . 295

Micrococcus rugosus olearius (g1'. 1000 diam.). . . . . . . . . . 296

Micrococcus rugosus olearius. Cullure sur plaque de gélatine (gr. 25id.). $290^{\circ}$

Micrococcus rngosus olearins, jenne culture sur angar. . . . . . . . 297

Micrococcus rugosus olearius, vieille culture sur agar. . . . . . 297

Hicrococcus flarus desilens. Cullure sur agar . . . . . . . . . 9917

Hicrococeus aurantiacus. Culture sur agar . . . . . . . . . . $29 ! 7$

Micrococeus roseus. Culture (gr. 1000 dian.) . . . . . . . . . 298

Micrococcus flaus desidens (gr. 1000 dian.) . . . . . . . . . 299

Hicrococcus aurmatiacus (gr. 1000 diam.) . . . . . . . . . . 500

Hicrococcus ruber agilis (gr. 800 diam.). . . . . . . . . . 501

Micrococcus ruber agilis (cils) (gr. 1000 diam.) . . . . . . . . 501

Micrococcus ruber agilis (cils) (gr. 1200 diam.) . . . . . . . . 502

Micrococe us ruber agiiis (eils) (91. 1800 diam.) . . . . . . . . .709

Hicrococcus citreus agilis (gr. 1000 diam.) . . . . . . . . . . 505

Micrococcus citreus agilis (cils) (gr. 2000 diam.). . . . . . . . . 505

\section{BLENNORRHAGIE}

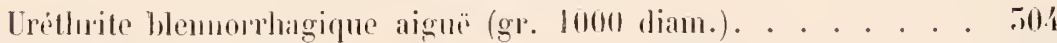

Uréln'ite blennorhagique aignë. I’us (gr. 1000 diam.) . . . . . . 70:

Uréthrite blemorrhagique. Gonocoques libres et il la surface de cellukes épithríliales gr. lono liam.) . . . . . . . . . . 506

Culture pure de gonocontes (gr. lono diam.) . . . . . . . . . 707

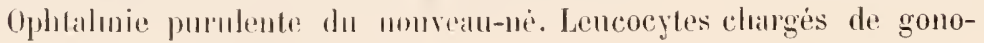
copques (gr. 10000 diam.). . . . . . . . . . . . . 508 Oplualnic purulente du nonvean-ne. Cionocoques el cellules épithi-

liales (gl. I (1010) diall1.).

\section{HÉMOGLOBINURIE DU BQEUF}

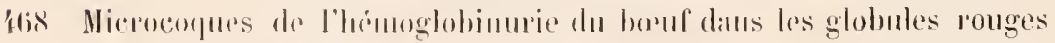

(g1. I000 dialt1.). . . . . . . . . . . . 5l

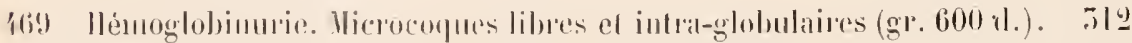

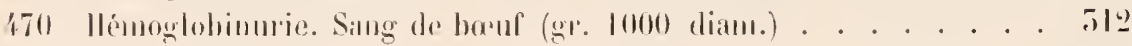

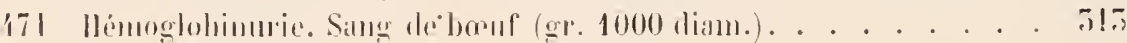




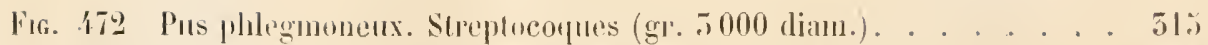

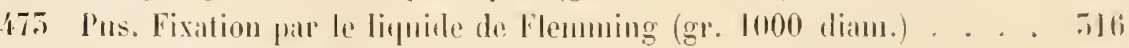

47' Lymphangitephlegmoneuse. P'réparation faite en aont 1882 (gr. 1000d.) 517

17. Serosite d’arthrite aignë (gr. 1000 diann.) . . . . . . . . . . . .

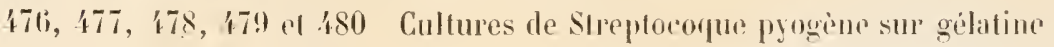

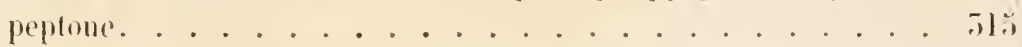

481 fre Cullure du pus à Streptocogues stur agill. . . . . . . . . 519

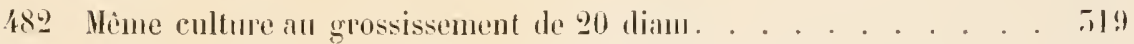

18.7 Qe Culture de Streptocoques sur agar (strite. 2e jour). . . . . . . T1!

48.t Plemésie purntente ancienne à Streptocopnes (gr. 150 dian.). . . 520

is: Plenrésie purulente am ienno à Streptocorques. . . . . . . . . 520

186 l'eurésic purulente à Streptocoques (gr. 200 dian.) . . . . . . 72)

487 Pleurésie purulente à Streptocoques (gr. 1000 diam.). . . . . . 721

488 Phlegmon streptococeique à marche lente. streptocoques inclus dans les leneocytes (gr. 700 diam.). . . . . . . . . . . . . . . . .

489 Phlegmon post-puerpéral tardif (כ̆ mois). Streptocorjues englobés dans les leucocytes (gr. 800 diam.). . . . . . . . . . 5y

\section{LA FIÈVRE PUERPÉRALE ET L'ÉRYSIPÈLE}

490 Fièrre puerpérale suraiguë. Sérosite péritonéale (g1'. 1000 diam.). . 527

491 Hammite puerpérale i Streptocoques. Acini remplis de Zooglées (gr. 80 dianı.) . . . . . . . . . . . . . . . . . . . . . . .

492 Fièvre puerpérale suraiguë. Zooglée tu loie ayanl tounè une cullure pure de Streptocoques (gr. 800 dianr.). . . . . . . . . . . 7〕!

495 Infection streptococcique. Zooglée de streptocoques dans le rein

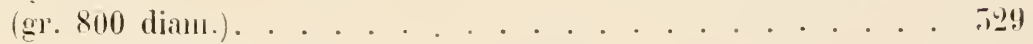

49 ' Streptocoque pyogène. Culture sur gẻlatine . . . . . . . . . 550

495 Streptocoque puerpéral. Culture sur gélatine . . . . . . . . . 5ill

496 ot 497 Streptocoque de l'érysipèle. Culture sur gélatine. . . . . $\$ .50$

498 et 499 streptocoque pyogene. Culture sur agap-igar . . . . . . הin

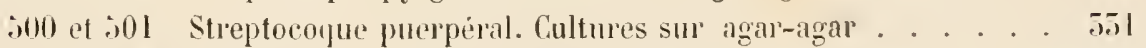

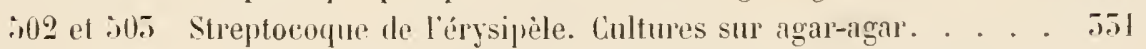

jo't Trois lapins inoculés à l'oreille du Streptocoque de l'érysipìle, du

Streptocoque puerperal et du Streptocoque pyogine, is heures après l'inoculation. Le premier hapin est mourant férysipèle infectieux). Le deuxieme est mort 2 '́ heures plus tard (fière puerpèrale). Le troisième n’a présenté quiun petit abeẻs arec lynplangite de peu d'itendue et a survecu. (Phlegmon cirronserit à Streptocoques) . . . . . . . . . . . . . . . . . .

$505,506,507,508,509$ et 510 Première culture du silc des viscères it l'urine provenant d'un cas d'érysipèle frane de lat face, suivi de de mort. 
Fug. 5ll Phlegmon sous-cutané survenu dans la convalescence d'un érysipèle.

Chainettes incluses dans les leucocytes (gr. 1000 diam.). . . . . $\mathbf{0 5 8}$

512 Erysipèle phlegmoneux post-puerpéral (gr. 1000 diam.). . . . . 545

5i.) Puslule du pouce d'une sage-femme contamince (gr. 800 diam.). . 544

51. Sirosité piritonéale d'une des femmes contaminées par cette sagefemme. . . . . . . . . . . . . . 54t'

515 Nephrite ascendante. Zooglie de Streptocoques (gr. 800 diam.). . . 549 SÉROTHÉRAIIF DE L'ISEECTION STREPTOCOC lịUE

5l6 Jeune cullure de Streptocoque pjogène sur le milieu de Marmorek (gr. y00 diam.). . . . . . . . . . . . . . . . 351

ذ17 Culture ancienne de Streptocoque sur le mème milieu (gr 1000 d.). 539

bls Streptocoque de l'anasarque du cheval (gr. 1000 diam.). . . . . 5o't

\section{STREPTOGOGGUS HOMINIS GRASSUS}

¿19) el ¿20 Streptococcus pyngenes crassus. Culture sur gélatine. . . Tob

¿21 et 522 Streptococcus pyogenes communis. Culture sur gélatine . . . 556

5.9 ol 59.4 Streptococens pyogenes crasus. Culture sur agar . . . . . . 557

52 i) el soti Streptococcus myogenes communis. Culture sur agar . . . . 557

527 Streplococeus pyogenes crassus. Culture sur agar (gr. 1000 diam.) . 558

528 Streptococcus myogenes crassus. Culture sur bouillon (gr. 1000 diam.) 558

\section{STREPTOGOGGUS PYOGENES LIQUEFAGIENS}

¿2!) et 5.00 Streptococcus pyogenes liquefaciens. Culture sur gẻlatine. . . 5in!

501 et 50 Streptococcus pyogenes liquefaciens. Culture sur agar . . . . 55!

53̄̄ Streplococcus pyogenes liquefaciens. Culture sur bouillon (gr. 1000 d.). $\quad 560$

\section{STREPTOGOQUE DE L'IMPÉTIGO}

554 Impétign. Liquide d'une résicule récente (Leroux) (gr. 1000 diam.). 561

IISTOH.OGE UES VÉSICO-PISTULES CETANEES

5.35 Variole. Vésicule jeune (gr. 8 dian.). . . . . . . . . . . . 562

\$.rb Variole. lébut de la période de suppuration. Le derme est envahi (gr. 20 diam. . . . . . . . . . . . . . . 569

$\$ 37$ Streptoconue de l'impéligo. Culture sur bouillon (gr. 1000 dian.) . 565

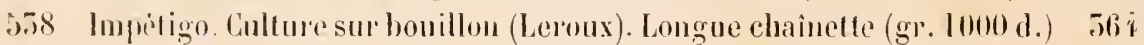

COHMENSALAME UU STREPTOCOQUE ET HE LA BACTÉRIME

5.5) Streptocoques et bactipidies associces dans une culture impure (gl'. 800 dianr.) . . . . . . . . . . . . . . 561

540 streptocoques ef bacteridies associces dins 111 vaccin impur (gl. 1060) diam.). . . . . . . . . . . . . 566

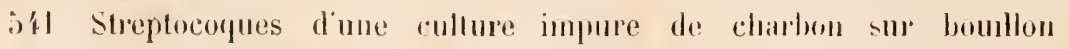
(gr. 1000 dialli,) . . . . . . . . . . . . . . . . . . . . . . . 





